Göttinger Studien zur Kulturanthropologie / Europäischen Ethnologie Göttingen Studies in Cultural Anthropology / European Ethnology

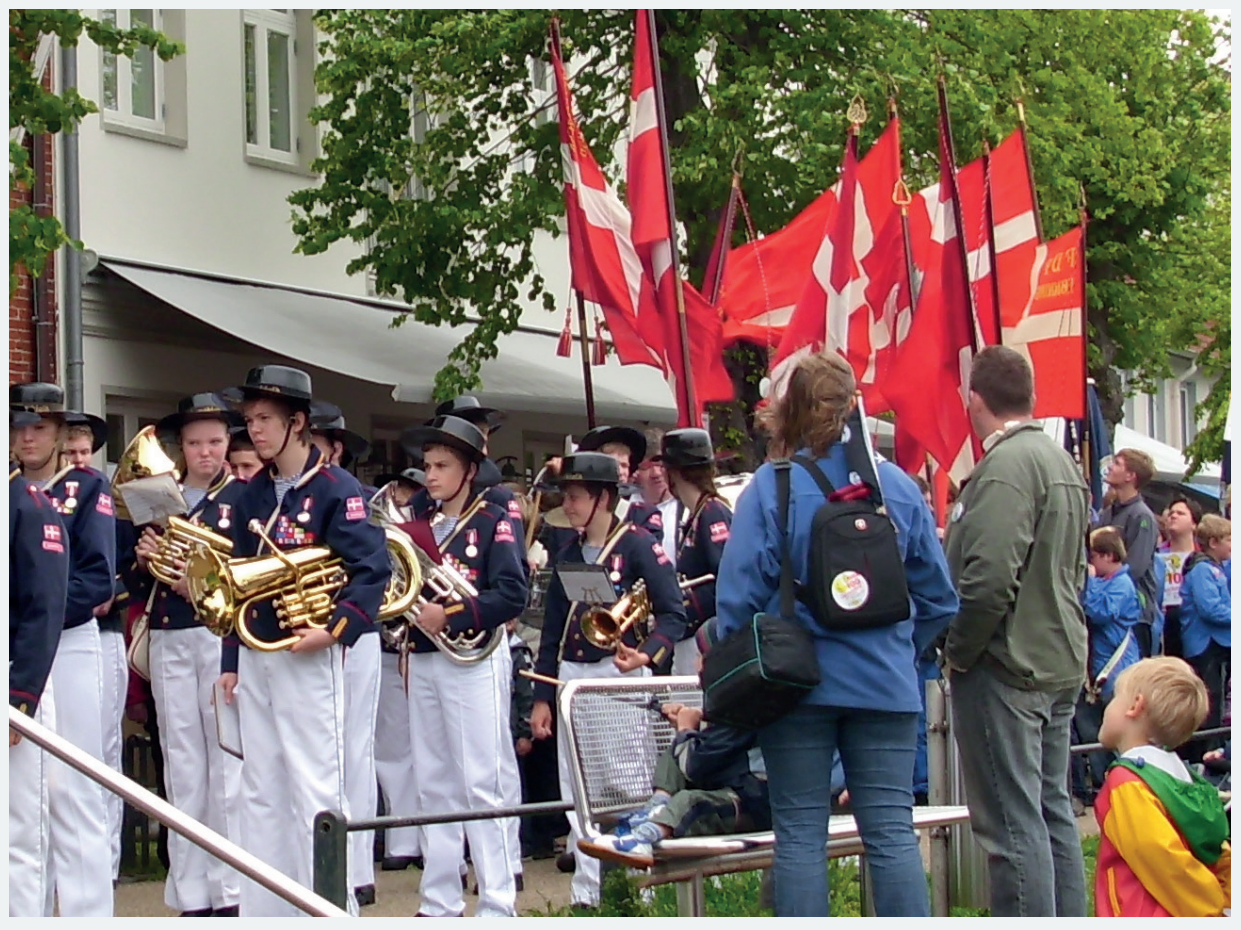

Levke Bittlinger

\title{
Dänischwerden und Dänischsein im Landesteil Schleswig
}

Zugehörigkeiten und Verortungsprozesse 

Levke Bittlinger

Dänischwerden und Dänischsein im Landesteil Schleswig

Dieses Werk ist lizenziert unter einer

Creative Commons

Namensnennung - Weitergabe unter gleichen Bedingungen

4.0 International Lizenz.

(c) (1) () 
erschienen als Band 10 in der Reihe „Göttinger Studien zur Kulturanthropologie/Europäischen Ethnologie“ im Universitätsverlag Göttingen 2020 
Levke Bittlinger

Dänischwerden und Dänischsein im Landesteil Schleswig

Zugehörigkeiten und

Verortungsprozesse

Göttinger Studien zur

Kulturanthropologie/Europäischen

Ethnologie, Band 10

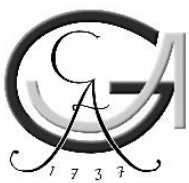

Universitätsverlag Göttingen

2020 


\section{Bibliographische Information der Deutschen Nationalbibliothek}

Die Deutsche Nationalbibliothek verzeichnet diese Publikation in der Deutschen Nationalbibliographie; detaillierte bibliographische Daten sind im Internet über $<$ http://dnb.dnb.de $>$ abrufbar.

„Göttinger Studien zur Kulturanthropologie/Europäischen Ethnologie“, herausgegeben von

Prof. Dr. Regina Bendix

Prof. Dr. Moritz Ege

E-Mail: rbendix@gwdg.de

Prof. Dr. Sabine Hess

E-Mail: mege@uni-goettingen.de

Prof. Dr. Carola Lipp

E-Mail: shess@uni-goettingen.de

Dr. Torsten Näser

E-Mail: Carola.Lipp@phil.uni-goettingen.de

E-Mail: tnaeser1@gwdg.de

Georg-August-Universität Göttingen

Institut für Kulturanthropologie/Europäische Ethnologie

Heinrich-Düker-Weg 14

37073 Göttingen

\section{Kontakt}

Levke Bittlinger

E-Mail: Levke.Bittlinger@phil.uni-goettingen.de

Dieses Buch ist auch als freie Onlineversion über die Homepage des Verlags sowie über den Göttinger Universitätskatalog (GUK) bei der Niedersächsischen Staats- und Universitätsbibliothek Göttingen (https://www.sub.uni-goettingen.de) erreichbar. Es gelten die Lizenzbestimmungen der Onlineversion.

Satz und Layout: Levke Bittlinger

Titelabbildung: Am Skipperhus vor Beginn des Straßenumzuges. Årsmøde

Tønning/Jahrestreffen Tönning am 29.05.2011 (Foto: Levke Bittlinger)

(C) 2020 Universitätsverlag Göttingen

https://univerlag.uni-goettingen.de

ISBN: 978-3-86395-427-7

DOI: https://doi.org/10.17875/gup2019-1205

eISSN: 2512-7055 
Für Wilma und Luise 



\section{Inhaltsverzeichnis}

1. Einleitung und Methoden........................................................................13

2. Theoretischer Hintergrund.....................................................................33

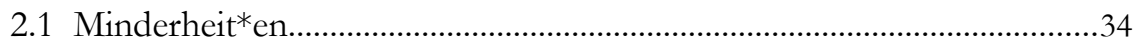

2.2 Ethnizität - Ethnisierung, Nation - Nationalisierung, Identität -

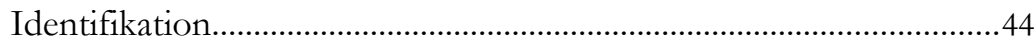

2.2.1 Ethnizität.....................................................................................45

2.2.2 Nation........................................................................................

2.2.3 Identität - Identifikation................................................................58

3. Die dänische Minderheit in Schleswig-Holstein.....................................61

3.1 Der Landesteil Schleswig und die Entstehung der dänischen

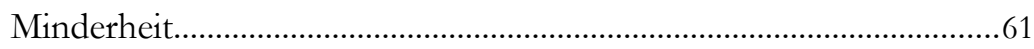

3.2 Dänische Institutionen im Landesteil Schleswig......................................69

3.2.1 Verein: eine kurze Einführung in Begriffe und Funktionen....70 


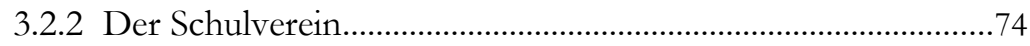

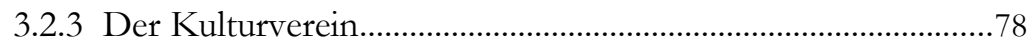

3.2.4 Weitere dänische Vereine in Südschleswig...............................80

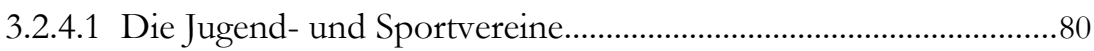

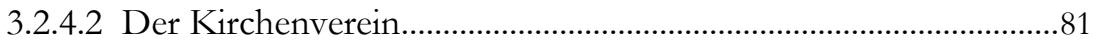

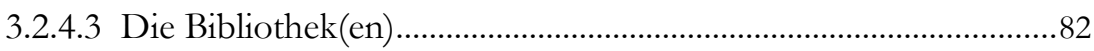

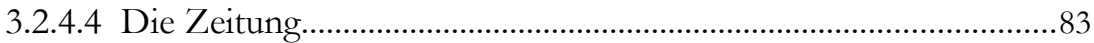

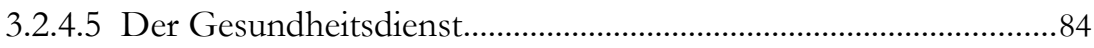

3.2.4.6 Der Südschleswigsche Wählerverband (SSW)..............................85

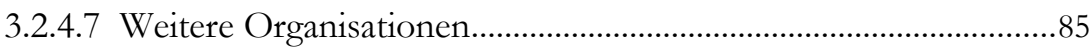

4. Dänischwerden I - Gründe und Hintergründe...............................87

4.1 Szenischer Einstieg in ein Dänischwerden und Dänischsein:

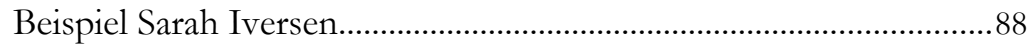

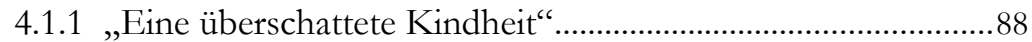

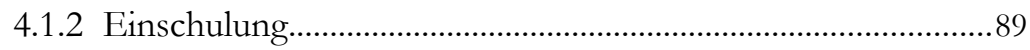

4.1.3 Zweite Geburt.........................................................................90

4.1.4 Dänemark....................................................................................92

4.1.5 Dänisch und deutsch? Leben in einer südschleswigschen Kleinstadt.

4.1.6 Verwitwet - nichts ist unmöglich............................................94

4.2 Gründe und Hintergründe für ein Dänischwerden................................95

4.2.1 Gründe für die Nachkriegsgeneration.....................................96

4.2.1.1 Materielle Gründe..............................................................................97

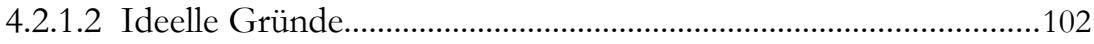

4.2.2 Gründe für ein Dänischwerden der Neudän*innen heute....107

4.2.2.1 Materielle Gründe...........................................................................109

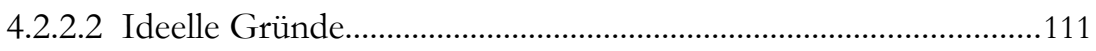

4.2.3 Weitere Gründe für ein Dänischwerden................................115 
5. Dänischwerden II - die Bedeutung der Schulen

5.1 Die Bedeutung der Schule: positive Erlebnisse und Gefühle....

5.1.1 Neue Erfahrungen im zwischenmenschlichen Umgang:

Vertrauen fassen durch gemeinschaftliche Erlebnisse

5.1.2 Die Schulwahl der Kinder der Nachkriegsdän*innen

5.1.3 Kinderferienreisen während der Schulzeit.

5.2 Die Rolle des Schulvereins: Anspruch, Wirklichkeit, Erwartungen,

Widersprüche

5.2.1 Ziele und Aufgaben des Dänischen Schulvereins und seiner Einrichtungen.

5.2.2 Erwartungen an die Angestellten des Schulvereins

5.2.3 Die dänischen Schulen und die Akteur*innen heute: Erwartungen und Praxen.....

5.2.4 Anspruch und Wirklichkeit, Abgrenzung und Offenheit: die dänische Schule als private oder öffentliche Schule.

6. Dänischwerden III: Integration in ein Dänischsein der Gegenwart.....177

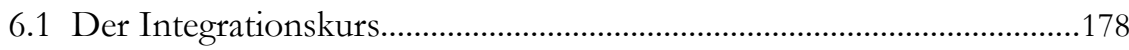

6.1.1 Ankunft - „und los geht's!!“ - szenischer Einstieg................181

6.1.2 Der erste Eindruck und „Intro“.............................................182

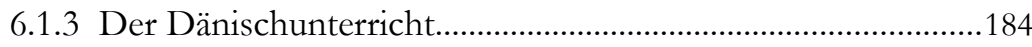

6.1.4 Exkursionen und kulturelles Rahmenprogramm....................185

6.2 Der Integrationsausschuss des Kulturvereins und Schulvereins..........188

7. Dänischsein und Dänischbleiben: Zugehörigkeiten, Erwartungen und Ideologien.

7.1 Dänischsein und Dänischbleiben im Verein: ein Ortsverband im Kulturverein SSF. 
7.2 Bindung an die Minderheit nach der Schulzeit. .205

7.3 Exkurs: Die Auswirkungen des Dänischseins auf das Berufsleben....216

7.4 Vorgaben und Erwartungen: Ambivalenzen und Widersprüche........219

7.5 Vielfalt im Dänischsein und das Abgrenzungsparadoxon .234

7.6 Die Beziehungen zum Königreich Dänemark: Abhängigkeit und „Aufklärung“.

8. Symbole, Mythen, Praxen der Zugehörigkeit

8.1 Dänischsein feiern und darstellen: (Jahres-)Feste. .260

8.1.1 Freitag, 27. Mai 2011, Drage. .262

8.1.2 Samstag, 28. Mai 2011, Friedrichstadt. .264

8.1.3 Sonntag, 29. Mai 2011, Tönning..... 265

8.1.4 Samstag, 09. Juni 2012, Friedrichstadt. .267

8.1.5 Samstag, 23. Juni 2012, Friedrichstadt: Sankt-Hans-Fest und Dansk Dag. .270

8.1.6 Sonntag, 09. Juni 2013, Tönning. 272

8.1.7 Årsmøderne: Die Bedeutung der Jahrestreffen .273

8.2 Gemeinsames Singen. 277

8.3 Æblekage und Boller: Speisen als Symbole. .281

8.4 Dannebrog: Flaggen und Fahnen als Symbole. 282

8.5 Die Rolle der Sprache. .285

8.6 Historisierungen, Mythen, Objektivierungs- und Legitimierungsversuche .296

8.7 Bekenntnis, Konversion und Beheimatung .312

9. Fazit und Ausblick: Dänischsein, Dänischwerden, Dänischbleiben...331

10. Anhang. 343

10.1 Übersicht über die Interview- und Gesprächspartner*innen .343

10.2 Amtszeiten und Funktionen der Funktionär*innen .345 


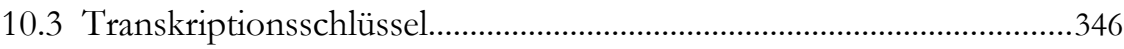

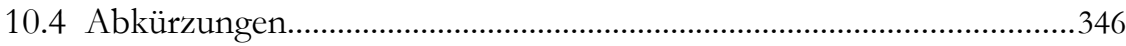

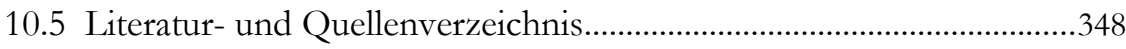

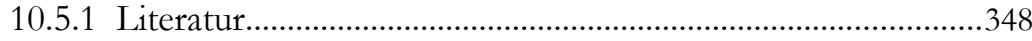

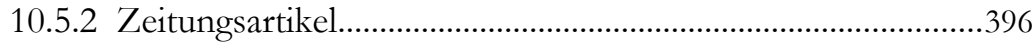

10.5.3 Radio-und Fernsehbeiträge, Filme........................................406

10.5.4 Vorträge...............................................................................406

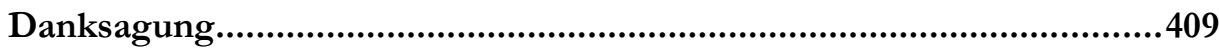





\section{Einleitung und Methoden}

„Der Däne in mir"

"Quizfrage: Wie kann ein Bayer ganz schnell Däne werden? Antwort: indem er nach Schleswig-Holstein qiebt; am besten in den nördlichen Landesteil, südlich von Flensburg. Dort muss er sich dann zum Dänentum bekennen - und schon ist er Mitglied der skandinavischen nationalen Minderbeit in der Bundesrepublik Deutschland. Dänische Vorfahren sind dabei entbehrlich, ebenso Kenntnisse der dänischen Sprache oder eine Schwäche für Smörrebröd. Das Bekenntnis reicht aus."

Gunther Latsch, Autor für „Der Spiegel“ (Latsch 29.04.2017: 52)

Mit diesen Worten nimmt Spiegel-Autor Gunther Latsch die dänische Minderheit in Schleswig-Holstein vor der Landtagswahl im Mai 2017 aufs Korn. Das, was in seiner Schilderung verwunderlich klingen mag, entspricht dem geschützten Status einer Bekenntnis- bzw. Gesinnungsminderheit und dem Prinzip ,Minderheit ist, wer Minderheit sein will ${ }^{6}$. Warum und wie dieses offene Prinzip entstanden ist 
und welche Auswirkungen es hat, ist Thema dieser Arbeit. Es werden die Fragen des Dänischwerdens und Dänischseins sowie dessen Auswirkungen untersucht. Warum werden Menschen dänisch, wie werden sie das, was tun sie, um dänisch zu sein und wie bleiben sie dänisch? Es geht darum, aufzuzeigen, warum Menschen sich selbst als dänisch bezeichnen, welche Praxen und Konstruktionen damit zusammenhängen und wie Funktionär*innen ${ }^{1}$ und Akteur*innen in ihrem Alltag damit umgehen und welche Widersprüche und Ambivalenzen, welche Strategien und symbolischen Aufladungen damit einhergehen können. Es wird die Frage beantwortet werden, ob man wirklich als Bayer, wie Latsch polemisch schreibt, dänisch werden kann und was man dafür tun muss, und was bestehende Minderheitsakteur*innen von einem erwarten, wenn man Minderheitsangehörige*r werden möchte. Die dänische Minderheit entstand durch politische Grenzverschiebungen und durch die individuelle Selbstidentifikation mit der Minderheit und die Wahl der Zugehörigkeit zu ihr, basierend auf nationaler Gesinnung. Dabei ist es nicht von Bedeutung, dass die Akteur*innen eine traditionelle oder verwandtschaftliche Verbindung zur Minderheit gehabt hätten oder haben (Kühl 2003: 101-102, 183 sowie TNB Summer School 26.08.2013 und Podiumsdiskussion DCBIB FL 31.10.2007). Es sind keine objektiven oder vermeintlich objektiven Kriterien wie Herkunft oder Religionszugehörigkeit nötig, um sich zur dänischen Minderheit zu bekennen. Dieses Prinzip der Voluntarität bedeutet auch, dass niemand vom Staat, von der Minderheit oder von Mehrheitsangehörigen als Minderheitszugehörige*r erfasst oder die Gesinnung von staatlichen Einrichtungen infrage gestellt werden darf (ebd.: 183).

Diese subjektive nationale Gesinnung führt einerseits zu Ambivalenzen, Uneindeutigkeiten, Überschneidungen, Widersprüchen, Unklarheiten und selbst gestellten Erwartungen und ist andererseits eine nahezu ideale Situation mit innovativer Bekenntnisoffenheit, Übergängen und Wahlmöglichkeiten und ohne Diskriminierungen. Gerade die freie Gesinnungswahl oder -nichtwahl und die damit verbundenen Uneindeutigkeiten für Akteur*innen wirft jedoch die Frage auf, welche Auswirkungen die gute rechtliche Lage auf die Minderheitssituation und die Menschen im Alltag hat. Das offizielle Nichtvorhandensein von objektiven Kriterien für das Bekenntnis zum Dänischsein bringt andere Identifizierungsstrategien der dänisch- und deutschgesinnten Akteur*innen mit sich als das Vorhandensein von vermeintlich objektiven Kriterien und deren offizielle Erfassung, wie es beispielsweise in Südtirol der Fall ist (Constantin 28.08.2013).

In Zeiten globaler Migration und Deutschlands Rolle als Einwanderungsland lohnt sich ein Blick auf die sogenannten autochthonen Minderheiten in Deutschland, die sich von immigrierten Minderheiten explizit abgrenzen. Um zu verste-

In dieser Arbeit wird im Sinne einer geschlechtergerechten Sprache die Sternchenvariante (Bsp. Bürger*innen) verwendet. Damit sind nicht nur Frauen und Männer gemeint, sondern auch alle anderen möglichen Geschlechtervariationen. 
hen, wie nationale Minderheiten funktionieren, sich verändern, wie Minderheitenakteur*innen Symbole und Bedeutungen verhandeln und Praktiken aufrechterhalten und welchen Einfluss Institutionen wie Vereine dabei haben können, wird hier ein kulturanthropologischer Blick auf die dänische Minderheit im Landesteil Schleswig geworfen. Der alltags- und praxistheoretische Ansatz eröffnet einen Zugang zu Widersprüchen und Ambivalenzen, Rechtfertigungsversuchen und Heimatbestrebungen, zu verwendeten Symbolen und Historisierungen, zur Rolle der Sprache und zu einer spezifischen Form der Integrationssteuerung in der Minderheit. Die Motivation für das Forschungsthema rührt einerseits von der Beschäftigung mit Ethnisierungsprozessen im Studium und andererseits von meinem Interesse an der deutsch-dänischen Grenzregion, dem skandinavischen Raum und meinen entsprechenden Sprachkenntnissen her.

Die Federal Union of European Nationalities (FUEN, dt. FUEV) ${ }^{2}$ mit Sitz in Flensburg konstatiert, dass es in Europa 47 Staaten mit 340 sogenannten oder sich selbst so nennenden Volksgruppen gibt. Damit gehört jede*r siebte Bürger*in, also über 100 Millionen Menschen in Europa, einer Minderheit an (Federal Union of European Nationalities 2014; Kühl 2003: 26; Pan, Pfeil 2016: 4; Pan 2016b: 228). Aus dieser Größe resultiert eine hohe Relevanz für die Erforschung von Minderheiten in Europa und der restlichen Welt. Dabei ist es wichtig zu verstehen, wie nationale Minderheiten funktionieren. Erkenntnisse, die anhand des Beispiels der dänischen Minderheit gewonnen werden, können hilfreich sein, auch andere Minderheitensituationen in anderen Regionen und Ländern besser zu verstehen und ggf. auftretende Probleme zu erkennen und einzuordnen. Die FUEN ist es auch, die eine EU-Bürgerinitiative ins Leben gerufen hat, bei der von April 2017 bis April 2018 mindestens eine Million Unterschriften in der EU gesammelt wurden, um damit die EU zu einem umfassenderen Minderheitenschutz zu drängen (Federal Union of European Nationalities 2017; Europäische Bürgerinitiative 2017).

Die dänische Minderheit ist neben den Friesen, den Sinti und Roma ${ }^{3}$ und den Sorben eine von vier anerkannten nationalen Minderheiten bzw. Volksgruppen in Deutschland, von denen alle außer der letztgenannten in Schleswig-Holstein ansässig sind. Die Situation im deutsch-dänischen Grenzgebiet mit den Minderheiten südlich und nördlich der Staatsgrenze wird zumindest in Teilen von einigen

2 Die FUEN/FUEV vereint mehr als 90 Mitgliedsorganisationen in 32 europäischen Ländern und ist damit der größte Dachverband der autochthonen nationalen Minderheiten in Europa (vgl. Federal Union of European Nationalities 2013).

Dazu zählen ca. 60.000 deutsche Sinti und ca. 10.000 deutsche Roma, die schon lange auf dem Gebiet der Bundesrepublik leben, nicht jedoch in der Gegenwart ab der Nachkriegszeit eingewanderte Roma von z. B. der Balkanhalbinsel (Hofmann 2015: 90). 
Expert*innen als ein - wenn auch nicht eins zu eins übertragbares - Modell für andere Minderheiten bewertet. Dies war ein erklärtes Ziel der Bonn-Kopenhagener-Erklärungen, so der schleswig-holsteinische Ministerpräsident von 1955, KaiUwe von Hassel. ${ }^{4}$

Ausgehend von einem der Ergebnisse meiner Magisterarbeit ${ }^{5}$, nämlich dass die langfristige Bindung der Menschen an das Dänische ohne praktische Anbindung im Alltag nicht gesichert ist, halte ich es nun für wichtig, ergänzend zu untersuchen, wie eine sogenannte nationale Gesinnung und Zugehörigkeit nach dem Ende der Schulzeit aufrechterhalten werden kann. Ausgangspunkt der vorliegenden Dissertation ist daher die Annahme, dass als Vereine organisierte Institutionen das zentrale „Instrument“ sind, „mit dem die dänische Minderheit [...] die ständige Reproduktion der Minderheit sicherstellt" (Christiansen 2008: 160). Das Dänischsein wird durch die Förderung des Zusammenhalts und der Bindung an die Minderheit aufrechterhalten. Für den Fall eines Bindungsverlustes befürchten Akteur*innen eine Assimilierung an die deutsche Mehrheit, gerade dann, wenn Menschen die dänische Schullaufbahn abgeschlossen haben, und dadurch den täglichen Kontakt zu dänischen Institutionen verlieren, wie das Beispiel eines Interviewpartners zeigen wird. „Die Minderheit ist, was sie macht, aber darunter fällt auch, was sie über sich selbst sagt " ${ }^{\text {" }}$, so der dänische Philosoph Klausen (Klausen 07.07.2016). Deshalb wird hier untersucht, welche kulturellen Praxis die Minderheitsakteur*innen ausüben und was sie über sich selbst sagen, was sie tun.

Da in dieser Arbeit die „exemplarische Erforschung“ (Schmidt-Lauber 2007a: 12) von Minderheiten- bzw. Gruppenbildung ,in lebensweltlichen Ausschnitten“ (ebd.: 12) im Fokus steht und die Geschichten und Sichtweisen von „handelnden, erfahrenden und deutenden Akteur*innen[n]" (ebd.: 12) beschrieben und analysiert werden sollen, wurden qualitative Datenerhebungsmethoden gewählt. Der praxistheoretische Ansatz erlaubt dabei eine „enge Verschränkung von Theorie, Methodologie und Empirie“ (Schäfer 2016: 14). Eine Hauptquelle zur „Erfassung und Analyse der subjektiven Perspektive“ (Hopf 2000: 350) des Samples sind

4 Der zugeschriebene Modellstatus wird von wissenschaftlicher Seite allerdings eingeschränkt, da die Minderheitensituationen und -kontexte für Minderheiten in anderen Regionen unterschiedlich sind (Kühl 2009: 273; Kühl 2006b: 24-26; Kühl 2005b; Kühl 2003: 167-168; vgl. Jürgensen 2003; vgl. Popova et al. 2016: 4, 20).

In meiner unveröffentlichten Magisterarbeit „Dänischwerden und Dänischsein in einer südschleswigschen Kleinstadt. Vom Schulbesuch in der Nachkriegszeit bis zum Rentenalter" (2010) habe ich bereits die zentrale Bedeutung des Besuchs einer dänischen Schule für die Bindung von Menschen an die dänische Minderheit herausgearbeitet. Die Erkenntnisse aus den Interviews mit Angehörigen der Nachkriegsgeneration sowie die Kapitel 4.1, 4.2.1, 5.1 und 7.2 beruhen auf der damaligen Forschungsarbeit.

6 „Mindretallet er hvad det gør, men herunder også hvad det siger om sig selv.“ Alle dänischsprachigen und norwegischsprachigen Zitate in dieser Arbeit wurden von der Verfasserin dieser Arbeit ins Deutsche übersetzt und werden in den Fußnoten im Original angeführt. 
zehn Interviews mit insgesamt elf Personen im Zeitraum von Juni 2008 bis Juli 2013. ${ }^{7}$ Weitere verwendete Methoden und damit Datenquellen sind teilnehmende Beobachtungen, die Analyse von Dokumenten sowie zahlreiche informelle Gespräche. Um dabei beobachtete ,[a]lltägliche Ausdrucksweisen und Handlungs-

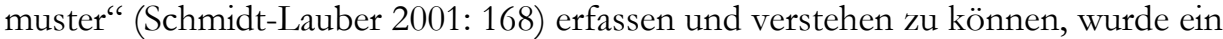
Feldforschungstagebuch mit Protokollen, Gedanken und Berichten geführt. Über einen Zeitraum von mehr als eineinhalb Jahren habe ich beim ,Freitagsklub ${ }^{68}$ immer wieder teilnehmende Beobachtungen gemacht. Dort lernte ich einige Interviewpartner*innen kennen und informierte mich über Neuigkeiten und aktuelle Diskussionen bei den anwesenden Akteur*innen der Minderheit. Nach ersten Feldforschungsaufenthalten wurde ein ausführlicher Leitfaden mit Fragen an das Feld erstellt, der für weitere Feldforschungen und Interviews im Sinne der Grounded Theory diente und der im Forschungsverlauf immer wieder angepasst wurde.

Da es keine offiziellen Daten darüber gibt, wer zur dänischen Minderheit gehört und wer nicht, ist es schwierig, das breite, unregistrierte und undefinierte Spektrum von möglichen Angehörigen der dänischen Minderheit abzudecken und einzelne Personen in einer annähernd repräsentativen Auswahl als Informant*innen zu gewinnen. Eine Schwierigkeit im Auffinden und Kontaktieren von potenziellen Gewährsleuten der dänischen Minderheit ist - abgesehen vom Kontakt zu ihnen über die dänischen Minderheitsvereine - deren Nichtsichtbarkeit im Alltag, so die Linguistin Karen Margrethe Pedersen:

Ihre Wohnorte liegen nicht in bestimmten Straßen oder Quartieren [...]. Sie arbeiten auch nicht an bestimmen Arbeitsplätzen, abgesehen von denen, die ihren Erwerb in den Institutionen und Vereinen der Minderheit haben. Ansonsten charakterisiert die Minderheit, dass sie kein eigenes Erwerbsleben hat. [...] Das macht es [...] schwierig die traditionellen ethnografischen Methoden anzuwenden und die Informanten der Min-

Die Länge der einzelnen digital aufgenommenen Interviews beträgt zwischen eineinhalb und drei Stunden. Die Gesamtlänge des Tonmaterials beträgt rund 19 Stunden und ist Grundlage für 408 Transkriptionsseiten.

8 Der Fredagsklubben, der Freitagsklub, findet jeden Freitagvormittag in Friedrichstadt statt und ist offen für jeden. Es gibt Kaffee und Kuchen, manchmal auch ein warmes Mittagessen, und es besteht die Möglichkeit des Austausches untereinander. Hier verabredet man sich für den gemeinsamen Besuch von Vorträgen, Konzerten oder Ausflügen. Viele der Teilnehmerenden bekennen sich zur dänischen Minderheit, einige sind nur da, weil sie es dort „nett“ finden oder weil ihr Ehepartner*innen dänisch gesinnt ist. Nicht alle können Dänisch sprechen, deshalb wird fast nur Deutsch gesprochen, es sei denn, es sind dänische Staatsbürger*innen oder Vereinsfunktionär*innen anwesend. Die meisten der Teilnehmenden kennen sich von früher aus der Schulzeit bzw. aus ihrer Kindheit in Friedrichstadt. 
derheit im öffentlichen Raum aufzusuchen, dort, wo sie sich bewegen, wenn sie von Zuhause auf dem Weg zur Arbeit sind, wenn sie in Geschäfte gehen oder einen Kaffee in einem Café in dem Viertel, in dem sie wohnen, trinken, wenn sie öffentliche Ämter oder Institutionen aufsuchen (Pedersen 2000a: 27). ${ }^{9}$

Ein anderes Problem bei der Datenerhebung für eine Dissertation über die dänische Minderheit hatte der Erziehungswissenschaftler Arthur Christiansen. Er wollte zufällig ausgewählte Personen von Mitgliederlisten dänischer Vereine und der dänischen Partei, dem SSW, per Fragebogen anonym befragen. Dieser Zugang wurde ihm aber aufgrund von vereins- und parteipolitischen Bedenken, aus Datenschutzgründen und aus Gründen der ihm vorgeworfenen vermuteten Unwissenschaftlichkeit von den meisten Organisationen verwehrt. ${ }^{10}$

Die hier genannten Voraussetzungen im Feld führten zu dem Entschluss, erstens das Schneeballprinzip anzuwenden, ausgehend von einer mir persönlich bekannten Gewährsperson, mit der ich das erste Interview führte, und zweitens potenzielle Interviewpartner*innen bei teilnehmenden Beobachtungen in dänischen Institutionen und Vereinen anzusprechen, sie kennenzulernen und so mit ihnen und weiteren Informant*innen in Kontakt zu treten. ${ }^{11}$

Für das Interviewsample aus der Nachkriegsgeneration wurden gezielt nur solche Menschen ausgewählt, die eine dänische allgemeinbildende Schule besucht haben, weil meine Anfangsvermutung ist, dass der Besuch der dänischen Schule im Wesentlichen dazu beiträgt, dass sich Leute dänisch fühlen. Die Gruppe wurde also aus der Forschungslogik heraus auf Rentner*innen eingegrenzt. ${ }^{12}$ Es geht darum herauszufinden, wie und wodurch Menschen, die auf ihr Leben zu-

9 „Deres bopæl er ikke i bestemte gader eller kvarterer [...]. De arbejder heller ikke på bestemte arbejdspladser, lige bortset fra dem der har deres erhverv i mindretallets institutioner og foreninger. Ellers er mindretallet karakteriseret ved ikke at have sit eget erhversliv. [...] Dette gør det [...] svært at benytte traditionelle etnografiske metoder og opsøge informanter fra mindretallet $i$ det offentlige rum som de færdes i når de tager hjemmefra og på arbejde, når de går $\mathrm{i}$ forretninger eller tager sig en kop kaffe på en cafe i det kvarter hvor de bor, og når de tager til offentlige kontorer og institutioner."

10 Christiansens Ansicht nach ist dies eine bewusste Verweigerungshaltung, um seine Studie über die dänische Minderheit zu blockieren „um nicht die ganze Konstrukthaftigkeit des Minderheitenmodells aufzudecken. Der derzeit diskutierte Veränderungsprozess in der Minderheit ist nämlich höchst politisch“ (Christiansen 2008: 194; vgl. a. Klatt 2009a: 136).

11 Vgl. auch den ähnlichen Ansatz von Pedersen (Pedersen 2000a).

12 Ich habe nur diejenigen interviewen können, die in Friedrichstadt und Umgebung geblieben oder dorthin zurückgekehrt sind und nicht solche Dänischgesinnten, die das Abitur am dänischen Gymnasium in Flensburg gemacht und anschließend studiert und deshalb Südschleswig verlassen haben, da es in dieser Region außer einer kleinen Einrichtung in Flensburg und einer Volluniversität in Kiel keine Universitäten gibt. Vielleicht hätten genau diese Leute andere Sichtweisen auf ihr Dänischsein gehabt und möglicherweise hätten sie sich eine andere Verbundenheit zum Landesteil aufgebaut. 
rückblicken, dänisch geworden sind und welche Auswirkungen der Besuch einer dänischen Schule statt einer deutschen Schulen in Bezug auf lebenslanges Dänischsein haben kann. ${ }^{13}$ Der Kreis von möglichen Interviewpartner*innen wurde geografisch eingegrenzt auf die Kleinstadt Friedrichstadt, an Eider und Treene im Süden des Landkreises Nordfriesland und damit an der Südgrenze Südschleswigs gelegen.

Nach einer Auswahl in Bezug auf das Alter konnte ich durch den o. g. persönlichen Vermittler und „Türöffner“" schnell Menschen gewinnen, die bereit waren, mir ein Interview zu geben. Acht meiner neun Interviewpartner*innen aus der Nachkriegsgeneration, vier Frauen und fünf Männer, haben im Nachkriegsjahrzehnt die am 24. September 1946 eröffnete dänische Hans-Helgesen-Schule in Friedrichstadt (vgl. Vollertsen 1994b: 139, INT03) ${ }^{14}$ besucht und sind jetzt Rentner*innen. Der neunte Interviewpartner dagegen wohnt jetzt in Friedrichstadt, kommt aber gebürtig aus Flensburg, und hat dort die dänische Schule besucht und auch bis zur Rente dort gelebt und gearbeitet.

Von den neun Gesprächspartner*innen (s. Anhang) haben fünf vor ihrer dänischen Einschulung die deutsche Volksschule in Friedrichstadt oder in einem der umliegenden Dörfer besucht. Die anderen drei sind direkt dänisch eingeschult worden, da sie etwas jünger sind, und die dänische Schule schon eröffnet war, als sie schulpflichtig wurden. ${ }^{15}$ Zwei von diesen dreien haben vor ihrer Einschulung den dänischen Kindergarten besucht.

Die familiäre Situation der Interviewpartner*innen sieht so aus, dass sechs Personen verheiratet und drei verwitwet sind. Die Männer im Sample sind alle ausgebildete Handwerker. Von den vier Interviewpartnerinnen haben drei die Schule nach der neunten Klasse verlassen und keine Berufsausbildung gemacht. Sie arbeiteten hauptsächlich als ungelernte Hilfskräfte, als Putzkräfte oder Altenpflegerinnen. Darüber hinaus engagierten sich manche in gemeinnützigen Vereinen wie dem Roten Kreuz. Ihre Hauptaufgabe war es aber, den eigenen Haushalt zu führen, die Kinder aufzuziehen, den Ehemann im Betrieb zu unterstützen (INT09)

13 Die Datenerhebung mit dieser Informant*innengruppe der Nachkriegsgeneration erfolgte weitgehend im Rahmen meiner Magisterarbeit. Aus diesem Umstand erklärt sich auch der zeitliche Abstand zum letzten Interview mit einer lokalen Akteurin aus der nachfolgenden Generation.

14 Das ist eine Art Grund- und Gemeinschaftsschule, damals mit den Schulklassen 1 bis 9, heute 1 bis 7 .

15 Otto Clausen ist zwar auch einer der Jüngeren aus meinem Sample, bei ihm lag der Grund für den Besuch der dänischen Schule aber auch darin, dass es in Flensburg schon seit 1920 dänische Schulen gab (Skoleforening for Sydslesvig 2009b). 
oder kranke Angehörige „zu Ende“ (INT06) zu pflegen. Nur eine der interviewten Frauen hat nach dem „Realexamen“ eine Berufsausbildung angefangen und auch abgeschlossen (INT02).

Der Kontakt zu den Menschen der zweiten Gruppe, den heutigen Neudän*innen, entstand über einen intensiven Feldforschungsaufenthalt bei einem Integrationskurs für neudänische Eltern (s. Kap. 6.1). Darüber hinaus führte ich mit einer lokalen Funktionärin des dänischen Kulturvereins in Friedrichstadt ein ausführliches Interview und einige weitere informelle Gespräche auf Versammlungen und Festen ihres Ortsvereins. Sie, Tina Zehntner, ist eine Generation jünger als die Nachkriegsinformant*innen. Der Kontakt zu ihr kam über teilnehmende Beobachtungen zustande.

Sprachlich gesehen sieht die Situation der meisten Südschleswiger*innen und aller Interviewten meines Samples aktuell so aus, dass Deutsch ihre Erstsprache ${ }^{16}$ ist. Dänisch dagegen ist Zweit- ${ }^{17}$ bzw. Drittsprache neben Niederdeutsch. Bei den teilnehmenden Beobachtungen in Friedrichstadt wurde untereinander überwiegend Deutsch gesprochen, aber auch etwas Dänisch mit Funktionär*innen, Lehrer*innen und Reichsdän*innen. Die Interviews wurden alle auf Deutsch geführt, teilweise mit vereinzelter Verwendung von dänischen und plattdeutschen Ausdrücken.

Bei der Wahl des Interviewverfahrens erschien eine „Verbindung unterschiedlicher Interviewformen $[\ldots]$ zwischen teilstandardisierten und narrativen Interviews“ (Hopf 2000: 353) bzw. „zwischen narrativen und Leitfaden-Interviewformen" (Helfferich 2005: 11) sinnvoll, damit zum einen eine Vergleichbarkeit der Interviews erreicht werden konnte, und zum anderen Raum blieb für individuelle Erzählungen. Deshalb wurde die Mischform eines wenn möglich teilnarrativen (vgl. ebd.: 159), sonst aber eher leitfadenorientierten, problemzentrierten Interviews gewählt. Die Fragen sollten zum Erzählen anregen, was bei den verschiedenen Interviewten unterschiedlich gut funktioniert hat und von der Erzählfreude und -übung sowie dem Grad von „Reflexivität und Eloquenz“ (Witzel 2000: o. S.) der Einzelnen abhing. Der Leitfaden für die Gespräche enthielt nach Themen sortierte Stichpunkte, die meiner Orientierung dienten, so auch vorgesehen bei problemzentrierten Interviews (vgl. Bausinger 1999a: 176), und sicherstellten,

16 Der Begriff Erstsprache ersetzt in der aktuellen sprachwissenschaftlichen Forschung den ,,mit einer negativen Bewertung früher Mehrsprachigkeit“ konnotierten Begriff der „Muttersprache“ (Andresen 2000: 192), welcher, äquivalent zu „Vaterland“, mit einer starken Verbindung von Nation und Einheitssprache konnotiert ist.

17 Im Unterschied zu Fremdsprachen sind Zweitsprachen in der Regel mit einer stärkeren „biograph. Bedeutung für den Lernenden“" und einer geringeren Steuerung des Lernens (z. B. in einem dänischen Umfeld und nicht nur zweimal wöchentlich in der Schule) verbunden. Außerdem kann eine Zweitsprache auf einem höheren Niveau angewandt werden, welches ,selbständiges, mehrere Register umfassendes und nicht auf eingeübte Situationen und Themen beschränktes Kommunizieren erlaubt“ (Glück 2000: 814). 
dass alle Themenbereiche angesprochen wurden. Die Reihenfolge der Stichpunkte im Leitfaden spielte im Interview keine Rolle, sondern es wurde versucht, „die Fragen situationsangemessen im Gespräch einfließen zu lassen“ (ebd.: 176). Zur Vermeidung einer zu starken Abweichung (vgl. Helfferich 2005: 159) vom allgemeinen Fokus auf das Dänischsein und -werden wurden keine rein narrativen biografischen Interviews (vgl. Hopf 2000: 353) geführt, obwohl inhaltlich die Biografien der Gesprächspartner*innen in Bezug auf ihr Dänischsein im Zentrum standen. Durch die Mischform sollte die emische Perspektive der Akteur*innen erfasst werden können, die durch meine etische Sicht auf das Feld ergänzt wurde (vgl. Roth, Roth 2001: 410-411). Der Vorteil von hauptsächlich problemzentrierten Interviews, die auf der Grounded Theory basieren (vgl. Witzel 2000: o. S.), ist „eine möglichst unvoreingenommene Erfassung individueller Handlungen sowie subjektiver Wahrnehmungen und Verarbeitungsweisen gesellschaftlicher Realität" (ebd.: o. S.). Die Akteursperspektive ermöglicht dabei das Einbeziehen von vorher oder im Interview durch „Prozessorientierung“ angeregter/n „Selbstreflexion[en]“ (ebd.: o. S.) der Interviewten in das Datenmaterial. Nach jedem Interview wurde ein Gesprächsprotokoll angefertigt, in dem Interviewsituation, -verlauf und -umgebung notiert wurden. Außerdem wurde darin beschrieben, wie es zu dem Kontakt kam, und ob es Besonderheiten oder Auffälligkeiten vor oder nach dem Gespräch oder währenddessen gab. Erste Analysen und Reflektionen an der eigenen Vorgehensweise wurden festgehalten.

Nach der Zusicherung der Anonymität begannen die bei den jeweiligen Interviewten zu Hause durchgeführten Interviews meist mit einer erzählgenerierenden „Einleitungsfrage“ (ebd.: o. S.), die darauf abzielte, die Interviewten erst einmal darüber berichten zu lassen, wie es dazu kam, dass sie die dänische Schule besuchten oder warum sie jetzt in der Minderheit aktiv sind, je nach der individuellen Situation der Interviewten. Es folgten ,allgemeine Sondierungen“ (ebd.: o. S.), also das Aufgreifen von genannten Stichpunkten oder sich aus der Erzählung ergebenden Fragen, die ergänzt wurden durch „Ad-hoc-Fragen“ (ebd.: o. S.) aus dem vorbereiteten stichwortartigen Leitfaden. Dieser war bei den ersten acht Interviews in die drei Hauptthemenbereiche ,Kindheit und Jugend', ,Berufsleben' und ,Rentenalter/Rückblick auf bisheriges Leben' gegliedert, jeweils mit Bezug auf das Thema Dänischsein. Das Interview mit der Ortsfunktionärin Tina Zehntner war ebenfalls durch einen Leitfaden gestützt. Der erste Themenbereich war dabei der persönliche Bezug der Interviewten zur Minderheit sowie Biografisches, bevor als zweiter Schwerpunktbereich ihre Sichtweise als Ortsfunktionärin des SSF auf die Minderheit, auf ihre Funktionärs- und Vereinstätigkeit und auf ihren Ortsverein und dessen Akteur*innen behandelt wurde. Dabei waren diese beiden Bereiche nicht strikt voneinander getrennt, sondern wurden immer wieder miteinander verflochten, beispielsweise als es um den Punkt Kontakt nach Dänemark ging, der persön- 
liche Kontakte sowie die Kontakte als Funktionärin beinhaltete. Tina Zehntner war sehr offen und hilfsbereit und schlug von sich aus weitere Informant*innen vor, die ich kontaktieren und befragen könne. Zum Teil waren das Leute, mit denen ich bereits gesprochen hatte. Mit anderen führte ich informelle Gespräche, wiederum andere konnte ich aus zeitlichen Gründen oder weil diese Personen weggezogen waren, nicht erreichen. ${ }^{18}$

Die Ergänzung der Interviews durch teilnehmende Beobachtungen ist deshalb besonders sinnvoll, weil dadurch gemachte Beobachtungen näher am eigentlichen Geschehen sind, auch wenn sie durch den unvermeidlichen Filter der Forschenden beschrieben werden. In Interviews wird darüber gesprochen, wie Geschehnisse sich aus Sicht eines Betroffenen vollziehen oder vollziehen sollten (vgl. Flick 2012: 281).

Ein zentraler Bestandteil der Datenerhebung waren die teilnehmenden Beobachtungen im Rahmen der Feldforschungsaufenthalte in Friedrichstadt, Tönning, Husum und Jaruplund. Im Rahmen meiner Magisterarbeit begann die Feldforschung bereits 2007 beim Besuch einer Podiumsdiskussion in der Flensburger Zentralbibliothek mit ehemaligen Schüler*innen der Flensburger Duborg-Skolen einige Jahre nach ihrem Abitur. Weitere besuchte Veranstaltungen waren beispielsweise ein Erntedankfest, ein Tag der offenen Tür des dänischen Gymnasiums in Schleswig ${ }^{19}$, Konzerte und Treffen des Hausfrauenvereins ${ }^{20}$. Außerdem habe ich dänische Gottesdienste besucht, die regelmäßig in der Friedrichstädter Mennoni-

18 Die anschließende vollständige Transkription der Interviews erfolgte in Anlehnung an Sabine Kowal und Daniel O'Connell größtenteils in „Standardorthographie“ (Kowal, O'Connell 2000: 441) und in „Zeilenschreibweise“ (ebd.: 439). Dort wo es starke oder besonders auffällige Abweichungen von der Standardsprache gab, wurde eine „literarische Umschrift“ (ebd.: 441) angefertigt. Geschehnisse in der Umgebung während des Gesprächs wurden bei inhaltlicher Relevanz vermerkt, ebenso die relevanten parasprachlichen Vorkommnisse wie Lachen, Husten, Füllwörter oder Pausen. Auch besondere prosodische Auffälligkeiten wie starke Betonungen von Wörtern oder Silben oder besonders auffällige Lautstärkewechsel wurden bei Relevanz in Bezug zur Fragestellung im Transkript berücksichtigt (vgl. Flick 2012: 380). Der Transkriptionsschlüssel befindet sich im Anhang dieser Arbeit (S. 346). Nach der Transkription und Korrektur derselben sowie mehrmaligem gründlichem Lesen aller Interviews wurden Kategorien gebildet. Diese wurden nach Themen und Lebensabschnitten kodiert und geordnet und anschließend in Anlehnung an Schmidt (2000), Fuchs-Heinritz (2005) und Witzel (2000) ausgewertet, sodass danach Einzelfälle herausgearbeitet bzw. anhand der Themen Beispiele und Belege extrahiert werden konnten. Es wurden bei der Erhebung und Analyse des Datenmaterials, teilweise durch eine thematische Codierung mit der Software Atlas.ti, auch Elemente von Glaser und Strauss Grounded Theory angewandt, wie z. B. das „Vergleichen“, die „Suche nach Ähnlichkeiten und Unterschieden“ "(Böhm 2000: 476 in Anlehnung an Busse; vgl. a. Froschauer, Lueger 2003: 163-165) in den im Interviews sowie der Vergleich mit „einschlägiger Literatur (Fachpublikationen, aber auch: journalistische[n] Arbeiten, Romane[n] und Erzählungen)“ (Böhm 2000: 476). Aufkommende Ideen und Einfälle wurden während der Analyse in Anlehnung an die Grounded Theory als sogenannte „Memos“ notiert (ebd.: 477).

19 A. P. Möller-Skolen.

20 Husmoderforeningen in Friedrichstadt. 
tenkirche von einem dänischen Pastor abgehalten wurden. Dieser veranstaltete jeweils vier bis sechs Mal im Jahr auch Film-, Vortrags- und Leseabende, an denen ich ebenso teilgenahm. Außerdem wurden Zeitungsausschnitte, Broschüren, Selbstzeugnisse sowie vor allem dänisch-, deutsch- und englischsprachige Fachliteratur beim Einstieg ins Feld und bei der Auswertung hinzugezogen. Zusätzlich habe ich dänisch- und deutschsprachige Vorträge ${ }^{21}$ über die Minderheit besucht.

Schwerpunkt der teilnehmenden Beobachtungen war zum einen der Besuch mehrerer Jahrestreffen ${ }^{22}$ über drei Jahre hinweg sowie eines Tages der offenen Tür, Dansk Dag, dänischer Tag genannt, inklusive Sankt-Hans-Fest der Minderheit in der Kleinstadt Friedrichstadt ${ }^{23}$. Ich besuchte 2008 eine Amtsvorstandssitzung in Husum und 2013 eine Distriktsjahreshauptversammlung in Friedrichstadt ${ }^{24}$. Zusätzlich beobachtete ich das Drachenbootrennen auf dem Westersielzug des Flusses Treene, bei dem Akteur*innen der dänischen Minderheit als Mannschaft teilnahmen. ${ }^{25}$ Ich besuchte die Husumer Bibliothek sowie die Flensburger Zentrale der Dänischen Bibliothek und nahm am Café Kik Ind (Café Guck Herein) in Husum teil.

Ein weiterer Schwerpunkt war meine Teilnahme an einem fünftägigen Integrationskurs für Eltern, die ihre Kinder dänisch eingeschult haben, selbst aber nicht aus der dänischen Minderheit kommen. Ausgehend vom Forschungsvorhaben, den Fokus auf die dänischen Minderheitsangehörige und -institutionen in Friedrichstadt zu richten, bot sich im Herbst 2013 die Chance, bei einem zentralen, südschleswigweiten Integrationskurs für Neudän*innen teilzunehmen (s. Kap. 6). Da dies eine gute Gelegenheit war, teilnehmend Integrationsmaßnahmen, kommunizierte Erwartungen und eingeübte Praktiken zu beobachten, weitete ich das Forschungsfeld aus. Daher gibt es in dieser Arbeit zum einen den Friedrichstädter Strang mit den Interviews sowie teilnehmenden Beobachtungen und zum anderen den Strang, der aus dem Integrationskurs und schleswigweiten Vereinsdokumenten, Zeitungsberichten und Diskussionen besteht. Ziel der Feldforschung beim Integrationskurs war herauszufinden, was Minderheitenfunktionär*innen Integrationswilligen in komprimierter Form über das Dänischwerden und -sein beibringen wollen. Es ging darum, welche Erwartungen an Neudän*innen gestellt und

21 z. B. „Hvor blev de af? Unge sydslesvigere møder verden“, „Sydslesvig for 40 år siden en filmrejse“ und „Skoler før og nu“ mit dem Archivar und Historiker Lars Henningsen in der Dänischen Zentralbibliothek Flensburg und „Ein europäisches Modell“ mit dem Historiker Jørgen Kühl in der alten Synagoge in Friedrichstadt.

22 27.05.-29.05.2011 in Drage, Friedrichstadt, Tönning; 08.06.-10.06.2012 in Drage, Friedrichstadt, Husum; 07.06.-09.06.2013 in Drage, Friedrichstadt, Tönning

$23 \quad 23.06 .2012$

$24 \quad 12.02 .2013$

$25 \quad 17.08 .2013$ 
mit welchen Ideologien sie konfrontiert werden würden und wie dies vermittelt werden würde. Außerdem ging es darum zu beobachten, wie die zu Integrierenden diese Erwartungen und Vorgaben aufnehmen würden.

Neben den oben genannten, selbst erhobenen Daten wie Interviews, Feldforschungstagebüchern und Notizen zu informellen Gesprächen habe ich auch eine von mir transkribierte Radioreportage über die dänische Minderheit (Werner 16.05.2016) sowie zahlreiche schriftliche Dokumente wie Protokolle, abgedruckte Reden, Jahrbücher der dänischen Minderheit analysiert (Sydslesvigsk Forening 2010; Sydslesvigsk Forening 2011; Sydslesvigsk Forening 2012; Sydslesvigsk Forening 2013b; Sydslesvigsk Forening 2014) Des Weiteren nutzte ich Rechenschaftsberichte, Onlineveröffentlichungen, Zeitungsartikel und Leserbriefe sowie einen dänischen Film mit Dokumentaranspruch für meine Forschungszwecke. ${ }^{26}$

Mit finanzieller Unterstützung des Südschleswigausschusses des dänischen Parlamentes in Höhe von rund $300.000 €$ (vgl. Rebsdorf 31.05.2013) haben Lars Feldballe Petersen, die Studienabteilung und das Archiv der Dänischen Zentralbibliothek 2014 den Film De glemte danskere, Die vergessenen Dänen, des Regisseurs Mads Kamp Thulstrup als DVD herausgegeben und gleichzeitig Unterrichtsmaterial für dänische Schulen mitproduziert (Petersen [2014]) ${ }^{27}$. Das Ziel des Filmes ist, der dänischen Bevölkerung zu erzählen, wer und was die Minderheit in Südschleswig ist, und wer die vergessenen Dänen sind (Nissen, Petersen 07.04.2014b). Die Filmemacher haben den Anspruch, keinen Werbefilm zu produzieren, sondern auch Konflikte in der Minderheit in Bezug auf Erwartungen an Minderheitsangehörige darzustellen. Dabei solle der Unterhaltungswert nicht zu niedrig ausfallen (ebd.). Der Film zeigt Widersprüche innerhalb der Minderheit zwischen Nationalisten und Pragmatikern. Allerdings ist die Ausrichtung des Film insgesamt propagandistisch und national-dänisch, obwohl er als „Dokumentarfilm“ angekündigt wurde (Rebsdorf 31.05.2013). Aus dem Film zitiere ich Originaltöne, die ich selbst transkribierte und ins Deutsche übersetzte.

Bei der Beschreibung und Analyse der Gründe und Hintergründe für den Besuch einer dänischen Schule muss man zwei Aspekte beachten: Erstens sind die Interviews, ähnlich Selbstzeugnissen aus der historisch-archivalischen Forschung, „subjektive[...] Quellen“ (Henning 2003: 119), die eine persönliche Sichtweise aus einer lebensgeschichtlichen Perspektive wiedergeben. Die Aussagen der Interviewten sind insofern vielfältige Wahrheiten und „Perspektiven auf die Welt statt [...] Entitäten in der Welt" (Brubaker 2007: 13). Des Weiteren kann nicht immer nachvollzogen werden, wie und wann sich die Sichtweisen der einzelnen Gewährsleute gebildet haben. Besonders deutlich wird dies vor allem bei der Schilderung von Kindheitsereignissen, zu denen auch die Einschulung in die dänische

\footnotetext{
26 Alle diese Dokumente sind im Quellenverzeichnis aufgeführt.

${ }_{27}$ Der dänischsprachige Film ist auch online unter http://mindretallet.dk/dokumentarfilm abrufbar.
} 
Schule gehört, für die ja weniger die Interviewten selbst, sondern eher ihre Eltern verantwortlich sind. Es ist anzunehmen, dass sich bei dem Erzählen darüber eigene Kindheitserfahrungen mit den Erzählungen der Eltern sowie der eigenen nachträglichen Reflexion ${ }^{28}$ bis ins Rentenalter über die damalige Situation vermischen (vgl. a. Schulze 2001: 171). Bei Sarah Iversen beispielsweise fällt auf, dass ihre Aussagen im Interview inhaltlich und vom Wortlaut her sehr ihrer Erzählung in einer ZDF-Filmdokumentation (s. FN 140 a. S. 88) ähneln. Hinzu kommt noch, dass sie ihre Geschichte auch schon vor dem dänischen Seksmandsudvalg ${ }^{29}$ referiert hat. Dieser war 2007 auf „Besichtigungstour“ (Sydslesvigsk Forening 06.09.2007) in Friedrichstadt. Das ist vielleicht der Grund, warum ihre Geschichte möglicherweise in einigen Punkten etwas, zurechtgelegt ${ }^{6}$ wirkt. Da diese Arbeit aber keine Erzählanalyse sein soll (vgl. a. Lehmann 1983), sondern es um die Gründe sowie Arten und Weisen des Wandels von Zugehörigkeit gehen soll, wird dieser Aspekt nicht weiter ausgeführt.

Ein anderer Aspekt, der beachtet werden muss, ist die potenzielle, unbeabsichtigte Einflussnahme auf die Aussagen der Interviewten durch verbales oder nonverbales Verhalten der Forscherin im Gespräch. Auch ist nicht auszuschließen, dass sich das beobachtete Feld während der Anwesenheit der Forschenden an diesen Umstand anpassen könnte oder „der Eintritt des Forschenden eine ,Störung6 bewirkt" (Schmidt-Lauber 2001: 172).

Außer eventuell bei den Rechtfertigungen der Interviewten für ihr Dänischsein habe ich kaum Veränderungen durch meine Person beobachten können. Ich nehme an, dass dieser Umstand der Einführung ins Feld und der Kontaktaufnahme zu den Gesprächspartner*innen durch einen Gleichgesinnten, also jemanden mit ähnlichen Zusammengehörigkeitsgefühlen geschuldet ist. Hätte ich versucht, mit den dänisch gesinnten Friedrichstädter*innen ohne diesen „Türöffner“ in Kontakt zu treten, wären die Forschungsbedingungen möglicherweise andere gewesen, da

28 Im Rahmen dieser Reflexion über Erleben in der Kindheit werden Erinnerungen ,[b]ewußt oder unbewußt“ ,immer wieder den Erfordernissen der Gegenwart angepaßt; die Vergangenheit wird dabei umgeschrieben und neu mit Sinn versehen“" (Rheinheimer 2001: 16).

29 Der Seksmandsudvalg war eine Kommission des dänischen Unterrichtsministeriums, die eigentlich „Udvalget vedrørende danske kulturelle anliggender i Sydslesvig“ (Ausschuss für dänische kulturelle Angelegenheiten in Südschleswig) hieß und 2010 durch den Sydslesvigudvalget des dänischen Parlaments ersetzt wurde (s. a. S. 86). Sarah Iversen berichtet im Interview auch vom Erfolg ihres Vortrages. Ein Däne habe sie folgendermaßen angesprochen: „Ich hab immer gesagt, sollen, wenn die eh in Deutschland dänisch sein wollen, dann sollen sie das doch auch sel ber bezahlen“ (INT03). Als dieser Däne dann aber Sarahs „ergreifenden“ Vortrag über ihr Leben in der dänischen Minderheit und die große Bedeutung der dänischen Hilfe vor dem Seksmandsudvalg hörte, änderte er seine Meinung und begriff, wie wichtig die dänische Unterstützung für Südschleswiger sein kann. Zum „Beispiel hab ich denn da ja auch vermutlich 'n danke Sarah, danke!“ (INT03) gehört. 
die Akteur*innen im Feld mir womöglich reservierter gegenübergetreten wären. Alle Akteur*innen und Gesprächspartner*innen sind mir sehr offen und herzlich sowie am Thema interessiert entgegengetreten, und ich konnte ihr „Vertrauen gewinnen" (Girtler 2001: 108). Bei teilnehmenden Beobachtungen habe ich an allem teilgenommen, was die Akteur*innen auch gemacht haben, so zum Beispiel auch bei einer Geldsammelaktion für ein Geburtstagsgeschenk für eine Teilnehmerin des Freitagsklubs. Ergänzend haben die Akteur*innen mir ihr Handeln zwischendurch etwas erläutert. Die Begeisterung vieler Teilnehmer*innen beim „Freitagsklub“ über meine Teilnahme und mein Interesse an ihnen ging sogar so weit, dass ich zu Beginn meines Rückzuges aus dem Feld immer wieder eingeladen und aufgefordert wurde „zu kommen“ und bei ihnen mitzumachen. Hatte ich nicht teilgenommen, wurde nachgefragt, was denn der Grund dafür gewesen sei. Als ich nach dem Ende der Feldforschung kurze private Besuche in Nordfriesland machte, wurde ich jedes Mal, wenn Freitag war, wieder dazu aufgefordert, ihre Veranstaltung zu besuchen, wobei ja alle Teilnehmenden Rentnern*innen sind und ich somit eigentlich nicht in die Zielgruppe ihres Freitagsklubs passe. Der meines Erachtens wissenschaftlich notwendige Rückzug aus dem Feld erleichterte den Blick auf das Feld, da sich dadurch der Abstand zum Gegenstand vergrößterte und die Involviertheit abnahm.

Im Nachhinein wäre eine konzentrierte Forschung, also eine zeitlich weniger auseinandergerissene Feldforschung und Datenerhebung durch Interviews wünschenswert gewesen. Dies ließ sich aber aufgrund von Berufstätigkeit neben der Promotion und dem Aufbau der Promotion auf meiner Magisterarbeit sowie dem räumlichen Abstand zwischen Arbeits- und Feldforschungsort zeitlich nicht verwirklichen. Gleichzeitig bedeutete der räumliche Abstand von rund 400 Kilometern zum Feld auch den Vorteil der erleichterten Loslösung vom Feld und ermöglichte es, einen Außenperspektive einzunehmen.

Bei ersten Begegnungen mit dem Feld im Jahre 2007 fiel mir auf, dass in mündlichen und schriftlichen Äußerungen von Minderheitenakteurinnen und -akteuren häufig das Wort Identität fiel. Ich konnte beobachten, dass sich Menschen, die sich zur dänischen Minderheit bekennen, ständig mit diesem Begriff und seinen möglichen Inhalten auseinandersetzen, sei es in den Medien wie der Zeitung Flensborg Avis, in Romanen über die dänische Minderheit oder in Broschüren über dänische Institutionen in Südschleswig. Diese Art der permanenten Auseinandersetzung und Rechtfertigung der eigenen Zugehörigkeit scheint spezifisch zu sein für Akteur*innen in Minderheiten, die das Gefühl haben, ihre Identiät/en rechtfertigen zu müssen.

Zweifellos ist Identität ein modischer Begriff; aber sprachliche Moden auch solche der Wissenschaftssprachen - kommen nicht von ungefähr. Von Identität ist deshalb soviel die Rede, weil Identität zum Problem geworden ist. Der Begriff verkörpert, so weit die Konnotationen im 
Einzelnen auseinanderlaufen mögen, ein Moment von Ordnung und Sicherheit inmitten des Wechsels; und sein besonderer Reiz liegt dabei darin, daß er nicht eigentlich die Bedeutung von Starrheit oder Erstarrung vermittelt, sondern daß er verhältnismäßig elastisch etwas Bleibendes in wechselnden Konstellationen anvisiert (Bausinger 1999b: 204).

Meine Beobachtungen und dieses Zitat verdeutlichen, dass sich Angehörige der dänischen Minderheit deshalb besonders mit ihrer „Identität“ befassen, weil sie im Spannungsfeld zwischen dänischer Minderheit und deutscher Mehrheit stehen. Nichtdänischgesinnte halten ihr „Deutschsein“ im Landesteil Schleswig aufgrund der deutschen Umwelt und ihres deutschen Passes für selbstverständlich, für nicht erklärungsbedürftig, während Dänischgesinnte das Bedürfnis haben, ihr „Anderssein“ in Bezug auf die Mehrheitsgesellschaft gegenüber sich selbst und anderen zu begründen. In der deutschen Mehrheit oder in anderen Gruppierungen in Südschleswig gibt es ebenso Konstruktionen und kulturelle Praktiken zur Identifikation. Diese sind aber nicht so augenscheinlich wie bei der dänischen Minderheit, die sich in Abgrenzung zur Mehrheit konstituiert, während sich die Mehrheit nicht als spezifische Gruppe definiert und abgrenzt. In Bezug auf die deutsche Minderheit in Dänemark schreibt Michael S. Byram:

the fact that in many respects the members of the minority are indistinguishable is not important. What is important is that they declare themselves to be members, that they have features of their lives which they take to be indicators of identity. (Byram 1986).

Dies kann auf die dänische Minderheit südlich der Grenze übertragen werden, denn auch dort kommt es darauf an, dass man sich zur Minderheit bekennt und sich dann selbst bekenntnisfördernde Indikatoren konstruiert. Es kommt bei der Zuordnung zur dänischen Minderheit also nicht auf vermeintlich objektive Kriterien an, sondern auf Zuschreibungen, die als Prozesse zu begreifen sind. Diese Zuschreibungen und die dazugehörigen kulturellen Praktiken sowie die Erwartungen der Minderheit und ihrer Funktionäre und Mitglieder an andere Mitglieder sollen in der vorliegenden Arbeit genauer untersucht werden.

Eine Besonderheit dabei ist, dass es im deutsch-dänischen Grenzraum kaum wirtschaftliche Differenzen und Spannungen untereinander gibt. Der Grenzraum ist im Vergleich zu vielen anderen Grenzräumen in der Welt nahezu konfliktfrei. Es gibt keine geografische oder berufliche Separierung zwischen Minderheits- und Mehrheitsmitgliedern, abgesehen von Menschen, die für Minderheitsvereine arbeiten und sie selbst daher solche Separierungen aktiv praktizieren. Gerade aufgrund der im Verhältnis zu vielen anderen Minderheiten problemfreien Minoritätssituation und der rechtlich freien Situation der Minderheit ist es wichtig zu beobachten, 
welche Prozesse der Minderheitenkonstituierung und -aufrechterhaltung in Südschleswig ablaufen. Die Abwesenheit von ethnischen und religiösen Unterschieden macht den Blick frei auf Ethnisierungs- und Nationalisierungprozesse in der Minderheit und ihre Wirkungsmacht auf die Akteur*innen. Der hier untersuchte Zeitraum liegt zwischen dem Zweiten Weltkrieg und November 2013, also bis zum Ende der Amtszeit Dieter Paul Küssners, dem langjährigen SSF-Landesvorsitzenden. Ergänzend wird auch ein Ausblick auf die Zeit danach gegeben.

In dieser Arbeit soll untersucht werden, wie die Vielfalt der Akteur*innen der dänischen Minderheit ihre Zugehörigkeit und Gesinnung aushandeln, wie sie agieren, worauf sie Bezug nehmen, wie sie sich verorten und beheimaten, wie sie Sinn stiften und welche Praktiken sie im Alltag entwickeln, welche Prozesse und Entwicklungen ablaufen und welche Erwartungen von wem gestellt und erfüllt oder nicht erfüllt werden. Es geht darum, wie Menschen dänisch werden und wie sie das Dänischsein praktizieren und ob und wie sie dänisch bleiben, also wie Doing Being Danish, das Doing Becoming Danish bzw. das Doing Danish Minority funktionieren (s. Kap. 3.2.1). Dabei werden Alltagspraxen, Erwartungen und subjektive Aushandlungen und Selbstverständlichkeiten der Akteur*innen beleuchtet (vgl. Gerndt 1981: 12). Es wird gezeigt, mit welchen Mitteln Dänischsein konstruiert wird, welche Symbole und historische Mythen, welche Metaphern und Zuschreibungen für das Minderheitendänischsein verwendet werden.

Dabei habe ich die Akteur*innen in die beiden Gruppen Nachkriegsdän*innen und heutige Neudän*innen ${ }^{30}$ unterteilt. Die Ausgangshypothese ist, dass sich aus ihrem jeweiligen Lebenskontext verschiedene Motive, Praxen und Zugehörigkeiten ergeben. Ich folge dabei den von Irene Götz aufgestellten Prämissen zur Erforschung von Identitäten, die eine Mikroanalyse bzw. die Analyse von Fallbeispielen beinhalten und von der grundsätzlichen „Vorstellung von der Konstruiertheit, Pluralität und Kontextspezifik der Identitäten“ ausgehen (Götz 2010: 210). Dort formuliert Götz auch den Leitsatz über die Dialektik von „Enttraditionalisierung und Retraditionalisierung“" in der Moderne (ebd.: 210) ${ }^{31}$. Dabei gilt es, den „Rückgriff auf tradierte Bilder des Regionalen und Nationalen in Zeiten des Umbruchs $[\ldots]$ auf seine Halt und Orientierung stiftende Funktion hin" zu untersuchen (ebd.: 210), gerade in Zeiten von Gesinnungsfreiheit und europäischer Freizügigkeit. Dabei können die Gebilde wie Region, Nation, Religion, Gemeinde, Landkreis, denen Sinn und Bezug zugeschrieben werden, austauschbar sein, je

30 Neudän*innen sind Dän*innen, deren Eltern mit der dänischen Minderheit selbst als Kinder nichts zu tun hatten, und die selbst nicht auf einer dänischen Schulen waren. Es gibt Neudän*innen in der Nachkriegszeit und Neudän*innen heute. Schon 1923 sprach der Journalist Jacob Kronika von „Neudänen“, „Nydanske“ (Kronika 2001: 409).

31 Der Beginn der Moderne ist nicht klar definiert, sondern ungefähr am dem Ende des 18. Jahrhunderts anzusetzen. Die Moderne geht einher mit der Industrialisierung und dem Zeitalter der Aufklärung. 
nachdem, welches dieser Gebilde passende Sinnstiftungsinhalte liefern können (ebd.: 214). Beate Binder regt an, danach zu fragen, ,wie Imaginationen der/von Heimat“ oder eben von nationaler Gesinnung und Minderheitenbekenntnis „mit strukturellen gesellschaftlichen wie politischen Inklusions- bzw. Exklusionsmechanismen verbunden sind“ (Binder 2010: 204).

Ziel der Arbeit ist nicht, eine Analyse von vermeintlichen Unterschieden zwischen Mehrheit und Minderheit anzufertigen (vgl. Byram 1986: 140), sondern das Herausarbeiten von kulturellen Praktiken, Abgrenzungen und (Selbst-)Zuschreibungen der dänischen Minderheit und der darin auftauchenden Widersprüche und Ambiguitäten. „What is significant [...] is the emphasis given to differences by the members themselves“, betont Byram mit Rückgriff auf Fredrik Barth (ebd.: 140). Die Minderheit soll in dieser Arbeit nicht infrage gestellt werden, sondern als ein Beispiel dienen, anhand dessen der konstruktivistische Charakter von Gruppenzugehörigkeiten herausgearbeitet wird.

Schaut man auf den bisherigen Forschungsstand zur dänischen Minderheit in Südschleswig, so stellt man fest, dass es bisher „eine Vielzahl von Abhandlungen, Büchern und Artikeln“ gibt (Kühl 2005d: 41), die aber hauptsächlich von Historiker*innen und von Angehörigen der Minderheit geschrieben wurden und deren Untersuchungszeitraum zwischen dem Ende des Zweiten Weltkrieges und den Bonn-Kopenhagener Erklärungen liegt. ${ }^{32}$ Daneben existieren einige wenige kulturanthropologische (Adriansen 2013; Adriansen 2011; Adriansen 1990) und sprachwissenschaftliche (Pedersen 2000a) Untersuchungen. Ebenso wurden einige Erinnerungen von Zeitzeugen publiziert (Henningsen 2000; Henningsen 2003a; Johannsen-Bojsen 1981). Über die Partei der dänischen (und friesischen) Minderheit, dem Südschleswigschen Wählerverband (SSW), und die Geschichte der Minderheit bis in die 1970er-Jahre wurde ebenfalls geforscht (Nonnenbroich 1973). Analog zur dänischen Minderheit gibt es über die deutsche Minderheit in Dänemark einige Studien, beispielsweise einen Aufsatz über den Gebrauch verschiedener Sprachen in deutschen Schulen in Nordschleswig (Byram 1985) sowie weitere Schriften (Jebsen 2008; Jebsen 2009; Jebsen 2010; Jebsen 2011). Des Weiteren gibt es einen Bericht über die Sichtweise einer Dänin, die zur Gründung der dänischen Schule nach Friedrichstadt gekommen war (Guttormsen 1995). ${ }^{33}$ Es exis-

32 Z. B. Henrik Becker-Christensen (1995; 1994; 1998), Uwe Danker (1997), Lars N. Henningsen (2009a; 2011a), Martin Klatt (2001; Klatt, Kühl 2006), Jørgen Kühl (2003; 2005; 2005c; 2006b; 2006a), Johan Peter Noack (1989a; 1989b; 1991a; 1991b; 1997a; 1997b) und Nils Vollertsen (1993; 1994a; 1994b). Der Historiker Kühl, ein profilierter Minderheitsforscher, bekennt sich zur dänischen Minderheit und ist Direktor des dänischen Gymnasiums in Schleswig.

33 Auf die hier genannten Publikationen werde ich Laufe dieser Arbeit Bezug nehmen. Daher werden die Inhalte der Monografien und Sammelbände an dieser Stelle nicht näher ausgeführt. 
tierten dagegen bisher nur wenige Studien im Bereich der „Identitäts“-Forschung über die dänische Minderheit (Kühl 2004), daher sind hier eine große Forschungslücke und „Desiderata [...] in der zeitgeschichtlichen Erforschung des Themas" (Kühl 2005d: 42) zu beklagen. Identitätsbildende und -tragende Faktoren für die Dän*innen in Südschleswig sind kaum untersucht worden (Kühl 1994: 50). „Das gilt besonders für die Zeit nach den Bonn-Kopenhagener Erklärungen aus dem Jahr 1955“ (Kühl 2005d: 42, 47; vgl. a. Kühl 2003: 121, 123). Qualitative und mikrohistorische Studien über einzelne Akteur*innen in der dänischen Minderheit fehlen ebenfalls (Kühl 2005d), abgesehen von Christiansens Dissertation (Christiansen 2008). Es mangelt außerdem an Untersuchungen, die Ethnisierungs- oder Gruppenbildungsprozesse und -strategien von Akteur*innen beleuchten. Diese Lücke soll durch die vorliegende Dissertation geschlossen werden. Hierbei soll keine Bewertung der dänischen Minderheit vorgenommen, keine politischen Ziele angestrebt, keine aktivistische Ziele verfolgt, sondern aufgezeigt werden, wie Prozesse der Identitätsbildung und -aufrechterhaltung ablaufen und funktionieren, ganz im Sinne von Max Webers Aussage beim Ersten Deutschen Soziologentag (vgl. Weber 1911: 39-40). Ich betone auch, dass ich die Existenzberechtigung der dänischen Minderheit nicht infrage stelle, sondern sie im Gegenteil als Bereicherung und als Selbstverständlichkeit für das Grenzland ansehe. In dieser Arbeit geht es ausdrücklich nicht um die Politik des SWW ${ }^{34}$, sondern der Fokus liegt auf dem Schulverein Dansk Skoleforening for Sydslesvig und dem Kulturverein Sydslesvigsk Forening (SSF). Diese Arbeit verfolgt keinen geschichts-, erziehungswissenschaftlichen oder organisationssoziologischen Ansatz. Auch wird der Transnationalismusansatz hier nicht verwendet, da er sich im Hinblick auf eine Untersuchung von sich explizit als nationalen bezeichnenden Minderheiten, die direkt auf den deutschen und auch auf den dänischen Nationalstaat Bezug nehmen, nicht eignet. Allein das Vorhandensein staatsgrenzenüberschreitender Verbindungen zwischen Menschen bedeutet nicht die Überwindung nationalstaatlicher Prinzipien von Zugehörigkeiten und Nationalitäten oder das Einläuten postnationaler Strukturen (vgl. Brubaker 2015: 7). Wie in dieser Dissertation noch gezeigt werden wird, beziehen sich Minderheitsdän*innen explizit auf den kinstate bzw. home-state Dänemark, der immer strenger die Zugehörigkeit der Individuen zu ihm regelt.

Der Aufbau dieser Arbeit gestaltet sich folgendermaßen: Nach dieser Einleitung inklusive Methodenteil (1) wird der theoretische Hintergrund zu den Bereichen Minderheiten, Ethnizität und Ethnisierung, Nationenbildung sowie Identität und Identifikation dargelegt (2), bevor in Kapitel 3.1 der historische Hintergrund der dänischen Minderheit und des Landesteils Schleswig beschrieben wird. Es

34 Es gibt einige Publikationen, die sich mit dem SSW beschäftigen (Klatt, Kühl 2006; 2008a; Christiansen 2006; Henningsen et al. 1998; Mortensen 1990). 
folgt eine Schilderung der Funktion von Vereinen sowie eine Übersicht über die wichtigsten dänischen Minderheitsvereine in Schleswig mit den Schwerpunkten Schul- und Kulturvereine (3.2).

Der Hauptteil dieser Dissertation beginnt mit einem szenischen Einstieg in das Thema anhand des Beispielfalls Sarah (4.1). Dort wird in dichter Beschreibung der Lebenslauf einer Anhängerin der dänischen Minderheit aus der Nachkriegszeit nachgezeichnet. Anschließend werden Gründe für das Dänischwerden dargelegt, unterteilt in die Nachkriegsgeneration und die Neudän*innen in der Gegenwart. Dabei wird unterschieden zwischen materiellen und ideellen Gründen (4.2).

Hierauf folgt eine Abhandlung über die Bedeutung der dänischen Schulen für den Prozess des Dänischwerdens in Südschleswig (5). Dabei werden zum einen die Perspektiven der Nachkriegsgeneration mit ihren im Rentenalter geschilderten Erlebnissen im für sie neuen System der dänischen Schule berücksichtigt. Zum anderen geht es gegenwartsbezogen um die Rolle und die Ziele des Schulvereins und seiner Funktionär*innen im Hinblick auf Erwartungen an Eltern und Lehrer*innen sowie die daraus beobachteten Diskussionen und Widersprüche, wie beispielsweise der Konflikt zwischen dem Privatschulstatus und der Auffassung, dass dänische Schulen öffentliche Schulen sein wollen. Zuletzt werden die Auswirkungen der reichsdänischen Finanzierung der Schulen auf die Vereinspolitik des Schulvereins erörtert.

In Kapitel 6 schließt sich die Analyse eines der Schwerpunkte der Feldforschung an. Dabei geht es um die Frage, wie der Schulverein und der Kulturverein der dänischen Minderheit versuchen, heutige Neudän*innen anhand eines Integrationskurses in der dänischen Heimvolkshochschule in die dänische Minderheit zu integrieren. Zum besseren Verständnis findet man in diesem Abschnitt ebenfalls szenische Beschreibungen des Feldes. Es folgt die Analyse des Kurses sowie der generellen Strategie der beteiligten Vereine im Bereich Integration.

Das vorletzte Hauptkapitel (7) widmet sich der Frage, wie Menschen, die dänisch geworden sind, dänisch sind und dänisch bleiben, also wie Minorisierung und Minoritätsschaft im Landesteil Schleswig funktionieren können. Es wird untersucht, welche Strategien und Konstruktionen Menschen anwenden, um eine längerfristige Bindung und Zugehörigkeit zu einer bestimmten Minderheit zu erreichen. Das Kapitel nimmt das des Kulturvereins in den Fokus. Es folgt eine Analyse der Vorgaben der Kulturvereinsfunktionär*innen an alte und neue Minderheitsdän*innen. Danach löst sich die Perspektive von Einzelvereinen und konzentriert sich auf übergreifendere Themen in der Minderheit. Dazu gehören die Heterogenität der Minderheitsakteur*innen zwischen Nationalist*innen und Pragmatiker*innen, die Auswirkungen der finanziellen Abhängigkeit vom Königreich Dänemark auf die Minderheit. 
Kapitel 8 beginnt mit einer szenischen Schilderung der Jahresfeste der Minderheit. Diese und weitere Symbole und die damit in Verbindung gebrachten $\mathrm{Zu}$ gehörigkeitsgefühle zur Minderheit werden dargelegt. Das Spektrum reicht von gemeinschaftliche Praxen wie dem Singen, über die Verwendung bestimmter Speisen, das Zeigen des Dannebrogs (der dänischen Flagge) bis hin zu direkten Äußerungen von Gefühlen durch Akteur*innen. Zuletzt wird untersucht, wie der dänischen Sprache eine symbolische Bedeutung zugeschrieben wird und welche Historisierungen und Mythen geschaffen werden. Die damit zusammenhängenden Legitimationsversuche werden analysiert. Sodann werden das nationale Bekenntnis mit einem religiösem Bekenntnis verglichen und Parallelen zu alltagskulturellen Beheimatungsprozessen gezogen. Es folgen zuletzt eine Zusammenfassung und Schlussbetrachtung sowie ein Ausblick (9). 


\title{
2. Theoretischer Hintergrund
}

\author{
„Nation is a form of idenity. Individuals \\ identify with their nation in the same way \\ that they might identify with other forms of \\ collective identity, such as religion, tribe, race, \\ and ethnicity." \\ Adeed Dawisha (Dawisha 2009)
}

Dieses Zitat des irakisch-amerikanischen Politikwissenschaftlers Dawisha deutet an, dass es bei Zugehörigkeiten zu Nationen oder ethnischen Gruppen oder anderen Kollektiven sowie bei Identitätsprozessen Parallelen in Bezug auf alltagskulturelle Praxen und Konstruktionen gibt. Daher wird es in diesem Kapitel nicht nur um die Frage gehen, was eine Minderheit ist, sondern auch um den theoretischen Hintergrund zu Nationalisierung und Nationenbildung sowie zu Ethnizitäts- und Identitätsbildung. 


\subsection{Minderheit*en}

Minderbeit ist man nicht, Minderheit wird man, wenn man es will. ${ }^{35}$

Der Begriff Minderheit ist nicht per se definierbar. Selbst der erste Hohe Kommissar für nationale Minderheiten, Max van der Stoel, 1992 ernannt durch die Konferenz für Sicherheit und Zusammenarbeit in Europa (KSZE), der Vorgängerorganisation der OSZE, hatte keine klare Definition des Begriffes Minderheit (Kühl 2003: 71). Minderheiten seien so vielfältig, dass keine Definition richtig sein könne, so Jennifer Jackson-Preece (Jackson-Preece 19.08.2013). Auch Jan Diedrichsen, von 2008 bis 2015 Direktor der FUEV, betont: ,there is no proper minority definition“ (Diedrichsen 26.08.2013). Vor allem gibt es keine Begriffsdefinition, die von allen Beteiligten akzeptiert werden würde (Kühl 2003: 45). Allerdings sei klar, dass Minderheiten zahlenmäßig gegenüber einer Mehrheit in der Unterzahl sind (ebd.: 22). In der Praxis gebe es Definitionen von einzelnen Minderheitengruppen in Abgrenzung zur jeweiligen Mehrheit durch einerseits objektive Kriterien (Kühl 2003: 17; Kühl 2017: 29). Dazu würden Sprache, Kultur, Traditionen, Geschichte und teilweise Religion zählen, so der dänisch-deutsche His toriker Jørgen Kühl. Andererseits gebe es subjektive Kriterien, die auf (Selbst)Identifikation mit der Minderheit beruhten (Kühl 2003: 17; Kühl 2017: 29-30). Aus kulturanthropologischer, nicht-essenzieller Sichtweise muss diese Haltung zu objektiven Kriterien infrage gestellt werden und mit dem Begriff „Objektivität“ muss äußerst vorsichtig umgegangen werden, da es keine ,objektiven“ Definitionen von „Sprache“, „Kultur“, „Tradition“, „Geschichte“ und „Religion" gibt. Diese hat man nicht qua Geburt, sondern man kann sie erlernen, praktizieren, aufrechterhalten, verändern oder ablegen. Daher taugen diese Begriffe auch nicht zur Definition einer Minderheit. Meist werden von Minderheitenakteur*innen vermeintlich passende „Kriterien“ für Abgrenzungen gesucht und nicht passende ausgeblendet. Die Annahme, dass eine gemeinsame Sprache zu einer klar abgrenzbaren gemeinsamen „Identität“ führe, ist einerseits anhand der dänischen Minderheit widerlegbar und beruht andererseits auf der Idee von Johann Gottfried Herder (1744-1803), dass Sprache und nationale Identität zusammengehörten (vgl. Anderson 2005: 72-73; vgl. Bendix 1997: 34-44). ${ }^{36}$

35 Abwandlung der Aussagen „Kulturerbe ist man nicht, Kulturerbe wird man“ (Bendix 2008; Noyes 2010; Kirshenblatt-Gimblett 1995) und dem Prinzip ,Minderheit ist, wer will‘.

36 Zu Herders Verbindung zwischen Sprache und Nation bzw. Volk und Charakter der Nationsangehörigen s. beispielsweise Kapitel 11 in „Abhandlung über den Ursprung der Sprache“ (Herder 1997). Herder hat durch das Sammeln von Volksliedern und durch sein Kulturrelativismus in der Romantik die Kategorie Volk gefestigt (Bendix 1997: 35). Er sah in der Volkspoesie in der jeweiligen Landessprache eine ,authentic expression of socially and ethnically different 
In Europa kam ab dem 19. Jahrhundert die Idee des Nationalstaats auf. Der dadurch entstandene Nationalismus ist eine „Fiktion“ von „Staaten mit ethnisch homogener Staatsbevölkerung“ (Pan, Pfeil 2016: 3). Die meisten der heutigen europäischen Staaten ,sind als Nationalstaaten konzipiert“, obwohl sie „,in Wirklichkeit multinationale Staaten mit traditionellen Volksgruppen bzw [sic] nationalen oder ethnischen Minderheiten sind“, schreiben Pan und Pfeil im „Handbuch der europäischen Volksgruppen“ (ebd.: 4). Hier wird deutlich, dass der Begriff der ethnischen oder nationalen Minderheit untrennbar verbunden ist mit dem europäischen Konstrukt des Nationalstaates (vgl. a. Wolff 2017: 89). Im Zuge der Nationalisierung in Europa wurden herrschaftlich-politisch begrenzte Räume mit „ethnischen und sprachlichen Zugehörigkeit[en]“ aufgeladen (Seifert 2009: 40). Die Idee der Einheit von ethnischen und sprachlichen Grenzen gehört der Moderne an und ist daher relativ neu (vgl. Seifert 2009: 40; vgl. Anderson 2005: 7273).

Es ist wichtig, den Begriff der Minderheit nicht als starres Konstrukt oder als klar abgrenzbare, statische Einheit zu verstehen, sondern ihn als dynamisches, uneindeutiges, nicht klar abgrenzbares Gebilde anzusehen, welches sich verändern und verschiedene Ausprägungen haben kann. ${ }^{37}$ Minderheitszugehörigkeiten können wandelbar sein und verschiedene Akteursaktivitäten beinhalten. Minderheitensein ist etwas Fließendes und sollte als individuelle Entscheidung betrachtet werden (Jackson-Preece 19.08.2013). Man ist also nicht Minderheit, sondern man wählt es und wird es. Eine Bindung an eine Minderheit ist situativ, relational oder kontextabhängig (vgl. a. Kühl 2003: 26; 47).

Die dänische Minderheit wird trotz der oben genannten Erkennntnisse immer wieder als nationale, autochthone Minderheit definiert (Schmalz-Jakobsen et al. 1997; vgl. Martini 1997: 222; Pan 2016b: 222-225). Dabei wird „national“ hier rechtlich gesehen „als Oberbegriff für ethn., kulturelle, sprachl. und relig. Minderheiten verwendet" (Martini 1997: 222), deren Angehörige überwiegend deutsche Staatsbürger*innen sind. Autochthon meint, dass diese Mitglieder der Minderheit „schon vor der Staatsgründung auf dem Territorium des heutigen Staates lebten“ (ebd.: 222) und „,im engeren, rechtlichen Sinne“ auch als „ethnisch“ bezeichnet

peoples“ (ebd.: 40).

37 Der Gebrauch der Begriffe wie ,Minderheit', ,nationale Gesinnung', ,deutsch` oder ,dänisch` in der vorliegenden Arbeit geschieht in Hinblick auf diese Problematisierungen in Kapitel 1 und 3, ohne dass der konstruktivistische Charakter jedes Mal neu im Text gekennzeichnet wird. 
werden (Polm 1995: 340). ${ }^{38}$ Die Definition unterscheidet diese Minderheiten von eingewanderten Minderheiten in Deutschland, wie beispielsweise aus Polen oder aus der Türkei.

Als Minderheit gelten die sogenannten authochthonen Minderheiten laut der dortigen Definition deshalb, weil sie ,sich von der Mehrheit durch tatsächliche u./od. vermeintliche Merkmale wie Herkunft, Sprache, Religion, Kultur bzw. durch eine Kombination von Elementen dieser Bereiche“ (Martini 1997: 222) abgrenzen. In der Formulierung ,vermeintliche Merkmale“ liegt die Crux dieser primordialistischen Definition: Zum einen „,haben die einzelnen Angehörigen [einer Minderheit] auch viele Merkmale mit Angehörigen anderer Minderheiten wie auch der Mehrheit gemeinsam“ (ebd.: 223), sodass vorgebliche Merkmale nie eine klare Abgrenzung schaffen. Zum anderen sind viele dieser vermeintlichen Merkmale konstruiert. Sie spielen - außer vielleicht in der sozialen Praxis - rechtlich gesehen keine Rolle, da die dänische Minderheit nur per Selbstdefinition existiert. Es gilt: „Das Bekenntnis zum dänischen Volkstum und zur dänischen Kultur ist frei und darf von Amts wegen nicht bestritten oder nachgeprüft werden." (Artikel II. 1 der Bonner Erklärung vom 29. März 1955, abgedruckt in Kühl et al. 2005: 520; vgl. a. Becker-Christensen 1996: 316; Pedersen 2000a: 26; Spoorendonk 2001: 43; Sigaard-Madsen 1995: 135; Kühl 2005d: 30; Kühl 2006b; Kühl 2009: 299; Vollertsen 1994b: 257). Das 1998 in Deutschland als Bundesgesetz in Kraft getretene Rahmenübereinkommen zum Schutz nationaler Minderheiten schreibt überdies vor, dass ,[j]]ede Person, die einer nationalen Minderheit angehört,“ „das Recht [hat], frei zu entscheiden, ob sie als solche behandelt werden möchte oder nicht." (Art. 3 Abs. 1 SEV Nr. 157) ${ }^{39}$.

In Artikel 4 des Rahmenübereinkommens wird die Gleichheit aller Menschen vor dem Gesetz festgelegt. Artikel 5 regelt den Schutz ,ihre[r] Kultur“ und der „wesentlichen Bestandteile ihrer Identität, nämlich ihre Religion, ihre Sprache, ihre Traditionen und ihr kulturelles Erbe“ (SEV Nr. 157). Das Besondere an der dänischen Minderheit in Schleswig ist also die Möglichkeit des Wechsels der selbstgewählten Zugehörigkeit, des Bekenntnisses. Der im Rahmenübereinkom-

38 Dazu zählen in der vorliegenden Arbeit nicht die allochthonen Minderheiten, die „[i]n der sozialwissenschaftlichen Praxis“ teilweise auch als „ethnische Minderheiten“ bezeichnet werden. Damit sind nämlich ,auch alle Migrantengruppen“ gemeint, „die sich ebenfalls durch tatsächliche und/oder vermeintliche Merkmale [...] von der dominanten Mehrheit unterscheiden“ (ebd.: 341).

39 Sammlung Europäischer Verträge - Rahmenübereinkommen zum Schutz nationaler Minderheiten. Aus juristischer Perspektive ist „Deutschland seinen Verpflichtungen aus seiner Mitgliedschaft im RÜ weitgehend nachgekommen“ (Hofmann 2015: 101).

Diese in der vorliegenden Arbeit vorkommende Zitierweise mit zwei hintereinander gestellten Zitaten $(, \ldots “, \ldots$...) rührt daher, dass die Textteile im Original in umgekehrter Reihenfolge stehen und daher nicht mit eckigen Klammern und Auslassungspunkten angeführt werden können $(, \ldots[\ldots] \ldots ")$. 
men verbriefte Schutz vor Diskriminierung wird in Deutschland im Grundgesetz (Art. 3 Abs 1 GG) und im Allgemeinen Gleichbehandlungsgesetz (AGG) geregelt. Es ist im deutsch-dänischen Grenzraum keine Gewalt gegen Minderheitsakteurinnen und keine erzwungene Migration aufgrund von Zugehörigkeiten geschehen (vgl. Kühl 19.08.2013). Weiterhin ist das Besondere an der dänischen Minderheit, dass sie eine Art Parallelgesellschaft aufgebaut hat und sich von der Mehrheit abgrenzt, die Angehörigen aber gleichzeitig auch in die Mehrheit integriert sind (vgl. Kühl 19.08.2013; Feischmidt 2003: 160, 168). Angehörige aller nationalen Minderheiten haben, wie alle anderen Staatsbürger*innen vor dem Grundgesetz auch, das Recht auf Versammlungsfreiheit und „Anspruch auf freie Meinungsäußerung und auf Gedanken-, Gewissens- und Religionsfreiheit“" (Art. 7 SEV Nr. 157).

Wendet man das Koordinatensystem für die Beziehung zwischen nationaler Minderheit und einem Staat von Jørgen Kühl (Kühl 2003: 55-63) an, dann ist die dänische Minderheit in Deutschland eine nationale Minderheit mit einem Bezugsland, nämlich Dänemark. Kühl nennt die Minderheit folglich „,kin-minority“ mit einem dazugehörigen „,kin-state“ (ebd.: 56-57). Deutschland ist in Kühls Sprachgebrauch ein „state“, der eine inklusive, das heißt integrierende, respektvolle, anerkennende Minderheitenpolitik betreibt (ebd.: 56). Rogers Brubaker verwendet statt „kin-state“ die Begriffe „homeland“ (Brubaker 1996: 58) und „mother country“ (ebd.: 67). Minderheiten seien darüber hinaus dynamische und relationale Konzepte, nicht statische Einheiten (ebd.: 60).

In der Regel, und so auch bei der dänischen Minderheit, gelten als Angehörige einer nationalen Minderheit in Deutschland nur deutsche Staatsbürger*innen, nicht aber dänische Staatsbürger*innen, die in Deutschland oder im Landesteil Schleswig leben oder andere ausländische Staatsangehörige, so das Grundgesetz, die Bonn-Kopenhagener Erklärungen und die Rahmenkonvention des Europarates von 1995 (vgl. Kühl 2003: 23; Kühl 2009: 325; Kühl 2017: 30). Deutsche werden als Inländer*innen und Dän*innen als EU-Ausländer*innen behandelt. Es

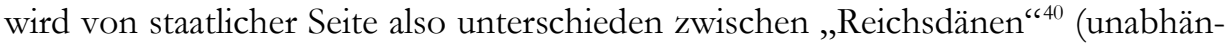
gig davon, ob sie sich selbst zur dänischen Minderheit rechnen) und deutschen Bürger*innen, die sich der dänischen Minderheit zugehörig fühlen. Dänische Staatsangehörige, die in Schleswig arbeiten, werden aber von vielen Akteur*innen aber auch als Angehörige der Minderheit angesehen. ${ }^{41}$ Vom deutschen Staat gibt

40 Dieser Begriff wird im Dänischen (rigsdansker) benutzt für dänische Staatsbürger aus dem Königreich in Abgrenzung zu Minderheitsdänen in Schleswig (vgl. z. B. Sydslesvigsk Forening 08.10.2010)). Der übersetzte Begriff ,Reichsdäne‘ ist nicht analog zu den sogenannten ,Reichsdeutschen' zu sehen.

41 Von ihnen haben aber ca. 90 bis $95 \%$ einen deutschen Pass (Kühl 2004: 323). Bei der dänischen Minderheit entspricht die Selbstdefinition also nicht hundertprozentig der staatlichen 
es keine speziellen Rechte für Angehörige der dänischen Minderheit, abgesehen von der Befreiung von der $5 \%$-Klausel des SSW im schleswig-holsteinischen Landtag. Die Angehörigen der dänischen Minderheit besitzen dieselben Rechte, die für alle anderen deutschen Staatsbürger*innen auch gelten. Die Rechte der Angehörigen der Minderheit definieren sich folglich durch die Rechte für deutsche Staatsbürger*innen und für dänische Staatsbürger*innen in Deutschland, unabhängig von ihrer Minderheitenzugehörigkeit. In Deutschland ist der rechtliche Minderheitenschutz über das Grundgesetz abgedeckt, in dem steht, dass niemand aufgrund von Sprache, Glauben oder Anschauung benachteiligt werden darf (Art. 3 Abs. 1, 1 GG). Es wurden allerdings zum Schutze vor Benachteiligung und Diskriminierung von Minderheitenangehörigen und allen anderen Personen in Europa eine Reihe von weiteren Gesetzen und Richtlinien eingeführt. die im folgenden beschrieben werden. Sie sollen die Rechte aller Bürger*innen sichern, unabhängig von ihrer nationalen Gesinnung, ethnischen Zugehörigkeit oder sprachlichen Alltagsrealität.

Zum einen gelten die Allgemeine Erklärung der Menschenrechte/UN-Menschenrechtscharta durch die UN im Jahre 1948 sowie der internationale „menschenrechtliche[...] Minderheitenschutz" in der Europäischen Menschenrechtskonvention von 1950 und die Grundrechtecharta der Europäischen Union (bes. Art. 10 Abs. 1; Art. 14 Abs. 3; Art. 21 Abs. 1; Art. 22 GRCh) ${ }^{42}$, die durch den Vertrag von Lissabon im Jahre 2009 in Kraft trat, sowie den UN-Pakt über bürgerliche und politische Rechte von 1966 (IPBPR) und die Erklärung über die Rechte von Personen, die nationalen oder ethnischen, religiösen oder sprachlichen Minderheiten angehören $^{43}$ von 1992 (Pan, Pfeil 2016: 12; Pan 2016c: 243; Thürer 2015: 47). Diese Regelungen werden durch den ,positiven Volksgruppenschutz“ (Pan, Pfeil 2016: 12) ergänzt. Zu dieser Art von Schutz gehören außerdem die 1998 in Kraft getretenen folgenden zwei Abkommen: das Rabmenübereinkommen zum Schutz nationaler Minderheiten (MindSchRÜbk) und die Europäische Charta der Regional- oder Min-

Fremddefinition. Eine andere Minderheit, bei der sich diese Definitionen unterscheiden können, ist die Gruppe der Sinti. Viele haben einen deutschen Pass, werden aber nicht als Deutsche angesehen. Sie selbst sehen sich „als Deutsche mit einer besonderen Geschichte, eigenen Erfahrungen, einer eigenen Muttersprache und eigenen kulturellen Traditionen" (Hansen 1995a: 153). Aus diesem Grund sollte man bei der Beschäftigung mit ethnischen Gruppen die Bedeutung der Staatsangehörigkeit, die im Grunde nur eine Formalität ist, nicht überschätzen. In dieser Arbeit werden die Begriffe Gruppe und Minderbeit verwendet. Dabei sind immer flieBende, nicht fest abgrenzbare, nicht klar definierbare, einander überschneidende, heterogene Zusammenschlüsse von Menschen gemeint und keine starren Einheiten mit festen Grenzen.

42 „Konvention zum Schutz der Menschenrechte und Grundfreiheiten“ (EMRK); „Charta der Grundrechte der Europäischen Union“ (GRCh), darin bes. Art. 21 Abs 1. Mehr zur Frage der Minderheiten in der EU s. (Pan 2016a). Zum Thema Minderheiten und Wirtschaft s. (Pan 2016d).

43 Vom 18.12.1992, Resolution Nr. 47/135 der Generalversammlung der Vereinten Nationen, U.N. Doc. A/RES/47/135. 
derheitensprachen des Europarates, auch Sprachencharta genannt (Pan, Pfeil 2016: 13; Rein, Hilger 2008: 55). In den Regelwerken verpflichten sich Staaten dazu, Minderheiten und Minderheitensprachen zu schützen, aber die Abkommen enthalten keine einklagbaren Rechte für Individuen. Pan und Pfeil sehen in den beiden Konventionen den „Grundsatz der positiven Diskriminierung“ enthalten, also einen „Ausgleich[...]“ von Benachteiligungen, die systembedingt sind (Pan, Pfeil 2016: 14), weil es beispielsweise sein kann, dass Minderheitsangehörige keinen Schulunterricht in ihrer Erstsprache bekommen. Die Sprachencharta trat in Deutschland am 01.01.1999 als Bundesgesetz in Kraft. Das Rahmenübereinkommen, welches seit 01.02.1998 in Deutschland gilt, „verpflichtet“ den Staat „zu Schutz- und Fördermaßnahmen" im Bereich Bildung und Schulen (Rein, Hilger 2008: 60).

Die Position des Europarates zum Minderheitenschutz ist konträr zur Lage der Minderheiten in Deutschland. Der Europarat ist der Auffassung, dass nur „die statistische Erfassung der nationalen Minderheiten“ einen Schutz eben dieser gewährleisten könne, denn es könne „,nicht geschützt werden“, „,was nicht bekannt sei“" (Pan 2016b: 228). In Deutschland dagegen muss sich niemand in Bezug auf einen Minderheitsstatus definieren. Jede*r kann sich bekennen, wie er*sie es möchte. Hierbei wird die Differenz zwischen Nichtdefinition und Freiheit des Bekenntnisses auf der einen Seite und der Definition und damit statischer Festschreibung auf der anderen Seite besonders deutlich. In Deutschland werden seit 1945 „grundsätzlich keine statistischen Daten auf ethnischer Basis erhoben“, da durch solche Daten die „Verfolgung und Ermordung nationaler Minderheiten [...] während der nationalsozialistischen Gewaltherrschaft" „erleichtert worden seien“ (Hofmann 2015: 88). Die Auffassung, dass nationale Identität anhand von objektiven Kriterien festgemacht werden kann, ist mittlerweile also gesetzlich und im Sinne eines modernen Kulturbegriffs ${ }^{44}$ obsolet und wird bei den Minderheiten in Deutschland und Dänemark offiziell nicht angewendet (vgl. Adriansen 1994:

44 Anstatt von ,Kulturen` spricht der schwedische Sozialanthropologe Ulf Hannerz von Kontex ten (Hannerz 1995: 70-71). Die Ethnologin Tsypylma Darieva betont, dass „Kulturen nicht mehr als räumlich begrenzbare Gebilde verstanden“ werden (Darieva 2007: 83). 
11-12). ${ }^{45}$ Es ist verboten, die Minderheitenzugehörigkeiten oder die Muttersprache(n) staatlicherseits zu überprüfen oder zu registrieren (Kühl 2003: 111, 185). Die nationale Identität ist also privat, individuell und subjektiv (ebd.: 185).

Als „Gesinnungsminderheiten“" werden die „Minderheiten [bezeichnet], die kraft der persönlichen Zugehörigkeitswahl des Einzelnen entstanden sind“"46, so die dänische Kulturanthropologin Inge Adriansen (Adriansen 2003: 54; vgl. Adriansen 1994: 11; Pedersen 2000a: 16). So kann es durchaus vorkommen, dass eine imaginäre Nationalitätsgrenze „quer durch die Familien“ (Danker 1997: 8) oder gar durch eine Einzelperson bei der Wahl einer neuen „Nationalität“ verläuft (Adriansen 2003: 54). Das „Fehlen“ von objektiven Zugehörigkeitskriterien und -voraussetzungen sowie nach außen hin sichtbaren Merkmalen oder historischen Zusammenhängen macht das Bekenntnis zum Dänischen im Prinzip so frei ${ }^{47}$, dass es auch beliebig sein kann. Akteur*innen können deshalb das Bedürfnis haben, Begründungen für ihr Bekenntnis zu konstruieren. Die „Gesinnung“ darf nirgendwo amtlich festgehalten werden. Sie darf nicht staatlich erfasst und festgehalten werden, beispielsweise in einem Zensus. ${ }^{48}$ Die Mitgliedschaft in einem dänischen Verein gilt zwar nicht als Beweis, aber als Indiz für eine dänische Gesin-

45 Gesinnung ist etwas, das ,außerhalb der Begriffe wie Kultur, Abstammung und Sprache liegt“ (Christiansen 2008: 60) und eine Art „Grundhaltung eines Menschen“ (ebd.: 60), die nicht überprüft werden kann, die aber veränderbar ist (vgl. ebd.: 61). Die Gesinnung ist eine Art Gefühl und Wahl (ebd.: 61, 62). „Nationale Identität ist eine individuelle Beschlusslage, man entschließt sich sozusagen“ dänisch zu werden. Er nennt dies „Gesinnungswahl“ (Jørgen Kühl i. Interview m. ebd.: 59). Die nationale (und damit - in Anlehnung an Brubaker - auch ethnische) Gesinnung wird schon von Ernest Renan als Konstruktion beschrieben: „Il y a dans la nationalité un côté de sentiment; elle est âme et corps à la fois; [...] Une nation est une âme, un principe spirituel. Deux choses qui, à vrai dire, n'en font qu'une, constituent cette âme, ce principe spirituel. L'une est dans le passé, l'autre dans le présent. L'une est la possession en commun d'un riche legs de souvenirs; l'autre est le consentement actuel, le désir de vivre ensemble, la volonté de continuer à faire valoir l'héritage qu'on a reçu indivis. L'homme, Messieurs, ne s'improvise pas. La nation, comme l'individu, est l'aboutissant d'un long passé d'efforts, de sacrifices et de dévouements" (Renan 1947: 902-904; vgl. a. Schneider 2001: 19).

Mit Hinweis auf Max Weber, für den „eine dänische Gesinnung nichts anderes darstellen würde wie [sic] der Glaube an dänische Kultur“" (Christiansen 2008: 62), ist Gesinnung also ein „Bekenntnis“, „,eine individuelle zeitlich zu verortende Zustandsbeschreibung““ (ebd.: 62), die durch die Bonn-Kopenhagener Erklärungen nicht hinterfragt oder angefochten werden darf und zu der sich jeder frei bekennen kann. Das Gesinnungsprinzip ist das Gegenteil vom nationalen „,Blut und Boden'-Ideal“ früherer Zeiten (vgl. Graw-Teebken 2008: 166). Gesinnung ist subjektiv und kann veränderlich sein.

46 „sindelagsmindretal, det vil sige mindretal, der er opstået [...] i kraft af den enkeltes personlige valg af nationalt tilhørsforhold.“

47 „Die individuelle Identifikation steht jedem frei“ (Kühl 2004: 325).

48 Die Auswirkungen von Kategorisierung und Definition von vermeintlicher Zugehörigkeit und die daraus resultierenden Probleme bei einer Volkszählung hat Wolfgang Göderle in seinem Buch „Zensus und Ethnizität“ über die Situation in Österreich zwischen 1848 und 1910 beschrieben (Göderle 2016). 
nung. Man geht davon aus, dass Personen, die selbst oder deren Kinder eine dänische Schule besucht haben oder besuchen, sich überwiegend selbst als dänisch bezeichnen.

Der Begriff Gesinnungsminderheit erleichtert die Erklärung, warum viele Angehörige der dänischen Minderheit hauptsächlich Deutsch sprechen und erklärt auch, warum es möglich ist, dass Familien, die eigentlich nicht aus Südschleswig kommen, sich auch zur Minderheit bekennen können (vgl. Kühl 27.07.2016). Hier ist man frei in der Gesinnung, ohne Kriterien wie Sprachbeherrschung, Herkunft oder objektiver Verwandtschaft.

Somit gibt es keine klar definierbare dänische Minderheit ${ }^{49}$, und deshalb liegen auch keine offiziellen Zahlen vor, wie viele Personen sich zur dänischen Minderheit rechnen. ${ }^{50}$ Schätzungen gehen aber von circa 50.000 Menschen aus (vgl. Spoorendonk 2001: 43; Kühl 2005d: 32; Pedersen 2000b: 16-17). Der geschätzte Anteil der Minderheit an der Gesamtbevölkerung im Landesteil Schleswig beträgt heute ca. 8-10 \% (Kühl 2003: 111). Andere Schätzungen, die doppelte Mitgliedschaften in kulturellen und politischen Vereinen herausrechnen, beziffern die dänische Minderheit heute auf ca. 30.000 bis 35.000 Menschen (Hansen 2002: 189; Boehm 1992: 18-19; Clausen 2014: 80). ${ }^{51}$ Bei der Anzahl der Zugehörigen zur dä-

49 Für den allgemeinen Begriff Minderheit „existiert keine international anerkannte Definition“ (Schwarz 2008: 112). Nerissa Schwarz führt auch an, dass „,[d]as Beispiel der Roma zeigt, wie schwierig es ist, die Zugehörigkeit zu einer Minderheit zu definieren, und dass einem essentialistischen Kulturverständnis entspringende Kategorien, wie eine gemeinsame Sprache, Religion oder Bräuche, nicht unbedingt dafür geeignet sind“ (ebd.: 113). Überdies ist „eine grob vereinfachende Darstellung von Minderheiten als quasi einheitliche Gemeinschaft [...] diskriminierend“" (ebd.: 115). Auch wenn das offene Gesinnungsprinzip gelegentlich belächelt wird (vgl. Latsch 29.04.2017) oder Absurditäten und Widersprüche erzeugt (s. z. B. Kap. 4.2.2 , 5.2.4, 8.6), so verhindert das klare Definieren und Erfassen von Minderheitszugehörigkeit Diskriminierung und erlaubt Mischformen, Veränderungen und Nichtfestschreibung von Gesinnungen, was wiederum Freiheit bedeutet. Des Weiteren würden Zählungen ökonomisch-politische Festschreibungen im negativen Sinne fördern und gesellschaftliche Diskussionen darüber evozieren, ob sich Minderheitenförderung und -finanzierung lohnen (Elle 2011: 209). Das könnte dazu führen, dass ohnehin kleine Minderheiten, die schützenswert sind, aufgrund ihrer geringen Größe nicht geschützt werden, so Ludwig Elles Formulierung des bei Zählungen drohenden Paradoxons (ebd.: 211). Die Größe einer Minderheit sagt nichts über die Sinnhaftigkeit von Schutzmaßnahmen aus. Elle bewertet zurecht, dass ,[i]n unserer durch Pluralismus, Individualismus, Mobilität, Flexibilität und Mehrfachidentitäten, somit von Hybridität gekennzeichneten Zeit“ „,jede Form von starrer Festlegung einer Zugehörigkeit“ „überholt und weltfremd“ ist (ebd.: 212).

50 Das Gleiche gilt auch für die Größe der anderen drei nationalen Minderheiten in Deutschland sowie für die Zahl der Sprecherinnen und Sprecher der Regional- und Minderheitensprachen (Rein, Hilger 2008: 58; Hofmann 2015: 87-88).

51 Eine ausführlichere Diskussion verschiedener Schätzungen der Anzahl der Minderheitsangehörigen findet sich in (Kühl 2006b: 42-49) und (Kühl 2003: 111-114). 
nischen Minderheit gab es zwischen 1920 und heute große Schwankungen, die sich zwischen geschätzten 5.000 und 100.000 bewegten. Es wird angenommen, dass es neben den Dän*innen rund 1.000 bis 2.000 Fries*innen in Nordfriesland gibt (Kühl 2003: 111). ${ }^{52}$

Eine politikwissenschaftliche Studie an der Universität Hamburg scheint anhand einer Telefonumfrage herausgefunden $\mathrm{zu}$ haben, dass es im Norden Deutschlands, also ausdrücklich in einem Gebiet, welches über den Landesteil Schleswig hinausgeht, 104.000 Menschen gibt, die sich zur dänischen Minderheit bekennen (Schaefer-Rolffs, Schnapp 2015: 3). Im Landesteil Schleswig förderte die Studie eine Zahl von 42.000 Minderheitendän*innen zutage (ebd.: 3). Diese Studie bleibt uns allerdings schuldig, was genau die Befragten unter einem Dänischsein verstehen.

Während in Deutschland das Gesinnungsprinzip für die dänische Minderheit gilt, welches keine objektiven Kriterien zur Zugehörigkeit enthält, funktioniert die Definition in Dänemark anders. Angehörige der dänischen Minderheit in Südschleswig haben in Dänemark einige Privilegien gegenüber anderen deutschen Staatsbürger*innen. Es besteht die Möglichkeit, dänische Studienunterstützung $(\mathrm{SU})^{53} \mathrm{zu}$ bekommen sowie einen erleichterten Zugang zur dänischen Staatsbürgerschaft (vgl. Udlændinge-, Integrations- og Boligministeriet - Infødsretskontoret 06.10.2015: 2). Da der Minderheitenstatus also Vorteile mit sich bringt, stellt der dänische Staat konkrete Kriterien für die Angehörigkeit zur dänischen Minderheit auf. Gesinnung allein reicht hier als Kriterium nicht aus (vgl. Kühl 28.07.2016). Deshalb werden die folgenden drei objektiven Kriterien zur Definition eines*r Minderheitsdänen*in herangezogen: Geburt in Südschleswig, ganzer oder teilweiser dänischer Schulbesuch, aktives Engagement für die dänische Minderheit in Südschleswig (Aftale om Indfødsret, Bilag 1 Abs. 5. s. Udlændinge-, Integrations- og Boligministeriet - Infødsretskontoret 06.10.2015; vgl. Kühl 28.07.2016). Der Erwerb der dänischen Staatsangehörigkeit für Südschleswiger*innen ist bisher an einen zwei Jahre andauernden, ununterbrochenen Aufenthalt in Dänemark geknüpft (Aftale om Indfødsret, Bilag 1 Abs. 5.)..$^{54}$

52 Diese sind politisch ebenfalls durch den Südschleswigschen Wählerverband vertreten. Auch der dänische Kulturverein SSF hat eine friesische Sektion, die Frïsk Foriining.

53 Diese staatliche Ausbildungsförderung wird unabhängig vom Einkommen der Eltern bezahlt und ist daher und aufgrund ihrer Höhe sehr attraktiv für dänischsprachige Abiturient*innen (Bornemann 13.09.2012).

54 Seit 2015 gibt es allerdings in der aktuellen dänischen Regierung Diskussionen über eine Änderung dieser Regelung, sodass auch Südschleswiger*innen, die nicht nach Dänemark gezogen sind, sondern dauerhaft in Südschleswig wohnen, seit dem 01.09.2015 das Anrecht auf eine dänische Staatsbürgerschaft und die doppelte Staatsbürgerschaft (z. B. deutsch und dänisch, Lov om ændring af lov om dansk indfødret) bekommen können. Der Hintergrund dieser Änderungswünsche ist ein extrem verschärftes Staatsbürgerschaftsgesetz, welches von der rechts- 
Die Veränderlichkeit und Offenheit der Gesinnungswahl führt dazu, dass auch „Personen, die keine traditionelle Bindung an [die] dänische oder deutsche Minderheit haben, sich dennoch der Minderheit annähern und um Aufnahme bitten können“ Jørgen Kühl i. Interview m. Christiansen 2008: 59-61). Beim Eintritt in Minderheitenvereine gibt es keine offizielle „Gesinnungskontrolle“ oder Sprachprüfung (Kühl 2004: 325), aber man muss „sich ihrer Zielsetzung“ anschließen (ebd.: 325). Allerdings können sich Menschen laut Gesetz auch dann zur Minderheit rechnen, wenn sie nicht Mitglied in einem dänischen Verein sind, denn die Zugehörigkeit ist im Grunde eine individuelle Entscheidung, so die Sprachwissenschaftlerin Karen Margrethe Pedersen (Pedersen 2000a: 16), und die „dänische Minderheit ist nicht identisch mit den dänischen Minderheitenorganisationen und -institutionen“ (Kühl 2005a: 341). ${ }^{55}$ Es gibt also Selbst-, Gruppen- und Fremddefinitionen von Zugehörigkeit. Diese Zugehörigkeiten basieren oftmals auf der Imagination von vermeintlich objektiven Kriterien, „die nicht unbedingt den Tatsachen entsprechen“ (Kühl 2005d: 20). Bei der Konstruktion einer vermeintlich definierbaren Gruppe wird die Imagination der Gruppe, die ,in der Regel zu groß [ist], um tatsächlich zu ,beschließen“", eine Gruppe „sein zu wollen“ (Schneider 2001: 32), unterstützt - analog zum Nationbuildingprozess - durch Institutionen, Geschichte und einen „nationalen Diskurs“ (ebd.: 32). Als Alternative zum Begriff Minderheitssein verwende ich in dieser Arbeit auch die Wortkonstruktion Minoritätsschaft und den von Brubaker auf Englisch verwendeten Begriff minorityhood (vgl. Brubaker 2015: 8). Den Prozess der Minderheitswerdung bezeichne ich alternativ auch als Minorisierung, ohne damit die negative Bedeutung zu verbinden, die Regine Roemheld beschreibt (Roemheld 1983: 41-43).

konservativen Regierung beschlossen wurde (Nygaard 18.01.2017b). Die vorgeschlagenen Kriterien für den Erwerb der dänischen Staatsbürgerschaft für Angehörige der dänischen Minderheit sind folgende fünf, von denen drei erfüllt sein müssen: dänischer Schulbesuch, eine*e Vorfahre*in mit dänischer Staatsbürgerschaft maximal vier Generationen zurück, drei Jahre ununterbrochener Wohnsitz in Dänemark oder einem nordischen Land, aktiver Einsatz für die dänische Minderheit als Vereinsfunktionär*in über mindestens zehn Jahre, mindestens zehn Jahre Beschäftigung bei einer Organisation der dänischen Minderheit (Johannsen 15.02.2017). Diese Kriterien sind für die meisten Südschleswiger*innen nicht erfüllbar (vgl. a. Nygaard 18.01.2017a), schon gar nicht für jüngere Menschen. Ansonsten widerspricht vor allem das zweite Kriterium der Abstammung den Bonn-Kopenhagener Erklärungen.

55 Die dänische Minderheit ist also kein Verein, der auf Vereinskriterien wie Mitgliedschaft, Struktur, Ziel, Loyalität, Dauer beruht (1978: 42-43). 


\subsection{Ethnizität - Ethnisierung, Nation - Nationalisierung, Identität - Identifikation}

Die vorliegende Untersuchung ist im Bereich zwischen Ethnizitäts-, Nationalitäts- und Identitätsforschung angesiedelt, da der Schwerpunkt auf dem Dänischwerden und Dänischsein von Akteur*innen liegt. Des Weiteren streift diese Arbeit in Ansätzen die Migrations- und Konversionsforschung, auf die an dieser Stelle aber nicht explizit fachgeschichtlich und fachverortend eingegangen werden soll. Zusammenfassend lässt sich festhalten, dass „Minderheitenidentitäten keine festen und fertigen Identitäten sind, sondern multiple Identitäten ${ }^{* 56}$, so der erziehungswissenschaftliche Minderheitenforscher Alexander von Oettingen in einem deutsch-dänischen Sammelband zur Minderheitenpädadogik (Oettingen 2012: 31). Das heißt auch, dass man nicht einfach dänisch wird und dann dänisch ist, sondern dass Dänischwerden und Dänischsein lebenslange, veränderliche Prozesse sind (ebd.: 32).

Aus der Bezeichnung der Dänischgesinnten als „ethnische Minderheit“ (Polm 1995: 340) und als „,nationale Minderheit“ (Kühl 2005d: 9) folgert der Historiker Jørgen Kühl, dass die Angehörigen der dänischen Minderheit eine Gruppe bilden, die „eine eigenständige und kollektive Ethnizität“" besitzt (ebd.: 21). Daraus ergibt sich die entscheidende Frage, ob und wie man Ethnizität sowie Nation definieren kann. ${ }^{57}$

Der Zusammenhang zwischen Ethnizität und Nation ergibt sich durch die vielen Parallelen zwischen diesen beiden Phänomenen. Wie Ernest Renan schon 1882 in seiner Rede „Qu'est-ce qu'une nation?“ in der Sorbonne sagte: „L'existence d'une nation est [...] un plébiscite de tous les jours" (Renan 1947: 904). Dieses tägliche Plebiszit, das tägliche Entscheiden für das Konstrukt Nation und das Füllen desselben mit Inhalten, mit Erinnerungen und Seele (vgl. ebd.: 903904) findet sich auch bei Konstrukten wie Ethnien oder Minderheiten wieder. Das tägliche Bekenntnis zur dänischen Minderheit, die Gemeinsamkeiten und das gemeinschaftliche Erleben sind wichtig für die Existenz der Minderheit. Denn: „Wie sollte man sonst dänisch sein?“, fragt Karin Johannsen-Bojsen (JohannsenBojsen in Paszel 2005: Anhang). Jørgen Kühl greift bei diesem Aspekt auf Renan zurück, indem er sagt, dass die Zugehörigkeit zur Minderheit „eine individuelle, tägliche Volksabstimmung ${ }^{\text {“58 }}$ sei, die „kontinuierlich bekräftigt werde“559 (Kühl 23.09.2006). Die Minderheitenzugehörigkeit könne allerdings auch abgewählt werden. Kühl fasst zusammen, dass es sich bei der dänischen Minderheit in Deutschland um eine Abstimmungs- und nicht um eine Abstammungsminder-

\footnotetext{
56 „Mindretalsidentiteter er ikke faste og færdige identiteter, men multible identiteter.“

57 Zur Begriffsgeschichte der Ethnizität s. a. Heinz (1993) und Sekulić (2008).

58 „en individuel daglig folkeafstemning“"

59 „bekræftes kontinuerligt““
} 
heit handele (ebd.). Das bedeutet, dass es bei der Zugehörigkeit zur Minderheit nicht um biologische oder historische Abstammung geht, sondern um die Wahl des Dänischseins, also um eine Abstimmung ${ }^{60}$. Bei der Wahl und der Praktizierung des Dänischseins berufen sich Menschen auf konstruierte Kriterien und Rechtfertigungsgründe, wie diese Arbeit zeigen wird. Gerade weil man die Begriffe Ethnizität, Nationalisierung und Identifizierung mit Vorsicht behandeln muss, werden sie im Folgenden detaillierter problematisiert.

\subsubsection{Ethnizität}

Der Begriff Ethnizität ist so „,vieldeutig“, dass er „sich nicht zum wissenschaftlichen Gebrauch" eignet, so die Kulturanthropolog*innen Elisabeth und Olaf Bockhorn (Bockhorn, Bockhorn 2000: 4). Deshalb ist es umso wichtiger, dass zwischen einer wissenschaftlichen ${ }^{61}$ und einer alltäglichen Verwendung dieses Begriffs unterschieden wird (Bockhorn, Bockhorn 2000: 5; vgl. a. Kaschuba 2001: 19). Konkreter haben Regina Bendix und Herman Roodenburg in ihrer Einführung zum Sammelband „Managing Ethnicity“ über die Begriffe Ethnizität und Nationalismus Folgendes formuliert: „Invented, imagined, administered, and manufactured: these are among the key adjectives found in current scholarship on both ethnicity and nationalism" (Bendix, Roodenburg 2000: xi), während im Alltagsdiskurs ,the assumption that ethnicity is a natural, innate, historically rooted and politically legitimating quality remains far more powerful“" (ebd.: xi).

Die unterschiedlichen Begriffsverwendungen in Wissenschaft und Alltag rühren unter anderem von der Existenz eines primordialistischen, essentialistischen, objektivistischen Ansatzes (vgl. Povlsen 2008: 251-253) in den Anfängen der Ethnizitätsforschung her. Dieser wurden später abgelöst von konstruktivistischen, relativistischen, kognitivistischen und performativen subjektivistischen Ansätzen in der Wissenschaft ${ }^{62}$, während es im Alltagsdiskurs häufig bei primordialistischen

${ }^{60}$ Werner Sollors plädiert gegen eine Verwendung des Begriffs Ethnizität und unterscheidet zwischen Kontruktionen, die sich auf Konsens und Abstammung berufen: „I propose that for the purposes of investigation group formation, inversion, boundary construction and social distancing, myths of origin and fusions, cultural markers and empty symbols, we may be better served, in the long run, by the vocabulary of kinship and cultural codes than by the cultural baggage that the word ,ethnicity' contains. My concern has therefore shifted from ethnicity to the cultural construction of the codes of consent and descent" (Sollors 1986: 39, m. Rückgriff auf Abner Cohen, s. a. 4-6).

${ }^{61}$ Zur kritischen Rolle der Wissenschaft bei der Konstruktion der Analysekategorien „Ethnie“ und „Volk“ trägt die Textsammlung von Eckhard H. Dittrich und Frank-Olaf Radtke (1990a) bei.

62 Vgl. die ausführlicheren Abhandlungen darüber bei (Banks 1996: 39; Brubaker 2007: 19; Feischmidt 2007: 52; Heinz 1993: 278, 281, 285-286; Kaschuba 2003: 139-141; Kohl 1999: 285-287; Schenk 2001: 371; Sokolovskii, Tishkov 2006: 190; Reiterer 2007). 
Denkweisen blieb. Dabei war und ist Ethnizität Thema in mehreren Fächern, beispielsweise in ,anthropology, sociology [...], social geography [...], social psychology, sociobiology, social work and educational theory, and even literary studies" (Banks 1996: 1). Aufgrund der Literaturmenge zu Ethnizität in den verschiedenen wissenschaftlichen Disziplinen begrenze ich mich hier hauptsächlich auf Fredrik Bath, Rogers Brubaker, Benedict Anderson, Eric Hobsbawm, John Coakley, Richard Jenkins und Thomas Hylland Eriksen.

Der primordialistische Ansatz sieht „ethnische Vergesellschaftung“ als „,natürlich" (Schenk 2001: 371) und Ethnizität als angeboren und gegeben (Banks 1996: 39), als „objektiv“ an, so die Kritik von Brubaker (Brubaker et al. 2009: 1). Vertreter dieser veralteten Richtung sind der Auffassung, dass die Welt in klar abgrenzbare, feste, nach innen homogene Einheiten unterteilt sei, so Vertreter des kognitiven Interaktionismusansatzes (vgl. Ruane, Todd 2004: 213; vgl. Brubaker 2007: 19; vgl. Sokolovskii, Tishkov 2006: 190).

Beim konstruktivistischen Ansatz dagegen wird davon ausgegangen, dass vermeintliche Gruppen oder in diesem Fall die dänische Minderheit ein „Produkt eines Prozesses der sozialen Konstruktion" sind (François et al. 1995: 14). Allerdings muss man hier kritisch anfügen, dass dieses Produkt nicht fest, starr und endgültig ist, sondern dass die dazugehörigen Prozesse ständig weiterlaufen. Man könnte auch von einer Gemeinschaft sprechen, die ,abstractly imagined by their members" wird (Eriksen 2002: 91 in Anlehnung an Benedict Anderson), also eine „[i]magined communit[y]“ (Anderson 2006) bildet. Dabei ist es nicht relevant, ob die Gemeinsamkeiten, an die die Gruppe glaubt,

empirisch erfaßt und nachgewiesen werden können. Wichtig ist nur, daß sich Individuen dieser Gruppe zurechnen (individuelle Selbstdefinition), von den anderen Individuen der Gruppe dazu gerechnet werden (kollektive Selbstdefinition) und daß andere, die außerhalb dieser Gruppe stehen, die Zugehörigkeit der einen zur Gruppe akzeptieren (Fremddefinition) (Hansen 1995a: 153).

Es geht hier also um den subjektiven Glauben der Teilnehmenden an eine ethnische Gruppe, es geht um ihre Sichtweisen und ihr Selbstverständnis, die bei der konstruktivistischen Sichtweise entscheidend sind (vgl. Brubaker et al. 2009: 1). Bahnbrechend für einen Wechsel von primordialistischen zu konstruktivistischen Sichtweisen war Fredrik Barths „Introduction“ zum Sammelband Ethnic Groups and Boundaries. Mit diesem Text veränderte Barth die allgemeine Auffassung von Ethnizität und Gruppenidentität als gegebene Tatsachen ${ }^{63}$, so Thomas Hylland

63 Fredrik Barth hat 1969 mit seiner Einleitung zum Sammelband Ethnic Groups and Boundaries die Annahme in den Ethnowissenschaften, dass kulturelle Variation unveränderbar ist und dass sich Gruppen durch kulturelle, abgrenzbare Faktoren eindeutig unterscheiden, verändert. Dabei betonte Barth zwei grundlegende Einsichten. Zum einen würden Grenzen bestehen, obwohl 
Eriksen (Eriksen 2003: 157; vgl. a. Kößler, Schiel 1995). Barth richtete den Fokus weg von vermeintlich starren Inhalten von Gruppen hin zu den von ihnen geschaffenen Grenzen, Abgrenzungen und auf das Kategorisieren von Gruppen (Barth 1969: 15). Abgrenzungsmechanismen entstünden beim Kontakt einer Gruppe zu einer anderen, wobei die Kollektive dabei nicht fest seien, sondern ihre Abgrenzungsmerkmale zu anderen aktiv aufrecht erhalten und sich dadurch als Gruppe reproduzieren (Jenkins 2008: 118-124). Barth hat im Vergleich zur früheren Ethnizitätsforschung ein „dynamischeres Modell für Ethnizität“ (Eriksen 2003: 158) ${ }^{64}$ entwickelt (vgl. Kohl 1999: 271), auch wenn seine Formulierungen wie beispielsweise „different cultures“ (Barth 1969: 15) kritisch anzusehen sind (Jenkins 2008: 119), da unklar bleibt, was genau mit „Kultur“ gemeint ist. Obwohl Barth betont, dass sich Gruppen durch Abgrenzung konstituieren, impliziert er auch, dass es abgeschlossene Einheiten gebe und keine Grauzonen oder Mischungen (Eriksen 2003: 171-172). 1994, 25 Jahre nach der Erstausgabe von Ethnic Groups and Boundaries, schreibt Barth jedoch, sich selbst korrigierend, in der Einleitung seines norwegischen Sammelbandes Manifestasjon og prosess, dass

\footnotetext{
Menschen diese überquerten. Auch und gerade wegen des Austausches mit anderen über Grenzen hinaus gebe es kategorische ethnische Unterscheidungen und Abgrenzungen, so Barth (Barth 1969: 9-10). Denn Gruppen bestünden auf der Basis von Abgrenzungen voneinander, die auch durch soziale Beziehungen über Grenzen hinweg gefestigt würden. Barths Schwerpunkt bei ethnologischen Untersuchungen ist daher nicht die Analyse der kulturellen Inhalte von Gruppen sein, sondern wie Gruppen und ihre Grenzen erschaffen und aufrechterhalten werden. Es geht also nicht um die Untersuchung von „Ethnien“ und ihren vermeintlichen Unterschieden, sondern um Ethnisierungsprozesse. Barth weist darauf hin, dass bei Ethnisierungsprozessen diejenigen Gruppenunterscheidungsmerkmale der Akteur*innen hervorgehoben werden, die die Akteur*innen selbst als signifikant ansehen. Andere Merkmale würden ignoriert oder bestritten. Diese Auswahl an passenden Elementen für die Gruppenidentität ähnelt dem Prozess der selektiven Auswahl von für die Akteur*innen in ihr Selbstbild passenden Elementen aus der Historie (Barth 1969: 14; vgl. Eriksen 2005: 158-159). Barth schreibt, dass Gruppen sich nicht nur über ihre kulturellen Inhalte, sondern durch ihre Grenzen, sie sich aber auch verschieben können, definieren und abgrenzen (vgl. Eriksen 2002: 37; Heinz 1993: 129; Kohl 1999: 271-272). Diese Grenzen würden durch gezielt herausgegriffene Differenzen zu anderen Gruppen gebildet. Menschen würden „ethnische Identitäten benutzen, um sich selbst und andere zum Zweck der Interaktion zu kategorisieren“, also abzugrenzen (Heinz 1993: 128). Gruppen würden bestehen bleiben, ,solange die Dichotomisierung zwischen Mitgliedern und Außenseitern fortdauert" (ebd.: 129). Außerdem versucht Barth zu zeigen, dass ethnische Gruppen sozial konstruiert werden (Banks 1996: 12). Regina Bendix erwähnt dazu: „Fredrik Barth's classic Ethnic Groups and Boundaries (1969) [...] already hinted at the essentially constructed nature of ethnicity, and dwelled on cultural difference" (Bendix, Roodenburg 2000: x-xi; vgl. SchmidtLauber 2000: 396).

64 „mere dynamisk model for etnicitet“
} 
,Kulturen' nicht als ganze, abgetrennte und innen homogene Einheiten betrachtet werden können. Ganz im Gegenteil sind die Wirklichkeitskonstruktionen der verschiedenen Menschen immer unterschiedlich. [...] Um solche Unterschiede zu beschreiben, sagen wir, dass alle Menschen positioniert sind, unterschiedlich in $[\ldots]$ allen Faktoren, die uns kumulativ beeinflussen, in dem, wie wir uns orientieren und wie wir unsere Wirklichkeit auffassen/konstruieren (Barth 1994a: 10-11). ${ }^{65}$

Der amerikanische Soziologe Rogers Brubaker plädiert dafür, nicht von ethnischen Gruppen ,als substantielle[n] Einheiten“ auszugehen, die klar voneinander abgrenzbar sind, da man diesen verdinglichten Kollektiveinheiten „Interessen und Handeln" zuschreiben könne (Brubaker 2007: 17). Das Gegenteil, nämlich „die Tendenz, abgegrenzte Gruppen als fundamentale Analyseeinheiten (und grundlegende Konstituenten der gesellschaftlichen Welt) zu benutzen" nennt Brubaker „Gruppismus" bzw. „groupism“ (ebd.: 11). „,E]thnische und andere Gruppen“" würden dabei „als Entitäten gefasst" (ebd.: 11).

Daraus würde auch folgen, dass Gruppen „,nach innen homogen“ seien und „nach außen [...] mit gemeinsamen Zielen“" handelten (ebd.: 17). Diese Sichtweise entspräche einer „Welt als multichrome[m] Mosaik“ (ebd.: 17) aus Einzelbausteinen, wie es ganz ähnlich Brigitte Schmidt-Lauber als „Container verschiedener Kulturen im Sinne abgegrenzter, nebeneinander stehender Einheiten" beschreibt (Schmidt-Lauber 2007a: 9). Kulturphänomene werden bei diesem „BehälterRaum"-Modell (Rolshoven 2003: 191) immer mit einem klar definierten Raum in Bezug gesetzt (Seifert 2009: 40). Brubaker bestreitet nicht, dass bestimmte Akteur*innen einen „[e]thnischen Commonsense“ (Brubaker 2007: 18) bilden. Dieses Denken in ethnischen Gruppen, dieses „Verdinglichen“ sollte aber nicht vom Forscher oder von der Forscherin übernommen werden, sondern stattdessen als Prozess beschrieben, analysiert und erklärt werden (ebd.: 19-21). Dazu müsse Ethnizität als Ethnisierung verstanden werden, die relational, prozessual und dynamisch ablaufe und keine Gruppe schaffe, sondern stattdessen ein veränderliches ,Zusammengehörigkeitsgefühl ${ }^{\text {“66 }}$ hervorbringe (vgl. Brubaker 2007: 22; vgl. Sekulić 2008: 457). Dabei solle gezeigt werden, dass dieses potenziell vorhandene Zusammengehörigkeitsgefühl kontextabhängig, ,variabel und zufällig“" sei und nicht „fest und gegeben“ (Brubaker 2007: 22, 23). Zusätzlich schlägt Brubaker vor, Gruppen nicht als feste Kategorien zu betrachten, sondern zu untersuchen, wie Funktionär*innen und Akteur*innen sich bestimmte Kategorien heraussu-

65 „,kulturer ${ }^{6}$ ikke kan betraktes som hele, atskilte og internt homogene enheter. Tvert imot er forskjellige menneskers konstruksjoner av virkeligheten alltid ulike [...]. For å beskrive slike forskjeller sier vi at alle mennesker er posisjonerte, ulike i [...] alle faktorer som kumulativt påvirker hvordan vi orienterer oss og hvordan vi oppfatter/konstruerer vår virkelighet" 
chen, um diese mit einem Zusammengehörigkeitsgefühl aufzuladen und um Menschen, die nicht in diese wie auch immer ausgewählten Kategorien passen, aus ihrer Zusammengehörigkeit auszuschließen (ebd.: 23-25). Die von den Protagonisten selbst gebildeten Kategorien wie z. B. Alter, Geschlecht, Herkunft, Aussehen, Staatsangehörigkeiten, der gemeinsame Besuche einer dänischen Schule, erlebte Gemeinsamkeiten und dänische Sprachkenntnisse sein. Ethnizität wird also gemacht, und Gruppen werden von Akteur*innen auf der Basis „kulturellen und psychologischen“" Materials und mithilfe von Kategorien als „Projekte“ konstruiert (ebd.: 26-27).

Es geht also in der heutigen kulturanthropologischen Forschung darum, wie Menschen sich selbst auffassen und definieren, welche sozialen Beziehungen sie eingehen und nicht darum, wie sie vermeintlich sind (vgl. Adriansen et al. 2003: 234, 235; Heinz 1993: 279). Schließlich hebt Brubaker noch „die kognitive Dimension der Ethnizität" hervor (Brubaker 2007: 31) ${ }^{67}$ Ethnizität und Nation seien nach diesem Ansatz keine ,things in the world“, sondern „ways of seeing the world“ (Brubaker et al. 2009: 14). Das bedeutet konkret, dass Ethnizität nur eine Sichtweise ist, die das Sehen, Deuten, Schlussfolgern und Erinnern von Akteur*innen beeinflusst (Brubaker 2007: 31). Darunter falle beispielsweise

das stillschweigende, als erwiesen angesehene Hintergrundwissen, das in Personen verkörpert und in institutionalisierten Routinen und Praktiken eingebettet ist, durch die Gegenstände, Orte, Personen, Aktionen oder Situationen als ethnisch [...] charakteristisch oder bedeutungsvoll erkannt werden (ebd.: 32).

Brubakers kognitiver Ansatz unterstützt den konstruktivistischen Anspruch, den relationalen und dynamischen Charakter von Ethnizität und Nation als fließende und zufällige Ergebnisse von sich wiederholenden Prozessen der Kategorisierungen, der Verschlüsselungen, der Rahmungen zu betrachten (Brubaker et al. 2009: 18).

Mit diesem Ansatz hat Brubaker gezeigt, wie, wann und durch wen und was Ethnizität und Zusammengehörigkeitsgefühle hergestellt und verändert werden (vgl. Brubaker 2007: 32, 34, 37). Weiterhin kann vor diesem Hintergrund im Rahmen der Kulturanthropologie untersucht werden, wie Zusammengehörigkeit im Alltag von Akteur*innen angenommen, geschaffen, angewandt und ergänzt, diskutiert, weitergegeben oder ignoriert wird. Zusammengehörigkeitsgefühle beste-

${ }^{67}$ Auch Fredrik Barth betonte die kognitive Seite von Ethnizität, indem er nur die von Akteur*innen selbst als wichtig erachteten Merkmale der Differenz als Kriterien für Zugehörigkeit definierte (vgl. Heinz 1993: 127-128). 
hen „,keineswegs nur aus Ideologie und Imagination“, sondern „,beruhen auch auf konkreten sozialen Praktiken“, betont der Kulturanthropologe Wolfgang Kaschuba (Kaschuba 2003: 144). Diese subjektivistische Sichtweise beinhalte, dass Ethnizität nicht auf wirklichen „Gemeinsamkeiten“ beruhe, sondern auf „Glaubensüberzeugungen, Wahrnehmung, Verständnis und Identifikation“" (Brubaker 2007: 96) ${ }^{68}$ oder auf der aktiven Konstruktion von Differenz oder Grenzen (Sökefeld 2007: 31). ${ }^{69}$ Daher stünden „Kategorisierungen und Klassifizierungen“, die schon Fredrik Barth als Grundlage für Ethnizität definiert habe, im Fokus des Interesses (Brubaker 2007: 96; Feischmidt 2007: 54).

Aus der Tatsache, dass der Schwerpunkt auf der Wahrnehmung liegt, folgert Brubaker, dass eine kognitive Betrachtungsweise Ethnisierungsprozesse verdeutliche und ein Containermodelldenken vermieden werde. Gruppen können als ,gemeinsame Sicht- und Denkweisen über soziale Erfahrungen und eine gemeinsame Art, diese zu strukturieren und so soziale Welt zu interpretieren" definiert werden (Brubaker 2007: 96-97, 116). Nicht Gruppen als Einheiten, sondern die Gruppenbildung durch „Klassifikation, Kategorisierung und Identifikation“ und „Ethnizität als Form des Verstehens, Interpretierens und Einordnens von Erfahrung" ist das Thema einer kognitiven Sichtweise (ebd.: 117, 127). Ethnizität handele von ,myths and beliefs in common origins“ (Smith 2009: 29; vgl. a. Coakley 2004; vgl. a. Köstlin 2007: 33; vgl. a. Schöpflin 1997). Brubaker unterscheidet nicht bewusst zwischen „Ethnie“, „Rasse“ und „Nation“, da es sich dabei im Grunde um ganz ähnliche Gruppenbildungsprozesse und Zuschreibungen handele (Brubaker 2007: 120-121) und nicht nur Nationen, sondern auch ethnische Gruppen oder Rassen ,imagined“ seien (Brubaker 2007: 121; Anderson 2006) ${ }^{70}$. Nationale Zugehörigkeit ist genauso konstruiert wie ethnische oder Minderheitenzugehörigkeit. Daher ist meines Erachtens auch die Definition der dänischen Minderheit als ,ethnische“ oder „nationale“ oder ,autochthone“ Minderheit irrelevant. Sie für Staaten und Funktionär*innen nur als ein legitimierendes und sich abgrenzendes Label ${ }^{71}$, welches bestimmte politische oder finanzielle Vorteile mit sich bringen kann. Der konstruierte Dualismus zwischen „Wir“ und „den Anderen“ (Beck-Gernsheim 2004) bzw. ,Eigen versus Fremd" fungierte bereits als

68 Der Begriff „Glaubensüberzeugung“ begründet die Anwendung der Konversionstheorie in Kap. 8.7 in Bezug auf den Gesinnungswechsel, besonders im Falle Sarah Iversens (s. Kap. 4.1). Der „Glaube an Identität“ diene der Legitimierung und „Reproduktion“ der dänischen Minderheit, so Arthur Christiansen (2008: 87).

69 Vgl. a. Eriksen (2005: 158-159); Østergård (2005: 566); Hansen (2001: 27); Schmidt-Lauber (1996: 318-319); Kohl (1999); Marselis (2005: 43); Adriansen (1994: 18).

70 Dies betonen ebenso Jens Schneider mit Rückgriff auf Barths 1969 herausgegebenen Sammelband „Ethnic Groups and Boundaries“ (Schneider 2001: 21) und Martin Sökefeld (2007: 32).

Vgl. ebenso Assmann, Friese (1999).

71 „ethnicity can function merely as categorical ascriptions or labels used to classify people“ (Eriksen 2002: 41; Eriksen 2002) 
Grundlage für Nationalismus und beinhaltete eine ,Andersheit im Inneren“ sowie eine Abgrenzung nach außen. Aus „differenten Kulturen“ wurden „Minderheitenkulturen“ (Tschernokoshewa 2007: 13). Die Abgrenzung nach außen wird nicht nur von Minderheiten, sondern auch von vermeintlich ethnischen Gruppen und von Nationen praktiziert.

Für die Umsetzung der Minderheitsprojekte sind nicht nur einzelne Akteur*innen verantwortlich, sondern vor allem ,ethnopolitische Unternehmer“ (Brubaker 2007: 20), also Funktionär*innen, Politiker*innen, Organisationsvorsitzende und Institutionen, wie u. a. ,politische Parteien, ethnische Vereinigungen, die Organisationen der sozialen Bewegungen, Kirchen, Zeitungen“" (ebd.: 28). Einzelakteur*innen nehmen viele Aspekte und Zuschreibungen der Entrepreneure in ihre eigenen Argumente, Sichtweisen und Einstellungen auf. Siniša Malešević, Professor an der School of Sociology am University College Dublin, Irland, nennt die Funktionär*innen einer Gruppe auch „ethno-national mobilizers“ (Malešević 2004: 588). Diese nutzen historische Mythen und Darstellungen vermeintlich ethnischer Kollektivität, um Einigkeit nach innen und kollektive Abgrenzung nach außen zu beschwören (ebd.: 588). Diese Mythen haben, so Malešević, mehr mit gegenwärtigen Herausforderungen zu tun als mit tatsächlichen historischen Begebenheiten. Die Mythen sollen Geschlossenheit und kollektive Differenz beschwören. Dafür werden historische Legitimierungen konstruiert und die nationale oder ethnische Gruppe als homogen dargestellt (ebd.: 588). Der Religionssoziologe Martin Riesebrodt nennt diese Elite „Spezialisten“ im Unterschied zu „Laien“ (Riesebrodt 2007: 43, 137) bzw. „charismatisch begabte[...]“ versus „«normale[...]» Personen“ (ebd.: 43) 72 , während der irische Historiker John Coakley in Bezug auf Eliten in Nationalstaaten und bei nationalen Gruppen von „brokers of power“ im Gegensatz zu einfachen Angehörigen spricht (Coakley 2004: 533).

Joseph Ruane und Jennifer Todd bezeichnen die Elite als „ethnic entrepreneurs“ und „dominant actors“ (Ruane, Todd 2004: 213, 226). Diese Unterscheidung ähnelt meiner Unterscheidung zwischen Funktionär*innen und Akteur*innen. Coakleys These ist, dass Eliten mithilfe von historischen Mythen ihre Ideolo-

72 Diese Idee beruht eigentlich auf Max Weber und Pierre Bourdieu, die die Herausbildung von Produzenten/Spezialisten und Konsumenten/Laien,durch die Urbanisierung und der damit einhergehenden Spezialisierung und Unabhängigkeit von der Natur und den Jahreszeiten begründen. Daher gebe es eine Rationalisierung von Arbeitsprozessen und bessere Berechenbarkeit von Mittel und Zweck, Erfolg und Misserfolg. Natur wurde zum Problem, Katastrophen würden zum Sinnproblem werden und man suche nach (religiösen) Erklärungen, sittlichen Maßstäben, ethischer Orientierung - sprich neuen Regeln. Spezialisten bedienten diese Sehnsucht, z. B. Pastoren oder hier Vereinsfunktionär*innen (Reuter 2018: 179-182). 
gien, Politiken und Entscheidungen in der Gegenwart versuchen zu legitimieren (Coakley 2004: 534, 540-553). Im Unterschied zu den Anhänger*innen der „foundationalism“-Theorie (vgl. Ruane, Todd 2004: 210-212), bedeutet das nicht, dass die „nationalist elite“ sich die Inhalte, Symbole und Gefühle beliebig ausdenkt, sondern diese als solche identifiziert und Menschen davon überzeugt, an diese Inhalte zu glauben (ebd.: 211).

In dieser Arbeit wird man in Übereinstimmung mit Brubakers Ansatz sehen, dass diese Zugehörigkeit oder das Zusammengehörigkeitsgefühl zur dänischen Minderheit auf subjektiven Faktoren beruht. Es gibt aber Versuche, diese Subjektivität zu objektivieren, wie in Kapitel 8.6 beschrieben. ${ }^{73}$

Die dänische Minderheit gründet, so der Ansatz meiner Arbeit, nicht auf vorgeblich kulturellen Eigenschaften - das wäre ein eher primordialistischer Ansatz -, sondern ist im Rahmen von Grenzverschiebungen, historischen Umständen und politischen Positionen der Akteur*innen entstanden und imaginiert (vgl. Schneider 2001: 45).

Die ethnische oder kulturelle Zugehörigkeit ist keine naturhafte Gegebenheit. Sie beruht vielmehr auf historischen Prozessen und ist wandlungsfähig und veränderbar. Sie ist eine Form der Selbstidentifikation und damit eine Art Selbstdarstellung, ein Bild, das man von sich selbst entwirft. Damit gehört sie in den Bereich des Imaginären. Schließlich hat sie einen strategischen, instrumentellen Charakter und ist an bestimmte Ziele gebunden (Terray 1995: 385). ${ }^{74}$

Diese Zugehörigkeit wird also imaginiert und ist nicht naturgegeben. Diese Imaginationen aber werden trotzdem durch die Betonung vermeintlich objektiver Kriterien durch Akteur*innen unterstützt. Des Weiteren haben diese Vorstellungen von Gemeinschaft konkrete Auswirkungen auf die Realität der Beteiligten, wie noch genauer beschrieben werden wird. ${ }^{75}$

73 Über die Notwendigkeit, die „practical category of ethnicity“ (Ruane, Todd 2004: 216-217) mit Inhalten zu füllen und die Art, wie Akteur*innen dies tun und wie zufällig das sein kann s. den Aufsatz von Ruane und Todd (ebd.).

74 Der imaginäre Charakter von ethnischer oder kultureller Zugehörigkeit findet sich nicht nur bei Minderheiten, sondern generell bei Zugehörigkeiten. Eine explizite Mehrheitszugehörigkeit wäre genauso imaginär, wenn sie beobachtet und beschrieben werden würde. Zum Prozesscharakter von Ethnizität (vgl. Schmidt-Lauber 2000: 401; Schmidt-Lauber 1996: 319).

75 S. bes. Kap. 7. Zur Einführung sei hier ein kurzer Überblick über Studien, die aus konstruktivistischer und kulturanthropologischer Sicht Minderheiten erforscht haben, gegeben: Anhand einer rumänischen Stadt in Siebenbürgen hat die Kulturanthropologin Margit Feischmidt ,das Phänomen Ethnizität" und dessen Konstruktion im und Auswirkungen auf den Alltag untersucht. Dabei hat sie vor allem die Ursprungsmythen von Ungarn und Rumänen unter die Lupe genommen (Feischmidt 2003). Zum selben Thema hat Marilyn McArthur 1990 eine kulturanthropologische Studie herausgegeben (McArthur et al. 1990), während Katharina Eisch über „Deutsche in Böhmen“ forschte (Eisch 2001: 162; vgl. a. Eisch 1999) und Gesa Snell die deut- 


\title{
2.2.2 Nation
}

\author{
„Die politische Wissenschaft ist sich dabinge- \\ hend einig, daß Nationen nicht nur etwas \\ sehr Neuartiges, sondern auch etwas äußerst \\ Künstliches sind. Keines der Kriterien, welches \\ die Angebörigen einer Nation üblicherweise \\ als ,natürliches" Merkmal ihrer Gemeinsam- \\ keit nennen, bält einer empirischen Überprü- \\ fung stand. Weder die ethnische Zusammenge- \\ börigkeit, noch die gemeinsame Sprache oder \\ die miteinander geteilte historische Erfahrung \\ macht eine Nation aus. Eine Nation ist eine \\ Nation, weil sie eine Nation sein will." \\ Thomas Hase \\ (Hase 2001: 89)
}

sche Minderheit im Kopenhagen des frühen 19. Jahrhunderts untersuchte (Snell 1999). Historisierungen und Ethnisierungen von deutschen Namibiern hat Brigitta Schmidt-Lauber untersucht (Schmidt-Lauber 1996). Regina Römhild hat sich mit der situationsabhängigen Veränderlichkeit des Konstrukts „Deutschsein“ (Römhild 1998: 8) und der Selbst- und Fremdverortung bei Russlanddeutschen beschäftigt. Sie sieht den gerade auch in dieser Arbeit behandelten Aspekt der Geschichtskonstruktion als ,zentralen Gegenstand der anthropologischen Auseinandersetzung“" mit Ethnisierungen (ebd.: 29-30, m. Rückgriff auf Chapman, McDonald und Tonkin). Siegfried Baur, Irma von Guggenberg und Dietmar Larcher haben eine Studie herausgegeben mit dem Titel „Südtirol im Spannungsfeld zwischen ethnischer und postnationaler Gesellschaftsstruktur", in der sie u. a. die dortige Funktion der Zweisprachigkeit in Behörden und den „ethnischen Bekenntniszwang“ untersuchen, die beide dem Machterhalt bestimmter Gruppen dienen (Baur et al. 1998). Untersuchungen mit einem Bezug auf ,Identitäten' und Ethnizität in Schulen haben beispielsweise Gisela Unterweger (Unterweger 2002) und Werner Schiffauer, Gerd Baumann, Riva Kastoryano und Steven Vertovec in Bezug auf Klassen mit Schüler*innen verschiedener Staatsbürgerschaften, Herkunft und Migrationshintergrund gemacht, die in einem Sammelband mündeten (2002).

Die Geschichts- und Geografiemythen zur Konstruktion des Nationalbewusstseins anhand des Ursprungsmythos einer sumerisch-ungarischen Verwandtschaft in Ungarn hat Róbert Keményfi untersucht (Keményfi 2009). Die Konstruktion von ethnischem Bewusstsein der deutschen Minderheit in Nordböhmen und im Erzgebirgsvorland in Tschechien hat Sandra Kreisslová unter die Lupe genommen (Kreisslová 2009). Von der nationalen Minderheit der Sorben in Deutschland handeln schwerpunktmäßig die Sammelbände rund um Elka Tschernokoshewa (2001; 2007; 2009b; 2011b) sowie (Toivanen 2001). Einen konstruktivistischen Blick auf die Minderheiten im deutsch-dänischen Grenzland wirft Peter Thaler, der betont, dass Identitäten komplex und subjektiv gebildet werden (Thaler 2007). 
So beschreibt der Religionswissenschaftler Thomas Hase das Konzept ,Nation“ mit Rückgriff auf Benedict Anderson. „Nationalismus ist vor allem ein politisches Prinzip, das besagt, politische und nationale Einheiten sollten deckungsgleich sein. Nationalismus als Empfindung - oder Bewegung - läßt sich am besten mit Hilfe dieses Prinzips definieren", so der Anthropologe und Soziologe Ernest Gellner (Gellner 1991: 8). Der Nationalstaat beruhe im Gegensatz zu vornationalstaatlichen Gebilden, wie beispielsweise Königreichen, auf der Idee „of being unique, special and different from other nation-states“ (Malešević 2013: 65). Menschen füllen das Konzept einer Nation also mit Inhalten, sie konstruieren es. Denn, so Gellner: „Der Mensch macht die Nation“ (Gellner 1991: 17). Akteur*innen machen dies, indem sie sich gegenseitig als Angehörige einer Nation anerkennen, sich gegenseitige Rechte und Pflichten einräumen und damit ihre nationale Mitgliedschaft bestätigen (vgl. ebd.: 17). Das Konstrukt ,Nation' ist „in seinem modernen und fundamental politischen Sinn sehr jungen Datums“ (Hobsbawm 2005: 29).

Der Tatbestand, eine Nation(alität) zu besitzen, ist kein inhärentes Attribut der Menschlichkeit, aber er hat diesen Anschein erworben. Tatsächlich sind Nationen wie Staaten historische Phänomene und keine universelle Notwendigkeit. Weder Nationen noch Staaten existieren zu allen Zeiten und unter allen Umständen. Darüber hinaus sind Nationen und Staaten nicht dasselbe Phänomen (Gellner 1991: 16).

Bezogen auf Nationen und Nationalismus geht der konstruktivistische Ansatz davon aus, dass ,Nation' keine festgelegte Einheit ist, sondern eine praktische Kategorie:

Nationalism can and should be understood without invoking „nations“ as substantial entities. Instead of focusing on nations as real groups, we should focus on nationhood and nationness, on "nation“ as practical category, institutionalized form, and contingent event. „Nation“ is a category of practice, not [...] a category of analysis (Brubaker 1996: 7).

Daher sollte man in der heutigen Forschung nicht danach fragen, was eine Nation ist, sondern eher:

how is nationhood as a political and cultural form institutionalized within and among state? How does nation work as practical category, as classificatory scheme, as cognitive frame? What makes the use of that category by or against states more or less resonant or effective? (ebd.: 16) 
Nationen existieren nicht einfach, sie werden von Menschen als Kategorien verwendet, sie entstehen durch Praxen und werden als gesellschaftlich herausgebildete Praktiken ${ }^{76}$ institutionalisiert (ebd.: 21). Dies kann übertragen werden auf von den Akteur*innen als national definierte Minderheiten oder als ethnisch bezeichnete, vermeintlich abgrenzbare Gruppen.

In Europa wurde der moderne Nationalismus gegen Ende des 18. Jahrhunderts erfunden (ebd.: 1). Die bis dahin vorherrschende Herrscherloyalität wurde dabei durch ein Nationalitätsdenken ersetzt (Østergaard 1985: 149; Scharff 1969c). Die im 19. Jahrhundert geführten Debatten über „Volk, Staat, Nation, Sprache und Volksgemeinschaft ${ }^{677}$ sprengten, so Østergaard, die ,alten europäischen, multi-nationalen Staaten wie die Habsburger Monarchie, das Osmanische Reich - und den dänisch-holsteinischen Gesamtstaat ${ }^{\text {"78 }}$ (Østergaard 1985: 156; vgl. Kap. 3). Nach der Französischen Revolution rückten „Forderungen nach liberalen und demokratischen Reformen“ „die Vorstellung der Nation als neues Legitimationsmuster staatlicher Ordnung“ im Gegensatz zur Monarchie in den Vordergrund (Thaler 2013: 24). ${ }^{79}$

Anhand der dänischen Minderheit in Südschleswig wird deutlich, dass nationales Gefühl und Staatsbürgerschaft nicht unbedingt zusammenfallen. Dies sei an folgendem Beispiel aus der Flensborg Avis illustriert: Bei einem Juniorensportler, der als deutscher Staatsbürger und Angehöriger der dänischen Minderheit in einem dänischen Segelklub trainiert, aber nicht für Dänemark bei den Nordischen Meisterschaften starten darf, führt dieser Umstand, dass die Teilnahme an die Staatsbürgerschaft und nicht an die gefühlte Nationalität gebunden ist, zu großer Enttäuschung und Frustration und dem Einreichen von Beschwerden durch ihn und seine Angehörigen (Thöming 13.06.2014). Hier wird sichtbar, dass zur dänischen Minderheit zu gehören nicht damit gleichbedeutend ist, formal zum dänischen Staat zu gehören, was wiederum ein Kriterium für die Teilnahme an sportlichen Wettbewerben ist. Andrea Graw-Teebken schreibt in ihrer Dissertation, dass „Zugehörigkeit zu einer Nation, die Nationalität“ mehr sei „als nur die Staatsange-

${ }^{76}$ Zu den Begriffen Praxen und Praktiken in der Praxistheorie s. (Schatzki 2016). Eine Praxis wird von Theodore R. Schatzki als „,[m]enschliches Handeln und Verhalten“, als „,körperliche[r] Vollzug sozialer Phänomene“ bezeichnet, die ,im Rahmen von Praktiken“ stattfinden, also in „kulturell vorstrukturierten ways of doing “ (Hervorh. i. Orig.). „Praktiken sind situationsübergreifende analytische Einheiten“ (ebd.: 46). Das bedeutet, das Praxen im Rahmen von Praktiken, also Verhaltensmustern und Handlungsweisen, stattfinden.

77 „folk, stat, nation, sprog og folkefælleskab“

78 ,gamle europæiske multi-nationale stater som det habsburgske monarki, Osmannerriget - og den dansk-holstenske helstat"

79 Mehr über die Konstruktion von Sprachgrenzen im deutsch-dänischen Grenzraum im 19. Jahrhundert s. Teebken (2006). 
hörigkeit“, da Nationalität eine „Schicksalsgemeinschaft“ sei „,und somit der Nachfolger religiöser Gemeinschaften" (Graw-Teebken 2008: 53). Das Beispiel aus dem Sport zeigt, dass Nationalität nicht nur mehr, sondern auch etwas anderes bzw. weniger sein kann als Staatsangehörigkeit. Letztlich ist es wichtig, sich dessen bewusst zu sein, dass die gefühlte Zugehörigkeit zu einer Nation (oder zu mehreren) nicht dasselbe ist wie der Besitz einer bestimmten Staatsbürgerschaft (oder mehrerer).

Die Differenzierung zwischen Staatsbürgerschaft und nationalem Zugehörigkeitsgefühl hat schon Eric J. Hobsbawm beschrieben (Hobsbawm 2005: 8). Der Historiker marxistischer Ausrichtung weist in seinem Buch „Nationen und Nationalismus. Mythos und Realität seit 1780“ darauf hin, dass es „,[w]eder subjektive noch objektive Definitionen“ von „Nation“ gebe, die brauchbar und hinlänglich seien (ebd.: 19). Das Nationalstaatskonstrukt beinhalte in vielen Fällen nicht nur ein Verwaltungssystem, ein Rechtssystem und Gründungsmythen, sondern eben auch die Idee von gemeinsamer Sprache, von einer gemeinsamen kulturellen Grundlage, einer gemeinsamen Gesinnung. Mögliche Kriterien für eine objektive Definition von Nation, wie zum Beispiel die selbst nicht objektiv definierbaren Begriffe Ethnizität oder Sprache ${ }^{80}$, seien „so verschwommen, wandelbar und mehrdeutig und als Anhaltspunkte zur Orientierung von Reisenden ebenso nutzlos wie Wolkenformationen zur Orientierung von Reisenden im Vergleich zu Wegzeichen“ (ebd.: 16). Sie taugen nicht, würden jedoch von Funktionär*innen des Staates trotzdem für Propagandamaßnahmen gebraucht (ebd.: 16; s. Kap. 5.2).

Das Zugehörigkeitsgefühl zur Nation als alleinige Grundlage ebendieser und als Abgrenzung zu anderen menschlichen Gebilden zu verwenden, funktioniere ebenfalls nicht, da diese Gefühle zu komplex und wandelbar seien (vgl. ebd.: 19). Hobsbawm beschreibt eine Nation daher zunächst als eine

ausreichend große Gemeinschaft von Menschen [...], deren Mitglieder sich als Angehörige einer »Nation« betrachten. Ob sich allerdings eine solche Gemeinschaft auch selbst so versteht, läßt sich nicht einfach feststellen, indem man Autoren oder politische Wortführer von Organisationen befragt, die für die Gemeinschaft den Status einer »Nation« beanspruchen (ebd.: 19).

Schon hier wird deutlich, dass es einen Unterschied zwischen der „von oben konstruiert[en]" Nation inklusive ihrer Vertreter*innen und den Sichtweisen „von unten“ gibt (ebd.: 21-22), ähnlich wie es in Kapitel 2.2.1 für Ethnizitätskonstruktio-

80 Vgl. die wissenschaftliche Diskussion beispielsweise über den Status des Niederdeutschen als Sprache, Dialekt oder Varietät des Hochdeutschen oder die Diskussion zum Sprach- bzw. Dialektstatus von Bosnisch-Serbisch-Kroatisch (vgl. a. Andersen 26.05.2017). 
nen gilt. Der Nationalstaat mit einem vermeintlich homogenen Volk plus nationalen Minderheiten ist also, so Hobsbawm, eine Konstruktion des späten 19. Jahrhunderts (ebd.). Die Nationalstaatsidee blühte dann im 20. Jahrhundert besonders stark auf (Arquint 2011: 28; Mandler 24.09.2014). Ab dem 21. Jahrhundert geht dieser Ansatz zurück und wird langsam vom Transnationalismusansatz abgelöst. Für den Hintergrund meiner Untersuchung darf nicht vergessen werden, dass die dänische Minderheit durch die Bildung des deutschen und des dänischen Nationalstaates erst als nationale Minderheit im Gegensatz zur konstruierten Mehrheit formuliert wurde (vgl. a. Graw-Teebken 2008: 17).

Die von Hobsbawm geforderte Untersuchung von Identifikationen und Perspektiven von Alltagsakteur*innen mit ihren Veränderungen und Entwicklungen in Bezug auf Nation oder Nationsbegriffen und in Abgrenzung zu Funktionär*innen und Organisationen (Hobsbawm 2005: 22) ist ein kulturanthropologisches Feld, in dem sich die vorliegende Arbeit bewegt. Der Fokus auf den lokalen Akteur*innen im Vergleich zu Organisationsfunktionär*innen ist auch damit begründet, dass, wie es Hobsbawm im Bezug auf Nationen ausdrückt, „offizielle Ideologien von Staaten und Bewegungen keine Anhaltspunkte für das [bieten], was in den Köpfen selbst ihrer loyalsten Bürger oder Anhänger vorgeht“ (ebd.: 22).

Der Wunsch, nationale Zugehörigkeit dingfest machen zu können, sie klar definieren zu können, muss enttäuscht werden, da sie nur schwer zu fassen ist, sich verändert und hauptsächlich darin besteht, ,was sie nicht ist“ - in Abgrenzung zu etwas, das anders ist (Graw-Teebken 2008: 13):

Nationale Identität beruht [...] immer auf einer Illusion von Homogenität, und diese Homogenität soll auch durch Nationalsprache erzeugt werden. In Grenzregionen zeigt sich aber, besser als anderswo, die Ambivalenz und Veränderbarkeit nationaler Identifikatoren (ebd.: 275).

Neben Hobsbawm folge ich dem konstruktivistischen Ansatz Benedict Andersons, der Nationalismus als kommunikative Handlung sieht und nicht von einer Konstruktion ausgeht, die willkürlich ist (vgl. a. Graw-Teebken 2008: 35; vgl. Langewiesche 2003). Anderson erkennt „Nation-Sein“ und „Nationalismus“ als „kulturelle Produkte einer besonderen Art“ an und definiert Nation als „eine vorgestellte politische Gemeinschaft", die ,als begrenzt und souverän“ imaginiert wird (Anderson 2005: 14, 15). Das konstruierte Gemeinschaftsgefühl ist im Alltag wirksam und veränderlich. Die nationale Identität werde ,täglich neu geschaffen durch die soziale Praxis“, so Graw-Teebken in Anlehnung an Ernest Renan (GrawTeebken 2008: 63).

Dass das Thema nationale Minderheiten und Nationalismus trotz Globalisierung und Weltgesellschaft noch aktuell ist, zeigt folgendes Zitat: 
[1] seems that the nation-state still remains the key organizing principle of our age. Rather than being a relic of past areas, nationalism has demonstrated a vibrancy and strength that very few, if any, contemporary ideologies could match. Although the waning, and even ultimate death, of nation-states and nationalisms has been proclaimed on numerous occasions over the past century or so, there are more nationstates in the world today than ever before (Malešević 2013: 5).

Dieses Phänomen ist auch an den Bestrebungen zahlreicher Regionen zur eigenen Nationalstaatsbildung zu erkennen: Schottlands Abstimmung im Jahre 2014 zur Abtrennung vom Vereinigten Königreich, die Unabhängigkeitsbestrebungen von Katalonien, dem Baskenland und Flandern und der 2016 beschlossene Brexit, also der Austritt Großbritanniens aus der Europäischen Union.

Zusammenfassend lässt sich sagen, dass nationale Geschichtsbilder und sogenannte Nationalkulturen nicht ausschließlich von ethnopolitischen Eliten im luftleeren Raum konstruiert werden, aber sie werden zur Legitimierung für gegenwärtige und zukünftige politische Entscheidungen genutzt. Der Prozess der Aneignung, Ausübung und Aushandlung von als national deklarierten Praxen ist eine Form der Nationalisierung (vgl. Feischmidt 2003: 46, 61). Bei der dänischen Minderheit kann man ebenfalls eine Nationalisierung beobachten und diese Minderheitswerdung, Minorisierung oder Minoritätisierung nennen. In der vorliegenden Arbeit wird im Folgenden auf die in diesem Unterkapitel genannten Aspekte und Begriffe zurückgegriffen werden.

\subsubsection{Identität - Identifikation}

Ähnlich wie „Ethnizität“ ist der Begriff „Identität“ lange diskutiert und meist unklar, mehrdeutig und unpräzise definiert worden (vgl. Hall 2004: 168-169). Differenz zwischen vermeintlichen Gruppen existiert nicht einfach, sondern wird aktiv „durch Ethnizität“ von den Beteiligten konstruiert. Das bedeutet, dass nicht nur Ethnizität, sondern auch damit zusammenhängende Identität(en) konstruiert wird/werden (Sökefeld 2007: 31). Identität kann ebenso wie Ethnizität im Grunde vieles sein. Aber oft werden akademische und gesellschaftliche Gebrauchsweisen dieses Begriffes miteinander vermischt. Einige Autor*innen vermeiden sogar eine Definition dieses Begriffs oder halten sich nicht an selbst gegebene Definitionen, so Sökefeld (ebd.: 31). In einigen Kontexten verweist „Identität“ auf eine individuelle Selbst-Identität, in anderen dagegen auf Gemeinsamkeiten mit anderen, wodurch vermeintliche Kategorien oder Gruppen gebildet werden (Byron 2006: 294). Aus Stuart Halls diskurstheoretischer Sichtweise ist „Identifikation“ „nicht determiniert“, sondern eine „Konstruktion“, „ein Prozess, der niemals abgeschlossen ist" (Hall 2004: 169). „Identifikation“ ist „,kontextabhängig“ und ,ein Prozess der Artikulation" (ebd.: 169), etwas, das man tut, nicht etwas, das man hat (Jenkins 2008: 5). Für die Konstruktion von „Identitäten“ erfinden Akteur*in- 
nen Traditionen und Narrative sowie symbolische Handlungen (Hall 2004: 171). Identität, so Hall, kann „,nur über die Beziehung zum Anderen“ konstruiert werden (ebd.: 171). Identität wird geschaffen durch einen Schließungsprozess nach außen und die Betonung von Unterschieden (ebd.: 171), wie es Barth für Ethnizität beschrieben hat.

Wenn man „Identität als analytische Kategorie“ (Brubaker 2007: 47) verwende, müsse es aber eine eindeutige Begriffsdefinition geben. Daher plädiert Rogers Brubaker nach einer umfassenden Kritik an der unterschiedlichen Verwendung dieses Begriffs in der Wissenschaft und an Erik Erikson ${ }^{81}$, Erving Goffman und Peter Berger, die das Wort Identität ${ }^{82}$ geprägt haben (ebd.: 48-66), für die Verwendung von besser definierten Alternativbegriffen, die eher der Analyse von Prozessen dienen (ebd.: 60, m. Rückgriff auf Alberto Melucci). „Identifikation und Kategorisierung“, „Selbstverständnis und gesellschaftliche Verortung“ sowie „Gemeinsamkeit“, „Verbundenheit“ und „Zusammengehörigkeitsgefühl“ sind Brubakers Vorschläge statt ,kollektive[r] Identität“, welche ein „Gefühl, einer unverwechselbaren, abgegrenzten Gruppe anzugehören“ beinhalte, „was sowohl eine gefühlte Solidarität oder Einheit mit anderen Gruppenmitgliedern umfasst, als auch eine gefühlte Unterschiedenheit [sic] von oder sogar Antipathie gegen genau benannte Außenseiter“ (ebd.: 67, 71, 73, 74, teilweise m. Rückgriff auf Max Weber). ${ }^{83}$ Identifikation sei ein brauchbarerer Begriff, der im Gegensatz zu „Identität“ einen aktiven Prozess und keinen Zustand beschreibe und der nicht verdinglicht werden könne (ebd.: 67, 71). Er beinhalte, dass Akteur*innen sich selbst und andere abhängig von Kontext und Situation „charakterisieren“, „lokalisieren“, „verorten“, kategorisieren (ebd.: 67) ${ }^{84}$ Dies geschehe erstens im Verhältnis zu anderen, also „relational“, und zweitens durch Einordnung von Personen in bestimmte Kategorien anhand von bestimmten Attributen, also „kategorial“ (ebd.: 67). Die Fremdidentifikation geschehe nicht nur durch andere Personen, sondern auch durch Institutionen und Organisationen, die die Macht haben, jemanden zu klassifizieren. Beispielsweise können zu diesen Einrichtungen auch Schulen ${ }^{85}$ gehören (ebd.: 68-

81 Fachliteratur aus der Psychologie zum Thema Identität soll hier nicht behandelt werden, da es den Rahmen dieser Arbeit sprengen würde.

82 Den Begriff „Identität“ kritisieren auch Kaschuba (2003: 139); Jenkins (2008: 14) und Malešević (2006).

83 Zur Produktion von Zusammengehörigkeitsgefühlen s. a. Schneider (2001: 21-22). Den Fokus auf die Sichtweise der Akteur*innen zu lenken fordert auch Christiansen (2003: 235-236).

84 Zum Prozess- und Aushandlungscharakter von Selbst- und Fremdidentifikation s. a. Dannenbeck (2002: 35-36); Brubaker (2007: 68-69).

85 Auch Martin Sökefeld nennt mit Rückgriff auf Michel Foucault die Schule als eine Institution, in der „,nationale Identität“ eingeübt werde (Sökefeld 2007: 41). Vgl. dazu auch Margit Feischmidt (Feischmidt 2007: 55). Analog zum „Prozeß des nation-making“ strebt möglicherweise auch die 
69). Diese spielen, so meine Beobachtungen, im Falle der dänischen Minderheit eine bedeutende Rolle in der „Produktion und Verbreitung von Identifikationen und Kategorien“" (Brubaker 2007: 69; vgl. a. Eriksen 2003: 155, 156). Die Bezeichnungen „Selbstverständnis und gesellschaftliche Verortung“ stünden für eine „situative Subjektivität“ (Brubaker 2007: 71). Dies beinhalte „das Gefühl, wer man ist, an welchem gesellschaftlichen Ort man sich befindet und wie man [...] zu handeln bereit ist“" (ebd.: 71). Auch bedeutet diese Formulierung „ein praktisches Verständnis im kognitiven und emotionalen Sinne, das Personen von sich selbst und ihrer gesellschaftlichen Welt haben“ (ebd.: 71, m. Rückgriff auf Pierre Bourdieu). Auch der britische Kultur- und Sozialanthropologe Marcus Banks definiert „ethnic identity“ als individuelles, subjektives „feeling of belonging to some ethnically defined group“ (Banks 1996: 9), ähnlich wie Irene Götz ,[n]ationale Identität“ als „das subjektive Gefühl oder Bewusstsein, einer Nation anzugehören“ beschreibt (Götz 2001: 309-310). Sie merkt an, ähnlich wie ich es für den Begriff Ethnizität beschreibe (s. Kap. 2.2.1), dass Forschende den unscharfen Begriff „kollektive Identität“ als konstruiert auffassen, dieser aber „für die Akteur*innen selbst oft objektive Gültigkeit“ besitzt, „,so dass kollektive Identitäten im Alltag als »essenzialisierte« Wirklichkeiten vermittelt werden, die in machtvoller Weise homogenisierend und ausgrenzend wirken können“ (Götz 2011: 69). Das bedeutet, dass auch wenn Wissenschaftler*innen die Begriffe in einer konstruktivistischen Sichtweise benutzen, diese Begriffe bei Akteur*innen trotzdem wirkmächtig sein können. Außerdem erlaubten Begriffe wie „Zusammengehörigkeitsgefühl“ im Unterschied zu „Identität“ eine Differenzierung verschiedener Ausprägungen „von Gemeinsamkeit und Verbundenheit“ (Brubaker 2007: 7576). Hier wird deutlich, dass es Zusammenhänge zwischen den Begriffen Ethnizität, Nationalität und Identifizierung gibt, die alle das Konzept Minderheit speisen, sei es eine als ethnisch oder als national deklarierte Minderheit.

Die Entstehungsanalyse von Zusammengehörigkeit, Gruppenbildungsprozessen und Unterschiedskonstruktionen ist ein spezifisch kulturanthropologischer Ansatz (Schneider 2001: 13). Dazu gehört auch die Analyse der „soziale[n] Praxis“, die Kaschuba als „Identität" versteht, und das Aufzeigen der „Aushandlung“ von Vorstellungen des „sozialen So-Seins“ (Kaschuba 2003: 135, 134; vgl. a. Dannenbeck 2002: 35). Identität ist also nicht, sondern ,gestaltet sich, indem sie praktiziert und gelebt wird“ „im Austausch mit anderen Menschen“, so Gisela Unterweger in ihrer Studie über eine multikulturelle Schulklasse in der Schweiz (Unterweger 2002: 195).

Institution Schule die Schaffung von Zugehörigkeit zur dänischen Minderheit als eine „sprachliche und kulturelle Vereinheitlichung nach innen" an (Schneider 2001: 31). 


\section{Die dänische Minderheit in Schleswig-Holstein}

In diesem Kapitel werden zum einen die Hintergrundinformationen zum Verständnis der Situation der dänischen Minderheit in Südschleswig bereitgestellt und zum anderen wird eine Kontrastfolie für die geschichtsbezogenen Legitimierungsstrategien von Akteur*innen geschaffen, welche in Kapitel 8.6 aufgegriffen werden. Anschließend folgt ein Überblick über den Begriff Verein und die wichtigsten dänischen Minderheitsvereine im Landesteil Schleswig.

\subsection{Der Landesteil Schleswig und die Entstehung der dänischen Minderheit}

Die außergewöhnliche Situation im deutsch-dänischen Grenzland ist durch komplizierte historische Umstände entstanden (vgl. Göttsch 2006: 383; vgl. GöttschElten 2016: 152 ${ }^{86}$. Darauf soll hier nur kurz eingegangen werden, und zwar in den

86 In diesem Zusammenhang veranschaulicht eine oft zitierte Aussage des englischen Premierministers von 1855 bis 1858 und von 1859 bis 1865, Henry John Temple, 3. Viscount Palmerston, die Komplexität der schleswig-holsteinischen Geschichte: „Palmerston said with more wit than accuracy that only three persons in Europe were completely acquainted with the truth, the Prince Consort who was dead, a German professor who was in a lunatic asylum, and himself and he had forgotten it" (Robertson 1918: 156). Auch Lytton Strachey, ein britischer Biograf, hebt in seinem Werk über Queen Victoria die Undurchschaubarkeit der Schleswig-Holstein-Fra- 
Bereichen, in denen es für die Auswertung des vorliegenden Materials relevant erscheint. ${ }^{87}$ Der Überblick soll zum besseren Verständnis der Situation der dänischen Minderheit im Landesteil Schleswig beitragen, insbesondere weil einige der ethnopolitischen Akteur*innen (vgl. S. 51) in den dänischen Organisationen sowie ein Teil der Interviewten und einige Nichtdänischgesinnte in ihrer Argumentation auf bestimmte historische Ereignisse verweisen.

Bereits ab dem 9. Jahrhundert gehörte das Gebiet nördlich der Flüsse Eider und Levensau zu Südskandinavien, kann also im Prinzip als dänisch bezeichnet werden und gehörte nicht zum fränkischen Reich (Hirte 2003: 41-42, 44, 45; vgl. Hansen 2000b). Dabei ist zu bedenken, dass es bis ins 18. Jahrhundert keine Nationalstaaten im heutigen Sinne gab. Zwischenzeitlich war Schleswig selbstverwaltet (Thaler 2013: 22), dann stark mit Holstein durch verwandtschaftliche Beziehungen unter den Ritterschaften oder Verpfändungen von schleswigschen Gebieten an holsteinische Grafen und vor allem durch wirtschaftliche Beziehungen verbunden (vgl. Scharff 1969c: 220). ${ }^{88}$ Vom Mittelalter bis 1863 war das Herzogtum Schleswig aber mehr oder minder stark mit Dänemark verbunden. Einige Teile Schleswigs unterstanden direkt dem dänischen König, andere Gebiete gehörten zum dänischen Gesamt- bzw. Konglomeratstaat ${ }^{89}$ oder waren dänische Lehen, die von der deutschen Kanzlei in Kopenhagen administriert wurden. Von 1460 bis 1544 war der Herzog von Schleswig in Personalunion auch König von Dänemark (beginnend mit Christian I.), bevor das Herzogtum von 1490 bis 1523 und dann

ge in der zweiten Hälfte des 19. Jahrhunderts hervor: „the dreadful Schleswig-Holstein question - the most complex in the whole diplomatic history of Europe" (Strachey 1948: 137 (Erstausgabe 1921)). Der dänische Historiker Steen Bo Frandsen spricht ebenfalls von „einem sehr komplexen Beziehungsgeflecht" im deutsch-dänischen Raum (Weber 2015: 196), ebenso Carsten Porskrog Rasmussen (2008b: 20).

87 Ausführliche Abhandlungen über die Geschichte des deutsch-dänischen Grenzlandes, über die Zugehörigkeit einzelner Bereiche Schleswig-Holsteins zu Dänemark, über die zahlreichen Grenzverschiebungen, über Sprachgrenzen und über die Entstehung der Minderheiten findet man z. B. in den Sammelbänden Becker-Christensen (1995); Bregnsbo et al. (2016); Danstrup et al. (1962); Frandsen (2013); Henningsen (2009a); Lange (2003); Rasmussen et al. (2008b); Rheinheimer (2006b) und den Monografien Bohn (2001); Bohn (2006); Degn (1994); Findeisen (1999); Kühl (2003); Lauring (1964); Opitz, Scheiblich (2002); Yüksekkaya (2002). Die Konstrukthaftigkeit des Raumes und die unterschiedliche Bedeutung des Begriffs Schleswig aus deutscher und dänischer Perspektive hebt Lars Henningsen hervor (Henningsen 1998).

88 Diese Verbundenheit wurde u. a. durch die Existenz des damaligen schleswig-holsteinischen Landtags und Landesrats belegt (Lange 2003b: 155-156, 157).

89 Beide Begriffe, sowohl Gesamtstaat (helstat) als auch Konglomeratstaat, werden für das dänische Reich verwendet, welches aus Dänemark, Norwegen, Island, Grönland, den Färöern und den Herzogtümern Schleswig und Holstein, sowie der Grafschaft Oldenburg und einige Überseekolonien wie beispielsweise St. Croix, St. John und St. Thomas in der Karibik bestand. Der Gesamtstaat war ein Vielvölkerstaat (Frandsen 2005: 327, 334). Eine Diskussion der Begriffe Gesamtstaat vs. Konglomeratstaat liefert der schwedische Historiker Harald Gustafsson (1998). Statt helstat wird präziser auch der Begriff Oldenburgische Monarchie verwendet (Østergård 1998: 282). 
1544 erneut aufgeteilt wurde und der König von Dänemark nur noch Herzog der königlichen Gebiete in Schleswig war (Rasmussen 2008b: 17-18; Rasmussen 2008a: 73). ${ }^{90}$ Die Anbindung der Herzogtümer Schleswig und Holstein an den dänischen Gesamtstaat dauerte bis 1864 (Bohn 2006: 77). Neben diesen Teilen gab es gemeinschaftlich regierte Bereiche in Schleswig und Holstein, andere waren herzoglich (und nicht königlich) regiert, es bestand also ein ,territoriale[r] Flickenteppich“91 (Bohn 2006: 78; Bregnsbo 2006: 213, 214). Es gab außerdem zahlreiche Interessenskollisionen bei den Ämterüberschneidungen zwischen Herzögen und dänischen Königen (Frandsen 2016: 17).

Im Gegensatz zum Landesteil Holstein gehörte Schleswig mit der Südgrenze bestehend aus Eider und Levensau ${ }^{92}$ allerdings nie zum Heiligen Römischen Reich Deutscher Nation wie Holstein und Lauenburg, nie zum Deutschen Bund und war verfassungsrechtlich nie lübisch, unterlag also nicht dem Sachsenspiegel, sondern war bis zur preußischen Zeit immer jütisch (Hammel-Kiesow, Pelc 2003: 120; Lange 2003b: 157, 162; Poulsen 2013: 120; Scharff 1969c: 220; Scharff 1969b: 10; Bregnsbo 2013: 153-155; Bregnsbo 2006: 212; Bohn 2006: 91). Der dänische Gesamtstaat hatte dabei einen ,übernationalen Charakter“ (Scharff 1969c: 222). Auch wenn der Historiker Alexander Scharff in seiner Begrifflichkeit

90 Eine ausführliche Übersicht über die Herzöge und Regenten Schleswigs und Holsteins liefert der Sammelband (Rasmussen et al. 2008b).

91 Dies ist beispielsweise an der Geschichte der Insel Föhr zu erkennen, die bis 1864 geteilt war in einen westlichen Teil, der zusammen mit der Insel Amrum als Enklave direkt zum dänischen Königreich gehörte, aber im Gebiet des Herzogtums Schleswig lag. Diese Enklave wurde von der dänischen Kanzlei in Kopenhagen verwaltet. Hier galt bis 1900 das Dänische Recht. Im Gegensatz dazu galt im Herzogtum Schleswig, welches in der deutschen Kanzlei in Kopenhagen verwaltet wurde und zu dem der östliche Teil Föhrs gehörte, Jütisches Recht (Jacobsen 1938: 177; Nielsen 1922).

92 Die Eider wurde schon im Jahre 811 als Grenzfluss zwischen Karl dem Großen und Hemming, dem dänischen König, festgelegt (Henningsen 2009b: 13-14). Vorher diente das um 650 begonnene - und bis 1200 erweiterte - nördlich der Eider gelegene Bauwerk Danewerk („Dänenwerk“, auch „Dannewerk“, dän. „Danevirke“, „Dannevirke“) als südliche Grenze Dänemarks (Findeisen 1999: 33, 34; Gemeinde Dannewerk). Daneben war das Gebiet zwischen Danewerk und Eider lange Zeit durch Sümpfe, Wälder und Ödland charakterisiert, welches eine natürliche Grenze darstellte (Findeisen 1999: 34; Henningsen 2009b: 13). Vor der Frühneuzeit bestanden Grenzen nicht unbedingt aus Linien, sondern ,, herrschaftliche Einflussgebiete waren voneinander in der Regel durch breite Grenzgürtel [...] getrennt (Seifert 2009: 42). Diese „Grenzsäume“ waren eher durch naturräumliche Gegebenheiten oder durch Mobilitätseinschränkungen charakterisiert als durch politisch gezogene Grenzlinien (Seifert 2009: 42, 43; vgl. a. Anderson 2005: 27). Benedict Anderson betont, dass Grenzen in der Vormoderne „durchlässig und unklar“" waren, und „Souveränitäten gingen kaum wahrnehmbar ineinander über“ (Anderson 2005: 27, 28). Zur Geschichte und Erforschung des Danewerks und dessen Nutzung in nationaler Propaganda s. Dobat (2016). 
zwischen „Deutschen“ und „Dänen“ unterschied, so hob er doch korrekterweise hervor, dass das „Herzogtum Schleswig [...] weder völkerrechtlich noch nach seiner Nationalität ein „deutsches Herzogtum“ [war], sondern ein [...] Grenz- und Übergangsland, in dem sich Deutsche und Dänen mischten und begegneten“" (Scharff 1969c: 221; Scharff 1969b: 11; vgl. a. Göttsch-Elten 2016: 152). Dieses Gebiet ist aber nicht mit der heutigen Vorstellung eines (dänischen) Nationalstaates gleichzusetzen. Die Herzogtümer hatten als Lehen eine „staatsrechtliche[...] Sonderstellung" im Gesamtstaat und gehörten nicht zu dessen Kernland, dem Königreich Dänemark (Bohn 2006: 78, 87). Obwohl die Handelsschiffe in den beiden Herzogtümern, darunter auch Altona, unter dem Dannebrog fuhren, stand das kulturelle Leben unter dem Einfluss der Hansestädte Hamburg und Lübeck (ebd.: 82, 84).

Als die Sprache in Schleswig ab dem 19. Jahrhundert mit nationaler Zugehörigkeit in Verbindung gebracht wurde (s. Kap. 8.5) und es eine „wachsende[...] nationalstaatliche[...] Identitätspolitik“ (Göttsch 2006: 384) gab, entstand seit 1842 ein Konflikt zwischen Deutsch- und Dänischgesinnten im Herzogtum. Befürworter eines deutschen Schleswig-Holsteins bezogen sich auf das Ripener Abkommen $^{93}$ von 1460 und den Mythos der schleswig-holsteinischen Doppeleiche ${ }^{94}$. Sie engagierten sich in Liedertafeln und Sängerfesten und benutzten die schleswig-holsteinische Flagge sowie das Lied „Schleswig-Holstein meerumschlungen“" ${ }^{(95}$ als antidänische Symbole (Hansen 2003: 437). Währenddessen pochten die Dän*innen und Dänischgesinnten, wie sie es teilweise auch heute noch tun, auf die Zugehörigkeit Schleswigs zum dänischen Königreich seit der Wikingerzeit. Auch benutzen sie den mittelalterlichen Grenzwall Danewerk ${ }^{96}$ und das Skam-

93 Das Ripener Abkommen enthält den berühmt gewordenen niederdeutschen Satz: „Unde dat se bliven ewich tosamende ungedelt“ (Und dass sie bleiben ewig zusammen ungeteilt), der von Deutschgesinnten als eine Grundlage für die staatsrechtliche Einheit Schleswigs und Holsteins gedeutet wurde, aber nach neueren Erkenntnissen wahrscheinlich nur bedeutete, dass ein Landesfrieden in beiden Herzogtümern und zwischen ihren Ritterschaften bestehen sollte (Lange 2003b: 155-156, 157, 165, m. Rückgriff auf Carsten Jahnke; vgl. a. Henningsen 2009b: 17).

94 „Die Doppeleiche ist eine Eiche, die über zwei Stämme verfügt, welche manchmal im unteren Teil zusammengewachsen sind [...] und eine gemeinsame Krone bilden. Sie wurde im Zuge des Konflikts zwischen Dänen und Deutschen über den völkerrechtlichen Status Schleswig-Holsteins Mitte des 19. Jahrhunderts zum Symbol für die Zusammengehörigkeit der Herzogtümer Schleswig und Holstein stilisiert.“ (O. A. 2009). Daneben wird die Eiche oft als besonders deutscher Baum gedeutet. Doppeleichen stehen für ein untrennbares Ganzes. Sie wurden im späten 19. Jahrhundert zahlreich in Schleswig-Holstein als nationales deutsches Symbol gepflanzt (ebd.).

95 Dieses Lied wird aufgrund des Textes und der Entstehungsgeschichte als antidänisch interpretiert, wird aber heute als Hymne des Bundeslandes Schleswig-Holstein genutzt.

96 Am Danewerk in der Ortschaft Dannewerk liegt heute dass SSF-eigene Museum zum Wall und über die dänische Minderheit. 
lingsbanke-Fest ${ }^{97}$ als Symbol für Schleswigs Dänischsein (ebd.: 437-438). Auch wissenschaftsgeschichtlich war das alte Herzogtum Schleswig vor allem im 19. und 20. Jahrhundert geprägt von nationalistisch-politischer Instrumentalisierung von Fächern wie Archäologie und Altertumswissenschaft, Linguistik, Geschichtswissenschaft sowie Ethnografie (vgl. Frandsen 2016; vgl. Adriansen 2016c; vgl. Steigerwald 2016). ${ }^{98}$

Erst ab 1864, also nach dem Deutsch-Dänischen Krieg, wurden die Herzogtümer Schleswig (inklusive des heutigen Nordschleswigs) und Holstein als Kondominium gemeinschaftlich von Preußen und Österreich regiert. Das ist nach 400 Jahren „dänisch-schleswig-holsteinische[m][...] Gesamtstaat“ der Zeitpunkt, ab dem das Herzogtum Schleswig nicht mehr unter dänischer Herrschaft und Verwaltung steht (Hansen 2003: 456). Ab 1865 wurde Schleswig ${ }^{99}$ preußisch verwaltet, ab 1866 wurde das Herzogtum Holstein durch Preußen annektiert. Schließlich bestand die gesamte Region ab Oktober 1867 als preußische Provinz SchleswigHolstein im Norddeutschen Bund (ebd.: 456-459). 1871 wurde Schleswig dann Teil des Deutschen Reiches unter Kaiser Wilhelm I. (ebd.: 459). Die neue Zugehörigkeit zu Preußen vor 150 Jahren bedeutete eine grundlegende Reformierung der staatlichen Verwaltung. ${ }^{100}$ Eine Zuschreibung des Gebietes zu einer Nation im heutigen Sinne ist also erst ab dem Beginn des Deutschen Reiches, dem ersten deutschen Nationalstaat, also ab dem Jahr 1871 möglich. Damit folgte in dem Raum, in dem zuvor dem Nationalen nur wenig Bedeutung zugemessen wurde, eine „massive[...] preußische[...] Verdeutschungspolitik“, in der sich die dänischen Anhänger ,in der politischen Opposition“ befanden (Graw-Teebken 2008: 210).

Die Eider war von 811 bis 1864 die ,staatsrechtliche“ Südgrenze Dänemarks ${ }^{101}$, aber keine „Volksgrenze“, so der Historiker Lars N. Henningsen (Henningsen 2013: 213). Das bedeutet, dass ,der südlichste Teil von Schleswig [...] im-

${ }^{97}$ Fest Dänischgesinnter im Jahre 1843 auf dem geografisch höchsten Punkt Gesamtschleswigs (von der Eider bis zur Königau) zwischen Kolding und Christiansfeld im heutigen Dänemark gelegen (Hansen 2003: 438; vgl. Henningsen 2009b: 13).

98 Frandsen schlägt daher sinvollerweise vor, den Übergangscharakter der Region in der Forschung mitzudenken und das darin enthaltene Kontinuum zwischen deutsch und dänisch sowie der vielen regionalen Kontexte einzubeziehen statt einer einseitig-nationalen Betrachtung oder Interpretation den Vorzug zu geben (Frandsen 2016: 18, 22).

99 Ebenso Lauenburg.

100150 Jahre nach der Eingliederung Schleswig-Holsteins als Provinz in Preußen veranstaltet das Landesarchiv in Schleswig eine Ausstellung dazu s. (Schleswig-Holstein 2017); s. a. Bohn (2006: 95).

101 Der Fluss Eider wurde ,als Abgrenzung zwischen dem Einflussbereich des Frankenherrschers Karl des Großen und des Dänenkönigs Hemming herangezogen“" (Thaler 2013: 22). 
mer zum deutschen Kulturraum“ gehörte. Henningsen betont, dass eine dänische Bewegung im Südteil Südschleswigs, also von der Eider bis zur Linie HusumSchleswig erst ab 1945 anzutreffen sei (ebd.: 213), auch wenn das einige interviewte Akteur*innen anders sehen, wie in dieser Arbeit noch gezeigt werden wird (vgl. Kap. 8.6). Die Eider habe als Grenze, so Inge Adriansen, „seit dem Hochmittelalter praktisch keine Rolle mehr gespielt", da sie keine Zoll- oder Sprachgrenze war (Adriansen 2013: 238). Andrea Graw-Teebken hebt ebenfalls die Bedeutungslosigkeit der Eider als Grenze hervor (Graw-Teebken 2008: 257), ebenso Dirk Meier (Meier 2016: 9), der Historiker Alexander Scharff (Scharff 1969b: 11) und Frank Lubowitz (Lubowitz 2013: 250). Die langjährig benutze Phrase ,Dänemark bis zur Eider' dänischer Politiker (Adriansen 2013: 239) entsprang wohl „einem wirkungsmächtigen Mythos“ (ebd.: 240). Die Eider wurde „zu einer mentalen wie politisch bedeutsamen Grenze“ (ebd.: 240) gemacht, die nach dem Zweiten Weltkrieg auch für die dänische Minderheit „Symbol und Erinnerungsort“ wurde (ebd.: 240). ${ }^{102}$ Der Eider als Grenzfluss wird also heute nachträglich eine viel größere Bedeutung zugeschrieben, als sie es mutmaßlich über viele Jahrhunderte hinweg für die damaligen Menschen hatte. Die Vorstellung einer Nation oder nationalen Minderheit beinhaltet immer eine Begrenzungsimagination, so Benedict Anderson (Anderson 2005: 16). Akteur*innen der dänischen Minderheit schreiben der Eider diese Grenzfunktion zu, wie die Interviewauswertungen zeigen werden.

Nach dem Ersten Weltkrieg wurde im Versailler Vertrag eine Volksabstimmung zur deutsch-dänischen Grenze angeordnet, durch die der Verlauf der seit 1920 geltenden Grenze bestimmt wurde (Wulf 2003a: 553-555; Danker 1997: 6). ${ }^{103}$ Sie liegt auf der Höhe südlich von Tondern/Tønder und nördlich von Flensburg. Damit wurde das alte Herzogtum Schleswig in ein dänisches Nordschleswig und ein deutsches Südschleswig geteilt und Fragen „ethnischer Zugehörigkeiten der Bevölkerung beidseitig der Grenze“ aufgeworfen (Boie 2008: 93). ${ }^{104}$ Eine Besonderheit der deutsch-dänischen Grenze ist, dass es nach der Volksabstimmung keine Vertreibungen und keinen Austausch von Menschen gegeben hat, sondern auf beiden Seiten Minderheiten entstanden, die in ihren jewei-

102 Dass die Eider als symbolischer Erinnerungsort von dänischer Seite heute immer noch Bedeutung hat, zeigt die 2014 herausgegebene Publikation von Haarløv (Haarløv 2014), in der collagenartig dem Lauf der Eider mit Bildern und kurzen Texten gefolgt wird. Das Buch dient als Grundlage für Ausflüge von Dän*innen an die Eider, damit diese deren Bedeutung nicht vergessen, so der dänische Autor. Zu dänischen bzw. deutschen Erinnerungsorten im Grenzland und ihren jeweiligen nationalen Deutungen s. a. Frandsen (2009); Adriansen (2011); Adriansen (2010).

103 S. a. die Dissertation der Kulturanthropologin Nina Jebsen zu Propagandaanalysen während der Volksabstimmungen (Jebsen 2015).

104 Über die Hintergründe der deutsch-dänischen Gesinnungsgrenze im Verhältnis zur Staatsgrenze im 19. Jahrhundert ausführlicher Hansen (2006). 
ligen Herkunfts- und Wohnorten bleiben konnten. Nach dem Zweiten Weltkrieg $^{105}$ wurde der Grenzverlauf erneut diskutiert, da sich viele Südschleswiger*innen aufgrund äußerer Umstände (s. Kap. 4.2) als dänisch bekannten und auf eine Grenzverschiebung in Richtung Süden hofften. Seit 1996 gilt nicht nur für Deutschland, sondern auch für Dänemark das Schengener Abkommen, was zu einer offenen Grenze zwischen den beiden Staaten geführt hat, abgesehen von den wiedereingeführten stichprobenartigen Grenzkontrollen Dänemarks seit dem Zustrom von Geflüchteten aus dem Nahen Osten und Afrika ab 2015.

Die oben beschriebenen historischen Hintergründe haben auf beiden Seiten dänische bzw. deutsche Minderheiten hervorgebracht (vgl. Klatt 2009b: 178; Kühl 2005d: 23, 27; Sigaard-Madsen 1995; Wulf 2003a: 555). ${ }^{106}$ Das ehemalige Herzogtum Schleswig bildet das Gebiet „Sønderjylland“, auch Nordschleswig genannt, und südlich der Grenze bis zur Eider den Landesteil Schleswig ${ }^{107}$, auch Südschleswig genannt (Henningsen 2009a: 10; Sigaard-Madsen 1995: 135; vgl. Yüksekkaya 2002: 11). Die dänische Minderheit, ebenso wie das Gegenstück auf dänischer Seite, die deutsche Minderheit, sowie die sich selbst so nennende Volksgruppe der (Nord-)Friesen sind nationale Minderheiten, die traditionell in der Region Schleswig beheimatet sind und nicht durch Migration entstanden. ${ }^{108}$ Grenzziehungen und sprachlich-kulturelle Veränderungen bewirkten das Entstehen dieser drei Minderheiten im alten Herzogtum Schleswig (vgl. Kühl 2003: 101).

Der Begriff Südschleswig bzw. Südschleswiger*in wird in der Regel nur von der dänischen Minderheit benutzt und markiert die Zugehörigkeit zur dänischen Minderheit (Pedersen 2000a: 17; Kühl 2004: 334-335; Kühl 2005d) ${ }^{109}$. Dieser Be-

Im Nationalsozialismus und Zweiten Weltkrieg konnte die dänische Minderheit „ihre Existens grundlage“" aufrechterhalten, auch wenn sie zwischenzeitlich bedrängt wurde (Wulf 2003b: 600). „Das Dänische in Südschleswig geht zurück bis vor 1864, aber die dänische Minderheit in ihrer heutigen Form wurde durch die deutsch-dänische Grenze von 1920 geschaffen“ („Det danske i Sydslesvig går tilbage til før 1864, mens det danske mindretal i sin moderne form er skabt af den dansk-tyske grænse fra 1920"), fasst Nils Vollertsen zusammen (1993: 5). Südschleswig ist ca. 5200 Quadratkilometer groß.

108 Die Friesen besiedelten die schleswigschen Nordseeinseln und Helgoland ab dem Jahre 800 und die schleswigsche Westküste ab 1100 und kamen aus dem Siedlungsgebiet zwischen Rhein- und Emsmündung.

109 Der Begriff „Südschleswig“ kannn aber auch mit einem gleichzeitigen Deutsch- und Dänischsein konnotiert sein, wobei sich das Deutschsein auf die Staatsangehörigkeit und das Land, in dem man lebt, bezieht, während die Menschen „Dänemark als ihr kulturelles Mutterland“ ansehen (Sigaard-Madsen 1995: 134; vgl. dazu den Begriff kin-state auf S. 141). Einwohner*innen des Landesteils Schleswig, die keinen Bezug zur dänischen Minderheit haben, bezeichnen sich im Allgemeinen nicht als Südschleswiger*innen (Skovmand 2006: 57). Nur Dänischgesinnte bezeichnen sich als „Südschleswiger“" (Spoorendonk 2001: 43-44). Diese Aussage stimmt mit den Selbstbezeichnungen der Interviewten als Südschleswiger*innen überein. Als Gruppe bezeichnen sie sich umgangssprachlich als Dän*innen. 
griff wird in der vorliegenden Arbeit deshalb auch für Minderheitendän*innen verwendet. Zum heutigen Landesteil Schleswig gehören die kreisfreie Stadt Flensburg sowie die Landkreise Schleswig-Flensburg, Nordfriesland, der nördliche Teil von Rendsburg-Eckernförde und ein Teil von Kiel.

Ermöglicht wurde die in der Einleitung genannte freie Wahl der nicht nachzuprüfenden Gesinnung der dänischen Minderheit durch die auf Drängen der britischen Militärregierung vom schleswig-holsteinischen Landtag verabschiedete Kieler Erklärung vom 26.9.1949, in der „,[d]as ,subjektive Prinzip“ [...] verbrieft“ wurde: „Däne ist, wer Däne sein will““ (Danker 1997: 21). Auch regelte sie eine „ungehinderte Pflege der dänischen Sprache und Kultur“ (Jürgensen 2003: 655). Als die Bundesrepublik 1955 der NATO beitreten wollte, spielte Dänemark als NATO-Mitglied sein Vetorecht mit dem Ziel des Schutzes der dänischen Minderheit aus (Jürgensen 2003: 655; Klatt 2009b: 233). Daraufhin wurde die Kieler Erklärung durch die Bonn-Kopenhagener-Erklärungen ersetzt, die das ,subjektive Nationalitätenprinzip“ (Danker 1997: 27) fortführten. Das ebenso enthaltene Gegenseitigkeitsprinzip gilt in Bezug auf das freie Bekenntnis und die freie Ausübung „der jeweiligen Sprache und Kultur“ (Jürgensen 2003: 656) im anderen Land und in Bezug auf die finanzielle Unterstützung der jeweiligen ,eigenen“ Minderheit auf der anderen Grenzseite. ${ }^{110}$ Bestehende Ungerechtigkeiten wurden 1955 beseitigt. Dazu zählte und zählt beispielsweise die Befreiung der dänischen Minderheitenpartei SSW von der 5 \%-Klausel bei der Landtagswahl. Man muss aber anmerken, dass die Bonn-Kopenhagener-Erklärungen kein Gesetz, kein verbrieftes Völkerrecht und kein binationaler Staatsvertrag sind, sondern eine gegenseitige „Absichtserklärung der beiden Parlamente“ (Harck 2005: 331) Deutschlands und Dänemarks. Erst durch die neue Verfassung Schleswig-Holsteins von 1990 wurden das freie Gesinnungsprinzip sowie der Schutz der dänischen Minderheit rechtlich festgelegt: „Das Bekenntnis zu einer nationalen Minderheit ist frei; es entbindet nicht von den allgemeinen staatsbürgerlichen Pflichten" (Art. 6 Verf $\mathrm{SH}^{111}$ ). Die genannten Prinzipien der Gegenseitigkeit und Gesinnungsfreiheit sowie die ähnlichen ökonomischen Verhältnisse auf beiden Seiten der Grenze in einem vereinten Europa haben ein besonders tolerantes Verhältnis zwischen Deutsch- und Dänischgesinnten gleich welcher Staatsangehörigkeit geschaffen.

\footnotetext{
110 „Der dänische Staat und mehr noch privat organisierte dänische Grenzvereine brachten Mittel auf, um die dänische Kulturpolitik und insbesondere das dänische Schulwesen südlich der Grenze zu fördern“ (Jürgensen 2003: 652-653).

111 Fassung vom 02.12.2014. Dies ist ebenfalls im Rahmenübereinkommen zum Schutz nationaler Minderheiten festgelegt: Art 3 Abs 1 MindSchRÜbk. Den „Minderheitenschutz nach der schleswig-holsteinischen Landesverfassung“ analysiert genauer die Juristin Birte Köster (2009) in ihrer Dissertation.
} 
Neben den dänischen Schulen, die bereits vor 1945 gegründet worden waren und die nach dem Zweiten Weltkrieg wiedereröffnet wurden, gab es auch zahlreiche Neugründungen. Diese waren für „Reichsdänen“ (Klatt 2009b: 185) ${ }^{112}$ und Südschleswiger*innen ,das Entscheidende im großen Projekt, Südschleswig dänisch zu machen“ (ebd.: 204). Laut dem Historiker Martin Klatt wurden dänische Schulgründungen aufgrund lokaler Wünsche in die Wege geleitet und nicht durch die Initiative des dänischen Schulvereins (ebd.: 206).

Die schleswig-holsteinische Landesregierung hatte 1988 unter Ministerpräsident Björn Engholm das Amt einer*eines Minderheitenbeauftragten eingerichtet, welches mit einer kurzen Unterbrechung bis heute existiert. Die offizielle Bezeichnung dieses Amtes ist „Die Beauftragte des Ministerpräsidenten in Angelegenheiten nationaler Minderheiten und Volksgruppen, Grenzlandarbeit und Niederdeutsch“ (Schleswig-Holsteinische Landesregierung 2016).

Ministerpräsident Torsten Albig berief 2012 Renate Schnack (SPD), um ihn und die Regierung in Fragen zu den drei nationalen Minderheiten in SchleswigHolstein zu beraten. Schnack stand bis zur Landtagswahl im Mai 2017 im Dialog mit Akteur*innen von Mehrheit und Minderheit und diente als Mittlerin zwischen den jeweiligen Akteur*innen und der Landesregierung. Seit dem 28. Juni 2017 regiert in Kiel eine neue, sogenannte „Jamaika“-Koalition aus CDU, den Grünen und der FDP unter dem Ministerpräsidenten Daniel Günther, der als neuen Minterheitenbeauftragten Johannes Callsen (CDU) einsetzte.

\title{
3.2 Dänische Institutionen im Landesteil Schleswig
}

\author{
„In mein' Verein bin ich bineingetreten, \\ weil mich ein alter Freund darum gebeten, \\ ich war allein. \\ Jetat bin ich Mitglied, Kamerad, Kollege - \\ das kleine Band, das ich ins Knopfloch lege, \\ ist der Verein. [...] \\ Und doch ist das Gefühl so schön, zu wissen: \\ sie können mich ja gar nicht missen \\ in mein' Verein. \\ Da draußen bin ich nur ein armes Luder. \\ Hier bin ich ich - und Mann und Bundes- \\ bruder \\ in vollen Reihn.
}


Hoch über uns, da schweben die Statuten.

Die Abendstunden schwinden wie Minuten in mein' Verein."

Theobald Tiger alias Kurt Tucholsky Erstveröffentlichtung 1926 (Tucholsky 1997)

Nach dem Zweiten Weltkrieg kam es zu einem Zuwachs an dänischen Vereinen in Südschleswig und zu einem explosiven Anstieg der Mitgliederzahlen in diesen Vereinen (s. S. 97) ${ }^{113}$. Die Gründe dafür waren materieller und ideeller Art (Hansen 2002: 183). Der deutsche Staat war in der direkten Nachkriegszeit im Prinzip abwesend, während Dänemark als ein offener und responsiver Staat auftrat (ebd.: 198), der dänische Organisationen und das dänische Vereinsleben zwischen Staatsgrenze und Eider massiv förderte. Ähnlich wie die nationale Minderheit der Sorben organisieren sich die Dänen und Däninnen seit 1920 ,überwiegend in den Vereinen“ (Toivanen 2001: 40, 53-57). Zuerst soll nun kurz der Begriff, Verein“ problematisiert werden, bevor die wichtigsten Vereine der dänischen Minderheit kurz vorgestellt werden.

\subsubsection{Verein: eine kurze Einführung in Begriffe und Funktionen}

Ein Verein lässt sich ganz allgemein als eine Organisation, als ein institutionalisierter Zusammenschluss auf freiwilliger Basis von Menschen mit persönlichem Kontakt untereinander definieren und dient oft als dauerhafter oder längerfristiger Raum und Treffpunkt für Gemeinschaft, Geselligkeit, Interessenvertretung und regelmäßige Ausübung gemeinsamer Tätigkeiten oder zur Verfolgung gemeinsamer Ziele (vgl. Duden 2017; Schmitt 1963: 65; Nipperdey 1976: 174, 177; Foltin 1984: 5-8; Grosshennrich 1980: 29; vgl. a. Bühler 1978; vgl. a. Siewert 1978). Wichtig für die Definition einer Gruppe als Verein dabei ist der Faktor Regelmäßigkeit (Freudenthal 1968: 11). Der Aspekt des persönlichen Kontakts ist ein entscheidender Unterschied zwischen Vereinen und beispielsweise Nationen: „[E]in persönlicher Kontakt unter den Mitgliedern“ und damit eine „,soziale Integration innerhalb“ einer Gruppe und das dadurch entstehende „,Wir'-Bewußtsein“ ist für den Begriff Verein im volkskundlichen Sinne zentral (Schmitt 1963: 9). ${ }^{114}$

Rechtlich wird ein Verein im deutschen Vereinsgesetz als „Vereinigung, zu der sich eine Mehrheit natürlicher oder juristischer Personen für längere Zeit zu einem gemeinsamen Zweck freiwillig zusammengeschlossen und einer organisier-

\footnotetext{
113 Einen detaillierten Überblick über die Organisationen der dänischen Minderheit geben Kühl (2003) und Sydslesvigsk Forening (2014).

114 Zur Geschichte der Organisationsform Verein s. Bendix (1989); Grosshennrich (1980: 16-24); Schmitt (1963: 9-14); Nipperdey (1976: 175).
} 
ten Willensbildung unterworfen hat" definiert ( $\int 2$ VereinsG). Hierbei werden wieder die bereits erwähnten zentralen Punkte eines Vereins deutlich: Zusammenschluss, Gemeinschaft, Freiwilligkeit, Dauer und gemeinsame Ziele. Zugleich gibt es eine gesetzliche Freiheit zur Bildung von Vereinen ( $\int 1$ VereinsG). Im Gegensatz zur Gesellschaft bürgerlichen Rechts existiert der Verein unabhängig von den individuellen Mitgliedern (vgl. Brockhaus Enzyklopädie Online 2012c; vgl. Nipperdey 1976: 174). ${ }^{115}$

Das Spektrum an Vereinen bezüglich „Zielsetzung, Struktur und Funktion“, ist sehr weit gefächert (Broo 1989: 1). Im englischsprachigen Raum entspricht der Ausdruck voluntary association der im Deutschen relativ offenen Bedeutung von Verein (vgl. a. Foltin 1984: 5). Im Dänischen verwendet man das Wort forening. Bei der vorliegenden Untersuchung konzentriere ich mich auf in das Vereinsregister eingetragene Vereine der dänischen Minderheit, speziell auf den Kulturverein SSF und den Schulverein Skoleforening. Am Rande werden u. a. auch der Jugend- und Sportverein SdU, der Kirchenverein und der Bibliotheksverein thematisiert.

Die gesellschaftlichen Hauptfunktionen von Vereinen in postmodernen Gesellschaften hat G. Prakash Reddy, ein indischer Kulturanthropologe, nach seiner Feldforschung in Dänemark beschrieben. Die erste Vereinsfunktion ist, dass sich jedes Individuum seine eigene Gemeinschaft im Zusammensein mit anderen Gleichgesinnten durch Freundschaften und Vereinsmitgliedschaften bildet. Die

115 Ein Verein existiert also weiter, auch wenn Mitglieder austreten und neue Personen in den Verein eintreten. Juristisch wird unterschieden zwischen nicht-wirtschaftlichen und wirtschaftlichen Vereinen (\$S 20, 21 BGB), wobei ein nicht-wirtschaftlicher Verein seine „Rechtsfähigkeit durch Eintragung in das Vereinsregister des zuständigen Amtsgerichts“ (\$ 20 BGB) erhält und auch „Idealverein“ genannt wird, da er ,,auf die Förderung politischer, religiöser, kultureller oder geselliger Zwecke gerichtet“" ist (Brockhaus Enzyklopädie Online 2012c). In der vorliegenden Arbeit soll es ausschließlich um nicht-wirtschaftliche Vereine gehen, da nur solche Vereine im gewählten Feld vorkommen. Wirtschaftliche Vereine haben das Ziel, Gewinne zu erwirtschaften oder ihre Mitglieder ökonomisch zu fördern (ebd.) und werden ,,in Ermangelung besonderer bundesgesetzlicher Vorschriften" durch die Bundesländer ernannt (\$ 22 BGB). Kernelement eines jeden Vereins ist die Mitgliederversammlung, die den Vorstand, das geschäftsführende Organ und die gesetzlichen Vertreter des Vereins wählt. Weiterhin muss es eine Vereinssatzung geben. Rechtsfähigkeit wird durch einen Eintrag ins Vereinsregister erlangt (ebd.).

Vereinsgründungen werden oft aufgrund des Bedürfnisses nach einem rechtlichen Rahmen für das Handeln von Menschen als Gruppe vorgenommen. Vereine haben Vorstände, die als offizialisierte Ansprechpartner mehr Handlungsspielraum haben als einzelne Personen, da andere Institutionen Vereinsfunktionär*innen ernsthafter wahrnehmen als Privatpersonen (vgl. Häußer 2012: 37). Ebenso werden Mitglieder und der Vorstand vor der Haftung mit ihrem Privatvermögen geschützt, wenn ihr Zusammenschluss die Rechtsform eines rechtsfähigen Vereins hat (\$) 31, \54 BGB). Vereine unterliegen bestimmten „Ordnungskategorien“ (Schwering 1979: 540), die einen geregelten Rahmen um einen Zusammenschluss von Menschen bilden und so für sie mehr Rechtssicherheit im Gegensatz zu losen Gruppierungen sorgen. 
zweite Funktion von Vereinen ist die Unterstützung und Entwicklung von Demokratie- und Gleichheitsprinzipien und -ideologien. Aber es gibt neben der Wertevermittlung auch weitere Funktionen von Vereinen: Sie dienen als Raum für persönliche Begegnungen, Diskussionen und Meinungsbildung mit einem großen inhaltlichen Spektrum (Reddy [2001]: 31). Vereine bieten eine „Identifikationsmöglichkeit“ und stellen „Orientierungsgruppen“ dar (Nipperdey 1976: 181). Sie dienen nicht nur generell als zentrale Organisationen in Gesellschaften (vgl. Bendix 1989: 44) und als Rahmen für soziale Interaktion (vgl. ebd.: 19), sondern sind auch für die dänische Minderheit in Südschleswig das wichtigste institutionelle Element. Von der Wiege bis zur Bahre sind fast alle Angebote für Dänischgesinnte durch Vereine organisiert. Das weite Spektrum reicht von der ärztlichen Mütter- und Säuglingsbetreuung über Kindergärten und Schulen sowie Freizeitangebote bis zur dänischen Altenpflege und dänischen kirchlichen Beerdigungen. Daher ist es wichtig, die Rolle und Funktion der Vereine für die Bildung und Aufrechterhaltung der dänischen Minderheit genauer zu untersuchen, was Ziel der vorliegenden Arbeit ist. Die Zugehörigkeit zur Minderheit ist frei und nicht an die Mitgliedschaft in einem dänischen Verein gebunden. Jedoch erreichen (Minderheiten-)Vereine als formelle Organisationen Individuen auf mehreren Ebenen, wie beispielsweise durch die Teilnahme an Vereinsveranstaltungen und Festen, durch das Einrichten von sozialen Räumen, die formelle und informelle Kontakte mit Gleichgesinnten und Zugehörigkeitsidentifikationen ermöglichen.

Dänische Vereine übernehmen ein großes Spektrum öffentlicher Aufgaben, die aber hauptsächlich auf Dänisch stattfinden (sollen). Jørgen Kühl bezeichnet diese Konstruktion als parallelgesellschaftliche Struktur (Kühl 19.08.2013; vgl. a. Kühl 1996). Da diese Institutionen als Alternativen zu (deutschen) staatlichen Einrichtungen auftreten, aber keine staatlichen (deutschen) Einrichtungen sind, benötigen sie, um agieren zu können und geschäftsfähig zu werden, eine Rechtsform. Also organisieren sie sich überwiegend als Vereine, während ein Teil ihrer deutschen Äquivalente staatliche Institutionen (z. B. Schulen), Kirchen (z. B. die Evangelisch-Lutherische Kirche in Norddeutschland) oder öffentlich-rechtliche Gebietskörperschaften mit öffentlichen Trägern wie einer Stadt, einem Land oder dem Staat sind (z. B. Bibliotheken) ${ }^{116}$. Vereine der Minderheit funktionieren also im Großen und Ganzen wie Staaten für die Bevölkerung, sodass folgende Aussage von Siniša Malešević über Nationalstaaten auf die Minderheitenorganisationen der Dän*innen in Südschleswig übertragen werden kann: ,There is no doubt that social organisations are the principal and most effective vehicles for social action" (Malešević 2013: 8). Um Menschen zu steuern, müsse es Organisationen geben, so Malešević (ebd.: 8). Auf die große Bedeutung der Organisationen für die Auf-

116 Eine Analyse verschiedener rechtlicher Organisationsformen wie beispielsweise Gebiets- und Personalkörperschaften, Stiftungen und Gesellschaften sowie deren Vor- und Nachteile für nationale Minderheiten in Deutschland liefert Detlev Rein (2014). 
rechterhaltung der dänischen Minderheit hat Arthur Christiansen hingewiesen (Christiansen 2008). Seiner Auffasung nach instrumentalisieren die Akteur*innen der Minderheit die Vereine und Verbände zur Schaffung einer verbindenden Gemeinsamkeit zwischen den Minderheitsakteur*innen (Jensen 2009: 255). Das Minderheitensein wird durch Aktivitäten, Reden, geschaffene Strukturen und aktive Funktionär*innen der Institutionen mit Inhalten gefüllt, wie sich in dieser Arbeit zeigen wird. Das Doing Being Danish Minority ${ }^{117}$ passiert hauptsächlich in den Vereinen. In dieser Hinsicht gebe ich Christiansen recht, wenn er konstatiert, dass die Vereine unerlässlich für die Aufrechterhaltung der Minderheit sind, und dass sie „den nachwachsenden Generationen ein minderheitliches Bewusstsein vermitteln“ (ebd.: 255). Die Akteur*innen in der Minderheit glauben an die Gültigkeit der Kategorien „Sprache, Kultur, Gebräuche“ als definierende Merkmale für die Minderheit, so Christiansen (ebd.: 251). Er dekonstruiert dies als reinen Glauben an die Gemeinsamkeit. Diesen Glauben nennt er „Nationalstaatskonstrukt“ (Christiansen 2008: 73; vgl. a. Jensen 2009: 254; s. a. Kap. 8.5, 8.7), welcher von „den Funktionären der Minderheitsorganisationen und den Lehrern der dänischen Schulen, bewusst oder unbewusst künstlich aufrecht erhalten werden" (Jensen 2009: 251), ähnlich wie es im 19. Jahrhundert „,von bürgerlichen Eliten“ bei der Konstruktion von „Nation als Abstammungsgemeinschaft“ (ebd.: 254) passiert sei. Dafür ist Christiansen sowohl von sich angegriffen fühlenden Funktionär*innen ${ }^{118}$ als auch vom Historiker Martin Klatt kritisiert worden (Jensen 2009: 256; Klatt 2009a: 136). Dass Minderheiten, wie auch Mehrheiten und auch Nationalstaaten ein Konstrukt sind, ist aus kulturanthropologischer Sichtweise nichts Neues, allerdings verkennt Christiansen, dass die konstruierten Kategorien durchaus im Alltag wirk-

117 Diese Bezeichnung habe ich in Anlehnung an „Being Danish“ (Jenkins 2012), „Doing Gender Doing the Balkans“ ( 2012) und an „Doing Gender“ (West, Zimmermann 1991) gebildet, ähnlich wie es auch Familienforscher*innen für ihr Thema mit „Doing Family“ machen (Jurczyk et al. 2014) oder wie der Religionswissenschaftler Jörg Rüpke es für den Begriff Religion formuliert: Religion ist nicht, sondern wird gemacht, so Rüpke (Rüpke 11.05.2017). Being Danish spiegelt die Perspektive des Dänischen als etwas, das Menschen in ihrem Alltagsleben tun, wider. Die Praxis der Sinnzuschreibungen und Symbolisierungen im Grenzland nennt Göttsch-Elten doing border (Göttsch-Elten 2016: 152). Auch Grenzen sind also nicht, sondern werden „im konkreten Alltagshandeln" ausgehandelt und konstruiert (Seifert 2009: 49), also gemacht. Hier wird also das Ziehen von Grenzen zwischen Gruppen verschiedener nationaler Gesinnungen und Zugehörigkeiten vorgenommen, und das Füllen dieser Zugehörigkeiten mit Inhalten kann als Doing Minority bezeichnet werden.

118 Christiansen hat vermutlich recht, wenn er die Reaktion einiger Funktionär*innen auf sein Untersuchungsergebnis als Abwehr gegen seine Dekonstruktion ihres Handelns und Glaubens deutet und die Minderheit als etwas, das „nicht auf kulturellen, sprachlichen oder abstammungsbedingten Ansätzen" beruht [...], sondern in erster Linie eine gemachte Regelung" ist (Christiansen in Jensen 2009: 256). 
sam sind und nicht ignoriert werden können. Die vorliegende Arbeit mit einem kulturanthropologischen Ansatz zielt daher darauf ab zu schauen, welche Kategorien die Akteur*innen für sich selbst konstruieren, warum und wie sie das machen und welche Auswirkungen das auf ihren Alltag haben kann. Ein Überblick über die wichtigsten Vereine und Institutionen der dänischen Minderheit wird im nächsten Abschnitt gegeben (s. a. Kap. 7).

\subsubsection{Der Schulverein}

Die dänische Minderheit betreibt dänische Schulen, Kindergärten und Kinderkrippen im Landesteil Schleswig. Alle diese Schulen sind im eingetragenen Verein Dansk Skoleforening for Sydslesvig, dem dänischen Schulverein für Südschleswig, organisiert. Dieser wurde 1920 in Flensburg gegründet. ${ }^{119}$

Aktuell unterhält der Verein 46 dänische Schulen inklusive zweier Gesamtschulen mit Gymnasialteil mit insgesamt circa 5.700 Schülern, zusätzlich 56 dänische Kinderbetreuungseinrichtungen mit ca. 2.170 Kindern (Dansk Skoleforening for Sydslesvig a; Sydslesvigudvalget, Dansk Skoleforening for Sydslesvig 2015: 3), darunter in Friedrichstadt eine Grund- und Gemeinschaftsschule bis zur siebten Klassenstufe, die Hans-Helgesen-Skole ${ }^{120}$, einen Kindergarten sowie die Skolefritidsordning $(S F O)$, dt. Schulfreizeitordnung, eine - in dieser Form besonders für den skandinavischen Raum spezifische - Nachmittagsbetreuung für Kinder und Jugendliche, die südschleswigweit ca. 780 Kinder besuchen (Dansk Skoleforening for Sydslesvig a, BDO Statsautoriseret Revisionsaktieselskab 01.03.2016). Zusätzlich zu den Angeboten für Kinder und Jugendliche offeriert der Schulverein auch Erwachsenenbildungskurse, wie beispielsweise Dänischkurse. ${ }^{121}$

Rechtlicher Hintergrund für die dänischen Schulen ist erstens die UN-Grundrechtecharta von 1948, in der Eltern das Recht zugesprochen wird, „die Art der Bildung zu wählen, die ihren Kindern zuteil werden soll“ (Art. 26 Abs. 3 AEMR). Zweitens gibt es einen Minderheitenschutz in der EU-Grundrechtecharta, in dem

119 Name des Vereins bei der Gründung: Dansk Skoleforening for Flensborg og Omegn (Dänischer Schulverein für Flensburg und Umgebung). Blickt man zurück auf die Geschichte des Schulvereins, so stellt man fest, dass es 1945 in deutsch-dänischer Grenznähe neun dänische Schulen gab, in der 450 Kinder unterrichtet wurden. Die Zahl der Schulen und Schülerinnen und Schüler stieg dann nach Kriegsende rasant an. Bereits 1946 wurden 5.400 Kinder in 36 Schulen, 1947 9.200 Kinder in 50 Schulen und 1948 15.400 Kinder in 60 Schulen unterrichtet (Rerup 1982: 407; Hansen 2002: 183; s. a. Kapitel 4.2).

1202013 wurden auf der Hans-Helgesen-Skole 15 Schülerinnen und Schüler in die erste Klasse eingeschult (Flensborg Avis 12.08.2013).

121 Eine ausführliche Darstellung der Mitglieder-, Kinder-, und Schülerzahlen aller Einrichtungen der Dansk Skoleforening for Sydslesvig findet sich in der im Internet publizierten Resultataftale, dt. Ergebnisvereinbarung, des Schulvereins mit dem Sydslesvigudvalget, dt. dem Südschleswigausschuss, im dänischen Parlament (Sydslesvigudvalget, Dansk Skoleforening for Sydslesvig 2015). 
unter anderem das „Recht der Eltern, die Erziehung und den Unterricht ihrer Kinder entsprechend ihren eigenen religiösen, weltanschaulichen und erzieherischen Überzeugungen sicherzustellen“ (Art. 14 Abs. 3 GRCh) verbrieft wird. Drittens regelt die Landesverfassung Schleswig-Holsteins, dass Eltern entscheiden, ob ihre Kinder eine dänische Minderheitenschule besuchen und dass diese vom Land mitfinanziert wird (Art. 12 Abs. 4 und 5 Verf SH). Viertens sind die dänischen Minderheitsschulen im schleswig-holsteinischen Schulgesetz als Privatschulen verankert ( $\int 113$ Abs. 2; $\int 115$ Abs. 4; $\int 124$ SchulG; Kühl 2005a: 356; vgl. a. Kap. 5.2.4).

Die FUEV hat 2007 eine Erklärung verabschiedet, die das Grundrecht auf Bildung spezifizieren soll: Bildung sei „ein essentieller Bestandteil des Minderheitenschutzes und der Minderheitenförderung“" (Schultz, Walde 2007: 7). Sie trage „dazu bei, die Identität von Angehörigen der autochthonen, nationalen Minderheiten zu stärken“ und ist „Voraussetzung, um die Angehörigen der [...] Minderheiten zu befähigen, ihre Identität, Kultur, Sprache, Geschichte, Eigenart, Tradition, kulturelles Erbe und Überlieferung zu bewahren, zu pflegen und weiterzuentwickeln“ (ebd.: 7). Diese Forderungen sind positiv zu bewerten, allerdings werden die hier genannten Begriffe wie beispielsweise Tradition, kulturelles Erbe, Kultur und Identität weder definiert noch kritisch reflektiert. Sie deuten auf ein Containermodelldenken hin, bei dem diese Kategorien als statisch, unveränderlich, klar abgrenzbares Kontinuum betrachtet werden.

Weiterhin lässt sich feststellen, dass es dänische Minderheitsschulen in Südschleswig schon lange vor dem Inkrafttreten des Rahmenübereinkommens zum Schutz nationaler Minderheiten und vor dem Inkrafttreten der Europäischen Charta der Regional- und Minderheitensprachen gab. Eine Besonderheit an der Situation im deutsch-dänischen Grenzgebiet ist, dass seit dem Ende des Zweiten Weltkriegs die Existenzberechtigung der dänischen Schulen nie infrage gestellt worden ist. Daher unterstützen die beiden 1998 in Kraft getretenen Konventionen die Lage der dänischen Minderheit symbolisch, aber die durch sie bewirkten Änderungen waren aufgrund der Fortschrittlichkeit der rechtlichen Lage der Minderheit nicht notwendig.

Die dänischen Schulen und Kindergärten werden zu rund $49 \%$ vom dänischen Staat, zu ca. $34 \%$ vom Land Schleswig-Holstein, zu $10 \%$ aus den Kassen der Kommunen und Landkreise, zu $7 \%$ durch die Nutzer und Nutzerinnen, z. B. durch Kindergartengebühren, und zu $2 \%$ aus anderen Einnahmearten finanziert. Die Gesamteinnahmen und damit auch fast die gesamte Ausgabenhöhe lagen im Jahre 2015 bei 110.227.715 € (Dansk Skoleforening for Sydslesvig a, BDO 
Statsautoriseret Revisionsaktieselskab 01.03.2016). Dänemark zahlte 2015 rund 53,5 Millionen $€^{122}$ inklusive Summen für Projektfördermaßnahmen an die dänischen Kinderbetreuungseinrichtungen und Schulen in Südschleswig.

Die faktische Höhe des Zuschusses des Landes Schleswig-Holstein wird im Schulgesetz geregelt, welches besagt, dass der Betrag für die Minderheitsschulen zu 100 \% dem Schülerkostensatz, also dem Durchschnittsbetrag pro Schüler*in in öffentlichen Schulen des vorangegangenen Kalenderjahres, entspricht ( $\int 113$ Abs. 2 und $\int 124$ SchulG). ${ }^{123}$ Die dänischen Schulen sind kleiner und haben kleinere Klassen, eine bessere Ausstattung und eine bessere „Unterrichtsversorgung als vergleichbare öffentliche Schulen im Land“ (Landesrechnungshof SchleswigHolstein 2014: 98). ${ }^{124}$ Dänische Schulen unterrichten wegen des Deutsch- sowie Dänischunterrichts auf muttersprachlichem Niveau mehr Stunden pro Woche und die Lehrkräfte haben ein höheres Gehalt als an deutschen Schulen (ebd.: 98). Damit sind die Kosten pro Kopf wesentlich höher als in öffentlichen Schulen. Daher ist der dänische Schulverein zusätzlich auf die anderen finanziellen Quellen, also Gelder aus Dänemark, angewiesen. Die Schulen erheben keine Schulgebühren; nur die Kinderbetreuungseinrichtungen, wie Kindergärten, erheben Gebühren, so wie kommunale Einrichtungen es auch tun.

122 Diese Zahl setzt sich nicht nur aus dem laufenden Jahresbudget (Drifttilskud) zusammen, sondern auch aus Bau- und Projektzuschüssen. S. a. Kap. 7.6.

123 Im Jahre 2009 wechselte die schleswig-holsteinische Landesregierung von einer Großen Koalition aus SPD und CDU zu einer konservativen Regierung aus CDU und FDP mit einer sehr knappen Mehrheit. 2010 änderte diese Landesregierung die Zuschüsse für die dänischen Minderheitsschulen. Das bedeutete, dass die dänischen Schulen pro Schüler*in nur noch 85 statt 100 \% des Schülerkostensatzes vom Land bekamen. Dieser Beschluss löste enorme Proteste aus. Diese kamen von staatlicher Seite aus Dänemark und vor allem aus den Reihen der Minderheit selbst. Auch nicht-konservative Politiker im Land protestierten gegen die Geldkürzungen und sahen in diesen Verstöße gegen die Bonn-Kopenhagener-Erklärungen, gegen das Landesschulgesetz und gegen den allgemeinen Minderheitenschutz. Im Juni 2010 fand daraufhin „die größte jemals durch die Minderheit organisierte Protestaktion“ an verschiedenen Orten in Südschleswig mit insgesamt rund 15.000 Teilnehmenden statt (Kühl 2011: 306). Im September 2010 wurden dem verantwortlichen Ministerpräsidenten, Peter Harry Carstensen, mehr als 51.500 Unterschriften als Protest gegen seine Kürzungen übergeben. Erst mit dem Regierungswechsel im Juni 2012 führte die neue Landesregierung aus SPD, Die Grünen und SSW die 100 \%-Finanzierung wieder ein (Kühl 2011: 303-317; Nygaard 11.01.2014).

124 Die Klassenstärke in dänischen Schulen ist 19 bis $33 \%$ niedriger als in öffentlichen Schulen (ohne Duborg-Schule), Schüler*innen bekommen rund $15 \%$ mehr Unterricht und haben 1,8 mal mehr Lehrer*innen (gerechnet in Vollzeitstellen), so der Landesrechnungshof 2006 (Landesrechnungshof Schleswig-Holstein 2006: 120). Die Lehrkräfte des Schulvereins geben im Vergleich zu deutschen Schulen rund 14-28\% weniger Unterrichtsstunden und verdienen gleichzeitig rund 15 bis $20 \%$ mehr, kritisiert der Landesrechnungshof (ebd.: 121). Daraus resultiert, dass dem Schulverein ein dänischer Schüler bzw. eine dänische Schülerin mehr als doppelt so viel kostet wie dem Land Schleswig-Holstein ein*e Schüler*in auf einer öffentlicher Schule (ebd.: 122). 
Generell gilt also, dass die absolute Höhe der Zuschüsse aus Dänemark, vom Land Schleswig-Holstein und den Kreisen und Kommunen von der Anzahl der Schülerinnen und Schüler bzw. der zu betreuenden Kinder abhängt. Das bedeutet: je mehr Kinder und Jugendliche die Institutionen des dänischen Schulvereins besuchen, desto mehr Geld fließt dem Verein aus Dänemark und vom Land Schles wig-Holstein und den Kommunen zu. Dieser monetäre Aspekt wird später erneut im Zusammenhang mit den daraus entstehenden, beobachteten Ambivalenzen zwischen Offenheit und Abgrenzung aufgriffen (Kap. 7.6).

Die Entwicklung der Schüler- und Kinderzahlen im dänischen Schulsystem in Südschleswig ist in den letzten Jahren „stabil“ gewesen, so der Direktor des Vereins von 2000 bis 2016, Anders Molt Ipsen, im Jahrbuch der Minderheit 2014 (Ipsen 2014: 155; Dansk Skoleforening for Sydslesvig a, BDO Statsautoriseret Revisionsaktieselskab 01.03.2016). Im Jahre 2015 gab es im Schulverein insgesamt rund 931 Vollzeitstellen für die Kinderkrippen, Kindergärten, Schulen und die Skolefritidsordning.

Der Schulverein berücksichtigt sowohl die schleswig-holsteinischen als auch die dänischen Unterrichtslehrpläne (Dansk Skoleforening for Sydslesvig a, BDO Statsautoriseret Revisionsaktieselskab 01.03.2016). Die Abschlüsse der dänischen Schulen werden in Dänemark und in Deutschland anerkannt. Arbeits- und Unterrichtssprache, fachsprachlich medium, in den Einrichtungen des dänischen Schulvereins ist Dänisch. Im Fach Dänisch ist auch der Unterrichtsgegenstand, subject, Dänisch. Nur im Deutschunterricht sind sowohl subject als auch medium Deutsch. Damit handelt es sich bei den dänischen Schulen nicht um bilinguale Schulen, da Deutsch ausschließlich im Fach Deutsch und nicht als medium in den anderen Fächern verwendet wird (Hattesen 1990: 14; Søndergaard 1983: 88; vgl. Menke 1994: 121). Sowohl Dänisch als auch Deutsch werden ab der ersten Klasse auf muttersprachlichem Niveau unterrichtet. ${ }^{125}$

125 Mehr zu den Zielen und ausführlich zum Schulverein s. Kap. 5.2. 


\subsubsection{Der Kulturverein}

Der zentrale dänische Verein ist der 1920 gegründete SSF, Sydslesvigsk Forening e. V., der Südschleswigsche Verein ${ }^{126}$ (Sigaard-Madsen 1995: 138). Der SSF sieht sich selbst als „die kulturelle Hauptorganisation“"127 der dänischen Minderheit, die zur Aufrechterhaltung und Unterstützung des Dänischseins in Südschleswig beitragen soll (Skovmand 2006: 23; Jürgensen 2003: 627). ${ }^{128}$

Durch viele kleine und große Arrangements auf lokaler und regionaler Ebene werden die Menschen in die dänische Gemeinschaft eingebunden, was zu einem Zusammengehörigkeitsgefühl führt, so Dieter Paul Küssner, der SSF-Vorsitzende in den Jahren 2003 bis 2013 (Skovmand 2006: 23; Hansen in Sydslesvigsk Forening 2013a: 54). Der SSF ist offiziell nicht der Dachverband aller dänischen Vereine in Südschleswig, erhebt aber Anspruch darauf, der Hauptansprechpartner, -koordinator, -arrangeur und -finanzierer der meisten dänischen Aktivitäten zu sein (vgl. Sigaard-Madsen 1995: 148; Sydslesvigsk Forening Husum Amt). Das Ziel des Vereins ist laut Satzung, ,die dänische Sprache zu verbreiten und zu pflegen, die dänische und nordische Kultur zu bewahren und zu fördern und dänisches Gemeinschaftsleben in Südschleswig zu betreiben “129 ( ${ }^{\text {( } 2}$ Satz 1 Sydslesvigsk Forenings Vedtægter Sydslesvigsk Forening 2009b). Laut der stellvertretenden Vorsitzenden Gitte Hougaard-Werner sei das Ziel des Kulturvereins, die Minderheit nach innen zu bewahren und nach außen zu präsentieren (Hougaard-Werner 14.10.2013).

Die Organisation des SSF gestaltet sich folgendermaßen: Der Verein wird geleitet von einem schleswigweiten Hauptausschuss, ist aber unterteilt in sieben regionale Distrikte, die wiederum aus lokalen Ämtern, den Ortsvereinen, bestehen ( $\int 1$ Satz 2 Sydslesvigsk Forenings Vedtægter Sydslesvigsk Forening 2009b).

Auf der Landesebene hat der SSF drei feste Ausschüsse. Erstens den Theaterund Konzertausschuss, der sich um Veranstaltungen in diesem Bereich kümmert. Die Ausschussmitglieder suchen aus, welche kulturellen Gruppen und Angebote die Ortsvereine und Ämter buchen und ihren Mitgliedern präsentieren können. Der Ausschuss pflegt Kontakte nach Dänemark, prüft eingereichte Vorschläge auf ihre Tauglichkeit und unterstützt mit diesem Service die lokalen SSFAkteur*innen inhaltlich und finanziell. Das Komitee beurteilt auch die Eignung

126 Den slesvigske Forening (SF). Seit 1946 heißt der Verein: Sydslesvigs Forening (SSF); seitdem hat der SSF keine politischen Aufgaben mehr. Die „,politische Interessensvertretung der dänischen Minderheit und der national-friesischen Volksgruppe“ übernimmt seit 1948 der Südschleswigsche Wählerverband (SSW) (Sigaard-Madsen 1995: 140; vgl. a. Jürgensen 2003: 653). „den kulturelle hovedorganisation“.

128 Ein Teil des SSF ist ein friesischer Verein, die Friisk Forening, auf die in der vorliegenden Arbeit nicht weiter eingegangen werden soll.

129 ,at udbrede og pleje det danske sprog, værne om og fremme dansk og nordisk kultur og drive folkeligt dansk virke i Sydslesvig““ 
der Angebote für Kinder (Hougaard-Werner 14.10.2013). Diese zentrale Einrichtung erleichtert den ehrenamtlichen Ortsvorständen ihre Arbeit, könnte aber auch als zensierende Vorinstanz gedeutet werden, die darüber entscheidet, ob ein Theater- oder Musikangebot für die Minderheit geeignet ist. Die einzelnen ehrenamtlichen Ortsvorsitzenden sind zeitlich meist nicht in der Lage, in Dänemark nach kulturellen Angeboten zu suchen und mit den Kulturschaffenden zu verhandeln, so die Auskunft der lokalen SSF-Vorsitzenden (2010-2015) Tina Zehntner (INT10). Es ist zu beobachten, dass in vielen Ortsgruppen dieselben Künstler wiederholt auftreten, wie beispielsweise die Gruppe „Almost Irish“ an der gesamten Westküste.

Zweitens gibt es den Kulturausschuss. Dieser funktioniert ähnlich wie der Theater- und Konzertausschuss, nur bezieht sich dieser auf alle anderen Kulturangebote abseits von Theateraufführungen, Konzerten und Vorträgen (ebd.). Pro Jahr werden rund 50 Veranstaltungen mithilfe des Kulturausschusses organisiert, die jährlich von gut 5.000 Menschen besucht wurden (Kirsten Vognsen Weiß in Sydslesvigsk Forening 2013a: 26).

Drittens gibt es den Arsmødeudvalg, den Jahrestreffenausschuss, in dem Gitte Hougaard-Werner Vorsitzende ist. Das Ziel dieses Ausschusses und der von ihm koordinierten und mitorganisierten dreitägigen Jahrestreffen sei, sich als Minderheit nach außen und innen zu zeigen, was den Zusammenhalt stärken solle (Hougaard-Werner 14.10.2013). Der Ausschuss bietet zum Beispiel einen Rednerpool an, aus dem lokale Vereine Rednerinnen und Redner aussuchen können, die dann bei ihren lokalen Festen auftreten. Beim Jahrestreffen 2013 fanden vom 7. bis zum 9. Juni 43 Veranstaltungen in ganz Südschleswig statt (Sydslesvigsk Forening 2013a: 28; s. a. Kap. 8.1).

Weitere Komitees des SSF sind der Bildsammlungsausschuss, der Humanitäre Ausschuss für Senioren, der Eigentums- und Umweltausschuss, der Werbe- und Mitgliedsbeitragsausschuss, der Medienausschuss, der Organisationsausschuss und der Buchführungs- und Revisionsausschuss (Sydslesvigsk Forening f).

Die Finanzierung des Vereins sieht folgendermaßen aus: Der SSF bekommt jedes Jahr zwischen 3 und 4 Millionen $€$ vom dänischen Staat (Sydslesvigudvalget, Sydslesvigsk Forening 2014) sowie vom Land Schleswig-Holstein zwischen 300.000 und $400.000 €$ Zuschuss (ebd.).

Spenden an den SSF sind steuerlich absetzbar, der jährliche Mitgliedsbeitrag dagegen nicht. ${ }^{130}$ Die Mitgliedschaft kostet seit $201422 €$ pro Jahr für erwachsene Einzelmitglieder, $35 €$ pro Jahr für Haushalte bzw. Familien und $5 €$ pro Jahr für Jugendliche (Sydslesvigsk Forening; Sydslesvigsk Forening 2013a: 53).

130 E-Mail-Auskunft der SSF-Vereinskonsulentin Tine Andresen, 12.11.2013. 
Die Mitgliederzahlen in der Nachkriegszeit entwickelten sich von 2.700 bei Kriegsende über 11.800 gegen Ende 1945 und stiegen weiterhin stark an, sodass 1946 66.000 Mitglieder verzeichnet wurden. Die Spitze wurde 1948 mit fast 75.500 Anhängern erreicht (Rerup 1982: 407; Hansen 2002: 183; s. a. Kap. 3.1). 2013 hatte der Verein 14.214 Mitglieder (Sydslesvigsk Forening: 45).

\subsubsection{Weitere dänische Vereine in Südschleswig}

Nach der Präsentation des Schulvereins und des kulturellen Hauptvereins der dänischen Minderheit werden nun in einer kurzen Übersicht weitere Minderheitsvereine vorgestellt.

\subsubsection{Die Jugend- und Sportvereine}

Sydslesvigs danske Ungdomsforeninger (SdU), übersetzt Südschleswigs dänische Jugendvereine, wurden 1924 aus verschieden kleineren Vereinen unter dem Namen De sydslesvigske ungdomsforeninger, dt. Die südschleswigschen Jugendvereine, gegründet und 1947 mit dem heutigen Namen versehen (Hansen et al. 1998: 5; Nygaard 24.05.2014a). Wie auch bei den anderen dänischen Vereinen gab es in der Nachkriegszeit eine rasante Zunahme der Mitgliederzahlen (Hansen et al. 1998: 5, 21). Im Jahre 2014 hatten die SdU knapp 12.000 Mitglieder (Nygaard 24.05.2014a) und bestanden aus ca. 100 Vereinen in Südschleswig (Kühl 2005a: 363-364). Hauptaufgabe dieses Dachverbandes der dänischen Jugend- und Sportvereine in Südschleswig ist die Organisation des Sports und der Freizeitbeschäftigungen für Jugendliche, im Sportbereich auch für Erwachsene. Die Pfadfinder und die pfadfinderähnliche dänische Jugendorganisation FDF, Frivilligt Drenge og Pige-Forbund, dt. Freiwilliger Jungen- und Mädchen-Verband, stehen ebenfalls unter dem Dach der SdU. Zusätzlich betreiben die SdU Kurszentren, ein kulturelles Veranstaltungszentrum Aktivitetshuset, dt. Aktivitätshaus, Sporthallen und Bootshäuser sowie Freizeitheime und ein Schullandheim, die Lejrskole.

Das Ziel des Dachverbandes ist es, „die dänische Jugend- und Sportarbeit voranzubringen und die folkelige Arbeit in Südschleswig zu stärken “131, so \ 2 der Satzung (Sydslesvigs danske Ungdomsforeninger SdU 2016a: 1).

Gitte Hougaard-Werner betont in ihrem Vortrag vor neudänischen Eltern im Integrationskurs, dass dänische Freizeiteinrichtungen für die Bindung der Menschen an die Minderheit wichtig seien (Hougaard-Werner 14.10.2013; vgl. Kap. 5.1 u. 6). Ähnliches liest man in einem Zeitungsartikel über Kirstin Asmussen, die seit 2014 SdU-Vorsitzende ist. Sie äußert sich darin über das Hauptziel der dänischen Sport- und Freizeitvereine: „Es geht darum, die jungen Leute zu erreichen. Ein Teil der dänischen Minderheit zu sein, soll für die Jugendlichen nicht nur der

131 „Organisationens formål er at fremme det danske ungdoms- og idrætsarbejde, samt at styrke det folkelige arbejde i Sydslesvig“" Zum Begriff folkelig s. FN 262 auf S. 156. 
Besuch einer dänischen Schule sein. Die Minderheitsidentität soll sich über das ganze Leben erstrecken“132 (Asmussen in Nygaard 24.05.2014b). Die SdU biete Freiräume, in denen man das dänische Minderheitenleben leben könne, so Asmussen weiter (Asmussen in ebd.). In diesen solle es „Input und Erlebnisse“ geben, „die das Dänische im Gemüt füttern“"133 (Asmussen in ebd.). Junge Menschen für Sportaktivitäten im Verein zu aktivieren sei nicht ganz einfach, räumt die SdUVorsitzende ein, ,aber wenn wir es verstehen, die Ware zu verkaufen, können wir sie wohl erreichen“134 (Asmussen in ebd.). Das Dänischsein wird hier als Ware bezeichnet, die an den Mann und die Frau gebracht werden soll. Diese Begrifflichkeit deutet auf den konstruktiven Charakter des Dänischseins und der Minderheit hin. Dänisch ist man nicht, Dänischsein kann man käuflich erwerben bzw. sich an-essen („füttern“) oder einverleiben.

In den SdU gebe es zwei unterschiedliche Ansätze bei den Akteur*innen: 30 \% seien pragmatisch-sachorientiert und fänden Aktivitäten und Gemeinschaft wichtiger als Gesinnung, während der Rest eher auf die Gesinnung und dänische Sprachkompetenz poche und Angst vor dem Verlust des Dänischseins habe, so die dänischen Sportsoziologen Jørn Hansen, Anebine Danielsen und Thomas Skovgaard (Hansen et al. 1998). In der Praxis seien die meisten Mitglieder in SdUVereinen aber zweisprachig, allerdings gebe es einen Übungsleiter*innenmangel, und folglich könne man nicht immer dänischsprachige Trainer*innen in allen Vereinen erwarten (ebd.).

Die SdU bekamen im Jahre 2015 rund 4,7 Millionen $€$ Finanzmittel aus dem Königreich Dänemark; vom Land Schleswig-Holstein kamen rund $34.000 €$ an Zuschüssen (Sydslesvigs danske Ungdomsforeninger SdU 2016b: 17; s. a. Kap. 7.6).

In Friedrichststadt sind die SdU durch den Kanuklub Ejder Viking Sydslesvig, dt. Eider Wiking Südschleswig, und durch den Frederiksstad danske Ungdomsforening, dt. Friedrichstadt dänischer Jugendverein, vertreten (Sydslesvigs danske Ungdomsforeninger $\mathrm{SdU}$ ).

\subsubsection{Der Kirchenverein}

Der eingetragene Verein Dansk Kirke i Sydslesvig, kurz DKS, Dänische Kirche in Südschleswig, ist als Zweig der Dänischen Seemanns- und Auslandskirchen ein Teil der dänischen lutherischen Staatskirche Folkekeirken (Danske Sømands- og

\footnotetext{
132 „Det drejer sig om at få fat på de unge. At være en del af det danske mindretal skal for de unge ikke bare være at gå i en dansk skole. Mindretalsidentiteten skal kunne strække sig igennem hele livet."

133 ,input og oplevelser, der fodrer det danske i sindet“

134 „Men hvis vi forstår at sælge varen, kan vi godt få fat på dem.“
} 
Udlandskirker; Dansk Kirke i Sydslesvig a; Dansk Kirke i Sydslesvig b). Der Kirchenverein ist seit seiner Gründung im Jahre 1959 zuständig für die 35 dänischen Kirchengemeinden und 24 Pastorinnen und Pastoren (Dansk Kirke i Sydslesvig e) und beruft sich auf die bis ins Jahr 1588 zurückgehende Tradition, in Schleswig dänischsprachige Gottesdienste abzuhalten, beispielsweise in der Flensburger Heiligengeistkirche (vgl. Jacobsen 26.11.2013; Dansk Kirke i Sydslesvig d). Die kirchliche Leitung hat ein Probst in Flensburg inne, während die bischöfliche Leitung im dänischen Haderslev/Hadersleben sitzt. Die Kirche hat knapp 6.300 Mitglieder (Sydslesvigsk Forening 2012: 137). Kirchenmitglied wird man durch Vereinsbeitritt. Man zahlt einen Mitgliedsbeitrag in Höhe von $5 \%$ der Einkommenssteuer (Dansk Kirke i Sydslesvig 2016), aber keine durch das Finanzamt erhobene Kirchensteuer, wie es für Mitglieder der deutschen Landeskirche im Landesteil Schleswig, also der Evangelisch-Lutherischen Kirche in Norddeutschland (Nordkirche), üblich ist. Der Mitgliedsbeitrag zur dänischen Kirche ist steuerlich absetzbar (E-Mail-Auskunft der SSF-Vereinskonsulentin Tine Andresen, 12.11.2013). Entscheidend für die dänische Kirche ist, dass das kirchliche Angebot überwiegend auf Dänisch abgehalten wird, Bibeltexte und Lieder auf Dänisch gelesen bzw. gesungen werden und die Pastor*innen der dänischen Liturgie folgen (Greve 19.02.2009). „Eine selbständige kirchliche Erweckung hat nicht stattgefunden. Der Wunsch nach dänischen Gottesdiensten ist als Teil der allgemeinen politischen Bewegung entstanden." (Henningsen 2005: 227). Diese Aussage belegt, dass die dänischen Kirchen eine parallele sprachlich-politische dänische Alternative für deutsche Kirchen sind, aber keine Glaubensalternative religiöser Art darstellen. Sie praktizieren „dasselbe Glaubensbekenntnis“ (ebd.: 228). Daraus kann man schließen, dass die in der Nachkriegszeit begonnene „Ausbreitung der dänischen Kirche $[\ldots]$ ein integrierter Teil der politisch-nationalen Neubesinnung" war (ebd.: 227).

Auch in der Kleinstadt Friedrichstadt gibt es eine dänische Kirchengemeinde (Dansk Kirke i Sydslesvig c). Sie wurde von 2004 bis April 2014 von Pastor Victor Greve und von Februar 2015 bis Frühjahr 2019 von Pastor Ulrich Vogel betreut. Letzterer war auch für die dänische Kirchengemeinde in Husum zuständig. Gottesdienste werden in der Kirche der Mennonit*innen in Friedrichstadt abgehalten. An Gründonnerstagen gibt es traditionell einen deutschsprachigen Gottesdienst in der dänischen Gemeinde. Weiterhin werden Konfirmationsunterricht, Vorträge, Lese- und Filmklubs angeboten.

\subsubsection{Die Bibliotheke(en)}

In Südschleswig gibt es eine als Verein organisierte Dänische Zentralbibliothek, Dansk Centralbibliotek for Sydslesvig e. V., und zwar in Flensburg mit Filialen in Husum, Schleswig und Eckernförde sowie zwei Bibliotheksbussen, die einmal monatlich in allen kleineren Orten, wie zum Beispiel Friedrichstadt, Halt macht. Des Weiteren kümmert sich die Dansk Centralbibliotek um einige Schulbüchereien in 
Südschleswig. Darüber hinaus gehören zur DCBIB eine umfangreiche Sammlung von Lokal- und Regionalliteratur in verschiedenen Sprachen, die sogenannte Slesvigske Samling, die Schleswigsche Sammlung, die alles über Süd- und Nordschleswig, also über das alte Herzogtum Schleswig, sammelt, sowie die Forschungsabteilung mit Archiv Studieafdelingen og Arkivet. Es werden Kunstausstellungen sowie Vorträge arrangiert.

Die Dansk Centralbibliotek ist offen für alle. Es wird nicht nach Sprachkenntnissen oder nationaler Zugehörigkeit gefragt. Die Bibliothek hat ca. 15.000 Nutzer*innen (Nygaard 12.04.2014). 2015 betrug die Anzahl der Entleihungen in allen Filialen einschließlich der Bücherbusses 494.135 (Dansk Centralbibliotek for Sydslesvig) bei einem Gesamtmaterialbestand von 392.327 Medien (Dansk Centralbibliotek for Sydslesvig). Zweck des Bibliotheksvereins ist, die dänische Minderheit mit Medien zu versorgen, dänische und skandinavische Kultur zu vermitteln, Kenntnisse über Südschleswig zu generieren und zu sichern, zu forschen und Dokumente zu archivieren (Sydslesvigudvalget, Dansk Centralbibliotek for Sydslesvig 2014: 2). Die Organisation hat 47 Mitarbeitende und bekommt rund 3,4 Millionen $€$ pro Jahr (2013) vom dänischen Staat, was einen dänischen Finanzierungsanteil von $86 \%$ bedeutet (ebd.: 5).

\subsubsection{Die Zeitung}

Seit 1869 wird eine heute zu $75 \%$ dänisch- und zu $25 \%$ deutschsprachige Tageszeitung herausgegeben, die Flensborg Avis, kurz FLA (vgl. Spoorendonk 2001: 43; Sigaard-Madsen 1995: 150; Kühl 2005a: 353-370). Diese Zeitung ist nicht wie die anderen dänischen Minderheiteninstitutionen als Verein, sondern als Aktiengesellschaft organisiert. Aus Dänemark fließen jährlich circa 3,4 Millionen $€$ an Zuschüssen an die Zeitung (Sydslesvigudvalget, Flensborg Avis 2014: 4), die sonst ökonomisch nicht überleben könnte (Informelles Gespräch mit FLA-Mitarbeiter Niels Tönnsen ${ }^{135}$ ).

Die täglich erscheinende Auflage (außer sonntags) ist mit Ausnahme an Donnerstagen und an einem Samstag pro Monat, 4.983 Exemplare hoch (Stand: 31.12.2014; Flensborg Avis AG 2015). Jeden Donnerstag erscheint eine drei- bis fünfseitige Beilage in der Flensborg Avis. Diese heißt Kontakt und wird direkt vom Kulturverein SSF erstellt und veröffentlicht. Sie unterliegt nicht der FLA-Redaktion. In dieser Beilage werden SSF-Veranstaltungen angekündigt und im Sinne des SSF wird über diese berichtet. Einmal im Montag erscheint samstags in der Avis die Schulvereins-PR-Beilage Fokus. An den Beilagentagen wird die Flensborg Avis

135 Name geändert. 
in erhöhter Auflage gedruckt und an alle Mitglieder des Schulvereins, also an alle Eltern, die Kinder im Minderheitsschulsystem angemeldet haben, bzw. an alle SSF-Mitglieder versendet. Auch der Kirchenverein hat einmal in der Woche eine selbstgestaltete Kirchenseite in der Zeitung. Darüber hinaus erscheint gelegentlich eine Beilage der Partei SSW, die Stimme des Nordens. Diese vier Vereinsbeilagen in der Flensborg Avis sind PR-Organe, durch die die Werte der Vereinsmitglieder beeinflusst werden sollen. Die aktive Gestaltung der Inhalte erfolgt nicht durch Zeitungsredakteur*innen, sondern durch die dänischen „brokers of power“ (Coakley 2004: 533) selbst, also durch die Funktionär*innen und Pressesprecher*innen der Vereine.

Der Win-win-Effekt besteht darin, dass die Flensborg Avis ihre Auflage an bestimmten Tagen steigern kann und Nicht-Abonnent*innen erreicht. Dadurch können zusätzliche Einnahmen generiert werden. Die Vereine SSF, Schulverein, Kirche und der SSW können günstig ihre Hausmeldungen durch das Anhängen an ein ohnehin versendetes Medium verbreiten, und das auch an Menschen, die nicht Vereinsmitglieder sind, sondern nur FLA-Abonnent*innen. Diese Eigenwerbung des Schulvereins, des Kulturvereins und der Kirche sowie der Partei SSW ist eine Reaktion auf die Distanzierung der Flensborg Avis von den Minderheitsvereinen und den Versuchen der Zeitung, objektiver und unabhängiger über die Minderheit und ihre Vereine zu berichten (Clausen 2014: 112). ${ }^{136}$

\subsubsection{Der Gesundheitsdienst}

Der dänische Gesundheitsdienst Dansk Sundhedstjeneste for Sydslesvig e. V. ist zuständig für häusliche (Alten-)Pflege, den schulärztlichen Dienst in den dänischen Schulen, Hilfe und Beratung bei gesundheitlichen Fragen hauptsächlich von Kindern und Schwangeren und bietet Sanatoriumsaufenthalte für Kinder der Minderheit in Dänemark an (Dansk Sundhedstjeneste for Sydslesvig 2009). Zusätzlich leistet der Gesundheitsdienst Sanitätsdienste bei Minderheitsgroßveranstaltungen wie den Jahresfesten. Mitglied im Gesundheitsdienst sind Minderheitenvereine wie der SSF, der Kirchenverein und der SdU. Der Sundhedstjeneste bekommt keinen vom dänischen Südschleswigausschuss gewährten finanziellen Zuschuss (Kulturministeriet 2014). Allerdings zahlt das dänische Gesundheitsministerium dem Gesundheitsdienst rund 3,6 Millionen $€$ jährlich (Kulturministeriet et al. 2017). Die Kosten für häusliche Pflege werden wie bei anderen Pflegediensten auch größtenteils durch die Pflegekassen sowie durch die zu Pflegenden und deren Angehörige finanziert.

136 Den Zusammenhang von „Identität und Mediennutzung“ bei der dänischen Minderheit hat Swea Starke in ihrer Dissertation untersucht (Starke 2014). 


\subsubsection{Der Südschleswigsche Wählerverband (SSW)}

Politisch vertreten werden die dänische und die friesische Minderheit durch die 1948 gegründete Partei Südschleswigscher Wählerverband (SSW), Sydslesvigsk Valgerforening (dän.), Söödslaswiksche Wäälerferbaind (fries.). Der SSW bekam in Übereinstimmung mit dem Parteiengesetz ( $\int 25$ Abs. 2 Nr. 3 Buchst. b PartG) im Jahre $2015467.064 €$ als Zuschuss aus Dänemark (Sydslesvigudvalget, Sydslesvigsk Vælgerforening 2014). ${ }^{137}$ Der SSW ist von der Mitgliederzahl her (2013: 3.690 Mitglieder) (ebd.) die drittgrößte Partei in Schleswig-Holstein. Der Wählerverband hat drei Mandate im Kieler Landtag und stellte bis Mai 2017 mit Anke Spoorendonk einen Ministerposten in der Regierungskoalition mit der SPD, den Grünen und dem SSW. Der SSW ist von der Fünfprozentklausel bei Landtagswahlen befreit ( $\int$ 3 Abs. 1 LWahlG). ${ }^{138}$ Seit Juni 2017 ist der SSW wieder in der Opposition, während eine Koalition aus CDU, Grünen und FDP das Land regiert. Der SSW ist seit 1958 durchgängig mit mindestens einem*r und maximal vier Abgeordneten im schleswig-holsteinischen Landtag vertreten.

\subsubsection{Weitere Organisationen}

Es gibt noch einige weitere Minderheitsvereine bzw. Organisationen in Südschleswig bzw. mit Bezug zur dänischen Minderheit. Die an Bedeutung für die Minderheit und für die Analyse in der vorliegenden Studie wichtigsten davon werden im Folgenden erwähnt.

Im (Land-)Frauenverein Den slesvigske Kvindeforening e. V., Der schleswigsche Frauenverein, der lange Den sydslesvigske Husmoderforening e. V., Der südschleswigsche Hausfrauenverein, hieß und auch Aktive Kvinder, Aktive Frauen, genannt wird, organisieren sich Frauen zum Austausch, Kaffeetrinken, Stricken und Basteln oder zu gemeinsamen Ausflügen.

Der dänische Verein Granseforeningen, Grenzverein, kümmert sich in Dänemark um Kontakte nach Südschleswig und macht Lobbyarbeit für Südschleswig in Dänemark. Er ist nach der Grenzabstimmung 1920 aus einer dänisch-nationalen Orientierung heraus entstanden, um das Dänischsein gegen deutsche Interessen zu unterstützen (Klatt 2006: 428; Grænseforeningen).

137 Ausländische Spenden bzw. solchen von außerhalb der EU an deutsche Parteien sind ansonsten aus Staatsschutzgründen nicht erlaubt bzw. streng reglementiert (\$25 Abs. 2 Satz 3 PartG).

138 Die Befreiung von der Fünfprozentklausel gilt auch für den Bundestag ( $\$ 6$ Abs. 3 Satz 2 und $\S$ 20 Abs. 2 Satz 3 BWahlG). Allerdings tritt der SSW dort zurzeit nicht an. Es gibt seit 2019 aber erneut Diskussionen innerhalb der Partei, ob diese bei der nächsten Bundestagswahl (voraussichtlich 2021) antreten soll. 
Zentral für die dänischen Staatsangelegenheiten in Bezug auf Südschleswig ist der Sydslesvigudvalget, lange auch wegen der Anzahl seiner Mitglieder Femmandsoder Seksmandsudvalget, Fünfmanns-/Sechsmannsausschuss, genannt, ein ständiger parlamentarischer Ausschuss im Folketing, das dänisches Parlament).

Weiterhin gibt es die Organsiation Sydslesvigske Borns Ferierejser, Ferienreisen südschleswigscher Kinder, die heutzutage die Ferienaufenthalte von südschleswigschen Kindern in Familien oder Sommerlagern in Dänemark organisieren.

Der Sydslesvigsk Samråd, der Südschleswigsche Rat, ist eine Konferenz der wichtigsten neun dänischen Minderheitenvereine im Landesteil Schleswig. Der Rat trifft sich sechs Mal im Jahr (Det Sydslesvigske Samråd 2016) und soll Fragen der Minderheit erörtern und die Gesamtperspektive der Minderheit im Blick behalten, statt die Interessen einzelner Vereine zu vertreten. Die Vereine senden Repräsentant*innen in den Samråd.

Die Ergebnisse der in Kapitel 1 beschriebenen Datengenerierung werden im Folgenden aufgearbeitet und analysiert. Der Hauptteil wird dazu mit einer halbliterarisch-narrativen Darstellung ähnlich einer dichten Beschreibung begonnen, die Lesende in die Situation der Interviewten hineinversetzen soll (vgl. Geertz 2002; Kaschuba 2003: 219-220). Anhand des Fallbeispiels einer wahren lebensgeschichtlichen Erzählung soll veranschaulicht werden, warum und wie jemand dänisch wird. Viele Elemente aus dieser Geschichte kommen auch bei den anderen Interviewpartner*innen vor. Danach folgen Beobachtungen, Analysen und Ergebnisse. 


\section{Dänischwerden I - Gründe und Hintergründe}

Im Hauptteil dieser Arbeit wird unterschieden zwischen dem Prozess des Dänischwerdens und den Praktiken des Dänischseins. Diese Trennung ergab sich während der Forschung von Anfang an, da die beobachteten und befragten Akteur*innen unterschiedliche Gründe für ihr Dänischwerden angaben und angeben und aus unterschiedlichen Kontexten kommen. Dies hat zum einen Auswirkungen auf ihr Dänischsein, zum anderen gibt es beim Dänischsein auch viele Gemeinsamkeiten der Akteur*innen mit unterschiedlichen Dänischwerdungsprozessen. ${ }^{139}$ Mit dem Begriff Dänischsein soll aber nicht impliziert werden, dass wer einmal dänisch geworden ist, auch einen festen Status erreicht hat. Das Dänischsein oder Dänischbleiben oder -nichtbleiben ist kontextual, prozessual und individuell.

Nach einem szenischen Einstieg in die Materie anhand des Fallbeispiels Sarah Iversen werden in Kapitel 4 die Gründe und Kontexte für das Dänischwerden in den zwei untersuchten Gruppen, den Neudän*innen aus der Nachkriegszeit und

139 Bei der Literaturrecherche hat sich herausgestellt, dass diese Trennung eine probate Methode der Darstellung und Analyse ist. Beispielsweise weist der Religionspädagoge Bernd Schröder zum Thema Lernen von Religion und Bekenntnis (analog zum Erlernen von nationaler Gesinnung) auf die Notwendigkeit der Unterscheidung zwischen dem „Zum-Glauben-Finden[...]“ und dem „Im-Glauben-Bleiben[...]“ (Schröder 2012: 210) hin. Schröder unterscheidet weiterhin zwischen „Glaubensinhalt" und „Glaubensakt“ (ebd.: 209), also übertragen auf die Minderheit zwischen dem reinen Bekenntnis und dem Füllen des Bekenntnisses mit Inhalten. 
den Neudän*innen aus der Gegenwart, dargelegt. Anschließend wird in Kapitel 5 beschrieben und analysiert, welche Rolle die dänischen Schulen des dänischen Schulvereins bei der Dänischwerdung, also bei der Minorisierung von Personen, spielen. Dabei geht es um evozierte Emotionen, Ansprüche und Erwartungen, Praxen sowie damit zusammenhängende Widersprüche und Ambivalenzen. In Kapitel 6 wird darauf aufbauend der Aspekt der Integration in die Minderheit behandelt. Schwerpunkte sind dabei ein Integrationskurs sowie die Integrationsstrategien von Schulverein und Kulturverein. In Kapitel 7 folgt die Analyse der beobachteten Praxen in Bezug auf Bindungen und Zugehörigkeiten, Aushandlungen und Verortungen mit Schwerpunkt auf dem dänischen Kulturverein sowie auf minoritätsübergreifende Beobachtungen. Zuletzt geht es in Kapitel 8 um Symbole, Mythen und Zugehörigkeitspraxen, einleitend um die dänischen Jahresfeste, anschließend u. a. um Flaggen und die Rolle der Sprache, bevor Legitimierungsversuche unter die Lupe genommen werden und Zugehörigkeitsprozesse bei der dänischen Minderheit mit religiösen Zugehörigkeiten verglichen werden.

\subsection{Szenischer Einstieg in ein Dänischwerden und Dänischsein: Beispiel Sarah Iversen}

\subsection{1 „Eine überschattete Kindheit ${ }^{\star 140}$}

Ein Vormittag im Winter. Die Mutter kommt vom Einkaufen wieder und ist so ganz anders. Sie ruft ibre Tochter zu sich. Sarah. Ibre Brüder, der ältere ist schon dreizehn und gerade in der Schule, der jüngere ist erst ein Jabr alt, sind nicht dabei. Das tut sie sonst nie, die Mutter, Sarah zu sich zu rufen und sich zu ibr zu hocken. Mit ernster Miene. „Bald kommen Leute", sagt die Mutter, "und die bolen euch ab, die bringen euch weg. " beunrubigen. Die Mutter meint, dass man sie zu guten Deutschen erziehen würde. Das sei schon in Ordnung. Darüber solle sie nicht traurig sein. Sarah spürt die Angst, auch wenn sie erst fünf ist. Sie kelammert sich an die Mutter und weint. Bettelt, bei ibr bleiben zu dürfen. Das war Sarahs erstes Leid, bewusst erlebt, die Angst gespürt und noch lange erinnert.

140 Zitat aus dem ZDF-Dokumentarfilm „Wer wohnte in der Synagoge von Friedrichstadt“ von Heike Mundzeck (2004), gesehen während des Interviews zusammen mit Interviewpartnerin Sarah Iversen .Die Hauptquelle dieser lebensgeschichtlichen Erzählung ist die Erinnerung von Sarah Iversen, die sie im Interview am 14.06.2008 erzählt hat. Ergänzt wurden diese Informationen durch den hier genannten Film Außerdem habe ich eigene Beobachtungen und Ortskenntnisse eingebunden. Eine Analyse dieser Geschichte folgt in den nachfolgenden Kapiteln.

141 Alle Zitate in diesem Textabschnitt, sofern nicht anders angegeben, sind Originalzitate aus dem Interview mit Sarah Iversen am 14.06.2008. Dort gibt sie eigene Aussagen und von ihr erinnerte Worte anderer, z. B. ihrer Mutter, wieder. 
Wie kommt es dazu? Einige Wochen nach den Novemberpogromen 1938 und der Deportation der Friedrichstädter Juden trifft Sarahs Mutter Leute auf einer der vielen schachbrettartig angelegten Straßen der Stadt. Wie üblich unterhält man sich über dieses und jenes. Doch die Mutter, sie kann die Nazis nicht leiden ${ }^{142}$, verplappert sich, verliert ein schlechtes Wort über die „Reichskristallnacht". Eine Nazi-Frau hört das. Die Mutter ist in Panik, der Vater nicht da. Sie fasst den Entschluss, sich von ihrer Tochter zu verabschieden, falls sie von der Gestapo verhaftet wird und die Kinder von ibr getrennt werden. Sicher ist sicher.

„Meine frühe Kindheit hat man mir dadurch kaputt gemacht", sagt Sarah später, als sie über diese Geschichte nachdenkt. Passiert ist nichts. Es kam niemand. Keiner wurde abgeholt. Gott sei Dank.

Das Schlimmste geschah nicht. Das bedeutet aber nicht, dass ihr Leben so unbeschwert war wie das der anderen Kinder. Ihr Vater, Friedrichstädter, war Zenge Jehovas. Ihre Mutter war evangelisch. Sarahs Name wurde in der Nazi-Zeit als besonders jüdisch aufgefasst. Sie wurde 1933 geboren, wuchs mit einem alttestamentarischen Vornamen auf. Mitten im Nationalsozialismus, der auch im kleinen Städtchen wütete, welches 1621 von Niederländer*innen zwischen den Flüssen Eider und Treene gegründet wurde. Aus Protest geht Sarahs Mutter, die sich weigert, in die Deutsche Frauenschaft einzutreten, immer mit zwei Taschen auf die Straße, eine für jede Hand, damit keine Hand mehr für den Hitlergruß frei ist, während der Vater aus der Bibel gegen Hitler zitiert. ${ }^{143} \mathrm{~W}$ as das alles bedeutet, merkt Sarah am Verhalten der anderen Kinder und Erwachsenen.

\subsubsection{Einschulung}

Sie wollen nicht mehr mit Sarah reden, nur zwei, drei Freundinnen spielen noch ab und zu mit ihr. Sieben Monate nach Kriegsbeginn wird Sarah im April 1940 eingeschult, in die einzige Volksschule der Stadt. Sie liegt in der Hinterstadt in der Westerlilienstraße, auch Schulstraße genannt. Die Lehrerin ruft Sarah nach vorne: „Schreib deinen Namen an die Tafel!" Was ist das für ein Name? Die Schülerschar ruft die Antwort: „Ein jüdischer Name!“ - „Mögen wir Juden?", fragt die Lehrerin. „Nein, wir mögen Juden nicht," schallt es im Chor zurück. Die Lehrerin macht weiter: „Mögen wir dann Sarah?" - „Nein, Sarah mögen wir auch nicht", ist die Antwort aus der Klasse. Das ist Sarahs Stempel. Ein Erlebnis, das sie auch später nicht mehr vergisst.

142 „hendes mor, der ikke kunne fordrage Hitler og hans kumpaner“ (Johannsen 12.09.2003: 7)

143 Diese Geschichte erzählt Sarah Iversen zum Anlass ihres 70. Geburtstages einem Journalisten der Flensborg Avis. „Og faderen [...] plejede at citere fra biblen: - Der står, du skal ikke tjene andre guder end mig. Derfor kan jeg heller ikke tjene Adolf Hitler, sagde han“ (ebd.). 
Sarahs Vater ist Schneider, daraus entwickelt die Lehrerin eine Idee. Sarah muss sich vor der versammelten Klasse aufstellen. Sie hat Angst, ist nervös, kennt die Bloßstellungen, die Missachtungen, die Stiche, die täglich kommen. Sarab soll einen Faden durch ein Nadelöhr qiehen, ihr Vater sei schließlich Schneider. Wie soll das gelingen? Sie zittert am ganzen Körper. Das ist ibre Kindheit.

In den 1970ern wird das Gebäude der deutschen Volksschule abgerissen, das Symbol für Sarahs Leid, fünf Jahre lang, tagein, tagaus. Große Erleichterung. Eine größere Freude hätte man ibr nicht machen können, sagt sie später rückblickend. Das rote Gebäude aus Ziegelsteinen dagegen, die dänische Hans-Helgesen-Schule, mit der sie nur Gutes verbindet, ist später ihr Zubause geworden.

\subsubsection{Zweite Geburt}

Mai 1945, der Krieg ist zu Ende, der Nationalsozialismus vorbei, aber die Leute sind dieselben geblieben. Die Schule ist geschlossen. Doch für Sarah ändert sich vorerst nur wenig. Die Ausgrenzung durch die anderen hört nicht plötzlich auf. Doch im Sommer 1946 kommt ein Lichtblick vom Himmel, genauer aus Richtung Norden: Sarab bört in den Straßen der Stadt, dass eine dänische Schule gegründet werden soll. Ihr Vater sagt, dass jetə̧ ein neues, ein gutes Leben für Sarah anfängt, dass das Leid ein Ende hat, dieser Krieg nun endlich auch vorbei sei. Sie ist die vierzehnte Schülerin, die dort auf der neuen Schule angemeldet wird, ihr jüngerer Bruder ist der fünfzebnte. Einige Wochen später, am 24. September, geht es los: Eröffnung und erster Schultag in den neugebauten Baracken an der Brückenstraße. Da ist Sarah dreizehn. Als Sarah mittags nach Hause kommt, sitzt der Schock noch tief: „Das können wir aufgeben", sagt sie zu ihrer Mutter. Diese Sprache, ,die kann kein Mensch lernen“. Probieren solle sie es, ermuntert die Mutter sie, probieren, Dänisch zu lernen. Sarah nimmt diese Herausforderung an. Das ist der Beginn von etwas ganz. Neuem. Einem neuen Leben. Sarah erlebt diese befreiende (Johannsen 12.09.2003: 7) Veränderung als „Geburt“, so berichtet sie mir gut fünfzig Jahre danach. Die Jugendliche mit ,null Selbstvertrauen" taucht ein in eine neue Welt, in der sie behandelt und beachtet wird wie alle anderen. Fragen an die Klasse sind auf einmal auch Fragen an sie. So ungewohnt, aber doch die Grundlage für Sarahs Dänischwerden und Dänischsein. Hier fängt es an. Nach dem raschen Erlernen der neuen Sprache im ersten Jahr auf der dänischen Schule macht sie in dieser anderen Welt völlig neue Erfahrungen: „Ich konnte plötzlich lachen, ich gehörte plötzlich dazu!" Sarah fühlt sich wie im Paradies. Sie lernt Dänisch, lernt, was Selbstbewusstsein heißt. Sie empfindet das Dänische als Rettung aus der Hoffnungslosigkeit. Ibre Begeisterung kennt keine Grenzen. Überschwänglich berichtet sie von damals. Geradezu euphorisch saugt sie jedes bisschen Aufmerksamkeit auf. Das kennt sie aus der Zeit auf der deutschen Schule gar nicht. „Gut, das ist gut!“, sagt die Lehrerin zu der zarten 13-Jährigen. Wen sie damit wohl meint, fragt sich Sarah noch, bevor sie merkt, dass die Lehrerin wirklich mit ibr spricht. „Naja, die kennt mich ja nicht", denk.t sie, ,wenn sie mich erstmal kennt, sagt sie so etwas nicht mehr. "Noch nie hat jemand außerhalb der Familie so etwas zu ibr gesagt. „Gut", wie das schon klingt. Erst mit der Zeit lernt sie, was es heißt, gelobt zu werden, beachtet zu werden. Sie entwickelt Vertrauen zu diesen Leuten und es wächst ibre Liebe zum Dänischen. Was bleibt ibr auch anderes übrig? Die Schulzeit auf der Hans-Helgesen- 
Schule ist schön. Sarah spürt, dass dort mehr ist, dass es wie eine Familie ist. Speziell die Lehrer gefallen Sarah, sie sind nicht so distanziert wie auf der deutschen Schule. Sie sprechen mit den Schüler*innen. Die Schüler*innen dürfen die Lehrer sogar duzen und mit dem Vornamen ansprechen. Wie zu Hause, nein, es ist ein Zuhause, eine Familie. Das ist eine fantastische Zeit für Sarah. „Für mich war das die heile Welt", erzählt sie später. Sarab wird in der Stadt sicher gehänselt und geschnitten, wie die anderen „Dänenschüler"144 auch. Aber Sarah grüßst sie alle freundlich. Sie sieht nicht hin und merk.t es nicht, wenn die Schüler der deutschen Schule sie aufziehen, jedenfalls kann sie sich mehr als 50 Jahre nach ibrer Schulzeit nicht mehr daran erinnern. Stattdessen ist sie damit beschäftigt, sich wohl zu fühlen, alles positiv zu sehen. Sarah geht es auf der dänischen Schule so gut, dass ibr sogar die Gleichaltrigen ,leid“ tun, „die weiterhin die deutsche Schule besuchen" müssen. Dort gibt es blaue Briefe nach Hause, wenn es Probleme gibt. Auf Sarahs Schule ist es dagegen so, dass die Lehrer dann erst einmal mit den Eltern sprechen.

Sarah ist begeistert vom Zusammenhalt, vom Gemeinschaftsgefühl und von der gegenseitigen Hilfe der dänischen Schüler untereinander, ,das war ja auch so schön, wir haben zusammen ja glatt noch gelernt, wenn einer das nicht so [konnte]. “- „Wir haben dem anderen geholfen“, erzählt sie in der Retrospektive von der Zusammenarbeit der Schüler.

Das Freizeitangebot, auch das gefällt Sarah: Der Jugendverein, die Pfadfindergruppe, die Sportangebote, aber vor allem auch die Ferien im Königreich. Sarah wird während der Schulzeit jedes Jahr im Sommer für einige Wochen nach Sjalland, dt. Seeland, verschick.t, um dort ihre Ferien zu verbringen. An viele Erlebnisse dort erinnert sie sich noch heute. Besonders an die Geschichte, als sie ihren Pflegevater, einen Pastor, bittet, den Nachttopf mit Kirschen aus dem Garten mitzubringen. Das dänische Wort für Schüssel fällt ibr nicht ein. Schüssel oder Topf, das ist ja wohl so in etwa das Gleiche. Die dänische Gastfamilie amüsiert sich noch lange darüber und das Wort skålen, $d t$. Schüssel, wird sie nie wieder vergessen.

„Herrlich“, den ganzen Tag lang spielt Sarab zusammen mit dänischen Kindern, abends kommt sie „abgekämpft wieder nach Hause" zu ihrer zweiten, diesmal kinderreichen, Gastfamilie, weil die Pastorenfamilie vom ersten Dänemarkbesuch ibr zu langweilig ist. Die tollen Erlebnisse der Dänemarkverschickung in den Sommerferien fangen schon bei der Anreise an. Sarah und die anderen Kinder werden mit Bussen, Lastwagen und Zügen aus ganz. Südschleswig nach Flensburg gefahren. Dort laufen sie über die Grenze, und mit dänischen Zügen geht es von Padborg in ihre Bestimmungsorte. Alles obne die Eltern, ein paar freiwillige Lehrer sind als Begleiter dabei, und die älteren Schülerinnen müssen auf die jüngeren aufpassen, dafür sorgen, dass sie an der richtigen Station aussteigen, sie an die Hand nebmen. Bevor sie von den Gasteltern, die sie von Briefen oder vielleicht sogar noch aus dem letaten Jahr kennen, abgeholt werden. Wenn sie Glück haben, sogar mit einem Auto. ${ }^{145}$ Zur Sicherheit sind die Kinder alle mit einem Zettel um den Hals ausgerüstet.

144 INT01.

145 INT02. 
Auf der Rückreise, mit bunderten von Erlebnissen im Gepäck, satt gegessen und erbolt, in $V$ orfreude auf zu Hause, auf die eigenen Geschwister und deren Erlebnisse, geht das Abenteuer weiter: Sie schmuggeln Zwerghühner ${ }^{146}$, die sie von den Gasteltern geschenk.t bekommen haben, durch den Zoll. Bangen darum, ob der Hahn im Rucksack ausgerechnet in dem Moment keäht, als die Grenzschützer ibr Zugabteil kontrollieren. Glück gehabt.

\subsubsection{Dänemark}

Gegen Ende der Schulzeit kommt der Lehrer eines Tages zu Sarah nach Hause. Er schlägt den Eltern vor, Sarah zu fördern, sie nach ihrem Mittelschulexamen auf eine weiterführende Schule in Dänemark zu schicken. Sarah kommt nach Sonderburg, in die alte dänische Hafenstadt am Alsensund, unweit der Grenze. Nach dem Krieg gibt es in Dänemark Ressentiments gegenüber Deutschen, aber Sarahs „Halteband“ ist ibre südschleswigsche Herkunft, das akzeptieren die Dänen. Auf der Frauenfachschule „da haben wir geübt, wir Friedrichstädter. " Sie wollen das können, was die Däninnen schon längst konnten: rauchen. „Wir haben uns eingeschlossen in unser Zimmer" im Internat der Schule. Dort sitzen sie und üben. Versuchen, den Hustenreiz zu unterbinden, „das war toll. "- „Als wir es konnten, hatten wir die Sucht. "So etwas wie das Rauchen lernt man in Dänemark: „Die größten Frauen, die dicksten Zigarren“, die „sind ja auch öffentlich rauchend durch die Gegend gegangen."D as kennen die deutschen Dänen gar nicht von zu Hause. Sarah lernt, wie es ist, richtig dänisch zu sein, mit allem, was dazugehört, abends um neun Kaffee trinken und danach Rote Grütze mit Sabne essen. Rod grode med flode. „Super. "Sarah wünscht sich, dass die Grenze „dicht" gemacht wird und sie nicht wieder nach Hause fahren muss, dass sie einen Grund hat, im Königreich zu bleiben. Aber das geschieht nicht. So muss sie nach zwei Jabren wieder nach Hause fahren, nach Deutschland, nach Südschleswig. Das kann sie ihrer Mutter sonst nicht antun. Die hat schweres Asthma, sie muss sich um sie kümmern, sie muss ibre Dänemarkträume opfern. Ich „,bin ja Deutsche“, aber ,ich wäre gern Dänin gewesen" und dort geblieben, erzählt Sarah später. So wie ibre beiden Brüder: Der eine lebt immer noch dort. Beide sind mit Däninnen verbeiratet. Sarah hat „später irgendwann mal drunter gelitten", dass sie wieder zurück nach Deutschland gegangen ist. „Da hab ich mich der Familie quasi so geopfert, nech, ich hab das sicherlich ganz. viele Male bereut, es sind ja auch, der Rektor der Schule, der dänischen Schule, der hat ein Gespräch mit meinen Eltern gesucht, ich möchte doch bitte weitergehen, eh, weil meine Resultate ${ }^{147}$ recht gut waren und, ob ich nicht weitergehen könne, 'ne Fachbochschulreife und dann studieren in Dänemark, nä. Nee, wurde von meinen Eltern kategorisch [abgelehnt] und ich hab den Kopf mit geschüttelt."

Zurück in Deutschland gehen dann die Probleme wieder los. Der Grund ist diesmal aber ein anderer. Jetzt wird Sarah in Friedrichstadt nicht mehr wegen ibres Vaters schlecht behandelt, sondern ausgerechnet, weil sie die dänische Schule besucht hatte. Sarah bemüht sich um eine

\footnotetext{
146 Vgl. auch die Geschichten vom Schwein, das auf dem Bahnsteig wegrennt und wieder eingefangen werden muss oder als sich in einem Fall aus einem geschenkten Hahn über die Jahre ein ganzer Hühnerhof entwickelt (Johannsen, Midskov 2004: 19).

147 Danismus, der ,Schulnoten` bedeutet.
} 
Lehrstelle. „Das war Diskriminierung hoch drei. Ich wollte gerne zur Sparkasse, also Rechnen, Mathematik, die Zablen, die haben mir immer viel bedeutet und bin ich hin. Ja, sagt der, das kannst du gut werden, aber erst kommen die Friedrichstädter, und dann kommen die Flüchtlinge und wenn wir denn noch niemanden haben, dann kommst du. "Sarah zäblt anscheinend in den Augen des städtischen Sparkassenchefs nicht zu den Friedrichstädter*innen, obwobl sie doch dort geboren und aufgewachsen ist.

Sarahs Mutter erkerankt zu diesem Zeitpunkt noch schwerer. Eine Lehre kommt für Sarah auch deshalb nicht mehr infrage. „Hab also sozusagen kein' Beruf gehabt, [...] ich wurde [...] eine Putzfrau, den Haushalt geschmissen, sechs Personen waren wir mit Wäsche, kein Staubsanger. Das war wirklich harte Arbeit." - „Meine Hände haben das [...] nicht gut verdaut." Sie zeigt ihre roten, geschundenen Finger. Später hat Sarab dann stundenweise gearbeitet: „In einer Gerberei, im Lobnbüro, ich habe im Akkord gearbeitet, [...] im Elektrogeschäft", Fernseher verkauft. Dort ist es auf einmal doch von Vorteil für Sarah, dass sie ehemalige Dänenschülerin ist, Dänisch sprechen kann. Wenn Touristen aus Dänemark kommen, günstig technische Geräte erstehen wollen oder auch nur Ersatzbatterien für ibre Fotokameras suchen, dann steht Sarah mit ibren Sprachkenntnissen im Mittelpunk.t. „Die haben sich immer ganz tierisch gefreut [...], waren so dankbar" und ",heilfrob", dass da jemand war, mit dem sie sich in ibrer Erstsprache unterhalten konnten.

\subsubsection{Dänisch und deutsch? Leben in einer südschleswigschen Kleinstadt}

Schließlich heiratet Sarah einen deutschgesinnten Friedrichstädter und bekommt zwei Kinder.

Wie ist es als Südschleswigerin mit einem deutschen Mann? „Angefangen hat es so, dass ich zurückgesteckt hab', dass ich eben nicht zu irgendwelchen Veranstaltungen mehr gegangen bin und eh, nach Jahren hab ich gesagt, das kann ich nicht." Nachdem sie selbst beim 25-jährigen Geburtstag ibrer Hans-Helgesen-Schule nicht dabei ist, erkennt sie, dass etwas Wichtiges in ibrem Leben fehlt: der Kontakt zum Dänischen, also der Rückhalt ihrer „Familie“. Sarahs Mann sagt zwar nie etwas konkret gegen die dänischen Deutschen, aber sie merkt ihm trotzdem im Laufe des Lebens an, dass er nicht gerade mit dem Dänischen sympathisiert. „Damals war das auch so, [...] was der Mann sagt, das wird getan. "Das ist schlimm für Sarah. Deshalb beginnt sie, sich wieder mit den anderen Dänischgesinnten von früher zu treffen, sich in den dänischen Vereinen zu engagieren. Nur für ibre beiden Töchter ist es zu spät. Sarah kann sich am Anfang ibrer Ehe im „Kampf“ mit ihrem Mann nicht durchsetzten. Ihre Kinder besuchen desbalb die deutsche Schule. Sarahs Mann will das so. „Und dann hab' ich gesagt, und wenn ich die anmelde einfach" "bei der dänischen Schule, „, da sagte er, ja dann meld' ich sie wieder raus. " Aus Rücksicht, um diesen Konflikt nicht auf den Rücken der Kinder auszutragen, gibt Sarah nach. Die Töchter bereuen das später. Eine versucht das auszugleichen, indem sie ihre eigenen Kinder auf die dänische Schule schick.t. Dafür sind die Enkelkinder heute noch dankbar, ist Sarah überzengt. 
Schließlich wird Sarah 1980 gefragt, ob sie nicht Lust hätte, als Sekretärin an der HansHelgesen-Schule, die jetzt in einem Backsteingebäude in der Schleswiger Straße untergebracht ist, zu arbeiten. Da ,hätte man mich eben so gut fragen [können], wie ist es Sarah, möchtest du wieder nach Haus'? So ein Gefühl hatt' ich, wie nach Haus und ich bin da fünfzehn Jahre gewesen und diese fünfzehn Jahre hab ich mich wirklich zu Hause gefühlt." - „Das war für mich 'ne Herzens-, gefühlsmäßige Sache. "Wieder ist es eine dänische Institution, die ibr neue Hoffnung gibt, eine Zukunftsperspektive bietet, anstelle eines Lebens mit wechselnden Aushilfsjobs obne Anerkennung. Sarah ist wieder mittendrin im Dänischen. „Gefühlsmäßig ist das meine Welt", sagt sie und wird im Laufe der Zeit immer freier in ibren Gesinnungsentscheidungen, wendet sich wieder aktiver zum Dänischen hin. Sie beginnt, sich mehr in dänischen Vereinen zu beteiligen: besonders in der Kirche und dem Südschleswigschen Verein, wo sie lange im $V$ orstand ist. Sie ist aber auch Mitglied im Südschleswigschen Wählerverband und im dänischen Hausfrauenverein. Aber jetrt, so findet Sarah, sollen Jüngere die Arbeit machen, nur in der Kirche ist sie noch richtig aktiv. Sie mag zwar auch die deutsche Kirche, aber der dänischen Kirche füblt sie sich stärker verbunden. Sie gehört der dänischen Gemeinde wie einer Familie an, ähnlich wie es für sie schon früher mit der Schule war, denn auch in der Kirche erlebt sie ein starkes Gemeinschaftsgefübl: „Wir sind immer füreinander da, und das ist so eine tolle Gruppe, wir treffen uns auch privat." Sarah betont: „Es kommt alles aus dem [...] Wir-Gefühl heraus" und aus der „Liebe zur dänischen Sache".

\subsubsection{Verwitwet - nichts ist unmöglich}

Jetrt, wo ibr Mann nicht mehr lebt, ist sie unabbängig und genießt ibre Freibeit, macht das, was sie möchte. Sie wohnt in einer kleinen Senior*innenwohnung in einer der Kopfsteinpflasterstraßen in der hinteren Altstadt Friedrichstadts, Blumen schmücken die beschaulichen Häuserfassaden. Sarah wählt jetฉt ibre Freizeitbeschäftigungen selbst aus. Entscheidet dem Gefühl und ihrem Terminkalender nach, ob sie die dänischen Gottesdienste besucht, die „der süße Pastor“, „ein moderner junger Mann" aus Dänemark, in der kleinen Mennonitenkirche neben der Alten Münze am Mittelburggraben abhält, bevor sich die Gemeinde gemütlich aufmacht, vorbei an der Gracht, um danach durch die kleine, aber belebte Fußgängerzone zum prachtvollen Paludanushaus aus dem 17. Jahrbundert zu gehen, vorbei an der italienischen Eisdiele, dem griechischen Restaurant und der königlich-privilegierten Apotheke aus dem 18. Jabrhundert. Im dänischen Versammlungs- und Gemeindehaus genießen sie Kaffee und Kuchen im Pastorengarten oder feiern gemeinsam mit den anderen dänischen Vereinen Erntedank, Ostern oder Weihnachten. Falls es darum geht, den dänischen Lesekreis oder die Filmvorfübrung zu besuchen oder mit ibrem deutschen Chor für einen Auftritt zu proben, entscheidet sie sich nach dem Prinzip, wer zuerst kommt, mablt querst. Sie macht bei der Veranstaltung mit, von der sie zuerst gehört und bei der sie als erstes zugesagt hat. Egal ob es dänisch oder deutsch ist. Wobei die Auswabl für sie als Südschleswigerin natürlich besonders groß ist, da sie aus deutsch- und dänischsprachigen Angeboten wählen kann und sie sich das Beste herauspick.t. Deutsch ist ibre Erstsprache, Dänisch ihre Zweitsprache, ihre Partei und ihr Kulturverein sind südschleswigsch. Dänisch wäre vielleicht, dänische Flaggen zu besitzen, Sarah hat keine einzige Flagge. Sarah ist deutsch, 
aber sie liebt Dänemark, betont sie selbst. Doch eines steht schon jetzt fest: Obwohl ibr Mann „,deutsch" beerdigt wurde, hat sie für sich diese Entscheidung getroffen: „Ich werde dänisch beerdigt, ganz garantiert werde ich das. "

\subsection{Gründe und Hintergründe für ein Dänischwerden}

Dänischwerden und Dänischsein ist, wie oben schon gezeigt, eine Wahl, beruht also auf einer individuellen Entscheidung. So ist es auch in Bezug auf eine der insgesamt vier nationalen Minderheiten Deutschlands, den Sorben, beschrieben worden:

Seit es die Moderne gibt, ist auch klar, dass die Zugehörigkeit zum Sorbentum sich zunehmend als Entscheidung des Individuums erweist. Deshalb sind die besten Sorben jene, die ihr Sorbischsein reflektieren. Wenn man aber sorbisch nicht mehr, wie in einer ständischen Gesellschaft, durch Geburt und Abstammung ist, sondern dies einer Entscheidung bedarf, dann existieren Minderheiten, die sich für die Minderheit entscheiden. Daher rührt auch die Beobachtung, dass einige der besten Sorben von außen kommen, weil sie sich bewusst für die Sache entschieden haben (Köstlin 2007: 35).

Das obige Zitat zeigt, dass die nationalen Minderheiten einen konstruktiven Charakter haben, da dadurch Neusorben manchmal die „besseren“ Sorben werden können ${ }^{148}$.

Bei der Konstituierung der dänischen Minderheit spielt in der Zeit nach dem Zweiten Weltkrieg vor allem der sozialgeschichtliche Hintergrund eine große Rolle. Die dänische Gesinnung wurde ideologisch gefüllt und konstruiert (vgl. Oltmer 2007: 152-153). Eine Gruppe, der man sich zurechnen kann, schafft „Orientierung in komplexen Gesellschaften“ und ein Gefühl von „Sicherheit“ (Hansen 1995a: 153; Eriksen 2003: 168; Rheinheimer 2001: 10). Dieser Aspekt spielt auch bei der dänischen Minderheit eine große Rolle, wie später in Kapitel 8.7 noch näher ausgeführt werden wird, gerade in Bezug auf die Bewältigung von schwierigen Situationen (Hansen 1995a: 153-154). Dies gilt sowohl für die Nachkriegsgeneration als auch für heutige Dän*innen, von denen sich einige durch die Globalisierung und eine immer komplexere Welt bedrängt fühlen.

148 S. das Beispiel einer thüringischen Mutter, die zur „,richtigen“ Minderheitendänin wird und sehr engagiert ist (Kap. 6). 
In diesem Kapitel werden zuerst die Gründe, Hintergründe und Entwicklungen des Besuchs von dänischen Schulen und dem damit verbundenen Dänischwerden nach dem Zweiten Weltkrieg aufgeführt. Dabei soll vor allem auf die sogenannten „Neudän*innen ${ }^{\text {“149 }}$ eingegangen werden, also diejenigen, die erst ab diesem Zeitpunkt Kontakt zur Minderheit hatten. Das sind „Personen, die von außen in das Dänische kamen“ (Henningsen 2003b: 9) ${ }^{150}$; (Vollertsen 1994b: 11; vgl. a. Danker 1997) und deren Familien vor dem Gesinnungswechsel nichts mit der dänischen Minderheit zu tun hatten (vgl. Henningsen 2003b: 10). Sie werden in Anlehnung an eine entsprechende Bezeichnung für Migrant*innen auch ErsteGenerations-Dänen genannt.

Anschließend wird beschrieben, wie die neun Interviewpartner*innen ihre persönliche Situation erlebt haben und heute schildern, aus welchen materiellen, ideellen und ideologischen Gründen es zu einer Entscheidung für eine dänische Einschulung als Einstieg in das Dänischwerden kam. Danach sollen die Gründe des Dänischwerdens für heutige Neudän*innen erörtert werden.

\subsubsection{Gründe für die Nachkriegsgeneration}

Gründe dafür, sich nach dem Zweiten Weltkrieg zur dänischen Minderheit zu bekennen, waren vor allem die vorherrschenden sozialen, politischen und ökonomischen Verhältnisse, die auf „die totale deutsche Kapitulation“ folgten (Danker 1997: 6). Man litt an Versorgungsengpässen und am massiven Zuzug von „Ostflüchtlingen" (Kühl, Bohn 2005: 564). Nach dem Krieg erhöhte sich die Bevölkerungszahl in Schleswig-Holstein um rund $100 \%$ (Klatt 2001: 378). SchleswigHolstein gab es als Land erst ab 1946. Hier wurden prozentual zur Bevölkerungszahl besonders viele Flüchtlinge aufgenommen, da auf dem Lande relativ wenig Infrastruktur zerstört war, so der Historiker Martin Klatt (ebd.: 387-388). Dadurch entstand bei vielen die Angst vor einer „Überfremdung [...] [der] Heimat" (Vosgerau 1990: 63). ${ }^{151}$ Die Menschen hofften auf materielle Hilfe aus Dänemark und eine neue Möglichkeit, sich ideell zu verorten (vgl. Sigaard-Madsen 1995: 140; Runge 1993: 138). Aus diesen Gründen entstand bei einigen die Forderung des Anschlusses an Dänemark mit einer Grenzverschiebung Richtung Süden an die Eider (Danker 1997: 7, 9; Klatt 2005: 110). Gleichzeitig fand ein ge-

149 Der Begriff „Neudän*innen“ in Bezug auf die Nachkriegsgeneration ist nicht zu verwechseln mit der später in dieser Arbeit beschriebenen Gruppe der heutigen „Neudän*innen“, die im Weiteren nur als „Neudän*innen“ bezeichnet werden, während die „Neudän*innen“ der Nachkriegsgeneration im weiteren überwiegend als „Nachkriegsdän*innen“ bezeichnet werden. „personer, som udefra kom ind i det danske“"

151 Martin Klatt weist in seiner Dissertation (Klatt 2001) nach, dass in der Nachkriegszeit die neuen Mitglieder der dänischen Minderheit aus dem Raum Südschleswig stammen mussten (Klatt 2009a: 136). Erst später wurde die Herkunft der Nachkriegsdän*innen, darunter beispielsweise Flüchtlinge aus den ehemaligen deutschen Ostgebieten, nicht mehr berücksichtigt. 
waltiger Anstieg der Mitgliederzahlen im Südschleswigschen Verein (SSF) statt, der aber nur kurzfristiger Natur war (vgl. Sigaard-Madsen 1995: 139; Vollertsen 1994b: 15-16; Hansen 2000a: 93; Klatt 2001: 387-389, 391; Jürgensen 2003: 653). „Zur dänischen Minderheit bekannten sich“ direkt nach Kriegsende „mehr als 20 mal so viele Menschen als zuvor“ (Danker 1997: 7; vgl. Kühl, Bohn 2005: 564), obwohl die Bevölkerung dieser Region „1920 zu 80 \% Deutsch gestimmt hatte“ und „1932-1933 zu 60-70 \% NSDAP gewählt hatte“ (Klatt 2005: 111). „Auch die Schülerzahlen [der dänischen Schulen] stiegen entsprechend von 450 Schülern und Schülerinnen 1945 auf etwa 13.300 Schüler 1950“ (Sigaard-Madsen 1995: 139).

\subsubsection{Materielle Gründe}

„Der Weg in die dänische Minderheit und ins Dänentum bot[...] sich als Rettung an" (Becker-Christensen 1996: 312), so der Historiker und dänische Generalkonsul in Flensburg Henrik Becker-Christensen (vgl. Adriansen 1990: 120). Dies bestätigen auch die Erzählungen meiner Interviewpartner*innen. Denn durch sogenannte „Speckpakete“ aus Dänemark konnte der Mangel an Grundnahrungsmitteln behoben werden. Das führte zu einer doppelten Tagesration an Nahrungsmitteln für die Empfänger*innen der dänischen Hilfen im Vergleich zur Restbevölkerung (Klatt 2009b: 189). Durch die Unterstützung „der Südschleswig-Hilfe“ kamen „kinderreiche Familien, Alleinstehende und Kranke wieder zu Kräften durch Lebensmittel, Seife, Waschmittel und andere Lebensnotwendigkeiten “152 (Vollertsen 1994b: 240). Sie waren am dringendsten auf die „Südschleswig-Hilfe, die die schlimmste Not linderte, “153 angewiesen und entschieden sich aus diesem ,,wichtigen sozialen Motiv“ heraus eher für „das Dänische ${ }^{\text {“154 }}$ als ökonomisch besserstehende Bevölkerungsgruppe (ebd.: 18). Martin Klatt betont: „,[D]ie soziale Herkunft der Neumitglieder zeigt, dass es nicht die ,herrschende Klasse' war, die dänisch wurde“ (Klatt 2005: 113), sondern hauptsächlich ,gelernte und ungelernte Arbeiter“ (Klatt 2005: 114; vgl. Klatt 2009b: 191). Dies trifft auch auf die Interviewpartner*innen für diese Arbeit zu. ${ }^{155}$ Die materielle (und teilweise ideelle) Not war bei ihnen im Vergleich zu anderen sozialen Gruppen am größten und damit

\footnotetext{
152 „Børnerige familier, enlige og syge kom igen til kræfter af Sydslesvig-hjælpens mad, sæbe, vaskemidler og andre fornødenheder"

153 „Sydslesvig-hjælpen, som lindrede den værste nød“

154 „vigtigt socialt motiv“ und „det danske“

155 Auch schon nach der Volksabstimmung 1920 kam ein Großteil der dänischen Minderheitsangehörigen aus der Schicht, die sozial am schlechtesten gestellt war: Sieben von zehn Angehörigen der Minderheit in Flensburg kamen aus der Arbeiterschicht (Nygaard 12.10.2013).
} 
auch die Bereitschaft, eine neue ,ethnische Orientierung“ zu konstruieren oder sich einer solchen anzuschließen (Hansen 1995a: 154; vgl. auch S. 324 in d. vorl. Arbeit). Ähnlich formuliert es auch der Kulturanthropologe Konrad Köstlin:

The need for something constant and firm, for roots, rituals and ethnicity, gains importance in consideration of the sea of bearings, acceleration and movements in which the individual seems in danger of drowning. Here the ethnic argument seems to offer a fascinating and saving way out (Köstlin 2000: 8).

Aber er fügt hinzu, dass das ,ethnische Argument“ „simply racist“ ist (ebd.: 8). Die materiellen Hilfen wurden in der Regel nur an diejenigen verteilt, die Mitglieder des Minderheitenvereins SSF waren. Anfangs gab es Wartezeiten nach Eintritt in den Verein, bevor die materiellen Hilfen einsetzten, damit diese nicht ausschließlicher Grund für den Eintritt waren (Danker 1997: 7-8; Klatt 2009b: 188189; Guttormsen 1995: 120). ${ }^{156}$ Neben den Paketen waren auch folgende materielle Faktoren für den starken Zulauf zur dänischen Minderheit relevant: „[D]as vorbildliche dänische Gesundheitswesen, dänische Kindergärten und Schulen sowie - für Kinder des Hungers sehr wertvolle - Landverschickungen in das dänische Jütland“ (Danker 1997: 8). Die genannten Aspekte spielen auch bei meinem Interviewsample eine Rolle. Beispielsweise erzählt Brigitte Thomsen im Interview, dass sie auch aus pragmatischen Gründen auf die dänische Schule kam, obwohl sie vorher „keinen Kontakt zum Dänischen“ hatte (INT02). „Das ist ganz einfach 'ne [...] Lösung gewesen, 1946 war hier [im Dorf] keine Schule“ mehr, die war geschlossen worden, ,und dann hat mein Vater irgendwann gesagt, das Kind muss ja mal wieder in die Schule“ (INT02) ${ }^{157}$. So kam Brigitte als Achtjährige auf die dänische Schule nach Friedrichstadt, obwohl es dort auch eine wieder-

156 Die Voraussetzungen für einen Wechsel zur dänischen Gesinnung und für einen Eintritt in den Südschleswigschen Verein waren direkt nach dem Zweiten Weltkrieg im Gegensatz zu heute noch an Kriterien gebunden. Dazu gehörten Faktoren wie der „Wohnsitz im Wirkungsbereich des SSV [SSF], dem Mindestalter von 18 Jahren, keiner vorherigen Mitgliedschaft in der NSDAP“ (Sigaard-Madsen 1995: 140). Auch spielte hier ein heute überholtes Kriterium wie Herkunft eine Rolle, denn ,[a]ußerdem konnten Personen als Mitglieder aufgenommen werden, die die ersten drei Bedingungen erfüllten und von Personen abstammten, deren Mitgliedschaft möglich wäre oder die zwei Großeltern hatten, deren Geburtsort nördlich der Eider lag“ (ebd.: 140). Für die Einschulung von Kindern in die dänische Schule galt die im Oktober 1945 von der britischen Militärregierung erlassene Bedingung, dass mindestens ein Elternteil Mitglied im SSF war, sodass also nicht jeder eine dänische Schule besuchen durfte (ebd.: 144).

157 Die Quellenlage zu der Aussage, dass es im Dorf 1946 keine Schule mehr gab, ist uneindeutig: Auf Herrnhallig, einem Ortsteil Koldenbüttels, gab es zwischen 1939 und September 1947 keine Schule mehr (Janzen 2015: 105). Die Koldenbüttler Küster-/Kirchschule jedoch wurde am 9.5.1945 geschlossen und am 9.10.1945 wieder eröffnet für die 3. und 4. Klasse. Es fehlen Angaben zur 1. und 2. Klassenstufe (ebd.: 156). Auch die Auflistung der Lehrkräfte zeigt, dass die Schule nicht länger als einen Sommer) geschlossen war (ebd.: 166, 169-170). 
eröffnete deutsche Schule gab und die Schulen in ihrem Dorf schon Ende 1945 wiedereröffneten, so der Erinnerungsbericht eines geflüchteten Kindes (Roland 2016). Da sie aus einer „Kate“ kam, ging es ihrer Familie ökonomisch nicht gerade gut, sie mussten aber nie hungern, so Brigitte im Gespräch. Bei Frieda Theben, geboren 1940, gab es ebenso pragmatisch-materielle Gründe für die dänische Einschulung. Da ihr Vater in Kriegsgefangenschaft war, nahm ihre zu der Zeit alleinerziehende Mutter das Angebot der dänischen Schule und der dänischen Speckpakete an. Nicht zuletzt wollte Frieda nach ihrem sechsten Geburtstag im Spätsommer 1946 unbedingt eingeschult werden, und die einzige Schule, die dafür im September 1946 in Frage gekommen sei, war die dänische, so ihre Aussage. ${ }^{158}$ Die gleichaltrigen Ingo Erhard und Sönke Nissen führen als Anlass für den Besuch der dänischen Schule ebenso die materielle Not an. Die Bedürftigkeit armer Leute wurde anfangs etwas gelindert durch die Verteilung von Broten und teilweise warmen Mahlzeiten in der Schule und vor allem durch die Möglichkeit, in den Ferien nach Dänemark geschickt zu werden (s. S. 142). Aus Dankbarkeit und Verbundenheit für die Hilfen aus Dänemark blieben meine Gesprächspartner auch nach den Paketlieferungen auf der dänischen Schule. Sönke Nissen berichtete: „Meine Mutter hat gesagt, hier, die haben uns geholfen und du bleibst [... ] in der [dänischen] Schule und damit hat sich das" (INT05). Erik Nissen kam auch aus einer sozial eher schwachen Familie, wurde 1949 als Dreijähriger im dänischen Kindergarten ${ }^{159}$ angemeldet und durfte als Vierjähriger zum ersten Mal in den Sommerferien zu einer Gastfamilie ins Königreich reisen.

Dramatischer und physisch relevanter gestaltete sich die Situation bei Otto Clausen und Frauke Erhard. Auch hier kam es aus materieller Not zum Besuch der dänischen Schule. Sie berichten im Interview und in informellen Gesprächen gleich am Anfang von diesem Auslöser: Ihre Familien waren auf die Hilfe des dänischen Gesundheitsdienstes angewiesen. Otto Clausen, seine Mutter und sein älterer Bruder hatten

Lungentuberkulose, $[\ldots]$ und Lungentuberkulose war damals 'ne tödliche Sache. [...] Das konnte in Deutschland auch nicht so geheilt werden. Die Möglichkeiten waren nicht [vorhanden] und da sind wir [die Familie] zu der dänischen Minderheit gekommen (INT04).

Der Wechsel zur Minderheit wurde durch Otto Clausens Familie vollzogen, nachdem Otto als Viereinhalbjähriger nach eineinhalb Jahren Aufenthalt ohne seine Eltern in einem dänischen Sanatorium wieder nach Südschleswig kam. Er hatte

\footnotetext{
158 Das Schuljahr auf der deutschen Schule in Friedrichstadt fing schon im April 1946 an, da war Frieda aber erst fünf Jahre alt und noch nicht schulpflichtig.

159 Gegründet 1948 (Vollertsen 1994b: 193).
} 
dabei die deutsche Sprache verlernt und erkannte seine eigene Mutter nicht wieder. ${ }^{160}$ Aus Dankbarkeit und Verbundenheit war es auch für Ottos Eltern selbstverständlich, ihn quasi „automatisch“ (INT04) in einem dänischen Kindergarten anzumelden und ihn dänisch einzuschulen: „Wir sind also fürchterlich geholfen worden“ (INT04) betont Otto Clausen, obwohl es ,zur damaligen Zeit [...] eigentlich verpönt [war], in der dänischen Minderheit zu sein. Zumindest bei Arbeitgebern. War nicht so prickelnd“" (INT04). Aber der Besuch der dänischen Schule,

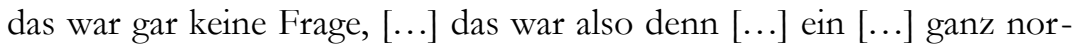
maler Prozess, dass wir also dann weiterhin bei den Dänen blieben und auch weiterhin die dänische Schule besucht haben und bei meinen Kindern war das eigentlich auch gar keine Frage (INT04),

denn

ohne dem [die Hilfe], weiß ich ja nicht, ob ich noch hier gewesen wäre, wenn, wenn die Deutschen, das war damals 'ne aussichtslose Sache, es sind viele $[\ldots]$ damals während dieser Mangelzeit ja an Lungentuberkulose gestorben (INT04).

Ein weiterer Vorteil des Besuchs der dänischen Schule waren für Otto Clausen die allsommerlichen Erholungsurlaube im Königreich. Solche Ferien hätte sich seine Familie nicht leisten können. Otto glaubt, sein Leben der dänischen Hilfe zu verdanken. Bei Frauke Erhard war es dagegen der jüngere Bruder, der krank war. Er hatte eine Augenkrankheit und war kurz davor zu erblinden. Durch die Hilfe der dänischen Gemeindeschwester wurde diese Krankheit mit Salben und anderen Medikamenten geheilt. „Zu ihr konntest du immer kommen, wenn [du] irgendwas hattest [...], da warst immer gut aufgehoben" (INT08), auch wenn man noch nicht im dänischen Verein war. Fraukes Bruder wurde nach seiner Genesung dänisch eingeschult, während Frauke selbst gleichzeitig von der deutschen Volksschule zur dänischen Hans-Helgesen-Schule wechselte. Auch bei ihnen kommt die in Otto Clausens Fall schon erwähnte große Dankbarkeit zum Tragen.

160 Otto Clausen berichtet, dass überliefert worden sei, dass er bei der Rückkehr nach Flensburg seine Mutter gefragt haben soll: „Frøken, er du min mor?““ („Fräulein, bist du meine Mutter?“", INT04). 
In ihren Erinnerungen an ihre Kindheit berichtet Karin Röh ebenfalls, dass es für sie eine „Befreiung “6161 war, als sie 1946 die Möglichkeit bekam, in die dänische Schule zu gehen. Denn ,dort gab es Schulhefte und Bleistifte, und die waren sogar kostenlos, da gab es Pausenbrote, da gab es eine Kleidungsverteilung" ${ }^{\text {"162 }}$ (Röh 2012: 69).

Nach Aussagen von Dänischgesinnten in informellen Gesprächen gab es aber auch Beispiele für Familien, die Hilfe aus Dänemark bekamen, sich danach aber wieder von der dänischen Minderheit abwandten ${ }^{163}$ (vgl. S. 205). In den Interviews und in der Fachliteratur gibt es widersprüchliche Angaben bezüglich der Frage, ob und inwiefern das Dänischsein absolute Voraussetzung für materielle Hilfe war. Einige schreiben, dass nur Mitglieder des schleswigschen Vereins materielle und medizinische Hilfe bekamen (vgl. S. 99). Andere berichten, dass alle, die es nötig hatten, versorgt wurden. Die Interviewpartner*innen deuten in dieser Frage an, dass sie damals Kinder waren und sich nicht umfassend daran erinnern können, ob, wie viel, wie lange und in welcher Form andere Unterstützung aus Dänemark bekamen. Vielleicht hat auch die Hoffnung auf Hilfe große Bedeutung bezüglich der Hinwendung zur dänischen Minderheit gehabt, unabhängig von der tatsächlichen Unterstützung. Bei diesem Aspekt muss die Bewertung der Hilfe im Nachhinein immer im Kontext der Konstruktion der eigenen Biografie gesehen werden.

Egon Clausen konstatiert, dass nicht alle Familien in Südschleswig Hilfe aus Dänemark bekamen, sondern nur diejenigen, die die nationale Gesinnung wechselten und dänisch wurden (Clausen 2014: 176).

Allerdings führte der dänische Schulbesuch in der Nachkriegszeit nicht zwangsläufig zu einer Identifizierung mit der Minderheit. Denn vor allem „,[m]it der Normalisierung der wirtschaftlichen und gesellschaftlichen Verhältnisse und dem Entstehen eines deutschen demokratischen Staates schwand der Zustrom zur dänischen Bewegung, die Mitgliederzahlen gingen zurück“" (Becker-Christensen 1996: 313; s. a. Kap. 3). ${ }^{164}$

\footnotetext{
161 „befrielse“

162 „Dér var skolehæfter og blyanter, og de var endda gratis, dér var madpakker, dér var tøjuddeling“"

163 Der als Schimpfwort gebrauchte Ausdruck „Speckdäne“ wurde nach dem Krieg von Deutschgesinnten für diejenigen verwendet, die aus materiellen Gründen dänisch wurden und „die Zugehörigkeit ihrer Region zu Deutschland in Frage stellten“ (Felbick 2003: 504). Diejenigen, die aus materiellen Gründen dänisch wurden und auch dänisch blieben, verwendeten diesen Begriff meiner Beobachtung in informellen Gesprächen nach für die Menschen, die erst dänische Hilfe annahmen und nach einiger Zeit der dänischen Minderheit den Rücken kehrten, also in den Augen Dänischgesinnter untreu und undankbar waren.
} 


\subsubsection{Ideelle Gründe}

Es gab in der Nachkriegzeit nicht nur materielle, sondern auch ideelle und ideologisch-politische Gründe für das Dänischwerden. Dazu gehörten beispielsweise auch „Wut, Scham und Enttäuschung“ über die „deutschen Verbrechen“" und die Sehnsucht nach einer „stabile[n] Demokratie“ (Danker 1997: 8) und Frieden in einem dänischen Staat. Außerdem hofften einige, sich beim Wechsel der Nationalität aus der Verantwortung für die Verbrechen während der Zeit des Nationalsozialismus stehlen zu können ((Danker 1997: 8; vgl. Kühl, Bohn 2005: 564; Becker-Christensen 1996: 312; Thaler 2013: 36; Hougaard-Werner 14.10.2013). ${ }^{165}$

Das neuentdeckte Wissen um die dänische Geschichte des Landes, grenzüberspannende Familienbande, die jetzt besonders hervorgehoben wurde, und die Erkenntnis, daß man den Menschen nördlich der Grenze ähnlicher war als den neuen Mitbürgern aus dem Osten, erleichterte den Übergang zum Dänentum (Becker-Christensen 1996: 312; vgl. a. Kap. 8.6).

Eine Verschiebung der Staatsgrenze Richtung Süden hätte die Lösung von vielen ideellen (und auch materiellen) Problemen bedeutet:

$[\mathrm{W}]$ arum ein demokratisches Staatswesen aus dem Nichts aufbauen, wenn man die dänische Demokratie importieren konnte, welche zugleich Abhilfe der materiellen Not und auch die Befreiung von den zahlreichen Flüchtlingen in Aussicht stellte (Klatt 2005: 112). ${ }^{166}$

Von einer Grenzrevision erhofften sich viele „converts“ (vgl. Kap. 8.7) auch politische und ökonomische Stabilität, allerdings beruhte ihre ,national reorientation“ auf einer fragilen, subjektiven Entscheidung, die auch wieder rückgängig gemacht werden konnte (Thaler 2009: 91).

Einige erwarteten wohl auch, dass der Landesteil Schleswig als Reparation vom Kriegsverlierer Deutschland an das Königreich Dänemark abgegeben werden müsste und sie dann von der neuen Ordnungsmacht besser behandelt wür-

164 Die Beeinflussung der nationalen Zugehörigkeit im Herzogtum Schleswig durch ökonomische und soziale Faktoren vor dem 20. Jahrhundert in der Mitte des 19. Jahrhunderts hat Hans Schultz Hansen untersucht (Hansen 2016).

165 Dieser Aspekt trifft auf die Interviewten dieses Samples nicht zu, da sie damals noch Kinder waren. Die Frage, wie es bei denjenigen Eltern aussah, die dem Regime nicht kritisch gegenüberstanden, kann in dieser Arbeit nicht beantwortet werden, weil die Interviewten darüber keine Informationen haben bzw. dies nicht thematisieren. Ausführlicher zum Thema Nationalsozialisten und dänische Minderheit s. Martin Klatt (2004).

166 Vgl. dazu auch (Vollertsen 1994b: 16, 18). Zum Zusammenhang zwischen den Nachkriegsflüchtlingen und der Südschleswigschen Bewegung siehe die ausführliche Abhandlung von Martin Klatt (2001). 
den, wenn sie sich in vorauseilendem Opportunismus dänisch bekennen würden (vgl. Klatt 2005: 111-112). Dies vermutet auch Interviewpartner Heinrich Schmied,

weil nämlich eh sich viele [in den dänischen Verein] reinmeldeten, noch in der Hoffnung oder vielleicht falsche[n] Hoffnung, nä, aus vielleicht Opportunismus, das weiß ich nicht, vielleicht haben sie sich etwas anderes drunter versprochen mit 'ner Wiedervereinigung. Das spökelte ${ }^{167}$ ja damals rum (INT07),

obwohl die dänische Regierung eigentlich schon im Mai 1945 beschlossen hatte, dass „die Grenze festliegt" ${ }^{\text {“168 }}$ (Noack 1995: 111; vgl. a. Kühl, Bohn 2005: 564; Becker-Christensen 1996: 312-313).

Betrachtet man das Fallbeispiel Sarah Iversen, wird deutlich, dass bei ihr vor allem ideelle, ideologische und soziale Gründe hinter dem Dänischwerden stehen. Um der Verfolgung und Diskriminierung der Nationalsozialisten und deren Mitläufer*innen zu entgehen, die sie aufgrund der Religion des Vaters und der politischen Einstellung der Eltern erleidet, wird Sarah 1946 in die dänische Schule eingeschult und erlebt dies im Nachhinein als den zentralen Wandel in ihrem Leben (vgl. a. Kap. 4.1). Sarah empfindet die dänische Schule und deren Lehrer*innen als Retter*innen und Befreier*innen von der Unterdrückung, die sie erfahren hat. Durch die Hilfe aus Dänemark beginnt für Sarah ein neues Leben. Alles ist anders, der Umgang miteinander, die Erlebnisse, die sie und ihre Mitschüler*innen gemeinsam haben, die Ferien in Dänemark, ihre soziale Integration in der Schüler*innenschaft und die Abgrenzung zu denjenigen, die sie diskriminieren.

Ein ganz ähnliches Motiv für den Besuch der Minderheitenschule hatte auch die Familie von Heinrich Schmied, geboren 1935. Seine Eltern „waren [...] nicht gerade [...] Kommunisten, aber sie waren Sozialdemokraten“ und sein „Vater hatte denn ein ziemlich loses Mundwerk" (INT07). Schmieds Eltern hatten keine besondere Verbindung zur Minderheit, abgesehen davon, dass sein Großvater davon enttäuscht war, dass Südschleswig 1920 nicht dänisch wurde. Seine Eltern erwarteten nach den Zweiten Weltkrieg, dass die Grenze in Richtung Süden verschoben

167 Spökeln (niederdeutsch): spuken, herumgeistern.

168 „Grænsen ligger fast“, Aussage des dänischen „statsminister“ Vilhelm Buhl am 9. Mai 1945 (Klatt 2009b: 181; Jürgensen 2003: 653; Noack 1996) Noack 1996 ist die deutsche Fassung des dänischen Originals (Noack 1995). 
würde, was aber nicht geschah (Schmied 2000) ${ }^{169}$. Schmied berichtet im Interview von Diskriminierungen auf der deutschen Schule wegen der in den Augen der Nationalsozialist*innen unerwünschten politischen Haltung der Eltern:

Und da hatten wir auch in der [deutschen] Schule d'runter zu leiden, wie so viele andere [...]. Also hier saßen wir auf der letzten Bank, zusammen mit den [...] Zeugen Jehovas und denn [sic] die anderen Kommunistenkinder und Sozialistenkinder und denn [sic] Sonstige, die froh waren, dass sie da überhaupt sitzen durften (INT07).

In dieser Situation empfanden der Interviewte und dessen Eltern die neu gegründete dänische Schule als attraktiv, da mit ihr die Diskriminierung im alltäglichen Schulumfeld aufhörte. Außerdem nennt Heinrich als weiteren Grund für seine dänische Einschulung, dass er von seinem Vater positive Berichte über Dänisches aus dessen Zeit im „Arbeitsdienst ${ }^{\star 170}$ im Königreich gehört hatte. Als Kind wusste er bis zu seiner dänischen Einschulung ansonsten nur, ,dass es Dänemark gibt, aber wir konnten uns uns ja unter den Nationalitäten gar nichts vorstellen“ (INT07).

Dann hieß es plötzlich, ja die dänische Schule wird hier wieder aufgemacht [...] und denn sech Vatter denn, dann ist dat ja gut, wenn ihr da in die dänische Schule kommen könnt, dann werde ich mich dafür einsetzen, nur wir Kinder verstanden es noch ni ${ }^{171}$ (INT07).

Ähnlich wie bei Heinrich Schmied war auch bei Holger Thietje, geboren 1946 in Harrislee, die politische Überzeugung der Großeltern, bei denen er aufwuchs, ausschlaggebender Grund für eine dänische Einschulung. Holger Thietjes Großeltern hatten bis Kriegsende mit dem Dänischen nichts zu tun und beherrschten kein Dänisch, so Thietje in der Zeitung Flensborg Avis. Sein Großvater befand sich während des Nationalsozialismus in einem „negativen Fokus“ (Thietje in $\mathrm{Ny}$ gaard 10.06.2015), da er auf dem Dachboden die sozialdemokratische Flagge versteckt hatte, englisches Radio hörte und Freunde hatte, die von der Gestapo abgeholt wurden. Thietje interpretiert dies einem Journalisten der Flensborg Avis gegenüber als ganz normalen Grund dafür, dass sie nach Kriegsende Angehörige der Minderheit wurden (Thietje in ebd.). Holger Thietje wurde daraufhin dänisch eingeschult und ging nach dem Realschulabschluss beruflich nach Dänemark. Er baute sich dort ein Leben auf und wohnt dort bis heute (ebd.).

\footnotetext{
169 Die Literaturangabe Schmied 2000 ist anonymisiert, da die korrekte Angabe des Namens die Anonymität Heinrich Schmieds aufheben würde.

170 „arbejdstjeneste“ von 1940 bis 1943

171 sech (niederdeutsch): sagte; ni (niederdeutsch): nicht
} 
Zurück nach Friedrichstadt: Von der neuen dänischen Schule hatten Brigitte Thomsen und Erik Nissen vor ihrer Einschulung von Verwandten „schon viel Gutes“ gehört, „dass die Kinder da [...] individuell behandelt werden“ (INT02) und „hellauf begeistert“ waren (INT02.). Sie berichteten, „Mensch, da ist das schön, [...] da müsstest du auch hin“" (INT01).

Mit der Einschulung schließlich wird die Grundlage zum Dänischsein gelegt, wobei Sarah Iversen rückblickend betont, dass es gar nicht so sehr darauf ankam, dass die rettende Institution dänisch war, denn, „das hätte auch 'ne chinesische Schule sein können, die eröffnet [wurde], bloß weg von der [deutschen Schule]“ (INT03). Es hätte also auch eine andere Einrichtung die rettende Funktion übernehmen können. Anstelle des Dänischwerdens hätte es auch eine Hinwendung zum Britischen sein können, da es auch Care-Pakete aus Großbritannien gab (vgl. Henningsen 2003b: 10; Lange 2003a). Das Dänische erschien vielen aber vielleicht wegen der geografischen Nähe angebrachter, naheliegender oder durch die deutsch-dänische Geschichte des Grenzlandes glaubwürdiger. Der aufgebaute dänische Mythos erschien den Akteur*innen plausibler, um noch einmal (Coakley 2004) aufzugreifen.

Erik Nissen meint ebenso, dass der Besuch der dänischen Schule sich nicht aus besonderer Verbindung zum dänischen Staat heraus begründen lässt, sondern hauptsächlich zufällig ,aus der Zeit heraus geschehen ist, nach dem Krieg“ (INT01). Das sich aus dem Besuch der dänischen Schule heraus entwickelnde Zusammengehörigkeitsgefühl war also nicht „fest und gegeben“ (Brubaker 2007: 22), sondern entwickelte sich aufgrund einer bestimmten Situation und ist bis heute als nicht statisch anzusehen. In anderen Regionen Deutschlands gab es die Möglichkeit des Besuchs einer dänischen Schule nicht. Dort haben möglicherweise Kirchen, Vereine, Pfadfindergruppen oder ein Umzug in eine andere Gegend ähnlich heilsam in Bezug auf Zugehörigkeitsgefühle wirken können. Die Situation in Friedrichstadt und Südschleswig war insofern besonders, da sie die Möglichkeit bot, auf eine andere Schule zu gehen und dort in einer Art Parallelwelt zur deutschen Mehrheit zu leben und anders sozialisiert zu werden.

Als bezeichnend für die Offenheit und Toleranz gegenüber gesellschaftlichen Außenseiter*innen und für die Integrationsbereitschaft der dänischen Minderheit nach dem Zweiten Weltkrieg wird von zwei Interviewpartnern die Geschichte Jana Ukanowskys ${ }^{172}$ erzählt. Sie ist 1930 geboren und kommt ursprünglich aus einem Dorf in der Nähe Friedrichstadts. In der Nachkriegszeit heiratete sie einen ehemaligen polnischen Zwangsarbeiter und wurde deshalb von der Mehrheit der Bevölkerung in ihrer Umgebung diskriminiert und ausgegrenzt (INT06, INT07).

172 Name geändert. 
Daraufhin fand sie Anschluss in der dänischen Minderheit, in der Menschen sie akzeptierten. Sie schulte ihre Kinder später in die Hans-Helgesen-Schule ein, half dort bei der Essensausgabe, ging fortan in die dänischen Gottesdienste und war bis zu ihrem Tod in der Minderheit, in der Kirche, bei Festen und Leseabenden aktiv.

„Wenn einer für die dänische Minderheit und für die dänische Kirche eingetreten ist, dann ist es sie. Die hat auch nirgendswo [sic] hingehört [...]. [Wurde] in Friedrichstadt überhaupt nicht akzeptiert und da kamen die Dänen“ (INT06) und haben sie aufgenommen, nachdem sie vorher von Friedrichstädtern als „Polenweib“ (INT06) beschimpft worden war. „Also, wenn einer für die dänische Minderheit und für die dänische Kirche eingetreten ist, dann ist es sie. [...] Also die [ist] wirklich dänisch" (INT06). Ihre Kinder und Enkelkinder wanderten zum Teil nach Dänemark aus, weil das das Land ist, mit dem sie statt Diskriminierung Positives verbinden. Den Berichten der Interviewpartner*innen zufolge könnte man also die dänische Schule sowie die anderen Einrichtungen der dänischen Minderheit nach dem Zweiten Weltkrieg als eine Art Auffangbecken für sozial Diskriminierte, ökonomisch Benachteiligte, religiös und politisch Ausgestoßene betrachten. Karin Röh erinnert sich in ihrem Buch daran, dass diejeningen, die Nothilfe aus Dänemark bekamen, von den Deutschen verachtet und als „Speck-Dänen“ beschimpft wurden (Röh 2012: 74). Allerdings ist sie sehr skeptisch geworden gegenüber Nationalismus, Kirchlichem und Fundamentalistischem (ebd.: 74), da sie im Gegensatz zu meinen Interviewpartner*innen auch eine negative Seite am Dänischen erlebt hat. Sie berichtet, dass sie „von unseren dänischen Lehrern nur abfällige Bemerkungen über die Deutschen und ihr ganzes Wesen gehört hatte. Alles Dänische war per definitionem das Beste ${ }^{\text {(1733 }}$ (ebd.: 74). Heute fordert Röh das Einstellen des Zuschusses für die Minderheit aus dänischen Steuergeldern, da sie die Minderheit für künstlich hält (ebd.: 176-177), aber dabei den konstruktiven Charakter aller Gruppierungen oder Nationalitäten nicht beachtet.

Zusammenfassend lässt sich für die Interviewten sagen, dass sie nicht einfach dänisch sind, sondern durch unterschiedliche Umstände erst dänisch geworden sind. ${ }^{174}$ Dabei bedeutet diese Art von „Gesinnungswechsel“ (Becker-Christensen

173 „af vores danske lærere kun hørte nedsættende bemærkninger om tyskerne og alt deres væsen. Alt dansk var per definition bedst"

174 Die Betonung des Prozesses des Dänischwerdens anstelle des einen Zustand beschreibenden Begriffs des Dänischseins erfolgt in Anlehnung an Barbara Kirshenblatt-Gimbletts „Folklore is made not found“ (Kirshenblatt-Gimblett 1995: 369) und Regina Bendix” „Kulturerbe ist nicht, es wird." (Bendix 2008: 340). Die meisten interviewten Akteur*innen sind also nicht einfach dänisch oder dänisch gesinnt, sondern sie sind dänisch geworden. Daraus lässt sich schließen, dass eine Minderheit kein Konstrukt ist, sondern als ein laufender Prozess gesehen werden kann (vgl. Kaschuba 1995: 291). Ebenso weist Inge Andriansen auf denselben Aspekt hin: „[D]er dynamische Charakter des Nationalbewusstseins [sollte] die ganze Zeit unterstrichen und hervorgehoben werden. Bewusstsein und Identität sind nichts von vornherein Gegebenes, 
1996: 312) auch, dass man gleichzeitig der deutschen Mehrheit angehören kann, da ,[n]ationale Identität [...] zumindest bei nationalen Minoritäten oftmals keine Frage des Entweder-Oders [ist], sondern [...] das Faktum des Sowohl-als-Auch“" (Kühl 2004: 329) einschließt, wie in den nächsten Kapiteln deutlich gemacht wird. Vorher soll es jedoch um die Gründe des Dänischwerdens für heutige Neudänen gehen.

\subsubsection{Gründe für ein Dänischwerden der Neudän*innen heute}

Blicken wir auf die Gegenwart und die heutigen Neudän*innen, die für ihre Kinder das dänische Schul- und Kinderbetreuungssystem wählen. Die Motive für diese Entscheidungen konnte ich überwiegend durch teilnehmende Beobachtungen und informelle Gespräche erfassen. Auch bei dieser Gruppe gibt es sowohl materiell-pragmatische als auch ideelle Gründe. Diese sind aufgrund der veränderten gesellschaftlichen Situation im Vergleich zur Nachkriegszeit aber anders gelagert und überschneiden sich, wie nun gezeigt wird.

Die größte Gruppe dieser Neueinsteiger*innen in die Minderheit kommt über die Anmeldung ihrer Kinder im dänischen Kindergarten bzw. an der dänischen Schule. Dies bestätigt mir auch Tina Zehntner in ihrer Rolle als SSF-Vorsitzende des Distriktes Friedrichstadt (bis 2015) im Interview. Allerdings räumt sie ein, dass sie im dänischen Schulverein eigentlich lieber „UNSERE Leute haben wollen“. Damit meint sie Kinder aus Familien, die schon zur dänischen Minderheit gehören und nicht Neueinsteiger*innen sind. Hier wird wieder die Ambivalenz deutlich, die auch im Kapitel über die Funktion der dänischen Schule noch beschrieben wird: Man will unter sich bleiben, gleichzeitig sichern Neueinsteiger*innen in die Minderheit aber die weitere Existenz der Minderheiteninstitutionen (vgl. Kap. $5.2)$.

nichts, was in der Vergangenheit geschaffen oder in den Genen festgeschrieben ist („, den nationale bevidstheds dynamiske karakter [bør] hele tiden understreges og fremhæves. Bevidsthed og identitet er ikke noget på forhånd givet, noget der er skabt af fortiden eller nedlagt i generne“ Adriansen 1994: 18). Ebenso kann man an dieser Stelle auf die Aussage des dänischen Schriftstellers und Literaturnobelpreisträgers Johannes Vilhelm Jensen (1873-1950) hinweisen, der in Bezug auf die dänische Nationalität geschrieben hat: „Man wird nicht dänisch geboren, das ist etwas, was man wird.“ („Man fødes ikke dansk, det er noget man bliver.“, zit. n. Schrøder 1995: 133). Wobei dies nicht nur speziell für die dänische Minderheit gilt, sondern auch für Dänemark und übertragen für Nationalitäten allgemein. Das Dänischsein in Südschleswig wurde und wird nämlich ähnlich wie „das Dänischsein“ („Danskheden“) in Dänemark ,eingeübt durch Schulen, Medien und Kulturpolitik, aber auch durch die Organisationen und die Sozialpolitik“" (,,indlært gennem skoler, medier og kulturpolitik, men også gennem organisationerne og socialpolitikken“ Østergård 1992: 408). 
Eine Untersuchung von Karen Margrethe Pedersen ergab, dass nur ein oder zwei Elternteile von der Hälfte der dänischen Schüler*innen der untersuchten 6. Klassen selbst auf einer dänischen Schule in Südschleswig oder in Dänemark waren (Pedersen 2000a: 54). Das zeigt, dass überraschend viele Menschen ohne dänischen Hintergrund ihre Kinder dänisch einschulen. Allerdings muss man bei dieser Aussage beachten, dass dieser Untersuchung die Annahme zugrunde liegt, dass die Eltern nur dann einen dänischen Hintergrund haben, wenn sie selbst eine dänische Schule besucht haben. Diese Definition der Zugehörigkeit wird von Angehörigen der Minderheit oft verwendet und wurde von Pedersen für ihre Studie übernommen. Gleiches konnte ich auch bei meinen Feldforschungen beobachten. Es könnten sich aber auch Menschen zur Minderheit gehörig fühlen, die weder in Dänemark noch in Südschleswig eine dänische Schule besucht haben. Von den von Pedersen untersuchten Schüler*innen hatten nur rund $10 \%$ Dänisch als Erstsprache zu Hause (ebd.: 57), wobei die Erstsprache noch nicht viel über die Zugehörigkeit zur Minderheit aussagen muss.

Jørgen Kühl bezeichnet die Integration von Neudän*innen als Disassimilierung von Menschen aus der Mehrheit, die sich in die Minderheit integrieren (Kühl 19.08.2013) ${ }^{175}$. Wie Nationalstaaten ihre Bürger*innen durch konstruierte „eindeutige und starre Identitätskategorien“ (Feischmidt 2003: 109) zu integrieren versuchen, so macht das analog dazu auch die dänische Minderheit mit Neudän*innen (s. Kap. 6).

Um einen Vergleich zur Integration von Migrant*innen in Deutschland herzustellen: Die Erwartungen in Bezug auf Integration in die dänische Minderheit und in die dabei gleichzeitig beobachtete Angst vor Assimilierung von Dänischgesinnten in eine deutsche Mehrheit ist das Gegenteil von der gesellschaftlich erwarteten Integrationsleistung von Immigrierten nach Deutschland. Von ihnen wird Integration in die Mehrheit erwartet, die für viele Menschen Assimilierung und Teilhabe bedeutet (Achour 2016: 133; vgl. a. Heckmann 2015). Eingewanderte können Integrations- und Sprachkurse belegen sowie Prüfungen dazu absolvieren (Bundesministerium des Innern 2014: 51; Achour 2016: 134). Es wird von Konservativen eine Anpassung dieser Zugewanderten an eine sogenannte deutsche „Leitkultur“ gefordert, wie es Friedrich Merz 2000 formlierte (Achour 2016: 132; vgl. Sprenger 2014). Allerdings wird oft vergessen, dass Integration von Neubürger*innen bedeutete, dass ,sich auch das Land selbst verändert" und neu definiert wird, „was »Deutschsein« bedeutet“ (Kösemen 2016: 99).

Die bisherige deutsche Wahrnehmung von Migration ist gerahmt durch zwei Vorstellungen: die Angst vor Integrationsverweigerern und mi-

175 Dagegen wird beispielsweise die griechische Minderheit in Istanbul immer kleiner. Nicht weil Menschen sich zur Mehrheit assimilieren, sondern weil sie nach Griechenland oder in andere europäische Länder auswandern (vgl. Güsten 10.06.2017). 
grantischen Parallelgesellschaften sowie den Anspruch einer auf traditionellen Vorstellungen basierenden deutschen Leitkultur, in die sich alle Migrantinnen und Migranten einzufügen haben (ebd.: 101).

Dies gilt umgekehrt auch für das Dänischsein und die dänische Minderheit. Allerdings ist für die Mehrheitsgesellschaft beobachtet worden, dass erzwungene Integration nicht funktioniert, sondern eher Widerstände produziert (ebd.: 98).

\subsubsection{Materielle Gründe}

Lotti Wiese, Rentnerin aus Arnis im Landkreis Schleswig-Flensburg und Interviewte im dänischen Film De glemte danskere, spricht selbst kaum Dänisch und hatte bis zum Wechsel ihrer Kinder auf die dänische Schule keinen Bezug zur Minderheit. Im Filmgespräch mit Journalist Marc Peetz erzählt sie in einer Mischung aus Hoch- und Plattdeutsch, dass ihre Kinder aus pragmatischen Gründen von der deutschen in die dänische Schule wechselten. Hintergrund war die Schließung der deutschen Schule in Deutschlands kleinster Stadt Arnis mit rund 300 Einwohner*innen. Stattdessen sollten die Kinder auf eine neu gegründete Dorfgemeinschaftsschule Habertwedt im Nachbarort Grödersby gehen. Damit wollte sich Familie Wiese nicht zufriedengeben und entschied sich aus Protest und wegen der größeren Nähe zum Wohnort für das dänische Schulsystem. Dort erfuhren sie eine große „Herzlichkeit“ und fragten sich, warum sie nicht schon viel früher dorthin gewechselt seien. Später saß Lotti für den SSW im Stadtrat von Arnis (Petersen [2014]).

Ein weiteres Beispiel für einen pragmatischen Grund, das eigene Kind dänisch einzuschulen, ist Larissa, 43 Jahre alt, aus der Nähe von Kiel mit ihrem fünfjährigen Sohn. Sie sagt, sie wisse nicht, ob sie wirklich Teil der Minderheit sei, aber der Vater ihres Kindes, welches sie allein erziehe, sei Däne und wohne in Norwegen. Daher möchte sie, dass ihr Kind auch die Sprache ihres Vater könne und mit Skandinavien vertraut werde und das sei mit dem Besuch des dänischen Ausbildungssystems der Minderheit recht einfach möglich. Larissa selbst hatte bisher nichts mit der dänischen Minderheit zu tun, ist aber bereit, Dänisch zu lernen. Gegenüber anderen Integrationsmaßnahmen tritt sie distanziert-skeptisch auf, sie sieht sich selbst als Deutsche und hat wenig Grund, das zu ändern (TNB 15.10.2013).

Ähnlich pragmatisch argumentiert Inken, 47, Lehrerin an einer deutschen Gesamtschule in Eckernförde. Ihr Sohn, 7 Jahre alt, solle nicht die gleiche Schule besuchen, in der sie selbst unterrichte, und eine deutsche Alternativschule sei zu weit von ihrem Wohnort an der Ostküste entfernt. Inken kenne mehrere Lehrer*innen an deutschen Schulen, die ihre Kinder lieber dänisch einschulten (Informelles Ge- 
spräch 17.10.2013). Eigentlich, so Inken leise im Gespräch zu mir, wolle sie ja am liebsten, dass ihr Sohn nach der vierten Klasse auf die A.-P.-Møller-Schule gehe. Das ist eine 2008 eröffnete dänische Gesamtschule mit Gymnasialteil in Schleswig, die zu den modernsten weiterführenden Schulen Europas zählt. Sie habe sich die Schule am Tag der offenen Tür angeschaut und sei von ihr begeistert gewesen. Inken bedauere aber, dass ihr Sohn die A.-P.-Møller-Schule aufgrund ihres Wohnortes erst ab der gymnasialen Oberstufe wird besuchen dürfen und er bis zur zehnten Klasse in die dänische Schule in Eckernförde gehen muss. Inken möchte ebenso, dass ihr Sohn eine zweite Sprache auf hohen Niveau lerne und ein ihrer Meinung nach besseres Schulsystem durchlaufe. Inkens Grund für die Wahl des dänischen Schulsystems beruht eindeutig auf der Ausstattung der dänischen Bildungseinrichtungen und dem damit verbundenen Wunsch einer besseren Ausbildung ihres Kindes. Mit dem Dänischen hat Inken nichts zu tun.

Im Gespräch ergänzt Inken, sich für ihren rein materiell-pragmatisch erscheinenden Ansatz rechtfertigend, dass ihr der Europagedanke sehr wichtig sei (TNB 16.10.2013). Dieser Wunsch steht im scharfen Kontrast zur offiziellen Sicht der Vereinsfunktionär*innen, die immer wieder betonen, keine bilingualen, multikulturellen, deutsch-dänischen oder europäischen Schulen bereitstellen zu wollen, sondern stattdessen ein explizit dänisches Angebot machen (vgl. Kap. 5). Inken merkt im Gespräch selbst, dass es von Minderheitenakteur*innen möglicherweise nicht wirklich akzeptiert wird, aus ganz pragmatischen Gründen ein Kind dänisch einzuschulen und damit u. a. von dänischen Steuergeldern zu profitieren. Sie versucht, ihre Motivation durch einen ideellen Überbau zu ergänzen und konstatiert, dass sie Dänemark schon immer toll gefunden habe und ihre Tante einen dänischen Modefimmel hätte und diese ihr Haus mit dänischen Möbeln eingerichtet habe und immer nach Dänemark in den Urlaub fahre (Gespräch u. TNB am 17.10.2013). Diese triviale, ideelle Konstruktion beruhend auf dem Modegeschmack der Tante zeigt, wie wenig Ernsthaftigkeit Inken beim Dänischwerden und Dänischsein an den Tag legt und wie stark ihr rein materielles Interesse an den Minderheitsschulen ist. ${ }^{176}$ Der wenig überzeugende Rechtfertigungsversuch soll die wirtschaftlichen Interessen Inkens verschleiern. Die Hauptmotive des Besuchs der dänischen Minderheitsschulen sind für die Eltern eine bessere Ausstattung und die dänische Sprache, um schließlich bessere „Sprach- und Karrieremöglichkeiten“177 zu haben (Meyer in Dittrich 14.07.2006a). Weitere Veranlas-

176 Dass es aus pragmatischen Gründen auch andersherum kommen kann, zeigt der Zeitungsbericht aus der Flensborg Avis vom 08.07.2014, in dem eine Mutter, die der dänischen Minderheit angehört, sich darüber beklagt, dass sie ihren dreijährigen Sohn in eine deutsche Krippe geben muss, weil diese länger geöffnet hat als die entsprechenden dänischen Einrichtung. Sie fürchtet nun, dass ihr Sohn später schlechter Dänisch sprechen wird und dass die Familie einen Teil ihrer Identität verlieren wird, wenn die Anknüpfung an den dänischen Kindergarten fehlt (Mølvig 08.07.2014).

177 „sprog- og karrieremuligheder“ 
sungen zur Wahl der dänischen Schulen sind längere Öffnungszeiten der Kinderbetreuungsangebote und die Möglichkeit, nach dem Abitur im Studium vom dänischen Ausbildungsfördersystem ${ }^{178}$ zu profitieren. Dem Dänischsein wird ein Wert zugeschrieben, in dänischen Schulen wird spezifisch dänisches soziales und kulturelles Kapital vermittelt und gelehrt, an dem die Teilhabe attraktiv erscheint. Den Eltern geht es also weniger um einen Nationalismus, den sie allerdings in Kauf nehmen, sondern um eine Verwertungslogik. Im Gegensatz zu Minderheitsangehörigen in anderen Regionen Europas, die ihre Kinder aufgrund der Hoffnung auf bessere „Aufstiegsmöglichkeiten“ und soziale und räumliche „Mobilitätschancen“ (Feischmidt 2003: 159) in Mehrheitssschulen schicken, haben die neudänischen Eltern genau dieselben Gründe für die Wahl der dänischen Minderheitsschulen für ihre Kinder, nämlich die Erweiterung des potenziellen Arbeitsplatzradius, eine vermeintlich bessere Ausbildung sowie erlangte Zweisprachigkeit durch den Besuch dänischer Schulen. Eine Umorientierung der nationalen Gesinnung aufgrund der Annahme, sich dadurch Vorteile sichern zu können, scheint nichts Außergewöhnliches zu sein. Die Wahl des dänischen Schulsystems mit der Inkaufnahme von Gesinnungserwartungen wird von den Akteur*innen als eine gute Bildungsinvestition für die Zukunft bewertet. Das gleiche Phänomen wird auch von Margit Feischmidt für die Volksgruppen in Siebenbürgen beschrieben (Feischmidt 2003).

Nach der Schilderung der erhofften materiellen Vorteile für Gesinnungswechselwillige bzw. Schulopportunist*innen soll es im Folgenden um die ideellen Gründe für das Dänischwerden und die Überschneidungen mit den materiellen Motiven gehen.

\subsubsection{Ideelle Gründe}

Ein Beispiel für Eltern, die mit der dänischen Minderheit nichts zu tun hatten, aber ihre Kinder in den dänischen Kindergarten bringen und dänisch einschulen, sind Lotte und Bernd Lorenz aus Norderdithmarschen. Sie wohnten bis vor kurzem 14 Kilometer von Friedrichstadt entfernt, südlich der Eider, der Grenze zu Holstein und derjenigen Grenze, die für das Dänischsein eine große Rolle spielt, da ihr von vielen Dän*innen eine große Bedeutung als 1.000-jährige Südgrenze des dänischen Reiches zugeschrieben wird (s. Kap. 8.6) und es in Holstein keine dänischen Minderheitseinrichtungen gibt, da es südlich der Eider und damit außerhalb Südschleswigs liegt.

\footnotetext{
178 Statens Uddannelsesstøtte - SU
} 
Lotte und Bernd Lorenz sind Lehrerin bzw. Lehrer an deutschen Schulen. Bernd hatte in seiner Ausbildung zum Lehrer ein Praktikum an einer dänischen Schule absolviert. Dort wurde bei ihm die Begeisterung für das dänische Schulsystem geweckt. Daraufhin beschlossen seine Frau und er, ihre Kinder jeden Tag mit dem Auto nach Friedrichstadt zu bringen, damit diese dänische Institutionen besuchen konnten. Diese Entscheidung ist ein Ausdruck der Unzufriedenheit der Familie Lorenz mit dem deutschen Schulsystem, von dem sie als Lehrer*in allerdings selbst ein Teil mit gewissem Mitgestaltungsspielraum sind. Schließlich entschließt sich die Familie, nach Friedrichstadt zu ziehen, um sich dort besser in die dänische Minderheit integrieren zu können. Auch der Kindergarten- und Schulweg für die beiden Kinder verkürzt sich durch den Umzug aus Dithmarschen nach Friedrichstadt erheblich. Bernd und Lotte nehmen seit einigen Jahren, also auch schon vor ihrem Umzug, regelmäßig an Veranstaltungen des SSF und des Schulvereins teil (TNB, INT10).

Der Schulleiter der dänischen Jes Kruse-Skolen in Eckernförde an der Ostküste des Landes, Peter Müller, hebt im Interview mit NDR Info in Abgrenzung zu deutschen Schulen hervor, dass seine Schule nicht nur für Lehrer*innen und Eltern da sei, sondern die Kinder im Vordergrund stünden: „,wir sind als Kinder ein sehr, sehr wichtiges [sic] Teil ja, den, den [sic] Ursache, weswegen es ja überhaupt Schule gibt“ (Müller in Werner 16.05.2016). „[B]ei der dänischen Pädagogik steht die Person im Mittelpunkt", hebt die Radioreporterin hervor (ebd.). Weiter versucht der Beitrag, anhand eines Beispiels mit zwei zerstrittenen Kindern, die sich auf Anraten ihrer einfühlsamen Lehrer*innen zum Gespräch zusammensetzen und sich wieder vertragen, zu zeigen, dass es in dänischen Schulen eine besondere pädagogische Haltung gibt (ebd.). Es wird ebenfalls berichtet: „Eltern, die so etwas selbst als Schüler erfahren haben, überlegen nicht lange, welches Schulsystem sie für ihre Kinder wählen sollen“ (ebd.). Mit „so etwas“ ist hier der dänische pädagogische Ansatz gemeint, ohne dass dieser explizit erläutert wird. Dänische Pädagogik, so die Elternratsvorsitzende Silvia Krabowski-Völlmer, ,ist wo man sich wohl gefühlt hat" (Krabowski-Völlmer in ebd.). Der Vater eines Kindes, welches die Jes Kruse-Skolen besucht, Lutz Müller Thomsen, erläutert seine Sichtweise auf die dänische Pädagogik folgendermaßen: „Ich guck mir das Kind an. Was braucht das Kind? Und daraus entwickeln sich die Entscheidungen. Und nicht, wie krieg ich 'n möglichst hohen Leistungsstandard in meiner Klasse organisiert" (Müller Thomsen in ebd.).

In der Reportage auf NDR Info kommt eine Mutter aus Eiderstedt zu Wort, die mit dem Dänischen bisher nichts zu tun hatte, aber jetzt ihre dreijährige Tochter in den dänischen Kindergarten gegeben hat und dies recht unkonkret mit der dänischen Pädagogik begründet: „Wir finden das dänische System, was Kinder angeht, einfach besser“" (namentlich nicht geannten Mutter in ebd.). 
Die häufige Begründung von Eltern, ihre Kinder aufgrund einer „dänischen Pädagogik “'179 dänisch einzuschulen, wird vom Philosophen Klausen dekonstruiert (Klausen 07.07.2016), indem er danach fragt, was genau diese spezielle dänische Pädagogik ausmache, außer dass es pädagogische Arbeit für die dänische Minderheit und auf Dänisch sei. In der Nachkriegszeit war die Differenz zwischen deutscher und dänischer Pädagog*innenausbildung noch groß, denn die dänischen Lehrkräfte wurden damals in modernerer Pädagogik ausgebildet. Diese beruhte auf einer Zusammenarbeit mit Schüler*innen auf Augenhöhe und ohne körperliche Züchtigung. Dies stand im Gegensatz zu den Kolleg*innen in Deutschland während und kurz nach der Zeit des Nationalsozialismus. Auch in Dänemark werde mittlerweile, so Klausen, mehr und mehr Wert auf Prüfungen und Noten gelegt und deutsche Schulen seien heute nicht mehr ,,autoritär oder altmodisch“"180 (ebd.). Dass die Klassenstärke geringer ist, so ein wiederkehrendes Argument der Eltern, liegt auch daran, dass die Minderheit vor allem außerhalb Flensburgs, wie der Begriff Minderheit schon beinhaltet, zahlenmäßig in der Minorität ist und weniger Schüler*innen zu betreuen sind. Das kann aber auch auf andere Privatschulen zutreffen und würde noch keine Einschulung in das dänische System logisch rechtfertigen, abgesehen davon, dass die Wahl der Schule im Landesteil Schleswig frei ist und nicht gerechtfertigt werden muss.

Ähnlich sieht es bei der Integrationskursteilnehmerin Luise aus. Luise und ihr Mann wohnen mit ihren beiden Kindern in der Nähe Rendsburgs. Ursprünglich kommen sie aus Thüringen, sind aber aus beruflichen Gründen in das nördlichste deutsche Bundesland gezogen. Sie wohnten bis vor ein paar Jahren noch südlich des Nord-Ostsee-Kanals in Holstein. Da ihre Kinder aber dänisch eingeschult werden sollten, sind sie extra auf die andere Kanalseite gezogen, damit sie im Landesteil Schleswig leben können. Denn nur dann können sie Teil der dänischen Minderheit werden und ihre Kinder dänisch einschulen. Ihr Sohn ist 14 Jahre alt, ihre Tochter steht mit 17 Jahren kurz vor dem Abitur an der A.-P.-Møller-Schule in Schleswig.

Luise sagt mit leicht thüringischem Akzent, dass sie sich für die dänische Minderheit entschieden habe und jetzt auch alles, was dazugehöre, konsequent verfolge. Sie ist in ihrem Dorf im SSF, SSW, in der dänischen Kirche und im dänischen Sport- und Jugendverein SdU aktiv. Sie geht seit Jahren regelmäßig zum privaten Dänischunterricht bei Hans Thomsen, der auch beim Integrationskurs 2013 Dänisch unterrichtete. Luise hat für sich und ihre Familie das ganze Minderheitspaket gewählt und engagiert sich sehr für das Dänische. Deshalb ist sie in möglichst vie-

\footnotetext{
179 „dansk pædagogik“

180 „autoritær eller gammeldags“
} 
len dänischen Vereinen aktiv. Luise ist eine Powerfrau, sie kann von allen Teilnehmenden beim Jaruplundkurs am besten Dänisch und sie ist im Unterricht am aktivsten dabei. Da ihre Kinder schon älter sind, hat sie schon ein paar Jahre mehr Erfahrung im Dänischsein und Dänischsprechen.

Beate und Klaus Mertens kommen aus Husum. Ihre Tochter ist 8 Jahre alt und geht in die dänische Schule. Sie ist in derselben Klasse wie die Tochter von Traute. Beate und Klaus können ein bisschen Dänisch, trauen sich aber kaum, die Sprache zu sprechen. Sie haben das dänische Schulsystem für ihre Tochter gewählt, weil es dort kleinere Klassen gebe (Nygaard 22.02.2014; vgl. a. Kütemeier 2000: 107), wie es z. B. für die Friedrichstädter Hans-Helgesen-Schule auch zutrifft. Sie schwärmen von der Rundumbetreuung ,aus einer Hand“, wie sie sagen. Die Tochter ist vormittags in der Grundschule und geht dann gemeinsam mit den Schulkamerad*innen zur Nachmittagsbetreuung Skolefritidsordning (SFO - Schulfreizeitordnung, s. Kap. 3.2.2). Die Lehrer*innen und die Nachmittagsbetreuer*innen würden miteinander kommunizieren und sich gegenseitig informieren, falls es irgendwelche Probleme gebe. Es sei alles nicht so anonym wie im Mehrheitssystem, jeder würde jeden kennen und alles sei so gemütlich und angenehm. Alle würden miteingebunden. ${ }^{181}$

Die Einschulung und die damit aus Minderheitensicht im Idealfall eintretende freie, aber konsequente Entscheidung für das Dänischsein mit den dazugehörigen Konsequenzen ist nicht immer ganz einfach. Lutz Müller Thomsen, neudänischer Vater, erläutert im Radiobeitrag auf NDR Info:

Das ist ja auch keine so ganz einfache Entscheidung, denn, wenn man sich ja sacht, ja ich mach da mit, ich schließ mich der dänischen Minderheit an, muss man das ja auch machen, denn es ist blöde, auf dem halben Weg dann zu sagen, ach, nein, das finde ich dann doch doof und dann die Kinder dann von der Schule runterzunehmen und sie dann wieder irgendwo anders einzufädeln, das ist nicht nur, dass wir jetzt einfach ne Schule haben, die eine weitere Fremdsprache unterrichtet, sondern das ist schon son bisschen das Eintauchen in die dänische Kultur (Müller Thomsen in Werner 16.05.2016).

Die Radiosprecherin ergänzt: „Praktisch heißt dieses Eintauchen erst einmal, die Sprache zu erlernen“ (ebd.). Die hier genannten ideellen Motive für die Wahl des Dänischen haben langfristig materielle Auswirkungen. Sprachkenntnisse, gute Betreuung durch kleinere Klassen, deutsch-dänische Schulabschlüsse und ein gutes

181 Der Aspekt der Komplexitätsreduktion und der Suche nach Beheimatung wird ab Seite 324 in Kapitel 8.7 vertieft. 
Netzwerk innerhalb der Minderheit erhöhen die Chancen auf dem deutschen und vor allem auf dem dänischen Arbeitsmarkt und sind somit langfristig erworbenes Sozial- und Bildungskapital.

\subsubsection{Weitere Gründe für ein Dänischwerden}

Es gibt Akteur*innen in der dänischen Minderheit, die weder aufgrund von wirtschaftlicher oder sozialer Not nach Ende des Zweiten Weltkrieges noch durch pragmatisch-materielle Interessen in der Gegenwart zur dänischen Minderheit gekommen sind, sondern einen anderen Hintergrund haben. Sie haben andere Erklärungen für ihr Dänischsein und ihren dänischen Schulbesuch, wie folgende vier Beispiele zeigen.

Tina Zehntner, geboren 1976, in einer südschleswgischen Kleinstadt wohnend, kommt aus einer dänisch-gesinnten Familie. Schon Zehntners Mutter war durch ihre Eltern, also Zehntners Großeltern, Teil der dänischen Minderheit geworden. Zehntners Vater kam ursprünglich aus Göttingen, ist aber durch seine Ehefrau, Zehntners Mutter, zur dänischen Minderheit gekommen und dort integriert. Zehntner besuchte als Kind den dänischen Kindergarten und wurde anschließend in das dänische System eingeschult. Sie machte schließlich an der Flensburger Duborg-Schule, einer dänischen Gesamtschule mit gymnasialer Oberstufe, Abitur. Danach ging sie durch Vermittlung eines ihrer ehemaligen Lehrer für ein Krankenpflegestudium nach Sønderborg/Sonderburg in Dänemark und kehrte schließlich in die Kleinstadt zurück. Von dort aus pendelte sie anschließend täglich 90 $\mathrm{km}$ zur Arbeit nach Apenrade/Aabenraa in Dänemark bis sie eine Anstellung beim Dänischen Gesundheitsdienst für Südschleswig fand. Da Zehntner mit dem Dänischsein großgeworden ist, ist es für sie „das Natürlichste der Welt“ (INT10). Sie „war schon immer so“ (INT10). Zehntner begründet ihr Dänischwerden und ihren dänischen Schulbesuch mit der Abstammung von ihrer Mutter und ihren Großeltern. Die dänische Sprache beherrschte sie „von Anfang an“ und die Minderheitenzugehörigkeit empfindet sie als „ganz natürlich“, als „ganz normal“ und als nichts Besonderes (INT10). Zehntner ist durch eine für sie selbstverständliche Sozialisation mit der Minderheit großgeworden. Sie sagt, dass der Besuch der dänischen Schule für sie selbst keine Besonderheit darstellte, sondern die logische Konsequenz ihres Minderheitenhintergrundes sei (INT10). Daher fällt es ihr im Interview schwer, zu erklären, was es für sie bedeutet, dänisch zu sein. Erstaunlich ist bei dieser kommunizierten Selbstverständlichkeit die Tatsache, dass Zehntner darüber hinaus sagt: „Mama hat das damals für uns gewählt und .. meine Großeltern haben das für un-.. Mama gewählt“ (INT10). Die vorher von Zehntner ausgedrückte Normalität wird durch diese Aussage, dass die Großeltern und ihre Eltern das Dänische hätten abwählen können, eingeschränkt. Zehntner ist sich also be- 
wusst, dass das Minderheitensein abwählbar ist, dass es bei einer Abstimmungsminderheit Wahlmöglichkeiten gibt, obwohl sie für sich die Minderheitsangehörigkeit als Selbstverständlichkeit begreift und sie sich aktiv in der Minderheit engagiert. Die Kulturanthropologin Margit Feischmidt in Siebenbürgen hat in ihrer Studie ebenfalls herausgearbeitet, dass eine bestimmte Minderheitenzugehörigkeit und Schulwahl für Akteur*innen nicht erklärungswürdig, sondern ,normal“ sei (Feischmidt 2003: 158). Teil dieses selbstverständlichen Umgangs mit dem Minderheitsdasein seitens der Akteur*innen ist dabei, dass der eigene dänische Schulbesuch und der Schulbesuch der eigenen Kinder unangezweifelte Entscheidungen sind. Tina Zehntner berichtet im Interview, „das war denn überhaupt keine Diskussion, aso [sic] unser Kind kommt in die dänische Schule... gehörts... weiß ich nicht, gehört einfach [da]zu“" (INT10).

Hella Lassen ist das zweite Beispiel für die Wahrnehmung des eigenen Dänischseins als Selbstverständlichkeit. Hella, 58 Jahre alt, Buchhalterin bei der Dansk Centralbibliotek in Flensburg (Lund 06.04.2017), kommt aus Struxdorf, dänisch Strukstrup, in Südangeln, und sie sagt im Filminterview, dass ihre Familie schon lange dänisch gesinnt war und schon lange für das Dänischsein in Angeln engagiert war (Nissen, Petersen 07.04.2014a; Petersen [2014]).

Auch für die Flensburgerin Maike Lohse, das dritte Beispiel, ist die Zugehörigkeit zur dänischen Minderheit Normalität. Durch die Wahl ihres Großvaters und ihrer Mutter ist sie als Kind dänisch eingeschult worden (Werner 16.05.2016).

Das letzte Beispiel für die traditionell der dänischen Minderheit Angehörigen ist Katrine Hoop aus Flensburg. Sie wuchs in Vollerwiek auf Eiderstedt im Kreis Nordfriesland auf und wohnte mit ihren Eltern in der dortigen dänischen Schule. Ihr Vater war Leiter dieser Schule. Sie lebte anschließend 17 Jahre in Hamburg und zog dann nach Flensburg, wo sie bis heute wohnt (Sørensen 2008). ${ }^{182}$ Katrine berichtet, dass die Schule in ihrer Kindheit der Kern eines gut funktionierenden Netzes war, welches allen Mitgliedern das Gefühl gab, Teil einer besonderen Gemeinschaft zu sein (Hoop in ebd.). „Ein Teil des Dänischen zu sein, fühlte sich wie ein Privilegium an ${ }^{\text {“183 }}$, so Hoop. Man habe die dänische Pädagogik, Wärme, Gemütlichkeit und Nähe genießen können (Hoop in ebd.). Alle hätten sich bewusst für das Dänische entschieden, und das führte zu einem Zusammengehörigkeits- und Zugehörigkeitsgefühl (Hoop in ebd.). Die Minderheitenzugehörigkeit ist also nicht einfach da, sondern sie ist eine Wahl, eine Abstimmung im Gegenstz zur Abstammung, wie hier erneut deutlich wird. Die Sprache war dabei kein Gesinnungsindikator, da Hoops Umfeld mehrsprachig war: Dänisch, Hochdeutsch, Plattdeutsch und Sonderjysk, Südjütisch. Sie betont in einem Leserbrief in

\footnotetext{
182 Seit arbeitete ab Juni 2016 als Projektleiterin für Oplev Sydslesvig (Erlebe Südschleswig), ein Projekt der Dänischen Bibliothek, dem SSF, dem Schulverein und dem Jugendverein der Minderheit (Sydslesvigsk Forening 12.05.2016).

183 „Det føltes som et privilegium at være en del af det danske.“
} 
der Flensborg Avis: „Mein dänischer Schulbesuch hat mein Leben so entscheidend geformt, dass ich wieder nach Hause nach Südschleswig ziehen musste, um meinem Sohn die gleichen guten Bedingungen zu geben“184 (Hoop 01.03.2014).

Gemeinsam ist allen Akteurinnen dieser Gruppe, dass ihre Eltern schon Teil der dänischen Minderheit waren und sie selbst ihre Zugehörigkeit zur Minderheit als etwas Normales, als etwas Natürliches sehen. Für sie ist ihre dänische Schulausbildung etwas Selbstverständliches, das die Tradition ihrer Eltern oder eines ihrer Elternteile fortsetzt. Sie kennen kein anderes System als das der Minderheit, sie mussten sich nicht umstellen, es treten bei ihnen keine Widersprüche zwischen der Zugehörigkeit ihrer Eltern und ihrem eigenen dänischen Schulbesuch auf. Auch bei ihnen spielt die dänische Schule eine große Rolle, da hier das Dänischsein gelernt, eingeübt und bekräftigt wird.

Kapitel 4 hat gezeigt, dass Menschen ihre Zugehörigkeit(en) bzw. die ihrer Kinder aufgrund der äußeren Umstände überdenken, ändern, beibehalten oder erweitern können. Besonders einfach ist dieser Wandel, wenn Personen von ihm profitieren können, wie die hier beschriebenen materiellen und sozialen Vorteile des Dänischseins zeigen: „Many people change their ethnic identity only if they can profit by doing so“" (Roosens 1989: 13; vgl. a. Eriksen 2003: 160).

184 „Min danske skolegang har formet min [sic] liv så afgørende, at jeg var nødt til at flytte hjem til Sydslesivg for at give min søn samme gode betingelser." 



\title{
5. Dänischwerden II - die Bedeutung der Schulen
}

\author{
„F]ür das Fortbestehen der dänischen Min- \\ derheit spielt es zuallererst eine bedeutsame \\ Rolle, dass ibre Institutionen stark sind. Das \\ gilt insbesondere für die Arbeit mit Kindern \\ und Jugendlichen, die die Minderheit mit ei- \\ nem gut entwickelten Institutionsnetzoverk. \\ von Kindergärten, Schulen und Freizeitein- \\ richtungen organisiert hat. Dadurch wurden \\ institutionelle und kulturtragende Rahmen \\ für die Reproduktion der Minderheit geschaf- \\ fen, unterstütrt sowobl durch andere Minder- \\ heitsorganisationen als auch durch gesellschaft- \\ liche Vereine und die Kirche. " 185 \\ Morten Meisner, Lebrer an der \\ Duborg-Skole (Meisner 2012: 54)
}

185 „[F]or det danske mindretals fortsatte eksistens spiller det først og fremmest en betydningsfuld rolle, at dets institutioner står stærkt. Det gælder især arbejdet med børn og unge, hvor mindretallet med et veludviklet institutionsnet har kunnet organisere disse gennem børnehaver, skoler og fritidshjem. Dermed er der, støttet af andre mindretalsorganisationer såsom folkelige foreninger og kirken, skabt institutionelle og kulturbærende rammer for mindretallets reproduktion. “ 
Das Eingangszitat zeigt die große Bedeutung der Institutionen für die Konstituierung und Aufrechterhaltung der dänischen Minderheit. Nachdem im vorherigen Kapitel die Gründe für das Dänischwerden, für die Wahl des Dänischen, dargestellt wurden, geht es in diesem nun darum, was nach der Anmeldung von Kindern im dänischen System, also in Kindergärten und Schulen, passiert. Es werden Erwartungen und Praxen untersucht, die von und an Akteur*innen der Minderheit gestellt werden sowie daraus folgende Widersprüche und Konflikte. Es geht um die Konsequenzen der Wahl des Dänischen. Dabei ist es wichtig zu beachten, dass das Dänischsein und die damit verbundenen Erwartungen nicht statisch sind, sondern es ständige Aushandlungs- und Veränderungsprozesse gibt. Selbst wenn sich jemand als dänisch bezeichnet, bedeutet das nicht, dass es keine Veränderungen und Kontextwechsel mehr gibt. In diesem Kapitel geht es um die individuelle Bedeutung der Schule für einzelne Akteur*innen, hauptsächlich aus der Nachkriegsgeneration einerseits und die Rolle des Schulvereins für die gesamte Minderheit, ihre Ziele und Erwartungen sowie auftauchende Widersprüche andererseits. Die Erwartungen und Praxen des Dänischseins nach der Schulzeit, also in den Vereinen, werden später in den Kapitel 7 und 8 anhand des dänischen Kulturvereins SSF und der dänischen Jahresfeste behandelt.

\subsection{Die Bedeutung der Schule: positive Erlebnisse und Gefühle}

Heinrich Schmied wurde 1947 im Alter von 12 Jahren zusammen mit seinen beiden Schwestern, damals 15 und 10 Jahre alt, in die dänische Schule in Friedrichstadt eingeschult. Das war für Schmied und seine Schwestern der Beginn ihres persönlichen Dänischseins. Der älteste Schmied-Bruder war 1949 bereits 19 Jahre alt und wurde vom Arbeitsamt ins Rheinland vermittelt, um dort in der Industrie zu arbeiten. Aus diesem Grund „fand er keinen Weg zum Dänischen“ im Gegensatz zu seinen Geschwistern (Schmied 2003) ${ }^{186}$. Hier sowie im szenisch-biografischen Bericht über Sarah Iversen (Kap. 4.1) zeichnet sich bereits ab, dass der Besuch einer dänischen Schule eine entscheidende Rolle bei der Identifikation mit der dänischen Minderheit spielt und für die Aufrechterhaltung der Minderheit essenziell ist.

Der Schulbesuch ist der Dreh- und Angelpunkt für das Dänischwerden und Dänischsein, denn „Schulen [...] gehören zu den wichtigsten Institutionen des modernen Nationalstaats“ (Feischmidt 2003: 143), und sie scheinen auch für nati-

186 Hierbei handelt es sich um eine gedruckte und veröffentlichte Quelle des Interviewpartners Heinrich Schmied (INT07). Nähere bibliografische Angaben, die der Autorin dieses Textes vorliegen, würden die zugesicherte Anonymisierung des Gesprächspartners aufheben. In der vorliegenden Arbeit wird diese Literaturangabe daher stattdessen als „Schmied 2003“ geführt. 
onale Minderheiten eine entsprechend hohe Relevanz zu haben, da sie „zur Reproduktion des kulturellen Kapitals“ beitragen „sowie zum Ausbau der Beziehungen innerhalb der Gruppe“ (ebd.: 144). Die Zugehörigkeit zur Minderheit bei der Nachkriegsgeneration wird durch eine idealisierte „Erinnerungsgemeinschaft" an die Diskriminierung während des Zweiten Weltkrieges und die danach folgende gemeinsame, als Erlösung empfundene Schulzeit sowie durch „ein gemeinsames Schicksal“ gefördert, welches wie eine "Solidar- und Erfahrungsgemeinschaft" (Schmidt-Lauber 1996: 320) empfunden wird. Dabei ist die Schule „ein sinnstiftendes Element im Kontext der biographischen Selbst- und Fremdverständigung“ (Nittel 2001: 444).

Mit Rückgriff auf Maurice Halbwachs betonen auch François, Siegrist und Vogel die „zentrale Rolle [...], welche die gemeinsam geteilte Erinnerung für die emotionale Bindung des einzelnen an eine Gemeinschaft spielt" (François et al. 1995: 23). Zur geteilten Erinnerung kann der Glaube an ein ähnliches materielles und emotionales Schicksal vor der Gründung der dänischen Schule gehören, wie im Kapitel 4.1 für einige Angehörige der dänischen Minderheit dargestellt werden konnte. Die ideelle Gemeinschaft wird durch gemeinsame oder ähnliche Erlebnisse auf der Schule und in der Freizeit hergestellt (vgl. Eriksen 2002: 67). Die Schule ist „eine Sozialisationsinstanz“, weil sie ein „Stück gemeinsamer Biographie“ für Menschen schafft (Henecka, Wöhler 1978: 33, m. Rückgriff auf Durkheim).

Werner Schiffauer, der die Bedeutung der Schule bei der Integration von Immigrierten in Nationalstaaten untersuchte, hat festgestellt, dass die Schule ein zentrales Element zur Erlangung von Identifikation mit einem aufnehmenden Staat ist (vgl. Schiffauer 2002: 1). Seine Kollegin im selben Projekt, Sabine Mannitz, bestätigt im Sammelband, „Staat - Schule - Ethnizität“, dass das „öffentliche[...] Schulwesen als wichtige Sozialisationsinstanz" gilt (Mannitz 2002: 324). Schiffauer ergänzt: „Das wirkungsvollste Mittel zur Herstellung von Identifikation und Solidarität liegt dabei in der Schaffung eines nationalen Selbstbildes" (Schiffauer 2002: 8). Bei der dänischen Minderheit verhält es sich sehr ähnlich, nur dass es sich hier nicht um Immigrierte handelt, sondern um ortsansässige Kinder, die in eine andere als die öffentliche deutsche Schule gehen und dort dänisch sozialisiert werden. Die „Identifikation“ mit anderen dänischen Schüler*innen und die „Solidarität“ ${ }^{\text {‘187 }}$ unter ihnen ist relativ groß. Die dänischen Schüler*innen werden - analog zu Schiffauers Ergebnis - von einem zufälligen, aus der Not heraus geborenen Verband zu einer Art dänischer „Identitätsgemeinschaft“. Schulen, die nach einem dä-

187 Den Begriff „Gemeinsamkeits- und Solidaritäts-Empfinden“ findet man schon bei Weber, Winckelmann (2002: 530). 
nisch beeinflussten, an schleswig-holsteinische Vorgaben angepassten Lehrplan ${ }^{188}$ und einem ebensolchen Schulsystem in Südschleswig arbeiten, also Teil einer anderen, nämlich dänischen „,[s]tandardised mass education“ sind, können wie ,an extremely powerful machine for the creation of abstract identifications" (Eriksen 2002: 90) wirken. Dieses Bildungssystem ,enables a large number of people to learn, simultaneosly, which ethnic group they belong to and what are the cultural characteristics of that group“ (ebd.: 90) ${ }^{189}$ in Abgrenzung zur Sozialisation ${ }^{190}$ an deutschen Schulen.

Um die große Bedeutung der Institution Schule für die individuelle Bindung von Menschen an eine Gesinnungsminderheit nachzuweisen, werden nun die Erlebnisse und Erzählungen, also die rückblickende Selbstsicht der Nachkriegsgeneration der dänischen Minderheit dargestellt und analysiert. Die empirische Datenerhebung bestand aus Interviews mit neun Personen (vgl. Kap. 1), von denen acht nach dem Zweiten Weltkrieg in der Kleinstadt Friedrichstadt die 1946 neu gegründete Hans-Helgesen-Skole besuchten. Niemand von ihnen bezeichnete sich vorher als dänisch oder der Minderheit zugehörig.

Im hier untersuchten Sample der Nachkriegszeit erscheinen folgende Elemente für die persönliche Bindung und Zugehörigkeit zum Dänischen während des Schulbesuches zentral: Erstens werden völlig neue Erfahrungen im zwischenmenschlichen Umgang gemacht, zweitens werden Vertrauen und positive Gefühle durch gemeinsame oder besondere Erlebnisse entwickelt. Drittens tragen die allsommerlichen Kinderferienreisen nach Dänemark zu einer Bindung an das Dänische bei. ${ }^{191}$ Im Folgenden wird beschrieben, wie und durch welche Erlebnisse und Faktoren in der Schulzeit sich anhand dieser drei Elemente eine Bindung der Interviewten an die dänische Minderheit entwickelte.

188 Vgl. \ 3 der „Vedtægter for Dansk Skoleforening for Sydslesvig vedtaget af Fællesrådet den 27. maj 1997, ændret den 2. februar 2006“" (Skoleforening for Sydslesvig 2009a; Dansk Skoleforening for Sydslesvig 1990: 8).

189 Vgl. Kap. 2.2.1: Die Bezeichnung von Menschen als abgrenzbare „ethnische Gruppe“ ist nicht besonders sinnvoll.

190 Sozialisation, „describes the process through which people and especially children are made to take on the ideas and behaviour appropriate to life in a particular society. As such it describes an essentially passive process and takes for granted a theory of the person as 'an individual in society" (Toren 2006: 512).

191 Mehr zu den Kinderferienreisen nach Dänemark s. die Examensarbeit von Jensen ([2016]). Über die Sichtweise eines SSF-Funktionärs zur Bedeutung dieser Reisen für die Bindung an die dänische Minderheit und das Dänische s. Küssner (16.06.2014). 


\subsubsection{Neue Erfahrungen im zwischenmenschlichen Umgang: Vertrauen fassen durch gemeinschaftliche Erlebnisse}

Wenn es um ihre Zeit auf der dänischen Schule im Vergleich zu ihren Erfahrungen auf der deutschen Volksschule geht, dann berichten die Interviewten der Nachkriegszeit begeistert von einem ganz anderen Umgang untereinander und beispielsweise von einem „Miteinander mit den Lehrern“ (INT05). Sie heben den Respekt hervor, der ihnen von den dänischen Lehrern entgegengebracht wurde und den sie von der vorher besuchten deutschen Volksschule nicht kannten. Sönke Nissen lobt beispielsweise das Lehrer-Schüler-Verhältnis: „die Lehrer waren anders, die waren zuvorkommender. [...] Man hatte das Gefühl, man is [sic] wer als Kind und wurde irgendwie anders behandelt, [...] harmonischer" (INT05) und „intensiver“ (INT02, INT05) als auf der deutschen Schule. Man wurde ernst genommen und unterstützt (INT07). Interviewpartner Heinrich Schmied berichtet: „Wir merkten nur, dass wir plötzlich, wollen wir mal sagen, wahrgenommen wurden“ (INT07). In der dänischen Kirche und Schule „hatten wir plötzlich Pastoren und Lehrer, die uns zeigten, dass es doch auch etwas anderes gibt als $[\ldots]$ sturer [sic] Bürokratismus [...] und Obrigkeitshörigkeit“ (INT07), während er „,mit der deutschen Schule [...] keine gute Erfahrung gemacht" (INT07) habe. Auf der Hans-Helgesen-Schule wurden sie „als Kinder, die etwas lernen wollten“, „akzeptiert" ${ }^{\star 192}$ (Schmied 2003 ${ }^{193}$ ). Den Komparativ „,menschlicher“ erwähnen gleich drei Gesprächspartner*innen (INT02, INT03, INT06). ${ }^{194}$ Es habe bei den Dänen „nicht diesen Zwang ${ }^{\text {“ } 195}$ wie „,bei den Deutschen“ gegeben (INT04). Bei den Dänen „ist alles son büschen netter und 'nen büschen kameradschaftlicher“" (INT04), schwärmt Otto Clausen. Im Vergleich zur deutschen Schule war dieses Verhältnis "'nen himmelweiter Unterschied. Die Lehrer waren ja nicht, nicht die da oben, die waren eben neben uns, zwischen uns" (INT02), die haben einem geholfen, wenn man z. B. krank war und Fehltage hatte, betont Brigitte Thomsen, die vor ihrem

$192,[$, [] den danske skole blev vi taget alvorligt. Vi blev accepteret som det vi var: børn, som ville lære noget."

193 S. a. FN 186 auf S. 120

194 Vgl. auch: „Skolerne var menneskelige og retfærdige. De var alt det, som det tyske samfund ikke var.“ („Die Schulen waren menschlich und gerecht. Die waren all das, was die deutsche Gesellschaft nicht war" (Vollertsen 1994b: 155)).

195 Auf die Frage, ob er ein konkretes Beispiel dafür habe, dass es auf der deutschen Schule anders und nicht so gemütlich zugegangen sei, antwortet er, dass er das im Kontakt mit gleichaltrigen Schülern der deutschen Schule so „erlebt“ und er das ,also immer wieder gehört“ habe. „Das war auf jeden Fall gar keine Frage.“ (INT04). Er ergänzt: „Da hat man also doch 'ne Menge gehört und [...] mitgekriegt, dass [...] also sehr zwangvoll, es war zu der Zeit [...] noch strenger $[\ldots]$ an den deutschen Schulen." (INT04). 
deutschen Volksschullehrer Angst hatte (INT02). Ähnliches berichtet auch die pensionierte Flensburger Lehrerin des Skoleforeningen und gleichzeitig Schriftstellerin Karin Johannsen-Bojsen:

[D]ie Dänen [haben] eine gute Art und Weise mit den Kindern umzugehen. [...] [Sie] sind oft weniger formell, weniger steif als die Deutschen. Da gibt es oft weniger soziale Hierarchien, z. B. in Dänemark sagen alle Schulkinder , du' zu ihrem Lehrer (Johannsen-Bojsen in Paszel 2005: Anhang).

Alle haben sich geduzt, wie es in Dänemark üblich ist, so erzählt es Erik Nissen in einem informellen Gespräch. ${ }^{196}$ Er hat sich wohlgefühlt auf der Hans-Helgesen-Schule, es hat ihm dort „sehr, sehr gut gefallen“ und er hat es „sehr gut gehabt" (INT01). Ganz ähnlich empfanden es auch Frauke und Ingo Erhard (INT08/09). In Egon Clausens Buch findet man ganz ähnliche Beschreibungen der dänischen Schulzeit der Nachkriegsgeneration. Über Gerhard Tabbert wird darin berichtet, dass ,in dem Augenblick, in dem er seine Beine in die dänische Schule setzt, alles anders wurde. Es kam eine Sicherheit in sein Leben, die er nicht mit Worten beschreiben kann. Auch er und seine Familie hatte vorher mit dem Dänischen nichts zu tun (Clausen 2014: 175). ${ }^{197}$

In den Nachkriegsjahren gab es noch Diskriminierungen und deutsche Propaganda gegen die dänische Minderheit, wie beispielsweise schikanierende antidänische „Schmierereien“ an dänischen Gebäuden und „Speckdänen“-Beschimpfungen (Klatt 2009b: 221, 222-223). Einige der Interviewten berichten ebenfalls von dieser Kehrseite der Medaille, dass sie ,natürlich auch ab und an mal gehänselt" (INT04) wurden von Schüler*innen der deutschen Schulen oder dass sie zu ihnen „körperlichen Kontakt in Form von Kämpfen“ (INT01) hatten und auf ihrem Schulweg ,gegen den Strom“ der deutschen Schüler*innen laufen mussten und als „Speckdänen“ (INT01) ${ }^{198}$ und „dumm“ (INT07) beschimpft wurden. Eine Gesprächspartnerin berichtet, dass ihre Freundin und sie, weil sie auf der dänischen Schule waren, beim Tanzkurs im Gegensatz zu den Mädchen der deutschen Schule gezielt nur „die blödesten Jungs“ (INT02) abbekamen. Birte Kohrts beschreibt die Trennung zwischen Mehrheit und Minderheit in der Nachkriegszeit:

Es ist nicht mehr so eine starke Abgrenzung zwischen den beiden Bevölkerungsschichten, wo man sich damals, als ich Kind war, sich viel-

\footnotetext{
196 Vgl. zur Bedeutung des Duzens S. 325 d. vorl. Arbeit.

197 Vgl. a. den Konversionsaspekt in Kapitel 8.7.

198 „Diesen Speckdänenruf da, den ham wir schon des öfteren hör'n müssen, nä, aber wir sind keine Speckdänen, wir sind ja nicht wegen der Pakete drangeblieben, sondern weil uns das so gefall'n hat, das Land und Leute und so" (INT01; vgl. Sydslesvigsk Forening 2000: 3).
} 
mehr abgegrenzt hat. Und man spielte fast nur mit den Kindern aus der Schule (Kohrts in Werner 16.05.2016).

Die Lehrer*innen haben sich „einfach Zeit genommen“ (INT01) und eine gewisse „Gemütlichkeit“ (INT01, INT04), und „Geborgenheit“ (INT01) im zwischenmenschlichen Verhältnis geschaffen. Otto Clausen ergänzt: „Also der Däne sagt hyggelig dazu und das ist es auch“ (INT04). ${ }^{199}$ Das Ergebnis der dänischen Historikerin Marianne Brink Jensen stimmt mit diesen Aussagen überein. Jensens Gewährspersonen berichten ebenfalls über einen anderen Umgang von Erwachsenen mit Kindern im Königreich Dänemark im Vergleich zum Nachkriegssüdschleswig:

Der Aufenthalt nach dem Zweiten Weltkrieg bedeutete für das südschleswigsche Kind kurzfristig eine Möglichkeit den Nachkriegsnachwirkungen und den autoritären Erwachsenen zu entkommen. In Dänemark

199 Zum Aspekt der bygge muss Folgendes erläutert werden: Die beiden Abiturient*innen des Jahres 2016 der A.-P.-Møller-Schule in Schleswig, Stine und Markus, betonen ebenso bygge: „Also in der dänischen Kultur, finde ich, ist das Wichtigste dieses, das gibt ein Wort, das ist bygge, das ist son bisschen gemütlich, aber man findet nicht wirklich die perfekte Übersetzung dafür und es ist einfach so gemütlich, dieser Zusammenhalt, der denn dadurch entsteht" (Abiturient Markus in Werner 16.05.2016). Seine Mitschülerin Stine ergänzt: „Dieses bygge, das kann man einfach nicht übersetzen, das ist son ganz bestimmtes Gefühl, ob’s jetzt Familie, Freunde oder ob man für sich selbst einfach was Gutes tut, das ist einfach .. es füllt einen mit Wärme, Glück. Ich weiß nicht, wie Schokolade, irgendwie sowas dazwischen. Das ist wirklich für mich ganz, ganz, ganz, 'n ganz tolles Gefühl" (Abiturientin Stine in ebd.). Die beiden Abiturient*innen bedienen sich des immer wiederkehrenden Klischees des Dänischen. Sie behaupten, hygge, Gemütlichkeit, könne man nicht ins Deutsche übersetzen. Diese Behauptung ist ein stereotyper Ausdruck des Nichtübersetzen-Wollens zur Abgrenzung von nichtdänischen Menschen, was wiederum Zusammenhalt und Zugehörigkeit fördert. Auch für das deutsche Wort ,gemütlich' wird postuliert, dass es unübersetzbar sei und jede Übersetzung nur einen Teil des Begriffsumfanges erfasse und dass es als spezifisch deutsch angesehen werde. So beschreibt Schmidt-Lauber diese allgemein verbreitete Vorstellung (Schmidt-Lauber 2003: 170-171). Die gleiche „Einzigartigkeit eines Schlüsselbegriff im Umfeld der Gemütlichkeit beanspruchen auch andere Sprachen und Kulturen für sich“ (ebd.: 171), so eben auch die Dänen mit bygge und byggelig, was diese Begriffsbedeutungszuschreibungen als Konstrukt entlarven. Schmidt-Lauber arbeitet weiterhin heraus, dass in Deutschland im 19. Jahrhundert der Begriff Gemütlichkeit zur „Konstruktion nationaler Identität" beitrug (ebd.: 151). Später wurde das Konzept erneut für die Schaffung von deutschem, nationalem "Zusammenhalt" und für ,nationale Integration und nationale Gesinnung" verwendet (ebd.: 151). Gemütlichkeit dient auch zur Abgrenzung von der bedrohlichen, komplexen Welt und bietet Sicherheit (vgl. ebd.: 61-63), was auch für Neudän*innen eine Rolle bei der Minderheitskonstruktion spielt (s. Kap. 8.7). Durch den auf der dänischen Schule geschaffenen Zusammenhalt werden „[d] urch soziale Interaktionen [...] Gefühle aufrechterhalten und Beziehungen gefestigt" die laut Subkulturtheorie der Konversionsforschung dazu führen, dass die Akteur*innen „Einflüssen von außen zu widerstehen in der Lage“ sind (Wohlrab-Sahr et al. 1998: 12). Andersherum ist von diesem äußeren Druck auch der innere Zusammenhalt einer Gruppe abhängig (Eriksen 2005: 165 ", m. Rückgriff auf Simmel;" 168-169). 
machten vielen Bekanntschaft mit einem entspannteren Verhältnis zwischen Kindern und Erwachsenen (Jensen [2016]: 76). ${ }^{200}$

Einige Gesprächspartner*innen berichten von den Vorteilen, die es aus ihrer Sicht in der dänischen Schule gab und durch die sie sich gegenüber nichtdänischen Schüler*innen abgrenzten: Die Klassen seien kleiner und die Betreuung durch die Lehrer*innen viel besser gewesen (INT02, INT04). „Wenn Kinder Probleme hatten [...], da ist ja immer geholfen worden, da hat man nie gesagt ,Friß Vogel oder stirb!' [...], sondern es [...] gab immer freiwillige Lehrer, die dann Nachhilfeunterricht gemacht haben in der Schule“ (INT04). Zum guten LehrerSchüler-Verhältnis trug außerdem entscheidend bei, dass die Lehrer*innen aus Dänemark kamen und somit erstens kaum mit menschenverachtendem nationalsozialistischem Denken belastet waren und sie zweitens eine andere Ausbildung durchlaufen hatten, die auf dem „Grundtvigschen Gedanken, dass nur ein dummer Bürger 'n gefährlicher Bürger ist, und dass Bildung auch unten [in die unteren sozialen Schichten] hin muss" ${ }^{\text {"201 }}$ (INT07), beruhte. Die antiautoritärer und „kindgerechte[r]“ (Johannsen-Bojsen in Paszel 2005: Anhang) ausgebildeten Lehrer*innen waren „,mehr Pädagogen und haben weniger auf die Gesellschaft geguckt, also woher du kamst“" (INT07). Die geringe Bedeutung des sozialen Status der Eltern und die daraus resultierende Gleichbehandlung aller Schüler*innen hebt auch Brigitte Thomsen als positiv im Vergleich zur deutschen Schule hervor (INT02). Brigitte Thomsen und Erik Nissen sind überzeugt davon, dass die dänische Schule für sie viel besser war und es immer noch ist als die deutsche Schule (INT02). Diese Abgrenzung zur deutschen Schule ist wichtig für die Identitätsbildung und für die rechtfertigende Erklärung des eigenen Lebensweges. Beim Vergleich der neuen dänischen mit der alten deutschen Schule ist zu beachten, dass dieser subjektiv ist und keine*r der Interviewten beide Schulen gleichzeitig besucht hat. ${ }^{202}$ Erik Nissen glaubt, dass die dänische Alternative in Südschleswig besser für ihn gewesen sei (INT01), da ihm „das Dänische [...] sehr gelegen“ habe, dass er es auf der dänischen Schule „doch sehr gut gehabt hat“ (INT01), obwohl er keinen direkten Vergleich mit deutschen Schulen gemacht hatte. Er

200 „Selve opholdet efter Anden Verdenskrig gav på kort sigt et sydslesvigsk barn en mulighed for at slippe væk fra efterkrigsdønninger og autoritære voksne. I Danmark fik mange af dem kendskab til et mere afslappet forhold mellem børn og voksne.“

201 Nikolai Frederik Severin Grundtvig $(1783$ - 1872) war ein dänischer Theologe, Schriftsteller, Philosoph, Politiker, Historiker, Vertreter der Aufklärung und Verfechter des Humanismus. Er sammelte Psalmen und prägte entscheidend die dänische Gesellschaft. Er trat für eine Bildung für alle ein und konzipierte das skandinavische (Heim-)Volkshochschulsystem (vgl. a. Andresén 2000).

202 Deshalb kann und soll in dieser Arbeit nicht versucht werden, dänische und deutsche Schulen objektiv zu vergleichen bzw. herauszufinden, wie die Schüler deutscher Schulen ihre Schulzeit empfunden haben. Sicherlich fanden einige Jahre nach Kriegsende auch auf deutschen Schulen pädagogische Neuerungen statt. 
betont die umfangreiche Betreuung, die es auch außerhalb der Schule im dänischen Sportverein, im Jugendverein ${ }^{203}$ und in der dänischen Pfadfindergruppe ${ }^{204}$ gab. Heute als Rentner freut er sich im Nachhinein, dass er das Dänische in Friedrichstadt „so erleben durfte“. Er hat „da sehr viel Spaß dran gehabt und immer noch“, er ist sich dessen bewusst, dass „das was Besonderes“ (INT01) war, die Möglichkeit, dänische Alternativen zu deutschen Institutionen nutzen zu können. Auch Frieda Theben hatte der Umgang mit den Lehrer*innen und den anderen Schüler*innen auf der dänischen Schule so gut gefallen, dass sie ihrem aus dem Krieg zurückgekehrten Vater, der über Friedas mittlerweise erfolgte dänische Einschulung ,entrüstet, schwer entrüstet“ war, gar mit Selbstmord drohte, falls er sie in die deutsche Schule schicken würde: „Dann gehe ich in den Burgwall, dann er-

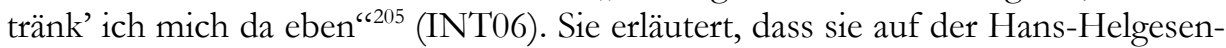
Schule ,schon Fuß gefasst" hatte (INT06) und keinen Schulwechsel wollte.

Nicht nur Sarah Iversen (s. Kap. 4.1) sieht im Besuch der dänischen Schulen den Anfang einer neuen Alltagswelt für sich selbst. Auch Rosemarie Tüchsen ${ }^{206}$ aus St. Peter-Ording sieht ihren dänischen Schulbesuch und die Entscheidung ihres Vaters für die dänische Minderheit als ungemein positiv für ihr persönliches Leben: „Rosi ist ihrem Vater bis heute dankbar für seine Entscheidung, denn für sie eröffnete sich dadurch eine völlig neue Welt.“ (Werner 16.05.2016). Ihr Vater entschied sich für das Dänischsein 1947, so berichtet Rosemarie:

Ich kam, wann war das, 47 kamen wir in die dänische Schule. Ja, mein Vater sprach Dänisch, war im Krieg gewesen, hatte die Nase voll von diesem ganzen Kram und sagte ,nie wieder' und ,jetzt gehen wir rüber ins Dänische' (Tüchsen in ebd.).

Die Konsequenz aus der Entscheidung ihres Vaters hebt Rosemarie mit Dankbarkeit hervor:

Wenn ich in der deutschen Schule geblieben wär', dann wär' ich rausgegangen nach der 8., 9. und denn beim Bauern ... anderes gabs ja nicht. Und das wollte ich nicht. Ich wollte keine Kühe melken. Das heißt, wenn ich nicht hier in die dänische Schule gekommen wäre, dann wär aus mir nichts Besonderes geworden. Das war damals so. Mein Vater

\footnotetext{
203 Ungdomsforeningen, eigentlich Sydslesvigs danske Ungdomsforeninger, SdU. S. Kap. 3.2.4. Hier ist die pfadfinderähnliche Organisation FDF, Frivilligt Drenge Forbund (Freiwilliger Jungenverband) gemeint, der heute Frivilligt Drenge- og Pige-Forbund (Freiwilliger Jungen- und Mädchenverband) heißt.

205 Der Burgwall ist eine Gracht, das heißt ein städtischer Wasserkanal in Friedrichstadt.

206 Name nicht geändert, weil es sich hierbei um veröffentlichte Aussagen handelt.
} 
war Arbeiter. Wir waren sechs Kinder und denn das war ja unerhört überhaupt, das 'ne Arbeitertochter ins, auf die Mittelschule ging. Was glauben Sie, was die da geredet haben im Dorf (Tüchsen in ebd.).

Dieses Zitat deutet ein anderes Menschenbild an dänischen Schulen an. Ein Vorstandsmitglied des dänischen Büchereivereins, Bjarne Troelsen ${ }^{207}$, konkretisiert das für ihn dänische Prinzip, dass ,nach dänischem Muster Bildung und Bücher überall für jeden zugänglich sind" (Troelsen in ebd.). Dänischsein bedeutet für Rosemarie Tüchsen, ehemalige Lehrerin an der mittlerweile geschlossenen dänischen Schule in St. Peter-Ording, genau dieser leichte Zugang zu Büchern in der Nachkriegszeit, den es, so impliziert ihre Aussage, an deutschen Schulen nicht gegeben habe: „Ich war sonne richtige Leseratte und in den dänischen Schulen gabs ja Bücher" (ebd.).

Durch das Leben in der dänischen Minderheit und aufgrund des dortigen, aus ihrer Sicht egalitäreren Menschenbildes wurden Rosemarie neue Möglichkeiten eröffnet, die sie in einem deutschen Leben nicht erwartet hätte. Sie ist schließlich Lehrerin statt Melkerin oder Bäuerin geworden.

Der Zusammenhalt der Dänischgewordenen und ihre Solidarität untereinander kann ein Leben lang halten. Küpers und Weibler betonen mit Rückgriff auf Simmel, dass „Emotionen die Individuen aneinander binden und die Gesellschaft durch unzählige Interaktionen konstituieren“ (Küpers, Weibler 2005: 65). Dabei gilt, dass die Art und Intensität der Zugehörigkeit bei den einzelnen Akteur*innenn stark variieren kann (Kühl 2004: 326). Diese Emotionen aber sind das, was die Gruppe der dänischen Minderheit ihren Angehörigen bietet, damit diese Solidarität und Loyalität gegenüber Gleichgesinnten zeigen (Eriksen 2003: 168; Hansen 1995b: 546; vgl. Beck-Gernsheim 2004: 36). Beispielsweise empfindet Brigitte Thomsen den Besuch der dänischen Schule mit den damit verbunden Erlebnissen und Kontakten nach Dänemark als den Grundstein für ihr Dänischsein. ${ }^{208} \mathrm{Ihr}$ verstorbener Ehemann dagegen hat sich nach dem Besuch der dänischen Schule von der Minderheit abgewandt, weil er „offenbar nicht so tiefe Wurzeln da gehabt" hat, so Brigitte, da er erst mit elf Jahren und nicht wie seine Frau mit acht Jahren auf die dänische Schule gewechselt war und seine dänische Schulzeit deshalb kürzer war als ihre (INT02). Ein ähnliches Phänomen vermutet auch Johannsen-Bojsen im Interview mit Paszel: Bei Kindern, die bei Eintritt in die dänische Schule schon etwas älter waren, konnte sich das Dänische ,nicht mehr so

Name nicht geändert, weil es sich hierbei um veröffentlichte Aussagen handelt.

Marianne Brink Jensen hat in ihrer Examensarbeit ebenfalls herausgearbeitet, dass die ,guten Erlebnisse" („De gode oplvelser") bei den Auftenhalten in den Pflegefamilien überwogen und bis in das Erwachsenenalter in guter Erinnerung blieben und die negativen Erlebnisse verdrängt wurden (Jensen [2016]: 33-40). Im Vergleich zur damaligen materiellen, emotionalen und gesellschaftlichen Situation in Südschleswig erschienen die Ferienaufenthalte für die meisten paradiesisch. 
durchsetzen“" wie bei den Jüngeren (Johannsen-Bojsen in Paszel 2005: Anhang). ${ }^{209}$ Die meisten derjenigen, die die dänische Schule gar nicht besucht haben, sind nicht dänisch geworden, denn, so auch Johannsen-Bojsen, „die dänische Schule [...] [ist] die entscheidende Stelle, wo die Weichen gestellt werden, ob man dänisch wird oder deutsch bleibt.“ Sie fügt hinzu: „Die dänische Schule spielt eine enorme Rolle“ auch für die weitere Biografie (Johannsen-Bojsen in ebd.: Anhang). Dies bestätigt auch die Aussage Max Webers: „Gemeinschaften können [...] Gemeinsamkeitsgefühle erzeugen, welche dann dauernd, auch nach dem Verschwinden der Gemeinschaft, bestehen bleiben und als ,ethnisch' empfunden werden." (Weber, Winckelmann 1972 dieser Ausgabe, sonst: 1921/22: 238). Das gelte besonders für Sprachgemeinschaften (ebd.: 238).

Die oben geschilderte gute Atmosphäre schafft, nach anfänglichen sprachlichen Schwierigkeiten, die Basis für das „Vertrauen“ (INT03, INT05), welches die Schüler*innen ihren Lehrer*innen allmählich entgegenbringen, wie es im Fallbeispiel Sarah Iversen schon geschildert wurde. Dabei hört es sich bei Sarah so an, als sei dieser Prozess der Vertrauensbildung relativ schnell gegangen, obwohl sich Vertrauen meist nur ,in einem längeren Wahrnehmungs- und Sozialisationsprozeß“' bildet, so die Historikerin Ute Frevert (2000: 183). Sarahs Situation war vor dem Wechsel zur dänischen Schule emotional so ausweglos, dass sie aus großer Not heraus zu den aus ihrer Sicht besonders netten Pädagog*innen aus Dänemark ungewöhnlich schnell Vertrauen aufbaute.

Sarah spricht häufig von „Gefühlen“, die mit diesem neuen Vertrauen und den Erlebnissen auf der dänischen Schule zusammenhängen. Frevert geht von „Vertrauen als einer Gefühlshaltung“ (ebd.: 183) aus. Gerade „Gefühlen [kommt] in Organisationen eine zentrale motivationale, verhaltensorganisierende sowie energetisierende Funktion zu“ (Küpers, Weibler 2005: 80). Deshalb sind die erlebten Gefühle so wichtig für die subjektive Bindung an die dänische Minderheit. Diese Subjektivität ist, wie durch die Bekenntnis- und Gesinnungsfreiheit der Bonn-Kopenhagener-Erklärung geregelt, die Basis der Minderheit. Das Bekenntnis zum Dänischsein beruht also auf einem Zugehörigkeitsgefühl, welches primär durch Erlebnisse und damit verbundene positive Erfahrungen in der Schule und in den personell mit der Schule stark verflochtenen Vereinen geschaffen wird. Denn vor

209 In dieser Arbeit werden immer wieder Analogien vom Minderheitenwerden und -sein zur Identifikation mit und dem Praktizieren von Religion gezogen, so auch bei der Aneignung des Dänischseins im Vergleich zur Aneignung von Religion. Denn auch Theologen und Religionspädagogen betonen die Wichtigkeit der frühen Aneignung von Religion, Glauben und Sozialisation für die Einbindung von Menschen in eine religiöse Gemeinschaft, so z. B. Michael Meyer-

Blanck und Birgit Weyel (Meyer-Blanck, Weyel 2008: 31, 33, 176). 
dem Schulbesuch hatten die Familien der Interviewpartner*innen, wie in der Einleitung schon betont, keine Verknüpfung zur dänischen Minderheit (vgl. Skovmand 2006: 8; vgl. a. S. 96).

Zur Schaffung des Minderheitenselbstbildes und des Zusammenhaltes dienen die gemeinsamen Erfahrungen, die die Schüler*innen der dänischen Schule gemacht haben. Heinrich Schmied beurteilt „die Erlebnisse, die wir gehabt haben“ als wichtig für das Zugehörigkeitsgefühl zur dänischen Minderheit (INT07). Davon waren „das allerschönste" die Spiele und Unternehmungen im Freiwilligen Jungenverband FDF (INT07), von denen auch schon Erik Nissen (INT01) berichtete. Da war ein Lehrer, „ein hundertprozentiger Pädagoge“ (INT07), der hatte sich für eine Jugendgruppenfahrt auf die dänische Insel Seeland mehrere Aktionen ausgedacht:

Dann saßen wir da bei Kerzenlicht, dann ging das Fenster auf, dann fiel 'ne Flasche rein. Botschaft von der schwarzen Hand und dann waren wir unterwegs. [Oder] vor unseren Augen wurde da von Fischern 'nen Junge von uns entführt, war inszeniert, nä, und denn mussten wir ja raus und suchen, nä, nachts (INT07).

Diese Art von „Schlüsselerlebnisse[n]“ habe, so Heinrich Schmied, den „Zusammenhalt" und das Gruppengefühl zwischen den Jungen der dänischen Minderheit geprägt. In ähnlicher Weise schreibt Arthur Christiansen, dass der durch Erlebnisse geschaffene „Glaube an Gemeinsamkeit [...] von den Mitgliedern der dänischen Minderheit als Zuordnungsmerkmal [...] verinnerlicht" wird (Christiansen 2008: 231). Dieses Phänomen kann als „,spielerisch erzeugte[...] Gruppenidentität“" (Kaschuba 1995: 299) bezeichnet werden. Diese kann zu einer „,nationale[n] Selbstvergewisserung im Gefühl der Gemeinschaft" (ebd.: 299) führen, wie es in Schmieds Fall zutrifft.

Neben der inneren Bindung an die Minderheit durch Erlebnisse, Sozialisation und Emotionen gibt es auch noch eine Abgrenzung nach außen, erstens aufgrund von praktischen Ursachen: Man geht auf eine andere Schule als die Schüler der deutschen Volksschule und macht andere gemeinschaftliche Erlebnisse. Ein Interviewpartner konkretisiert es folgendermaßen: Bei den deutschen Schülern war das ,nicht so, nicht so, die haben nicht das erlebt, was wir erlebt haben. Es wurde ja [bei uns] auch sehr viel gemacht, also auch neben der Schule dann, dass man auch so Ausflüge machte und diese Sachen“ (INT04). 
Zweitens gibt es eine Abgrenzung durch Diskriminierung seitens der „deutschen" Gesellschaft. Dazu finden sich als Beispiele die Beschimpfungen als „Speckdäne“ (Kirsten Krienke in Svensson 1974: 19) ${ }^{210}$ und „Landesverräter “20211 (Schrøder 1995: 153). Nils Vollertsen, südschleswigscher Historiker, zitiert einen Zeitzeugen folgendermaßen: „Als ich von der deutschen auf die dänische Schule wechselte, verlor ich mit einem Schlag alle meine Schulkameraden. Keiner grüßte mich mehr ${ }^{\text {‘212 }}$ und kommentiert dies so: „Wenn man zur dänischen Bewegung gehörte, schloss die deutsche Gesellschaft einen aus“"213 (Vollertsen 1994a: 32). Sarah Iversen und Sönke Nissen können sich nicht an Beschimpfungen erinnern oder haben diese Form von „Fremddefinition“ (Hansen 1995a: 153) damals entweder nicht wahrgenommen oder im Laufe ihres Lebens verdrängt oder akzeptiert: „Sicherlich war das so, aber das hab ich nicht gemerkt, ich war so voll im Wohlfühlen“ (INT03). Mit negativen Erlebnissen kann sie „nicht mit dienen, aber das liegt vielleicht auch, deswegen hab ich mein Vorleben auch 'nen bisschen erwähnt, dass ich jetzt so euphorisch [bin], liegt an meiner Kindheit: Ich hatte keine" (INT03). An negative Erlebnisse auf der dänischen Schule, wie ungerechte Lehrer*innen oder mobbende Mitschüler*innen, kann Sönke Nissen sich ebenfalls nicht erinnern: „Ich glaub' nicht, dat irgendwann mal irgendwat Schlechtes gewesen ist" (INT05). Sönke Nissen gerät auch ins Schwärmen beim Gedanken an seine Schulzeit: „Die Dänenschule war ganz toll“ und „schön“, diese beiden Adjektive fallen sehr häufig im Interview. Rückblickend fasst er zusammen, dass er „dieser dänischen Schule viel zu verdanken" hat (INT05).

Der Grund für diese Diskriminierungen und Stigmatisierungen durch einen Teil der Mehrheitsgesellschaft könnte die Tatsache sein, dass „das Minderheitenschulwesen aufrecht erhalten“" wurde (Sigaard-Madsen 1995: 140).

[Ö]ffentliche Schulen wurden indes von der britischen Militärregierung geschlossen, SF-Mitglieder wurden durch Lebensmittel aus Dänemark unterstützt. Bei der deutschen Bevölkerung erzeugte diese Situation $\mathrm{Haß}$ und Verbitterung (ebd.: 140).

Die den Beschimpfungen zugrunde liegenden Vorurteile, wie das „Speckdänen“Stereotyp, werden erklärt, aber nicht gerechtfertigt dadurch, dass durch sie „das Aushalten gesellschaftl., sozialer, ökonom. u. rechtl. Ungleichbehandlungen in ei-

\footnotetext{
210 Vgl. a. Sydslesvigsk Forening (2000: 3); Danker (05.08.2006: 4); Schrøder (1995: 146); Vollertsen (1994a: 32); Klatt (2009b: 190). „landsforræderne“ (vgl. a. Klatt 2009b: 186)

${ }^{212}$ „,da jeg skiftede fra tysk til dansk skole [...], mistede jeg med ét alle mine kammerater. Ingen hilste på mig mere.“

213 „Når man hørte til den danske bevægelse, lukkede det tyske samfund én ude.“
} 
ner Gesellschaft“ (Hansen 1997: 197) erleichtert wird. Sie dienen „Ein- und Ausgrenzungen“ sowie „der Orientierung in unübersichtlichen Situationen und Verhältnissen" (Hansen 1995b: 546). Für diejeningen, die nach dem Krieg Südschleswiger*innen diskriminiert haben, könnten Vorurteile „einen symbolischen Wert in Gestalt von ,Selbstwertgefühlserhalt" haben“" (ebd.: 547). Das gilt gerade dann, wenn Neid und Missgunst aufgrund dänischer Hilfe eine Rolle spielten. Trotz einiger Beschimpfungen überwiegen aber die positiven Emotionen bei den Interviewten. Trotz allem ,hatten wir das Gefühl, wir haben es gut gehabt bei den Dänen“, sagt beispielsweise Otto Clausen zusammenfassend (INT04). Sarah Iversen verwendet im Interview das Wort „Gefühle“ zwölfmal. Es fallen damit einhergehend und in Bezug auf die Minderheit Stichwörter wie Herzenssache, Gefühlssache, dreimal der Begriff Wohlfühlen, sechsmal der Ausdruck Liebe zum Dänischen, „zur dänischen Sache“ und zu Dänemark (INT03).

Das geschilderte Spektrum an positiven Erlebnissen kann zu einer Veränderung der „Identität“ führen, wie Thomas Hylland Eriksen schreibt: „[S]ocial identities are relational“. Und: ,[T]here is a close relationship between identities and social circumstances. Identities may change as society changes" (Eriksen 2002: 62). Die Identifizierung mit der Minderheit kann durch soziale Umstände und in einem neuen Umfeld erzeugte Gefühle verändert werden. Diese Änderungen können nicht nur beim Dänischwerden, also dem Wechsel von Zugehörigkeiten, sondern auch bei Prozessen von Migration, zu denen Parallelen gezogen werden können, beobachtet werden. Die Migration bei den interviewten dänischgesinnten Akteur*innen gestaltet sich im Gegensatz zur Migration im klassischen Sinne eher kulturell und sozial und nicht räumlich im Sinne eines „neuen Wohn- und Lebensort[es]“ (Schmidt-Lauber 2007a: 8). Die Gesprächspartner*innen blieben am gleichen Wohnort ansässig, wechselten mit ihrer dänischen Einschulung lediglich das Schulgebäude und ihr soziales Schul- und Freizeitumfeld sowie ihre Sozialisationswelt und erlernten eine zweite Sprache. Sie begannen in ihren Augen ein neues Leben. Wesentlich bei diesem Migrationsprozess ist, wie Sarah Iversens Beispiel zeigt, die Verfolgung des allgemeinen Ziels der „Verbesserung der Lebensbedingungen" (Borkert et al. 2006: o. S.). Die Habilitationsschrift Brigitte Bönisch-Brednichs (Bönisch-Brednich 2002) zur Migrations- und Erzählforschung legt dar,

dass es offenbar für Auswanderer kaum möglich ist, eine als erfolgreich empfundene Lebensgeschichte ohne beständiges Vergleichen zwischen den differierenden Epochen des Lebens - die Zeit vor und nach der Migration - zu reflektieren. Allgemeiner gesagt gilt: Neben dem Schicksalsvergleich des eigenen Lebens mit dem Leben anderer ist es zur Identitätsbildung unerlässlich, Epochen und Übergänge in der eigenen Biographie festzulegen. Bei Migrationsvorgängen, bei lebensgeschichtlich gravierenden Krankheiten, bei „Partnerwechsel“ oder Scheidung, 
Berufswechsel und bedeutsamen Todesfällen drängt sich ein Ereignis oder eine Erfahrung so eindrucksstark ins Bewusstsein, dass die Epochenbildung auf Grund eigener Bewertung und auf Grund kultureller Vorgaben quasi „von allein“ entsteht (Lehmann 2007: 195 über Bönisch-Brednich).

Die Unterteilung in ein Vorher und ein Nachher beim Erzählen von Migrations prozessen oder anderen einschneidenden biografischen Ereignissen (vgl. ebd.: 195) kommt in unterschiedlicher Ausprägung auch beim Gesinnungswechsel der in der vorliegenden Arbeit interviewten Akteur*innen vor. Sie werden dänisch und bewerten diesen Umbruch als eine Art Neubeginn und drücken das beispielsweise mit dem Wort „Geburt“ (INT03) aus und „[t]heorisieren“ dies mit den damals vorherrschenden sozialen Verhältnissen (Lehmann 1980: 63-65). Die meisten Interviewten vergleichen sich mit denjenigen, die deutsche Schulen besucht haben. Einige grenzen ihr Leben vor dem Eintritt in das Dänischsein von ihrer heutigen Situation ab. Das sind Kennzeichen von Migrationsprozessen, wie sie aus der kulturanthropologischen Erzählforschung bekannt sind (vgl. Lehmann 2007: 197). Man kann die beschriebenen Prozesse auch mit einer religiösen Konversion vergleichen, welche in Kapitel 8.7 genauer beschrieben wird.

Für die meisten Interviewpartner*innen wurde durch den Besuch der dänischen Schule und ihre Sozialisation die allerwichtigste Grundlage für das Zugehörigkeitsgefühl zur dänischen Minderheit, für die dänische Gesinnung geschaffen. Heinrich Schmied geht sogar so weit zu sagen, dass einige Familien „durch die Kinder hier [auf der dänischen Schule], praktisch dänisch geworden sind, gesonnen sind“ (INT07). Dazu hat die dänische Schule „das Wesentliche gegeben“ (INT07), aber es kann auch „andere Gründe [geben], dass einige dänisch gesonnen sind“", z. B. der familiäre Einfluss von Ehepartner*innen (INT07). Einige Interviewpartner*innen betonen, dass der gute Kontakt zu den dänischen Lehrer*innen sogar in ihrer Freizeit bestand: „Wunderschön, wir hatten Lehrer rund um die Uhr.“ (INT01). „Wir haben überhaupt nicht gewusst, das da ja auch mal Feierabend war, wenn unser Herz was bewegte, dann klingelten wir" (INT06) bei den Lehrer*innen und „es war eine wunderschöne Zeit“ (INT06) dort auf der dänischen Schule. Sönke Nissen hatte auf einer persönlichen Ebene „ein tolles Verhältnis“ zu seinem Klassenlehrer, „da bin ich gekommen, wie Sohn im Haus“ (INT05), das wäre auf der deutschen Schule undenkbar gewesen, so Sönke. Diesem Lehrer hat er sogar beim Umzug geholfen, und er konnte sich bei ihm auch privat Rat holen (INT05). 


\subsubsection{Die Schulwahl der Kinder der Nachkriegsdän*innen}

Alle Interviewpartner*innen und ihre Familien der Nachkriegsgeneration haben Kinder bekommen. Dieser Abschnitt geht der Frage nach, ob diese eine dänische Schule besucht haben und warum viele im Gegensatz zu ihren Eltern deutsch eingeschult wurden. Die Perspektive der Interviewten auf die Schulwahl ihrer eigenen Kinder ist deshalb besonders interessant, weil hierbei eine kritischere und weniger verklärte Haltung zur dänischen Schule erkennbar ist als bei der Erzählung über die eigene Schulzeit.

Alle acht Familien der neun Gesprächspartner*innen hatten bei der Wahl zwischen deutscher und dänischer Schule für ihre Kinder erneut einen Anlass, sich mit ihrem persönlichen Dänischsein auseinanderzusetzen. ${ }^{214}$ Sechs Familien haben ihre Kinder deutsch eingeschult, zwei Familien haben sich für eine dänische Schullaufbahn entschieden. Fragt man erstere nach ihren Gründen dafür, dass ihre Kinder nicht wie sie selbst eine dänische Schule besucht haben, stellt sich heraus, dass es zwei Gruppen mit verschiedenen Ansichten gibt, die im Folgenden beschrieben werden. Anschließend wird die dritte Gruppe präsentiert, zu der diejenigen gehören, die ihre Kinder dänisch eingeschult haben.

Die Vertreter*innen der ersten Gruppe (INT01, INT05, INT06, INT08, INT09) begründen die Wahl der deutschen Schule für ihre Kinder rückblickend damit, dass sie zum einen selbst eigentlich deutsch seien, zum anderen ihre Umgebung deutsch sei und sie deshalb keinen Anlass gehabt hätten, eine dänische Schule für ihre Kinder zu wählen. Sie befürchteten außerdem Nachteile für ihre Kinder in einer deutschen Gesellschaft, wenn diese eine dänische Schule besucht hätten. Der Ruf der dänischen Schulen auf dem Land war nicht besonders gut. In den 1960er- und 1970er-Jahren ,,war die Zeit noch wirklich so, wie es heute nicht mehr ist, wenn man dann sich hier 'ne Stellung suchte, im öffentlichen Dienst und so weiter, da wurde [sic] [...] Unterschiede gemacht" (INT07) zwischen dänischen und deutschen Schulabschlüssen.

Der Widerspruch zwischen der Begeisterung der Interviewten für die dänische Schule und den Befürchtungen, die eigenen Kinder auf dieselbe Schule zu schicken, lässt sich wahrscheinlich auf die Tatsache zurückführen, dass nach dem Krieg besonders viele arme, sozial benachteiligte oder gesellschaftlich am Rande stehende Familien vom Angebot der dänischen Institutionen wegen ihrer eigenen Notlage Gebrauch machten. Für die Eltern und die Kinder bestand aber im Gegensatz zur Nachkriegsgeneration dann in den 1960er Jahren nach dem sogenannten Wirtschaftswunder keine materielle oder soziale Notwendigkeit mehr, ${ }^{215}$

214 In einigen Familien kam diese Frage schon mit der Wahl des Kindergarten auf (z. B. INT01).

Nicht alle haben diesen Anlass genutzt, um sich intensiv mit der Frage ihres persönlichen Dänischseins auseinanderzusetzen.

215 Frauke Erhard erzählt im Interview, ,dass die Zeit damals anders war [...] und deswegen haben wir das mit unseren Kindern 'n bisschen anders gemacht“ (INT09). 
sich dem Dänischen zuzuwenden bzw. dänisch zu bleiben. Sie waren nicht mehr arm oder benachteiligt und wollten daher verhindern, dass ihren Kinder Nachteile aufgrund des dänischen Schulbesuchs entstehen könnten. Wie bewusst diese Entscheidung für ihre Kinder getroffen wurde, lässt sich im Nachhinein nur schwer rekonstruieren. Einige betonen aber, dass sich die Wahl der deutschen Schule durch äußere Umstände ergeben habe und auf keiner ausführlichen Auseinandersetzung mit dieser Frage beruhe. Einem Interviewpartner, Erik Nissen, und seiner Ehefrau war es vermutlich nicht so wichtig, dass ihre Kinder die dänische Schule besuchten, denn aufgrund von persönlichen Differenzen mit einer Kindergartenangestellten schickten sie den dort angemeldeten Sohn nach kurzer Zeit in den deutschen Kindergarten. Damit war für sie die Frage der Schulwahl, auch für ihr zweites Kind erledigt. Eine andere Interviewte berichtet zu diesem Thema, dass sie sich damals bewusst gegen eine dänische Einschulung ihrer Kinder entschieden habe. Sie meint: „[W]enn die [Kinder] in Deutschland was werden wollen“ (INT06), dann wäre dies keine gute Lösung gewesen. Auch fand sie die organisatorischen Bedingungen für diejenigen Kinder, die auf dem damals einzigen dänischen Gymnasium in Südschleswig Abitur machen wollten, zu schlecht, da diese dann mit dem Bus täglich in das ca. 60 Kilometer entfernte Flensburg hätten fahren oder in das dortige dänische Internat hätten ziehen müssen. Zwar ist diese Gesprächspartnerin vom aktuellen Schulleiter der Hans-Helgesen-Schule begeistert $^{216}$, ,aber nach wie vor würde ich meinen Kinder davon abraten [auf die dänische Schule zu gehen], nach wie vor", sagt Frieda Theben (INT06). Ihre Begründung, die etwas widersprüchlich wirkt, ist folgende:

Naja, man kriegt die Grundbegriffe nicht, wogegen ich sagen muss, also was Lehrstoff angelangt [sic], waren wir den Deutschen weit voraus. Das merk ich noch jetzt bei meinem Partner, so wenn wir denn so, naja, griechische Mythologie, das hatten wir alles. Cäsars Ermordnung da auf die Geschichte, die römische Geschichte und das hab ich heut noch drauf, das hat der nie [gelernt]. [...] Oder in Mathe, dass ich das heute besser kann als [er] (INT06).

Frieda Theben versucht, mit dieser Aussage dem Vorurteil entgegenzuwirken, dass auf dänischen Schulen weniger Bildung vermittelt worden sei. Sie räumt ein, dass sie teilweise andere Dinge gelernt habe als Leute, die deutsche Schulen besucht hätten. ${ }^{217}$ Sie habe daher Lücken nur in bestimmten Bereichen, wie beispiels-

216 „haben nen wunderbaren Rektor jetzt“ und ,ja, also also ganz, ganz toll“ (INT06)

217 Der Grund für unterschiedliche Erinnerungen an den Schulstoff muss nicht zwangsläufig an unterschiedlichen Lehrinhalten liegen, sondern kann auch durch andere Faktoren beeinflusst werden, wie unterschiedliches kognitives Erinnerungsvermögen, Interessen, Lernmotivation und 
weise bei spezifisch deutschen Themen in Erdkunde und Geschichte. Sie meint, dass sie Probleme mit der deutschen Sprache habe, da ihre Schulbildung ja mit Ausnahme des Deutschunterrichts komplett dänisch ausgerichtet war. Ein anderer Gesprächspartner berichtet ebenso von Defiziten in der Beherrschung der deutschen Sprache:

Wir hatten natürlich, und da musst man natürlich auch sagen, du hattest natürlich 'nen bisschen Defizite im Deutschen so, nä, also das schon. Da hatte ich auch Schwierigkeiten immer, auch nachher in der Berufsschule und so weiter (INT08).

Diese geschilderten Schwierigkeiten wollten die Eltern ihren Kinder ersparen. Bei keinem der Gesprächspartner*innen dieser Gruppe kamen im Rückblick ernsthafte Zweifel auf, ob die damalige Entscheidung richtig gewesen sei. Niemand äußert Bedauern darüber, dass die eigenen Kinder deutsche Schulen besucht haben, und sie berichten auch nicht davon, dass ihre Töchter und Söhne dies jemals beklagt hätten. Obwohl die Interviewten dieser Gruppe den eigenen Besuch der dänischen Schule als sehr positiv für sich selbst werten und sie dankbar für diese Möglichkeit sind, bedeutet es jedoch nicht zwangsläufig, dass sie 20 bis 30 Jahre später für ihre eigenen Kinder den gleichen Weg wählen würden. ${ }^{218}$ Insbesondere dann nicht, wenn sich die äußeren Umstände, die damals zu ihrer eigenen dänischen Einschulung führten, geändert haben. Im Grunde bedeutet das, dass sie die dänische Schule nicht immer und für jeden als sinnvoll erachten und sie auch mögliche negative Auswirkungen eines dänischen Schulbesuchs im Hinterkopf behalten.

Die beiden interviewten Frauen der zweiten Gruppe (INT02, INT03) haben ihre Kinder nicht dänisch eingeschult, bedauern dies aber heute. Die Verantwortung für diese Entscheidung geben sie ihren jeweiligen, verstorbenen Ehemännern. In einem Fall war der Mann selbst auch auf einer dänischen Schule. Er war aber der Meinung, dass er dadurch Nachteile gehabt habe. Seine Argumente, die seine verwitwete Frau, Brigitte Thomsen, im Interview schildert, ähneln denen der ersten Gruppe. Dasselbe gilt für die Bedenken des Mannes von Sarah Iversen. Dieser war selbst auf einer deutschen Schule, und für ihn kam eine dänische

Vermittlungsmethoden.

218 Diese Ambivalenz erinnert an vergleichbare Bewertungen von Institutionen wie Krankenhäusern, Kurkliniken oder psychotherapeutischen Einrichtungen. Viele Menschen sind dankbar für die Hilfe, die ihnen dort angeboten wird. Ihnen gefällt möglicherweise der Aufenthalt oder das Programm dort, aber sie würden niemandem wünschen, auch dorthin kommen zu müssen, weil das bedeutet, dass Menschen in die Notwendigkeit kommen, in eine solche Einrichtung eingeliefert werden zu müssen. Dies will man möglichst vermeiden. 
Schule für seine Töchter nicht in Betracht. Seine Frau konnte sich nicht gegen ihn durchsetzen, was zur damaligen Zeit, so Iversen, aber auch nicht üblich gewesen wäre. $^{219}$

Die beiden Frauen dieser Gruppe begründen ihr Bedauern nicht nur damit, dass sie selbst dänisch sind und sich gewünscht hätten, dass ihre Kinder durch einen Besuch der dänischen Schule auch dänisch geworden wären, sondern auch damit, dass generell „Die Betreuung besser, ja, die Klassen kleiner“ (INT02) sind und „die Lehrer [...] einfach mehr Zeit“ (INT02) für die Schüler*innen haben. Ebenso glauben sie, dass die außerschulische Betreuung besser ist. Für Brigitte Thomsen gilt dies heute noch, besonders in Bezug auf Kinder, die lernschwach sind oder einer besonderen Betreuung ${ }^{220}$ bedürfen. Dieser Aspekt erinnert stark an die Situation nach dem Krieg. Damals wurde sozial schwachen oder armen Kindern auf der dänischen Schule geholfen. Kinder, die nicht so dringend auf Hilfe angewiesen waren, besuchten überwiegend die deutschen Schulen. Dieser Punkt wird in Bezug auf ihre Enkelkinder ebenfalls von Ingo und Frauke Erhard aufgenommen, die ihre eigenen Kinder deutsch eingeschult haben. Sie spekulieren, ob es für den einen Enkel mit Legasthenie und das andere kranke Enkelkind nicht besser gewesen wäre, beide dänisch einzuschulen: Dann „hätte man es vielleicht einfacher gehabt mit den[en] auf der Dänenschule“ (INT09), weil die ,sich mehr damit abgeben“ (INT08), ,mit den Kindern“ (INT09).

Die dritte Gruppe der Interviewten hat ihre Kinder dänisch eingeschult. Dabei handelt es sich um den aus Flensburg stammenden Otto Clausen (INT04) und den ehemaligen SSW-Politiker Heinrich Schmied (INT07). Beide zeichnen sich in Bezug auf die Minderheit durch zwei Besonderheiten im Vergleich zu den anderen Gesprächspartner*innen des Samples aus. Der eine ist familiär, politisch, kulturell, ausbildungstechnisch und intellektuell in die dänische Minderheit integriert, der andere durch geografisch-kulturelle Gegebenheiten und seine persönliche (Überlebens-)Geschichte.

219 Sarah fügt in diesem Zusammenhang außerdem hinzu, dass die Schulwahl der Kinder nicht das einzige Problem mit ihrem Mann in Bezug auf das Dänische war, sondern dass sie rückblickend begriffen hätte, dass ihr Mann es zudem lieber gehabt hätte, wenn auch sie nicht dänisch gesinnt gewesen wäre. Aber sie meint, er musste sich „damit abfinden, dass ich das war, denn da [bei der Minderheit] hat er mich gefunden. Und da [...] hat er auch nie [was] gesagt, nicht, ich habs nur im Laufe des Lebens, gemeinsamen Lebens gemerkt“ (INT03). Denn ,angefangen hat es so, dass ich zurückgesteckt hab', dass ich eben nicht zu irgendwelchen Veranstaltungen mehr gegangen bin $[\ldots]$ da hab ich bös drunter gelitten“" (INT03).

Z. B. glaubt Brigitte Thomsen, dass die dänische Schule ihrem Sohn, der Legastheniker ist und aufgrund einer Hüftfehlstellung zeitweise gehbehindert war, besser unterrichtet und sozial integriert hätte. 
Heinrich Schmieds - in Relation zu anderen Friedrichstädter Minderheitendän*innen - besonders starkes Verhältnis zu Dänemark und zur dänischen Minderheit rührt hauptsächlich von drei Gegebenheiten her: Zum einen ist er als einziger meiner Gesprächspartner*innen mit einer Dänin verheiratet, die bis zu ihrem Rentenalter im dänischen Kindergarten gearbeitet hat. Dadurch entstand ein starker persönlich-familiärer Bezug zum Dänischen. Zum anderen besuchte Heinrich als junger Mann Ende der 50er-Jahre in Dänemark eine Art politische Weiterbildungsschule ${ }^{221}$, sodass er auch unabhängig von seiner Ehepartnerin persönliche Kontakte nach Dänemark hat und dort seine „dänische Gesinnung gefestigt“ sieht, beziehungsweise als „Dänisch-Südschleswiger“ seine „Wurzeln gefunden hat" (Schmied 2003) ${ }^{222}$. Des Weiteren war er im SSW" 223 als Kommunalpolitiker sehr aktiv und ist in zahlreichen anderen Vereinigungen tätig, beispielsweise als Mitglied im „Hauptvorstand“ (INT07) ${ }^{224}$ der dänischen Kirche in Südschleswig. Heinrichs Kinder sind zwei-, teilweise sogar dreisprachig aufgewachsen: „Ich hab [...] Deutsch mit meinen Kindern gesprochen und Jytte ${ }^{225}$ hat Dänisch gesprochen, [...] halb Dänisch und halb Englisch, als sie Dänisch konnten, hat meine Frau mit denen Englisch gesprochen." (INT07). Durch die genannten Voraussetzungen ist die dänische Sprache bei Heinrich Schmied alltäglicher als bei den anderen Dänischgesinnten des Samples und denjenigen, die ich bei den teilnehmenden Beobachtungen getroffen habe. Deshalb erscheint der Besuch der dänischen Schule für die Kinder dieser Familie selbstverständlicher. Außerdem wäre eine deutsche Einschulung seiner Kinder nicht besonders glaubwürdig für seine dänische Parteiarbeit im SSW gewesen.

Für Otto Clausen, der bis vor kurzem in Flensburg wohnte, ist es auch eine Selbstverständlichkeit, seine Kinder auf eine dänische Schule zu schicken. Der Grund dafür liegt in seiner starken emotionalen Bindung an das Dänische, was aus seiner Biografie herrührt. Seiner Ansicht nach verdankt er Dänemark sein Leben durch die Möglichkeit des schon erwähnten Sanatoriumsaufenthaltes. Nachdem er davon im Interview berichtet, fährt er direkt anschließend fort: „So und dann hat sich das also ja gegeben, meine Kinder sind also dann [auf die] dänische Schule gegangen“ (INT04). Im weiteren Verlauf des Gesprächs verliert er kaum noch ein Wort darüber, dass diese Tatsache besonders oder diskussionswürdig sei. Zum anderen gründet diese Selbstverständlichkeit, mit der er seine Kinder dä-

221

222

S. a. FN 186 auf S. 120.

223 richstädter Stadtrat, zwischenzeitlich 2. stellvertretender Bürgermeister, Mitglied im Amtsrat und Vorsitzender einiger politischer Ausschüsse auf kommunaler Ebene (Schmied 2003).

224 Schmied meint den „Kirkerådet“ (Kirchenrat) der „Dansk Kirke i Sydslesvig“ (Dänische Kirche in Südschleswig).

225 Name geändert. Jytte ist Heinrichs Ehefrau. 
nisch eingeschult hat, darauf, dass das dänische Milieu wegen der unmittelbaren geografischen Nähe zum kin-state in Flensburg größer ist als in der Kleinstadt am südlichen Rande Südschleswigs. Flensburg ist erstens das Zentrum der dänischen Minderheit und zweitens eine sogenannte Mittelstadt mit rund 90.000 Einwohnern. Daher ist die Dichte an dänischen (und auch deutschen) Angeboten hier viel höher als in den ländlichen Gebieten. Für den Besuch dänischer Institutionen und Schulen gibt es in Flensburg eine längere Tradition und ein wohlwollenderes Umfeld.

Zusammenfassend betrachtet gibt es, mit Ausnahme zweier Gesprächspartner*innen, einen deutlichen Widerspruch zwischen der scheinbar grenzenlosen Begeisterung der Interviewten über ihre eigene dänische Schulzeit und ihrer Entscheidung als Erwachsene, ihre eigenen Kinder nicht auch eine dänische Schule besuchen zu lassen. Begründet werden könnte dies nur durch einen Wandel der äußeren Umstände, der bei den Interviewten zum Besuch der dänischen Schule führte. Bei denjenigen, die persönliche Kontakte (durch Aufenthalte in Dänemark im Erwachsenenalter, Heirat mit dänischen Staatsangehörigen) und eine größere geografische Anbindung an Dänemark (langjähriger Wohnort Flensburg mit gröBerer Präsenz der Minderheit dort) haben und sich darüber hinaus aktiv in der Minderheit engagieren (Ämterübernahme in Vereinen, Teilnahme an Veranstaltungen), bleibt die Bindung zur dänischen Gesinnung bestehen bzw. stellt sich als ausgeprägter heraus. Die Schule ist die Grundlage des Dänischseins, welches aber im Erwachsenenalter weiter gepflegt werden muss, um die Bindung nicht zu verlieren. Diejenigen, die sich nach der dänischen Schulzeit in ein deutsches Umfeld integriert haben, verlieren eher den Kontakt zum und die Identifizierung mit dem Dänischen, sie praktizieren seltener ein Dänischsein und engagieren sich weniger in den Institutionen als Menschen, die sich der Minderheit stark verbunden fühlen.

\subsubsection{Kinderferienreisen während der Schulzeit}

Alle Gesprächspartner*innen berichten begeistert von den Kinderferienreisen für dänische Minderheitsschüler*innen, die seit 1919 alljährlich in den Sommerferien stattfinden und von der Organisation Sydslesvigske Borns Ferierejer, Ferienreisen Südschleswiger Kinder, durchgeführt werden (Grænseforeningen 09.01.2017). Diese Initiative geht aus einer Zusammenarbeit des Grenzvereins Granseforeningen mit dem Dänischen Schulverein hervor (vgl. Kühl 2005a: 371; Johannsen, Midskov 2004; Rasmussen 2009: 119-220; Klatt 2009b: 207). Nach dem Zweiten Weltkrieg stieg der Bedarf an Plätzen in Gastfamilien aufgrund der großen Not in Südschleswig rasant an (vgl. Johannsen, Midskov 2004: 16). Einige Informant*innen erzählen bildhaft Geschichten von diesen Dänemarkaufenthalten als Ferienkinder. 
Andere fassen allgemeiner zusammen, dass es „toll“ war (INT05), dass man dort Dänemark richtig kennenlernen und seine Sprachkenntnisse erheblich verbessern konnte (INT05). Die Aufenthalte im Königreich waren für alle insgesamt ,'ne tolle Zeit" (INT04).

Etwas konkreter schwärmen Brigitte Thomsen und Erik Nissen von der Ferienverschickung. Es war nicht ganz einfach, einige Wochen alleine ohne Eltern weg zu sein, die Anreise war anstrengend, aber es überwiegen, wie auch bei Sarah Iversen, die positiven Erlebnisse, das intensive Lernen der Sprache, das Kennenlernen von Dän*innen und das unbeschwerte Leben ohne Armut und Not: „Das war natürlich, als wenn man ins Schlaraffenland kam" (INT02). Im Vergleich zur Situation nach dem Krieg in Deutschland war ,der Standard [...] natürlich um einiges höher" (INT02). „Die hatten schon [ein] Auto“ (INT06), berichtet eine andere Gewährsperson, die ganz ähnlich wie Brigitte Thomsen ergänzt: „Das war für mich Schlarara, Schlaraffenland“ (INT06). Zwei Interviewte betonen, dass die Ferienaufenthalte ,'ne ganz tolle Sache“ (INT02) und „wunderschöne Ferien“ (INT01) waren. Auf die Frage, ob sie kein Heimweh gehabt habe, meint Brigitte rückblickend: „Es muss so nett da gewesen sein, dass ich das nicht gehabt hab ““ (INT02). Brigitte erlebte, obwohl sie selbst auch von einem kleinbäuerlichen Betrieb kam, in Dänemark eine Art ländliche Idylle, so erscheint es ihr jedenfalls im Nachhinein. Noch heute schwärmt sie vom Hagebutten- und Erbsenpflücken, von der Johannisbeerernte und, da ihre Gastfamilie schon viel früher Strom hatte als ihre Familie zu Hause, vom Ausprobieren eines richtigen Staubsaugers: So etwas „kannte ich ja überhaupt nicht“ (INT02). Ihre Gastmutter brachte ihr die richtige Staubsaugetechnik bei, daran erinnert sich Brigitte noch deutlich, ,dass man da mit langen Bewegungen saugen muss und nicht so [mit kurzen]“ (INT02). Auch Erik Nissen erinnert sich in einem informellen Gespräch an dieses für ihn besondere, weil neuartige Gerät. Seine Gastfamilie hatte einen NilfiskStaubsauger, mit dem Erik freiwillig möglichst lange saugen wollte, während der gleichaltrige Gastbruder froh war, diese Arbeit nicht übernehmen zu müssen. Das Eintauchen in eine neue Welt durch das Dänischwerden erfolgte also nicht nur sozial und erziehungstechnisch, sondern auch in technischer Hinsicht.

Zahlreiche Interviewte und ihre Familien halten bis heute Kontakt zu ihren ehemaligen Gasteltern, -geschwistern und deren Kindern. Daraus entwickelten sich häufig langjährige Freundschaften zu den Menschen in Dänemark, die für die Südschleswiger*innen eine wichtige Rolle spielen, weil dadurch persönliche Kontakte ins kulturelle „Mutterland“, also zum kin-state ${ }^{226}$, gepflegt werden (Kühl 2006b: 388). Sie versuchen, sich kulturell, politisch, sprachlich und gesellschaftlich auf dem Laufenden zu halten. Dazu passt auch die Aussage des Historikers Jør-

226 Ein kin-state ist ein Land, mit dem „eine Minderheit verknüpft ist“ oder mit dem sich eine Minderheit „aktiv identifiziert“. Die dänische Minderheit sieht Dänemark ,als sprachliches, kulturelles oder nationales Heimatland“ (Kühl 2005d: 11-12). S. a. Kap. 2.1. 
gen Kühl, dass diese „Kontakte zwischen den Familien [...] oft ein ganzes Leben halten, manchmal sogar vererbt werden“ (vgl. Kühl 2005a: 371; vgl. Johannsen, Midskov 2004: 11). Eriks häufige Ferienaufenthalte als Kind und die dort gemachten Erlebnisse wirken auch heute noch emotional nach und klingen sehnsüchtig:

Speziell im Sommer, dann kriegte ich immer das große Kribbeln oder bekomme es immer noch, da muss ich einfach mal rüber nach Dänemark, muss die dänische Fahne seh'n, den blauen Himmel muss ich sehen und 'nen Hot Dog essen (INT01).

In Dänemark sollten sich die Kinder nach dem Zweiten Weltkrieg erholen und sattessen: „In den schweren Zwischenkriegs- und Nachkriegsjahren war die Ferienkinderarbeit im hohen Maße eine soziale Aufgabe“"227 (Grænseforeningen 09.01.2017). Ein wichtiger Aspekt ist, dass die Kinder in den Ferien unter „kulturelle[r] und sprachliche[r] Beeinflussung" (Kühl 2005a: 371) des kin-states standen und die „häuslichen dänischen Verhältnisse kennenlernen“ konnten ${ }^{228}$ (Grænseforeningen 09.01.2017). Die Kinder wurden in Dänemark reichlich mit Lebensmitteln versorgt und mit neuen Kleidungsstücken ausgestattet, sie bekamen, wie in Sarah Iversens Beispiel beschrieben, teilweise sogar Kleintiere geschenkt. Emil Schrøder beschreibt die Situation der zurückkehrenden Ferienkinder folgendermaßen: „Da waren sie wie verwandelt und glichen kleinen Prinzen und Prinzessin-

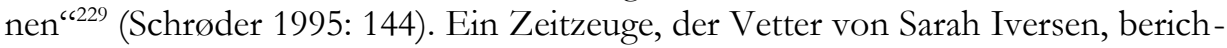
tet übereinstimmend, dass er in den Nachkriegsjahren aufgrund der materiellen Not im Vergleich zu seiner Zeit als Kleinkind erheblich dünner geworden war. Doch „war ich denn [sic] in den Ferien in Dänemark aufm Bauernhof, als ich denn wiederkam, haben sie mich gar nicht wiedererkannt, so dick war ich wieder geworden" (INT08).

Neben den Dänemarkaufenthalten in den Sommerferien berichtet Brigitte Thomsen auch mit leuchtenden Augen von ihrer Klassenfahrt nach Norwegen. Durch finanzielle und logistische Unterstützung von „Patenleute[n]“ in Dänemark wurde eine Skifahrt ermöglicht. „Das war schon enorm“, „da haben wir uns auf Skiern da amüsiert" (INT02) und anschließend, so Brigitte stolz, wurde sogar in Frederikshavn in Dänemark in der Zeitung über die Klassenreise berichtet. Hintergrund dieser Aufenhalte in Dänemark und den anderen skandinavischen Ländern ist Folgender: „Neben einem kostengünstigen Ferienerlebnis werden durch die durchorganisierten Urlaubsfahrten Sympathien für Dänemark und den skandi-

\footnotetext{
227 „I de svære mellemkrigs- og efterkrigsår var feriebørnsarbejdet i høj grad en social opgave.“

228 „lærer hjemlige danske forhold at kende“

229 „Da var de som forvandlede og lignede små prinser og prinsesser.“
} 
navischen Raum „ganz nebenbei“ unterschwellig mitvermittelt.“ (Boehm 1992: 37). Damit „bleibt genug Raum zur Propagierung eines sich subjektiv als andersgeartet empfindenden Bewußtseins beim jugendlichen Individuum“ (ebd.: 38).

Die Gründe für die drei- bis vierwöchige Verschickung der Kinder nach Dänemark nach dem Zweiten Weltkrieg bis in die Mitte der 1970er-Jahre hinein sowie deren Auswirkungen wurden von Marianne Brink Jensen untersucht. Nach dem Krieg wurden die Kinder aus materieller Not verschickt und kamen mit Koffern voller neuer Kleidung, Geschenken, Lebensmitteln und teilweise lebendigen Tieren wieder zurück. Gleichzeitig wurden die deutschen Eltern in Südschleswig für einige Wochen entlastet. Ab den 1960er-Jahren nahm die Notwendigkeit der Versorgung der Kinder ab. Stattdessen traten Erlebnisse in den Mittelpunkt der Reisen, wie beispielsweise Zoobesuche oder Vergnügungsausflüge und ideelle Gründe, so Jensen in ihrer Magisterarbeit (Jensen [2016]: 28-30; Mølvig 06.08.2016). In Bezug auf die Kinderferienreisen dieser jüngeren Gruppe und im Gegensatz zur Nachkriegsgeneration konnte Jensen also feststellen, dass die Verschickung nach Dänemark nicht aufgrund von materieller Not geschah, sondern aus Familientradition und der Chance, überhaupt zu verreisen (Jensen [2016]: 75). Die Art und Weise, wie die Gastfamilien die südschleswigschen Ferienkinder behandelten, habe einen entscheidenden Einfluss auf die spätere Identifizierung der Kinder mit dem Dänischen und der dänischen Gesinnung gehabt (ebd.: 75, 7).

Die Auswirkungen dieser Reisen für die Kinder seien laut Jensen eine Stärkung ihrer „Identität ${ }^{\star 6230}$. Sie brächten ,die dänische Kultur und Lebensart mit zurück $^{\text {‘231 }}$ aus dem Königreich nach Südschleswig (Mølvig 06.08.2016). Von 1949 bis 1974 konnte Jensen feststellen, dass die Kinder in Dänemark lernten, dass man dort anders miteinander umging und dass die Unterschiede zwischen Erwachsenen und Kindern nicht so groß sein mussten, wie in Deutschland (ebd.). Die Erziehung in Dänemark war anders als im damaligen Deutschland. Der Kontakt zu den Pflegeeltern war herzlicher und enger als der Kontakt vieler Kinder zu ihren Eltern in Südschleswig (Mølvig 06.08.2016; Jensen [2016]).

Die Reisen finden auch heute noch statt, sind aber kürzer, also nur ein bis zwei Wochen lang. Nicht alle Kinder besuchen dänische Familien, einige nehmen auch an Kinderferienlagern in Dänemark teil.

\footnotetext{
230 ,identitet“

231 „den danske kultur og levemåde med tilbage“
} 


\title{
5.2 Die Rolle des Schulvereins: Anspruch, Wirklichkeit, Erwartungen, Widersprüche
}

\author{
„Wir sind eine geschlossene offene Gesell- \\ schaft! ${ }^{232}$ \\ Udo Jessen, seit 2014 Vorsitzender des \\ Dansk Skoleforening for Sydslesvig e. $V$. \\ (Jessen 2012: 106)
}

Nachdem exemplarisch anhand der Nachkriegsgeneration aus einer emischen Perspektive heraus die zentrale Bedeutung der Institution Schule für die nationale Gesinnung gezeigt wurde, soll nun der Blick auf die Gegenwart gerichtet werden. Dabei werden die Rolle des Schulvereins, seine Ziele und die damit verbundenen Erwartungen für heutige Neudänen unter die Lupe genommen. Es geht in diesem Abschnitt konkret um die Funktion und Aufgabe der Schulen und Kindertageseinrichtungen des Dänischen Schulvereins in der Gegenwart (s. a. Kap. 3.2.2). Dabei stehen nicht die inhaltliche, pädagogische Vermittlung von offiziellen Inhalten oder der sogenannte „heimliche[...] Lehrplan“ (Zimmermann 2006: 123; Jackson 1975: 29) oder der Unterricht an sich im Vordergund. Dies sollten besser Fachdidaktiker*innen anhand von teilnehmender Unterrichtsbeobachtung beforschen. Es soll hier auch nicht um die kulturanthropologische Erforschung von „Schulkultur" gehen (vgl. Bendix et al. 2010; vgl. Keßler 2017). Stattdessen werden die explizit geäußerten und implizit vermittelten Erwartungen an Angestellte und Mitglieder, also an die Eltern, sowie die Sichtweisen der Akteur*innen auf die Schule und die draus entstehenden Widersprüche zwischen Abgrenzungs- und Öffnungsstrategien dargestellt und analysiert. Des Weiteren geht es um die finanzielle Abhängigkeit des Schulverein von Dänemark und deren Auswirkungen.

\subsubsection{Ziele und Aufgaben des Dänischen Schulvereins und seiner Einrichtungen}

Die allgemeine Rolle der Schulen bzw. der Kindertagesstätten ist „die zweite Sozialinstitution nach der Familie, wo das Kind eine Erweiterung seines Sozialraums und damit eine Entwicklung [...] erlebt“" (Byram 1990: 136). Es handelt sich hierbei also um einen Raum für die sekundäre Sozialisation. Zur generellen Funktion der Institution Schule schreibt der Entwicklungspsychologe Peter Zimmermann:

232 ,Vi er et lukket åbent selskab!“ 
Ihre ausgewiesene Aufgabe ist die Sozialisation von Kindern und Jugendlichen. Diese Aufgabe erfüllt die Schule auf den ersten Blick über geplanten und kontinuierlichen Unterricht und durch systematisch und rational aufgebautes Lernen. [...] in der Schule geschieht bekanntlich mehr als bloße Wissensvermittlung (Zimmermann 2006: 117).

Die Institution Schule fungiert ,als Vergesellschaftungsinstanz“, sie hat einen „Bildungsauftrag“ und ist „biographisch relevant“, wie die Erziehungswissenschaftlerin Christine Wiezorek anhand ihrer Studie mit ostdeutschen Jugendlichen gezeigt hat (Wiezorek 2005: 351) und wie es bei der Nachkriegsgeneration der dänischen Minderheit zu beobachten war.

In Kindergärten machen Kinder „erste Schritte in öffentliche Räume“ und erweitern dort ihren ,sozialen Aktionsradius“ um „spezifische Fähigkeiten und Kompetenzen“ (Colberg-Schrader, Derschau 1991: 335). Dies gilt heutzutage ebenso für die Betreuungseinrichtungen für Kinder, die jünger als drei Jahre sind. Daher spielt der Schulverein für die Aufrechterhaltung der dänischen Minderheit eine zentrale Rolle. Erziehungssoziologisch gesehen hat ein Schulsystem die Aufgabe, „soziale Strukturen und die damit verbundenen ökonomischen, politischen und kulturellen Handlungssysteme zu reproduzieren" (Rolff 1997: 10). Eine starke ideelle Bindung an die Minderheit hängt von einer frühen Ausbildung dieses Bewusstseins im Kindesalter ab, so die dänische Historikerin und Folkloristin Inge Adriansen analog über das nationale Bewusstsein (Adriansen 1994: 11). Sie führt an, dass die Schule „,einer der wichtigsten Orte für Erziehung, Einflussnahme und Indoktrinierung“ sei und man dort die „,nationale Identität durch den Unterricht aufsaugt" (ebd.: 11) ${ }^{233}$. Die dänische Schule gilt als Ort, an dem die Schüler*innen zu ,kleinen Dänen gemacht“ werden (Kühl 18.03.2008). Ähnliches bestätigt auch Sigaard-Madsen:

Träger der Minderheitenschulen mit dänischer Unterrichtssprache Deutsch wird ab dem zweiten Schuljahr in muttersprachenähnlichem Unterricht gelehrt - ist der dänische Schulverein. [...] [S]ie [sind] keine neutralen, Zweisprachigkeit vermittelnden Schulen, sondern Schulen mit einer Priorität für die Belange der dänischen Minderheit (SigaardMadsen 1995: 145).

Die Funktionen des staatlichen Schulsystems für die Gesellschaft sind ähnlich wie die Funktionen der dänischen Schulen für die Konstituierung der dänischen Minderheit. Das Schulwesen hat für die dänische Minderheit eine „Reproduktionsfunktion“, eine „Sozialisationsfunktion“ (Christiansen 2008: 95), eine „Kulturfunktion“ und eine „Legitimations- und Integrationsfunktion“ (ebd.: 96). Diese

233 ,et af de vigtigste steder for opdragelse, påvirkning og indoktrinering“; , ,indsuget [...] nationale identitet gennem undervisning" 
Funktionen werden durch eigene Lehrpläne, andere Bildungsziele und Erziehungsstile sowie die „sprachliche Homogenisierung“ „durch Verwendung der dänischen Sprache trotz deutscher Muttersprache“ und die Verbreitung von ,[n]ationale[n] [...] Identitätsbildern“ umgesetzt (ebd.: 87). Auch spielt der ,monetäre [...] Bezug zu Dänemark“ eine Rolle (ebd.: 87), da von dort eine finanzielle Unterstützung der dänischen Schulen in Südschleswig erfolgt. Nicht nur bei der dänischen Minderheit spielt das Schulwesen für die Konstruktion von Zugehörigkeit eine entscheidende Rolle. Auch Margit Feischmidt hebt die Wichtigkeit von Schulen und Sprachverwendung für die rumänische Nationalisierung und die „kulturelle[...] Homogenisierung" nach dem ersten Weltkrieg in Cluj-Napoca gegenüber der ungarischen Minderheit in Siebenbürgen hervor (Feischmidt 2003: 79). Auch dort kamen die Lehrer der neuen rumänischen Schulen aus dem rumänischen „Altreich“, um die Bevölkerung zu rumänisieren (ebd.: 79), ähnlich wie der dänische Schulverein, der hauptsächlich dänische, südschleswigsche und dänisch ausgebildete Lehrkräfte einstellt.

Die Sprachwissenschaftlerin Helen Avery bestätigt die grundlegende Bedeutung der Schule für eine ideelle, nationale Einigkeit (Avery 2008: 283). Von einer Situation ähnlich der dänischen Minderheit und ihrer Art und Weise der Vermittlung von spezifisch nationalen Inhalten in Abgrenzung zu den öffentlichen Schulen des Landes berichtet Brigitta Schmidt-Lauber über Deutsche in Namibia:

Die Überzeugungskraft dieser romantischen Bilderwelt [der deutschen Namibier vom deutschen Wald und kalter Weihnacht] rührt weniger aus der Erfahrung, vielmehr handelt es sich um ein aktiv tradiertes, ein vermitteltes Wissen. Lieder, Gedichte oder Märchen, Literatur und Schulunterricht lehren Inhalte einer, deutschen Identität` (Schmidt-Lauber 1996: 324).

Ähnlich wie es Nina Jebsen für die deutsche Minderheit im dänischen Nordschleswig festgestellt hat, gilt auch für die dänische Minderheit in Südschleswig, dass die dänischen Kindergärten und Schulen Orte sind, ,an denen sich die sozialen Kontakte der Minderheitenkinder aufbauen und [die] sich so als Basis für den Zusammenhalt der gesamten Minderheit erweisen“ (Jebsen 2008: 133). Die Institution Schule ist also die Einrichtung, in der sich ein Bewusstsein für die nationale Gesinnung und Minderheitszugehörigkeit entscheidend ausbildet. Richard Jenkins stützt die Beobachtung, dass die Schule die nationale Gesinnung entscheidend prägt, indem er Folgendes in Bezug auf ethnische Zugehörgkeiten formuliert: "The strength and meaning of ethnic attachments is, in part, a reflection of early socialisation and formative experiences" (Jenkins 2012: 33). Auch das Ergebnis des von Werner Schiffauer, Gerd Baumann, Riva Kastoryano und Steven Vertovec herausgegebenen Sammelbandes „Civil Enculturation“ stützt dieses These 
(Schiffauer et al. 2004). Eine in Großbritannien, Frankreich, Deutschland und den Niederlanden durchgeführten Schulstudie ergab, dass Schulen Enkulturation betreiben und die Individuen in ihnen Glauben, Wissen und Verhaltensweisen erlernen, die benötigt werden, um in einem Staat zu funktionieren (Mannitz 2004; vgl. a. Römhild 2007: 162).

Michael S. Byram hat Ähnliches ebenso für die deutsche Minderheit in Dänemark festgestellt. Das Minderheitenschulwesen diene ,as a locus of socialization into crucial minority attributes" (Byram 1986: 154) unterstützt durch andere Minderheitenorganisationen. Byram bestätigt, dass „the school's part cannot be overestimated“" (ebd.: 154). Die Schulen würden die selbstkonstruierten Grenzmarker der Minderheit im Kontrast zur Mehrheit aufrechterhalten, so Byram (ebd.: 154). Hier wird die von Barth und Brubaker beschriebene Distinktion zu anderen praktiziert (s. Kap. 2.2), „denn nur angesichts einer Mehrheit kann man sich als eine Minderheit erleben“" (Jebsen 2008: 131). Bestehendes Wissen darüber, wie die dänische Minderheit funktioniert und funktionieren soll und was es heißt, dänisch zu sein, soll in Südschleswig in den Schulen an die nachfolgenden Generationen weitergegeben werden. Dort wird also versucht, das Minderheitensein in Abgrenzung zu deutschen Schulen zu reproduzieren (vgl. Christiansen 2008). Die Vermittlung von vermeintlich eigenen nationalen Werten und Ideologien und spezifischen Vergangenheitsbildern ist ein entscheidender Teil für die Konstituierung einer nationalen Gruppe wie der dänischen Minderheit (vgl. a. Coakley 2004).

Dänische Schulen haben laut schleswig-holsteinischem Schulgesetz die Aufgabe, die kulturelle Eigenständigkeit der Minderheit zu sichern ( $\mathbb{S} 124$ Abs. 1 SchulG, vgl. a. Kap. 5.2.3). Gemäß Vereinssatzung ist der Zweck der Schulen, eine „dänische, pädagogische Tätigkeit für die dänische Minderheit “'234 (Dansk Skoleforening for Sydslesvig c) für die Zielgruppen Kinder und Erwachsene auszuüben. In den dänischen Schulen werden daher spezielle dänische oder minderheitsdänische implizite und explizite Loyalitätserwartungen gelehrt und gelernt. Überdies wird eine dänische Sichtweise auf die Geschichte des alten Herzogtums Schleswig vermittelt, wie in Kap. 8.6 genauer beleuchtet wird.

Die vom Schulverein betriebenen Institutionen sind keine binationalen, bilingualen oder internationalen Einrichtungen, sondern explizit dänische Angebote, die die Aufgabe haben, „,das Verbundenheitsbewusstsein der Schüler mit dem dänischen Bevölkerungsteil in Südschleswig und dem dänischen Volk zu fördern“`235 (Dansk Skoleforening for Sydslesvig c) und der dänischen Bevölkerung in Schleswig zu dienen (Dansk Skoleforening for Sydslesvig a, BDO Statsautoriseret Revisionsaktieselskab 01.03.2016).

\footnotetext{
234 „dansk pædagogisk virksomhed for det danske mindretal“

235 „at fremme elevernes bevidsthed om samhørighed med den danske befolkningsdel i Sydslesvig og med det danske folk“
} 
Phänomene wie Zweisprachigkeit und Bikulturalität werden aus Sicht der Minderheitsfunktionär*innen wie Gitte Hougaard-Werner nicht gewünscht und nicht gefördert. Wenn man das Dänische wähle, dann sei es besser, wenn das ganze Fundament auch dänisch sei oder werden würde, ansonsten sei es nur verwirrend für die Kinder (Hougaard-Werner 14.10.2013; vgl. Byram 1990: 136, 145). Die Eltern sollten ihren Kindern das Dänischsein „vorleben“. Bent Søndergaard schätzt die dänischen Schulen daher als „politisch-ideologische Minoritätsschulen“ ein, „die historisch begründet sind“, und in denen „elementare zweisprachigkeitspädagogische Prinzipien ganz vernachlässigt werden“ (Søndergaard 1983: 85). Das Besondere an den Schulen der dänischen Minderheit im Vergleich mit anderen Minoritäten in Europa ist, dass Dänisch dort als Institutionssprache verwendet wird und überwiegend erst in diesen Institutionen gelehrt und gelernt wird, während Deutsch, aber auch Niederdeutsch und Friesisch, zu Hause und in der Freizeit verwendet werden, wohingegen bei zahlreichen anderen Minderheiten in Europa die Kinder zu Hause die Minderheitensprache sprechen und erst in der Schule die Sprache der Mehrheit lernen (Thaler 2009: 95).

Das dänische Schulsystem soll, so die Funktionär*innen des Vereins, keine Sprachschule oder bilinguale Schule darstellen, sondern explizit eine Minderheitsschule sein (INT10; Hougaard-Werner 14.10.2013). „Es ist eine Katastrophe, wenn einige Lehrer ihre Schulen als international ansehen “236, proklamiert der SSF-Generalsekretär Jens A. Christiansen in der Flensborg Avis (Christiansen in Mølvig 22.10.2016). Allerdings besagt die Vereinssatzung, dass die Schüler befähigt werden sollen, auch in der deutschen Gesellschaft zu leben (vgl. Dansk Skoleforening for Sydslesvig a, BDO Statsautoriseret Revisionsaktieselskab 01.03.2016). Mit Bilingualität wird zwar aufgrund der Erlangung von kulturellem und sozialem Kapital nach Pierre Bourdieu (vgl. Gombos 2017: 57) geworben, aber sie wird im Unterricht nicht praktiziert, abgesehen vom deutschsprachigen Deutschunterricht. Bikulturalität ist nicht gewünscht, sondern Dänischsein wird erwartet.

Die Wahl der dänischen Schule ist laut Verfassung des Landes Schleswig-Holstein frei: „Die Erziehungsberechtigten entscheiden, ob ihre Kinder die Schule einer nationalen Minderheit besuchen sollen." (Art. 12 Abs. 4 Verf SH). Voraussetzung für eine dänische Einschulung ist aufseiten des Vereins die Mitgliedschaft mindestens eines Elternteils im dänischen Schulverein. Das Elternteil werde „dadurch“, laut Auffassung des Vereins, „ein Teil der dänischen Minderheit" (Dansk Skoleforening for Sydslesvig b): 237 „Die Mitgliedschaft im Verein beinhaltet, dass das Mitglied sich zur dänischen Minderheit bekennt.“238 (Dansk Skoleforening for

\footnotetext{
236 „Det er en katastrofe, når nogle lærere ser deres skoler som internationale.“

237 "dermed blive en del af det danske mindretal“

238 „Medlemskabet i foreningen indebærer, at medlemmet bekender sig til des danske mindretal.“
} 
Sydslesvig o. J.a). Dafür muss dem „Zweckparagrafen“239 in der Satzung (Dansk Skoleforening for Sydslesvig c) zugestimmt werden, so das Reglement. Auf der Vereinshomepage wird betont, dass das freie, gesetzlich garantierte Gesinnungsprinzip von der Skoleforening nicht kontrolliert werde, stattdessen die Aufnahme von Kindern aber auf eine ,gut abgesicherte[...] Grundlage“240 gestellt werden solle. Daher suchen die Verantwortlichen der dänischen Kindergärten und Schulen das Gespräch mit den Eltern, um ihnen die Ziele des Schulvereins zu vermitteln und dabei zu betonen, dass die Institutionssprache Dänisch ist (ebd.; INT10; Hougaard-Werner 14.10.2013). So schreibt es die Satzung der Skoleforening vor (Dansk Skoleforening for Sydslesvig 2011: \ 3 Abs. 4). Dieses Vorgehen deutet den im nächsten Unterkapitel näher ausgeführten Kontrast zwischen der expliziten Offenheit einerseits und der andererseits implizit erwarteten Anpassung an die Minderheit bereits an.

Die Schule hat eine große „Prägekraft“, so die Kulturanthropologin Nina Jebsen über die Situation bei der deutschen Minderheit in Nordschleswig (Jebsen 2008: 133), zu der man Analogien ziehen kann. Diese große Bedeutung der Schule haben auch die Funktionär*innen der dänischen Minderheit erkannt. Der bis 2014 amtierende zweite Vorsitzende des dänischen Schulvereins Udo Jessen hat in einem Aufsatz beschrieben, was aus seiner Sicht die Kernaufgabe des dänischen Schulvereins in Südschleswig ist: die Vermittlung dänischer Sprache und dänischer Kultur zum Nutzen der Dansk Skoleforening selbst und für die ganze Minderheit. Weitere Aufgaben der Schulen, Krippen und Kindergärten seien die Vermittlung von Wissen über die Minderheit, über das Leben der Minderheit und über die dänische Kultur, neben der Vermittlung von allgemeiner Bildung (Jessen 2012: 101, 105, 106). Dabei wird „Kultur“ bzw. „dänische Kultur“ nicht definiert. Es wird versucht, die nicht näher definierten Inhalte und Narrative des Dänischseins über einen langen Zeitraum vom Säuglingsalter bis zum Erwachsenensein zu vermitteln (vgl. ebd.: 102). Funktionär Jessen sieht die Schule als wichtigsten Lebensnerv und Einflussbereich der dänischen Minderheit und als deren Stärke und Ressource an und erläutert, dass der Schulverein mit seinen Institutionen als Kulturzentrum und Bindeglied zwischen (fast) allen anderen Vereinen fungiere (ebd.: 102-103). Diese Aussage erklärt das Verhalten des Schulvereins gegenüber den anderen institutionellen Akteur*innen der Minderheit. Die Skoleforening tritt recht selbst- und machtbewusst gegenüber den anderen Minderheitsinstitutionen, also Vereinen, auf. Sie ist die Vereinigung, die den größten Anteil der Gelder aus Dänemark bekommt. Das sind rund $73 \%$ ohne Projektförderungen, rund $42 \%$ mit Projektzuschüssen der gesamten, an südschleswig gezahlten dänischen Mittel. Das sind für den Schulverein insgesamt rund 54 Millionen $€$ pro Jahr. Dies steht

\footnotetext{
239 „formålsparagraf“،

240 ,velfunderet grundlag“
} 
einerseits in Konkurrenz zum Anspruch des Sydslesvigsk Forening e. V. , dem SSF, die kulturelle Hauptorganisation der Minderheit sein zu wollen (vgl. Kap. 3.2.3). Andererseits versuchen beide Vereine, gemeinsam für die Minderheit zu arbeiten, wie in Kapitel 6.1 genauer beschrieben wird. Oft sind die Akteur*innen der Minderheit gleichzeitig in den unterschiedlichen Minderheitenvereinen, wie dem SSF und dem Schulverein, aktiv.

Ein weiterer Grund der großen Bedeutung des Schulvereins für die Minderheit ist, dass dessen Gebäude nicht nur vom Schulverein selbst, sondern auch von den anderen lokalen dänischen Vereinen genutzt werden (ebd.: 106), so wie es in Tönning auf Eiderstedt der Fall ist: „Die Aula der dänischen Uffe-Skole dient als Saal für ALLE Feierlichkeiten. Sonntags hält die dänische Gemeinde hier ihren Gottesdienst. Dann kommt hinter einer Wand der Altar zum Vorschein" (Werner 16.05.2016). Auch Kaffeerunden anlässlich des Besuchs des dänischen Bücherbusses finden hier statt. Würden einige Schulen und Schulgebäude nicht existieren, hätte das Auswirkungen auf die anderen Vereine, weil es dann kaum noch Versammlungsorte sowie inhaltliche und personelle Anknüpfungspunkte für Akteur*innen der Minderheit auf Ortsebene gäbe.

Ohne die Arbeit der dänischen Schulen sei die Minderheit ernsthaft in Gefahr, so Udo Jessen. Ohne die Vermittlung von Sprache und Kultur im dänischen Schulsystem bliebe nicht viel vom Minderheitendenken zurück und eine Assimilierung an die Mehrheitsbevölkerung drohe, so der Vorsitzende. Die Bedeutung des dänischen Bildungssystems in Südschleswig für die Aufrechterhaltung der Minorität könne dementsprechend gar nicht hoch genug bewertet werden (Jessen 2012: 101-103). Die Angst vor der Assimilierung in die Mehrheit ${ }^{21}$ steht im Kontrast zur Bewertung Jørgen Kühls, der bei der dänischen Minderheit eine Disassimilierung beobachtet (s. S. 108). Allerdings widerspricht Kühl Funktionär Jessen nicht in seiner Schlussfolgerung, derzufolge die Schulen bei der Abwanderung von Menschen aus der Mehrheit in die Minderheit eine große Rolle spielen. Die entscheidende Bedeutung des dänischen Schulsystems für die Minderheit beschreibt nicht nur Jessen, sondern ebenfalls die SSF-Funktionärin und Lehrerin beim Integrationskurs (s. Kap. 6), Gitte Hougaard-Werner. Sie behauptet, dass es im mitgliederbasierten Schulverein Konsens sei, dass die dänische Schule „so dänisch wie möglich, so deutsch wie notwendig' ${ }^{\text {‘242 }}$ sein solle (Hougaard-Werner 14.10.2013). Die Minderheit lebe davon, dass die Kinder in eine dänische Schule gehen könnten. Je früher die Kinder in das dänische System kämen, desto besser. Am besten

241 Die Angst vor Assimilierung der Minderheit in die Mehrheit findet sich auch bei der ungarischen Minderheit in Cluj-Napoca, die skeptisch gegenüber sogenannten Mischehen oder zu viel Austausch mit der rumänischen Mehrheit ist (Feischmidt 2003: 279).

${ }^{242}$ „så dansk som muligt, så tysk som nødvendigt“ (Hougaard-Werner 14.10.2013) 
sei es, wenn die Kinder vor der Schule den dänischen Kindergarten besuchten (ebd.). Hougaard-Werners Aussage gründet auf der Idee, dass je mehr Zeit die dänische Institution für die Ausbildung zum Dänischsein habe, umso wahrscheinlicher werden die jungen Leute zu aktiven Minderheitendän*innen. Je länger die Kinder im Alltag und in ihrer Freizeit im Kontakt mit dem Dänischen seien, desto dänischer würden sie werden (ebd.). Nachmittags können die Kinder neben dem Sport- und Jugendverein (SdU) vor allem bei der freiwilligen Skolefritidsordning, also der Nachmittagsbetreuung, weiter das Dänischsein lernen und praktizieren. Peter Huber kommentiert in der Flensborg Avis die Situation in einem Leserbrief. Er schreibt, dass Schüler*innen ,in eine unbehagliche, sektenähnliche Situation gepresst werden“2433 (Huber 22.11.2013). Damit meint er möglicherweise den Versuch der dänischen Institutionen, möglichst früh und möglichst lange pro Tag und bezogen auf das Lebensalter, Zugriff auf Kinder der Minderheit zu bekommen, um sie ganzheitlich dänisch zu machen.

Aufgrund der beschriebenen Bedeutung der dänischen Schulen für die Bekenntnisminderheit bekennt Funktionär Jessen öffentlich, dass die dänische Schule eine Gesinnungsschule ${ }^{244}$ (Jessen 2012: 104), eine „Bekenntnisschule“ (dpa 24.12.2012) sei. Daraus leitet er die Forderung ab, dass der Schulverein eine Beeinflussung der jungen Menschen und ihrer Eltern durchführen könne. Er betont, dass es dabei keine ideologische Gehirnwäsche gebe, sondern pädagogische Arbeit geleistet werde (Jessen 2012: 103, 106; Dansk Skoleforening for Sydslesvig 24.12.2016). Es bestehe im Verein der Wunsch, dass die Kinder ,aus eigenem freien Willen “245 dänische Südschleswiger werden wollten (Jessen 2012: 103). Junge Menschen seien nach der Entscheidung für das dänische System über einen langen Zeitraum hinweg, nämlich von der Kindertagesstätte bis zum Abitur, „unter der Obhut ${ }^{\text {‘246 }}$ des Schulvereins (Dansk Skoleforening for Sydslesvig 24.12.2016).

Der Norweger Per Gildberg, Vorgänger von Jessen in dessen Funktion als Vorsitzender, erläutert das Pochen des Vereins auf den Status als konsequente dänische Gesinnungsschule in der Flensborg Avis damit, dass dies das zentrale Prinzip zur Erhaltung des Minderheitsstatus sei (Gildberg in Reese 21.08.2012). Gildberg befürchtet, dass sich ohne die Einhaltung dieses Prinzips Willkür ausbreiten könnte, was die gesamte dänischen Minderheit unterlaufen und unglaubwürdig machen würde. Die Existenz der dänischen Schulen und der Minderheit sei dann in Gefahr (Gildberg in ebd.). Dies kann auf ein Bewusstsein bei den

\footnotetext{
243 „De bliver presset ind i en ubehagelig sektlignende situation“

244 Den Begriff „Gesinnungsschule“ verwendet nicht nur der Schulvereinsfunktionär, sondern auch die dänische Sprachwissenschaftlerin Karen Margrethe Pedersen (1990b: 14), während der Linguist Hubertus Menke von „Weltanschauungsschule“ spricht (Menke 1994: 121).

245 ,af egen fri vilje“

246 „under vores favn“"
} 
Funktionär*innen hindeuten, welches beinhalte, dass die Existenz der dänischen Schulen als nicht selbstverständlich erachtet wird, sondern der Rechtfertigung bedürfe und es dadurch einen starken Selbstzweck und Selbsterhaltungstrieb gibt. Die Minderheit ist nicht einfach nur da und deshalb gibt es Minderheitsschulen. Sondern ohne die Minderheitsschulen gäbe es die Minderheit nicht und damit gäbe es auch keine Minderheitsschulen mehr. Aus ideologischen Gründen und möglicherweise zur Erhaltung der eigenen Posten und somit von Geldern wollen die Funktionär*innen die Minderheit mitsamt den Schulen aufrechterhalten.

Der Spagat der dänischen Bildungseinrichtungen bestehe darin, einerseits die Schüler*innen darauf vorzubereiten, „dass sie gute Südschleswiger, gute Dänen werden ${ }^{\text {‘247 }}$, andererseits sollten die Kinder lernen, eigene Entscheidungen zu treffen, darunter möglicherweise auch eine Abwahl der dänischen Minderheit Jessen 2012: 105). Der 2013er-Abiturient der Duborg-Skole, Claas Johannsen, konstatiert im Film De glemte danskere, Die vergessenen Dänen, dagegen kritisch, dass die Schulen in Südschleswig mit seinen Worten eine Dänenfabrik seien. Die Schüler kämen als Deutsche in die Schule und als fertige Dänen wieder heraus (Petersen [2014]). Der dänische Schulbesuch sei ein identitätsstiftender und identitätsstärkender Prozess, und niemand komme unbeeinflusst durch das dänische Schulsystem in Südschleswig, gibt der dänische Generalkonsul in Flensburg Henrik Becker-Christensen in seiner Rede zum Jahrestreffen am 10.06.20106 in Wanderup zu (Rung Nielsen 11.06.2006).

Der Schulverein mache es den neuen Mitgliedern gegenüber sehr deutlich, welche Erwartungen an sie gestellt würden. Die Mitgliedschaft im SSF für Neudän*innen, die ihre Kinder auf die dänische Schule schicken, solle dringend empfohlen werden, aber freiwillig bleiben, so Gildberg weiter (Gildberg in Dürkop 16.11.2013). Er betont, dass der Schulverein seine Räumlichkeiten für jegliche dänische Kulturarbeit und Freizeitaktivitäten zur Verfügung stelle. Die Institution fordere zusätzlich alle ihre Mitglieder auf, den SSW zu wählen, die Flensborg Avis zu abonnieren, die Dänische Kirche zu nutzen und beim SdU mitzumachen (Gildberg in Dürkop 16.11.2013; Gildberg in Sydslesvigsk Forening 2013a). Hier wird die Inkonsistenz zwischen Auf- und Anforderungen sowie Erwartungen an Mitglieder einerseits und andererseits dem Bewusstsein, dass man niemanden zu etwas zwingen kann und die eigenen Erwartungen möglicherweise undemokratisch sind, deutlich. Durch starken sozialen Druck und Propaganda wird im Schulverein versucht, die Vereinsziele durchzusetzen und Mitglieder dazu zu bringen, auch in anderen dänischen Vereinen Mitglied zu werden. Der Schulverein tritt nicht nur als Bereitsteller von Kinderbetreuungseinrichtungen und Schulen auf, sondern will

247 ,at blive gode sydslesvigere, gode danskere“ 
auf das ganze Leben seiner Mitglieder zugreifen, auf die Freizeit, auf den Glauben, auf die politische Einstellung durch Vorgaben, die einigen Menschen Orientierung geben, andere aber auch bevormunden könnten.

Die ideologischen Ziele des Schulvereins stehen im Kontrast zu den Ergebnissen von Erziehungswissenschaftler*innen. Beispielsweise hat Alexander von Oettingen, Prorektor des University College Syddanmark und Leiter des dortigen Zentrums für Minderheitenpädagogik, das pädagogische Idealmodell einer Minderheitenschule folgendermaßen beschrieben:

Am Ende der Kindergartenzeit eines Kindes oder am Ende der Schulzeit eines Schülers steht kein bestimmtes Minderheitenleben oder Bekenntnis zur Minderheit. Die Schulen der Minderheit liefern das Kind nicht bei der Minderheit ab, sondern an ein öffentliches Leben, welches ein Minderheitenleben beinhalten kann, aber nicht muss. Man kann die Minderheit auch abwählen - aber auch das muss gelernt sein. Sowohl in der Minderheit leben zu wollen, als auch nicht in der Minderheit leben zu wollen, müsse erst gelernt werden (Oettingen 2012: 27). ${ }^{248}$

Dieses offene Konzept der freien Wahl wird vom Schulverein nicht vertreten. Der Lektor am University College Syddanmark und Lehrer an der dänischen Duborg-Schule in Flensburg, Morten Meisner, analysiert die Satzung des Dänischen Schulvereins und bewertet dabei die darin vorkommende Formulierung „Einführung in die dänische Sprache und Kultur" als zweideutig und wenig offen. Einführung könne erstens Introduktion oder zweitens Einimpfung (,indpodning “) bedeuten. Das seien, so Meisner, zwei verschiedene pädagogische Ansätze und die Satzung in diesem Ausdruck zweideutig. Meisner liest weiterhin aus dem Zweckparagrafen des Schulvereins heraus, dass die zweite Bedeutung, also nicht Einführung, sondern Einimpfung gemeint sein müsse, da es dass Ziel des Schulvereins laut dessen Satzung sei, „das Bewusstein über die Zugehörigkeit zum dänischen Volk zu stärken “249. Meisner unterstellt also dem Schulverein, dass das Gemeinschaftsbewusstsein mit dem dänischen Volk durch Indoktrinierung umgesetzt werden solle und dass das Denken in nationalen Einheiten wie Minderheit und Mehrheit und rigsdanskere - Reichsdänen - im Nationalismus des 19. Jahrhunderts wurzele (Meisner 2012: 59-60; Thürer 2015: 46). Søren Harnow Klausen, Philosophieprofessor an der Syddansk Universitet in Odense, kritisiert in einem

248 „I slutningen af barnets børnehavetid eller i slutningen af elevens skoletid fremstår ikke et bestemt mindretalsliv eller en bekendelse til mindretallet. Mindretallets skoler afleverer ikke barnet til mindretallet, men til et offentligt liv, som kan inkludere et mindretalsliv, men ikke behøver det. Man kan også vælge mindretallet fra - men det skal også læres. Både det at ville leve i et mindretal og ikke at leve i et mindretal skal først læres.“

249 ,at fremme bevidstheden om samhørighed med det danske folk“ 
Zeitungsfeature ebenfalls die oben genannten Formulierung im Zweckparagrafen des Schulvereins: Es bleibe unklar, was genau dänisch sei und daher auch, was das Bewusstsein über die Zugehörigkeit genau sein solle (Klausen 07.07.2016).

Meisner schränkt gleichzeitig aber die Erwartungen ein, die man in Bezug auf Minderheitsschulen stellen kann, indem er fragt, ob eine pädagogische Tätigkeit an einer Schule einer nationalen Minderheit überhaupt frei sein kann von Beeinflussung in eine bestimmte Minderheitsrichtung und hin zu einer bestimmten Minderheitsmeinung, ohne gleichzeitig als illoyal gegenüber der Minderheit aufgefasst zu werden (Meisner 2012: 66). Meisner versucht, die Ambivalenz der Ziele des Schulvereins und seiner Funktionär*innen zu ergründen. Sollen die Schüler der Minderheitsschulen zu dem Schluss kommen, dass die dänische Kultur die beste sei, fragt er, oder kann sich die Minderheit auch darüber freuen, dass ein*e Schüler*in durch eine Pädagogik auf kritischer, aufgeklärter, demokratischer Grundlage zu dem Entschluss kommt, sich nicht in einer normativen Präsentation dänischer Kultur heimisch zu fühlen (ebd.: 66).

Der Erziehungswissenschaftler Carl Boehm formuliert in seiner Dissertation, dass die dänischen Schulen das Ziel hätten, die „Gewinnung, Erhaltung und Festigung der nationalen Substanz des südschleswigschen Dänentums“ (Boehm 1992: 34, 39) zu gewährleisten. Die Schülerzahlen in den dänischen Schulen hätten daher in den 1990er-Jahren stetig abgenommen. „Dieser Trend dürfte sich in den nächsten Jahren verstärken, falls der SSV das um sich greifende Negativ-Image der dänischen Schulen als Danisierungs-Instrumente nicht ausräumt. “'250 (ebd.: 34, 39). Diese Prognose Boehms war seinerzeit sicherlich nicht ganz unbegründet. Allerdings wendete sich die Situation in der wirtschaftlich schlechten Lage in Deutschland ab den 2000er-Jahren. Damals gab es viele Arbeitsplätze in Dänemark, und der Besuch der dänischen Schulen sowie die damit verbundene Vermittlung der dänischen Sprache auf hohem Niveau wurde aus wirtschaftlich-materiellen Gründen wieder attraktiv. Dieser Effekt wurde verstärkt durch die Eröffnung der A.-P.-Møller-Schule in Schleswig. Sie wurde mit Mitteln des A.P. Moller $F_{0} d^{251}$, einer vom dänischen Reeder Arnold Peter Møller gegründeten Stiftung, gebaut. Die Schule ist im Vergleich zu deutschen Schulen außerordentlich gut ausgestattet, was für einige Neudänen ein Grund ist, das dänische System für ihre Kinder zu wählen (vgl. Kap. 4.2.2).

Mit der Abkürzung SSV meint Boehm die heute unübliche deutsche Bezeichnung Südschleswiger Verein statt Sydslesvigsk Forening (SSF).

251 „A.P. Møller og Hustru Chastine Mc-Kinney Møllers Fond til almene Formaal“ (A.P. Møller Fonden). Auf Dänisch heißt die Schule A.P. Moller Skolen, auf Deutsch A.-P.-Moller-Schule. Das dänische Gymnasium in Flensburg heißt Duborg-Skolen, auf Deutsch Duborg-Scbule. 
Zusammenfassend lässt sich sagen, dass die dänischen Schulen nicht nur in der Nachkriegszeit, sondern auch heute das zentrale Element für die Konstituierung und Aufrechterhaltung der Minderheit sind. Daraus folgen ein bestimmtes Selbstverständnis und bestimmte Erwartungen an Angestellte und Mitglieder des Vereins.

Aus dem beschriebenen Selbstverständnis des Schulvereins durch Satzung und Funktionär*innen als Gesinnungsschule ergeben sich die im nächsten $\mathrm{Ab}$ schnitt behandelten Erwartungen an die eigenen Angestellten, anhand derer die ideologischen Vorgaben noch deutlicher herausgearbeitet werden.

\subsubsection{Erwartungen an die Angestellten des Schulvereins}

Die Erwartungen des Schulvereins an die eigenen Angestellten sind, so der Vereinsvorsitzende, das diese neben ihrer eigentlichen Arbeit als Lehrer*in, ein großes Engagement und einen Einsatz für die dänische Minderheit auch außerhalb der Arbeitszeit zeigen (Jessen 2012: 108). Dies sei für die Angestellten eine „einzigartige Möglichkeit ${ }^{\star 652}$, die Minderheit mit Inhalten zu füllen, so Jessen (Dansk Skoleforening for Sydslesvig 24.12.2016). Dazu zählen beispielsweise die Mitgliedschaft in dänischen Vereinen, Vorstandsarbeit oder Jugendgruppenarbeit. Dadurch können die Angestellten, die meist in Dänemark ausgebildet seien, „eine lebensnotwendige Sprach- und Kultureinspritzung aus dem dänischen Mutterland weitergeben“" ${ }^{\text {253 }}$ (Jessen 2012: 108). Die Analyse von Meisner aus dem vorherigen Unterkapitel scheint sich hier zu bestätigen, denn hier verwendet ein Funktionär explizit die Einspritzungsmetapher. Eine ähnliche Formulierung benutzt auch der Generalsekretär des Kulturvereins SSF, Jens A. Christiansen, beim dänischen Folkemodet im Jahre 2014, einem nationalen Volkstreffen auf Bornholm. Dort kritisiert er diejenigen südschleswigschen Lehramtsstudierenden, die täglich von Flensburg nach Hadersleben/Haderslev in Dänemark pendeln und nicht zum Studium nach Dänemark umziehen. Diese würden folglich keine „reichsdänische Salzwassereinspritzung ${ }^{\text {‘254 }}$ bekommen (Christiansen in Møllekær 16.06.2014).

Diese Injektionsmetaphern deuten auf eine spezielle Sichtweise der Vorsitzenden hin, denn Spritzen gibt man Körpern, also abgeschlossenen Einheiten, die entweder krank sind und geheilt werden oder die durch Impfung vor etwas Negativem geschützt werden sollen. Udo Jessen sieht folglich die Minderheit als eine abgegrenzte Einheit, die vor einer vermeintlich negativen Assimilierung mit der deutschen Mehrheitsbevölkerung geschützt werden müsse. Indirekt kritisiert er damit zuweilen auch die aus seiner Sicht zu heilenden, also dänisch zu machenden Minderheitenangehörigen, die neu in der Minderheit sind oder die eine So-

\footnotetext{
252 „unik mulighed“

253 „videregive en livnødvendig sprog- og kulturindsprøjtning fra det danske moderland“

254 „rigsdanske saltvandsindsprøjtning““
} 
wohl-deutsch-als-auch-dänisch-Haltung haben. Die Injektionsmetapher könnte auch für die Injektion von Treibstoff in einen dann besser laufenden Motor stehen, der ohne diese Einspritzungen nicht richtig läuft.

Auf der Homepage des Schulvereins wurde ein Papier des Vorstandes und der Direktion des Schulvereins von 1999 zu dessen Informationspolitik veröffentlicht. Darin wird dem eigentlichen Inhalt vorangeschoben, dass besagtes Papier Standpunkte und Haltungen in Bezug auf Angestellte des Schulvereins wiedergebe, es aber kein Regelwerk sein solle. Der Schulverein proklamiert anschließend, und konträr dazu, dass er ein „offener Verein“ ${ }^{\text {“255 }}$ (Dansk Skoleforening for Sydslesvig o. J.b) sei. Aus dem Papier wird ebenso deutlich, dass neue Mitarbeiter*innen des Vereins im gesamten dänischen Alltagsleben ${ }^{256}$ in Südschleswig geschult werden und sie lernen sollen, welche anderen Minderheitenorganisationen es gibt und was ihre jeweiligen Aufgaben sind (ebd.). Von den angestellten Lehrer*innen sowie Pädagogen*innen wird nicht nur erwartet, dass sie ihrer ganz normalen Arbeit nachgehen, sondern darüber hinaus auch als Schlüsselpersonen in ihrer Freizeit bei der Vermittlung dänischer Sprache und Kultur fungieren (ebd.). Ende 2016 gab es ein vom Schulverein organisiertes „Speeddating“, auch „Dialogtreffen““257 genannt, für neu eingestellte Mitarbeiter*innen, die dort alle Minderheitenorganisationen kennenlernen und dabei auf den richtigen Kurs gebracht werden sollten. Der seit 2014 im Amt befindliche Vorsitzende Jessen konstatiert in der Mitgliederzeitung des Schulvereins Fokus, dass man als Mitarbeiter*in „moralisch verpflichtet sei, alle Organisationen und Vereine der Minderheit zu kennen“6258 (Dansk Skoleforening for Sydslesvig 24.12.2016). „Wenn man einen Job südlich der Grenze gewählt hat, hat man die ganze Minderheit gewählt" ${ }^{\text {‘69 }}$, ergänzt Jessen (ebd.). Die Mitarbeitenden seien „,per Definition“ nicht „,irgendwo angestellt $^{\text {‘260 }}$ (ebd.). Lehrer*innen des Schulvereins sollen folglich nicht nur Angestellte sein, die ihrer normalen Lehrtätigkeit nachgingen, als ob sie in Dänemark an einer Schule angestellt seien, sondern sie sollen sich bewusst machen, dass sie für eine Minderheiteninstitution arbeiteten. Es werde erwartet, dass Reichsdänen südlich der Grenze zu Minderheitsdänen werden.

Hier werden explizit und implizit Erwartungen formuliert, sich im Sinne des Schulvereins und der dänischen Minderheit zu verhalten. Es wird zwar kein Zwang ausgesprochen, aber dennoch sozialer Druck durch das Formulieren von

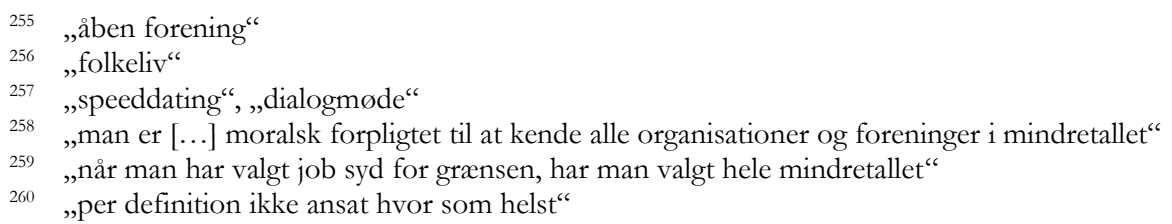


Erwartungen nicht nur auf Mitglieder, sondern sogar auf Angestellte ausgeübt. Das bedeutet, dass der Schulverein hier nicht nur auf die Arbeitskraft der Pädagog*innen Zugriff haben möchte, sondern ebenfalls auf deren Freizeitgestaltung und ideologische Haltung.

Nicht nur Funktionär*innen des Dansk Skoleforening fordern ein Engagement von den Lehrer*innen über den Unterricht hinaus ein, sondern auch der Sydslesvigsk Forening e. $V$. In dessen Satzung steht, dass der Verein von seinen Mitgliedern erwarte, dass sie ihre Kinder in dänische Kindergärten und Schulen schickten ( 5 Satz 1 - Sydslesvigsk Forenings Vedtægter Sydslesvigsk Forening 2009b). Jörn Fischer, der Vorsitzende des SSF-Kreisverbandes Husum, verlangte 2016 auf der Amtsjahreshauptversammlung, dass alle beim dänischen Schulverein angestellten Lehrer*innen und Pädagog*innen Mitglieder im SSF werden sollten (Fischer in Meyer 14.05.2016; Hansen 19.05.2016). Die damit erneut angestoßene Debatte sei sehr alt, so der SSF-Generalsekretär Jens A. Christiansen, rühre aber daher, dass immer weniger Lehrer*innen und Pädagog*innen in der Nähe ihrer Schule bzw. ihrer Kinderbetreuungseinrichtung wohnten und sie sich deshalb vor Ort kaum für die Minderheit über ihre Arbeitszeit hinaus engagierten (Christiansen in Meyer 14.05.2016). Die versammelten Mitglieder erweiterten Fischers Forderung auf die Angestellten anderer Minderheiteninstitutionen, wie der Bibliothek, dem Gesundheitsdienst und dem Kirchenverein, so der Bericht des Journalisten Meyer in der Flensborg Avis (ebd.). Da Jörn Fischer selbst CDU- und nicht SSW-Mitglied ist, wurde möglicherweise eine Forderung nach einer quasi-obligatorischen Minderheitenparteimitgliedschaft ausgespart.

Die Forderungen der Versammlung nimmt einen Monat später der SSF-Ortsvorsitzende Henry Bohm aus Bredstedt im Kreis Nordfriesland in seiner Rede zum Westküsten-Jahrestreffen der dänischen Minderheit in Husum ${ }^{261}$ wieder auf (Bohm 25.06.2016). Bohm fordert darin alle Akteur*innen der dänischen Minderheit auf, nicht nur bruger, also passive*r Nutzer*in der Minderheit zu sein, sondern sich stattdessen aktiv zu engagieren und an der Entwicklung der Kinderbetreuungseinrichtungen oder des eigenen Arbeitsplatzes interessiert zu sein und diese mitzubeeinflussen (ebd.). Bohm weist darauf hin, dass die Angestellten der Minderheit mit ihrer, laut Bohm, hochbezahlten Anstellung allein nicht den folkelig Teil, also den bürgerlich-alltäglich-gesellschaftlichen Teil der Minderheit ausmachten. ${ }^{262}$ Dieser folkelig Teil der Minderheit spiele sich in den Vereinen und bei

261 Freiluftsveranstaltung am 12.06.2016. Die Rede wurde am 25.06.2016 in der Flensborg Avis unter der Rubrik Zeitungsfeature/Kronik abgedruckt.

262 Folkelig hat keine direkte Entsprechung auf Deutsch, kann aber je nach Kontext mit gesellschaftlich, bürgerlich, gemeinschaftlich, das Volk betreffend, populär, typisch dänisch übersetzt werden. Zur Entsprechung im Englischen siehe (Jenkins 2012: xiv). In seinem 1954 gehaltenen und 1969 erneut publizierten Vortrag verwendet der Historiker Alexander Scharff den deutschen Begriff „,volklich“ für folkelig (Scharff 1969a). 
den Veranstaltungen ab, so der SSF-Ortsvorsitzende (ebd.). Konkret dringt Bohm darauf, dass die Angestellten der Minderheitenorganisationen eine Vorbildrolle übernähmen und aktiv und sichtbar zeigten, dass sie Südschleswig etwas angehe ${ }^{263}$ und beispielsweise Eltern aktiv aufforderten, sich ebenfalls an Veranstaltungen der Minderheit zu beteiligen (ebd.). Bohm verlangt bürgerlich-kulturelles, freiwilligunbezahltes und langjähriges Engagement für die Minderheit. Ohne dieses Minderheitenleben außerhalb der Öffnungszeiten, wie Bohm das Freizeitengagement nennt, sei die Minderheit eine Illusion und werde nicht überleben können (ebd.).

Wie bei der deutschen Minderheit nördlich der Grenze ist auch bei der dänischen Minderheit Folgendes schon von Byram Beschriebenes zu beobachten: „some teachers contribute to the continuing debate of the minority's ideas, attitudes, policies and self-definition which maintains a high level of awareness among the membership." (Byram 1986: 155).

An den beschriebenen Plädoyers und Lobbyist*innenaussagen wird deutlich, welche Erwartungen Funktionär*innen an die Angehörigen der Minderheit stellen. Sie wollen das rein pragmatische Ausnutzen der Angebote verhindern und fordern nicht nur ein Bekenntnis zur Minderheit, sondern auch Engagement und Einsatz. ${ }^{264}$ Als Angestellte*r bei einem Minderheitenverein hat man nicht einfach nur einen Job beispielsweise als Lehrer*in, sondern wird darüber hinaus gefordert.

\subsubsection{Die dänischen Schulen und die Akteur*innen heute: Erwartungen und Praxen}

Nachfolgend wird dargelegt, welche Rolle der Schulvereins für Neudän*innen heute hat und welche Erwartungen an die Eltern gestellt werden, die ihre Kinder in das dänische Schulsystem geben und die ich überwiegend im Rahmen des Integrationskurses (s. Kap. 6) befragt habe. Auch der Umgang der Eltern mit diesen Erwartungen wird beleuchtet.

Die Gemeinsamkeit der von mir untersuchten heutigen Neudän*innen und den in dieser Arbeit behandelten Nachkriegsdän*innen ist, dass sie alle zu einem bestimmten Zeitpunkt neu in der dänischen Minderheit und vorher nichtdänisch waren. Die Nachkriegsgeneration wurde von ihren nichtdänischen Eltern dänisch

263 In Anspielung auf das Motto des Jahrestreffens der dänischen Minderheit 2016 „Sydslesvig hvad rager det dig?“, übersetzt: „Südschleswig - was geht es dich an?“.

264 Die von Bohm angemahnte Tendenz, Vereine und Organisationen eigennützig zu verwenden, ohne sich mit Haut und Haaren zu engagieren, ist auch ein Phänomen, welches in der deutschen Mehrheitsgesellschaft bekannt ist. Es gibt die Tendenz, dass Menschen lieber für konkrete Leistungen zahlen, beispielsweise die Nutzung von Geräten in einem Fitnessstudio, als dass sie sich in ihrer Freizeit aktiv für einen Sportverein engagieren, was auch Verpflichtungen, wie z. B. Arbeitseinsätze, beeinhaltet. 
eingeschult, die Neudän*innen in diesem Kapitel sind nichtdänische Eltern, die ihre Kinder ebenfalls dänisch einschulen. Genauso wie es in der Nachkriegszeit sehr viele Neudän*innen in den dänischen Schulen gab, gibt es in der Gegenwart in den dänischen Schulen ebenfalls einen recht hohen Anteil an neudänischen Einschulungen, wie das folgende Zitat des Historikers Kühl belegt:

Ein nicht näher feststellbarer, aber vermutlich erheblicher Anteil der Schüler in den dänischen Schulen stammt nämlich aus Elternhäusern ohne traditionelle Bindung an die Minderheit bzw. mit einem nicht-dänischen Hintergrund, wobei die Eltern bewusst eine Minderheitenschule für ihre Kinder gewählt haben. Diese Schüler werden zwar in der dänischen Minderheit sozialisiert, aber nicht alle identifizieren sich bei Ende ihrer Schullaufbahn als Dänen (Kühl 2006b: 48).

Eine weitere Parallele zur Nachkriegsgeneration ist in diesem Zitat zu finden, denn dort, so mein Ergebnis, identifizieren sich ebenfalls nicht alle als Erwachsene dauerhaft mit der Minderheit. ${ }^{265}$

Heutige neudänische Kinder lernen schnell, dass man durch den Besuch dänischer Einrichtungen dänisch wird. So berichtet der Schüler Kjell aus Eckernförde, Sohn von Nichtdän*innen, in einer NDR-Info-Radioreportage: „Man gehört schon mit drei Jahren zur dänischen Minderheit und manchen in'n dänischen Kindergarten und es ist einfach dann sowas, ja, das ist denn so. Es ist einfach ganz normal" (Kjell in Werner 16.05.2016). Das Dänischsein der Kinder funktioniert also unabhängig davon, welche Zugehörigkeiten die Eltern pflegen. Nach der Wahl des Dänischen werden bestimmte Erwartungen von den Funktionär*innen und den etablierten Angehörigen der dänischen Minderheit an die Eltern der neudänischen Kinder gestellt. Dazu gehört beispielsweise das konsequente Fortsetzen des dänischen Weges. Ein Wechsel zwischen den Minderheits- und den Mehrheitsschulen wird nicht gerne gesehen. Es gibt Fälle, bei denen Kinder den dänischen Kindergarten frühzeitig verlassen mussten, da bekannt wurde, dass die Eltern geplant hatten, das Kind in einer deutschen Grundschule einzuschulen. Tina Zehntner bestätigt diese Erwartung des Besuchs einer dänischen Schule statt einer deutschen Schule im Anschluss an den Kindergarten:

Das wird schon, jaja, das wird auch erwartet, weil sobald merkst, oh, die wollen gar nicht in die dänische Schule,... dann sollen sie, glaub ich, auch nicht im Kindergarten sein,... doch doch, also wenn du den dänischen Weg wählst, denn ja ganz (INT10).

265 Ich erinnere an die Zitate des Ehepaars Erhard, dass ,auf einmal wieder deutsch“ (INT08) war, denn ,eigentlich bist du ja Deutsche“ (INT09). 
Den Eltern wird nahegelegt, das ganze „Paket“ zu nehmen und nicht nur von dänischem Kindergarten und dänischer Schule zu profitieren. Selbst Zehntner, die zum Zeitpunkt des Interviews SSF-Ortsvorsitzende und selbst schon immer ein Teil der Minderheit war, wurde bei der Anmeldung ihrer Tochter Emma zu einem Gespräch mit der Kindergartenleiterin geladen. Sie bekam dort eine Mappe mit Informationsmaterial über alle dänischen Institutionen. Zehntner empfand es nicht als merkwürdig, dass auch sie als Funktionärin der Minderheit zu so einem Gespräch geladen wurde. Aus SSF-Vorsitzenden-Sichtweise findet sie es sehr wichtig, dass die Eltern von dänisch eingeschulten Kindern mindestens Mitglied im SSF werden. Das Vorgehen des Schulvereins erscheint sehr formalisiert und erfolgt ohne Rücksicht darauf, dass Funktionärin Zehntner bereits eine etablierte Minderheitendänin ist. Dieser Vorgang wirkt geradezu absurd, gerade auch, weil die Minderheit in Friedrichstadt sehr klein ist und alle Akteur*innen sich kennen und wissen, wie Zehntners dänischer Hintergrund aussieht. Das freie Gesinnungsprinzip wird durch das hier beschriebenene Verfahren eingeschränkt, indem die Funktionär*innen versuchen, die Gruppe der Minderheit formal nach außen abzugrenzen, um Glaubwürdigkeit nach innen und außen, auch in Richtung Dänemark, zu erlangen.

Beim Eintritt von Kindern in die Kinderkrippen, die Kindergärten oder die Schulen des dänischen Schulvereins muss mindestens ein Elternteil nicht nur Mitglied im Skoleforening werden, sondern sich darüber hinaus verpflichten, Dänisch zu lernen, sofern die Sprache nicht schon beherrscht wird (vgl. Dansk Skoleforening for Sydslesvig o. J.a). „Das ist Pflicht für alle Eltern, die ihre Kinder im dänischen Kindergarten anmelden. Nur so können sie ihre Kinder auf dem Weg auch im Schulalltag begleiten“ (Werner 16.05.2016). Als Hilfestellung zum Erwerb der Sprachkenntnisse werden Dänischkurse vom Schulverein angeboten (INT10; Jessen 2012: 107). ${ }^{266}$ Die Eltern werden nicht nur über den Schulverein, sondern auch über die gesamte „dänische Minderheit als Ganzes“2677 informiert (Dansk Skoleforening for Sydslesvig o. J.a). Der Historiker und gleichzeitig Schulleiter der A.-P.-Møller-Schule Jørgen Kühl nennt dies einen Vertrag mit der Minderheit, also ihr anzugehören und die Sprache zu lernen. „Abstrakt gesehen gehen sie einen sozialen Vertrag über das Minderheitensein inkl. Sprache, Kultur etc. ein und darüber, in die Minderheitsvorstellungswelt einzutreten“268 (Kühl 16.06.2016). Da-

\footnotetext{
266 Diese Sprachkurse machen $68 \%$ aller Weiterbildungskurse für Erwachsene des Schulvereins aus (Ipsen 2014: 155).

„det danske mindretal som helhed“

268 „Abstrakt indgår de en social kontrakt om at være mindretal med sprog, kultur etc. og indtræde i dets forestillingsverden."
} 
bei seien die „Geschäftsbedingungen“ „eindeutig“: „Das Dänische verpflichtet. “269 (ebd.). Diesen Anforderungen des Schulvereins folgt ihrer Meinung nach auch die SSF-Ortsvorsitzende in Friedrichstadt: „Was ich natürlich FINDE, is natürlich, dass ein Elternteil auf jeden Fall Dänisch sprechen soll, aso [sic] zumindest lernen sollte" (INT10). Allerdings gibt es keine konkreten Konsequenzen, falls Eltern die Sprachlernerwartungen ignorieren oder nur pro forma Mitglieder im dänischen Schulverein werden, ohne sich aktiv in der Minderheit zu engagieren (vgl. Møllekær 18.06.2014). Das dänische Angebot an guten und kostenlosen Privatschulen würde deutsche Eltern dazu bringen, sich halbherzig dänisch zu bekennen, nur um von dänischen Steuergeldern zu profitieren, so die Kritik von Karin Röh (2012: 160-161).

Auch der von mir teilnehmend beobachtete Integrationskurs in Jarplund, dänisch Jaruplund, ist eine Maßnahme zur Einbindung der Eltern in die dänische Minderheit und damit auch zur Bindung an den Schulverein. Die Notwendigkeit und der Zwang für mindestens ein Elternteil, Dänisch zu lernen, gründet in der Tatsache, dass die Arbeitssprache in den Institutionen überwiegend Dänisch ist und Elternbriefe auf Dänisch verfasst und Elternabende auf Dänisch abgehalten werden. Einige Eltern berichten mir in informellen Gesprächen allerdings, dass Informationen teilweise auch auf Deutsch wiederholt würden bzw. die Eltern auf Deutsch Fragen stellen dürften, damit sie das Wichtigste verstünden, auch ohne umfangreiche Dänischkenntnisse (INT10; Klaus und Beate am 15.10.2013). Die Eltern würden allerdings nicht alles so gut mitbekommen, wenn sie kein Dänisch sprechen, schränkt Zehntner als dänisch aufgewachsene Mutter und SSF-Funktionärin ein (INT10). Eltern ohne Dänischkenntnisse könnten ihren Kindern nicht bei den Hausaufgaben helfen, und Elternabende und Elternbriefe seien auf Dänisch. Die Hilfe bei den Hausaufgaben sei eine Erwartung, die der Direktor des Schulvereins an die Eltern stelle (Hougaard-Werner 14.10.2013). Eltern sollten die sprachliche Entwicklung, zum Beispiel die Lesefähigkeit ihrer Kinder, unterstützen können, so der Skoleforenings-Direktor von 2000 bis 2015 Anders Molt Ipsen (Ipsen 2014: 155). Das ginge nicht, wenn keine oder nur kaum Sprachkenntnisse bei den Eltern vorhanden seien. Die Herausforderung beim Dänischlernen sei, dass die Kinder viel schneller lernten als die Eltern, die sich damit oftmals schwerer täten: „Die Eltern, die müssen mehr pauken, um das zu schaffen und das ist das Wichtige, dass die Eltern sagen, okay, nun wollen wirs und dann fängt ein, ein für eine Familie, ein, ein Projekt an", so auch Schulleiter Peter Müller (Werner 16.05.2016). Die Autorin der hier zitierten Radioreportage, Ulrike Werner, berichtet, dass schon im Kindergartenalter einige Kinder mehr Dänisch könnten als ihre Eltern (ebd.). Viele Kinder würden die Spaltung zwischen den Institutionen und dem Zuhause bald bemerken, und das könne manchmal zu 
Konflikten führen, wenn die Eltern sich anders zugehörig fühlten als ihre Kinder, die eine dänische Schule besuchten (Kühl 16.06.2016). Diese Nachteile werden von einigen Familien freiwillig in Kauf genommen, da es so „schön“ sei bei den Dänen (TNB Klaus und Beate am 15.10.2013). An den beschriebenen Nachteilen leiden in deutschen Schulen dagegen Kinder aus immigrierten Familien, in denen die Eltern kein Deutsch sprechen. Hier werden die mangelnden Sprachkenntnisse als ein Problem empfunden, welches zu fehlender Integration und schlechteren Bildungschancen für die Kinder führt. Übertragen auf die dänische Schule stellt sich die Frage, wieso Eltern, die kaum Dänisch können bzw. denen es schwer fällt, Dänisch zu lernen, ihren Kinder diese Nachteile zumuten und sie dänisch einschulen. Die Vorteile der dänischen Schulen in Bezug auf erlangte Bildung und ein erlebtes Wohlgefühl überwiegen anscheinend gegenüber den Nachteilen.

Zur besseren Integration der neudänischen Eltern würden diese im Ortsverein Friedrichstadt von der SSF-Vorsitzenden über die Minderheit und ihre Strukturen informiert (INT10). Ihre Aufgabe sei, dass sie in den Kindergarten gehe und dort den Eltern erläutere, dass die dänischen Schulen keine Sprachschulen seien und von den Eltern erwartet werde, sich in den dänischen Minderheitenvereinen zu engagieren. Meist geschehe das im Rahmen einer Präsentation der dänischen Vereine und der Verteilung von Broschüren, Schreibblöcken, Kugelschreibern, Bleistiften, Linealen und Radiergummis mit SSF-Logo und Eintrittsformularen. Zehntner erzählt, dass sie solche Veranstaltungen auch mit dem dänischen Pastor zusammen bestritten habe. Häufige Reaktion unter den Eltern sei die Überraschung darüber, dass der Kulturverein SSF und die Partei SSW nicht das Gleiche seien (INT10).

Obwohl Zehntner zuerst festgelegte Erwartungen der Minderheit an Neueinsteiger*innen abstreitet, vertritt sie die Position, dass die Eltern, die ihre Kinder im dänischen Kindergarten anmelden, auch in den SSF eintreten sollten. Das erwartet Zehntner ebenso von den Pflegebedürftigen, die sich beim Dansk Sundhedstjeneste für den häuslichen Pflegedienst anmeldeten. Wenn Eltern das dänische System für ihre Kinder wählen,

dann sollen sie ja nicht auch nur die Rosinen rauspicken, also viele sehen das ja denn auch mal als Sprachschule oder so ... und da sagen wir denn, so der SSF ist so das mindste [dän.], das Mindeste, was wir finden, wo die sich reinmelden sollen, weil das ja auch .. die Leute .. WIR sind ja auch wieder die, die die Gelder geben für die [sic] Kindergarten, mh... fürn Theater und all sowas, also wir sind die mit dem Geld .. SSW und Kirche ist für uns immer son Ding, ja ... das Partei und Kirche, das, das... da sagen wir immer nix zu ... nä ... also das ist son ... aber so SSF, das ist ja ein Kulturverein, aso [sic] das finden wir, finden WIR so 
als Minimum, genau, wie wenn, bei- ich arbeite beim Dansk Sundhedstjeneste. Da finden wir auch als Minimum sollten die Leute zumindest im SSF sein, um unsere Pflege zu kriegen (INT10).

Dass der SSF den Kindergarten finanziert, stimmt nicht. Die Fördermittel kommen direkt vom dänischen Staat, den Kommunen und den Eltern über den Dansk Skoleforening an die Kindergärten. Der SSF gibt aber Zuschüsse für (kulturelle) Veranstaltungen oder Ausflüge des Kindergartens in Friedrichstadt.

Zehntner weist zurück, dass die Mitgliedschaft der Eltern im SSF kontrolliert werde: „eheh \{verneindend\} NEIN, natürlich nicht“ (INT10). Sie verneint auch, dass bei Eintritt in den SSF die Gesinnung, die Überzeugung oder die Motive für den Eintritt geprüft werden. Allerdings räumt sie ein, dass sie als Minderheitendän*innen „das schon schöner" finden, wenn nicht ausschließlich der Kindergarten gewählt werde. Pragmatisch deutet Zehntner aber ebenso an, dass man auf junge Neueinsteiger*innen auch zugehen müsse, damit sie sich noch mehr integrierten und vor allem im Vereinsleben engagierten (INT10). Zehntner relativiert ihre zuerst formulierten Erwartungen durch ihre Aussage, dass jede*r Mitglied werden könne. Die SSF-Ortsgruppe Drage-Schwabstedt, in der auch viele Friedrichstädter Minderheitsdän*innen aktiv sind, veröffentlichte am 01.03.2013 die Integrationsidee, dem Mitgliederschwund im Ortsverein entgegenzuwirken, indem die Eltern der Kinder im dänischen Kindergarten in den Kulturverein aktiv eingebunden würden (Sydslesvigsk Forening 07.03.2013).

Durch die geschilderten Prozeduren und Erwartungen beim Eintritt in den Skoleforening wird die ideologische Richtung vorgegeben, und es werden von Anfang an klare Erwartungen an die Eltern kommuniziert. Ziel dieses Vorgehens ist, Eltern, die ihre Kinder aus rein pragmatischen Gründen dänisch einschulen wollen, abzuschrecken, sowie sozialen Druck zur Anpassung an die Minderheit aufzubauen. Kinder sollen nicht zufällig dänisch eingeschult werden, sondern aufgrund einer bewussten Entscheidung für die Zugehörigkeit zur Minderheit. Die dänische Einschulung soll verbunden werden mit einem klaren Bekenntnis zur Minderheit. Allerdings hat, wie unten noch gezeigt werden wird, diese formale Prozedur kaum Auswirkungen auf das nationale Bekenntnis der neudänischen Eltern.

Die geschilderten Erwartungen des Schulvereins an die Eltern in Bezug auf das Dänischsein und die durch die Akteur*innen zu tragenden Konsequenzen aus der Wahl des Dänischen werden besonders deutlich bei der sogenannten Soskenderegel, der Geschwisterregelung, einem ungeschriebenen Gesetz des Schulvereins, das in der Flensborg Avis öffentlich diskutiert wurde. Auslöser für die intensive Diskussion waren einige Fälle, bei denen Familien dazu gedrängt wurden, alle ihre Kinder aus dem dänischen Schulsystem zu nehmen, da sie eines ihrer Kinder in eine deutsche Schule schickten (vgl. die Flensborg-Avis-Artikel Thöming 18.08.2012b; Thöming 18.08.2012a; Reese 21.08.2012). 
Ein Beispiel dafür ist eine Glücksburger Familie, die eines ihrer beiden Kinder aus dem dänischen Schulsystem abmeldete, weil es eine Entwicklungsstörung hatte und auf einer deutschen Schule besser gefördert werden konnte. Eine nichtmuttersprachliche, also dänische, Beschulung wäre eine zu große Belastung geworden. Daraufhin fühlte sich die Familie vom dänischen Schulverein dazu gedrängt, auch das zweite Kind von der dänischen Schule abzumelden, was nur durch ein ärztliches Attest für das erste Kind verhindert werden konnte. Dies wurde, neben der Sorge um ihr krankes Kind, als eine zusätzliche Demütigung der Familie durch den Schulverein empfunden (Thöming 06.09.2012a).

Ein weiteres Beispiel für die Anwendung der besagten Regelung ist eine andere Familie aus Glücksburg, die ein Kind auf ein deutsches Gymnasium geschickt hat, damit es dort mehr herausgefordert würde, während das zweite Kind weiterhin die dänische Schule in Glücksburg besuchen wollte, was durch den Schulverein verhindert wurde (Munk Nielsen 23.08.2012). Obwohl die Geschwisterregelung nicht in der Schulvereinssatzung festgehalten ist, wird sie durch die Schulvereinskonsulentin Susanne Ipsen aus Flensburg, Ehefrau von Schulvereinsdirektor (20002015) Anders Molt Ipsen, als feste Regel ausgelegt (Thöming 21.08.2012a).

Es geht bei der Geschwisterregelung also darum, dass der Schulverein bzw. der Vorstand des Schulvereins von seinen Mitgliedern erwartet, dass alle Kinder einer Familie dänisch eingeschult werden bzw. den dänischen Kindergarten besuchen und nicht einige Kinder das deutsche und andere das dänische Schulsystem besuchen. Der Schulverein will damit verhindern, dass es eine freie Schulwahl pro Kind gibt und Familien ihre Kinder in zwei verschiedenen Systemen anmelden (Thöming 06.09.2012d). Kinder werden vom Schulverein also nicht als Individuen gesehen, sondern in Abhängigkeit von ihren Geschwistern betrachtet.

Dass es im Sommer und Herbst 2012 zu einer breiten öffentlichen Diskussion in der Minderheit über diese Geschwisterregelung kam, führt der damalige Vorsitzende des Schulvereins (Amtszeit: 2008-2014), der norwegische Kinderarzt Per Gildberg, darauf zurück, dass in der Öffentlichkeitsarbeit des Schulvereins wohl nicht deutlich genug vermittelt wurde, was es heißt, die Minderheit zu wählen (Reese 23.08.2012). Dabei ist die Geschwisterregelung nicht neu, ${ }^{270}$ sondern wurde

270 Carl Boehm schreibt über die Geschwisterregelung und die Erwartung eines durchgehenden Besuchs der dänischen Kindergärten und Schulen: „Bei der Aufnahme in einem Minderheits-Kindergarten wird verlangt, daß sich die Erziehungsberechtigten verpflichten, ihr [sic] Kinder später eine dänische Schule besuchen zu lassen. Geben Eltern zu einem Zeitpunkt zu erkennen, daß ihre Kinder in öffentliche Schulen geschickt werden sollen, muß der Kindergartenplatz sofort geräumt werden. Dasselbe gilt auch, falls bekannt wird, daß Kinder derselben Familie in eine deutsche Schule geschickt werden. Kontinuierliche Beeinflussung des erwarteten Minderheitennachwuchses scheint im Vordergrund zu stehen und scheint Gesichtspunkten einer zeitweiligen Prägungsmöglichkeit vorzugehen“ (Boehm 1992: 35). 
von der Flensborg Avis anhand einiger Fallbeispiele lediglich wieder in den Raum gestellt. Im November 2013 erläutert Gildberg als Gast auf der SFF-Landesdelegiertenversammlung, dass der Schulverein alle Neuen über die Konsequenzen ihrer Wahl der dänischen Schule aufkläre. Er ergänzt: „Wir machen es ganz klar, welche Erwartungen wir an neue Mitglieder haben ““271 (Gildberg in Sydslesvigsk Forening 2013a: 23). Die Gesinnung ist also frei, aber nicht für Kinder, die Geschwister haben, so scheint es. Per Gildberg betont die Empfehlung des Schulvereins, dass entweder alle oder keines der Kinder einer Familie im dänischen System angemeldet sein dürften (Gildberg in Thöming 06.09.2012d). „Es dreht sich letzten Endes darum zu sagen, entweder deutsch-deutsche Schule oder dänisch-dänische Schule“272, so Anders Molt Ipsen (Molt Ipsen in Thöming 18.08.2012b). Gildberg wird in der Flensborg Avis proklamierend zitiert: „Wir akzeptieren nicht, dass Kinder allein wegen der Sprache in unsere Schulen kommen. Wir dürfen nicht als eine Alternative zu den öffentlichen, deutschen Schulen aufgefasst werden. “273 (Gildberg in Reese 24.08.2012).

Gildberg erläutert das Vorgehen des Schulvereins für den Fall, dass ein Kind von der dänischen Schule abgemeldet wird: Das festgelegte Prozedere sei, die Eltern zu einem Gespräch in die Schule oder in den Kindergarten einzubestellen, wo sie eine einheitliche Information bekämen (Gildberg in Thöming 06.09.2012d). Den Eltern werden dabei die Erwartungen der Schulvereinsfunktionär*innen vermittelt (Gildberg in ebd.). Gleichzeitig räumt Gildberg aber ein, dass, falls es Probleme mit einem Kind gäbe, Geschwisterkinder darunter nicht leiden sollten und nicht zwangsläufig vom dänischen Schulsystem ausgeschlossen würden, nur weil die Eltern sich inkonsequent verhielten (Gildberg in ebd.). „Keiner wird aus der dänischen Schule geworfen“2074, betont Gildberg konträr zu seinen obigen Äußerungen (Gildberg in Krueger 20.09.2012).

Ein Mitglied eines Elternkreises, dänischer Staatsbürger, Ulrik Thomsen, wohnhaft in Glücksburg, fordert, dass kein Kind aufgrund einer Ideologie geopfert werden dürfe. Die Geschwisterregelung sei fast extremistisch und habe nichts mit Dänemark zu tun. Sie sei stattdessen anti-dänisch, so seine Aussagen in der Flensborg Avis (Rasmussen in Thöming 06.09.2012b). Hier wird der Unterschied zwischen selbstverständlichem Dänischsein in Dänemark und dem Minderheitsdänischsein in Abgrenzung zu einer deutschen Mehrheit im Landesteil Schleswig deutlich.

\footnotetext{
271 „Vi gør det helt klart, hvilke forventninger vi har til nye medlemmer.“

272 „Det drejer sig om i sidste ende at sige, enten tysk-tysk skole eller dansk-dansk skole.“

273 „Vi accepterer ikke, at børn kommer i vores skoler alene på grund af sproget. Vi må ikke opfattes som et alternativ til de offentlige skoler."

${ }^{274}$ „Ingen bliver smidt ud af den danske skole.“
} 
Die Bibliothekarin der Dänischen Zentralbibliotek, Rita Jakobsen, ergänzt in der öffentlichen Diskussion auf Facebook, die in der Flensborg Avis wiedergege-

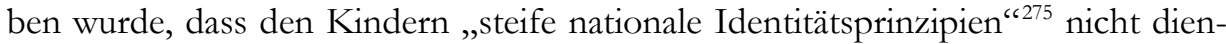
ten (Jakobsen in Munk Nielsen 23.08.2012). Ulrik Rasmussen wirft dem Vorsitzenden Gildberg in der Flensborg Avis vor, nicht zugeben zu wollen, dass die ungeschriebene Geschwisterregelung praktiziert werde. Dabei kenne Rasmussen 15 Elternpaare, deren Kinder aus der dänischen Schule ausgeschlossen worden seien (Rasmussen in Thöming 06.09.2012c). Der Schulverein behauptet, dass keine Kinder die dänische Schule verlassen müssen, aber die Mutter Nikki Dibbern berichtet in einem Leserbrief in der Flensborg Avis, dass der Schulverein die Eltern dränge, ihre Kinder aus dem dänischen System zu nehmen und ihnen, den Eltern selbst, dann die Verantwortung dafür zuzuschreiben versuche (Dibbern 06.09.2012). Anders Molt Ipsen weist die Verantwortung für das Verlassen der dänischen Schulen durch die Geschwisterkinder von sich und schiebt, genau wie Dibbern es beschreibt, die formelle Verantwortung dafür auf die Eltern (Molt Ipsen in Reese 23.08.2012), die sich dadurch jedoch bedrängt fühlen.

Einige Eltern sind der Meinung, dass die Geschwisterregelung, die nicht offiziell im Reglement des Schulvereins zu finden ist, ungesetzlich sei (Thöming 06.09.2012b). Die Eltern fühlen sich beschuldigt, das dänische Schulsystem nur wegen der zusätzlichen Sprache zu wählen, was sie selbst aber von sich weisen (ebd.). Die Vermutung, dass das dänische Schulsystem nur wegen des Erlernens einer weiteren Fremdsprache auf muttersprachlichem Niveau gewählt wird, ist sicherlich nicht bei allen Eltern ganz unbegründet. Es ist natürlich nicht opportun, dies öffentlich zuzugeben, und diese Mutmaßung trifft auch nicht auf alle Eltern zu. Thede Boysen, Leserbriefschreiber in der Flensborg Avis, hebt allerdings hervor, dass die dänischen Minderheitsschulen faktisch schon lange Sprachschulen sind, sie nur offiziell nicht so genannt werden, um die ,nationalideologische Unterstützungsgrundlage ${ }^{\text {‘2 } 276}$ nicht zu gefährden (Boysen 15.03.2016), sprich die Finanzierung aus dem Königreich.

Die ungeschriebene Geschwisterregelung ist ein Beispiel dafür, wie in Gemeinschaften Erwartungen geregelt werden und Gültigkeit erlangen können.

Die sozialen Tatbestände haben einen normativen Charakter. Die Verbindlichkeit einer Norm muß keineswegs explizit, etwa in Form von Gesetzen festgeschrieben sein. Ebensowenig bedürfen die positiven oder negativen Sanktionen grundsätzlich einer fomalen [sic] Kodifizierung. Im Gegenteil: der weitaus größere Teil der Erwartungen, die eine Gesell-

\footnotetext{
275 „stive nationale identitetsprincipper“

276 „nationalideologiske støttegrundlag““
} 
schaft an den Einzelnen heranträgt, wird mit sehr viel subtileren Mitteln sanktioniert (Hase 2001: 185-186).

Auch die SSF-Ortsvorsitzende aus Friedrichstadt, Tina Zehntner, kommentiert die Angelegenheit im Interview: Sie findet die Geschwisterregelung „zu doll“6277, und: „das fand ich jetzt nicht gut“ (INT10). Sie erläutert:

In Flensburg isses auch wieder was anderes, aber hier draußen, denn sind da vielleicht einfach einige Kinder, den[en] kann man einfach nicht die Förderung geben hier bei uns an der Schule... oder Kindergarten, dass sie denn eben ins deutsche System überwechseln müssen, aber bevor sie eben bis Schleswig oder Flensburg fahren müssen, wenn die noch klein sind (INT10).

Andererseits kritisiert Zehntner diejenigen, die zwischen den Systemen wechseln, weil es ihnen in dem einen System doch nicht so gut gefällt:

Ich mein, ich find aber auch nicht so, wie wir ham, ich kenn auch welche, ja, denn melden wir sie mal im dänischen und im deutschen System an und denn können wir ja sehen, was uns besser gefällt, das das geht nicht für mich, also das ... das find ich nicht schön. Entweder wähl ich das Dänische, aber denn auch ganz ... oder gar nicht, ... aber ... aber... wie gesagt ${ }^{\circ}$ das ist ja meine Meinung ${ }^{\circ}$ (INT10).

Nicht schlüssig an der Haltung des Schulvereins ist, dass dessen Funktionär*innen öffentlich ihre offizielle Haltung kundtun und gleichzeitig öffentlich machen, wie sie sich tatsächlich dem gegenüber verhalten. Das lässt außer Acht, dass betroffene Eltern ja auch die Zeitung lesen könnten. Schulvereinsfunktionär*innen behaupten also, dass kein Kind leiden solle und dass die Geschwisterregelung nicht offiziell im Schulvereinsreglement stehe. Gleichzeitig beschreiben sie aber das Vorgehen und die Erwartungen an die Familien. Zu sagen, die offizielle Haltung sei, dass alle Kinder einer Familie unbedingt das dänische System oder das deutsche System durchlaufen sollen und falls dem nicht Folge geleistet werde, so würden die Eltern zu Gesprächen geladen, ergibt wenig Sinn, wenn hinterhergeschoben wird, dass rein formell gesehen ohnehin kein Kind die dänische Schule verlassen muss, falls ein Geschwisterkind im deutschen System angemeldet wird, auch wenn einige Eltern aus der Praxis anderes berichten. Der fast drohend wirkenden Empfehlung und der Erwartungshaltung des Schulvereins fehlt es also an formaler Substanz. Es wird stattdessen versucht, sozialen Druck auf Eltern und Kinder auszuüben, um die eigenen ideologischen Interessen durchzusetzen. $\mathrm{Ob}$ die Geschwisterregelung heutzutage in einer Zeit mit der Zunahme an Patch-

277 regionalsprachlich: zu stark 
workfamilien noch angemessen ist bzw. auf diese überhaupt angewendet werden kann, soll hier nicht diskutiert werden. Die Frage, wie Familie und Geschwister durch den Schulverein definiert werden und zu welchen Konsequenzen es zwischen Geschwistern kommen kann, wenn ein Kind wegen des anderen die Schule verlassen muss, und das andere Kind dementsprechend in Sippenhaft genommen wird, bleibt durch den Schulverein unbeantwortet.

Ein weiterer Punkt in dieser Diskussion ist, ob und warum Familien keine Teilzugehörigkeiten haben können. Also warum soll nicht ein Elternteil dänisch und ein Elternteil deutsch sein können. Es wird Kindern also nicht unabhängig von der eigenen Gesinnung und den Gesinnungen ihrer Geschwister und Eltern freigestellt, für welche Gesinnung oder für welches Schulsystem sie sich selbst entscheiden. Um einen Vergleich mit Religionen zu ziehen, wie es auch der SdU-Geschäftsführer macht (Kring 15.06.2016; vgl. Kap. 8.7), und durch den die ähnlich gelagerten Prozesse offenbar werden, die bei der Wahl einer Religionszgehörigkeit und der Wahl der Zugehörigkeit zur dänischen Minderheit ablaufen, stellt sich folgende, unbeantwortete Frage: $\mathrm{Ab}$ welchem Alter sollte aus Sicht der Funktionär*innen ein Kind seine Gesinnung frei wählen dürfen? Die freie Wahl der Religionszugehörigkeit ist in Deutschland per Gesetz ab 14 Jahren möglich (\$ $5 \mathrm{KErzG}$ (Gesetz über die religiöse Kindererziehung), vgl. den Leserkommentar in der Flensborg Avis (Heidtmann 23.08.2012)). Betrachtet man die Position des dänischen Schulvereins, so werden Kinder in Bekenntnisfragen nicht als Individuen behandelt, sondern nur im Kollektiv mit ihren Geschwistern und Eltern und deren Bekenntnis (vgl. den Kommentar v. Alexander von Oettingen in der Flensborg Avis Thöming 21.08.2012b). Die beschriebene Geschwisterregelung steht im Widerspruch zur Aussage des damaligen zweiten Vorsitzenden Jessen (bis 2014) darüber, dass man den freien Willen der Kinder berücksichtige und eine Gesinnungskontrolle ablehne. Udo Jessen hält diese ebenfalls für kein brauchbares Instrument der Mitgliederpolitik (Jessen 2012: 103). Abgesehen von der Geschwisterregelung haben eine nichtdänische Gesinnung und ein Nichtlernen der dänischen Sprache durch die Eltern in der Praxis kaum Konsequenzen.

Der ehemalige Schulleiter der Friedrichstädter Hans-Helgesen-Schule und jetziger Konsulent des Schulvereins, Bjarne Stenger-Wullf, wertet die Nichteinhaltung der an die Eltern gestellten Erwartungen allerdings als eine Vernachlässigung des Kindes (Stenger-Wullf 2012: 129) ${ }^{278}$ Mit Nichteinhaltung meint Stenger-Wullf die Weigerung von Eltern, Dänisch zu lernen und sich damit nicht am dänischen Leben des Kindes zu beteiligen oder keinen Zugang zur dänischen Minderheit zu

278 Damit meint Stenger-Wullf die Situation, wenn sich Eltern nicht am dänischen Leben des Kindes beteiligten, kein Dänisch lernten oder keinen Zugang zur dänischen Kultur fänden, ihr Kind aber trotzdem Dänisch beschulen ließen. 
finden, obwohl sie ihre Kinder dänisch eingeschult haben (ebd.: 129). Der erste Vorsitzende des dänischen Schulvereins (bis 2014), Per Gildberg, bestätigt bei der SSF-Landesversammlung im November 2013: Wenn man „unsere Schulen oder unsere Institutionen wählt“, habe man „die dänische Minderheit als kulturellen Standpunkt für seine Familie gewählt ${ }^{\text {‘279 }}$ (Gildberg in Dürkop 16.11.2013). Gildberg impliziert durch die Nennung des Begriffs „Familie“ ein traditionelles Familienbild, nach dem nur komplette Familien Teil der Minderheit werden können, nicht aber einzelne Familienmitglieder.

Ein immer wiederkehrender Widerspruch in Bezug auf die dänische Minderheit offenbart sich, zusammenfassend formuliert, bei der Diskussion um die Geschwisterregelung: Einerseits ist das Bekenntnis zur Minderheit frei und darf nicht überprüft werden, so die Bonn-Kopenhagener-Erklärungen und die schleswig-holsteinische Landesverfassung, und Akteur*innen der Minderheit fühlen sich als Teil einer offenen, toleranten, dänischen Gesellschaft (Leserkommentare Dechange 23.08.2012 und Dibbern 06.09.2012). Trotzdem führen einige leitende Akteur*innen der Minderheit andererseits eine Art informelle, aber wirkende Gesinnungskontrolle durch, indem sie Eltern, die ein Kind deutsch einschulen, dringend raten, das andere Kind von der dänischen Schule zu nehmen. Und man beharrt auf Abgrenzung und einer Entweder-Oder-Wahl, anstatt individuelle Lösungen zu akzeptieren. Es kann konstatiert werden, dass die Geschwisterregelung Ausdruck des Wunsches der Schulvereinsfunktionär*innen und einiger Minderheitenakteur*innen nach Konsequenz und Eindeutigkeit in der nationalen Gesinnung ist. Die Gesinnung ist für sie zwar einerseits frei, andererseits bedeutet dies für die Funktionär*innen aber nicht, dass sie fließend oder veränderlich oder relational sein darf. Stattdessen wird das Recht auf Freiheit der Gesinnungswahl verbunden mit einer starren und strikten Erwartungshaltung, demzufolge eine einmal getroffene Entscheidung lebenslänglich und konsequent durchgehalten werden soll. Daraus kann man auf ein essenzialistisches Weltbild schließen. Die Gesinnung ist aus Sicht einiger nationalistischer Ideologen der Minderheit zwar frei, aber dies nur einmalig und bis zu einer gewissen Grenze.

Die Widersprüchlichkeit des dänischen Schulsystems wird auch durch den Aspekt der Kommodifizierung des Dänischseins befeuert. Obwohl die dänischen Schulen, wie oben gezeigt, ausdrücklich keine binationalen und keine bilingualen Schulen sein wollen, sondern dänische Gesinnungsschulen, wirbt der Schuldirektor des dänischen Gymnasiums in Schleswig und Historiker Jørgen Kühl mit der Kompetenz der Zweisprachigkeit der dänischen Schulabsolvent*innen (Kühl 19.08.2013; Kühl 2006b: 39). Einige Funktionär*innen möchten keine zweisprachigen, sondern dänische Bekenntnisschulen, werben aber genau mit dieser nicht-

279 „Vælger man vore skoler eller vore institutioner, har man valgt det danske mindretal som kulturelt ståsted for sin familie." 
praktizierten, nicht-postulierten Zweisprachigkeit. Diese besteht darin, dass der Unterricht auf Dänisch abgehalten wird, einmal abgesehen vom Deutschunterricht. Funktionär*innen sehen einerseits materiell-wirtschaftliche Bekenntnisgründe kritisch, aber heben gleichzeitig die wirtschaftlichen Vorteile der Minderheitsschulen, nämlich Zweisprachigkeit und Arbeitschancen in Dänemark, Deutschland und im Grenzgebiet, als positives Moment hervor und widersprechen somit der eigenen Ideologie, um Werbung für ihre Einrichtungen zu machen, die gleichzeitig, wie oben erläutert, eigentlich keine Bildungsalternative zum deutschen Schulsystem sein sollen. Die Hervorhebung der Arbeitschancen im Bereich der dänisch-deutschen Wirtschaftsbeziehungen ist ein wiederkehrendes Argument. Es wird immer wieder betont, dass Deutschland Dänemarks größter Handelspartner ist und gleichzeitig immer weniger Dän*innen im Königreich in der Schule Deutsch lernen, sodass der entstehende Bedarf mit Minderheitsangehörigen, die sowohl Deutsch als auch Dänisch beherrschen, gefüllt werden soll. Zudem spreche ja gerade diese Lücke für die Einrichtung binationaler und bilingualer Schulen beiderseits der Staatsgrenze statt des Betreibens konsequent dänisch-nationaler Schulen. Im nächsten Abschnitt werden die Widersprüche zwischen Anspruch und Wirklichkeit der dänischen Schulen in Bezug auf den formalen Status erörtert.

\subsubsection{Anspruch und Wirklichkeit, Abgrenzung und Offenheit: die dänische} Schule als private oder öffentliche Schule

Bezugnehmend auf das Eingangszitat von Kapitel 5.2 über die ,geschlossene offene Gesellschaft" (Jessen 2012: 106) wird in diesem Unterkapitel die grundlegende Ambivalenz und Widersprüchlichkeit innerhalb der dänischen Gesinnungsminderheit mit ihren Schulen des Skoleforening erschlossen. Hierbei geht es vor allem um den Widerspruch zwischen dem formal-rechtlichen Status als Privatschulen und dem Wunsch der Funktionär*innen, in einigen Belangen den Status einer öffentlichen Schule haben zu wollen.

Eltern sollen, so der Schulverein, ihre Kinder nicht aus pragmatischen, pädagogischen oder sprachlichen Gründen dänisch einschulen. Wie bereits in Kapitel 4.2.2 gezeigt, machen viele neudänische Eltern aber genau das. Auch der Bredstedter SSF-Ortsvorsitzende Henry Bohm räumt selbstkritisch in seiner Rede zum Jahrestreffen der Minderheit in Husum 2016 öffentlich ein, dass viele Eltern die Minderheit nutzen, um ihre Kinder in dänische Kindergärten und Schulen zu schicken, weil diese eine kostenlose Alternative zum deutschen Schulwesen seien und dies die Lernmöglichkeiten für ihre Kinder im Vergleich zu deutschen Schulen verbessern könne (Bohm 25.06.2016). Flemming Meyer, Vorsitzender des Südschleswigschen Wählerverbandes, unterstellt dagegen in der Flensborg Avis allen, die sich zur Minderheit bekennen, dass sie ein dauerhaftes Interesse daran haben 
müssten, dass ihre Kinder in dänischer Sprache und Kultur unterrichtet würden (Meyer in Reese 23.08.2012) und somit nicht aus rein materiellen Interessen handelten. Dies entspricht aber nicht der Realität aller Eltern. Der dänische Schulverein sei mit seinen Angeboten keine Alternative zum öffentlichen System, sondern, so Kühl, „ein existenzieller Teil der dänischen Minderheit“' ${ }^{\text {280 }}$ (Kühl 16.06.2016).

Einerseits sind die dänischen Schulen des Skoleforening for Sydslesvig e. V. Privatschulen, korrekter Ersatzschulen, auch „Schulen in freier Trägerschaft" genannt (\$115-\$118, \$124 SchulG, vgl. Kap. 3.2.2), weil der Schulverein eine juristische Person des Privatrechts, genauer ein eingetragener Verein ist ( $\$ 2$ Abs. 3 SchulG). Seitens der Funktionär*innen des dänischen Schulvereins gibt es andererseits aber immer wieder gegenteilige Äußerungen zum Status der Schulen als Ersatzschulen. Der damalige Vorsitzende des Schulvereins, Per Gildberg, konstatiert beispielsweise, dass die dänischen Schulen für ihn keine private Alternative zu deutschen Schulen seien, sondern dass er die dänischen Schulen als öffentliche Schulen für die dänische Minderheit betrachte, die man nicht wie private Schulen willkürlich wählen oder abwählen könne (Gildberg in Reese 21.08.2012). Gildberg reagiert im Mitgliedsblatt des Schulvereins, Fokus, folgendermaßen auf das Ergebnis der Koalitionsverhandlungen zwischen SPD, Grünen und SSW im Landtag 2012, das besagte, dass Minderheitsschulen finanziell mit den öffentlichen Schulen gleichgestellt werden sollten:

Ich bin froh und auf viele Arten über das Ergebnis erleichtert. Der wichtigste Punkt ist, dass man jetzt akzeptiert hat, dass unsere Schulen die öffentlichen Schulen für die dänische Minderheit sind. Damit folgt nicht nur eine ökonomische, sondern auch eine moralische Verpflichtung (Gildberg in Dansk Skoleforening for Sydslesvig 09.06.2012: 1). ${ }^{281}$

Gildberg geht davon aus, so die Pressemitteilung des Schulvereins, „dass der alte Passus im Schulgesetz darüber, dass die dänischen Schulen öffentliche Schulen für die dänische Minderheit sind, reaktiviert wird“282 (ebd.: 1). Auch der SSW betrachtet das dänische Minderheitenschulsystem in einem Landtagsantrag ebenfalls als öffentliches Schulsystem für die Minderheit (Harms 11.10.2017: 2).

Der Anspruch der dänischen Minderheit auf die Anerkennung als öffentliche Schule für die dänische Minderheit beruht auf dem Wunsch, finanziell wie öffentliche Schulen behandelt $\mathrm{zu}$ werden, also einen Zuschuss vom Land $\mathrm{zu}$ be-

\footnotetext{
280 „en eksistentiel del af det danske mindretal“

281 „Jeg er glad og på mange måder lettet over resultatet. Det vigtigste punkt er, at man nu har accepteret, at vores skoler er de offentlige skoler for det danske mindretal. Dermed følger ikke kun en økonomisk men også en moralsk forpligtelse."

282 ,at den gamle passus i skoleloven om at de danske skoler er de offentlige skoler for det danske mindretal, nu bliver genetableret“
} 
kommen, der zu $100 \%$ dem Schüler*innenkostensatz, also der Kosten für eine*n Durchschnittsschüler*in auf öffentlich-deutschen Schulen, entspricht ( $\$ 124$ SchulG). Andere private, allgemeinbildende Schulen in freier Trägerschaft, wie beispielsweise Waldorfschulen, werden dagegen nur mit $82 \%$ dieses Kostensatzes bezuschusst $(\$ 122$ SchulG). Ein in der Zeitung anonym zitiertes SSF-Vorstandsmitglied sieht einen Zusammenhang zwischen dem Status als Ersatzschule mit 100 \%- statt $82 \%$-Förderung und dem Anspruch, eine öffentliche Schule zu sein. Wenn man sich als Schulverein die Schüler*innen zu kritisch aussuche, könne man gleich einen $82 \%$-Zuschuss beantragen, wie er den privaten Schulen zustehe, die wiederum nicht jedes Kind aufnehmen müssten. Also nehme man entweder alle Kinder auf, die aufgenommen werden wollen, oder man sei eine normale Ersatzschule, die sich ihre Kinder aussuchen könne (Thöming 13.09.2012).

Weil Gildberg die dänischen Schulen als öffentliche Schulen bewertet, fordert er auch die öffentliche Übernahme der Schüler*innentransportkosten durch die Kommunen, wie es bei den öffentlichen Schulen der Fall ist. „Es bedeutet viel für unser Selbstverständnis, dass die unterschiedliche Behandlung im Hinblick auf die Schülerbeförderung aufgehoben wird“283 (Gildberg in Dansk Skoleforening for Sydslesvig 09.06.2012: 2). Auch der damalige zweite Vorsitzende des Schulvereins, Udo Jessen, freute sich über die anstehende Gleichberechtigung dänischer und deutscher Schüler: ,Jetzt werden wir zuerst froh sein, dass die unterschiedliche Behandlung von deutschen und dänischen Schüler*innen aufgehoben wird“284 (Jessen in ebd.: 2).

Die Aussage Gildbergs, dass der Schulverein eine öffentliche Schule für die Minderheit sei und damit seitens des Landes eine moralische Verpflichtung einhergehe, zieht weitreichende Konsequenzen nach sich, die die Funktionäre nicht zu bedenken scheinen. Aus der Logik Gildbergs würden sich ja andersherum ebenfalls Verpflichtungen des Schulvereins gegenüber der Öffentlichkeit ergeben und nicht nur einseitige Verpflichtungen des Landes gegenüber den dänischen Schulen. Mit dem Status einer öffentlichen Schule könnte die, wie Gildberg es im umgekehrten Falle nennt, „moralische“ Notwendigkeit, sich an bestimmte Gesetze zu halten, die für die öffentlichen Schulen des Landes Schleswig-Holstein gelten, einhergehen. Dies wird aber durch den Schulverein ignoriert, wie folgende Beispiele zeigen:

283 „Det betyder meget for vores selvforståelse, at forskelsbehandlingen med hensyn til elevkørslen bliver ophævet."

284 „Nu skal vi i første omgang være glade for, at forskelsbehandlingen af tyske og danske elever bliver ophævet.“ 
Zunächst können öffentliche Schulen nicht aufnehmen, wen sie wollen, sondern müssen alle Kinder aufnehmen, unabhängig von deren Gesinnung oder Familienzugehörigkeit ( $\$ 4$ Abs 7 SchulG). Ersatzschulen in freier Trägerschaft können sich dagegen ihre Schülerinnen und Schüler nach eigenen Kriterien, Überzeugungen, Gesinnungen und Ideologien aussuchen ( $\$ 7$ Abs. 3 SchulG; Oettingen 05.09.2012). Die Funktionär*innen im dänischen Schulverein knüpfen dagegen Bedingungen für Eltern und Kinder an den dänischen Schulbesuch. Sie wollen entscheiden, wer ihre Institutionen besuchen darf, sie haben Erwartungen an die Sprachkompetenz der Eltern, sie wollen eine Gesinnungseinrichtung sein und schließen, wie die Geschwisterregelung (s. Kap. 5.2.3) zeigt, einzelne Kinder vom dänischen Schulbesuch aus. Der Ausschluss von Kindern bei gleichzeitigem Anspruch, eine öffentliche Schule sein zu wollen, ist ein Widerspruch (vgl. a. ebd.). Kühl interpretiert diesen Widerspruch als eine Abgrenzung zur Aufrechterhaltung der Parallelgesellschaft der Minderheit (Kühl 19.08.2013).

Ein zweites Beispiel für einen Widerspruch ist eine vom Schulvereinsvorstandsmitglied André Pastorff in einem Leserbrief geäußerte Kritik. Er bemängelt, dass Funktionär*innen des Skoleforeningen mit ihrem Vereins- und Privatschulstatus für die eigene Nichteinhaltung öffentlich-rechtlicher Regeln für öffentliche Schulen argumentierten. Pastorff führt das Beispiel an, dass Anträge von Eltern an den Schulverein nicht schriftlich, sondern nur mündlich beantwortet und übliche Verwaltungswege nicht eingehalten würden, was sowohl gegen dänische als auch gegen deutsche Verwaltungsrichtlinien und -praxen verstoße (Pastorff 08.09.2012).

Drittens fordert nicht nur der Kulturverein SSF, sondern auch der Schulverein seine Mitglieder, also alle Eltern von Kindern in dänischen Kindergärten und Schulen, explizit in seinem Mitgliederorgan Fokus dazu auf, den SSWPolitiker Simon Faber bei der Oberbürgermeisterwahl in Flensburg zu wählen (Jessen 28.05.2016) ${ }^{285}$. Auch vor der Landtagswahl im Mai 2017 wurde Wahlwerbung für den SSW gemacht. Ein weiteres Beispiel ist die Werbung auf der Homepage des SSW-Kreisverbandes Nordfriesland durch den Schulleiter der dänischen Schule in Risum-Lindholm, Jörgen Jensen Hahn, der in einem Kapuzenpullover mit Schullogo und -schriftzug für den SSW posiert (Südschleswiger Wählerverband (SSW) 04.09.2017). Werbung und Wahlwerbung ist in öffentlichen Schulen eigentlich verboten, so das schleswig-holsteinische Schulgesetz ( $\mathbb{S} 29$ SchulG). Daran hält sich der eingetragene Verein Skoleforening in diesem Beispiel nicht, was aber rechtlich gesehen aufgrund des formalen Privatschulstatus, nicht zu beanstanden ist, aber den eigenen, öffentlich formulierten moralischen Ansprüchen, eine öffentliche Schule sein zu wollen, widerspricht.

285 S. a. S. 226. 
Der Schulverein misst also mit zweierlei Maß: Einerseits wird die Zuerkennung des Status einer öffentlichen Schule mit allen seinen Vorteilen gefordert, andererseits wird, mit den Worten Gildbergs, „moralisch“ gegen die Regeln, die für öffentliche Schulen gelten, verstoßen. Der Schulverein versucht, die Vorteile aus dem Anspruch eine öffentliche Schule sein zu wollen und als gleichzeitig nur eine Ersatzschule zu sein für sich zu nutzen, ohne die jeweiligen vermeintlichen Nachteile der beiden formalen Status in Kauf zu nehmen. Im nächsten Abschnitt wird untersucht, welche Rolle die dänische Finanzierung für die dänischen Schulen in Bezug auf Offenheit und Abgrenzung spielt und welche Erwartungen und ideologischen Ansprüche dadurch entstehen.

Die Geldzuwendungen (s. Kap. 7.6) aus Dänemark und Schleswig-Holstein für die dänischen Schulen sind abhängig von der Anzahl der im Schulverein angemeldeten Kinder. Je mehr Schüler*innen angemeldet sind, desto mehr Geld fließt an den Schulverein. Je größer die Klassen bzw. Gruppen sind, desto günstiger wird also der einzelne Schüler bzw. die einzelne Schülerin für den Schulverein. Dieser hat daher ein finanzielles Interesse an einer hohen Kinderzahl. Letzteres ist noch aus einem weiteren Grund wichtig für den Schulverein und die Minderheit als Ganzes: Gibt es zu wenige Schüler*innen an einem Ort, drohen Schulschließungen, wie beispielsweise die Schließung der dänischen Schule in Ladelund-Tinningsted im Kreis Nordfriesland 2016 zeigt (Dansk Skoleforening for Sydslesvig a, BDO Statsautoriseret Revisionsaktieselskab 01.03.2016). Karl Otto Meyer weist ebenfalls auf diesen Umstand hin: „Es ist sowohl menschlich als auch verständlich, wenn eine kleine Schule deutsche Eltern einbezieht, um existieren zu können “2826 (Meyer in Dittrich 14.07.2006b). Allerdings fordert er, dass man als dänische Institution die Eltern trotzdem über ihre Verpflichtungen aufklären sollte (Meyer in ebd.). Auch Anne Brixen ${ }^{287}$, Mitarbeiterin der Flensborg Avis, erzählt mir nach dem Besuch der Integrationskursgruppe in der Redaktion, dass die Minderheit auf die Neudän*innen angewiesen sei, damit die Schulen genügend Kinder hätten und nicht geschlossen werden müssten. Sie selbst frage sich aber, wo die Akzeptanzgrenze für nichtintegrationswillige Eltern liege, und ob der Staat Dänemark so viel Geld für diejenigen ausgeben könne, die eine „schöne“ Ausbildung und eine zweite Sprache für ihre Kinder wollten (Informelles Gespräch am 15.10.2013).

Diese Öffnung der Schulen für Kinder aus nichtdänischen Familien führt zu einem von Minderheitenfunktionär*innen als solches aufgefasstes Integrationsproblem (vgl. Kap. 6). Aus Dänemark gibt es überdies bei rechtspopulistischen

\footnotetext{
286 „Det er både menneskeligt og forståeligt, når en lille skole henter tyske forældre ind for at kunne eksistere."

287 Name geändert.
} 
Politiker*innen sowie einigen nationalistischen Minderheitenfunktionär*innen Stimmen, die sagen, dass wenn die Neudän*innen nicht dänisch genug oder gut genug integriert seien, es zukünftig keine Gelder mehr aus Dänemark geben werde. Dies wird als Argument gegen Nichtintegrationswillige verwendet, wobei unklar bleibt, ob das Argument wirklich schlüssig ist und die Angst vor dem Geldverlust berechtigt, oder ob es nur als Begründung für die eigene Auffassung vom Dänischsein und Dänischwerden herhalten muss.

Da sich Minderheitsakteur*innen aus historisch-ideellen und langfristig-finanziellen Gründen zum Königreich hingezogen fühlen, werden als Alternative zu dänischen Geldern keine (befristeten) EU-Fördergelder, wie beispielsweise aus dem INTERREG-Topf für binationale, bikulturelle, bilinguale, deutsch-dänische Schulen beantragt oder Europaschulen gegründet. Man will dänisch sein und dänisch bleiben, sich von der deutschen Mehrheit abgrenzen, gleichzeitig ist man aber von der eigenen Öffnung für deutsche Mitglieder abhängig (vgl. Søndergaard 1983: 84, 87). Bent Søndergaard fasste schon 1983 die Problematik mit dieser Kernfrage zusammen:

Wünscht man wenige Schulen mit wenigen Schülern, aber mit einem relativ hohen Maß an [...] „Dänentum“, oder wünscht man mehr Schulen mit mehr Schülern, aber mit einem geringeren $\mathrm{Ma}$ an sprachlich-kulturellem [...] „Dänentum“ (ebd.: 87).

Die Theorie, dass eine nationale Minderheit sich in Abgrenzung zur Mehrheit konstituiert, wird hier durch die Beobachtungen bestätigt. Dänischsein geht nur mit der und gleichzeitig in Abgrenzung zur deutschen Mehrheit. Man bekommt dänische Gelder, glaubt deshalb, dänisch und nicht deutsch sein zu müssen, aber gleichzeitig wird mehr Geld aus Dänemark überwiesen, wenn man auch Deutsche integriert, weil dann die Schüler*innenzahl steigt. Karl Kring formuliert diese ambivalente und vielschichtige Problematik, die nicht nur die Schulen und Kinderbetreuungseinrichtungen, sondern genauso die Sportvereine des SdU (s. Kap. 3.2.4, 7.6) betrifft, folgendermaßen:

Die Zukunft der Minderheit ist ein Balanceakt zwischen zu geschlossen sein und sich zu weit zu öffnen. Schließen wir uns zu sehr ein, stirbt sie [die Minderheit], öffnen wir die Minderheit zu sehr, stirbt sie auch. Wir müssen das Gleichgewicht finden zwischen dem Sich-Öffnen gegenüber anderen, ohne dass wir unseren Hintergrund verlieren. ${ }^{288}$ (K. Kring in Peetz 24.01.2014)

288 „Mindretallets fremtid er en balancegang mellem at være for lukket og åbne sig for meget. Lukker vi os for meget, dør det, åbner vi mindretallet for meget, dør det også. Vi må finde balancen $i$ at åbne os over for andre uden, at vi mister vores baggrund.“ 
Zusammenfassend lässt sich sagen, dass die dänische Schule von vielen Eltern als eine pädagogische Alternative zum deutschen Schulsystem und als Sprachschule aufgefasst wird (s. Kap. 4.2.2), obwohl der Schulverein genau dieses nicht will. Es gibt also einen Widerspruch zwischen Anspruch und Wunsch einerseits und andererseits dem Nutzer*innenverhalten in der Realität der dänischen Einrichtungen. Ziel der dänischen Schulen ist die Beeinflussung der Kinder und Jugendlichen in Richtung dänische Gesinnung. Man möchte dabei gleichzeitig offen und geschlossen sein.

Zukünftig wird die Nachfrage nach Kinderkrippenplätzen steigen, so der allgemeine Trend in Deutschland. Dementsprechend ist es ein prioritäres Ziel des dänischen Schulvereins, diesem allgemeinen Trend nachzukommen und das Angebot in den nächsten Jahren so weit auszubauen, dass jedes Kind, welches einen Krippenplatz bekommen soll, auch einen Platz bekommt (Ipsen 2014: 154). Diese Entwicklung sieht Udo Jessen positiv, da der dänische Schulverein dann noch früher mit der sprachpädagogischen Arbeit anfangen könne (Jessen 2012: 110). Das hätte zur Folge, dass die Akteur*innen auf die Kinder in jüngerem Alter einwirken könnten. Ein möglichst intensives und langes Verbleiben in der Minderheit binde die Kinder stärker an das Dänische (Hougaard-Werner 14.10.2013). Seine Zukunftsvision für das dänische Schulsystem in Südschleswig beschreibt der Vorsitzende Jessen als Ganztagsschule von 7 bis 19 Uhr, die als zentrales Kompetenzzentrum für die gesamte Minderheit wirken könne: Bildung, Gesundheit, Kultur-, Sport- und Freizeitangebote sollten unter einem Dach angeboten werden. Davon erhofft sich Jessen ein intensiveres Zusammenwachsen der Minderheit rund um die Uhr durch eine lange Zeit des gemeinsamen Erlebens. Das würde noch mehr Einflussnahme für das dänische Schulsystem auf Kinder im Sinne einer dänischen Gesinnung ermöglichen, aber auch eine damit zusammenhängende bessere sprachliche Ausbildung der Kinder. Das Dänischwerden würde dann noch früher beginnen und ggf. nachhaltiger wirken und damit die Aufrechterhaltung der Minderheit positiv beeinflussen. Denn die Sozialisierung in den Institutionen der dänischen Minderheit, besonders in der Schule, dient der Gesinnungsbildung, wie auch Jørgen Kühl im Interview mit Arthur Christiansen bestätigt (Christiansen 2008: 59). Dabei geschieht eine „[s]ymbolische Konstruktion ethnischer Identität“ durch „Rituale und die Vermittlung kollektiven Wissens“ (Schmidt-Lauber 1996: 323, 319) und eine „Konstruktion des Nationalen [...] über die „Nationalerziehung" in Schule" (Kaschuba 1995: 298).

Einerseits ist die Ganztagsschule positiv für Eltern, die beide berufstätig sind. Sie würde außerdem den allgemeinen Trend zur Ganztagsschule widerspiegeln, aber andererseits hätten die Kinder der Minderheitsschulen durch weniger Freizeitaktivitäten außerhalb der Minderheit als bisher weniger Kontakt zu Jugendlichen aus der Mehrheitsbevölkerung. Es stellt sich ebenfalls die Frage, ob ein tägli- 
ches zwölfstündiges Verbleiben der Kinder in dänischen Einrichtungen von Kinder und Eltern genutzt werden würde. Es gäbe dann weniger gegenseitige Offenheit und weniger Wahlmöglichkeiten in Bezug auf deutsche und dänische Vereine und damit weniger Überschneidungen. Eine dänische Ganztagsschule würde die ohnehin schon ausgeprägte Tendenz, alles oder nichts wählen zu müssen sowie die Trennung in eine deutsche und eine parallele dänische Minderheitsgesellschaft verstärken. Dies kann aus Sicht von Minderheitsdän*innen positive Auswirkungen haben, aus europäisch-transnationaler Sicht aber nationalistisch und stark abgrenzend wirken. Ein eigenes Schulsystem kann notwendig sein zur Aufrechterhaltung der dänischen Minderheit und der dänischen Sprachkompetenz. In Anlehnung an Romedi Arquint (2013: 128-129; vgl. a. Bittlinger 03.09.2012) wäre ein mögliches Konzept, dass alle Schüler*innen in der Region Schleswig die Minderheitensprache Dänisch lernen. Damit wären dann auch alle Kinder und Jugendlichen in deutschen Schulen gemeint und nicht nur Schüler*innen dänischer Schulen. Das würde die Minderheitensprache in der Mehrheit etablieren, gleichzeitig aber auch möglicherweise gewünschte, konstruierte Grenzen verwischen und die Minderheit als Parallelgesellschaft obsolet machen. Dieser postmoderne, nicht-nationalistische, sondern paneuropäische Ansatz entspricht aber nicht den Zukunftsvisionen des Schulvereins.

Kapitel 5 hat einerseits gezeigt, dass die Institution Schule essenziell für das Dänischwerden und Dänischbleiben der Menschen ist, die sie besuchen oder besucht haben. Dies gilt unabhängig von der Generationszugehörigkeit. Die Schule ist aber auch der Ort, an dem große Erwartungen an alle beteiligten Kinder, Eltern und Pädagog*innen gestellt werden, die in ideologisch-politischen Diskussionen ausgehandelt werden und starke inhaltliche Widersprüche innerhalb der Minderheit generieren können. Anhand der Analyse der Rolle der dänischen Schule können aber auch die Differenzen zwischen Funktionär*innen auf der einen und Akteur*innen auf der anderen Seite offenbart werden. Dieses Kapitel hat außerdem gezeigt, dass die dänische Minderheit keine abgeschlossene, homogene und kollektive Einheit ist, sondern heterogen in Bezug auf Bekenntnis, Erwartungen und Rolle der Angehörigen innerhalb der Minderheit, wie Rogers Brubaker schon generell für ähnliche Gruppierungen feststellte (s. Kap. 2.2.1). 


\title{
6. Dänischwerden III: Integration in ein Dänischsein der Gegenwart
}

\author{
Die dänische Gesinnung berubt auf ,eine [r] \\ subjektive [n] Identifizierung" mit der Min-

Jorgen Kühl (2004: 325)

Mette Bock, von 2014 bis 2016 Vorsitzende des dänischen Granseforeningen und seit 2016 dänische Kultur- und Kirchenministerin, weist darauf hin, ,,dass die Minderheit nur existiert, wenn sie es schafft, integrierend gegenüber den Neuen zu sein, die das Dänische meistens in Verbindung mit der Schulwahl für ihre Kinder wählen. “289 (Bock in Møllekær 16.06.2014). Daher ist es wichtig, im Anschluss an Kapitel 5.2 genauer zu untersuchen, wie die Minderheitenvereine und -funktionär*innen versuchen, Neudän*innen, vor allem neudänische Eltern, in Ergänzung zur Schule als wichtigsten Minderheitsanknüpfungsort für Kinder, zu integrieren. Dies konnte anhand einer fünftägigen Feldforschung und teilnehmenden Beob-

289 ,at mindretallet kun består, hvis det magter at være inkluderende overfor de nye, der oftest vælger det danske til i forbindelse med skolevalget for deres børn“ 
achtung bei einem Integrationskurs 2013 erhoben werden. Anschließend wird auf die Perspektive der Vereinsvorsitzenden und -ausschüsse von SSF und Skoleforeningen geblickt.

\subsection{Der Integrationskurs}

Im Herbst 2012 formulierten SSF und Schulverein einen erhöhten Integrationsbedarf für Neudän*innen: „Wir sind zu dem Ergebnis gekommen, dass es einen Bedarf für eine gestärkte Integrationspolitik gegenüber den »neuen Familien in der Minderheit« gibt, und dass dies einen gemeinsamen Einsatz erfordert" (Küssner in Thöming 13.09.2012). Kernstrategie solle dabei die kulturelle Einbindung derjenigen Eltern in den SSF sein, die ihre Kinder in das dänische Schulsystem einschulen (vgl. Bruhn 02.11.2012). Als neudänische Familien sind diejenigen anzusehen, deren Eltern selbst nicht auf einer dänischen Schule waren (vgl. Pedersen 2000a: 54-55, 131-155). Zur Umsetzung dieser Strategie wurde eine gemeinsame Arbeitsgruppe von SSF und Dansk Skoleforening für die „Integration der Neuen “2200 gegründet (Sydslesvigsk Forening; Bruhn 12.11.2012; Küssner 15.01.2013). Das Ziel der Arbeitsgruppe war, das Bewusstsein der Minderheitenzugehörigkeit positiv zu beeinflussen, zu stärken und Lust zu machen auf „unsere dänische Gemeinschaft ${ }^{\text {‘2211 }}$ (Sydslesvigsk Forening b). Bezieht man Bourdieus Theorie mit ein, so bedeutet der dänische Schulbesuch nicht nur die Einübung eines spezifischen Habitus, sondern auch die Erlangung von sozialem und kulturellem Kapital in der dänischen Minderheit. Ist dieses Kapital nicht vorhanden, und möchte man trotzdem Teil der Minderheit werden, so kann man einen Integrationskurs durchlaufen, der einen Teil des Fehlenden aufholen soll (vgl. Reuter 2018: 186). Das Bekenntnis zum Dänischen sei aus SSF-Sicht nur wenig wert, wenn es nicht konkret praktiziert werde, wenn nicht die neuen Eltern Mitglied im SSF würden und sich in der Minderheit engagierten (Sydslesvigsk Forening b). Es sei für alle Minderheitendän*innen wichtig, Mitglied in dänischen Vereinen zu werden, wenn es vor Ort die Möglichkeit dazu gibt. Hougaard-Werner wettert geradezu gegen eine doppelte Mitgliedschaft, was beispielsweise die Kirche betrifft. Sie sagt, wenn man religiös sei, solle man die dänische Kirche wählen. Auf Nachfrage einer Teilnehmerin des Integrationskurses, ob man nicht auch gleichzeitig in der deutschen Kirche bleiben könne, sagt sie: „Du brauchst nur eine Kirche. Geh in die dänische Kirche, dann brauchst du die deutsche Kirche nicht mehr" (Hougaard-Werner 14.10.2013). Im Kontrast zu dieser Aussage fühlt sich die Interviewpartnerin aus der Nachkriegsgeneration, Sarah Iversen, in der dänischen Kirchengemeinde zu Hause („Familie“), aber das bedeutet für sie keineswegs, nicht

\footnotetext{
$290 \quad$ „Integrere de nye“

291 „vort danske fælleskab“
} 
auch Angebote der deutschen Kirchengemeinde wahrzunehmen: „Also ich bin begeistert von der evangelischen Kirche hier in Friedrichstadt, es wäre alles gelogen, wenn ich auch nur EIN Wort dagegen sagen würde" (INT03). Eine weitere Interviewpartnerin, Frieda Theben, geht in beide Kirchen, sowohl in die dänische Gemeinde, in der sie mal im Kirchenvorstand war, als auch in die deutsche Gemeinde, in der ihr Sohn Diakon ist. Sie besucht mal den deutschen, mal den dänischen Gottesdienst (INT06). Funktionärin Hougaard-Werner dagegen hält es für das Natürlichste, dänische Vereine zu wählen. Nur wenn keine dänischen Alternativen zur deutschen Mehrheit vorhanden seien, sei es kein Problem, auch in deutschen Vereinen Mitglied zu werden. Sie formuliert hier also eine klare Abgrenzung und fordert ein Verlassen der deutschen Institutionen. Eine Kombination von beidem schließt sie in ihrer Rolle als Funktionärin aus. Das ganze Fundament solle dänisch sein (ebd.).

Zur Bewahrung der Minderheitsidentität sei eine Gemeinschaft von Werten und ein starker Zusammenhalt nötig (Sydslesvigsk Forening b). Daher solle eine sogenannte dänische Kultur vermittelt werden, damit diese dann aktiv in der Minderheit gelebt werden könne (ebd.). Diese Vermittlung solle in den sogenannten „Guten-Tag-Südschleswig-Kursen“292 (Küssner in Thöming 13.09.2012) unterrichtet werden und zu einem Mitverantwortungsgefühl für die Minderheit anregen. Die neue Arbeitsgruppe wolle dabei nicht provozieren, so der SSF, aber die Minderheit habe das Recht, die Gesinnung der Eltern zu beeinflussen (Sydslesvigsk Forening; Hougaard-Werner 14.10.2013). Die Arbeitsgruppe solle Werkzeuge entwickeln, wie zum Beispiel obligatorische und bewusstseinsbildende Integrationskurse für Eltern, die Ernennung von Kontaktpersonen zwischen Schulen und Vereinen und Sprachkurse (Sydslesvigsk Forening b), denn es sei für alle in der dänischen Minderheit verpflichtend, Dänisch zu können, so der ehemalige Vorsitzende des Schulvereins, Gerd Pickardt (Pickardt in Bruhn 12.11.2012). Bei diesen Erwartungen wird von den Funktionär*innen außer Acht gelassen, dass sich Menschen auch ohne Dänischkenntnisse und Vereinsmitgliedschaften zur Minderheit bekennen können.

Im Februar 2013 wurden die Ideen der oben eingesetzten SSF-SchulvereinsArbeitsgruppe konkreter: Für die Herbstferien 2013 wurde ein einwöchiger Integrationskurs für Familien an der Jaruplund Højskole, der dänischen Heimvolkshochschule in Südschleswig in Jarplund/Jaruplund geplant (Sydslesvigsk Forening a). Der Kurs beinhalte eine „Einführung in die dänische Minderheit“, ebenso eine „Präsentation der Institutionen und Vereine, der Struktur der Minderheit und Lektionen in dänischer Sprache und Kultur" (Teilnahmebescheinigung v.

292 „Sydslesvig goddag-kurser“ 
18.10.2013). Die Veranstaltung habe zum Ziel, als „Türöffner zur dänischen Minderheit ${ }^{6293}$ (ebd.) zu dienen, damit die Neuen einen guten Start in die Minderheit bekämen ${ }^{294}$ (ebd.). Der SSF ruft schon acht Monate vor Kursbeginn alle Pädagog*innen, Lehrkräfte, Vereinsfunktionär*innen und Ortsvorsitzende dazu auf, sich nach Familien umzuschauen, die für das Angebot geeignet seien. Diese sollten motiviert werden, sich anzumelden. Die Projektleiterin des Kurses, Heimvolkshochschullehrerin Signe Frantsen ${ }^{295}$, ruft die südschleswigsche Öffentlichkeit auf, sich an dem Projekt zu beteiligen. Sie hofft auf möglichst viele Zusammenarbeitspartner*innen für die laufende Konzeptionsphase sowie für finanzielle Unterstützung und für die Durchführung des Unterrichts.

Der Kurs soll den Erwachsenen Raum für Fragen und Diskussionen über Südschleswig bieten sowie Dänischunterricht auf zwei unterschiedlichen Sprachniveaus ermöglichen. Die Kinder können sich währenddessen kreativ und spielerisch austoben. Für alle gemeinsam sei das Singen dänischer Lieder, das Ansehen dänischer Filme und ein Ausflug ins Legoland nach Billund in Dänemark geplant. Um keine Neudän*innen abzuschrecken steht in der Ankündigung, dass während des Herbstkurses sowohl Dänisch als auch Deutsch gesprochen werden würde (vgl. ebd.).

Eine Adressatin des Aufrufs an Funktionär*innen, nach geeigneten Familien Ausschau zu halten, war Friedrichstadts SSF-Ortsvorsitzende Tina Zehntner. Im Interview äußert sie ihre Zweifel am Nutzen des einwöchigen Kurses (INT10). Allerdings sind ihr die genauen Inhalte dieses Kurses nicht bekannt, obwohl sie, so die Idee der Initiator*innen, Neueinsteiger*innen eigentlich diese Kurse aktiv ans Herz legen soll. Zehntner sagt, ihr sei es wichtiger, dass man das Dänische lebe (INT10). Damit macht sie klar, dass sie das Praktizieren des Dänischen sinnvoller findet als einen Kurs im Dänischsein zu belegen. Sie zweifelt daran, dass ein Integrationskurs Menschen der Minderheit zugehörig machen könne: „Ich weiß immer nicht, ob son Kursus was bringen würde“, weil „,ich LEB das ja son büschen" (INT10). Sie hat noch nie jemandem empfohlen, an einem Integrationskurs teilzunehmen, der 2013 beschönigend „Wir-wollen-gerne-mehr-überSüdschleswig-wissen-Ferien “2296 genannt wird (Sydslesvigsk Forening a). Ablauf, Ziele und Inhalte dieses Integrationskursen werden im Folgenden szenisch erzählt und durch analysierende Passagen ergänzt.

\footnotetext{
293 „døråbner til det danske mindretal“"

294 „kom godt i gang!“‘.

295 Name geändert. Signe ist dänische Staatsbürgerin, etwa 50 Jahre alt und seit vielen Jahren als Lehrerin an der Jaruplund Højskole angestellt.

296 „vi-vil-gerne-vide-mere-om-Sydslesvig-ferie“
} 


\subsubsection{Ankunft - „und los geht's!!“ - szenischer Einstieg ${ }^{297}$}

Mit dem Auto fahre ich am 14.10.2013 auf der vierspurigen Schnellstraße B200, die von Husum kommend in Richtung Flensburg führt, und nebme die erste Ausfahrt. Jarplund-Weding. Ab hier ist der Weg zur Dänischen Heimvolkshochschule Jarplund ausgeschildert: „Hojskole“. Es geht gleich rechts und dann wieder rechts auf einen Feldweg bis zu einer Baumreihe, dann erneut rechts in eine Sackgasse binein. Wir befinden uns in Deutschland, in Jarplund. Dänisch: Jaruplund. Am Ende des Feldweges, direkt unterbalb der Schnellstraße, von der man aber hier fast gar nichts wahrnimmt, liegt die Jaruplund Hojskole. Die Gebäude der Hojskole liegen hinter einem Lärmschutzwall, etwas abgelegen in ländlicher Umgebung. Das ist der Ort, an dem ich erneut teilnehmend beobachtend in die dänische Minderbeit eintauchen will. Auf dem Stromkasten für die Überlandleitung beim Parkplatz, steht auf Deutsch „Heimvolkshochschule Jarplund". Die Bauarbeiter, die den alten Anbau und das Gelände sanieren und renovieren, sprechen Deutsch miteinander. Ich steige aus und sage im Vorbeigehen „Moin“. Sie erwidern das. Es ist sonnig, aber kalt. Ich gehe auf das Hauptgebäude zu, links die Baustelle und eine weitere Baumreihe. Hans Thomsen ${ }^{298}$ kommt mir entgegen. Wir begrüßen uns kurz. und stellen uns gegenseitig vor. Er sagt, er wolle nur noch mal zu seinem Auto, wir sehen uns später drinnen. Ich frage ihn, wann das Programm anfange, es hätte im Vorfeld unterschiedliche Informationen darüber gegeben. Er meint $15 \mathrm{Uhr}$.

Ich bin verwirrt. Im Programmheft (Jaruplund Hojskole et al. 2013) stand für $13 \mathrm{Uhr}$ „Ankomst og indkvartering", Ankunft und Einquartierung. Im beiliegenden Anschreiben stand $15 \mathrm{Uhr}$ Ankunft. Ich rief vorher im Büro der Hojskole an, die Sekeretärin meinte recht unfreundlich: 13 Uhr! Jetzt ist es 13:15 Ubr. Ob, bin ich etwa zu spät bei der Feldforschung? Habe ich die Sekretärin vergrätrt, weil ich sie auf Organisationsfehler aufmerksam gemacht habe? Ich weiß, dass das bei „den Dänen“ gar nicht gut ankommt, so direkt nachzufragen. „Du er velkommen. "Punkt. Tschüß. Aufgelegt.

Ich gehe am Wobntrakt vorbei in das Hauptgebäude binein und treffe dort auf dem Flur zufällig Signe Frantsen, verantwortlich für den Kurs ,Sydslesvig - und los geht's!! '299, auf meiner Teilnahmebestätigung auch auf Dänisch „Südschleswig - Komm gut in Gang "300 genannt. In der aktualisieren Programmübersicht, die wir vor Ort bekommen, wird der Kurs „Intro zu

297 S. a. die Übersicht über die Teilnehmenden auf S. 345.

298 Name geändert. Hans Thomsen, 53, ist dänischer Staatsbürger aus Nordschleswig, Dänemark. Er gehörte dort der deutschen Minderheit an und jetzt der dänischen Minderheit in Südschleswig, sagt er. Seine Erstsprache ist Sønderjysk, also Südjütisch, eine Art Platt-Dänisch. Er sagt von sich, dass er neben Sønderjysk auch Dänisch mit südjütischem Dialekt und schleswigsches Deutsch spreche. Hans ist studierter Betriebswirt und Steuerberater, arbeitet aber als freiberuflicher Dänischlehrer und Übersetzer.

299 Sydslesvig $=$ Südschleswig. Der Titel ist dänisch-deutsch gemischt.

300 „Sydslesvig - kom godt i gang““ 


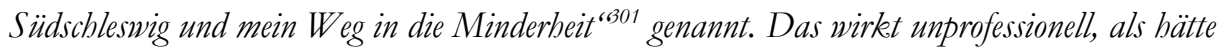
man schnell ein Programm zusammengeschustert und am Ende nicht mehr kontrolliert, ob überall dieselbe Version des Kurstitels steht.

Signe fragt mich auf Dänisch: Sprichst du Dänisch? Das wusste sie, weil ich ein paar Male vorher mit ibr gemailt hatte, zwecks Anmeldung und Programminformation. Aha, wohnst du in Frederiksstad oder in Göttingen? Ich: beides. Aha, du studierst also in Göttingen? Naja, ich schreibe meine ph.d. afhandling. Aha, spannend.

Ich frage schließlich Signe, wann der Kurs losgeht, ich hätte unterschiedliche Informationen dazu bekommen. Signe sagt, es gehe um 14 Ubr los. Das Zeitchaos klärt sich auf: Die Anreise ist zwischen 13 und 14 Uhr vorgesehen, 14 Uhr Begrüßung und Führung durch die Hochschule, 15 Uhr Beginn des eigentlichen Unterrichtsprogramms. Hätte man sich da untereinander nicht besser abstimmen können?

Die Hojskole hat 50 Betten plus Zusatzmatratzen. Wir sind nur 15 Teilnebmende. Es gibt zwei Familien, die zu dritt da sind. Da muss einer auf einer Matratze auf dem Kalten Boden schlafen, weil es keine Dreibettzimmer gibt und diesen Familien nicht zwei Zimmer zugewiesen werden. Das wirkt dilettantisch organisiert. Wie ungemütlich und zugig und kalt, so böre ich später von den betroffenen Bodenschläfern, die mehrere Matratzen übereinanderstapeln, um die Bodenkälte abzumildern.

Aus der Hälfte der Zimmer und aus dem Hörsaal hat man einen wunderschönen Ausblick auf den hauseigenen See. Es gibt noch eine Art Wobnzimmer, einen Vorraum, eine Bibliothek, die als Unterrichtsraum dient, ein Sekretariat, Werkstatträume, zwei große Speisesäle samt Küche, einen Aufenthaltsraum im Stil der 50er-Jahre mit dänischen Designermöbeln aus Holz. und einen Kamin, einen neu gebauten Veranstaltungssaal sowie Lebrer*innenunterkünfte.

Im Vorfeld des Kurses fragte ich die Veranstaltungsleitung, ob ich teilnehmen dürfte und meldete mich nach der Erlaubnis dazu offiziell an. Die teilnehmenden Eltern akzeptierten mich als teilnehmene Beobachterin und einige fragten interessiert nach, was ich erforsche. Anderen war das egal, und im Laufe des Kurses spielte meine Anwesenheit für die Eltern keine Rolle mehr. Einziger Unterschied zu den anderen im Rahmen der Teilnahme war, dass ich kein/e Kind/er dabei hatte, während alle anderen mit ein bis zwei Kindern teilnahmen.

\subsubsection{Der erste Eindruck und „Intro“}

Der Einstieg ins Feld für mich und der Einstieg in die Minderheit für die Teilnehmerinnen und Teilnehmer ist chaotisch und unorganisiert. Die Organisation wirkt unzulänglich, was sich auch auf den Punkt Kommunikation der Kursinhalte vor Kursbeginn bezieht. Später stellt sich nämlich heraus, dass einige der teilnehmenden Erwachsenen ganz andere Vorstellungen davon hatten, was sie im einwöchigen Lehrgang erwartet. Zum Beispiel kam Beatrix mit der Idee hierher, einen Sprachkurs mit Kinderbetreuung zu besuchen und keine ideologische Schulung. Auch

301 „Intro til Sydslesvig og min vej ind i mindretallet“ 
scheint es eher zufällig zu sein, dass man bei der Ankunft eine*n Ansprechpartner*in antrifft. Man geht einfach mal durch das Gebäude und guck.t, ob jemand da ist. Es gibt keine Rezeption oder Empfangsperson am Eingang.

Ähnliche Verwirrung wie bei der Ankunft und dem Kursbeginn herrscht beim täglichen Programm und bei der Abreise: Die Planer*innen hatten nicht bedacht, dass Eltern mit Kindern etwas mehr Zeit zwischen den einzelnen Programmpunkten benötigen. Signe ist sichtlich genervt, als am letzten Tag aufgrund noch fehlender Teilnehmender das Programm um eine dreiviertel Stunde verspätet startet. Missverständnisse und Nichtinformation zur Frage der Zimmerräumung sind der Grund. Wir erfahren um 08:45 Uhr, dass wir unsere Zimmer bis $10 \mathrm{Uhr}$ räumen müssen. Wie das? Um 09 Uhr fängt der Unterricht an. Wie sollen wir also in einer Viertelstunde unsere Sachen und auch die der Kinder packen und in die Autos laden sowie das Zimmer räumen? Auch dies wirkt unkoordiniert und nicht durchdacht, unprofessionell. Die schlechte Organisation des Kurses ist insofern verwunderlich, als dass die Jarplunder Heimvolkshochschule laufend Wochen-, Halbjahres- und Jahreskurse sowie Bildungsreisen, Sommerschulen, Vorträge, Konferenzen und Versammlungen organisiert. Möglicherweise wurde der Kurs von den Organisator*innen nicht so ernst genommen oder es gab Schwierigkeiten bei der Zusammenarbeit von Schulverein, Heimvolkshochschule und Kulturverein, was die inhaltliche Konzeption des Kurses anging.

Weiterbin wirkt es etwas kurios, dass sich die Dänin Signe über die Unpünktlichkeit der stereotyp vermeintlich immer pünktlichen Deutschen, die dänisch werden wollen, aufregt. Dabei ist sie selbst für den Zeitplan und dessen Kommunikation verantwortlich. Einige Teilnehmende kamen regelmäßig morgens zu spät zur morgensamling - der Morgenversammlung - und zum Unterrichtsbeginn. Nicht nur der enge Zeitplan ist der Grund dafür. Vielleicht waren einige in ibren Herbstferien, in denen der Kurs lag, eher auf Urlaub eingestellt als auf Unterricht und frühes Aufstehen?

Am ersten Tag des Integrationskurses beginnt schließlich um $14 \mathrm{Ubr}$ das Programm. Zuerst steht ein gemeinsamer Rundgang mit allen Teilnehmenden durch die Heimvolkshochschule auf dem Programm. Signe zeigt uns die Gebäude und das Gelände der Schule und stellt das weitere Programm vor. Um 15 Uhr präsentieren sich Gitte Hougaard-Werner ${ }^{302}$ und Hans Thom-

302 Gitte Hougaard-Werner, 42, ist eine sehr motivierende Persönlichkeit, die Leute mitreißen kann. Sie ist rhetorisch sehr geschickt und kann ihre ideellen Ziele gut unter die Leute bringen. Diese Fähigkeit nutzt sie für ihre praktische und ideologische Arbeit für das Dänischsein in Südschleswig. Gitte ist Lehrerin an einer dänischen Schule nahe Rendsburg und seit 2013 Vorsitzende des Jahrestreffenausschusses, also eine der Top-Funktionär*innen im SSF. Seit dem 09.11.2013 ist sie stellvertretende Vorsitzende des SSF-Landesverbands. Sie hat einen dänischen, seit 2016 zusätzlich auch einen deutschen Pass. Sie wohnt seit vielen Jahren in Südschleswig in der Nähe von Eckernförde. Als Neunjährige kam sie mit ihren dänischen Eltern, die in der Minderheit gearbeitet haben, in den Landesteil Schleswig. In Jaruplund übernimmt Gitte Hougaard-Werner nicht nur Teile der Kinderbetreuung, macht mit ihnen Musik und fährt mit dem gesamten Kurs nach Billund ins Legoland, sondern sie hält auch Vorträge für die Erwachsenen über die dänische 
sen im Hörsaal. Wir Erwachsenen ${ }^{303}$ hören anschließend einen Vortrag von Gitte HougaardWerner über die Minderbeit mit dem Titel „Intro zu Südschleswig “304 über die Entstehung der Minderheitensituation, die Geschichte Schleswigs, die Grenzverschiebungen aus dänischer Sicht, die Minderheitsinstitutionen und das freie Bekenntnisprinzip (Hougaard-Werner 14.10.2013).

\subsubsection{Der Dänischunterricht}

Wie in Kapitel 8.5 gezeigt werden wird, werden Dänischkenntnisse als Voraussetzung für das Dänischsein seitens der Vereinsfunktionär*innen erwartet. Daher wird im Integrationskurs großer Wert auf den Dänischunterricht gelegt. Im Laufe der fünf Seminartage in Jar(u)plund gibt es für die erwachsenen Teilnehmenden drei zweieinhalbstündige Sprachkurseinheiten, genannt „Turbo-Dansk“", Turbo-Dänisch. Die Kinder werden währenddessen mit dänischen Kinderliedern und einer Bastelwerkstatt beschäftigt. Die Gruppe ist von den Sprachkenntnissen her sehr heterogen. Hans Thomsen bemüht sich sehr, seinen Unterricht so zu gestalten, dass alle Teilnehmenden trotz ibrer unterschiedlichen Sprachkompetenz etwas lernen können.

Im ersten Unterrichtsblock Dänisch sind Ausspracheregeln das Thema. Danach soll sich jede*r selbst den anderen auf Dänisch vorstellen, und anschließend werden die dänischen Zablen eingeübt. Spielerische Elemente, wie ein Zablenmemoryspiel, werden integriert. Der erfahrene Dänischlehrer Hans verbindet Lernen mit Spaß. Wir bekommen Hausaufgaben auf, sollen beispielsweise ein Dänemarkrätsel lösen, und bekommen dafür eine Dänemarklandkarte geschenkt. Wir lernen die dänischen Münzen und Geldscheine kennen und sprechen darüber. Anschließend lernen wir Südschleswigismen, also typische Febler, die Minderheitendän*innen mit starkem deutschem Spracheinfluss im Dänischen machen. Dazu zählen auch die sogenannten falschen Freunde, die wir besprechen. Am letzten Kurstag nehmen wir im Dänischunterricht noch Lebensmittel und Präpositionen durch.

In allen Unterrichtsstunden beobachte ich unterschiedliches Engagement der neudänischen Eltern in Bezug auf das Sprachenlernen, welches auf die Integrationsbereitschaft übertragen werden kann: Luise und Beatrix sind sehr bemüht, Dänisch zu lernen. Luise kennt Hans schon aus vielen anderen Dänischkursen. Sie spricht schon relativ gut Dänisch und gibt sich sehr viel Mühe, ihre Sprachkenntnisse $\mathrm{zu}$ verbessern. Das spiegelt sich auch in ihrem allgemeinen Engagement in den Minderheiteninstitutionen wider. Beatrix kann kaum Dänisch, aber strengt sich sehr an, um mit allen anderen mitzuhalten. Ihr Hauptgrund für die Teilnahme am Integrationskurs sei primär, die Sprache zu lernen und dabei Kinderbetreuung zu bekommen. Sie hatte das Programm falsch verstanden. Da ihr

Minderheit.

303 Die Kinder werden währenddessen von Signes zwei Söhnen betreut. Sie erkunden das Heimvolkshochschulgelände und fahren auf dem hauseigenen See im Ruderboot. Anschließend backen sie draußen in der Kälte an einem Lagerfeuer Pfannkuchen mit zwei Eisenpfannen an langen Stielen.

304 „Intro til Sydslesvig“ 
Sohn im Vergleich zu den anderen Kindern aber noch viel zu jung ist, gestaltet sich die Betreuung für ihn schwierig, was Beatrix`Konzentration auf den Sprachkurs stört. Sie ist vom Angebot enttäuscht und ärgert sich am Ende darüber, dass sie $250 €$ für sich und $150 €$ für ihren Sohn als Kurgebühr zahlen musste. Dem Dänischsein steht sie während des Kurses recht gleichgültig gegenüber. Beatrix steht noch ganz am Anfang ihrer Integration in die Minderheit, so der Eindruck der Kursteilnehmenden.

Larissa und Traute habe eine schnelle Auffassungsgabe und mittleres Engagement beim Dänischlernen, während Klaus und Beate überfordert sind und sich wenig zutrauen. Sie haben ganz klar Hemmungen, Dänisch zu sprechen, die Sprache zu lernen und antworten lieber auf Deutsch. Trotzdem fühlen sie sich in der dänischen Minderheit zu Hause und haben ihre Tochter dänisch eingeschult.

Wer im Sprachkurs dagegen die Integration immer wieder torpediert, ist Inken. Da sie Lehrerin für Deutsch und Musik ist, könnte man erwarten, dass ihr das Lernen leichtfällt. Sie legt aber wenig Bemühungen und Lust an den Tag, Dänisch zu lernen. Sie spricht lieber Deutsch oder zur Not auch Englisch oder benutzt französische Vokabeln, wenn sie etwas auf Dänisch sagen soll. Da Inken mit dem Dänischen eigentlich nichts zu tun hat und haben will, nimmt sie die Danisierungsversuche eher widerwillig auf und verweigert ernsthaftere Integationsversuche.

Die Motivation aller Teilnehmenden ist nicht so groß, dass sie die Chance nutzten und außerhalb des Unterrichts untereinander und mit den Kursdozent*innen Dänisch sprechen. Während der gemeinsamen Mahlzeiten wird ausschließlich Deutsch gesprochen, alles andere erscheint ihnen $\mathrm{zu}$ anstrengend. Vielleicht fehlen Selbstdisziplin, Motivation, Mut und Überwindung, eine Fremdsprache zu sprechen, wenn ohnehin alle Deutsch verstehen.

Weiterhin stehen auf dem Programm des Kurses Angebote, die eine Kombination zwischen Sprachunterricht und der Vermittlung kulturellen Wissens darstellen: Es werden zwei dänische Filme gezeigt, die von den Teilnehmenden allerdings nur teilweise verstanden wurden, ein Vortrag über dänische Kultur und dänische Künstler*innen gehalten und Bingo auf Dänisch gespielt. Bei diesen Programmpunkten geht es um das Einüben nicht nur der Sprache, sondern vor allem der als dänisch deklarierten Praktiken, die als „dänische Kultur“ bezeichnet werden.

\subsubsection{Exkursionen und kulturelles Rahmenprogramm}

Zur Einführung in die dänische Minderheit besuchen wir im Integrationskurs am zweiten Tag die Dänische Zentralbibliothek, das Flensborghus samt SSF-Generalsekretariat und auf unseren Vorschlag hin die Stadtredaktion der Flensborg Avis. Spätabends gibt es als Tagesabschluss 
noch von der Küche der Heimvolkshochschule selbst gebackene Torten, Sekt und nach dänischer Tradition starken Kaffee, während Signe uns die Entstehung und den Hintergrund der Hojskole näher bringt.

Durch den Aufenthalt in der Heimvolkshochschule, in der wir die einzigen Gäste sind, gibt es viel Raum für uns, viele Gelegenheiten, sich kennenzulernen. Wir leben fünf Tage lang in einer eigenen Welt für uns. Das soll Gemeinschaft und Bindung an die Minderheit und ihre Inhalte schaffen. Kaffee und Kekse und gutes Essen sorgen für gute Laune unter den Teilnehmenden, gemeinsame Erlebnisse wie Ausflüge nach Flensburg und ins Legoland sollen Zusammenhalt herstellen. Allerdings läuft der Ausflug nach Dänemark so ab, dass alle gemeinsam im Bus dorthin gefahren werden, es vorbereitete Lunchpakete gibt, sich ansonsten vor Ort aber jede*r selbst beschäftigt und man nicht gemeinsam durch das Legoland geht. Wie dadurch der Zusammenhalt gestärkt werden soll, bleibt unklar. Während eines informellen Gesprächs mit Programmkoordinatorin Signe Frantzen und Dozentin Gitte Hougaard-Werner wird klar, dass der Programmpunkt Besuch des Legolands vor allem ein Lockmittel sei, um Eltern und Kinder zur Kursteilnahme zu motivieren. Allerdings kannten die meisten Teilnehmenden Legoland schon und hätten stattdessen lieber mehr Sprachunterricht gehabt.

Am vierten Tag des Integrationskurses steht ein Laternelaufen auf dem Programm. Dies wird im Integrationskurs vorbereitet, indem die Kinder Laternen aus Marmeladengläsern, Drabt, Farbe und Teelichtern basteln und alle, die lesen können, mit laminierten Zetteln ausgestattet werden, auf denen die dänischen Liedtexte abgedruckt sind. Bei der Durchführung abends draußen ist es viel zu dunkel, um die Texte zu lesen, was dazu führt, dass aufgrund mangelnder Textskenntnisse die dänischen Lieder nur mitgesummt werden bzw. Teilnehmerin Inken schließlich recht dominant mit der Gitarre in der Hand deutsche Laternenlauflieder anstimmt. Dies stößt der Kursleiterin Signe sauer auf. Inken rechtfertigt dies damit, dass wir alle die deutschen Texte auswendig könnten. Die Kursleiterin reagiert etwas befremdet, toleriert bzw. ignoriert aber schließlich, dass die Teilnehmenden im dänischen Integrationskurs die deutsche Texte verwenden.

Um zur Analyse zurückzukommen: Das es ein Laternelaufen im dänischen Integrationskurs gibt, ist insofern erstaunlich, als dass es diese Art der Veranstaltung in Dänemark eigentlich nicht gibt. Nur an den dänischen Minderheitsschulen in Südschleswig wird es aufgrund des deutschen Umfeldes praktiziert (TNB Signe Frantsen am 17.10.2013). Dazu seien die für das Laternelaufen geeigneten deutschen und niederdeutschen Lieder eigens ins Dänische übersetzt worden, obwohl alle Schüler*innen der dänischen Schulen auch Deutsch sprechen. Dieser Hintergrund führt zu der bizarren Situation, dass Deutsche, die sich mehr oder weniger halbherzig wegen ihrer Kinder zur dänischen Minderheit bekennen wollen und am Integrationskurs teilnehmen, eine nichtdänische, sondern deutsche Tradition auf dänisch zelebrieren sollen, die eigentlich an dänischen Minderheitsschulen nur wegen der entsprechenden Praxis an deutschen Schulen eingeführt wurde. Das Laternelaufen wurde also von dänischen Pädagog*innen an deutschen Schulen 
wahrgenommen und als etwas Positives gedeutet, sodass bei Kindern und Pädagog*innen der Wunsch aufkam, diese Praxis zu übernehmen und sprachlich anzupassen.

Am teilnehmend beobachteten Beispiel des Laternlaufens beim Integrationskurs wird außerdem die Nichtintegration bzw. Nichtanpassung an dänische Erwartungen durch die Neudän*innen deutlich. Hieran wird deutlich, dass der dänische Habitus bei den Kursteilnehmenden noch nicht inkorporiert ist. Ihnen fehlen die in der Lebensvergangenheit erlernten soziokulturellen Grundlagen, die Spielregeln, die Minderheitsdän*innen, in dänischen Schulen gelernt haben und die ihre Wahrnehmungs-, Denk- und Handlungsmuster prägen und sie damit von anders sozialisierten Menschen unterscheiden (vgl. Reuter 2018: 183-184, 186). Es entstehen also gegenseitige Irritationen, wenn die Spielregeln anderer nicht verstanden und nicht befolgt werden, was hier beobachtbar ist. Seitens der Lehrenden scheint die Auswahl dieses Programmpunktes nicht zu Ende gedacht worden zu sein.

Ähnliche Situationen der Überforderung mit dem Dänischsein und der Nichtanpassung an die Erwartungen, nicht nur im Sprachkurs, in dem Inken Späße auf Deutsch macht, anstatt ihre dänischen Aufgaben zu lösen, sondern auch geschehen auf einem Ausflug der Gruppe nach Flensburg, der im Folgenden wieder szenisch beschrieben wird:

Wir sitzen alle in einem Kleinbus des Schulvereins, und in der Flensburger Innenstadt ist ein außergewöhnlich langer Stau, der zu einer sehr langen Wartezeit im Bus führt. Vor lauter Langeweile stimmt Inken erneut gemeinsam mit einigen anderen Teilnehmenden Lieder an, allerdings wieder auf Deutsch, anstatt der bereits eingeübten dänischen Lieder (TNB am 15.10.2013). In der Dänischen Bibliothek in Flensburg spricht Inken laut einige Jungen auf Englisch an, um nach dem Weg zu fragen. Die Jungen sind verwirrt, können sie doch besser Deutsch als Englisch, vermutlich sogar besser Deutsch als Dänisch. Bei den umstehenden Bibliotheksmitarbeitenden kann peinliche Berührung beobachtet werden, da Inken gegen die dort vorberrschenden Erwartungen, Dänisch oder Deutsch zu sprechen, verstoßen hat.

Warum legt Inken ein von den Erwartungen abweichendes Verhalten an den Tag? Sie empfindet ein Fremdheits- und Ohnmachtsgefühl als Deutsche in einer dänischen Bibliothek ohne solide dänische Sprachkenntnisse, Sie fühlt sich fremd, wie im Ausland. Sie versucht das durch die reflexartige Verwendung des Englischen zu übertünchen (TNB am 15.10.2013).

Abschließend lässt sich konstatieren, dass Vereinsfunktionär*innen im Integrationskurs durch eine nette Atmosphäre, sehr gutes Essen, gemeinsames Singen, inhaltliche Schulungen und Sprachunterricht Erwartungen an Neudän*innen zu vermitteln versuchen, Praxen einzuüben und positive Gefühle zu erzeugen, die eine Gemeinschaftsbildung erleichtern sollen. Durch das Schaffen von schönen Erlebnissen, besonders für die Kinder, soll die emotionale Zugehörigkeit gestärkt werden. Allerdings war im Feld eine kritische Haltung einiger neudänischer Eltern 
gegenüber den Erwartungen der Minderheit an sie nicht zu übersehen. Im Erwachsenenalter ist es augenscheinlich schwieriger, überzeugend von einer Gesinnung zur anderen zu konvertieren, wenn die Motivation für die Wahl des Dänischen auf pragmatisch-ökonomischen Gründen beruht. Ein Teil der Eltern ist allerdings begeistert von der Minderheit und engagiert sich für das Dänische, auch wenn es noch an den Sprachkenntnissen hapert. Die Feldforschung hat außerdem gezeigt, dass die Erwartungen und erwarteten Praktiken, wenn überhaupt, dann nicht sofort von Neudän*innen übernommen werden. Erfolgreicher erscheint eine Danisierung und damit die Erfüllung von Erwartungen, wenn sie schon in einem möglichst frühen Alter beginnt (vgl. Kap. 5.1). Für Erwachsene, die nicht in der Minderheit aufgewachsen sind, ist es dagegen beobachtbar sehr schwer, dänische Praktiken und Praxen sowie einen vermeintlich dänischen Habitus den Erwartungen entsprechend korrekt auszuführen, auch wenn sie überzeugt sind von der Wahl des Dänischen. Eine Herausforderung dabei ist, zum einen zu erkennen und zu verstehen, welche Praktiken und Erwartungen anders sind und diese zum anderen so zu praktizieren, dass keine großen Widerstände aufseiten der altdänischen Minderheitsangehörigen hervorgerufen werden. Durch einen Integrationskurs allein wird niemand dänisch, sondern es werden Strukturen in der Minderheit erläutert, Erwartungen formuliert und kulturelle Praxen vorgestellt.

\subsection{Der Integrationsausschuss des Kulturvereins und Schulvereins}

Aus den oben angedeuteten Herausforderungen in Bezug auf die Differenz zwischen formulierten Erwartungen und dem Verhalten vieler neudänischer Eltern ergibt sich eine Initiative von Funktionär*innen des Schulvereins und des Kulturvereins, die 2013 in der Gründung eines Integrationsausschusses mündet. Darin wird nach dem Integrationskurs in Jar(u)plund, den ich teilnehmend beobachten durfte, der Integrationsansatz von SSF und dem Schulverein weiterverfolgt, Ideen werden gebündelt und konkrete Maßnahmen formuliert. Dieser Ansatz scheint eine Professionalisierung der Integrationsmaßnahmen zu sein. Der beobachtete Integrationskurs wirkte unorganisiert und improvisiert und beruhte auf dem Engagement Einzelner, aber nicht auf einem ausgearbeiteten und stringenten Konzept von Minderheitenfunktionär*innen.

Jon Hardon Hansen, SSF-Vorsitzender seit November 2013, sagte kurz nach seinem Amtsantritt, dass jede*r einzelne Minderheitenangehörige sich selbst nicht nur als normales Vereinsmitglied sehen sollte, sondern dass sich jede*r auch als Botschafter der dänischen Minderheit sehen müsse (Sydslesvigsk Forening 2013a: 32). Deshalb sei eine Integration von Neuen in die Minderheit und das Stellen von Anforderungen an diese Menschen sehr wichtig (Hansen in Dürkop 16.11.2013). Aus diesem Grunde wurde 2013 der Integrationsausschuss zusam- 
men von SSF und dem Dänischen Schulverein ins Leben gerufen. Er besteht aus jeweils vier Mitgliedern der beiden Vereine ${ }^{305}$ und hat die Aufgabe, sich Maßnahmen zu überlegen, damit neudänische Menschen sich mitverantwortlich für die Minderheiteninstitutionen fühlen und dadurch ein besseres Bewusstsein über das Minderheitensein erlangen. Es soll eine „Integrationspolitik“"306 erarbeitet werden (Hansen in Sydslesvigsk Forening 2013a: 31). Damit soll verhindert werden, dass neudänische Eltern ihre Kinder dänisch einschulen und sich gleichzeitig aber nicht für die dänische Minderheit engagieren, wie oben gezeigt. Die beiden Vereinsvorstände von SSF und Skoleforening möchten also nicht, dass Eltern einen Nutzen vom dänischen Schulverein haben, ohne im Gegenzug etwas für die Minderheit zu leisten (vgl. Kap. 5.2). Sie wollen stattdessen Instrumente entwickeln, um Eltern dazu zu bringen

ein Miteigentum am Innenleben unserer Institutionen und Organisationen zu fühlen, und dadurch ein Bewusstsein darüber zu erlangen, dass man Minderheitsbürger*in geworden ist, der im Stande ist, sich mit unserem dänischen Universum zu identifizieren. ${ }^{307}$ (Hansen in ebd.: 31).

Weiterhin solle gesichert werden, dass Minderheitsangehörige, „so viel dänische Sprache und Kultur“ praktizierten, „wie es möglich ist, in einem ansonsten deutschen Alltag“c308, so Dieter Paul Küssner als Funktionär in seinem Jahresbericht 2013 (Küssner in ebd.: 11). Küssner plädiert darin für eine gute Zusammenarbeit und einer Stärkung der Gemeinschaft durch den SSF zusammen mit dem Schulverein in einem Südschleswig ,,in Vereinigung “309 (Küssner in ebd.: 11).

Der Integrationsausschuss will zukünftig nicht mehr akzeptieren, dass Eltern von Kindern auf dänischen Schulen zwar die Absichtserklärung zum Engagement und zum Dänischlernen unterzeichnen (vgl. Kap. 5.2), diese aber praktisch nicht einhalten. Er beklagt die mangelnde Homogenität der dänischen Minderheit. Der Ausschuss geht, so das Protokoll von Ausschussmitglied Tine Andresen, sogar so weit zu sagen, dass das Bekenntnis zur Minderheit „keinen Wert“ habe, wenn nicht auch „konkretes Handeln und Interaktion“ mit dem Bekenntnis einhergingen (Andresen 14.05.2014: 1). Um dies zu verbessern schlägt der Ausschuss vor,

305 Dansk Skoleforening: Udo Jessen, Birgit Jürgensen-Schumacher, Thede Boysen, Berit Nommensen. SSF: Silke Weinzierl-Hanke, Jon Hardon Hansen, Jens A. Christiansen, Tine Andresen. ,integrationspolitik“

307 „føle et medejerskab til vore institutioners og organisationers indre liv, og derved opnår en bevidsthed om at være blevet mindretalsborger, der er i stand til at identificere sig med vort danske univers"

308 „så meget dansk sprog og kultur, der er muligt i en i øvrigt tysk hverdag“

309 ,i forening“ 
gemeinsam Werkzeuge zu finden und sich Maßnahmen zu überlegen, um das Minderheitenbewusstsein in einer positiven Art und Weise hervorzubringen und zu stärken und gleichzeitig Lust zu machen auf aktive Beteiligung an der südschleswigschen Gemeinschaft (ebd.: 1). Der Ausschuss geht davon aus, dass Engagement für die Minderheit zu einem Zugehörigkeitsgefühl mit der Minderheit führe, die wiederum Integration fördere (ebd.: 1). Ein Verständnis für die dänische Gemeinschaft in Südschleswig solle hervorgebracht und die dazugehörigen Werte vermittelt werden. Durch das Formulieren von Erwartungen an die Akteur*innen der Minderheit und durch die Festlegung von Werten schaffen die Funktionär*innen ihre eigenen Kriterien für das Dänischsein trotz der eigentlichen Gesinnungsfreiheit. Die Minderheit wird von Kühl als eine „verpflichtende Gemeinschaft ${ }^{\text {‘310 }}$ gesehen (Kühl 16.06.2016). Auch Küssner äußert in seinem Jahresbericht 2012 die Meinung, dass die Minderheit Erwartungen an neue Mitglieder stellen darf (Küssner 2012). Das Bekenntnis zur Minderheit solle ausgedrückt werden durch die Verwendung der dänischen Sprache und kulturelle Integration (ebd.). Sonst sei das Bekenntnis mangelhaft, ergänzt er (ebd.). Recht selbstgefällig sagt Küssner, dass eine Mitgliedschaft in der Minderheit, die ,gehaltvoll ${ }^{\ltimes 311}$ sein will, nur mit einer Mitgliedschaft im SSF vereinbar sei: „Mitgliedschaft im SSF und das Nutzen des breiten Kulturangebotes ist eine fast eine not-

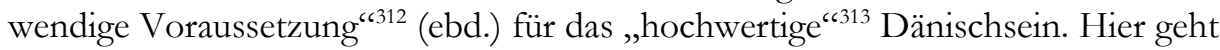
es also nicht nur um Dänischsein oder Nichtdänischsein, sondern es wird eine Wertigkeit innerhalb des Dänischseins formuliert.

Der Integrationsausschuss empfiehlt daher ganz konkret die Ausarbeitung einer gemeinsamen Wertegrundlage, die er auch „Missionspapier“ oder „Kanon““314 nennt (Andresen 14.05.2014: 2; vgl. a. Kap. 8.7). Dies soll bewirken, dass sich nicht nur die Eltern mit der Minderheit identifizieren, sondern auch die Angestellten der Minderheitenvereine „sich selbst ganz natürlich als Minderheitsangestellte oder Botschafter und nicht bloß als fachliche Mitarbeitende auffassen “315 (ebd.: 2). Eine Arbeitsstelle bei einer Minderheitenorganisation soll für die Angestellten nicht nur ein Job sein, sondern es wird ein klares Bekenntnis und ein Engagement mit Haut und Haaren erwartet. Das sind strenge Erwartungen an die Akteur*innen der Minderheit, die aus einer Angst vor Assimilierung der Minderheit in das deutsche Umfeld herrühren können.

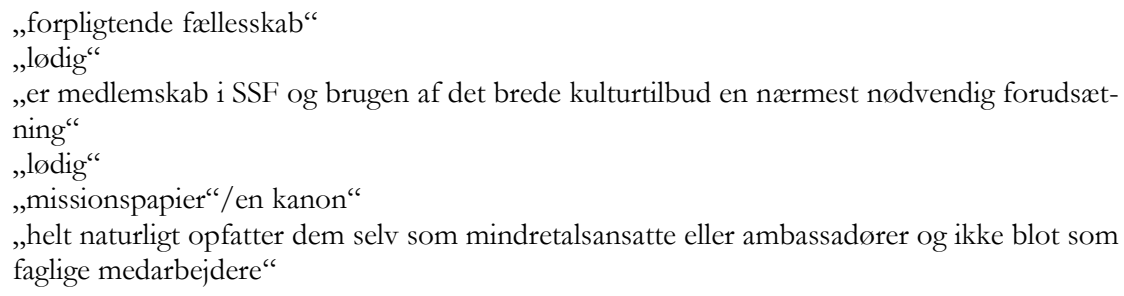


Hansen sieht das neue Projekt nicht nur als Aufforderung an neudänische Eltern, sich in die Minderheit zu integrieren, sondern er formuliert die Forderung an jeden „Minderheitenbürger ${ }^{\text {‘316, }}$, sich nicht nur als einfaches Vereinsmitglied oder Lehrer*in in der Minderheit zu sehen, sondern als „Minderheitsbotschafter*in“"317 zu engagieren (Hansen in Dürkop 16.11.2013). Das beinhalte, so Hansen auf der SSF-Landes-Jahreshauptversammlung, dass alle dazu verpflichtet seien, den Neuen den Weg in „unsere dänische Welt ${ }^{\text {‘318 }}$ zu zeigen (Hansen in ebd.). Ziel sei, so Küssner, dass „,wir es mit der Zeit ganz normal für ein Minderheitendasein finden, dass das Zuhause, die Schule und das Vereinsleben in Vereinigung eine Bekräftigung der Haltbarkeit der Gesinnungswahl ist“ ${ }^{\star c 319}$ (Küssner in Sydslesvigsk Forening 2013a: 12). Küssner konstatiert weiter, dass der Minderheitsalltag sich zu Hause, in der Schule und in den Vereinen formiere (Küssner in ebd.: 12).

Eine zum Zeitpunkt der Landesdelegiertenversammlung im November 2013 noch nicht abschließend diskutierte Kernfrage des Integrationsausschusses ist, welche Erwartungen die Minderheit an Neudän*innen, die „,vor dem Tor zum Dänischsein des Grenzlandes stehen und klopfen“, stellen kann oder sollte (Hansen in ebd.: 32). Falls es Anforderungen geben werde, so stehe die Frage im Raum, ob ein Nichteinhalten dieser Anforderungen sanktioniert werden solle, oder ob eine Sanktionierung „undänisch“6320 sei (Hansen in ebd.: 32).

Als vorbildliches Beispiel für einen Distrikt für eine gute Integration neudänischer Eltern in die Minderheit nennt der damalige stellvertretende Vorsitzende des SSF, Jon Jardon Hansen, auf der Landesdelegiertenversammlung am 09. November 2013 den Disktrikt Askfelt/Ascheffel im Landkreis Rendsburg-Eckernförde. Die „,neuen Eltern, die ohne Wurzeln im Südschleswigschen oder im Reichsdänischen, die das Dänisch für sich und ihr Kind bzw. ihre Kinder gewählt haben“321 (ebd.: 31) seien mit großem Erfolg integriert worden. Das konnte, so Hansen durch eine enge Zusammenarbeit zwischen Institutionen und Vereinen in Ascheffel und durch eine Einbeziehung der Eltern in Gemeinschaftsaktivitäten, Sprachkursangeboten „Aufklärung ${ }^{6322}$, ajourgeführte Webseiten und ein gutes E-MailNetzwerk gelingen (ebd.: 31$)$.

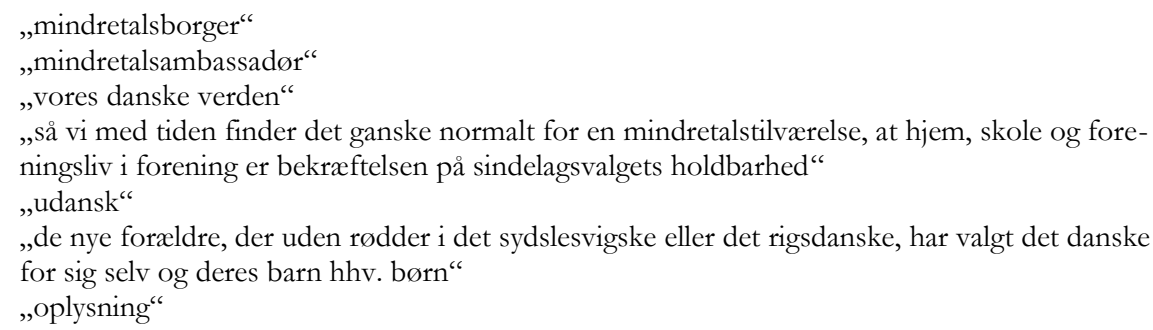


Der Integrationsausschuss plant, Eltern, die nur ihre Kinder im dänischen Schulverein anmelden ohne sich ansonsten zu engagieren, aus dem Schulverein auszuschließen. Der Einsatz für die Minderheit solle mindestens aus einer Mitgliedschaft im SSF, SSW oder SdU oder aus dem nachgewiesenen Besuch von Dänischkursen bestehen, so Flensborg-Avis-Chefredakteur Jørgen Møllekær in einem Leitartikel mit der kritischen Überschrift „Recht und Pflicht hält Einzug in Südschleswig ${ }^{\text {‘6323 }}$ (Møllekær 18.06.2014: 14).

Der Integrationsausschuss macht klar, dass alle Eltern willkommen seien. Sie sollen auf ihrem Weg in die Minderheit durch Mentor*innen aus der Minderheit unterstützt werden. Ohne dieses Mentoring sei es schwer, sich in der Minderheit zurechtzufinden, wenn man dort neu ist. Weiterhin sollten wieder „Intro“-Veranstaltungen zur Aufklärung sowie Dänischkurse angeboten werden (Møllekær 18.06.2014: 14; Dürkop 16.11.2013; Andresen 14.05.2014: 2), so wie beispielsweise der Integrationskurs in Jar(u)plund 2013. Neben Integrationskursen schlägt der Intergrationsausschuss einstimmig Veranstaltungen vor, auf denen „alte Neue“ den ,ganz Neuen“ über ihren Weg in die dänische Minderheit berichten (Andresen 14.05.2014: 3).

Des Weiteren wurde nach dem Streit um die sogenannte Geschwisterregelung im Jahre 2012 in die Homepage-Informationen zur Mitgliedschaft im Schulverein die Formulierung aufgenommen, dass der Schulverein von denjenigen, die eine Mitgliedschaft beantragen, erwarte, dass sie eine dänische Kinderbetreuung oder Schule für alle ihre Kinder und nicht nur für einzelne wählen. Nur in besonderen Fällen, so der indirekte Hinweis auf die 2012 diskutierten Fälle, solle eine Lösung gemeinsam mit den Eltern gefunden werden, die für das Wohl des Kindes am besten sei (Dansk Skoleforening for Sydslesvig o. J.a). Überraschenderweise wird die Zielgruppe der Arbeit des Integrationsausschusses von SSF und Skoleforening zwar mit neuen, erwachsenen Mitgliedern ohne dänischen oder dänisch-südschleswigschen Hintergrund benannt, aber was genau das heißt, wird nicht weiter ausgeführt. Eine Definition, was unter dänischem oder dänisch-südschleswigschem Hintergrund verstanden wird, fehlt auch im Protokoll der Vorstandssitzung des Schulvereins beim Tagesordnungspunkt Integrationsausschuss (Oetzmann 23.06.2014). Journalist und Vorstandsmitglied Niels Ole Krogh gibt laut Protokoll zu bedenken, dass die Zeit, in der man Menschen missionieren könne, vorbei sei. Er meint damit Schulungen zum vermeintlich richtigen Dänischsein.

Neben den gerade geschilderten Punkten, die der Integrationsausschuss einstimmig vorschlägt, gibt es noch weitere diskutierte, sogenannte Sonderstandpunkte des Ausschusses, die aber nicht von allen Mitgliedern des Ausschusses

323 „Ret og pligt inføres i Sydslesvig“ 
vertreten werden (Andresen 14.05.2014: 3). ${ }^{324}$ Dazu gehören die Forderung nach Beteiligung des SdU am Integrationsausschuss sowie der Wunsch nach Konsequenzen für Eltern, die ihre Kinder dänisch ausbilden lassen, sich aber nicht selbst in die Minderheit integrieren (wollen). Hintergrund dieses Wunsches ist ein ökonomisches Denken: Nach einer Schätzung des Ausschusses kostet die Ausbildung eines Kindes von der Krippe bis zum Abitur den Schulverein rund 100.000 €. Bisher könne dieses privatschulische Angebot im Gegensatz zu anderen Privatschulen kostenlos genutzt werden, ohne jegliche Art von Gegenleistung, nur begleitet von moralischen Appellen, sich zur dänischen Minderheit zu bekennen. ${ }^{325}$ Es gebe keinerlei Konsequenzen für ein fehlendes Bekenntnis. Die diesen Vorschlag vertretenden Ausschussmitglieder fürchten, dass zu viele Leute vom Angebot profitieren würden, ohne sich für die dänische Minderheit aktiv einzusetzen. Daher wird gefordert, das Nutzen der dänischen Ausbildungsmöglichkeit in Südschleswig an einen obligatorischen Beitrag für die Minderheitengemeinschaft zu koppeln (ebd.: 3). Es wird der Ruf nach einer legalen Möglichkeit laut, Leute aus dem Schulverein auszuschließen, wenn diese sich nicht aktiv für die dänische Gemeinschaft engagierten und sich nicht mit der Minderheit identifizierten. Beispielsweise würde dafür eine beitragsgebundene Mitgliedschaft in Minderheitenvereinen oder der Besuch von Dänischkursen reichen, so das Vorschlagspapier (ebd.: 3). Alternativ sollten die nicht-integrierten Eltern Schulgeld für ihre Kinder zahlen, vergleichbar mit Privatschulen (ebd.: 3).

Die Vorschläge des Integrationsausschusses von SSF und Skoleforening, sich Konsequenzen und Sanktionen für mangelnde Integration neuer Eltern in die dänische Minderheit zu überlegen, findet im Vorstand des Schulvereins keine Anhänger*innen. Der bis 2014 zweite Vorsitzende des Schulvereins, Udo Jessen, konstatiert gegenüber der Flensborg Avis, dass sich der Vorstand darüber

einig sei, dass es nicht hilft, die Eltern zu etwas zu zwingen. Deshalb müssen wir versuchen, einige Werkzeuge zu finden, mit denen wir den Eltern ein Gefühl von Miteigentümerschaft in der Minderheit geben können. Sie sollen sehen, welche Möglichkeiten sie innerhalb der Minderheit haben. Persönlich bin ich nicht der Auffassung, dass wir ihnen

325 Die geschilderte Rechnung lässt allerdings außer Acht, dass wenn es weniger Kinder auf dänischen Schulen gäbe, einige dieser Schulen geschlossen werden müssten oder die einzelnen Ausbildungsplätze pro Kind erheblich teurer würden. 
sagen sollten, was sie sollen und was sie müssen. ${ }^{326}$ (Jessen in Peetz 18.06.2014)

Udo Jessen stellt anschließend die Frage: „,Wer hat das Mandat, mein Dänischsein zu bewerten? ${ }^{\text {‘327 }}$ (ebd.).

Der Integrationskurs im oben beschriebenen Format und von einwöchiger Dauer wurde im Herbst 2014 wiederholt angeboten. Da die Beteiligung an den Kursen eher gering war und Eltern sich Urlaub nehmen mussten, um daran teilzunehmen, wurde das Konzept der Integrationskurse ab April 2015 umgestellt. Auf Initiative der ehemaligen Schulleiterin der dänischen Koppermølle Skole Kupfermühle-Schule - direkt an der dänischen Grenze, Charlotte Bassler, wurden seitdem Sprachwochenenden für in der Minderheit neue Familien durch SSF und Skoleforeningen angeboten. Das Paket enthält vier Wochenenden mit jeweils einer Übernachtung an der Jaruplund Højskole in Deutschland oder der Højskolen Østersøen in Apenrade/Aabenraa in Dänemark. Pro Wochenende gibt es Workshops für Eltern und Kinder sowie jeweils zehn Stunden Dänischunterricht für die Eltern. Ziel ist bei diesem Angebot auch die Integration der Neudän*innen in die Minderheit und ein darauffolgendes, aktives Engagement. Dieses Angebot erweist sich als stark nachgefragt. Im ersten Jahr gab es sechs Wochenenden mit 20 Familien. Im April 2016 gab es bereits 68 Familien auf der Warteliste für dieses Angebot (Thöming 21.06.2013). In der Mitgliederzeitung Fokus der Skoleforening wird eines dieser Wochenenden anhand einer teilnehmenden Familie unter dem Titel „Nach und nach färbt es ab“328 beschrieben. Die Familie Orth soll die dänische „Sprache und Kultur ${ }^{6329}$ (Skoleforening for Sydslesvig 23.04.2016) kennenlernen. Dadurch gleite das Dänische nach und nach in ihr Alltagsleben hinein, so die Meldung. Der Schulverein schreibt, es seien bisher „mehr als 200 Kinder und Erwachsene durch die Familiendänischkurse geschleust worden“ ${ }^{330}$ (ebd.). Die Initiatorin der Kurse, Charlotte Bassler, wird mit den Worten zitiert: „Es ist die Rede von einem wahrhaftigen Bombardement von Dänischem “331 (ebd.). Der Gebrauch der Begriffe „Durchschleusung“ in Bezug auf die Sprach- und Kulturkurse und das „Bombardement“ mit dem Dänischen zeugen von einem Containermodell-Kulturbegriff bei den Akteur*innen und einem Willen zur Missionierung zum Dänischen hin. Die Pressemitteilung verwendet auch die Formulierung

326 „enig i, at det ikke hjælper at tvinge forældre til noget. Derfor må vi prøve på at finde nogle redskaber, for at vi kan give forældrene en fornemmelse af medejerskab i mindretallet. De skal se, hvilke muligheder de hat inden for mindretallet. Personligt mener jeg ikke, at vi skal fortælle dem, hvad de skal, og hvad de må“

327 „Hvem har mandat til at vurdere min danskhed?“

328 "Lige så stille smitter det af.“

329 „,sproget og kulturen“

330 „,der er blevet sluset mere end 200 børn og voksne igennem familiedankskurserne“

331 „Det er tale om et sandt bombardement af dansk.“ 


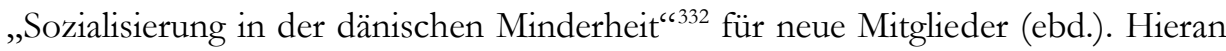
wird deutlich, dass das laut Gesetz freie Bekenntnis zur Minderheit aus Sicht der Funktionär*innen mit Sprachkenntnissen und kulturellen Praxen gefüllt werden muss. Diese sollten den Erwartungen der Entscheidungsträger*innen entsprechen. Im Familienkurs, bestehend aus jeweils vier Wochenenden, würden dänische Traditionen vermitteln, beispielsweise wie ein dänisches Weihnachtsessen auszusehen hat und was das Hochschulgesangbuch ist.

Familie Orth kommt ursprünglich aus dem Landesteil Holstein und „beschloss“, als sie in den Landesteil Schleswig umzog, „ein Teil der Minderheit zu werden und natürlich auch die Sprache zu lernen“333 (ebd.). Christina Orth berichtet im Fokus, dass sie dänische Traditionen für ihr Zuhause übernähmen. Sie tanzten beispielsweise um den Weihnachtsbaum und stellten an Geburtstagen einen Dannebrog, die dänische Flagge, auf. Diese Praxen werden als spezifisch dänisch wahrgenommen und dienen zur Markierung des persönlichen Dänischseins.

Zusammenfassend lässt sich sagen, dass das Dänischsein an alle Akteur*innen, seien es Neudän*innen nach dem Krieg, Kinder aus „,schon immer dänischen Familien" oder heutige Neudän*innen, sowohl institutionell als auch spontan vermittelt wird. Die institutionelle Seite wird durch die Vereine der dänischen Minderheit, wie dem Schulverein und dem Kulturverein SSF, übernommen. Die spontane Vermittlung geschieht in Gesprächen und bei gemeinsamen Aktivitäten der Menschen und wird unterstützt durch institutionelle Vorgaben und den Integrationskurs bzw. die Sprachwochenenden. Das gemeinsame Wissen, welches den Akteur*innen der imaginierten Gemeinschaft der Minderheit vermittelt wird, trägt zur Gemeinschaftsbindung bei und wird von Thomas Hase als ,zivilreligiöses Substrat" deklariert (Hase 2001: 185). Normalerweise werden Angehörige immigrierter Minderheiten in Deutschland dazu gedrängt, sich in die deutsche Mehrheitsgesellschaft zu integrieren (sog. Leitkulturdebatte, s. S. 108). Es wird vom deutschen Staat als problematisch angesehen, wenn der türkische Staat in Deutschland parallelgesellschaftliche Strukturen unterstützt, wie es beispielsweise beim religiösen, aus Ankara gesteuerten Verein DTIP passiert. Es gibt bei Einwanderern seitens der deutschen Mehrheit „Befürchtungen hinsichtlich eines migrantischen Rückzugs in ethnische »Parallelgesellschaften«" (Römhild 2007: 161). Gleichzeitig gibt es Deutsche, die sich selbst als zu sogenannten autochthonen Minderheiten gehörig bekennen oder bekehren lassen. Laut Gesetzgeber werden da parallelgesellschaftliche Strukturen ausdrücklich geschützt und von einem ausländischen Staat, hier vom Königreich Dänemark, finanziert. Die Integration in

\footnotetext{
332 „socalisering [sic] i det danske mindretal“

333 „,besluttete den [...] at blive en del af mindretallet og naturligvis også at lære sproget“
} 
die Minderheit verläuft ähnlich wie die Integrationsversuche in die Mehrheit, sie hat hier nur umgekehrte Vorzeichen. Der Begriff Parallelgesellschaft ist in der Regel negativ konnotiert und steht für eine gescheiterte Integration und parallele Gesellschaften, die nebeneinander her bzw. getrennt voneinander nach anderen Regeln leben und nicht miteinander leben (Münkler, Münkler 2016: 237-244). ${ }^{334}$

Das vorherige Kapitel hat gezeigt, dass es für erwachsene Neudän*innen schwer ist, sich dänische Praktiken anzueigenen und diese auszuführen. Aus diesem Kapitel lässt sich schließen, dass auf der anderen Seite auch die Funktionär*innen der Vereine lernen müssen, dass sich durch Rekrutierung von neuen Mitgliedern die Praktiken des Dänischseins und die Erwartungen an das Dänischsein ändern werden. Denn Praktiken werden „durch Teilnahme definiert und konstituiert" (Shove, Pantzar 2016: 97), wenn sich also die Teilnehmenden ändern, dann ändern sich auch die kulturellen und sprachlichen Praktiken. Dies trifft nicht nur auf Minderheiten zu, sondern auf alle kulturellen Praktiken, die „Gestalt und Form durch die Aktionen und Nichtaktionen vergangener, gegenwärtiger und potenzieller Praktiker annehmen“ (ebd.: 97). Durch die Integrationsinitiative des Kulturvereins und des Schulvereins wird aber der Einsicht Rechnung getragen, dass ,individuelle und kollektive Kompetenz“ (ebd.: 103) zentral ist für die Aufrechterhaltung, Reproduktion und Weiterentwicklung von kulturellen Praktiken, wie Shove und Pantzar anhand des Beispiels Floorball gezeigt haben.

334 Auch bei den Sorb*innen gibt es sogenannte „Neusorben“, das sind „Deutsche, die ihre sorbischen Wurzeln entdecken, Mitglieder in sorbischen Vereinen werden wollen“ oder ,,sich als Sorben bezeichnen könnten“ (Toivanen 2001: 139), da auch hier das Bekenntnis frei ist (ebd.: 138). Es wird auch um neue Mitglieder geworben, und zwar ebenso mit einigen Erwartungen an ihre politische und kulturelle Haltung (ebd.: 139) wie bei der dänischen Minderheit auch. 


\title{
7. Dänischsein und Dänischbleiben: Zugehörigkeiten, Erwartungen und Ideologien
}

\author{
Für das Dänischwerden und Dänischsein ist \\ die ,Selbstidentifikation als Däne, Dänisch- \\ gesinnter, dänischgesinnter Südschleswiger \\ oder Südschleswiger" zentral. \\ Jorgen Kühl (2005a: 342)
}

Die außerschulischen dänischen Institutionen und Vereine sind ein „Instrument, mit dem die dänische Minderheit mittels eines umfassenden Netzwerkes die ständige Reproduktion der Minderheit sicherstellt.“ (Christiansen 2008: 160). Das Dänische werde oftmals zum deutschen Alltag dazugewählt (Kühl 16.06.2016). Dies geschehe in der Regel ,via Kinderkrippen, Kindergärten und Einschulung, aber kann auch später im Leben durch die Mitgliedschaft beispielsweise im SSF passieren “ ${ }^{\text {‘335 }}$ oder durch Nutzung von oder Engagement in dänischen Minderheiteninstitutionen (ebd.).

335 „via vuggestuer, børnehaver og indskoling, men kan også ske senere i livet ved medlemskab i f.eks. SSF“" 
Wollen die Akteur*innen nicht, dass sich die Minderheit langsam auflöst, müssten immer wieder Momente geschaffen werden, die das Dänischsein aufrechterhalten, so Skovmand (2006: 1). ${ }^{336}$ Die Vereine fördern den Zusammenhalt und die Bindung an die dänische Minderheit, da sonst die Grundlage der Minderheit für die Akteur*innen, das dänische Gemeinschaftserlebnis, wegfallen würde und viele Südschleswiger*innen auf gesellschaftliche, kulturelle und soziale Angebote der Mehrheitsgesellschaft zurückgreifen würden. Die „Instrumentalisierung von Vereinen und Verbänden“ (Christiansen 2008: 87) sei unbedingt zur Aufrechterhaltung des „minderheitlichen Nationalstaats-Konstrukts“ notwendig (ebd.: 109). Ohne die Vereine gäbe es keine Orte mehr zur Generierung von gemeinsschaftlichen Gefühlen und Zusammenhalt. Wenn es die dänischen Institutionen nicht gäbe, mahnt die ehemalige Lehrerin und Buchautorin Johannsen-Bojsen, „mit wem soll[t]en sie dann dänisch sein?“ (Johannen-Bojsen in Paszel 2005: Anhang). Dort können sie andere (dänisch gesinnte) Menschen und auch Dän*innen aus dem Königreich treffen, die in Südschleswig wohnen und arbeiten. Die Institutionen sind also diejenigen Orte, an denen die Interviewpartner*innen Dänisch sprechen können, wenn sie wollen (vgl. INT02), während ihre „Haussprache“" (Christiansen 2008: 205; Pedersen 2000b: 380) ansonsten Deutsch oder Niederdeutsch ist. Neben dem persönlichen Engagement in Vereinen werden Erwachsene auch durch die starke Einbeziehung als Eltern in die Kindergärten und Schulen an die dänische Gemeinschaft gebunden. ${ }^{337}$ Zur Herausbildung und Aufrechterhaltung von „kulturelle[r] Identität“ sind nämlich „Bezugspunkte in Form von Menschen, die reflektieren, befürworten, ablehnen, etwas ganz anders machen oder ähnlich“ notwendig (Unterweger 2002: 195). Zugehörigkeiten entstehen also immer im Kontext mit anderen Menschen und sind nicht per se gegeben. Institutionen sind der „Bereich, in welchem sich für die Menschen der Minderheitenstatus manifestiert“" und wo „eine minderheitenspezifische Sozialisation“ erfolgen kann (Jebsen 2008: 131). Vereine und Schulen haben in Bezug auf Minderheiten wie der dänischen ,eine doppelte Funktion“, denn beide „unterbreiten ein inhaltliches Angebot auf den verschiedensten Ebenen und sind zugleich sozialer Erlebnisraum“ (ebd.: 133). Vereine bieten Treffpunkte für Menschen, sie sind aber nicht exklusiv in dem Sinne, dass die Akteur*innen nur Minderheitenvereine aufsuchen würden (ebd.: 134). Den Institutionen schreiben die Akteur*innen den Fortbestand einer Minderheit zu, so die Kulturanthropologin Nina Jebsen am Beispiel der deutschen Minderheit in Dänemark (ebd.: 143-144).

336 Sven Skovmand ist dänischer Journalist und Historiker.

337 Ein Interviewpartner berichtet, dass die Eltern von Kindern der dänischen Schule viel stärker von den Lehrer*innen in schulische Belange eingebunden würden als auf deutschen Schulen: $\mathrm{Da}$,ist ja sehr viel Mitsprache, also die, die [sic] Dänen machen ja eigentlich nie was ohne die Eltern [...]. Das ist auch son Unterschied. [...] Man wird auch sehr unterrichtet, worum [sic] man das nun macht und warum dieses hat oder wenns Probleme gibt genauso" (INT04). 
Da der Schulbesuch, wie in der vorliegenden Arbeit dargestellt, das zentrale Element für die Bindung von Personen an die dänische Minderheit ist, stellt sich die Frage, wie diese Zugehörigkeit nach Beendigung der Schulzeit bzw. außerhalb der Schulen aufrechterhalten wird. Dies soll anhand von Interviews mit Akteur*innen aus der Nachkriegsgeneration und einer lokalen Funktionärin sowie anhand von teilnehmender Beobachtung und informellen Gesprächen mit neudänischen Eltern nachfolgend beantwortet werden. Der Schwerpunkt liegt dabei auf dem Kulturverein SSF und den von ihm veranstalteten Jahresfesten. Daher beginnt dieses Kapitel mit einem Blick auf eine lokale Abteilung des Kulturvereins SSF in Friedrichstadt, bevor allgemeine Erwartungen des SSF und seiner „Virtuosen“" analysiert werden. Dabei werden auch verschiedene ideologische Richtungen und Widersprüche und das damit untrennbar zusammenhängende Verhältnis der Minderheit zum Königreich Dänemark erörtert.

\subsection{Dänischsein und Dänischbleiben im Verein: ein Ortsverband im Kulturverein SSF}

Zahlreiche dänische Minderheitsorganisationen sind in der von mir untersuchten Kleinstadt Friedrichstadt aktiv. Dazu gehören der Schulverein Dansk Skoleforening for Sydslesvig, der Kirchenverein Dansk Kirke i Sydslesvig (DKS), der (Haus-)Frauenverein Aktive Kvinder ${ }^{38}$, der Jugend- und Sportverein Sydslesvigs danske Ungdomsforening $(S d U)$, der dänische Gesundheitsdienst Dansk. Sundhedstjeneste for Sydslesvig, die Wählergemeinschaft Südschleswigscher Wählerverband (SSW) und vor allem der Kulturverein Sydslesvigsk Forening (SSF), um den es hier hauptsächlich gehen soll (vgl. a. Kap. 3.2). Alle dänischen Ortsvereine sind in Friedrichstadt erst seit dem Ende des Zweiten Weltkriegs aktiv (Hansen 2002: 184).

Veranstaltungen der Minderheit in Friedrichstadt werden teilweise von allen oder mehreren dänischen Vereinen getragen ${ }^{339}$, wie beispielsweise das Erntedankfest oder die Weihnachtsfeier. Teilweise sind die einzelnen Vereine allein verantwortlich.

Der SSF-Ortsverein Friedrichstadt, dem auch Angehörige der dänischen Minderheit aus dem Nachbardorf Koldenbüttel zugeordnet werden, hat 164 Mitglieder (Sydslesvigsk Forening d). Die Ortsgruppe des SSF veranstaltet regelmäßig das

\footnotetext{
338 Den slesvigske Kvindeforening, De sydslesvigske Husmoderforening. Heute auch modernisiert „Aktive Kvinder“ genannt (Auskunft der Vorsitzenden der Ortsgruppe Friedrichstadt Anke Möller am 09.07.2008).

339 „De Danske i Frederiksstad“ steht dann in der wöchentlichen Ankündigung im „Sydslesvig-Kalender" in der Flensborg Avis (Sydslesvigsk Forening 12.11.2009).
} 
Ejdercafé. Dies findet bei der Hans-Helgesen-Schule statt, es gibt Kaffee und $\mathrm{Ku}-$ chen, der Bücherbus kommt, und manchmal gibt es noch besondere Programmpunkte wie Vorträge, Kinderunterhaltung oder das Kennenlernen des Kanuklubs. Weitere Events sind der Bingoabend, der Neujahrsbrunch, das Sankt-Hans-Fest, das Jahrestreffen, die Generalversammlung, der Weihnachtsbasar im Paludanushaus, Ausflüge zu Konzerten, selbstveranstaltete Konzerte, der Fredagsklub, sowie ein Familienausflug (vgl. Sydslesvigsk Forening Frederiksstad 2010; Sydslesvigsk Forening Frederiksstad 2011a; Sydslesvigsk Forening Frederiksstad 2011b; Sydslesvigsk Forening Frederiksstad 2012). Das Erntefest im Herbst wird gemeinsam vom SSF und der Dänischen Kirche in Friedrichstadt und dem SSW veranstaltet. Dort gibt es einen Gottesdienst mit anschließendem Grillabend im Paludanushaus. Zusätzlich gibt es im SSF-Distrikt ein Grünkohlessen, eine regionale Spezialität. Hin und wieder gibt es besondere Aktionen, wie beispielsweise einen Weinoder Kochabend oder Vorträge (vgl. Sydslesvigsk Forening Frederiksstad 2013). Tina Zehntner ${ }^{340}$ erzählt im Interview, dass der SSF in Friedrichstadt viele Veranstaltungen zusammen mit anderen dänischen Vereinen organisiert und veranstaltet. Es „sind nur noch ganz wenig Sachen, die wir eigentlich alleine machen“ (INT10). Der Grund für die Zusammenarbeit ist: Die Teilnehmenden sind

eh die gleichen Leute und wir wollen lieber .. denn jeden Monat was anbieten können, wo denn [sic] eben 50 Leute kommen, als dass zwei, drei Sachen im Monat sind, wo denn immer nur zehn Leute kommen. (INT10; Mündliche Auskunft Rolf Ingwersen ${ }^{341}$; INT07)

Auch wenn es um Geschenke für Jubilar*innen geht, wird zusammengearbeitet. Statt „drei Leute mit 'ner kleinen Blume“ gibt es als Präsent nun „, ne große Blume von uns allen", also von allen Friedrichstädter Vereinen der Minderheit, in denen der Jubilar oder die Jubilarin Mitglied ist, so berichtet Ortsvorsitzende Tina Zehntner (INT10).

Eine weitere beliebte Gelegenheit, mit anderen dänischen Institutionen vor Ort zusammenzuarbeiten und gleichzeitig gegenüber der Mehrheit Präsenz zu zeigen, ist das jährliche Drachenbootrennen. Dies wird von der (deutschen) Friedrichstädter Rudergesellschaft ausgetragen, und alle Vereine und Firmen können sich anmelden. Akteur*innen der dänischen Minderheit aus Friedrichstadt aus den dänischen Vereinen tun sich dabei zusammen, da ein Team aus 25 bis 30 Leuten bestehen muss, damit man das Boot bei jedem Rennen mit 20 Paddlerinnen und Paddlern füllen kann und noch genug Leute zum Auswechseln und für

\footnotetext{
340 Ortsvorsitzende von 2013 bis 2015, stellvertretende Ortsvorsitzende von 2011 bis 2013 und 2015 bis 2016.

341 Name geändert. Bis September 2009 SSF-Amtssekretär in Husum, zu dessen Bereich auch Friedrichstadt gehört.
} 
die Betreuung an Land dabei hat. Die SSW-Vorsitzende Frauke Likowski ${ }^{342}$ organisiert das dänische Boot, und alle, die wollen, machen mit. Auch Zehntner, weitere SSF-Vorstandsmitglieder, der Pastor der dänischen Kirche, Parteimitglieder, Kanuklubanhänger*innen des SdU und Schulvereinsvertreter*innen wie Lehrer*innen und Eltern. Sie treten alle explizit und sichtbar als Minderheitsdän*innen auf und bilden in Anlehnung an die dänische Fußballnationalmannschaft von 1992, die überraschenderweise Europameister wurde, das Team „Danish Dynamite“. Sie tragen beim Paddeln alle einheitliche rote T-Shirts (Feldforschung am 17. und 18.08.2013). Und „,wer mitmachen will, darf mitmachen“ (INT10). Zehntner lädt mich sogar ein: ,also wenn du Lust hast, da mitzumachen, musst einfach bei Frauke ... [anrufen]“ (INT10).

Die Zusammenarbeit zwischen den dänischen Vereinen in Friedrichstadt, aber auch darüber hinaus wird auch insofern bei den meisten Veranstaltungen gepflegt, als dass viele Minderheitenangehörige gleichzeitig mehreren dänischen Institutionen angehören, wie man auch am Beispiel Zehntner sieht. Sie ist Mitglied in: SSF, SSW, SdU, Dansk Sundhedstjeneste, Dansk Kirke i Sydslesvig, Dansk Centralbibliothek, Dansk Skoleforening.

Das Paludanushaus, ein Treppengiebelhaus von 1637 im Besitz des SSF, wird auch von den anderen dänischen Vereinen außer dem Schulverein als Versammlungsort genutzt. Die Kirche nutzt die Räumlichkeiten zum Beispiel für Konfirmand*innengruppen, den Lese- und den Filmkreis sowie Kirchenvorstandssitzungen. Auch der SSW und die beiden Gruppen des Frauenvereins treffen sich regelmäßig dort. Das Haus wird darüber hinaus einmal pro Woche an das Friedrichstädter Frauenfrühstück ausgeliehen, einer Veranstaltung der Mehrheitsbevölkerung bzw. für alle Interessierten. „Früher was das ja undenkbar [...] da war'n ja nur WIR“ (INT10), deutet Zehntner eine Öffnung der Minderheit zur Mehrheit und eine Art Generationenwechsel an. „Und so ham wir uns auch wieder geöffnet“" (INT10). Die Stadt zahlt für die Raumnutzung des Frauenfrühstücks Miete an den SSF, aber abhängig von diesen Einnahmen sei der Verein nicht, betont Zehntner. Sie findet es gut, dass auch Mehrheitsvertreter*innen „mal ins Paludanushaus“ kommen (INT10). Beim Paludanushaus ist nach außen hin fast nicht sichtbar, dass es zur dänischen Minderheit gehört. Innen dagegen stehen drei dänische Tischflaggen, und an der Stirnseite des großen Saals hängen je ein Bild der dänischen Königin und des Prinzgemahls. Das Paludanushaus ist eines von den sechs am meisten genutzten SSF-Versammlungshäusern in ganz Südschleswig (Krogh 11.01.2016).

342 Name geändert. 
Der SSF-Nachbarortsverein Drage-Schwabstedt (dän. Drage-Svavsted) mit 141 Mitgliedern (Sydslesvigsk Forening c) veranstaltet jedes Jahr im Dezember eine Weihnachtsfeier für „Mitglieder und Freunde“6343 (Sydslesvigsk Forening Drage-Svavsted 2011) in seinem Versammlungshaus in Drage. Die Formulierung „Mitglieder und Freunde“ soll Offenheit gegenüber SSF-Mitgliedern aus anderen Distrikten und Nicht-Mitgliedern signalisieren. Besonders viele Friedrichstädter SSF-Mitglieder besuchen die Feste in Drage. Auf dem Programm stehen dabei Kaffee und Kuchen bei Kerzenschein und das Singen dänischer Lieder. Einer dänischen Tradition folgend wird auch um einen mit dänischen Flaggen behängten Weihnachtsbaum getanzt.

Neben dem Weihnachtsfest veranstaltet der Drager Ortsverein über das Jahr hinweg beispielsweise auch einen Smorrebrodsaften, einen Butterbrotabend, gemeinsame Fahrten zur Vestkystkultur, einer Konzertreihe der Minderheit an der Westküste, einen Fahrradausflug für die ganze Familie samt Grillabend, ein Jahrestreffen, einen Familienausflug sowie ein Erntefest samt Spanferkel und Musik. Auch ein eigener Bingoabend und eine Weihnachtsfeier für die Älteren werden veranstaltet. Zusätzlich wird das Ejdercafé, welches normalerweise einmal pro Monat in Friedrichstadt stattfindet, „ein paar Male im Jahr“ nach Drage verlegt (Sydslesvigsk Forening Drage-Svavsted 2012).

Es findet also eine Zusammenarbeit der SSF-Ortsvereine Friedrichstadt und Drage-Schwabstedt statt. Zehntner findet es spannend, die Kolleg*innen aus den anderen Disktrikten zu treffen und sich mit ihnen auszutauschen. Zweimal im Jahr gibt es dazu ein „Formandsmøde“ (INT10), also ein Vorsitzendentreffen. In Friedrichstadt werden die Termine mit den anderen dänischen Organisationen vor Ort und mit dem SSF Drage-Schwabstedt aufeinander abgestimmt. Die Mitglieder des SSF-Ortsvereins Friedrichstadt werden vom SSF-Distrikt DrageSchwabstedt eingeladen und nehmen dort teil, ebenso umgekehrt. Die Zusammenarbeit zwischen beiden Ortsvereinen bzw. zwischen den beiden Vorsitzenden war ,immer super, super, super gut“ (INT10), bis es im Februar 2013 zu einem Streit über ein Grünkohlessen kam (Reese 14.02.2013; Sydslesvigsk Forening 07.03.2013). Dabei beschuldigte der Ortsverband Drage den Ortsverband Friedrichstadt, dass dieser das traditionelle Grünkohlessen ,geklaut“ hätte, obwohl Tina behauptet, dass sie Olga, die Vorsitzende von Drage-Schwabstedt, vorher gefragt hätte, ob sie in Friedrichstadt auch mal ein Grünkohlessen machen dürften, weil diese Veranstaltung in Drage immer so gut lief. Zehntner ergänzt: „,Weil wir ja eben immer nach Drage fahren und warum sollen wir denn, warum sollen die denn nicht mal zu uns kommen?" (INT10). Tina hat gesehen, dass bei den Festen, die Drage veranstaltet, „der ganze Fredagsklub“ vom SSF Friedrichstadt“ da ist: „da sind über die Hälfte ist SSF Friedrichstadt [sic]“ (INT10). Nach Aus-

343 „medlemmer og venner“ 
kunft von zwei Teilnehmenden des Fredagsklubs gefällt es ihnen in Drage besser. Die Leute seien da freundlicher und es sei gemütlicher. In Friedrichstadt fühlten sie sich nicht gut in den Kulturverein integriert.

Da das Engagement im Vorstand Zehntner viel Arbeit macht und sie das geringe Engagement einiger Mitglieder für den Verein beklagt und weil auch schon der dänische Kindergarten in Drage und der dänische Kindergarten in Friedrichstadt zusammengelegt worden sind (TNB; vgl. Nygaard 04.07.2014a), frage ich sie, ob es Pläne gebe, die beiden Ortsvereine, die nur sechs Kilometer auseinanderliegen, zusammenzulegen. Tina Zehntner wiegelt ab: „Nee, nee, nee. [...] Das wollen wir auch gar nicht“ (INT10). „Aber ... nee, nee, da ham wir noch nich drüber [nach]ge-[dacht] und das brauchen wir auch nicht" (INT10). Ein Grund dafür ist, dass Drage auch eine relativ junge Vorstandsvorsitzende hat. Erst wenn es mal Personalnotstand geben sollte, kann sich Zehntner eine Zusammenlegung vorstellen: „das is denn nach unserer Zeit, wenn die sich zusammentun“ (INT10). Sie berichtet aber davon, dass die SSF-Mitglieder aus Koldenbüttel ja auch zu Friedrichstadt gehören, weil es nicht so viele sind. Auch wurde der SSW-Ortsverband aus Koldenbüttel mit dem Friedrichsstädter Ortsverband zusammengelegt. Dasselbe könnte mit der Partei SSW in Drage auch passieren, meint Zehntner.

Auf die Frage hin, welche Bedeutung die Reden von Dieter Paul Küssner ${ }^{344}$ und deren Inhalte bei der landesweiten Jahreshauptversammlung für Zehntner als Funktionärin und Mitglied auf Ortsebene haben, wiegelt Zehntner ab: „weiß nicht ... ich find da sowas ja uninteressant, muss ich dir ganz ehrlich sagen. [...] ich bin mal so büschen ... passiv, was das angeht“ (INT10). „Find das auch immer recht unspektakulär, diese Landsmøde“ (INT10). Zehntner berichtet, dass die Inhalte und Themen der Landesebene nicht lokal im Vorstand diskutiert werden, sondern „wir gucken, was bei uns hier passiert und was wir machen, was wir können und denn ... man fährt so sein eigenen [sic] Ding, also das, das tut man doch und uns ist ja auch wirklich freie Hand gelassen“ (INT10). Die Erwartungen von oben werden also erst einmal ignoriert.

Zehntner hat es noch nie erlebt, dass sich die Landesebene in die lokale Vorstands- und Vereinsarbeit eingemischt hätte. Sie sagt, „Eigentlich, glaub ich, jeder fährt sein Ding.“ (INT10), aber wenn man möchte, „KANN [man] natürlich auch fragen" (INT10). Sie deutet aber an, dass wenn am Jahresabschluss festgestellt werde, dass sie zu viel Geld übrig hätten, dann könne es passieren, „,dass sie denn eben sagen, komm ihr brau[...], denn nehmen WIR mal 'nen büschen Geld“ (INT10). Man versucht als Ortsverein also, das Geld, welches man je nach der

344 Küssner ist seit November 2013 ein Grand Old Man der dänischen Minderheit und Vizepräsident des FUEV. Ein Interview mit Dieter Paul Küssner kam auch nach dreimaliger Anfrage nicht zustande. 
Zahl der Mitglieder zentral von Flensburg aus zugeteilt bekommt, und welches man bei den eigenen Veranstaltungen einnimmt, unbedingt auszugeben. Dies kann z. B. durch das Veranstalten von Konzerten, Vorträgen, Kochkursen, Lesungen passieren. Auch Fahrtkosten, z. B. für die Anmietung eines Busses zur Fahrt zu Konzerten in anderen Distrikten werden mit dem überschüssigen Geld bezahlt bzw. bezuschusst.

Die Amtsebene des Vereins über den Distrikten Friedrichstadt und DrageSchwabstedt ist der SSF Husum Amt. Hier gibt es Angebote wie das Café Kik Ind jeden Donnerstag von 10 bis 18 Uhr in der Dänischen Bibliothek im Husumhus. Auf demselben Gelände gibt es Büroräume dänischer Institutionen, wie dem SSF, dem Gesundheitsdienst, der Zeitung Flensborg Avis und der Partei SSW. Auch Ausflüge für die ganze Familie, teilweise gemeinsam mit dem Amt Eiderstedt, werden veranstaltet; so zum Beispiel die Fahrt am 25. Mai 2013 nach Düppel bei Sonderburg in Dänemark zum Historiecenter, Geschichtszentrum, in der der deutsch-dänische Krieg von 1864 nachgestellt und museal behandelt wird ${ }^{345}$. Diese Fahrt ist so organisiert, dass ein Bus in Friedrichstadt startet, in Husum, Hattstedt und Bredstedt weitere Teilnehmende abholt. Die gleiche Route wird auf der Rückfahrt gewählt, um die Menschen wieder zurückzubringen (vgl. Sydslesvigsk Forening Husum Amt 2013).

Zehntner hat einen Kontakt zur Amtsebene, der „super gut“ (INT10) ist, besonders ihre Zusammenarbeit mit dem hauptberuflich angestellten Amtssekretär Rolf Ingwersen ${ }^{346}$. „Also ich brauch Rolf super, super viel [...], wenn ich was hab oder 'n Problem" (INT10), dann geht Zehntner zu ihm und holt sich Unterstützung. Beispielsweise haben Rolf und der Landessekretär Jens A. Christiansen geholfen, als es in Friedrichstadt ein Problem persönlicher Art im Verein gab: „Wir müssen den Leuten hier immer noch in die Augen gucken ... und da wollen wir denn eben eher, dass sie von oben runterkommen" (INT10) und sich um diese schwierigen Probleme kümmern, da diese mehr Distanz zu den Leuten hätten und sie diesen nicht ständig in der Kleinstadt begegnen würden. Diese Aussagen spiegelt die kleine Gemeinschaft der Minderheit wider, in der jeder jeden kennt und in der man sich nicht traut, Konflikte persönlich zu lösen aus Angst vor alltäglichen Konsequenzen oder Gesichtsverlust vor Ort. Zehntner sagt, sie bekomme „super Unterstützung vom, vom Amt, also von Rolf jetzt“ (INT10).

345 Mehr über Düppel als nationalen dänischen Erinnerungsort und Ort des deutsch-dänischen Krieges von 1864 s. Adriansen (2016a und 2016b), Buck (2008), Schlaber (2016). Düppel ist eines der Beispiele in der nationalen dänischen Geschichtsschreibung, die John Coakley als ,glorious defeats" (Coakley 2004: 549, vgl. Kap. 8.6) bezeichnen würde. Der konstruierte Mythos rund um Düppel wird museal und medial, zum Beispiel anhand der dänischen Filmserie „1864“ von Regisseur Ole Bornedal auf Grundlage des Buches von Tom Buk-Swienty, am Leben gehalten, obwohl das historische Ereignis eine Niederlage für Dänemark gegen Preußen und Österreich war.

346 Name geändert. 


\subsection{Bindung an die Minderheit nach der Schulzeit}

Die Bindung an die Minderheit hängt nicht nur vom Engagement in den Vereinen $\mathrm{ab}$, sondern das Engagement in den Vereinen ist auch umgekehrt vom Zugehörigkeitsgefühl zur Minderheit abhängig. Ein Beispiel kann dies veranschaulichen: Nach der Schulzeit waren Frauke und Ingo Erhard ihrer Meinung nach mit anderen Dingen als dem Dänischsein beschäftigt. Ingo machte eine Lehre, Frauke fing an, als ungelernte Kraft zu arbeiten. Dann heirateten sie, bekamen Kinder und zogen sie groß. Zwar haben beide die dänische Schule in Friedrichstadt besucht, sie sehen sich selbst heute aber als Deutsche und haben in der deutschen Kirche geheiratet, obwohl sie dänisch konfirmiert worden sind. Ihr ganzes berufliches und privates „Umfeld“ „war ja praktisch [deutsch]“ (INT08), „alles, jeder spricht deutsch mit dir, dann sprichst du nicht mehr dänisch“ (INT09). Ohne ein aktives Engagement im dänischen Milieu haben sie den Kontakt zur Minderheit verloren. Das Ehepaar war „auf einmal wieder deutsch“ (INT08), denn ,eigentlich bist du ja Deutsche“ (INT09). Sie sind diejenigen unter den Angehörigen der interviewten Nachkriegsgeneration, die am nüchternsten über ihre Zeit auf der dänischen Schule sprechen. An ihren Schilderungen ist zu merken, dass ihre emotionale Verbundenheit zur Minderheit sich nicht so stark durch ihre Biografie zieht, wie es bei Sarah Iversen oder Brigitte Thomsen der Fall ist. Die sich nach einiger Zeit bei manchen einstellende fehlende Notwendigkeit, sich dänisch zu bekennen, wird folgendermaßen beschrieben:

Im Gleichschritt mit der dt. wirtschaftlichen und gesellschaftlichen Wiederherstellung nach der Währungsreform 1948 und der Errichtung der Bundesrepublik 1949 gingen aber viele Anhänger wieder auf die dt. Seite zurück; auch die Ablehnung einer Grenzverschiebung nach Süden seitens der dän. Regierung führte zum Rückgang der D[änischen Minderheit] (Hansen 2000a: 93).

Das bedeutet auch, dass die Zugehörigkeit zu einer nationalen Gemeinschaft nicht unbedingt abgrenzbar, sondern „relational[...], prozessual[...] und dynamisch“ (Brubaker 2007: 12) sowie ,konjunktur- und kontextbestimmt“ (Kühl 2005a: 346, $344)$ ist. Sie ist abhängig ,von einer Reihe individueller Umstände und Faktoren“ (ebd.: 346, 344; vgl. Kap. 2). Die Zugehörigkeit zum Dänischen werde in einigen Situationen oder in ganzen Lebensabschnitten deaktiviert, wenn es nicht so relevant sei, zur Minderheit zu gehören (Kühl 16.06.2016). Sie kann aber in anderen Zusammenhängen wieder reaktiviert oder intensiviert werden (ebd.), wie folgendes Beispiel aus meinem Sample zeigt: 
Ingo und Frauke Erhard fahren im Interview fort: „Du hast gar kein’ Kontakt mehr zu denen, wenn nicht Erik und Julia ${ }^{347}$ nun nicht wären, ich glaub', ich, also ich muss sagen, ich glaub’ ich wär' gar nicht wieder eingetreten“ (INT09). Etwa ein halbes Jahr vor dem Interview sind Ingo und Frauke wieder in den SSF eingetreten. Der Anlass dafür war, dass sie durch Erik Nissen und seine Frau auf den „Freitagsklub“ aufmerksam gemacht wurden und sie, um Kontakte zu knüpfen, Leute zu treffen und Anschluss zu bekommen, jetzt regelmäßig daran teilnehmen. Seit Frühjahr 2008 fahren sie auf SSF-Ausflüge mit, bei denen die Plätze vorrangig und rabattiert an Mitglieder vergeben werden. Sie besuchen auch Konzerte der Minderheit. Für das Dänischsein, welches auch gegen Einsamkeit wirken kann, sind persönliche Kontakte zu anderen aktiven Minderheitsdänen entscheidend. Dieses Beispiel zeigt, dass die

Identifikation [mit der dänischen Minderheit] nicht immer national bedingt sein [muss]. Sie kann auch auf andere Interessen bauen, bei denen das nationale Element nur eine untergeordnete, nebensächliche, zufällige oder überhaupt keine Rolle spielt, gesehen im Verhältnis zu z. B. praktischen, ideellen, sozialen, lebensanschaulichen oder anderen Gründen (Kühl 2005a: 352).

Das Dänischsein ist nicht statisch. Es gibt auch ehemalige Schüler*innen der dänischen Schulen, die ihr Zugehörigkeitsgefühl zum Dänischen im Laufe ihres Lebens verändert haben (Kühl 2004: 328). Sei es, dass sich unterschiedlich starke Ausprägungen ihrer „Gesinnung“ (ebd.: 328) abwechselten oder dass sie ihr Engagement in dänischen Vereinen während ihres Berufslebens abbrachen und im Rentenalter ihre dänische ,Seite' wiederentdeckten, wie bei Frauke und Ingo Erhard (INT08, INT09) oder sich heute fast nicht mehr für die Minderheit oder das Dänische interessieren, wie Sönke Nissen (INT05). Andere wiederum betonen im Interview, dass sie immer dänisch sein werden (INT02, INT03, INT04). Dazu gehört auch Brigitte Thomsen, die erzählt, dass sie schon während der Schulzeit in den SSW eingetreten ist, und damals den Posten der Kassenwartin übernommen hatte. Ihre Mitgliedschaft im Südschleswigschen Wählerverband (SSW) und im Südschleswigschen Verein (SSF) und das damit verbundene Abonnement der dänischen Tageszeitung Flensborg Avis einmal in der Woche halte sie immer noch für die Grundlage, gleichzeitig auch für den Ausdruck ihres Dänischseins. Sie fühle sich zum „Dänischen hingezogen“ und „dann ist das nur 'ne logische Folgerung, dass man auch die Vereine unterstützt" (INT02). Auch ist sie, neben vier anderen Interviewpartner*innen, seit ihrer Schulzeit regelmäßige Nutzerin der dänischen Bibliothek:

${ }^{347}$ Name geändert. Julia ist die Ehefrau von Erik Nissen. 
Ich hab wahrscheinlich auch mehr dänische Literatur inzwischen gelesen als deutsche. Das heißt nicht, dass ich nicht auch die deutschen Klassiker Schiller und Goethe auch auf dem Schrank stehen [habe], aber ich hab' sie nicht alle gelesen. Schaffe ich wahrscheinlich auch nicht mehr. [...] Aber ich denke oft dänisch, und ja, es fällt mir auch nicht schwer, wenn ich ein Buch lese und dann hab' [ich] das weggelegt und mich fragt einer, was liest du gerade, ja Mensch, so und so. Dann weiß ich manchmal gar nicht, ist es auf Deutsch oder ist es auf Dänisch. [...] Also das fällt mir dann, denk' ich mal, nicht schwer, das auf Dänisch zu lesen (INT02).

Brigitte fühlt sich durch ihre Aktivitäten in der Minderheit dieser zugehörig. In Friedrichstadt wird mit dem Freitagsklub ${ }^{348}$ versucht, diejenigen an die dänischen Vereine zu binden, die sonst kaum noch Kontakt zur Minderheit haben, weil „die alten Schüler sich gar nicht mehr so sehen, die dänischen Schüler, viele sind wechgezogen, andere ham gar kein Interesse mehr, weil irgendwann wo [sic] nichts geboten wurde“" (INT01), da

hat sich der SSF Gedanken gemacht, wie kriegen wir das denn mal wieder in Gange, dass sie son bisschen miteinander kommunizieren und überhaupt mal wieder, ja, eben diese Treffs [der dänischen Minderheit] besuchen, und dann ham sie gesacht, lass uns doch mal versuchen, freitags ist Markttag in Friedrichstadt, vielleicht kann man das auf die Art und Weise mal wieder son bisschen ins Leben rufen (INT01).

Zusätzlich gibt es noch ein monatlich stattfindendes „Eidercafé“, Ejdercafé, welches nachmittags in der dänischen Schule stattfindet und eine Art Rahmenprogramm für den Halt des dänischen Bücherbusses ist. In vielen Gemeinden ist das Vorhandensein einer dänischen Schule für den Erhalt der lokalen Minderheit wichtig, da sie oftmals Gebäude für Versammlungen zur Verfügung stellt und dänische Lehrkräfte und Schüler vor Ort bindet. Diese Bedeutung hat auch der dänische Schulverein erkannt: „,Wird eine dänische Schule geschlossen, werden die Folgen oft ein merkbarer Rückgang [sic] in der ganzen lokalen dänischen Arbeit sein, sowohl kulturell als auch politisch.“ („Lukkes en dansk skole, vil følgerne ofte være en mærkbar tilbagegang i hele det lokale danske arbejde såvel kulturelt som politisk." (Skoleforening for Sydslesvig 2009b)). Ähnlich sehen das auch SSF-Vertreter des Ortsdistriktes in Hostrup. Sie haben Angst vor dem Umzug ihres Kindergartens nach Satrup, weil dann ein lokaler Treffpunkt wegfiele (Flamming 01.03.2014). In Friedrichstadt ist die Abhängigkeit vom Schulgebäude aufgrund der Existenz des Paludanushauses und der Möglichkeit, die Mennonitenkirche für Gottesdienste zu nutzen, nicht gegeben. Auch Michael S. Byram hat die Bedeutung der Schulgebäude für Aktivitäten der Minderheit auch außerhalb der Schulzeit anhand der deutschen nordschleswigschen Minderheit herausgestellt (Byram 1986: 155). 
Deshalb treffen sie sich jede Woche einmal. Finanziell unterstützt wird dieser regelmäßige Freitagsklub vom SSF. Diejenigen, die teilnehmen und Kaffee und Kuchen oder warme Speisen zu sich nehmen, bezahlen einen kleinen Obolus in die Gemeinschaftskasse. Der SSF-Sekretär Rolf Ingwersen nimmt als Ansprechpartner für organisatorische Fragen oder kulturelle Anregungen bis zu seiner Verrentung im Jahre 2009 teil. In dieser Funktion versuchte er beispielsweise herauszufinden, an welcher Art von Vorträgen oder Konzerten die Teilnehmer*innen interessiert sind. Die Diskussionen darüber moderierte er. Ist er nicht da, übernimmt Erik Nissen diese Aufgabe. Ingwersen sorgte außerdem dafür, dass der Freitagsklub als angekündigter Termin regelmäßig in den Veranstaltungsspalten der Flensborg Avis erscheint. Er überlegte mit den Teilnehmer*innen gemeinsam, wie dänische Freizeitangebote veranstaltet und finanziert werden können. Für diese Veranstaltung gibt es keine offizielle Struktur, sondern jeder kann sich so engagieren, wie er möchte, in „loser Zusammenform“ (INT01). So sind beispielsweise zwei Frauen für die Verpflegung zuständig. Der Freitagsklub ist ein offenes Angebot, das jede*r nutzen kann, aber dazu „müssen dann ja auch welche federführend dazu bereit sein, um das zu machen" (INT01), damit diese Initiative erhalten bleibt. Erik Nissen engagiert sich beim Freitagklub ${ }^{349}$, weil er mit Menschen umgehen und kommunizieren kann, ähnlich gut wie ein*e Muttersprachler*in Dänisch spricht, als Rentner Zeit hat, Leute treffen möchte und nach Jahren ohne Engagement in der dänischen Minderheit den Kontakt zum Dänischen wieder herstellen und aufrecht erhalten möchte:

Das hängt $[\ldots]$ vielleicht auch son bisschen mit dem Alter ${ }^{350}$ zusammen, dass man denn, ja, überhaupt mehr nachdenkt über viele, viele Sachen, nech und dass man es doch eigentlich doch sehr gut gehabt hat in der Schulzeit mit diesem ganzen dänischen Brauchtum, [...] Ausflüge, Lieder singen, 'ne andere Sprache sprechen können (INT01).

Das Beschriebene und das Zugehörigkeitsgefühl und die Gemeinschaft mit anderen sind genau die Elemente, nach denen sich Erik Nissen sehnt. Materiell hat er nichts vom Besuch des Fredagsklubben, aber, es sei so schön und nett dort. Deshalb nehmen er und seine Frau daran teil (INT01). Außerdem hat er am Dänischen „sehr viel Spaß“ (INT01). Mit dem Beginn seiner „Bundeswehrzeit“ (INT01) hatte Erik den Kontakt zum Dänischen „verloren“ (INT01). Die dänische Minderheit ist von ihm eine Zeit lang "gar nicht wahrgenommen “351 (INT01) worden, weil erst „,die Familie [kam], dann kam die Arbeit, das hatte alles

\footnotetext{
349 Am Freitagsklub nehmen aus dem hier verwendeten Sample neben Erik Nissen mit seiner Ehefrau auch Ingo und Frauke Erhard regelmäßig teil, manchmal kommen auch Heinrich Schmied und Otto Clausen mit seiner Frau.

350 Auch Brigitte Thomsen engagiert sich, seitdem sie in Rente ist, ,eher mehr“ (INT02), sie geht „zu mehr Veranstaltungen“ (INT02).
} 
Vorrang und irgendwann hat man gesagt, Mensch, worum [sic] komm' wir eigentlich gar nicht mehr zusammen?" (INT01) Das war 1997, daraufhin versuchte er, sich politisch für das Dänische zu engagieren. Er wurde SSW-Mitglied und beteiligte sich an der politischen Arbeit in einem neu gegründeten SSW-Ortsverein in Koldenbüttel nahe Friedrichstadt. Da dessen Vorsitzender sein Amt nach einigen Jahren aufgab, wurde die Ortsgruppe aufgelöst und Erik Nissen stand wieder alleine da, „ohne irgendwelchen Anhang, ohne irgendwelche Bindung“ (INT01) an die Minderheit. „Dann hab’ ich mir gedacht, ach, dann nimmst du die andere Sache, SSF, was ja die kulturelle Seite der dänischen Minderheit ist. [...] Ja und da fühl' ich mich eigentlich gut aufgehoben. [...] Wir sind dann Friedrichstadt mit angeschlossen." (INT01) Nicht zuletzt gehen Erik Nissen und seine Frau zu Konzerten, die von dänischen Vereinen organisiert werden, egal um welche Musikrichtung es sich dabei handelt, während sie die Konzerte anderer Anbieter nicht besuchen. ${ }^{352}$ Hieraus kann man schließen, dass sie sich erstens im dänischen Umfeld und mit anderen Dänischgesinnten erheblich sicherer bewegen und wohler fühlen, es also eine Art Beheimatung ist (s. Kap. 8.7), und für sie zweitens das Prinzip gilt, dass alles, was dänisch ist, gut ist, was auch ein Informant bestätigte (Informelles Gespräch Dorling ${ }^{353}$ 04.09.2017).

Ähnlich wie Erik Nissen erging es auch Brigitte Thomsen, die zwar seit ihrer Schulzeit im SSW, im SSF und in der dänischen Kirchengemeinde Mitglied ist, sich aber im Zeitraum von der Familiengründung bis zur Verwitwung nur wenig um ihr Dänischsein gekümmert hatte:

Ich hab' dann auch geheiratet und hab' mich auch vielleicht nicht intensiv genug d'rum gekümmert und kam ja eben auch dazu, dass mein Mann nicht so sehr dafür war, ich bin dann wohl ab und zu mal in die dänische Schule gegangen, wenn da noch 'nen Wiedersehenstreffen war oder so, aber ich hab' dann auch das kulturelle Leben nicht so ganz intensiv da verfolgt, muss ich sagen. Und da bin eigentlich wieder mehr aktiv geworden, nachdem mein Mann 1994 verstorben war, weil ich mich dann einfach auch dort mehr aufgehoben fühlte als hier irgendwo [im Dorf] (INT02).

351 Erik Nissen betont aber zur Legitimation seines Dänischseins, dass er in diesen Jahren zwar kein Mitglied im SSF oder SSW oder einem anderen dänischen Verein war („,das wurde dann erst später wieder aktuell“, INT01), aber dass er am Dänischen „wohl interessiert“ (INT01) gewesen sei und er die ganze Zeit über „,mit den [dänischen] Pflegeeltern in Verbindung“ (INT01) stand.

352 Das haben informelle Gespräche mit ihnen und teilnehmende Beobachtungen ergeben.

353 Name geändert. 
Das oben geschilderte Gefühl des Dänischseins schließt für die Interviewpartner*innen aber nicht aus, gleichzeitig auch in deutschen Vereinen aktiv zu sein oder gleichzeitig der Mehrheit anzugehören. Einige sind in verschiedenen deutschen Sport- oder Gesangvereinen, im Sozialverband Deutschland oder dem Deutschen Roten Kreuz oder in deutschen Kirchengemeinden aktiv. Eine Gesprächspartnerin ist Mitglied in einem deutschen Fremdenverkehrsverein ${ }^{354}$, um „Geld zu verdienen“ (INT02). Die Gesprächspartner*innen gehen bei der Wahl der Vereine und Freizeitaktivitäten - im Gegensatz zu den Vorgaben der Funktionär*innen (s. Kap. 5.2, 7.4) - ganz pragmatisch vor. Sie überlegen, wozu sie Lust haben, womit sie sich gerne beschäftigen möchten und nicht primär, ob ein Verein deutsch oder dänisch ist ${ }^{355}$, wobei das Angebot an dänischen Vereinigungen viel geringer ist als das Angebot der Mehrheitsgesellschaft. Sarah Iversen betont: „Ich glaube nicht, [...] dass ein Verein mir nicht genug wäre, weil er deutsch ist, also überhaupt nicht, das wär' schrecklich, das wär' ja schon fanatisch. Ich nehm' an den dänischen Vereinen teil, die mir gefallen“ (INT03). Den Südschleswiger*innen stehen deutsche und dänische Angebote offen. Sie haben jedoch eine größere Auswahl an Vereinen, bei denen sie aktiv werden können, weil sie die sprachlichen und kontextuellen Voraussetzungen für deutsche und dänische Angebote besitzen. Kühl beschreibt diese Tatsache so, dass ein Dänischsein für einige der Akteur*innen nicht ausschließe, dass sie auch deutsch seien, also beides seien und nicht in zwei abgrenzbaren „Kulturen“ handelten, als „Übergangsphänomene, die am besten als Kontinuum ohne klare Konturen bezeichnet werden können“ (Kühl 2005b: 473). Das bewirke z. B. eine „Bikultur“ oder „Bindestrichs-Identitäten oder regionale Identifikationen“ bei den Akteuren, aber nicht bei den Minderheitenorganisationen (Kühl 2005b: 473; vgl. a. Scheer 2014). Bei der Analyse muss also differenziert werden zwischen den Haltungen und den Handlungen der Institutionen und denen der einzelnen Individuen der Minderheit. Die Teilnahme an deutschen und dänischen Angeboten ist für Akteur*innen heute in der Minderheit kein Problem mehr, während in der Nachkriegszeit der Gesinnungswechsel noch eine Frage von einer „100\%-Wahl, einer Frage von schwarz oder weiß" war (Henningsen 2003b: 8). Doch heute sei das anders, heute werde das Dänischsein in Südschleswig eher kulturell-politisch, als kulturelle Vielfalt, definiert und nicht mehr als nationale Bewegung (ebd.: 8), so

354 Der lokale Tourismusverein dient zur Vermittlung von Ferienwohnungen zwischen Gästen und Vermieter*innen.

355 Wobei sich die nichtdänischen Vereine, da sie der Mehrheitsgesellschaft angehören, nicht als spezifisch deutsch bezeichnen, die Vereine der Minderheit sich aber spezifisch dänisch nennen. Entsprechendes pragmatisches Verhalten beschreibt auch Nina Jebsen für Akteur*innen der deutschen Minderheit in Dänemark (Jebsen 2008: 134). 
der Historiker. Diese Beschreibung der Praxen ist näher an der Lebensrealität der Minderheitsakteur*innen als die Ideologie der Minderheitenvereinsfunktionär*innen, die einseitige Vorgaben und Erwartungen formulieren.

Einige Interviewpartner*innen (INT01, 02, 03, 04, 07) halten ihr persönliches Dänischsein aufrecht, indem sie ihre dänischen Sprachkenntnisse nutzen und dänische Bücher lesen, die sie sich aus der dänischen Bibliothek ausleihen, Filmoder Leseabende besuchen, zu dänischen Bingoabenden, Konzerten, Theaterabenden oder Vorträgen gehen, bei gemeinsamen Veranstaltungen dänische Lieder singen, bei Erinnerungswerkstätten zur Minderheitengeschichte mitarbeiten, die dänischen Sankt-Hans-Feste, Jahrestreffen, Schuljubiläen oder dänische Gottesdienste besuchen. So ist beispielsweise Sarah Iversen (INT03) eines von drei Mitgliedern des Kirchenvorstandes. Fast alle betonen, dass sie bei Kommunalund Landtagswahlen immer dänisch stimmen, also den SSW wählen. Das sei ,'ne reine Gewissensfrage“ (INT04), betont einer. Ein Teil der Interviewten hisst zu bestimmten Anlässen eine dänische Flagge. ${ }^{356}$ Brigitte Thomsen sympathisiert bei Fußballänderspielen, in denen Deutschland gegen Dänemark spielt, mit der Mannschaft des Königreichs, weil sie die Deutschen „manchmal sehr überheblich" findet (INT02). Abgesehen von diesen Punkten meint eine Interviewte, dass sich ihr Dänischsein ansonsten ,im Alltag [...] nicht“ zeige (INT02) und man es „nach außen hin nicht festmachen“ (INT02) könne, es sei einfach „selbstverständlich“ (INT02) für sie selbst. Beispielsweise erzählt sie: „Ich kann nicht sagen, dass ich nun immer dänisch koche oder so, [aber] dass ich mich einfach mit der dänischen Kultur und der ganzen Lebensweise mehr identifizier' als mit der deutschen“ (INT02). Heinrich Schmied ergänzt: „Es ist das gesamte Gefühl“ (INT07), das einen dänisch mache. Und zur Aufrechterhaltung der Minderheit „können wir nicht mehr [...] tun, als dass wir, ja, Dänisch sprechen, dänisch denken, dänische Kultur versuchen zu leben“ (INT02). Aber materielle Vorteile haben die Angehörigen der Minderheit heute keine mehr gegenüber Nichtdän*innen, höchstens „kulturelle“ oder „persönliche Zufriedenstellung“ (INT07), so die Ansicht Schmieds. Andere Interviewte haben keine Antwort auf die Frage, woran man ihrer Meinung nach im Alltag sehe, dass jemand Dänisch ist. Einer aus dem Sample dagegen, Sönke Nissen, sagt von sich, dass er ,an sich“ und „eigentlich“ zur Minderheit gehöre und er „doch noch 'nen Teil davon“ sei (INT05), aber nachdem er elf Jahre in Berlin gelebt hatte, habe er eine Zeitlang den Kontakt zum Dänischen verloren:

356 Während einige Interviewte betonen, dass sie keine schleswig-holsteinische Flagge besitzen (INT02, INT03), berichtete mir eine Interviewpartnerin, dass sie schon einmal die dänische und gleichzeitig die schleswig-holsteinische Flagge gehisst hat, obwohl sie mit ihr antidänische und prodeutsche Ressentiments in Verbindung bringt (INT06). 
Ich weiß auch nich, also irgendwo hört dat nachher auf, so schön dat alles war, früher, so schön dat alles war, aber irgendwann is dann nachher aus und vorbei, nech? [...] Für mich war dat irgendwie alles vorbei, dat war 'ne abgeschlossene Zeit, ich hab's gehabt und das wars (INT05).

Dies belegt, dass das Dänischsein stark vom Wohnort und damit auch vom Vorhandensein dänischer Institutionen abhängt. Die einzigen Verbindungen zum Dänischen pflegte Sönke Nissen über alte Freunde in Dänemark und über seinen Vetter Erik Nissen. Der versucht manchmal, mit ihm wieder Dänisch zu sprechen oder er bringt ihm eine Ausgabe der Flensborg Avis mit, ansonsten sei das „son bisschen weg“" (INT05). Zu dänischen Veranstaltungen geht Sönke Nissen gar nicht, weil er sich nur ungern an Orten aufhalte, „wo viele Menschen sind“ (INT05). „Ich bin nicht so `n Typ, der sowas gerne macht“ (INT05), Leute treffen, aber er überlegt, ob er „hätte [...] weitermachen sollen, so wie Erik dat macht“ (INT05) und fügt sofort hinzu: „Vielleicht war man auch zu bequem“ damals (INT05). Aber Sönke ist stolz, dass er manchmal dänischen Tourist*innen, die er zufällig auf der Straße trifft, mit seinen Sprachkenntnissen weiterhelfen kann.

Motivation für das Engagement für die Minderheit ist bei vielen die Dankbarkeit für die Hilfe, die sie als Schulkinder bekamen (vgl. Kap. 4.2.1.1). „All das Gute, das mir hier geboten wird, das will ich nicht so einfach nur annehmen, ich nehme es dankbar an, aber ich will [mich] dafür revanchieren, ich will dann auch mal zurückzahlen“, so die in der Öffentlichkeit bekannte dänisch gesinnte Karin Johannsen-Bojsen (Johannsen-Bojsen in Paszel 2005: Anhang). Deswegen halte sie Vorträge und schreibe Bücher über das Dänischsein. Außerdem hat sie bis zur Pensionierung als Lehrerin in dänischen Schulen gearbeitet. Ein ähnliches Motiv hat auch Sarah Iversen aus meinem Sample. Durch den dänischen Beistand, der ihr damals angeboten wurde, ist es „bis heute [...] so geblieben, diese Liebe zu Dänemark“ (INT03), die sich in ihrem Engagement äußert: „Ich bin auch aktiv in den Vereinen, weil also ich fühl' mich innerlich dahin auch hingezogen" (INT03). So erklärte sich Sarah sogar bereit, vor dem dänischen Seksmandsudvalg aus ihrem Leben zu erzählen (s. a. S. 25), um für Verständnis und Unterstützung seitens der dänischen Politik zu werben. Bei Otto Clausen äußert sich das Engagement für das Dänische in der Treue zur dänischen Partei, die er aus Dankbarkeit für die lebensrettende Unterstützung (s. a. Kap. 4.2.1) aufrechterhält. Auch ist die Mitgliedschaft in dänischen Vereinen für ihn eine Selbstverständlichkeit:

Ich empfinde [...] bei den Dänen für mich jetzt persönlich 'ne, 'ne groBe Dankbarkeit, wenn man [...] also von den Eltern her gehört hat, dass wir also eh ja ich sag mal, fast nicht mehr gelebt hätten, dann ist das für mich $[\ldots]$ und meine Brüder empfinden genauso, 'ne große Dankbarkeit (INT04). 
Diese kommt auch in regelmäßigen Besuchen im kin-state zum Ausdruck: „Wir [Otto und seine Ehefrau] pflegen auch dieses Dänischtum. Wir fahren also [...] jedes Jahr mit dem Wohnwagen ausschließlich in Dänemark rum und genießen das auch“ (INT04). Auch findet er es toll, dass er nach seinem Umzug von Flensburg nach Friedrichstadt über sein Dänischsein gleich Kontakte zu anderen Leuten knüpfen konnte. Durch diese Gemeinsamkeit des dänischen Schulbesuchs und der Mitgliedschaft in dänischen Vereinen entstehen neue Verbindungen und persönliche Kontakte zu Menschen, die Gleiches oder Ähnliches erlebt haben (INT04). Otto Clausen meint auch, dass die Dänen eine andere Mentalität hätten, dass diese geduldiger und gemütlicher seien, während sich der Deutsche immer „fürchterlich aufregt“ (INT04). Ein anderer nennt im gleichen Zusammenhang das Beispiel des „Entspannens“ (INT01) ${ }^{357}$, welches er zentral für seine Version der dänischen Gemütlichkeit hält, die er sehr schätzt:

Für mich ist es [das Dänischsein] einfach die Geselligkeit, die Gemütlichkeit, denn man muss ja nur mal mit dem Wagen über die Grenze fahr'n, sich auf der Autobahn befindend [sic]. [...] Es ist gemütlich, es ist ruhig, es ist schön, es drängelt keiner und so ist es überall. [...] Und das ist das, was mir liegt (INT01).

Gemütlichkeit ist auch Sarah Iversens Vorstellung vom Dänischsein. Der Lesekreis mit dem Pastor „,ist immer mit Wein und so verbunden“ und „so richtig kuschelig“ (INT03). Eine andere Interviewpartnerin ergänzt, dass es ,jedesmal schön“ (INT02) ist, wieder nach Dänemark zu kommen.

Das Königreich wird von den Interviewten hierbei als Reiseziel idealisiert und andere Reiseziele werden ausgeschlossen oder verdrängt, um das Dänischsein zu markieren. Dänemark und Orte, wo Dänischgesinnte sind, werden als Sehnsuchtsorte beschrieben. Die geschilderte Gemütlichkeit, die für ein „Gefühl der Geborgenheit und des Geschütztseins“, für „Sicherheit gegenüber Menschen und Räumen“ und als „Rettungsanker“ (Schmidt-Lauber 2003: 61, 63) steht, ist eine Konstruktion und eine Idealisierung zur Legitimation der dänischen Zusammengehörigkeit. Sie ist des Weiteren auch dem Anlass geschuldet, denn sowohl im Urlaub als auch bei Senior*innenrunden in Vereinen wir ein lockeres Beisammensein gepflegt. Es stellt sich die Frage, warum es nur in dänischen, aber nicht in deutschen Vereinen Gemütlichkeit geben sollte. Die Konstrukthaftigkeit von „Gemütlichkeit" wird außerdem dadurch deutlich, dass Südschleswiger mit deutschem

357 ,avslappe“ 
Pass Dänen diese Gemütlichkeit zuschreiben, während dieses Phänomen im Alltagsdiskurs ansonsten „als spezifisch deutsch angesehen wird“ (ebd.: 170 ${ }^{358}$; vgl. a. Bausinger 2002: 157).

Zuletzt soll nun die Frage geklärt werden, warum sich Funktionärin Tina Zehntner, Ende 30, für den dänischen SSF engagiert. Sie ist Vorsitzende geworden, weil sie ,in den Vereinen immer aktiv war und denn ... meinte man, dass ich denn da Vorsitz machen soll“" (INT10). Da sie im SSF engagiert ist, ist es für sie ganz selbstverständlich, gleichzeitig auch im SSW aktiv zu sein (INT10). Sie mag „das ja auch gerne, dieses Helfen und so“ (INT10), sie macht ihre Arbeit für den SSF mit Freude. Hier kann eine Parallele zu ihrem Beruf gezogen werden: Als Krankenschwester hat sie einen typischen Helfer*innenberuf erlernt, den sie in der Altenpflege ausübt. Allerdings gibt sie zu, dass sie in Bezug auf die Vereinsarbeit manchmal keine Lust mehr hat, sich zu engagieren, aber ihre Vorstands- und Arbeitskollegin Tanja Günther ${ }^{359}$ sage ihr dann, ,wer soll das denn sonst machen?"“. Es sind kaum Alternativen aus der gleichen Generation für Vorstandsposten da. Zehntners Vorgängerin Freya Kristensen ${ }^{360}$ ist aus Friedrichsstadt weggezogen und daher nur noch als Beisitzerin im Verein aktiv. Zehntner findet es schade, dass die Helfer*innen bei den Veranstaltungen immer dieselben seien, aber sie schätzt die Lage trotzdem pragmatisch ein: „Ich glaub, das ist überall so [...] das ist wirklich auch im Sportverein, hier im deutschen, dass du immer da doch die gleichen Gesichter siehst" (INT10). Sie versucht, vor allem die Eltern bei den Vereinsfesten „zu integrieren“, indem sie sie bittet, Salate für Feste zu machen oder am Grill zu stehen. Sie möchte verhindern, dass sich der Eindruck verbreitet, den einige von der Minderheit und dem Verein haben, dass ,alles sonne zusammengeschworene Gemeinschaft is" und einige sich nicht trauen, einfach mitzuhelfen (INT10).

Ihre Aufgaben sind zahlreich und nehmen viel Zeit in Anspruch: Sie muss Vorstandssitzungen einberufen und Ausflüge, Veranstaltungen und Feste organisieren (,,ist auch son großer Rattenschwanz noch runterrum“ (INT10)). Ihre Aufgabe ist auch, Statistiken zu führen, „denn is da auch viel Papierkram“. Sie muss das Vereinshaus, das Paludanushaus, betreuen und vermieten und dänische Gästegruppen begrüßen und als lokale Ansprechpartnerin für Reisegruppen, Eltern oder Neueinsteiger*innen fungieren. Sie arrangiert Veranstaltungen zusammen mit der dänischen Kirche, der Partei und der Schule in der Stadt (INT10). Nur der Juli ist jedes Jahr „absolut SSF-freier Monat“ (INT10), freut sich Zehntner.

\footnotetext{
358 Brigitta Schmidt-Laubers Studie zur Gemütlichkeit enthält aber auch den Hinweis, dass sich eine ,[d]eutsche Gemütlichkeit“" womöglich von einer dänischen unterscheide (Schmidt-Lauber 2003: 170-172).

359 Name geändert.

360 Name geändert.
} 
Die Arbeit wird ehrenamtlich gemacht und kostet viel Zeit (INT10). Manchmal gibt es auch Kurse für Funktionär*innen. Diese werden von der Amts- und Landesebene organisert und drehen sich um Schlüsselkonpetenzen wie beispielsweise Teamwork. Die Teilnahme ist freiwillig. Es gibt, so Zehntner, keine ideologischen oder kulturvereinsspezifischen Schulungen (INT10).

Als SSF-Ortvorsitzende ist Zehntner gleichzeitig auch SSF-Amtsdelegierte und Delegierte bei der landesweiten SSF-Jahreshauptversammlung. Diese Veranstaltungen findet Zehntner etwas langweilig. Eine weitere Aufgabe Zehntners ist es, Vorschläge für Ehrungen von besonders verdienstvollen SSF-Mitglieder zu machen. Sie plant gerade, eine Frau vorzuschlagen, die sich sehr für den SSF und die Minderheit engagiert hat. Zehntner sieht ihre Aufgabe ebenfalls darin, Leute zum Mithelfen zu aktivieren. Einige Mitglieder fragen von sich aus, andere muss man gezielt ansprechen und die Arbeit dann verteilen. Zehntner ist in ihre Funktion hineingewachsen, „das LERNST du eben“, „man LERNT das eben“ (INT10).

Zehntner findet es „,total geil“, wenn „,neuere Gesichter“ zu Veranstaltungen der Minderheit in Friedrichstadt, wie beispielsweise der SSF-Jahrshauptversammlung, kommen. Wichtig für die Integration von den Neuen sei, dass man „,wirklich auf die Leute zugehe[... ]" und frage, ob sie sich nicht engagieren wollten (INT10). Denn das Dänischsein bedeutet gerade, so Zehntner, „dass man eben auch AKTIV mit ... in den dänischen Vereinen is“ (INT10) und „nicht nur Mitglied auf Papier“. Man solle „was dafür tun, dass das alles funktioniert“ in der Minderheit, ergänzt sie.

Ähnlich wie Zehntner sieht das Engagement von Kerstin Pauls in Tönning aus. Sie ist dort in fast allen dänischen Vereinen aktiv, wie aus der NDR-Info-Radioreportage hervorgeht: „Kerstin Paul schleppt Kannen und Tabletts, bestückt die letzten Tische mit Blumen, hat alles im Griff. Sie ist Mitte 30. Arbeitet beim dänischen Kulturverein in Tönning und ist bei jeder Aktivität dabei“ (Werner 16.05.2016).

Ich hab ja schon immer viel gemacht. Bin auch Kirchenvorsitzende, den dänischen Pfadfinder leite ich. Ich saß in vielen Vorständen, ich bin im Jugendverein Kassiererin, also ich war immer mittendrin, weil wir ja nicht viele sind hier und ähm, wir alle dadran [sic] arbeiten müssen, dass diese Minderheit bestehen bleibt und der Zusammenhalt immer da ist. Es ist eine Gemeinschaft und tja.. wenn man da so reingewachsen ist, ist einem das so wichtig irgendwie (Pauls in ebd.).

Kerstin betont, genau wie Zehntner, dass es ja nicht so viele Leute in der Minderheit gäbe und daher ihr persönliches Engagement von großer Bedeutung für die Aufrechterhaltung der dänischen Minderheit in Südschleswig sei. Auch der Aspekt des besonderen Zusammenhalts und der Gemeinschaft wird hier genannt. 


\subsection{Exkurs: Die Auswirkungen des Dänischseins auf das Berufsleben}

Betrachtet man den Aspekt der Auswirkungen des dänischen Schulbesuch auf die berufliche Karriere Einzelner, so stellt man Vor- und Nachteile fest, welche im Folgenden erörtert werden.

Das Berufsleben der Interviewpartner*innen der Nachkriegsgeneration gestaltete sich, auch abhängig vom Geschlecht, unterschiedlich. Zwei Frauen haben keine Ausbildung gemacht und begründen dies damit, dass sie keine Lehrstelle bekamen, weil sie die dänische Schule besucht haben. Hier wird das ethnisierte Zugehörigkeitsgefühl - um auf Brubaker (Brubaker 2007: 43) zurückzukommen - als Erklärung für geringe Chancen auf dem Ausbildungsmarkt verwendet. Nur am Rande ziehen die Frauen in Erwägung, dass es sich auch um Geschlechterdiskriminierung gehandelt haben könnte oder sie sich vielleicht nicht genug bemüht haben einen Ausbildungsplatz zu bekommen oder sie selbst aufgrund der damaligen Geschlechterrolle nicht die Notwendigkeit gesehen haben, unbedingt ausgebildet zu werden: „Wir wussten ja sowieso, dass wir heiraten, wir [Frauke und Ingo Erhard] kannten uns ja schon, was sollst du da nun auch noch 'ne Lehrstelle“ (INT09) suchen. Eine andere Interviewpartnerin bestätigt dies:

Es war nicht so leicht damals, überhaupt 'ne Lehrstelle zu kriegen und es war auch schon noch 'nen bisschen außergewöhnlich, dass man überhaupt was lernen wollte, das war schon noch mehr so, ach ja, irgendwo finden wir schon 'ne Stelle für dich im Haushalt und Mädchen heiraten ja sowieso dann bald (INT02).

Eine andere berichtet, dass ihr jüngerer Bruder nach der Schule mit 15 Jahren nach Dänemark ausgewandert ist, weil er ihrer Ansicht nach in Südschleswig „keine Lehrstelle“ bekam, „weil er die dänische Schule besucht hatte, das war Diskriminierung hoch drei“ (INT03), ebenso wie sie selbst keine Lehrstelle bekam (vgl. Bsp. Sarah Iversen, Kap. 4.1). Eine dritte Frau bekam zwar eine Lehrstelle als Verkäuferin, brach die Ausbildung aber aus gesundheitlichen Gründen und wegen eines aus ihrer Sicht unfairen Chefs vorzeitig ab (INT06). Die Männer in diesem Sample bekamen allerdings alle eine Lehrstelle im Handwerk, da damals viele Handwerker gebraucht wurden (INT08). Allerdings war das „doch schon recht schwierig [...]. Das war mit viel [sic] Vorbehalte [sic], [...] dass er mich genommen hat aus der dänischen Schule“ (INT04), so beschreibt einer der Männer das Verhaltens seines damaligen Chefs ihm gegenüber. „Es gab noch viele Vorurteile“ (INT04). Davon berichten mehrere Interviewte. Einige hatten zum Beispiel auf der Berufsschule Probleme wegen ihrer dänischen Vorbildung. Sie seien dort und in den Betrieben auf Skepsis gestoßen. Dies wurde möglicherweise noch durch die Tatsache verstärkt, dass sie auf der dänischen Schule andere Rechenmethoden gelernt oder Schwierigkeiten mit der deutschen Orthographie und Gram- 
matik hatten. Der Deutschunterricht auf der dänischen Schule war nach den Meinungen fast aller Interviewten unzureichend im Vergleich zu deutschen Schulen. Ein Interviewter meint, dass die Schüler in der Berufsschule von einigen Lehrern in der Sitzordnung bewusst in deutsch und dänisch getrennt wurden: „Deutsche Schüler links, dänische Schüler rechts. “ (INT01). Im Vergleich zu nicht dänisch ausgebildeten Schüler*innen fühlte sich eine andere Gesprächspartnerin unter besonderer Beobachtung einiger Lehrer: „Da hatte ich schon das Gefühl, der Lehrer guckt immer bisschen extra scharf auf meine Sachen, was ich so von mir gab“ (INT02). Ein anderer berichtet, dass Dänenschüler ,auf der Berufsschule [...] große Schwierigkeiten [hatten]“361 (INT07) und sie unter anderem als „Vaterlandsverräter“ (INT07) beschimpft wurden. Trotz der allgemeinen Begeisterung für die dänische Schule und der Überzeugung, eine bessere Allgemeinbildung als die Gleichaltrigen auf der deutschen Schule erhalten zu haben, benennt das Sample also auch negative Auswirkungen, die sie als Angehörige der Minderheit in einer deutschen Umgebung hatten.

Als einen Vorteil des Besuchs der dänischen Schule für das spätere Berufsleben könnte man die Erlangung dänischer Sprachkenntnisse nennen. Doch diese haben sich nur in wenigen Fällen als kleiner Vorteil, aber nie als wirkliche Notwendigkeit herausgestellt. So erzählen die Interviewten, dass sich dänische Tourist*innen oder Geschäftspartner*innen zwar sehr darüber freuen würden, wenn sie in ein deutsches Geschäft oder Lokal kämen und jemand sie auf dänisch bedienen könnte ${ }^{362}$, meistens würden die Dän*innen die deutsche Sprache aber ausreichend beherrschen. Andere dagegen berichten, dass sie das Dänische beruflich gar nicht verwenden konnten, weil sie in Bezug auf das Erwerbsleben vollständig in die deutsche Gesellschaft integriert waren und deshalb keine Notwendigkeit bestand, in Dänemark oder mit Dän*innen zu arbeiten. Der derzeitige Trend, dass aus dem Grenzgebiet zahlreiche dänischsprechende Kräfte im Handwerk, in der Industrie und im Gesundheitssektor Arbeit in Dänemark finden, hat sich erst nach dem Ende der Berufstätigkeit der meisten Interviewten entwickelt. Nur Sarah Iversen hat in ihrem Berufsleben einen direkten Bezug zu einer dänischen Institution gehabt, als sie in der Hans-Helgesen-Schule arbeitete (vgl. Bsp. Sarah Iversen, Kap. 4.1) und ihre Sprachkenntnisse dort anwenden konnte. Zusammen-

361 Es gibt im Landesteil Schleswig keine dänischen Berufsschulen. Zur Ausbildung können daher entweder deutsche Berufsschulen besucht oder es kann eine Ausbildung in Dänemark absolviert werden.

362 So bestätigt es auch Sönke Nissen, der früher ein eigenes Fischgeschäft hatte und als Nebenerwerbsgastwirt (INT05) gearbeitet hat. Dabei konnte er mit den dänischen Fischgroßhändlern oder dänischen Gästen Dänisch reden, das „war schon Vorteil [sic]“ (INT05), weil diese zuerst immer dachten, er verstünde kein Dänisch. 
fassend lässt sich sagen, dass die zusätzliche sprachliche Qualifikation der ehemaligen Schüler*innen der dänischen Schule in ihrem Berufsleben entgegen den Erwartungen an heutige „Dänenschüler“ in einem vielsprachigen Europa kaum nachgefragt und deshalb fast nicht eingesetzt wurde.

Beim Husumer Jahresfest 2012 erzählte mir ein Angehöriger der dänischen Minderheit von einem persönlichen Vorteil, sich zur Minderheit zu bekennen. Er heißt Wolfram Jepsen ${ }^{363}$ und ist Bundespolizist, war 2012 Anfang 40 und sollte vor einigen Jahren nach Frankfurt am Main versetzt werden. Das wollte er nicht, denn er wollte nicht aus seiner Heimat wegziehen. Da er keine sogenannten Sozialpunkte hatte, also keine Ehefrau und Kinder, die regional gebunden waren, gab es für ihn keine Chance, dieser Versetzung zu widersprechen. Daraufhin kontaktierte er den hochrangigen SSW-Politiker Nils Jensen ${ }^{364}$, der sich für ihn einsetzte. Das Argument war dabei die Minderheitencharta, die besagt, dass man die Minderheit und den Minderheitenstatus von Menschen schützen muss. Eine Versetzung nach Frankfurt würde bedeuteten, dass Wolfram sein Dänischsein nicht mehr ausleben könnte. Als Beleg für sein Dänischsein galt dabei der Besuch des dänischen Kindergartens und der dänischen Schule sowie die Mitgliedschaft in dänischen Vereinen und Organisationen wie dem SSW und dem SSF. Dieser Einsatz hat dazu geführt, dass Wolfram Jepsen vor der Versetzung bewahrt wurde. Dafür sei er Jensen noch heute dankbar. Wolfram komme deshalb, um alte Freunde und Bekannte und den Politiker zu treffen und um sein Gesicht zu zeigen, regelmäßig zu den Jahrestreffen. Dieser Fall ist ein Beispiel dafür, dass das Minderheitensein und die Zweisprachigkeit persönliche Vorteile bringen können. Wolfram ist stattdessen seinen Sprachqualifikationen entsprechend in einer deutsch-dänischen Polizeikooperation eingesetzt worden.

Der Besuch des dänischen Minderheitenschulsystems und das damit entstandene Dänischsein kann, wie gezeigt, positive, aber auch negative Auswirkungen auf das Berufsleben haben. Das Dänischsein kann also aufgrund von Minderheitenschutzrechten Menschen vor Versetzungen südlich der Eider bewahren und Sprachkenntnisse können zu beruflichen Vorteilen führen. Das Dänischsein kann aber auch als Stigma und Diskriminierungsgrund missbraucht werden. Überdies kann die berufliche Anbindung von Menschen an die Mehrheit in einem deutschen Alltag dazu führen, dass die Bindung an die Minderheit aus Zeitgründen und aufgrund des veränderten personellen Umfeldes nachlässt.

\footnotetext{
363 Name geändert.

364 Name geändert.
} 


\subsection{Vorgaben und Erwartungen: Ambivalenzen und Widersprüche}

Mit Begriff und Sache „Minderheit" ist nicht eine selbstverständliche, sondern eine ausdrücklich abweichende Orientierung gemeint, die zur „Identität" - einem ebenfalls in diesem

Sinne junge Begriff - beitragen soll. Dass $V$ ieles [sic] von dieser Abweichung dann als „ethnisch" benannt wird, gehört ebenso in einen wiederum jungen Zusammenhang, in dem diese Deutung entstand. Das Neue, das Moderne an der Minderbeit, einer Gruppe von zablenmäßiger Unterlegenheit und nichtdominanter Stellung, ist der gemeinsame und ausdrückliche Wunsch nach Bewabrung der eige-

nen Kultur, Sprache und Religion. [...] „Kultur" gilt als Ausdruck des Eigenen, einer eigenen Ordnung des Lebens. Dazu müssen die jeweiligen Eliten Begründungen finden und Narrative entwickeln, die diese Eigenart nicht nur symbolisch, sondern auch faktisch grundieren. Es wird ersichtlich, wie sehr für die Entstehung eines Bewusstseins der Besonderbeit auch das Vergessen notwendig ist. In der Regel nämlich hat die moderne Minderheit mehr Gemeinsamkeiten mit der Mebrheit als von ibr Trennendes.

Konrad Köstlin (Köstlin 2007: 31)

Das Eingangszitat dieses Unterkapitels zeigt einmal mehr, wie konstruiert eine Minderheit ist und wie essenziell für diese Konstruktion Deutungen, kulturelle Zuschreibungen und legitimierende Erzählungen sind. Es zeigt aber auch, dass es keine trennscharfe Abgrenzung zwischen Mehrheit und Minderheiten gibt. Meine teilnehmenden Beobachtungen haben gezeigt, dass sich viele Minderheitenangehörige im Alltag gleichzeitig auch als Teil der Mehrheit begreifen und Aktivitäten pragmatisch eher nach Interessen und weniger nach Gesinnungen wählen (s. Kap. 4.1.5). „Die Minderheitenexistenz überschneidet sich somit nicht nur mit der Mehrheit, sondern ist zugleich Bestandteil davon“, betont Kühl (Kühl 2017: 34). Diese „akademische Einsicht lässt sich jedoch nur schwer auf das Selbstverständnis von Minderheitenorganisationen übertragen, die für multiple nationale Identi- 
täten aufgrund des Legitimationsdruckes nur wenig Verständnis aufbringen können“ (ebd.: 34). Daher war es sinnvoll, in dieser Arbeit zwischen Akteur*innen und Funktionär*innen zu unterscheiden, auch wenn diese unterschiedlichen Rollen nicht immer klar zu trennen sind.

Der Kulturverein Sydslesvigsk Forening e. V., SSF (s. Kap. 3.2.3), ist für die Aufrechterhaltung des Dänischseins neben dem Schulverein immanent wichtig, wie die Beispiele aus der Nachkriegsgeneration gezeigt haben (Kap. 4.1.5, 7.2). Auch das Beispiel der Funktionärinnen Angelika Hesselbarth und Rosemarie Tüchsen des Eiderstedter SSF-Ortsvereins St. Peter-Ording unterstützt diese These:

Angelika hat den Vorsitz des kleinen dänischen Vereins vor über 20 Jahren von Rosi übernommen. Mit Einfallsreichtum und Hartnäckigkeit sorgt sie dafür, dass das dänische Leben in St. Peter-Ording erhalten bleibt (Werner 16.05.2016).

Der Ortsverein im Nordseebad mit seinen 22 Mitgliedern (Sydslesvigsk Forening e. V.) kann nur durch persönliches Engagement aufrechterhalten werden. Wie das funktioniert, wie die dänische Minderheit mit Inhalten gefüllt und aufrechterhalten wird und welche Widersprüche dabei entstehen, zeigt dieses Kapitel. Dabei liegt der Fokus auf den Funktionär*innen des SSF sowie auf Ausblicken zu Funktionsträger*innen anderer Minderheitsinstitutionen. Hier ist beachtenswert, dass bei der dänischen Minderheit besonders viele der Funktionär*innen dänische Staatsbürger*innen sind und somit, juristisch gesehen, EU-Ausländer*innen und nicht Minderheitsangehörige. Letztere sind bei den Funktionärsposten unterrepräsentiert (Kühl 2017: 30). Die in Dänemark wohnende Südschleswigerin Karin Röh moniert dies und fordert, mehr Funktionär*innenstellen mit Südschleswiger*innen zu besetzen (Röh 2012: 158).

Gerade weil eine nationale Minderheit - ähnlich wie eine Nation - übergeordnete, sakralisierte Ziele benötigt, um ihre Existenz zu rechtfertigen (vgl. Haugaard, Malešević 2002: 4-5), findet man in der dänischen Minderheit ideologische Vorgaben, die den Zusammenhalt nach innen sichern sollen. Ein Beispiel für solche ideologischen Vorgaben findet sich in den wöchentlichen Kommentaren des SSF, die meist ohne Autor*innenangabe vom Pressesprecher im Mitgliedsblatt Kontakt veröffentlicht werden, wie $z$. B. der folgende schlagwortartige, recht allgemein bleibende Aufruf: „Willkommen in einem neuen Arbeitsjahr für unsere gemeinsame Sache: die dänische Sprache und Kultur in Südschleswig stärken!‘‘365 (Sydslesvigsk Forening 10.01.2013). Die Rhetorik einiger Funktionär*innen der dänischen Minderheitenorganisationen enthält eine nationale Ideologie: Am Jahresanfang 2013 hält Dieter Paul Küssner, damals zehn Jahre lang Vorsitzender des SSF, eine Neujahrsrede vor dem SSF-Hauptvorstand (Küssner 15.01.2013),

365 „Velkommen til et nyt arbejdsær for vor fælles sag: styrke dansk sprog og kultur i Sydslesvig!“ 
die nicht nur online, sondern auch in der SSF-Mitgliederzeitung Kontakt ${ }^{366}$ veröffentlicht wird. In der Rede beginnt Küssner mit der Überbringung von Grüßen vom „offiziellen“ Dänemark, genauer dem Folketing, also dem dänischen Parlament, sowie den kulturellen Zusammenarbeitspartnern und „unserer Königin“367 (ebd.). Küssner zitiert drei Sätze von ihr im Wortlaut ${ }^{368}$ (ebd.). Damit versucht er, eine ideelle Gemeinschaft unter Dän*innen und Minderheitendän*innen zu generieren, da sich das Königshaus für die Konstruktion von nationalen Vergangenheitsbezügen und Nationalgefühlen gut eignet (Coakley 2004: 534-540). Danach plädiert Küssner dafür, dass der SSF weiterhin ein wertvolles Kulturprogramm für die SSF-Mitglieder entwickle, um die Zugehörigkeit zu stärken. Südschleswig sei Dänemarks „Vorgarten“, in dem das dänische Kulturerbe gepflegt und mit anderen geteilt werde, so Küssner (Küssner 15.01.2013). Die Aufgabe des Kulturvereins sieht der Vorsitzende darin, Treffen auf dänischer Wertgrundlage zu veranstalten, bei denen das Singen von dänischen Liedern und das Sprechen der dänischen Sprache dazugehören (ebd.; s. Kap. 8).

Die Vereinsarbeit sei ein sozialer und menschlicher Rahmen für die Freizeitund Kulturgemeinschaft der Minderheit (ebd.). Küssner fordert Mitglieder dazu auf, sich zu engagieren und Vereinsarbeit zu leisten und neue Mitglieder zu integrieren (ebd.). Zur Umsetzung der kulturellen Angebote seien Versammlungsorte, Vereine und Geld notwendig (ebd.). Der SSF sei der bürgerliche und kulturelle Versammlungsort der Minderheit (Küssner 2012). Küssner konstatiert, dass das politische Dänemark die Minderheit nicht vergessen habe, und er betont, „wenn wir an Dänemark festhalten, dann hält Dänemark an uns fest! Das ist eine Vertrauens- und Liebeserklärung, die verpflichtet ${ }^{\text {(369) }}$ (ebd.). Er tut dies in Anlehnung an die Aussage des ehemaligen dänischen Staatsministers Niels Neergaard im Jahr 1920: „Sie sollen nicht vergessen werden. Es ist eine Ehrenpflicht für jede Regierung sie zu unterstützen und mit allen gegebenen Möglichkeiten Sprache und

\footnotetext{
366 donnerstägliche PR-Beilage des SSF in der Flensborg Avis

367 „vores Dronning““

368 Küssner zitiert Königin Margrethe II: ,Jeg vil også sende min varme hilsen til det danske mindretal i Sydslesvig. Her er den danske ånd stadig i live. Den er forankret i gamle traditioner, men lever synligt også i nutiden. At danskheden får lov at blomstre syd for grænsen, ser jeg som et udtryk for venskab, respekt og godt naboskab mellem danskere og tyskere.“ („Ich möchte auch meinen warmen Gruß an die dänische Minderheit in Südschleswig schicken. Hier ist der dänische Geist noch am Leben. Er ist in alten Traditionen verankert, aber lebt sichtbar in der Gegenwart. Dass das Dänischsein südlich der Grenze blühen darf, sehe ich als Ausdruck von Freundschaft, Respekt und guter Nachbarschaft zwischen Dänen und Deutschen.")

${ }^{369}$ „,[H]vis vi holder fast i Danmark, så holder Dankmark fast i os! Det er en tillids- og kærlighedserklæring, der forpligter."
} 
Volkstum aufrechtzuerhalten, für welche sie sich so tapfer geopfert haben ${ }^{\text {‘3 } 370}$. Hier wird eine Nationalauffassung deutlich, die sich auf eine an ein Territorium gebundene Gemeinschaft und auf deren vermeintlich kulturspezifische Aspekte bezieht.

Den Geschäftsbericht zu seinem letzten SSF-Amtsjahr betitelt Küssner etwas pathetisch mit „Sydslesvig i forening“. Dabei bedient er sich des Wortspiels bzw. der Doppeldeutigkeit von forening, was zum einen die Institution Verein oder Vereinigung bedeutet und zum anderen Vereinigung im Sinne des substantivierten Verbs ,sich vereinigen', also „Südschleswig in Vereinigung“. Küssner fordert, dass sich die Minderheit überlegen müsse, wie sie zusammenhalten und gleichzeitig die Individualität der Angehörigen bewahrt werden könne (Küssner in Sydslesvigsk Forening 2013a: 9; Küssner 2013). Er überhöht in seiner Rede den SSF als „den größten Kulturvermittler in Südschleswig ${ }^{6371}$ (Küssner in Sydslesvigsk Forening 2013a: 9). Der Kern der SSF-Kulturarbeit sei, so der Vorsitzende, der „Wille, an der unbedingten Zusammengehörigkeit mit Dänemark, dem dänischen Volk und damit an der dänischen Sprache und Kultur festzuhalten “372 (Küssner in ebd.: 9). Dieses Plädoyer ist nationalistisch geprägt. Küssner selbst bezeichnet die Verbundenheit mit Dänemark als ein „tiefes und vertrautes Nationalgefühl“373 (Küssner 16.06.2014). Er impliziert, dass es „Normen und Erwartungen des Mutterlandes“6374 Dänemark an die dänische Minderheit gebe. In den Vereinen seien „dänisches Kulturleben, dänische Werte und dänische Art seit der Trennung von Dänemark gelebt und vermittelt worden ${ }^{\text {(3775 }}$ (Küssner in Sydslesvigsk Forening 2013a: 9). Dass die sogenannte Kulturarbeit gefördert und benutzt wird, um sich mit einer ,vermeintlich eigenen [...] Identität" gegenüber scheinbar anderen abzugrenzen, ist nicht neu, sondern wurde schon nach dem Ersten Weltkrieg von deutscher Seite bei der deutschen Minderheit in Dänemark praktiziert, wie Jennie Boie nachweisen konnte (Boie 2008: 97). Das „Deutschsein“ wurde dort und in Schleswig-Holstein „kulturell und politisch“ gefördert, um sich abzugrenzen und

370 „De skal ikke blive glemt. Det er en Ærespligt for enhver Regering at støtte dem og af yderste Evne opretholde Sprog og Folkelighed, som de har ofret taprest for" (Neergaard 2001: 241243). Neergaard war dänischer Staatsminister 1908-1909 und 1920-1924. S. a. S. 253.

371 „den største kulturformidler i Sydslesvig“

372 „viljen til at fasthole den ubetingede samhørighed med Danmark, det danske folk og dermed det danske sprog og dansk kultur"“

„dyb og fortrolig nationalfølelse“

„moderlandets normer og forventninger"

„har vi siden adskillelsen fra Danmark levet og formidlet dansk kulturliv, danske værdier og

dansk væremåde“. Zur Verwendung des Begriffs „Trennung“ für die Grenzziehung von 1920

s. S. 301. 
dem Dänischen beispielsweise mit der Überbetonung von (niederdeutscher) Sprache „eine spezifische Identität entgegenzusetzen“ und „ein geschlossenes ,WirGefühl“" zu schaffen oder auf eine Grenzrevision hinzuarbeiten (ebd.: 97, 115)

Küssner räumt ein, dass das dänische Kulturleben „notwendigerweise“ auch südschleswigsche Besonderheiten aufweise. Durch Küssners Wortwahl entsteht der Eindruck, dass er dies bedauert und er sich eine Änderung, eine Verdänischung des aktuellen Zustandes wünscht und die Situation nicht als positive Chance oder als Vorteil begreift. Er sieht die Minderheit als „Brückenbauer“ (Küssner in Sydslesvigsk Forening 2013a: 9) und als „friedliche Brücke“ (Küssner 08.06.2013) zwischen Dänemark und Deutschland. Auch Küssners Nachfolger, Jon Hardon Hansen, spricht von der Minderheit als „Brückenbauer“6377 zwischen Dänemark und Deutschland (Hansen 09.03.2017). Dies zeugt von der grundsätzlichen Vorstellung einer Trennung zwischen Deutsch und Dänisch und nicht von einem kulturellen Übergangsraum. Eine Brücke überwindet ein Hindernis oder eine Grenze, die Küssner in seinen Reden konstruiert. Küssner behauptet, an der „dänischen Lebensgrundlage“ werde „trotz eines deutschen Alltags “6378 festgehalten (Küssner in Sydslesvigsk Forening 2013a: 9). Küssner bezeichnet die Beziehung zur Mehrheit als „gute Nachbarschaft ${ }^{\text {‘379 }}$ (Küssner 15.01.2013). Er sieht die Minderheit als mit dem dänischen Volk verbunden und die deutsche Mehrheit als „Nachbarn“ ${ }^{\text {‘380 }}$ (Küssner 2012). Diese Kategorisierung beinhaltet eine klare Abgrenzung zwischen Mehr- und Minderheit durch den SSF-Funktionär. Nachbarschaft bedeutet hier keine doppeldeutige oder postmodern-hybride Zugehörigkeit, meint kein Sowohl-als-auch, sondern eine klare Einteilung in zwei Gruppen. Nachbarschaft bedeutet auch, dass Küssner die Dänischgesinnten nicht als Teil der Mehrheit sieht, was viele selbst aber tun. Die Minderheit lebe ,in zwei Welten “3811, so der aktiv abgrenzende Küssner (ebd.). Küssner konstruiert damit eine Grenze zwischen zwei vermeintlichen Entitäten, dem Deutschen und dem Dänischen, während die Akteur*innen in den Interviews und Gesprächen davon erzählen, dass sie beides seien und nicht so klar trennten. Diese Abgrenzung geht weiter, indem Küssner konstatiert, dass er das Eigene wertschätze und vom anderen lernen wolle (Küssner 15.01.2013). Er bedient sich also der Abgrenzung „Wir“

\footnotetext{
376 Dazu wurden damals schon Vereine eingesetzt wie der Heimatverein „Schleswig-Holsteiner Bund (SHB) oder der „Verein zur Pflege der Natur- und Landeskunde“ (Boie 2008: 98, 101). Es wurde ein dänisches Feindbild konstruiert, „ethnische[...] Erklärungsmuster[...] verwendet und ein Entweder-Oder-Denken postuliert" (ebd.: 115, 116). „brobygger" „det danske livsgrundlag fastholdt trods en tysk hverdag“" "godt naboskab“ „nabo“ „i to verdener“
} 
versus „, die Anderen [sic]“, nur dass er die bei Elisabeth Beck-Gernsheim untersuchte Perspektive der Mehrheit auf die Minderheit umkehrt (vgl. Beck-Gernsheim 2004). Dem gleichen, auf Entitäten beruhenden Weltbild folgt ebenfalls Hansen. Er fordert „ein friedliches, reiches, freundschaftliches, zusammenarbeitendes und gegenseitig [sic] inspirierendes Zusammenleben mit dem Deutschen und dem Friesischen, ohne dafür seine eigene, freie, persönliche und nationale Wahl aufzugeben.“ Diese bestehe darin, „dänisch sein zu wollen und sein Dänischsein froh und stolz zu leben" (Hansen 09.03.2017).

Die SSF-Vereinsarbeit solle „von einem soliden Fundament getragen werden, welches das Dänische nicht herunterspielt, das Sprachbewusstsein nicht lockert, um Multikulti nicht beherrschend werden zu lassen “382, so Küssners konservative Auffassung (Küssner in Sydslesvigsk Forening 2013a: 9). „Weder unsere Schulen noch unsere Vereine sind nach unserer Auffassung multikulturelle Sprach- oder Kulturträger, sondern gerade dänisch unterstützte Gesinnungsbewahrer ‘383 (Küssner 2012). Angehörige der Minderheit sollen also dänisch sein und nicht deutsch-dänisch ${ }^{384}$. Dänischsein werde hauptsächlich in Vereinen praktiziert. Daher sieht Küssner alle Mitglieder dazu verpflichtet, dem Vereinsleben „eine starke dänische Minderheitenstimme ${ }^{\text {‘385 }}$ zu geben (Sydslesvigsk Forening 2013a: 9). Alle hätten die Mitverantwortung für die ,verpflichtende Gemeinschaft" ${ }^{\text {‘386 }}$ (Küssner in ebd.: 10), eine Gemeinschaft, zu der man sich laut Gesetz eigentlich frei bekennen kann. Durch seine Wortwahl stärkt er bei seinen Zuhörer*innen Bilder von abgrenzbaren Kulturen und nationalistischem Gedankengut.

Dieter Paul Küssner weist in seiner Arsmode-Rede am 11.06.2016 in Hattstedt darauf hin, dass jeder frei sei, „eine nationale Identität zu wählen und sich dazu zu bekennen" und stellt dann die drei, seiner Ansicht nach klar abgrenzbaren Gesinnungen deutsch, friesisch und dänisch zur Option (Küssner 22.06.2016). Eine teilweise Identifikation mit diesen drei vermeintlichen Optionen und weiteren nationalen Gesinnungen oder Vermischungen erscheinen in Küssners Rhetorik nicht möglich. Er fasst zusammen, was aus seiner Sicht die dänische Minderheit und das Dänischsein ausmache:

Wir hissen die Flagge, singen Hochschullieder, lieben Kaffeetafeln, führen Gespräche auf Augenhöhe, verringern die Standesunterschiede,

\footnotetext{
382 „bæres af et solidt fundament, der ikke underspiller det danske, slækker på sprogbevidstheden for at lade multikulti være enerådende“

383 „Hverken vore skoler eller foreninger er efter vores opfattelse multikulturelle sprog- eller kulturbærere, men netop dansk støttede sindelagsbevarere.“

384 Dieser Aspekt wird auch in Kap. 5.2 über die Rolle der Schulen und des Schulvereins aufgegriffen.

385 „en stærk dansk mindretalsstemme“

386 „forpligtende fællesskab“
} 
streben Respekt und Freiheit in einer toleranten und nicht zuletzt eine gemütliche Gemeinschaft $\operatorname{an}^{387}$ (ebd.).

Durch diese klischeehafte Beschreibung und Nutzung von Symbolen, die dänisch konnotiert sind - wie Flagge zeigen und bygge -, werden ebenfalls Grenzen zur deutschen Mehrheit gezogen, die vermeintlich, so suggeriert er, keine Kaffeetafeln liebe, nicht miteinander auf Augenhöhe spreche und auf Gemütlichkeit, Freiheit und Respekt keinen Wert lege (s. S. 125 u. Kap. 8). Allerdings räumt Küssner in seiner Rede ein, dass das deutsche Umfeld immer einen Einfluss auf die dänische Minderheit habe und die oben geschilderten Ideale nicht komplett gelebt werden können. Man könne nur nach ihnen streben. Küssner suggeriert seinen Zuhörenden in seiner Rede, dass das Deutsche das Dänischsein verhindere und dass es einen kulturellen, klar abgegrenzten Gegensatz zwischen Deutsch- und Dänischsein gebe. Einfach Mensch sein zu können, ohne konstruierte nationale Grenzen, wird hier nicht als Option gedacht. Laut Küssner ist man dänisch oder deutsch oder „doppeltkulturell“" (ebd.), aber nicht gemischt oder mal so und mal anders. Dahinter steckt nicht nur eine Abgrenzungproklamation, sondern auch ein essenzialistisches Containermodelldenken, welches den kontextuellen und prozessualen Charakter von Zugehörigkeiten ignoriert.

Auch der SSF-Generalsekretär Jens A. Christiansen versucht, in seiner Lobbyarbeit ideologische Vorgaben gegen modernere Auffassungen von jüngeren $\mathrm{Ak}$ teur*innen der Minderheit durchzusetzen. Christiansen kritisiert, dass „sich viele Jüngere heute mehr als Teil einer Minderheit auffassen als ein Teil der dänischen Volksgruppe $^{6388}$ (Christiansen paraphrasiert in Mølvig 22.10.2016). Christiansen will, dass es nicht egal ist, ob man Deutsch oder Dänisch spreche. Er verbindet das Dänischsein klar mit dem Gebrauch der dänischen Sprache. „Die eigene dänische Identität soll tiefgehend sein und nicht nur oberflächlich“"389 (Christiansen in ebd.; s. a. Kap. 8.5).

Diese nationalromantische Propaganda von Funktionär*innen der Minderheit wird in einem Leserbrief in der Flensborg Avis vom kritischen SSF-Mitglied Hans-Otto Nielsen, emeritierter Physikprofessor aus Schleswig, aufs Korn genommen. Er schreibt, dass er nicht für eine ,gemeinsame Sache ${ }^{6390}$ kämpfe, seine

\footnotetext{
387 „Vi hejser flaget, synger højskolesange, elsker kaffebordet, har samtalen i øjenhøjde, mindsker standsforskelle, tilstræber respekt og frihed i et tolerant og ikke mindst hyggeligt fællesskab." $\mathrm{S}$. dazu a. Kap. 8 über Symbole und Kap. 5.2, welches im Widerspruch zu Küssners postulierten „Respekt und Freiheit" und Toleranz steht. „,mange yngre i dag opfatter sig mere som en del af et mindretal end som en del af en dansk folkegruppe“

389 „Ens danske identitet skal være dybtliggende og ikke bare være overfladisk.“

390 „fælles sag““
} 
Herzenssprache nicht Dänisch sei und er nicht dem dänischen Königshaus huldige und nicht an Versammlungen, gemütlichem Beisammensein, Spieleabenden oder Ausflügen teilnehme (Nielsen 27.03.2014).

Die Verbindungen zwischen den Vereinen und Organisationen der dänischen Minderheit untereinander sind stark. Es gibt viele personelle Überschneidungen, sowohl unter den Mitgliedern als auch bei den Funktionär*innen (vgl. auch die Erwartungen an die Akteur*innen in Kap. 5.2.2). Beispielsweise war Dieter Paul Küssner 10 Jahre lange SSF-Vorsitzender und gleichzeitig auch Rektor der Jaruplund Hojskole, die zum Schulverein gehört. Der SSF-Vorsitzende seit 2013, Jon Hardon Hansen, ist gleichzeitig dänischer Pastor auf Sylt und damit auch Vertreter der Kirchenvereins. Die stellvertretende Vorsitzende des SSF, Gitte Hougaard-Werner, ist gleichzeitig Lehrerin an einer dänischen Schule im Landkreis Rendsburg-Eckernförde und im Distrikt Eckernförde im SSF aktiv. Die Erwartung an Akteur*innen der Minderheit ist, dass sie in mehreren Vereinen Mitglied sind und sich aktiv in ihnen engagieren.

Die offizielle Position des SSF ist, dass der Kulturverein die Partei SSW offiziell unterstützt (Küssner in Sydslesvigsk Forening 2013a: 10). Dadurch und auch durch die personellen Überschneidungen sowie das konstruierte Bild einer ganzheitlichen Minderheit geht die Zusammenarbeit sogar so weit, dass der Kulturverein Sydslesvigsk Forening (SSF) in seinem offiziellen Mitgliedsblatt Kontakt seine Mitglieder direkt dazu aufruft, den Südschleswigschen Wählerverband (SSW) zu wählen. So ist es beispielsweise im Juni 2016 vor der Oberbürgermeisterwahl in der kreisfreien Stadt Flensburg geschehen. In einer Erklärung vom 02.06.2016 mit dem Titel „Unterstützt Simon Faber!“c391 ruft der SSF-Stadtvorsitzende Preben K. Mogensen gemeinsam mit der SSW-Stadtvorsitzenden Katrin Møller dazu

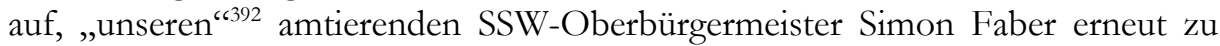
wählen (Sydslesvigsk Forening 02.06.2016a). Sie appellieren an alle Flensburger*innen und an alle Mitglieder der dänischen Minderheit, zur Wahl zu gehen und „selbstverständlich“ für den SSW-Kandidaten zu stimmen ${ }^{393}$ (ebd.). Im gleichen Mitgliederblatt gibt es zusätzlich auch die explizite Aufforderung des SSF im sogenannten Leitartikel „Stimm für Simon Faber!“‘394. Darin heißt es:

Der SSF empfiehlt seinen Mitgliedern, dänischen Staatsbürgern mit Wohnsitz in der Stadt und allen anderen mit Sympathie für das Dänische und Nordische zur Wahl zu gehen und für Simon Faber vom SSW zu stimmen. ${ }^{395}$ (Sydslesvigsk Forening 02.06.2016b).

\footnotetext{
391 „Bak op om Simon Faber!“

392 ,"Nores“

393 „,selvsagt stemme på SSWs kandidat“

394 „Stem på Simon Faber!“

395 „SSF anbefaler sine medlemmer, danske statsborger med bopæl i byen og alle andre med sympati for det danske og nordiske at gå til valg og stemme på Simon Faber fra SSW.“
} 
Dasselbe passierte auch vor der schleswig-holsteinischen Kommunalwahl am 26. Mai 2013. In einem gemeinsamen öffentlichen Brief im SSF-Presseorgan Kontakt rufen der Vorsitzende des SSW, Flemming Meyer, und der Vorsitzende des SSF, Dieter Paul Küssner, zur Wahl des SSW auf. „[W]as sonst“, sagen sie in ihrem Aufruf (vgl. Meyer, Küssner 23.05.2013).

Auch an diesen Aktionen erkennt man das aus Minderheitenfunktionärssicht ganzheitliche Bild des Dänischseins und die damit verbundenen Erwartungen an die Angehörigen der dänischen Minderheit. Das von den involvierten Akteur*innen oft als sprachlich-kulturell-historisches Phänomen beschriebene Dänischsein wird hier politisiert. Der Anspruch des SSW als Partei der dänischen Minderheit (und der Friesen) wird hier gefestigt. Dass eine politische Haltung nicht unbedingt etwas mit Dänischsein zu tun haben muss, wird hierbei außer Acht gelassen. Somit kann die Wahlempfehlung als Erleichterung für Akteur*innen aufgefasst werden, da sie die Komplexität der Wahlentscheidung erheblich reduziert. Wenn jemand gewählt hat, dänisch zu sein, dann ist klar, dass er oder sie nicht nur das Dänische im Alltag, sondern auch die Partei der dänischen Minderheit SSW wählen soll, was für einzelne Akteur*innen wiederum eine Reduzierung von Komplexität im Leben sein kann (s. Kap. 8.7).

Nachdem es hier bisher um schleswigweit agierende Funktionär*innen ging, blicken wir nun auf das Beispiel einer lokal agierenden Ortsfunktionärin, welches zeigt, dass von einigen Akteur*innen die eigene Zugehörigkeit als Normalität herausgestellt wird. Für sie, z. B. für Tina Zehnter ist es ,nur so natürlich, dass man denn eben mit im SSW ist, in der dänischen Kirche" (INT10). Sie war viele Jahre in den lokalen Vereinsvorständen von SSF, SSW und SdU. Zum Zeitpunkt des Interviews ist sie bereits einige Jahre SSF-Vorsitzende des Ortsvereins Friedrichstadt.

Zehntner betont im Interview, dass Minderheitensein für sie bedeutet, dass man dann ,ganzer Teil“" [sic] (INT10) sei, ,also entweder ganz oder gar nich, nur son halben Kram nich [sic]“" (INT10). Man solle sich nicht nur die Rosinen aus dem Angebot der Minderheit herauspicken, sondern möglichst das ganze Paket nehmen. Damit meint Zehntner die „dänische Kirche, SSF, SSW, ... SdU“ (INT10). Sie selbst ist zurzeit im SdU nicht so aktiv, weil sie und ihre Tochter sich im Moment nicht für das angebotene Sport- und Freizeitprogramm des SdU interessieren. Philosoph Søren Harnow Klausen dagegen konstatiert in einem zweiteiligen Zeitungsfeature, dass es ,keinen Grund gibt, zu fordern, dass man ,das ganze Paket kaufen“" soll“6396 (Klausen 07.07.2016). Auch Kühl erwähnt, dass „für viele die Angebundenheit [an die Minderheit] damit beginnt und endet, dass die Kinder

\footnotetext{
396 „der [sic] er ingen grund til at kræve at man skal «købe hele pakken»“
} 
in die dänische Schule kommen und gehen“6397 (Kühl 16.06.2016). Das Dänischsein zähle für diese Menschen also nur im Schulkontext, während ansonsten das Deutschsein favorisiert werde (ebd.).

Obwohl Tina Zehntner für sich in Anspruch nimmt, dass zum Dänischsein das Gesamtpaket dazugehöre, weist sie auf Nachfrage entschieden von sich, dass dieses ganze Paket von jedem in der Minderheit angenommen werden müsse. Dies ist ein Widerspruch zu ihren vorherigen Aussagen. Möglicherweise kommt diese Ambivalenz dadurch zustande, dass diese Aussagen einmal auf sie persönlich und einmal auf andere Mitglieder der Minderheit bezogen wird. Möglicherweise spricht Zehntner mal als Privatperson und mal als SSF-Funktionärin, die vereinspolitisch korrekt agieren möchte. Zehntner selbst ist zum Beispiel nicht im lokalen dänischen Kanuverein aktiv, da sie sich nicht für das Paddeln interessiert. Stattdessen ist sie mit ihrer Familie Mitglied in einem deutschen Sportverein (INT10). Das dortige Angebot spricht sie an. Früher war sie einmal im (deutschen) Spielmannszug aktiv (INT10). Das bedeutet, dass sie nicht in einen Verein eintritt, nur weil dieser dänisch ist. Ein anderes Beispiel dafür, dass sie selbst auch kein Gesamtpaket hat, ist, dass sie statt der Flensborg Avis die Husumer Nachrichten abonniert hat, was an der Westküste viele Minderheitenangehörige so handhaben. Das liegt u. a. daran, dass in der Zeitung der dänischen Minderheit kaum Nachrichten aus Nordfriesland stehen, diese aber von den Akteur*innen hauptsächlich nachgefragt werden.

Dänische Minoritätsschaft bedeutet für Zehntner also die selbstverständliche Mitgliedschaft in möglichst vielen dänischen Vereinen, ähnlich wie es Gitte Hougaard-Werner mit dem Bild des Blumenstraußes gegenüber den heutigen Neudänen formuliert: „Je mehr Blumen, desto besser, aber es ist auch mit einzelnen Blumen möglich, aber das ist nicht so schön ${ }^{\text {‘6398 }}$ (Hougaard-Werner 14.10.2013). Sie fordert ein komplettes, konsequentes und nachhaltiges Bekenntnis zur Minderheit. Man solle den ganzen Blumenstrauß nehmen und sich nicht nur einzelne Stängel herauspicken. Dieter Paul Küssner verwendet statt des Blumenstraußes den Begriff „die ganze Minderheitspalette ${ }^{\text {c6399 }}$ (Küssner 2012).

Diese Forderungen bedeuten nicht, dass das bildhaft formulierte Ideal im Alltag auch konsequent umgesetzt werden würde. Ein weiterer Widerspruch in den Aussagen Tina Zehntners ist in diesem Zusammenhang, dass sie die Bedeutung der dänischen Vereine gleichzeitig auch abwertet, indem sie sagt, dass „wenn du Mitglied werden willst, wirst du Mitglied, [...] das ist wie in jeden [sic] Turnverein auch“ (INT10). Dadurch stellt sie den für sie und für die Minderheit essenziellen Verein SSF auf eine Ebene mit allgemeinen (deutschen) Sportvereinen und

\footnotetext{
397 „For mange begynder og slutter tilknytningen [til mindretallet] med, at børnene kommer og går i dansk skole."

398 ,jo mere blomster, jo bedre, men det er også muligt med enkelte blomster, men ikke så skøn“

399 „hele mindretalspaletten“
} 
drückt aus, dass der dänische Kulturverein ein Verein wie jeder andere und damit nichts Besonderes sei. Sie relativiert mit ihrer Aussage die von anderen konstruierte große ideologische Bedeutung des dänischen Vereins. Dies tut sie fünfmal im Interview, was formal gesehen korrekt ist, da viele Sport- und Kulturvereine und auch der SSF im Vereingsregister eingetragene Vereine (e. V.) sind. Ideologisch widerspricht das aber Zehntners Aussage, dass der SSF ein Teil des Minderheitengesamtpaketes ist, welches aus Zehntners Sicht gewählt werden sollte, wenn man der dänischen Minderheit angehört. „Nur, für mich ist es eben so, dies Komplettpaket, wenn ich Minderheit wähle, also, sprich mein Kind in dänischen [sic] System, dann muss ich auch da noch mit runterrum arbeiten, aber das bin $\mathrm{ICH}$, das ist MEINE Meinung." Nach der Betonung der Normalität des Dänischseins räumt Zehntner ein, dass sie im Vergleich zu reinen Mehrheitsdeutschen einer besonderen Gruppe angehöre, und sie konstatiert, dass sie trotz ihres Selbstverständnisses als Minderheitendänin genauso in die Mehrheitsgesellschaft integriert sei wie andere Menschen auch (INT10). Zehntner sagt aber auch, dass man neben dem Engagement in dänischen Vereinen gerne ,auch noch Vorsitzende bei den Schützen sein" kann. Man ist ihrer Meinung nach nicht nur auf dänische Organisationen festgelegt. ,also du kannst natürlich beides sein, du kannst natürlich auch integriert sein in dem ............. in dem...... flertalsbefolkning [Mehrheitsgesellschaft]" (INT10).

Zur Normalität des Dänischseins gehört auch, dass man ein Leben beruflich und in der Freizeit überwiegend auf Dänisch in Südschleswig führen kann. So berichtet es der aus Dänemark kommende Schulleiter der dänischen Schule in Eckernförde, Peter Müller:

Das ist ja so, ich lebe hier auf dänisch. In der Schule spreche ich nur Dänisch, unter den Leuten, die auch zur dänischen Minderheit hören, da sprechen wir auch oftmals Dänisch und wie die Kinder sagen, was machst du denn, Peter, wenn du einkaufen gehn, wir haben in der Stadt Eckernförde viele Läden, wo ich weiß, da ist ein von uns alten Schüler und wenn wir uns da treffen wir, dann schlagen wir ja in Dänisch rüber [sic] (Müller in Werner 16.05.2016).

In der selben Reportage erzählt Maike Lohse etwas Ähnliches:

Hier in Flensburg kann man ja ein ein ganzes dänisches Leben führen. Mit allem. Und ich bin eigentlich.. im [sic] in meinem gesamten Freizeitleben eigentlich immer in dänischen Zusammenhängen. Ja, weil ich dänische Südschleswigerin bin. Und also für mich ist das Dänische ganz eindeutig, das ist für mich genauso selbstverständlich wie meine Nase [lacht] (Lohse in ebd.). 
Zur dänischen Minderheit zu gehören kann also heißen, ein dänisches Leben südlich der Grenze zu führen, sowohl beruflich als auch privat und in der Freizeit. Dies unterstützt auch der südschleswigsche Bibliothekar Karl Fischer von der Dansk Centralbibliotek mit seinem beruflichen Engagement für die Bereitstellung von Büchern und Medien für die ganze dänische Minderheit: „Er ist erfinderisch, wenn es um Wege geht, dänische Bücher in Südschleswig an alle Interessierten zu bringen. Die Minderheit soll dänisch leben können“, so die Sprecherin der schon zitierten NDR-Info-Radioreportage über die dänische Minderheit (ebd.). Zum Minderheitensein gehört also auch der leichte und kostenlose Zugang zu dänischer Literatur und dänischen Medien. Für Fischer ist dieses Engagement

letztendlich irgendwo friedensbewahrend in meinen Augen, nä. Denn Ausgangspunkt war ja, dass wir uns hier in dieser Region die Köpfe eingeschlagen haben, weil wir entweder deutsch oder dänisch waren. Wenn das möglich ist, so wie wir das hier in der dänischen Minderheit können, nicht nebeneinander und gegeneinander, sondern miteinander zu leben, dann kann das nichts anderes als gut sein für die Menschen (Fischer in ebd.).

Zusammenfassend lässt sich sagen, dass es für einige Funktionär*innen nichts Besonderes ist, dänisch zu sein bzw. der dänischen Minderheit anzugehören. Sie sehen ihr Dänischsein als eine Selbstverständlichkeit und als Normalität an. Die Mitgliedschaft in möglichst vielen dänischen Vereinen und das Engagement schaffen Akzeptanz und Glaubwürdigkeit für Dänischgewordene, obwohl nicht alle ideologischen Vorgaben immer konsequent befolgt werden. Es wird nicht gerne gesehen, wenn man sich nur „die Rosinen“ (INT10) herauspickt. Das Dänischsein soll idealerweise aktiv gelebt werden.

In Bezug auf die Integration von Neudän*innen heute (s. Kap. 6) werden auch Erwartungen an deren Dänischsein formuliert. Tina Zehntner hat beobachtet, dass einige in die dänische Minderheit hineinwachsen, andere „,von Null auf Hundert" gehen, sobald sie sich entschlossen hätten, bei der Minderheit mitzumachen (INT10). Die kommen in die Minderheit ,und leben das auf einmal“ (INT10). Andere integrieren sich kaum und werden kritisiert. Merkwürdig findet beispielsweise Interviewpartner Otto Clausen diejenigen, „die also bei den Dänen gerne mitmachen, die [...] mit den Dänen [aber] gar nichts zu tun haben“ (INT04), wie z. B. Eltern, die selbst deutsch sind und kein Dänisch können, ihre Kinder aber in den dänischen Kindergarten geben. Die Gründe dafür, die von den Interviewten nur ungern akzeptiert werden, können vielfältig sein, so Sarah Iversen:

Bequemlichkeit und $[\ldots]$ zu sagen, da kann ich mein Kind schon um 7 hinbringen und muss es erst um 14 Uhr wieder abholen, während die Deutschen hatten um 12 Schluss und [...] in den dänischen gabs denn 
[sic] auch noch Mittag, also sie brauchten noch nicht mal kochen (INT03).

\section{Otto Clausen berichtet Ähnliches:}

Sicherlich waren die Dänen und sind sie heute noch traurig und man erlebt das immer wieder und ich hab das gerade heute wieder gehört, wenn ein Kind [...] in den dänischen Kindergarten geht, weil dieser Kindergarten bis 3 Uhr geöffnet ist. [...] Und mein Kind geb' ich aber anschließend in die deutsche Schule, dann tun sie dem Kind damit keinen Gefallen und der dänischen Minderheit natürlich auch nicht. Also es ist schon so, dass dass [sic] man denkt, naja, wenn du dann in den dänischen Kindergarten gehst, dann gehst du hinterher ja auch in die dänische Schule [...], das sind [...] aber Sachen, da, da sind sie persönlich immer sehr traurig, weil solche Fälle hats zu unserer Zeit schon gegeben und die gibts [...] heute auch immer noch, und gerad' heute hab ich so'n Fall gehört, da ist [...] 'n Junge [...] aus [...] dem [dänischen] Kindergarten vorzeitig rausgenommen worden, weil die dänische Schule fängt irgendwie früher an. [...] Kommt jetzt in die deutsche Schule, und [...] hat das [...] in den Jahren also sehr gut gehabt und hat sich auch da ganz toll [integriert] und ja ist so, [...] aber man ist schon traurig, dass das denn [sic] so läuft. [...] Nicht? Dass das denn rein als Verwahranstalt benutzt wird, aber damit muss man halt leben (INT04). ${ }^{400}$

Bei dieser Argumentation fällt auf, dass hier pragmatische Gründe für den Besuch von dänischen Institutionen wie dem Kindergarten kritisiert werden, wobei die Eltern der Interviewten der Nachkriegsgeneration auch pragmatische Gründe hatten, ihre Kinder dänisch einzuschulen oder dänische Hilfe anzunehmen. Der Unterschied ist allerdings, dass die Interviewten Kritik an denjenigen üben, die die Minderheitsvereine pragmatisch nutzen, aber sich ideologisch nicht an sie gebunden fühlen. Die Kritiker*innen persönlich haben zwar auch Hilfe pragmatisch angenommen, aber sie haben von sich selbst das Bild, dass sie nach der erhaltenen Hilfe dem Dänischen ihrer Meinung nach treu geblieben sind und nicht anschließend ihre dänische Gesinnung wieder vergaßen oder verdrängten. Zum anderen fällt bei einigen Gesprächspartner*innen auf, dass sie kritisieren, dass einige kein Dänisch können, sie selbst gleichzeitig aber bei den Treffen des Freitagsklubs, des

400 Allerdings ist es heutzutage so, dass ,vor der Aufnahme in einen dänischen Kindergarten [...] Gespräche über Aufgaben und Ziele des dänischen Schulwesens geführt [werden], besonders mit dem Hinweis darauf, daß der Besuch eines dänischen Kindergartens als Vorbereitung auf den Besuch einer dänischen Schule anzusehen ist" (Sigaard-Madsen 1995: 146). 
Hausfrauenvereins und des SSF kaum Dänisch sprechen. Nur in Verbindung mit dänischen Staatsbürger*innen, wie den Lehrer*innen der Hans-Helgesen-Skole, dem Pastor oder einigen Funktionär*innen sprechen sie Dänisch, untereinander aber überwiegend Deutsch.

Der Interviewpartner Heinrich Schmied reflektiert als einziger der Interviewten darüber, dass das Dänischwerden kein abrupter Wechsel der Gesinnung ist: „Man kann nicht sagen, du bist von einem Tag auf den anderen Däne.“ Sondern dahinter stecke ein Prozess mit Erfahrungen und Erlebnissen, also „ein langsamer Übergang“, der mit der Zeit dazu führe, dass sich jemand dem Dänischen ,zugehörig“ (INT07) fühle. Dafür sei es auch wichtig, ein „bisschen Hintergrund“ einzubeziehen, also die „ganze Biografie“ einer Person und die „Historie“ der Region (INT07). Indirekt deutet Heinrich Schmied damit an, dass ein schneller Wechsel der Gesinnung auf ihn unglaubwürdig wirkt. Die Glaubwürdigkeit seines eigenen Dänischseins unterstreicht er mit dem „halbe[n] Jahr auf der Politikerschule“ (INT07), die er in Dänemark besucht hatte. ${ }^{401}$ Des Weiteren beurteilt er „Mischehen" (INT07) ${ }^{402}$ - so bezeichnet Schmied genau wie Dieter Paul Küssner Ehen mit einer*m deutsch- und einer*m dänischgesinnten Partner*in - als schlecht für die Zukunft der dänischen Minderheit, da dann deren Haussprache meist Deutsch sei und deren Kinder häufig eine deutsche Schule besuchten. Dasselbe befürchtet auch eine in der Diplomarbeit des Soziologen Gisbert Vorsgeraus erwähnte Gewährsperson. Sie grenzt sich stark von der „Mehrheit“ ab und äußert die Angst vor dem „sich zu Tode Öffnen“ der dänischen Minderheit (Vosgerau 1990: 83-84).

Bei der Analyse des erhobenen Materials wurde immer wieder deutlich, dass es Gegensätze zwischen den ideellen Vorgaben der Organisationsspitzen, also gewählten oder angestellten Funktionär*innen, und den „einfachen“ Akteur*innen auf Ortsebene bzw. kritischen Privatleuten gibt. Diese Unterscheidung macht auch der dänische Journalist Flemming Nielsen ${ }^{403}$ in seinem Kommentar zur Lage der dänischen Minderheit in der Flensborg Avis (Nielsen 03.05.2014: 23) und in seiner Rede zum Afstemningsfest, Abstimmungsfest, im dänischen Mögeltondern/Møgeltønder (Nielsen 10.02.2013). Nielsen kritisiert, dass die Funktionär*innen der Minderheiteninstitutionen weder selbstkritisch genug seien noch Kritik aus Dänemark annähmen. Sie reagierten auf positiv gemeinte, seriöse Einwände „mimosenartig und grantig ${ }^{\ltimes 404}$ (ebd.). Er wirft der Minderheit vor, dass es

\footnotetext{
401 Vgl. FN 169 auf S. 104.

402 Der Begriff „Mischehe“ wird auch von der Kulturanthropologin Margit Feischmidt benutzt (Feischmidt 2003: 159). Allerdings verwendeten Nationalsozialisten diesen Begriff abwertend für sogenannte arisch-nichtarische Ehen, sodass dieser Begriff als historisch belastet gilt.

403 Nielsen ist bereits in Rente, schreibt aber immer noch Artikel mit dem Schwerpunkt auf dem deutsch-dänischen Grenzland. Er ist ehemaliger Mitarbeiter der Regionalabteilung bei Danmarks Radio in Apenrade/Aabrenraa.

404 „mimose-agtige og tøsefornærmede“
} 
den Funktionär*innen nur um Macht und Geld gehe und nicht um die Sache der gesamten Minderheit (ebd.). Die Funktionär*innen verhielten sich „verwöhnt und selbstgefällig “405 (ebd.). Im Sydslesvigske Samråd gehe es beispielsweise dem kulturellen Hauptverein SSF nicht um die gemeinsame dänische Sache, sondern um mehr Einfluss für den Verein und dessen Funktionär*innen selbst. Anstatt die Kompetenzen innerhalb der Minderheit zu bündeln und zu nutzen, würde Projektgeld (vgl. Küssner 15.01.2013) verschwendet, um beispielsweise eine Firma aus Dänemark für eine PR-Kampagne im Königreich zu beauftragen, so Nielsen (Nielsen 03.05.2014; s. a. Kap. 7.6). Nielsen verurteilt mit harten Worten die ,internen Machtkämpfe, kleine Könige, die ihr kleines Reich verteidigen“, die man nur dann ganz verstehe, wenn man auch Schüler*in auf der Duborg-Schule gewesen sei (ebd.). Letzteres ist eine Anspielung auf vermeintliche Machenschaften eines überschaubaren, abgegrenzten Kreises von Personen, die sich noch aus Schulzeiten kennen. Neben dem SSF sieht Nielsen den Schulverein, die Partei SSW, den Sport- und Jugendverein SdU, die Dänische Kirche in Südschleswig und die Dänische Zentralbibliothek als die Hauptakteure institutioneller Art in diesem Spiel. Nielsen plädiert für eine zeitgemäßere, rationalere, modernere und vor allem zentralisiertere Eigenverwaltung der Minderheit, und er spricht sich gegen Machtspiele und gegen den gewichtigen Einfluss von „reichsdänischen“ Funktionären in Minderheitenorganisationen aus (Nielsen 03.05.2014; Nielsen 10.02.2013). Diese Machtkämpfe gegeneinander schadeten der gesamten Minderheit, schadeten ihrem Image in Dänemark und stellten damit dänische Steuergelder für die Minderheit infrage (Nielsen 10.02.2013). Nielsen konstatiert, dass die Vereinsspitzen versuchten, ein Idealbild der gesamten dänischen Minderheit zu pflegen (ebd.). Eine weitere Stimme aufseiten der Kritiker*innen ist Lene Bastiansen, ehemalige Lehrerin aus Harrislee, die in der Flensborg Avis und auf der Internetseite Grænsen.dk die Spitzen der Minderheiteninstitutionen kritisiert. Sie konstatiert, dass die organisierte dänische Minderheit undemokratisch von oben nach unten gesteuert werde und kritische Äußerungen mit Sanktionen bestraft würden, besonders bei denjenigen, die für eine Minderheitenorganisation, beispielsweise als Lehrer*in für den dänischen Schulverein, arbeiteten (Bastiansen in Vanghardt 01.07.2013; Nygaard 29.06.2013). Bastiansen bezieht sich mit ihren Einwänden auf die zwei Jahre zuvor geäußerte Kritik des Generalsekretärs der Grænseforeningen, Knud-Erik Therkelsen, der von einer vorherrschenden, repressiven Meinungsdiktatur in Südschleswig sprach, die den Bestrebungen nach möglichst hohen Zuschüssen aus Dänemark entspringe (Vanghardt 01.07.2013; Therkelsen 19.12.2011; s. a. Kap.

405 „forkælede og selvtilstrækkelige“ 
7.6). ${ }^{406}$ Eine Differenz zwischen den Funktionär*innen und den ,normalen` Mitgliedern sieht auch Karl Otto Meyer. Er hält den SSF für nicht besonders demokratisch, da es dort Führungstreffen und geschlossene Sitzungen gebe und der SSF einen Selbstanspruch auf Vertretung der ganzen dänischen Minderheit habe (Meyer in Dittrich 14.07.2006a).

Es deuten sich aus den vorherigen Kapiteln zahlreiche Ambivalenzen beim Dänischsein an. Peter Thaler charakterisiert die schleswigsche Minderheitensituation mit den Begriffen ,ambivalence, malleability and fluidity“ (Thaler 2007: 159) und ,ambiguity of minority affiliation“" (ebd.: 155). Dies soll im folgenden Unterkapitel genauer untersucht werden.

\subsection{Vielfalt im Dänischsein und das Abgrenzungsparadoxon}

In der Minderheit gibt es Auseinandersetzungen der Akteur*innen darüber, wer zugehörig sein darf, wer teilnehmen darf. Es geht dabei auch um Konkurrenz untereinander, um Deutungsmacht, um Macht über die Ausgestaltung der Spielregeln des Feldes, um Abgrenzung nach innen und nach außen (Distinktion). Und die Minderheit definiert sich als Feld in Abgrenzung bzw. in Unterscheidung zur Mehrheit und zu Dänemark. Aber die Minderheit ist auch ein potentiell offener Raum mit dynamischen Grenzen. Diese Grenzen sind das (Zwischen-)Ergebnis vergangener und gegenwärtiger soziale Konflikte und Konkurrenzkämpfe um z. B. Geld, Einfluss, Aufmerksamkeit oder Anerkennung (vgl. Reuter 2018: 188,189, 191). Die dänische Minderheit ist kein einheitliches, statisches Gebilde, sondern besteht aus unterschiedlichen Personen mit sehr unterschiedlichen Auffassungen in Bezug auf die Ideologie der Minderheit. Die beiden Eckpunkte des politischen Spektrums in der Minderheit sind auf der einen Seite die Nationalist*innen und auf der anderen Seiten die Modernist*innen und Pragmatiker*innen, die aus Sicht einiger Nationalist*innen opportunistisch agieren. Beispiele für Vertreter*innen beider Richtungen werden in diesem Kapitel dargestellt und analysiert.

$\mathrm{Zu}$ Beginn werden nun einige Beispiele für nationalistische Auffassungen aufgeführt, zu denen man Karl Kring, Interviewter im Film De glemte danskere, zählen kann. Kring nimmt für sich in Anspruch, für die ganze Minderheit zu sprechen. „Wir sind nicht dänisch, weil es so nett ist, dänisch zu sein [...] denn dann könnten wir das genauso gut vergessen ${ }^{\triangleleft 407}$ (K. Kring in Petersen [2014]). Kring fordert,

\footnotetext{
406 Als Reaktion auf Therkelsens Kritik forderte Dieter Paul Küssner, damaliger SSF-Vorsitzender, Beweise für Therkelsen Aussagen (Vanghardt 29.12.2011).

407 „Vi er ikke danske fordi der er så hyggelig at være dansk [...] så kunde vi lige så godt glemme det.“
} 
dass die Menschen in Südschleswig entweder gute Deutsche oder gute Dänen seien (s. a. Udo Jessens ganz ähnliche Forderung auf S. 151). Er hat kein Verständnis für Leute, die nicht eine der beiden Zugehörigkeiten konsequent für sich beanspruchen (K. Kring in ebd.). In einem Zeitungsartikel räumt Kring zwar ein, dass der Wechsel der nationalen Zugehörigkeit nicht von einem Tag auf den anderen passiere, sondern dass das ein Prozess sei, bei dem man sich mit der Geschichte und der Kultur beschäftige (K. Kring in Peetz 24.01.2014). Allerdings solle ein Bekenntnis zur Minderheit eine gewisse Tiefe haben, so Kring, und man könne nicht gleichzeitig deutsch und dänisch sein (K. Kring in ebd.). Kring erläutert nicht, warum das so ist. Die Minderheit, so seine Ansicht, solle auch durch die Sprache definiert werden, und Dänisch solle möglichst zur Alltagssprache bei allen Minderheitenangehörigen werden, fordert Kring (K. Kring in ebd.).

Kring wirft im Film De glemte danskere Marc Peetz, Journalist der Flensborg Avis, vor, dass wenn dieser sich nicht zwischen deutsch und dänisch entscheide, er die dänischen Steuergelder ungerechtfertigerweise ausnutzen würde, da Marcs Kinder die dänische Schule besuchen. Dies wertet Kring als „Schmarotzen“ (K. Kring in Petersen [2014]). In einem Zeitungsartikel über ihn wird er folgendermaßen zitiert: „Es ist heutzutage allzu leicht geworden Minderheit zu sein, wir müssen aufpassen, dass die Minderheit nicht verzerrt wird“408 (K. Kring in Johannsen 04.11.2014). Jens Kring, Karl Krings Sohn, äußert eine ähnliche Meinung in einem Leserbrief in der Flensborg Avis. Er sagt, dass junge Menschen, die behaupten, sie seien ein "Zwischending“ zwischen deutsch und dänisch oder sie seien beides, nicht mehr Teil der dänischen Minderheit seien, da es in Deutschland nur eine dänische Minderheit, aber keine deutsch-dänische Minderheit gebe. Er sieht dafür die Verantwortung beim Schulverein und beim SdU, weil diese es versäumt hätten, den Kindern beizubringen, warum sie dänisch seien und weil sie versäumt hätten, Leute auszuschließen, die sich öffentlich als nicht 100-prozentich dänisch bekennen (Kring 17.09.2014).

Das nächste Beispiel ist Karl Otto Meyer (1928-2016), ehemaliger Journalist und Flensborg-Avis-Chefredakteur (1963-1983) sowie langjähriger SSW-Landtagsabgeordneter (1971-1996). Er sagt in Petersens Film, dass es sein Traum sei, dass Südschleswig wieder einmal zurück nach Dänemark komme (Meyer in Petersen [2014]). Dies ist eine Forderung nach einer Grenzverschiebung in Richtung Süden. Meyer erkennt an, dass sich der Grenzverlauf zwischen Deutschland und Dänemark danach richtet, welche Bevölkerungsgruppe in der Mehrheit ist. Er hofft, dass die Dänen in Zukunft wieder in der Mehrheit in Südschleswig seien

408 „Det er blevet alt for let at være mindretal nu om dage, vi må passe på med, at mindretallet ikke forvanskes." 
und die Grenze dann verschoben werde (Meyer in Nygaard 14.03.2013; vgl. a. Vollertsen 07.04.2006). Dieser grenzrevisionistische Wunsch ist heute politisch obsolet und als national-konservativ einzuschätzen. ${ }^{409}$ Alle politischen Akteur*innen in Deutschland und Dänemark sind sich darüber einig, dass die deutsch-dänische Grenze seit der Volksabstimmung 1920 festliegt, abgesehen von der Dansk Folkeparti $(\mathrm{DF})^{410}$, einer dänischen national-konservativ-populistischen Partei am rechten politischen Rand. Hardliner Meyer konstatiert im Interview mit Flensborg-Avis-Chefredakteur Jørgen Møllekær, dass Kinder zu bekommen die einzige Art sei, eine Mehrheit für die dänische Minderheit zu erlangen, nämlich dadurch, dass die Minderheit somit größer werde (Meyer in Møllekær 24.12.2013; Meyer in Nygaard 14.03.2013). Diese Auffassung, dass Zugehörigkeit zu einer Gesinnungsminderheit mit genetisch-biologischen Faktoren zusammenhänge und durch Fortpflanzung gesichert werden könne, mutet deterministisch-biologistisch und reaktionär an.

Claas Johannsen, ehemaliger Vorsitzender der SSW-Jugend (2011-2013) und Abiturient des dänischen Gymnasiums in Flensburg, also ein jüngerer Minderheitenangehöriger, hat auch eine nationalistisch-ideologische Auffassung von der Minderheit. Er habe sich entschieden, der Minderheit anzugehören und jetzt kämpfe er genau dafür, obwohl dieser Kampf heute eher diffus sei (Johannsen in Petersen [2014]). Er kritisiert junge Minderheitenangehörige, indem er ihnen Gleichgültigkeit gegenüber der erkämpften Gleichstellung der Minderheit im Landesteil Schleswig vorwirft und behauptet, sie seien verwöhnt und würden zu unengagiert, zu unpolitisch und zu unkritisch sein. Des Weiteren kritisiert Johannsen abgrenzenderweise die seiner Meinung nach relativ starke Offenheit der dänischen Schulen. Alle könnten ihre Kinder auf dänische Schulen schicken. Alleine dieses Faktum ergebe ein Rechtfertigungsproblem für die dänische Minderheit, so Johannsen (Johannsen in ebd.). Er sucht nach vermeintlich objektiven Kriterien für eine Minderheitszugehörigkeit und fordert eine Legitimierung der Minoritätsschaft, dabei ist die dänische Minderheit durch die Bonn-Kopenhagener-Verträge und das Prinzip der freien Bekenntnises von jeglichem Rechtfertigungsdruck dem deutschen (aber nicht dem dänischen) Staat gegenüber befreit (vgl. Kap. 7.6). Es bleibt unklar, auf welche Weise sich Johannsen eine seiner Meinung nach sinnvolle Rechtfertigung für das Minderheitssein vorstellt.

409 Die politisch-aktionistische, grenzrevisionistische und tendenziöse Einstellung Karl Otto Meyers in den Nachkriegsjahren konnte der Historiker und Leiter der Forschungsabteilung der Dansk Centralbibliotek in Flensburg, Mogens Rostgaard Nissen, nachweisen (Nissen 23.03.2017).

410 Beispielsweise wird Martin Henriksen (DF) von Egon Clausen mit den Worten zitiert: „Vi må have det tilbage. Snart!“, dt: „Wir müssen es [Südschleswig] wiederbekommen. Bald!“ (Clausen 2014: 148). Auch Søren Krarup äußert einen Grenzrevisionswunsch in einem Zeitungsfeature (dän. „Kronik“) in der Flensborg Avis (Krarup 09.02.2013). 
Das Beispiel von Heiko Frost, im Jahre 2007 Leiter der Bildungsstätte der deutschen Minderheit in Dänemark am Knivsberg, hat starke Kritik aufseiten der Nationalisten provoziert. Wolfgang Dibbern kritisiert in einem Zeitungsfeature beispielsweise, dass Frost Leiter einer Einrichtung der deutschen Minderheit ist und gleichzeitig seine Kinder südlich der Grenze in eine dänische Schule schickt. Für Dibbern, ehemaliger Schulleiter, sind beide Tatsachen an eine aktive Minderheitenzugehörigkeit geknüpft und sollten jeweils eine Herzensangelegenheit sein. Hierdurch versucht Dibbern, an die emotionale Seite der Gesinnung zu appellieren. Eine gleichzeitige deutsche sowie dänische (Minderheiten-)Gesinnung hält Dibbern für eine ideelle Kollision und Verbiegung (Dibbern 15.08.2007). Frosts Begründung für die Wahl einer dänischen Minderheitenschule ist, dass diese „eine gute Schule sei“ (Frost in ebd.). Dibbern findet dies jedoch unpassend, denn die dänische Schule sei nicht für die deutsche Mehrheit südlich der Grenze da, sondern nur für bekennende Minderheitendänen. Obwohl das Bekenntnis zur Minderheit frei ist, kategorisiert Dibbern Frost als zur deutschen Mehrheit gehörig. Diese solle selbst gute Schulen anbieten, wenn sie glaube, ihre Schulen seien zu schlecht im Gegensatz zu den Schulen des dänischen Schulvereins. Auch Dibbern benutzt das Argument der Finanzierung der dänischen Minderheiteninstitutionen. Er befürchtet, dass der dänische Staat keine Gelder mehr nach Südschleswig schicken werden, wenn Mehrheitsdeutsche ohne echtes, verlässliches dänisches Bekenntnis die dänischen Schulen nutzten, nur weil diese ,gut“ seien. Allerdings wird hier außer Acht gelassen, dass Schulschließungen drohen, wenn zu wenige Kinder in die dänische Minderheit gelassen werden (vgl. Kap. 5.2). Auch hier wird von Dibbern nicht näher erläutert, was genau er sich unter „echt“ und „dänisch“ vorstellt.

Laut Dibbern geht es bei der Wahl des Arbeitgebers in Bezug auf Minderheiten nicht ausschließlich um Qualifikation und professionelle Arbeit, sondern unbedingt auch um die nationale, ideologische Gesinnung. Er zieht eine klare Trennung zwischen Deutschsein und Dänischsein und den seiner Meinung nach gegensätzlichen, miteinander unvereinbaren Zielen der beiden Minderheiten. Er unterscheidet hierbei ausdrücklich nicht zwischen privatem Bekenntnis und professioneller Berufsausübung. Als weiteres Beispiel nennt Dibbern, dass es seiner Meinung nach unmöglich sei, der deutschen Minderheit als Funktionär anzugehören und gleichzeitig Mitglied im dänischen Gronseforening zu sein. ${ }^{411}$ Dibbern schließt explizit eine Zusammenarbeit und eine Verwischung der Grenzen zwischen den Minderheiten aus und konstatiert, dass es nur ein Entweder-oder, aber kein So-

411 Dibbern nennt das Beispiel Stephan Kleinschmidt aus Sønderborg/Sonderburg, Politiker der Slesvigsk Parti (SP), der Partei der deutschen Minderheit in Dänemark. 
wohl-als-auch gebe. Implizit zieht er hier eine Grenze, indem er Freundschaft und Toleranz zwischen den Minderheiten zwar nicht ausschließt, diese aber als gegenseitig bezeichnet und damit von zwei abgrenzbaren Gruppen ausgeht (ebd.). Nach Fredrik Barth kann hier festgestellt werden, dass durch verbale Äußerungen versucht wird, die eigene Gruppe zu definieren und diese von vermeintlich anderen abzugrenzen.

Der Historiker Nils Vollertsen bringt diese beschriebenen Haltungen kritisch in der Flensborg Avis auf den Punkt. Er bewertet die Rhetorik des oben bereits erwähnten Dieter Paul Küssners, wie beispielsweise den Ausdruck, die dänische Minderheit sei ein „kultureller Leuchtturm“4412, als „konservativ“ und „liberalistisch ${ }^{\text {“413 }}$. Der DF-Politiker Søren Krarup wird von Vollertsen als Mann mit „einer altnationalen, dänischen Haltung ${ }^{\text {“4114 }}$ bezeichnet, der „für eine stark konservative, nationalistische und in der dänischen politischen Debatte stark das Dänischsein markierende Partei ${ }^{i c 415}$ im dänischen Parlament sitzt (Vollertsen 07.04.2006).

Gegenüber den konservativ-nationalistischen, grenzrevisionistischen Ansichten gibt es in der Minderheit auch pragmatische, postmoderne Vertreter*innen. Dazu gehört nicht nur Vollertsen, sondern beispielsweise auch Marc Peetz, Redakteur bei der Flensborg Avis, zum Zeitpunkt der Filmveröffentlichung im Jahre 201443 Jahre alt. Peetz fordert mehr Offenheit und Respekt von den Minderheitenakteuren, um das machen zu dürfen, was er möchte (Peetz in Petersen [2014]). Peetz möchte die Möglichkeit haben, in einer kulturellen Vielfalt zu leben und sich nicht für eine Seite entscheiden zu müssen (Peetz in ebd.). Auf die Entweder-oder-Forderung Karl Krings antwortet Peetz, dass wenn entscheidende Akteur*innen in der dänischen Minderheit nicht akzeptierten, dass er sich sowohl in Mehrheits- als auch Minderheitskontexten bewege, genauer, dass wenn er nicht in einer dänischen Institution arbeiten und gleichzeitig in einem deutschen Verein Fußball spielen dürfe, dass er sich dann aus der Minderheit abmelden werde. Die Mitspieler aus einem deutschen Fußballverein, der besser zu Peetz spielerischem Leistungsstand passe, würden schließlich auch akzeptieren, dass er sich in der dänischen Minderheit bewege (Peetz in ebd.). Peetz stört, dass einige in der dänischen Minderheit der Auffassung seien, dass man nicht beides sein könne, d. h. sich sowohl in der Minderheit als auch in der Mehrheit zu bewegen (Peetz in ebd.). Im direkten Gespräch kontert Jens A. Christiansen, SSF-Generalsekretär, dass Peetz ja aber auch sagen könne, er sei Teil der dänischen Minderheit und deswegen engagiere er sich in den dänischen Klubs und unterstütze diese, auch wenn er sportlich gesehen besser in einen deutschen Fußballverein passen würde

\footnotetext{
412 „kulturelt fyrtårn“

413 "liberalistisk“

414 „en gammelnational, dansk holdning“

415 „,for et stærkt konservativt, nationalistisk og i den danske politiske debat stærkt danskhedsmarkerende parti DF“
} 
(Christansen in ebd.). Christiansen unterstellt Peetz Gleichgültigkeit und wirft ihm vor, dass, wenn es egal wäre, wo Peetz spiele, die dänische Minderheit keine Zukunft mehr habe (Christiansen in ebd.), was ein Vorwurf der Illoyalität ist. Durch die Forderung nach ganzheitlichem Engagement und der Zuschreibung von Verantwortung an jeden Einzelnen für die Gesamtminderheit versucht Christiansen, sozialen Druck aufzubauen und möglicherweise ein schlechtes Gewissen zu generieren, damit sich Akteur*innen klar zur Minderheit bekennen und sich nach auBen hin abgrenzen anstatt pragmatisch über die konstruierten Grenzen zwischen Minder- und Mehrheit hinweg zu agieren.

Auch unter den älteren Angehörigen der Minderheit gibt es pragmatische Stimmen. So fragt sich Marie Tångenberg im Film De glemte danskere, ob man denn überhaupt zwischen Mehrheit und Minderheit wählen müsse. Nur wenn eine Gruppe bedroht sei oder infrage gestellt werde, dürften eigentlich Fragen danach aufkommen, auf welcher Seite man stehe bzw. was man wähle. Wieso könne man jetzt nicht einfach nur das sein, was man sein wolle und in Freiheit und Frieden leben (Tångenberg in ebd.).

Ein weiteres Beispiel für Pragmatismus ist der Torsdagskoret, der Donnerstagschor der Minderheit in Flensburg. Der Chor suchte einen neuen Chorleiter und engagiert Stefan Graw, der zwar Dänisch spricht, aber nicht der dänischen Minderheit angehört. „Und kommt von ganz woanders her: aus Münster. Seit 2001 lebt er in Flensburg. Wegen der Grenznähe beschloss er, Dänisch zu lernen“ (Werner 16.05.2016). Stefan Graw erläutert im Radiobeitrag:

In der Terminologie, die es hier oben gibt, bin ich ein Mehrheitsdeutscher, ein flertalstysker, und ehm, davon weich ich jetzt auch nicht irgendwie ab, dass ich jetzt sag, oh, ich möchte dann doch lieber ... nee. Also, ich sprech die Sprache, ich treff mich mit Leuten, die Dänisch sprechen, ehm ... ich leite den dänischen Chor, aber ehm, ja. Ich leite zur Zeit auch einen evangelischen Kirchenchor, obwohl ich katholisch bin (Graw in ebd.).

Eine Chorsängerin versucht, diese Entscheidung zu legitimieren: „Er hat mal bei uns ... mitgesungen, weil er selber Dänisch praktizieren wollte und ehm insofern haben wir dann gesagt, ist er doch in gewisser Weise mit uns verbunden" (unbenannte Chorsängerin in ebd.). Dieser Pragmatismus sorgt letztendlich dafür, dass der Chor weiterhin bestehen bleibt. Es fehlten Nachwuchssänger*innen, sodass „auch, Leute, die Dänisch gelernt haben gerade, die könnten auch gut im Chor sein, weil man da in einer freudigen Art und Weise die Sprache benutzt" (unbenannte Chorsängerin in ebd.). Man öffnet sich also für Neudän*innen oder Nichtdän*innen, die etwas Dänisch können oder lernen wollen, damit das Dänischsein durch die kulturelle Praktik des Chorsingens erhalten bleibt. 
Ein weiteres Beispiel für moderne und pragmatische Minderheitenvertreter*innen ist Katrine Hoop. Sie berichtet, dass in ihrer Kindheit der Kontakt nach Dänemark stark von positiven Gefühlen geprägt war und die Geschichte ihnen das Recht gab, das Dänische zum Deutschen hinzuzuwählen. Dänischsein ist für sie daher etwas Wählbares, etwas Positives und Freiwilliges. Gleichzeitig kritisiert Hoop die Auffassung einiger Minderheitsdän*innen, die Anspruch erheben auf eine möglichst häufige Verwendung der dänischen Sprache als Identitätsmarker. Sie kritisiert die Erwartung einiger, dass Minderheitsangehörige ihr Deutschsein abwählen und ablegen und sie geht nicht konform mit denjeningen, die fordern, dass immer das ganze dänische (Zugehörigkeits-)Paket gewählt werden soll. Hoop bemängelt das Fehlen von mehrkulturellen Modellen (Hoop in Sørensen 2008). Pragmatisch bezeichnet sie sich selbst als Mischprodukt und Hybrid, das sich in mehreren Kulturen auskennt. Wobei hier wieder ein Denken in abgrenzbaren kulturellen Einheiten zum Vorschein kommt, das Hoop ja eigentlich verhindern will. Für die heutige südschleswigsche Jugend solle es nicht mehr um die Wahl zwischen dänisch oder deutsch gehen, sondern um Mehrkulturalität und Vielfalt, auch wenn einige dies nicht als Kern Südschleswigs ansähen, sondern als Bedrohung für die Minderheit (Hoop in ebd.). Schließlich betont Hoop, dass es viele Arten gebe, dänisch zu sein. Das gelte sowohl für Südschleswig als auch für das Leben in Dänemark. Damit widerspricht sie den ideologischen Vorgaben der meisten Funktionär*innen.

Während Marc Peetz, Katrine Hoop und Marie Tångenberg ganz pragmatisch mit dem Minderheitensein umgehen, treten Claas Johannsen, Hella Lassen, Karl Kring, Jens A. Christiansen und Karl Otto Meyer sehr emotional und kämpferisch-abgrenzend auf. Es überwiegen bei ihnen nationalistische Ansätze und Konzepte zur Aufrechterhaltung der Minderheit statt pragmatischen, offenen Perspektiven. Die Pragmatiker*innen nutzen die Vorteile von Zweisprachigkeit und transkultureller Kompetenz und Mehrfachperspektiven, so wie sie auch Elka Tschernokoshewa und Dieter Kramer beschreiben (vgl. Tschernokoshewa, Kramer 2001: 9). Sie sehen darin folgende Vorteile: ,höhere Flexibilitätskompetenzen, breitere Handlungskompetenzen, Mobilität, Auflockerung von Grenzen und Abdichtungen, Ende der Eindeutigkeit.“ Dabei bewerten sie das „Ende der Eindeutigkeit" als „,wesentliches Signum der heutigen Zeit“ (ebd.: 9). Weiterhin heben Tschernokoshewa und Kramer hervor, dass „Minderheiten mit ihrem hybriden Leben“ „reiche Erfahrungen“ besitzen. „Zudem sind sie Experten nicht nur für Grenzüberschreitungen und Globalität, sondern auch für die Wertschätzung des Regionalen“ (ebd.: 9). Daher böten Minderheiten uns allen die Chance, „das Globale und Regionale zusammenzudenken, noch mehr, wenn wir daran interessiert sind, die Welt nicht als etwas Festes, Vorgeschriebenes und Naturwüchsiges [zu sehen], sondern sie in ihrer Ambivalenz und Ambiguität zu begreifen." (ebd.: 10). 
Nationalistische Auffassungen enthalten konstruierte Grenzen und Abgrenzungen. Sind die vorgestellten Grenzen zu durchlässig, so haben einige Akteur*innen Angst vor einer Assimilierung der dänischen Minderheit in die deutsche Mehrheit. Dies wird beispielsweise in der Jahrestreffenrede von Anders Kring, SdU-Direktor und ebenfalls Sohn von Karl Kring, am 11. Juni 2016 in Bredstedt deutlich (Kring 15.06.2016; vgl. a. Jebsen 2008: 119, 143-144; vgl. a. Hoop in Sørensen 2008). Assimilierung bedeutet für Anders Kring, dass die Grenzen unsichtbar werden oder nicht mehr vorhanden sind. Dann sei es unerheblich geworden, ob man deutsch oder dänisch sei. Dann würden Unterschiede, die eine Gruppe ausmachten, verwischt oder verschwinden. Er plädiert dafür, dass die Minderheit dies verhindere und dass funktionelle Grenzen aufrecht erhalten würden (Kring 15.06.2016). Er hält Grenzen für wichtig, da sie die Minderheit beschützten. Konflikte nach außen führten zu einer Stärkung des inneren Zusammenhaltes, so Anders Kring (ebd.). Daraus schließt er, dass eine Minderheit, die von auBen keinen Widerstand erfahre, ihre Grenzen vergesse und sich dadurch in die Mehrheit assimiliere (ebd.). „Im Grunde genommen ist es schlecht, wenn es zu leicht ist, Minderheit zu sein ${ }^{\text {“4116 }}$, so Kring (ebd.). Die Minderheit überlebe nur, wenn sie eine Grenze ziehen könne, denn ohne Grenzen oder Rahmen fallen Systeme auseinander bzw. ineinander zusammen (ebd.). Die „ewige Herausforderung des Grenzlandes" sei es, sich abzugrenzen und trotzdem zusammen zu sein. Die anderen wollen, ohne sich selbst aufzugeben. Das sei die Lösung, so der damalige SSF-Vorsitzende Dieter Paul Küssner (Küssner 15.01.2013), dessen Aussage in eine ähnliche Richtung geht wie die von Anders Kring. Ruane und Todd nennen übereinstimmend mit diesen Ängsten die Punkte ,intermarriages, integrated schooling, a sports team which gets cross-community support" (Ruane, Todd 2004: 227). Diese könnten eine Minderheit gefähren oder überflüssig machen. Auch die Funktionär*innen in der dänischen Minderheit problematisieren sogenannte Mischehen, sind gegen deutsch-dänische Schulen und gegen Dänischgesinnte, die deutsche Sportklubs besuchen, wenn es entsprechende dänische Angebote gibt. Möglicherweise deutete das auf die Labilität des Minderheitensystems und die damit verbundene Angst vor Auflösung der Minderheit hin oder auf die Angst, dass durch das Wahrnehmen deutscher Angebote dänische Veranstaltungen überflüssig werden würden und damit die ganze Minderheit redundant werden könnte (vgl. a. ebd.: 227). Dabei ist zu beachten, dass das geschaffene System eine Bindung an die Minderheit herstellt und nicht der vermeintlich ethnische oder nationale Charakter der Minderheit.

416 „I grunden er det skidt, når det er for let at være mindretal.“ 
„Die klare Festlegung auf das persönliche Bekenntnis als ausschließliches Entscheidungskriterium der Minderheitenzugehörigkeit hat auch erhebliche Schwankungen in der Mitgliedschaft bewirkt" (Thaler 2013: 38; s. a. Kap. 4.2.1.1). Peter Thaler betont, dass die „Wechselhaftigkeit und Vieldeutigkeit von Minderheitsidentität [...] ein schleswigsches Charakteristikum“" sei (Thaler 2006: 411).

Die Angehörigen der dänischen Minderheit und der deutschen Mehrheit haben größtenteils die gleiche (deutsche) Sprache, haben die gleiche Herkunft und die gleiche Religion. Die Gesinnung als einziges offizielles, aber sehr schwammiges Kriterium führe innerhalb der Minderheit seit Jahrzehnten zu Auseinandersetzungen über die selbst gestellten Minimalerwartungen an neue und alte Mitglieder (vgl. a. Thaler 2013: 38). Das Grundproblem, welches auf die dänische Minderheit zutreffe, sei laut des dänischgesinnten Friesen Thede Boysen: „Wenn eine Minderheit sich nach außen verschließt, stirbt sie an Sauerstoffmangel. Wenn sie $\mathrm{zu}$ offen ist, riskiert sie, dass sie sich selbst überflüssig macht“"417 (Boyen in Simonsen 16.10.2014a). Diese beiden Sätze verdeutlichen das ambivalente Dilemma einer Minderheit zwischen Offenheit und Abgrenzung. Eine Minderheit braucht Nachwuchs und muss diesen integrieren. Wenn aber jeder aufgenommen und nicht integriert wird, dann besteht bei den Akteur*innen die Angst vor Assimilierung (Vergleich zur dt. Minderheit: Jebsen 2009) und dann entfällt auch die Begründung für die Existenz der Minderheit und damit für die finanzielle Unterstützung aus Dänemark, die wiederum die Existenz der Minderheit aufs Spiel setzen würde. Boysen fordert daher eine transparente Diskussion über und eine Offenlegung der Erwartungen an alle Minderheitsangehörigen sowie die Möglichkeit, bei Nichteinhalten derselben Konsequenzen einzusetzen. Allerdings räumt Boysen ein, dass eine Beherrschung mehrerer Sprachen und „Kulturwerkzeu$\mathrm{ge}^{\text {‘418 }}$ im Landesteil immer schon Normalität gewesen sei und nicht bedeute, dass man die „eigene Kultur ${ }^{\ll 419}$ verneine (Boysen in Simonsen 16.10.2014a).

Im Gegensatz zu Boysen sieht Kathrine Hoop die Sache pragmatischer. Sie möchte nicht, dass Erwartungen an Minderheitenangehörige gestellt werden. Sie begründet dies damit, dass das Bekenntnis zum Dänischen das Deutschsein nicht ausschließen muss. Dänischsein sei kein „Konkurrent zum Deutschen, sondern eine Komplettierung der Mehrkulturalität in der Region “420 (Hoop in Simonsen 16.10.2014b). Auch der dänische Philosoph Søren Harnow Klausen bemerkt, es sei nicht so, dass sich deutsch und dänisch gegenseitig ausschließen, denn ein Bekenntnis zum einen schließe nicht aus, sich auch dem anderen zugehörig zu fühlen (Klausen 06.07.2016). Klausen betont, dass man sich sowohl eindeutig dä-

\footnotetext{
417 „Hvis et mindretal lukker sig om sig selv, dør det af iltmangel. Hvis det er for åbent, riskerer det at gøre sig selv overflødigt.“

418 „kulturredskaber“"

419 „,egen kultur“"

420 „konkurrent til det tyske, men som komplettering af flerkulturaliteten i regionen“
} 
nisch identifizieren kann als auch deutsch. „Eindeutige Identifikation muss nicht einseitig sein “421 (ebd.), denn es gehe nicht um Abstammung, sondern um Anerkennung von Gesinnung (vgl. ebd.). Bei der dänischen Minderheit handele es sich zum Teil um eine „zusammengesetzte Identität“"422 oder „gar eine zusammenge-

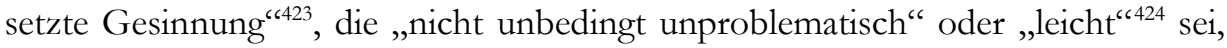
so Klausen. Er konstatiert, dass sich „Kulturelemente und Loyalitäten [...] schon vereinen lassen ${ }^{\text {‘ } 425}$, aber es trotzdem zu Spannungen kommen könne (Klausen 07.07.2016). Vermeintliche Kulturunterschiede sind demnach Konstruktionen (vgl. a. ebd.), allerdings beeinflussen sie trotzdem das Handeln der Akteur*innen. Sie sind also trotz ihres konstruktiven Charakters wirksam.

Ein Teil der grundlegenden Ambivalenzen innerhalb der dänischen Minderheit fasst Jørgen Møllekær, Chefredakteur ${ }^{426}$ der Flensborg Avis, in einem Leitartikel zusammen: Er reagiert auf Krings Mahnung, dass es heutzutage allzu leicht sei, Teil der Minderheit zu sein. Damit habe dieser gleichzeitig Recht und Unrecht. Das Minderheitsein solle einerseits modern sein, andererseits seinen Ursprung im Dänischen haben. Man soll dänisch sein, andererseits lebt man in einer deutschen Umgebung. Auf einige treffe daher die Losung „So dänisch wie möglich, so deutsch wie notwendig ${ }^{6427}$ zu (Møllekær 05.11.2014). Für andere gelte es, das Deutschsein nicht zu leugnen. „Das Minderheitenleben wird [...] auf unendlich viele und zum Teil schwer kommunizierbare Weisen geführt“ ${ }^{\star 428}$ (ebd.). Møllekær plädiert dafür, dass das Bekenntnis zur Gesinnungsminderheit eine aktive Wahl sei für diejenigen, die das wirklich wollten. Das Bekenntnis solle kein Zufall sein. Auch wenn der Alltag vieler Minderheitendänen deutsch sei, so sollte doch die Aufrechterhaltung der Minderheit gefordert werden. Andererseits solle sich keiner zu einem Schiedsrichter darüber machen, wann etwas oder jemand dänisch genug sei (ebd.). Im Vergleich zur Zeit des Nationalsozialismus sei die Lage der Minderheit heute geprägt von Frieden und Zusammenleben, es ,ist unglaublich leicht, Minderheit zu sein ${ }^{\text {“429 }}$ (ebd.). Das berge aber das Risiko, dass jede*r Einzelne nicht so viel zum Minderheitensein beitragen müsse. Der Chefredakteur benennt die Hauptherausforderung der Minderheit: „Offenheit oder Geschlossenheit ${ }^{\star 430}$

\footnotetext{
421 „Entydig identifikation behøver ikke være ensidig.“

422 ,sammensat identitet ${ }^{\text {“ }}$

423 ,endog et sammensat sindelag“

424 ,ikke nødvendigvis uproblematisk“, „let“

425 „Kulturelementer og loyaliteter“ „nok lader sig forene“

426 seit 2013

427 „Så dansk som muligt, så tysk som nødvendigt.“

428 „Mindretalslivet føres [...] på unendelig mange og tildels svært kommunikerbare måder.“

429 „det er ufatteligt let at være mindretal“

430 „Åbenhed eller lukkethed“
} 
(ebd.). Die Minderheit könne nur überleben, wenn es einen einfachen Zugang zu ihr gebe. Dieser Zugang dürfe aber nicht unkritisch sein und „dänische Werte, Kultur und Sprache ${ }^{\text {‘6331 }}$ dürften nicht losgelassen werden, so Møllekær (ebd.). Was genau „Werte“ und „Kultur“ sein sollen, bleibt offen. Diese Konzepte sind relativ unspezifisch, ebenso wie die Definition von „Sprache“. Diese „Unbestimmtheit" von Nationalismus und dessen „Mangel an programmatischem Gehalt" verleihe ,ihm innerhalb seiner eigenen Gemeinschaft potentiell allgemeine Unterstützung“, so Eric Hobsbawm (Hobsbawm 2005: 200). „Der Appell an eine ethnische Zugehörigkeit [...] kann die große Mehrheit der betreffenden Gemeinschaft mobilisieren, sofern er genügend unbestimmt oder irrelevant bleibt" (ebd.: 200).

Unter der immer wieder postulierten Offenheit der Minderheit, dem sogenannten „offene[n] Dänischsein“432 (Hansen 09.03.2017) versteht Hansen, dass „alle und jeder unsere Minderheit frei wählen können “4333 (ebd.). Dies impliziert, dass das Minderheitensein nicht offen ist, sondern ein klares, eindeutiges Bekenntnis voraussetzt. Die Offenheit besteht nur darin, dass das Bekenntnis zum Dänischen für jede*n möglich ist, aber wenn man sich dann für das Dänische entschieden hat, die Offenheit, gleichzeitig auch deutsch zu sein, aufhört, so der Tenor von Hansens Grundsatzrede. Obwohl Hansen einräumt, dass man heute in der Minderheit sagen könne, dass man weder Däne noch Deutscher sei, sondern Südschleswiger, konstatiert er weiter, dass die Minderheit eigentlich im Dänischen verankert sei. Die Existenzberechtigung der Minderheit „baut also darauf, dass die Mitglieder grundlegend dänisch sein wollen und sich ohne Vorbehalte dazu bekennen “434 (ebd.). Dabei erwarte er, dass sich neue Dänen mit der dänischen Geschichte und den dänischen „immateriellen Werten ${ }^{\text {“435 }}$ beschäftigen. Dazu zählt Hansen die Werte, die das dänische Kulturministerium in einer Volksumfrage in Dänemark gesammelt und in einem Danmarkskanon ${ }^{436}$, Dänemarkskanon, veröffentlicht hat (ebd.). Neudänen sollten sich integrieren, indem sie Dänisch lernten und sich in „die dänische Kultur, Tradition, Mentalität und den Humor einleben ${ }^{\text {‘ } 437}$, so Hansen (ebd.). Wodurch die Abgrenzung der Minderheit

\footnotetext{
431 „danske værdier, kultur og sprog““

432 ,åben danskhed“

433 ,at alle og enhver frit kan vælge vort mindretal“

434 „,bygger således på, at medlemmerne grundlæggende vil være danske og uforbeholdent bekender sig dertil“"

435 ,immaterielle værdier“

436 Die zehn dänischen Werte im Kanon sollen sein: Offenheit, Geschlechtergleichstellung, Wohlfahrtsgesellschaft, Vertrauen, die dänische Sprache, Vereinsleben und Freiwilligkeit, Gemütlichkeit/Hygge, christliches Kulturerbe, Freiheit, Gleichheit vor dem Gesetz (Kulturministeriet 2016).

437 „leve sig ind i den danske kultur, tradition, mentalitet og humor“
} 
nach außen zusätzlich befördert wird, zeigt das nächste Kapitel, in dem es um die finanzielle und die damit einhergehende ideelle Abhängigkeit der dänischen Minderheit vom dänischen Staat geht.

\subsection{Die Beziehungen zum Königreich Dänemark: Abhängigkeit und „Aufklärung“}

„Ein Vorteil für jene, die ihrer inneren däni-
schen Stimme folgen, ist in Städten wie
Schleswig und Flensburg zu sehen: bestens
ausgestattete Kindergärten und Schulen, üppig
alimentiert von der dänischen Regierung. "
Gunther Latsch, SPIEGEL-Autor

(Latsch 29.04.2017: 52)

Im Vergleich zur nationalen Minderheit der Sorben in der Ober- und Niederlausitz, die keinen kin-state haben (vgl. a. Toivanen 2001: 58), profitiert die dänische Minderheit kulturell, finanziell und sprachlich stark von Dänemark. Zuerst soll in diesem Kapitel ein Blick auf die Minderheiteninstitutionen in Bezug auf Dänemark geworfen werden, bevor anschließend die Perspektive des Königreichs auf die Minderheit und die Vernetzung zwischen Königreich und Südschleswig untersucht werden. Dabei wird es auch um die im Zitat von Spiegel-Autor Latsch süffisant angemerkte finanzielle Abhängigkeit von Dänemark und die damit verbundenen Erwartungen an Sprachgebrauch und Alltagspraxen der Minderheitsangehörigen gehen.

Das freie Bekenntnis zur dänischen Minderheit bringt ihren Angehörigen in Deutschland, abgesehen von der Befreiung des SSW von der $5 \%$-Hürde im schleswig-holsteinischen Landtag, kaum Vorteile. Auch deshalb spielt es für den deutschen Staat keine Rolle, dass es keine objektiven Kriterien für die Zugehörigkeit gibt. Obwohl die Gesinnung frei ist und vom deutschen Staat nicht nachgeprüft werden darf, hat der dänische kin-state klare Definitionskriterien für die Zugehörigkeit von Menschen zur dänischen Minderheit aufgestellt. Man muss daher unterscheiden zwischen der Selbstdefinition der Minderheit, der Definition durch Deutschland bzw. Schleswig-Holstein und der Definition von Menschen als Südschleswiger*innen durch Dänemark. Denn dort kann die Minderheitenzugehörigkeit einen Zugang zu Privilegien bedeuten. Vorteile können beispielsweise dänische Stiftungs- und öffentliche Fördergelder oder der erleichterte Zugang zur dänischen Staatsbürgerschaft im Vergleich zu anderen deutschen Staatsbürger*innen oder EU-Bürger*innen sein (Kühl 2006a: 400-401, 403-404). Damit können un- 
ter bestimmten Voraussetzungen dänische Rentenansprüche oder die Erlaubnis des dänischen Staates zum Kauf eines Ferienhauses in Dänemark einhergehen, welcher für deutsche Staatsangehörige in der Regel nicht gestattet ist. Diese Vorteile sollen nicht durch reine, vermeintlich beliebige Selbstidentifikationen missbraucht werden können (Kühl 2003: 183-184). Daher werden als objektive angesehene, dänische Kriterien für die Zugehörigkeit zur Minderheit daher vom Königreich festgesetzt. Diese sind erstens Geburt in Südschleswig, zweitens der Besuch einer dänischen Schule und drittens das Engagement und die Mitgliedschaft im Erwachsenenalter in Minderheitenvereinen in Südschleswig oder ähnliche Verbindungen zum Dänischen (Kühl 23.09.2006; Kühl 2003: 184; Kühl 2006a: 400-401).

Seit dem 01.04.2010 regelt ein dänisches Gesetz die Zuschüsse Dänemarks an die Minderheit im Landesteil Schleswig, das Südschleswiggesetz ${ }^{438}$. Die Zuschüsse werden jedes Jahr neu verteilt, ausgehandelt und in sogenannten Resultataftaler, den Ergebnisverträgen, jeweils zwischen den einzelnen Vereinen und dem Sydslesvigudvalget, dem Parlamentsausschuss für Südschleswig, festgehalten. Es gibt drei Arten von Zuschüssen: (1) den Driftstilskud, also einen Zuschuss zum laufenden Betrieb der jeweiligen Organisation, (2) den Zuschuss oder Kredit für Bauprojekte, also bygge- og anlagsprojekter, und (3) den Projektzuschuss, Projekttilskud. Wie die Aufstellung der finanziellen Zuschüsse in Kapitel 3.2 bereits gezeigt hat, ist die dänische Minderheit mit ihren Institutionen finanziell vom dänischen Staat abhängig. Die Höhe der Gelder ist markant und elementar wichtig für die Minderheit. Für das Jahr 2018 beträgt die Bewilligung des Südschleswigausschusses 61,2 Millionen $€$ (Nygaard 23.12.2017). „Die Minderheitenfunktionäre werden vom Nachbarland auskömmlich finanziert", so kommentiert es leicht spöttisch Gunther Latsch (Latsch 29.04.2017: 52). Auch der Ortsfunktionärin Tina Zehntner ist bewusst, dass die Minderheit abhängig von finanzieller Unterstützung aus Dänemark ist: „Ja, weil wenn das uns gekürzt wird, denn...... denn [sic] sieht das nicht mehr gut aus bei uns...... wenn wir kein Geld mehr aus Dänemark kriegen“ (INT10). Den Grund, warum es Steuergelder aus Dänemark für die dänische Minderheit gibt, sieht Zehntner korrekterweise in den „Bonn-København-Erklæringen“ (INT10). Sie erläutert: „Weil ich weiß ja auch nicht, aber... d, der deutsche Staat gibt ja auch 'n büschen was für die deutsche Minderheit... glaub nicht, so viel, wie wir aus Dänemark kriegen... aber..... nä, dass das Dänische noch gelebt wird“ (INT10). Ohne das Geld gäbe es keine Minderheitsorganisationen mehr und damit recht bald auch keine Minderheit in der jetzigen Form mehr, so Jørgen Kühl. Die Minderheit wäre ohne dänisches Geld zwar noch existent, denn es sei nicht allein das Geld, das die Minderheit produziere, aber die Minder-

438 Lov om Sydslesvigudvalget og tilskudsordninger på undervisningsministerens område for det danske mindretal i Sydslesvig, kurz Sydslesvigloven, Lov Nr. 287. 
heit brauche das Geld, sonst bleibe nur ein kleiner Kern übrig (Kühl in TV Syd 11.12.2014). Karen Margrethe Pedersen betont, dass die Gelder entscheidend seien für die Weiterexistenz der Dän*innen in Südschleswig (Pedersen in ebd.). Das dänische Geld halte die Institutionen der Minderheit am Laufen, beispielsweise dienten die Schulen nicht nur der Bildung, sondern auch als Kulturzentren und zur Aufrechterhaltung des Minderheitsnetzwerkes, so Udo Jessen vom Schulverein (Jessen in ebd.).

Ein großer Kritiker der dänischen Minderheit ist Egon Clausen aus Dänemark. Er veröffentlichte 2014 ein semidokumentarisches, halbsubjektives Buch mit Reiseschilderungen über die Südschleswiger*innen mit dem Titel „Im Grenzland. Reisebriefe aus Südschleswig “439 (Clausen 2014). Clausen bezeichnet die Minderheit darin als ein großes Theaterstück, als eine große Inszenierung. Er zitiert einige Minderheitenangehörige anonym mit den Worten „Potemkinsche Dörfer ${ }^{6440}$ und „der größte Bluff der Welt“441 (Clausen 2014: 213; vgl. Goffman 2010). Er hebt weiterhin hervor, dass Funktionär*innen der Minderheit Kritik nicht tolerieren würden und als Angriff interpretierten. Kritik dürfe aus ihrer Sicht nicht öffentlich ausgetragen werden, aus Angst vor dem Verlust von Einfluss und von dänischen Geldern (Clausen 2014: 104; s. a. Kap. 7.6). Letzteres führe dazu, dass man in der Minderheit nach außen wie eine ,große, glückliche Familie“"442 auftrete (ebd.: 104). Hier wird erneut eine Familienmetapher verwendet (s. a. S. 326). „Es werden hübsche Reden gehalten und kluge Zeitungsfeatures geschrieben über all das Wertvolle, für das man steht ${ }^{6443}$ (ebd.: 104). Gleichzeitig herrsche, so Clausen, nach innen eine Konkurrenzsituation der einzelnen dänischen Minderheitenvereine untereinander um die Gelder aus dem Königreich (ebd.: 104). Er kritisiert die Südschleswiger*innen scharf, indem er ihnen die Verbreitung von ausschließlich schönen Geschichten des Geldes wegen vorwirft (Clausen in Davidsen 12.04.2014). Ähnlich wie Egon Clausen kritisiert auch der ehemalige SdU-Geschäftsführer Karl Kring, dass die Minderheit versuche, gegenüber Dänemark ein geschmücktes, unehrliches Bild zu vermitteln. Er nennt das ,behaglichkeitskrank“6444 (K. Kring in Peetz 24.01.2014). Damit meint er, dass öffentlich keine Probleme und keine Kritik geäußert werde, sondern alles harmonisch aussehen solle aus Angst vor dem Ende

\footnotetext{
„I grænselandet. Rejsebreve fra Sydslesvig“

"Potemkins kulisser"

„verdens størte bluffnummer“; aufgrund der Anonymität der Aussagen lassen sich diese nicht verifizieren.

„stor, lykkelig familie“

„Der holdes smukke taler og skrives kloge kronikker om alt det værdifulde, man står for.“

„behagesyg“"
} 
des Geldflusses aus Dänemark. Welche Auswirkungen die Finanzierung der Minderheit auf die Propaganda der Funktionär*innen hat, soll im Folgenden geklärt werden.

Aufgrund der starken Abhängigkeit von dänischen Geldern, werben die Institutionen der Minderheit und ihre Funktionär*innen regelmäßig um finanzielle und politische Unterstützung des dänischen Staats. Auch in die Minderheit hinein werden bestimmte Erwartungen formuliert, die aufgrund der ansonsten potentiell schlechten Außenwirkungen gegenüber Dänemark zu einem Ende des Geldflusses führen könnten. So konstatiert Dieter Paul Küssner, dass die Aufrechterhaltung der Minderheit zum einen eine gewisse Sprachkompetenz und sowie zum anderen die Pflege des dänischen Liedguts beinhalte, sowie ein „starkes Band“445 ins Königreich erfordere (Küssner 15.01.2013). Ähnlich wie Migriertenvereine in Deutschland die „Brücke zum Herkunftsland“ aufrechterhalten (Römhild 2007: 169), so werden die sprachlichen, politischen, finanziellen und kulturellen Verbindungen nach Dänemark konstruiert und postuliert, auch wenn viele der Minderheitsdän*innen Neudän*innen sind und vor ihrer Bekehrung abgesehen von Urlauben kaum etwas mit dem Königreich zu tun hatten. Kulturreisen nach Dänemark seien wichtig zum Ajourieren der Minderheit, die ,im Abstand zur aktuellen Gesellschaftsentwicklung in Dänemark lebt“" ${ }^{\star 446}$, so Funktionär Küssner (Küssner in Sydslesvigsk Forening 2013a: 12) ungeachtet der internettechnologischen Entwicklungen der letzten zwei Jahrzehnte, die Teilhabe und Kontakte über geografische Distanzen hinweg enorm vereinfachen. Diese „Imaginationen“ der Minderheitsdän*innen sowie des Königreichs sind Teil der Verbindungen der Minderheit zum kin-state oder Mutterland (Kühl 2006a: 398-399). Die Vorstellungen werden ebenso wie das Minderheitsdänischsein allgemein mit Inhalten gefüllt, die „politischer, ethisch-moralischer, kultureller, sprachlicher oder historischer" Art sein können (ebd.: 399).

Als institutioneller Kontakt für die Minderheitenvereine tritt in Dänemark neben dem Südschleswigausschuss immer wieder der dänische Grenzverein Granseforeningen in Erscheinung. Dieser Verein hat Ortsgruppen in ganz Dänemark mit vielen vorrangig älteren Mitgliedern (Hougaard-Werner 14.10.2013). Der Grenzverein hilft bei der Organisation von Ferienreisen für Kinder und der Vermittlung von Gastfamilien für sommerliche Schüler*innenaustausche. Außerdem vergibt er Fördergelder für den Besuch einer dänischen Efterskole (s. FN 485 a. S. 265) im neuten oder zehnten Schuljahr. Zusätzlich werden sogenannte Kulturbotschafter*innen finanziert. Das ist ein Projekt, in dem junge Leute aus Südschleswig Schüler*innen in Dänemark von Südschleswig und der dänischen Minderheit erzählen. Eine weitere PR-Maßnahme des SSF in Dänemark ist die Wan-

\footnotetext{
445 „stærkt bånd“

446 „der lever på afstand af den aktuelle samfundsudvikling i Danmark“
} 
derausstellung Sydslesvig, die von einer lokalen Abteilung des Granseforening zur nächsten gesendet und in Bibliotheken und bei Messen präsentiert wird. Weiterhin gibt es in Christiansborg, dem dänischen Regierungssitz, aktive Lobbyist*innen. Es gibt einen Newsletter und das Sydslesvigmagasin für Funktionsträger*innen und Institutionen in Dänemark sowie Auftritte auf dem jährlichen Volkstreffen Folkemodet auf Bornholm (Sydslesvigsk Forening 2013a: 37). Jährlich lädt der Südschleswigausschuss im dänischen Folketing ausgewählte südschleswigsche Funktionär*innen in das dänische Parlament in Kopenhagen auf eine zwei Tage dauernde Reise ein (INT10). Zusätzlich gibt es ein kurzes Kulturprogramm, darunter zum Beispiel ein Besuch des Königlichen Theaters. „Da sind wir immer ganz viele“, „vom SSF, [...] von der Kirche und vom SSW“, „immer ein Bus voll“ (INT10).

Aufseiten des SSF gibt es auch Initiativen zur Sicherung dänischer Steuergelder: Auf der Landesdelegiertenversammlung 2013 in Husum handelt ein Tagesordnungspunkt vom Thema

Südschleswig in Dänemark - Pflege und Weiterentwicklung der Verbindungslinien zwischen der dänischen Minderheit und Dänemark. Aktive Patenschaften, Ausflüge, Veranstaltungen und gemeinsame Aktivitäten über die Grenze ${ }^{447}$ (ebd.: 33$)$.

Mit „Verbindungslinien“ meint der Generalsekretär des SSF, Jens A. Christiansen, Wissen und Kenntnis der Dän*innen über die dänische Minderheit und Kontakt der dänischen Südschleswiger nach Dänemark (Christiansen in ebd.: 33). Die Verbindungslinien sicherten, dass die dänische Minderheit in das Hier und Jetzt in Dänemark eingebunden werde, und dass die Menschen in Dänemark eine solide Kenntnis über ,uns als dänische Minderheit ${ }^{\text {“448 }}$ bekämen (Christiansen in ebd.: 33). Dieter Paul Küssner nennt Dänemark ideologisch und finanziell die „Lifeline ${ }^{(449)}$ der Minderheit (Küssner 2012) und meint, dass „die beste Langzeitsicherung der dänischen Minderheit die Bindungen zum dänischen Volk “450 sei (ebd.). Der SSF betont 2011, dass die Funktion der Jahresfeste eben genau die sei, „den Willen zu unterstreichen, an der Lifeline zu Dänemark festzuhalten“4451 (Sydslesvigsk Forening 12.05.2011).

447 „Sydslesvig i Danmark - pleje og videreudvikling af forbindelseslinjerne mellem det danske mindetal og Danmark. Aktive fadderskaber, udflugter, arrangementer og fælles aktiviteter hen over grænsen“" „os som dansk mindretallet“

„livline“ (Seefahrtssprache, auch Rettungsleine genannt) „den bedste langtidssikring af det dansk mindretals bindinger til det danske folk“ „understreger viljen til at fastholde livlinjen til Danmark“ 
Auch in seiner Jahrestreffenrede am 08.06.2013 in Eckernförde bedient Küssner sich vieler Mythen und Nationalmotive, um propagandistisch eine Identifizierung mit der dänischen Minderheit zu konstruieren. Küssner spricht von einer ,jahrhundertelangen warmen, freundlichen und unverbrüchlichen Symbiose zwischen Dänemark und den dänischen Südschleswigern ““452 (Küssner 08.06.2013). Er geht in seiner Rede allerdings nicht darauf ein, was er mit Symbiose meint und warum diese bereits jahrhundertelang andauern soll, denn die meisten der heutigen Minderheitendän*innen sind frühestens seit dem Ende des Zweiten Weltkrieges Teil der dänischen Minderheit (s. Kap. 4.2). Des Weiteren gibt es die heutige Minderheitensituation und die aktuelle Grenzziehung erst seit 1920. Küssner konstruiert einen Mythos mit einem Rückgriff auf die Vergangenheit (s. Kap. 8.6). Er greift hier wieder, wie schon vorher und wie andere Funktionär*innen beispielsweise auf dem Jahrestreffen in Tönning 2013, auf die Worte der ehemaligen dänischen Ministerpräsidenten Niels Neergaard und Poul Nyrup Rasmussen zurück. ${ }^{453}$ Küssner nennt die Schlagworte „Solidarität ${ }^{\star 454}$ mit Dänemark und Investition zur „Bewahrung von dänischer Sprache und Kultur für die dänischen Südschleswiger “455 (ebd.). Dadurch konstruiert Küssner Anhaltspunkte für eine Identifizierung mit dem Dänischen anhand von Merkmalen wie vermeintlich dänischer Kultur und dänischer Sprache. Aus dem finanziellen $\mathrm{Zu}$ schuss vom Königreich leitet er eine Verpflichtung gegenüber Dänemark ab (ebd.). „Das Dänische“ sollte „unsere innerste Lebensgrundlage“ sein, „ein Zugehörigkeitsgefühl, ohne das wir nicht sein können “456, so seine idealisierte Sichtweise. Dies ist ein Zirkelschluss, denn es soll dänische Gelder für die dänische Minderheit aufgrund ihrer dänischen Gesinnung geben, und weil es dänische Gelder gibt, soll die dänische Gesinnung aufrecht erhalten werden.

Jon Hardon Hansen, Pastor der dänischen Kirche auf Sylt und Nachfolger von Dieter Paul Küssner als 1. Vorsitzender des SSF, unterstreicht ebenfalls immer wieder die bestehende Verbindung nach Dänemark und nennt diese „die in der dänischen Gesinnung verankerten sprachlichen und kulturellen Bänder ${ }^{\ltimes 457}$, „welche die Minderheit zu einem Teil von Dänemark machen“458 (Hansen 21.07.2016). Küssner unterstreicht die Wichtigkeit dänischer Steuergelder für die dänischen Südschleswiger*innen: „Ohne dänisches Engagement, Wohlwollen

\footnotetext{
452 ,århundrelang varm, venlig og ubrydelig symbiose mellem Danmark og de danske sydslesvige$\mathrm{re}^{\text {" }}$

453 Niels Neergaard: „Sie sollen nicht vergessen werden“; Poul Nyrup Rasmussen „So lange ihr an uns festhaltet, halten wir an euch fest." S. dazu S. 253.

454 ,solidaritet ${ }^{6}$

455 „bevarelse af dansk sprog og kultur for de danske sydslesvigere“

456 „det danske [...] bør være vores inderste livsgrundlag - et tilhørsforhold vi ikke kan være foruden"

457 „det sproglige og kulturelle bånd forankret i et dansk sindelag“

458 „De bånd, der gør mindretallet til en del af Danmark“
} 
und Unterstützung würden große Teile der organisatorischen Minderheit erheblich schrumpfen, auch wenn der Kern der Minderheit weiterhin nach „Wir sind dänisch und wir werden Dänisch bleiben“ leben würde. “459 (Küssner in Sydslesvigsk Forening 2013a: 12). Dass der Kern der Minderheit dänisch bleiben wird, sagt Küssner, um den konstruktiven Charakter und die Abhängigkeit von Dänemarks Geldern nicht völlig zu enthüllen. Karen Margrethe Pedersen betont ebenfalls, dass die Staatsgelder entscheidend für die dänische Minderheit seien. Denn ohne sie gäbe es keine Kindergärten und Schulen, in denen die Kinder Dänisch lernen würden (Pedersen in O. A. 10.12.2014). Egon Clausen sieht die Hauptgefahr für die dänische Minderheit in der Unkenntnis der Dän*innen im Königreich über Südschleswig und die Minderheit sowie die daraus folgende mögliche Infragestellung des dänischen Staatszuschusses an die Südschleswiger (E. Clausen in Mølvig 17.10.2012).

Um dem Streichen von dänischen Gelder vorzubeugen, haben der Sydslesvigsk Samråd (Gemeinsamer Südschleswigscher Rat der wichtigsten Minderheitenvereine) und der SSF dänische Gelder des Sydslesvigudvalget in die Hand genommen, um ein „Aufklärungs- und Kommunikationsprojekt ${ }^{\text {“460 }} \mathrm{zu}$ initiieren (Christiansen in Sydslesvigsk Forening 2013a: 34). Diese „Aufklärungsarbeit“ wird auch von lokalen SSF-Funktionär*innen in die Tat umgesetzt. Tina Zehntner beispielsweise empfängt dänische Besucher*innengruppen in Friedrichstadt und klärt diese über die dänische Minderheit auf. Sie führt dänische Staatsbürger*innen durch die Stadt und zeigt ihnen die Orte der Minderheit, wie beispielsweise das Paludanushaus, wo die Besucher*innen ihre mitgebrachten dänischen madpakke, Lunchpakete, verzehren, oder sie reserviert Plätze in Restaurants (INT10). Bei den Gruppen handelt es sich meistens um Gruppen der Granseforening, manchmal sind es aber auch andere Gruppen, wie zum Beispiel die Naturschützer Naturens Venner, dt. Freunde der Natur. Wichtig bei dieser persönlichen Arbeit ist für Zehntner,

dass die das eben auch mehr verstehen, warum die Steu.., DEREN Steu, ich mein, die Spenden, das sind ja Steuergelder, die wir kriegen, nä, warum .. wir Geld kriegen aus Dänemark........ ich glaub, um den einfach zu zeig, den DÄNEN zu sagen, warum geben wir das Geld ... euer Steuergeld an die da unten (INT10).

\footnotetext{
459 „Uden dansk medleven, velvilje og støtte vil store dele af det organisatoriske mindretal skrumpe betydeligt, selvom kerne i mindretallet fortsat vil leve efter: vi er danske og vi vil vedblive at være danske.“

460 „oplysnings- og kommunikationsprojekt"
} 
Zehntners Meinung zur ,Aufklärungskampagne‘ des damaligen SSF-Landesvorsitzenden, die die Forderung beinhaltet, dass die Minderheit Dänemark zeigen müsse, dass sie wirklich dänisch sei, ist folgende: „Ja... aber, das ist natürlich schwer, weil wir sind ja nicht so dänisch, wir sind ja deutsch ... also wir sind ja... Sydslesviger halt" (INT10). Das Beidessein, also das Vorhandensein einer doppelten Identifizierung in Südschleswig wird hier erneut deutlich. Auch hier sieht man einen Widerspruch zwischen Anspruch und Wirklichkeit, zwischen den PR-Vorgaben der Landesebene und dem reflektierten Pragmatismus einzelner Akteur*innen.

Zusätzlich zur „Aufklärungskampagne“ wird auf der SSF-Landesdelegiertenversammlung dazu aufgerufen, mit Vorschlägen, Ideen und Diskussionsbeiträgen aufzuwarten, wie man den Geldfluss langfristig aufrechterhalten kann. Die Angst vor dem Verlust dieser Steuergelder ist bei der erheblichen Abhängigkeit von ihnen groß. Küssner betont in Bezug auf die Minderheit: „In unserer Welt ist es die nahe Gemeinschaft in den Distrikten, wo soziale Nähe und kulturelle Erlebnisse uns an die Minderheit binden" ${ }^{\text {“461 }}$ (Küssner in ebd.: 12). Durch persönlichen Kontakt nach Dänemark werde diese Bindung auch über die Staatsgrenze hinweg nach Norden hin gepflegt (Küssner in ebd.: 12).

Nicht nur für die Institutionen der Minderheit ist der Kontakt nach Dänemark wichtig, sondern auch für die Akteur*innen der dänischen Minderheit. Darunter fallen auch persönliche Verbindungen. So berichtet beispielsweise Tina Zehntner von regelmäßigen Sommerferienbesuchen bei ihrer dänischen Patenbzw. Pflegefamilie. Ihr Patenvater war der Patenbruder ihrer Mutter. Das heißt, auch Zehntners Mutter war als Sommerferienkind in derselben Familie wie Zehntner. Zehntner und ihre Patenschwester, die in den USA wohnt, überlegen jetzt schon, wie sie den Austausch ihrer eigenen Töchter organisieren könnten. Ein Vorschlag ihrer Pflegemutter war, dass ihre Enkelin und ihre Patenenkelin, also Zehntners Tochter, sich auf dem Hof der Großeltern/Patengroßeltern in Dänemark treffen könnten (INT10).

Nach dem Besuch des dänischen Schulsystems in Friedrichstadt und Flensburg war der nächste Kontakt mit Dänemark Zehntners Studium in Sønderborg/Sonderburg und ihre anschließende Tätigkeit als Krankenschwester in einem Krankenhaus in Apenrade/Aabenraa (INT10, s. a. S. 115). Einige SSF-Mitglieder und ehemalige Schulfreund*innen Zehntners wohnen mittlerweile in Dänemark. Zu diesen hält Zehntner weiterhin Kontakt.

Schauen wir nun auf die Perspektive Dänemarks und dessen Verhältnis zur dänischen Minderheit: Von staatlicher Seite gibt es folgende, häufig wiederholte Äußerungen in Bezug auf die Minderheit in Südschleswig: „Solange ihr an uns

461 „I vores verden er det distrikternes nære fælleskab, hvor socialt nærvær og kulturelle oplevelser fastholder os i mindretallet.“ 
festhaltet, halten wir an uns gegenseitig fest “462, so der ehemalige dänische Staatsminister Poul Nyrup Rasmussen im Jahre 2014 in einem Leserbrief in der Flensborg Avis (Rasmussen 07.10.2014) in Anlehnung an Niels Neergaard 1920 vom 11.07.1920 auf den Düppeler Schanzen. Darin enthalten sei die Aussage, dass es um „Recht, Pflicht und Respekt für Identität “463 gehe. Darin betont Rasmussen „unseren Zusammenhalt ${ }^{\star 464}$, also zwischen Dänemark und der dänischen Minderheit, und zweimal konstatiert er, dass „wir“, also Dänemark und die Südschleswiger, ,schließlich und endlich aus dem gleichen Holz geschnitzt“ und „,von der gleichen Sorte ${ }^{\ltimes 465}$ seien (ebd.). Rasmussens Abwandlung seines eigenen Statements aus dem Jahre 1999 („Solange ihr an uns festhaltet, halten wir an euch fest. “466) betont mit der Änderung ,an uns gegenseitig“ statt ,an euch“ noch mehr den Aspekt, dass Dänemark an Südschleswig Erwartungen stellt, die erfüllt werden müssen. Das Verhältnis soll reziprok sein und nicht einseitig.

Auch Königin Margrethe, die in ihrer Neujahrsansprache jährlich Grüße nach Südschleswig sendet, hat in ihrer Rede von 2015 auf Staatsminister Niels Neergaards Aussage „Sie sollen nicht vergessen werden“467 (Nygaard 11.05.2014) Bezug genommen: „Ihr seid nicht vergessen worden“468 (FLA/Ritzau 02.01.2015). Das dänische Königshaus spielt eine symbolische Rolle für viele Akteur*innen der Minderheit. Es hängen Bilder der Königin und des Prinzgemahls in ihren Versammlungshäuser, beispielsweise im Paludanushaus in Friedrichstadt (TNB) und in der Klitskole in St. Peter-Ording (Werner 16.05.2016). Einige Akteur*innen schauen sich königliche Hochzeiten, Taufen und die königliche Jahresansprache im Fernsehen an (ebd.). Königliche Familien stellen langjährige Personifizierungen von Nationen dar und sind damit Teil des konstruierten nationalen, kulturellen und historischen Mythos von monarchischen Staaten. Sie sind Werbung für die nationale Geschichte (Coakley 2004: 537; s. Kap. 8.6). Dies trifft auch auf die Rolle des Königshauses für Dänemark und die dänische Minderheit zu.

Abgesehen von der Erwähnung der Minderheit in den Reden des Staatsoberhauptes und der Politiker*innen wurde die dänische Minderheit im Dezember 2014 in den Medien präsenter. Der dänische Fernsehsender TV SYD strahlte eine dokumentarische Serie über die dänische Minderheit aus. Auf die Reihe mit dem

\footnotetext{
„Så længe I holder fast i os, holder vi fast i hinanden.“

„ret, pligt og respekt for identitet"

„Vores sammenhold“

"Vi er jo til syvende og sidst gjort af samme stof“; ,vi er af samme slags“

„Så længe I holder fast i os, holder vi fast i jer.“

„De skal ikke blive glemt.“

„I er ikke blevet glemt.“
} 
Titel „In Deutschland bin ich zu Hause“4469 folgte die Übertragung einer Debatte über die dänische Minderheit mit Vertreter*innen aus der Minderheit und aus dem Südschleswigausschuss des dänischen Parlamentes. ${ }^{40}$ Die Ausstrahlung beginnt mit der Feststellung, dass die Minderheit im Jahr 2013 rund 584 Millionen dänische Kronen ${ }^{471}$ vom dänischen Staat bekommen habe und der anschließenden Frage, ob das fast 100 Jahre nach der Grenzziehung notwendig und sinnvoll sei. Dabei werden die im Alltags- und nichtwissenschaftlichen Sprachgebrauch vermeintlich objektiven Kriterien der Zugehörigkeit zur Minderheit diskutiert und kritisiert. Es werden dabei zuerst Sprachkenntnisse und -anwendungshäufigkeit genannt und danach wird das freie Bekenntnis betont. Die Sendung wird wegen fehlender journalistischer Neutralität und dem Vorhandensein von Vorurteilen und Provokationen kritisiert. Das Menschenbild hinter den Fragen wird hinterfragt. Besonders die Frage nach dem Geldwert der Minderheit wird von SSWPolitikerin Anke Spoorendonk kritisiert (Spoorendonk 11.12.2014). Allerdings muss beachtet werden, dass es hier um dänische Steuergelder geht, deren Verwendung nachgewiesen und den Steuerzahler*innen gegenüber gerechtfertigt werden soll.

Dänemark ist nicht der einzige kin-state in Europa, der seine Minderheit im Ausland mit Geldern unterstützt. Deutschland stellt ebenfalls Gelder für seine Minderheiten zur Verfügung. Dies tut ebenfalls der ungarische Staat für die ungarische Volksgruppe in Siebenbürgen (Feischmidt 2003: 172).

Das Ergebnis von Margit Feischmidt in ihrer Dissertation über Rumänen und Ungarn in Siebenbürgen trifft auch auf die dänische Minderheit in Süschleswig zu: „Die Nationalisierung der ethnischen Minderheiten [...] wird vor allem von der Politik der Minderheitenelite und mit der Unterstützung der nationalen „Mutterländer" produziert.“ (ebd.: 100). Die kin-states spielen also bei der Konstruktion

469 „I Tyskland har jeg hjemme.

470 Debatte am 11.12.2014 mit Kim Andersen, Venstre, Sydslesvigudvalget; Martin Henriksen, Dansk Folkeparti, Sydslesvigudvalget; Troels Ravn, Socialdemokraterne, Sydslesvigudvalget; Jon Hardon Hansen, Vorsitzender Sydslesvigsk Forening; Udo Jessen, Vorsitzender Dansk Skoleforening for Sydslesvig; Kirstin Asmussen, Vorsitzende Sydslesvigs danske Ungdomsforeninger (Andersen 2014).

471 Rund 79 Millionen $€$, s. a. Ministeriet for Børn, Undervisning og Ligestilling (2016). Leider gibt es keine Übersicht, wie sich die Gesamtsumme genau zusammensetzt und an welche Organisationen die Gelder fließen. Daher ergibt die Addition der im Jahre 2013 gezahlten Gelder an den Schulverein, SdU, DCBIB, FLA, SSW und SSW nicht die Gesamtsumme von 79 Millionen $€$. Kleinere Summen werden an weitere dänische Vereine oder an Projekte gezahlt, die in den Jahresbudgets der großen Vereine nicht enthalten sind oder die zwar vom dänischen Staat, aber nicht vom Südschleswigausschuss kommen. Dazu gehören beispielsweise der Zuschuss des dänischen Gesundsheitsministerium zum dänischen Gesundheitsdienst in Südschleswig (ca. 3,6 Millionen $€$ ) und der Zuschuss des Kirchenministeriums an die Dänischen Kirchen in Südschlesig (ca. 2 Millionen €) (Kulturministeriet et al. 2017; vgl. a. Ebrecht 2004: 34). 
von nationalen Minderheiten eine große Rolle, ebenso wie die oben bereits genannten ethnopolitischen Unternehmer*innen. Feischmidt nennt sie „die „mittleren und größeren Unternehmer" der Nationalisierung" (ebd.: 100). Die Elemente der Nationalisierung werden, so Feischmidt, ,in verschiedenen historischen Momenten von bestimmen Eliten erfunden und im Dienste der Durchsetzung ihrer jeweiligen Interessen instrumentalisiert" (ebd.: 101). Die Interessen der Eliten der dänischen Minderheit sind Gelder aus dem Königreich sowie die damit verbundene Erhaltung der eigenen Arbeitsplätze.

Die Angst vor dem Ende des Geldflusses aus Dänemark für die dänische Minderheit und umgekehrt für die deutsche Minderheit in Dänemark aus Deutschland aufgrund von als unecht aufgefasster Gesinnung zeigt, wie problematisch dieses Finanzierungssystem sein kann. Es wirkt so, als dienten die dänischen Steuergelder als Argument gegen alles, was vermeintlich nicht dänisch genug ist, sodass die Minderheit und ihre Angehörigen nicht so sein können, wie sie wollen, sondern ihr Dänischsein aufgrund der Finanzierung aus Dänemark funktionärs- und dänemarkkonform performen müssen. Statt die ideellen Grenzen aufrechtzuerhalten, könnte die dänische Minderheit Gelder aus Deutschland und Schleswig-Holstein bekommen und die deutsche Minderheit Gelder aus Dänemark. Oder man könnte gemeinsam mit beiden Minderheiten EU-Gelder, beispielsweise aus dem InterregProjekt, beantragen. René Rasmussen schlägt vor, die Minderheitsschulen zu schließen und stattdessen Euroregionsschulen zu gründen, um europäischer zu werden (Rasmussen in Röh 2012: 175). Möglicherweise sind die EU-Gelder den Minderheitenfunktionär*innen zu projektbezogen und zeitlich begrenzt, also langfristig zu unsicher. Eine ideelle Bindung nach Dänemark inklusive PR-Maßnahmen erscheint sicherer, auch wenn es innerhalb der Minderheit zahlreiche Widersprüche und Ambivalenzen gibt.

Ein konkretes Beispiel für den Konflikt zwischen denjenigen, die hauptsächlich an der Sache interessiert sind und denjenigen, denen es um das Dänischsein und vor allem die Gelder aus Dänemark geht, ist ein Fall im SdU (s. Kap. 3.2.4) aus dem Jahre 2006: Die Flensborg Avis berichtete damals, dass Sportvereine der dänischen Minderheit in Südschleswig durch eine SdU-Vorstandsentscheidung nicht an dänischen Meisterschaften teilnehmen dürften, wenn die Mannschaftsmitglieder nicht ausreichend Dänisch können, obwohl sie sich für die Meisterschaft in sportlicher Hinsicht qualifiziert hatten (Simonsen 14.07.2006). Aufhänger des Zeitungsartikels war der Fall der G-Jugend-Fußballgruppe ${ }^{472}$ der Tonning Idretsforening, kurz Tonning IF. Die Mannschaft hatte das südschleswigweite Fußballturnier des SdU gewonnen und sich damit für die dänischen Meisterschaften

472 Unter 7 Jahre alte Kinder, dän. ,puslingeholdet“. 
qualifiziert. Der SdU schickte stattdessen aber eine Flensburger Mannschaft nach Dänemark, da die meisten der Tönninger Spieler*innen kein Dänisch konnten, so der SdU-Vorstand. Der damalige 2. Vorsitzende der SdU, Flemming Birkemose, konstatierte:

Wenn die SdU Teilnehmer auf Turniere in Dänemark schickt, sind diese offizielle Repräsentanten der Minderheit. Die Minderheit bekommt vom dänischen Staat eine große finanzielle Unterstützung für ihre Arbeit. Deshalb ist es ein schlechtes Signal, wenn wir ein Team schicken, dessen Mehrheit gar kein Dänisch kann ${ }^{473}$ (Birkemose in ebd.).

Dieses Vorgehen wirkt aus sportlicher Sicht unfair und zeugt von der Macht der obersten Funktionär*innen, aber auch von deren Angst, in Dänemark als nicht dänisch genug wahrgenommen zu werden und damit auch von der Angst vor dem Verlust dänischer Gelder. Das erweckt den Eindruck, dass den Flensburger Funktionär*innen der (überwiegend deutschsprachige) Auftritt von Tönninger Minikickern zu peinlich ist, um sie zu einem dänischen Fußballturnier zu senden. Hier scheint Politik eine größere Rolle zu spielen als Sport. Dieses Vorgehen erweckt einen undemokratischen und ungerechten Eindruck. Anstatt die Wirklichkeit so zu nehmen, wie sie ist, wird versucht, das in den Augen der SdU-Funktionär*innen nicht ausreichende Dänischsein gegenüber dem Geldgeber Dänemark zu vertuschen. Dabei hat die SdU-Führung keine Angst vor dem Ansehensverslust in Dänemark, der durch eine Bewertung dieser Praxis als undänisch oder scheinheilig entstehen könnte.

Alternativ hätte man das Team beispielsweise mit dänischsprachigen Betreuern oder mit einem Sprachcrashkurs unterstützen können. Oder man hätte in Dänemark die dänische Minderheit so repräsentieren können, wie sie ist, nämlich nicht unbedingt dänischsprachig. Der Journalist Anker Simonsen berichtet weiterhin, dass die meisten Sportvereine außerhalb Flensburgs nicht ausreichend Dänisch sprechende Spieler*innen hätten. Die SdU plädiere dafür, dass die nichtdänischsprachigen Spielenden durch dänischsprachige ersetzt würden oder man die Mannschaften auflösen müsse. Die Vereine würden vor dem jährlichen schleswigweiten Turnier darauf aufmerksam gemacht, dass eine Mannschaft, wenn sie zur Dänemarkmeisterschaft wolle, aus mindestens einem*r dänischsprachigen*r Betreuer *in und mindestens $50 \%$ dänischsprachigen Spielenden bestehen müsse (Simonsen 16.07.2006), ohne dass jedoch aus dieser Forderung klar wird, wie das nachgewiesen werden soll bzw. wie das gemessen werden würde und welche Qualitätskriterien dabei angelegt würden. Jeder SdU-Verein müsse selbst über die

473 „Når SdU sender deltagere til stævner i Danmark, er de officielle repræsentanter for mindretallet. Mindretallet får stor økonomisk støtte til sit arbejde fra den danske stat. Det er derfor et dårligt signal, hvis vi sender hold afsted, hvis flertal slet ikke kan dansk.“ 
eigene Sprachpolitik entscheiden, allerdings bekämen die Vereine nur für Jugendliche, die auch dänische Schulen besuchten, einen finanziellen Zuschuss vom SdU (Simonsen 14.07.2006). Der Schulbesuch wird hier also als ein Ersatzkriterium für das Messen der Dänischkenntnisse benutzt. Jugendliche, die zwar Dänisch beherrschen, aber eine deutsche öffentliche oder private Schule besuchen, werden im Umkehrschluss nicht gefördert.

Hier tritt erneut die sich durch die Minderheit ziehende Ambivalenz zutage, die sich darin zeigt, dass einerseits ausreichende Dänischkenntnisse und damit indirekt auch ein Dänischsein gefordert werden und andererseits ein Ausschließen der nichtdänischsprechenden Mitglieder das Ende der meisten Vereine bedeuten würde, da es dann nicht mehr genügend Aktive gäbe. Gerade bei Mannschaftssportarten wie Fußball sei es schwierig, rein dänische Gruppen zu bilden. Man „muss Mitglieder der Mehrheitsbevölkerung aufnehmen, wenn man seinen Mitgliedern Mannschaftssportarten anbieten möchte. Man kann ganz einfach nicht auf genügend Dänischsprechende zurückgreifen “"474 (Simonsen 16.07.2006). Hierbei wird wieder die Auffassung von Minderheitsfunktionär*innen deutlich, dass sich Sprachbeherrschung und nationale Gesinnung decken müssen. Sport dient als gesellschaftliches Verbindungselement und könnte gerade durch gemischte Mannschaften Verbindungen schaffen zwischen Mehrheit und Minderheit, was aber von SdU-Seite nicht gewollt ist. Anstatt nur dänische Gelder aus dem kin-state zu beantragen, könnten sich die SdU-Vereine auch um kommunale oder Landeszuschüsse bemühen. Im nächsten Kapitel geht es nun detaillierter um die bei der Minderheitskonstruktion verwendeten Symbole, Mythen und Praxen.

474 „,bliver nødt til at optage medlemmer fra flertalsbefolkningen, hvis den vil tilbyde holdidræt til sine medlemmer. Der er ganske enkelt ikke dansk-talende nok at trække pä“ 



\section{Symbole, Mythen, Praxen der Zugehörigkeit}

„Ein Symbol ist all das in einer Kultur, was etwas bedeutet."

Alois Habn (Hahn 1995: 84)

Ausgestattet mit selbst genähten Engelskleidern und Kerzenhaltern wurden Weihnachtslieder gesungen und anschließend ein Theaterstück aufgeführt: „Das war ein großes Erlebnis“ und „da hat das Publikum auch geweint“", weil es so schön und „so rührend“ war, berichtet Brigitte Thomsen rund 70 Jahre nach dem Ereignis immer noch beeindruckt vom spezifisch skandinavischen Luciafest an einem 13. Dezember während ihrer Schulzeit, bei dem sie „Luciapige“475 sein durfte (INT02).

„Ohne Symbole ist [...] keine Religion denkbar“ (Hase 2001: 84) und analog gilt dies auch für Minderheiten und nationale Gesinnungsgruppen. In diesem Kapitel werden daher die wichtigsten Symbole der dänischen Minderheitsakteur*innen beschrieben. Symbolische Wirkung entfalten können Gegenstände, Personen und „invented traditions“ also beispielsweise Feste und Rituale, die dann „social cohesion of the membership of groups, real or artificial communities" bewirken (Hobsbawm 1994: 9). Symbole sind also zur Markierung und Abgrenzung nach

475 Luciamädchen beim Luciafest genannten Lichterfest. 
außen und für die innere Kohäsion einer konstruierten Gruppe wichtig. Feste dienen als „gemeinsame Symbole“ (Christiansen 2008: 97) für die Bildung einer „erfundenen“ (vgl. Hobsbawm 1994: 1) Gruppe wie z. B. dieser Minderheit. „The use of presumedly typical ethnic symbols in nationalism is intended $[\ldots]$ to create a feeling of nationhood" (Eriksen 2002: 102), betont auch Thomas Hylland Eriksen in Bezug auf Nation-building-Prozesse.

Bei den Dänischgesinnten in Südschleswig werden dänischen Speisen, dem Singen, Flaggen und Fahnen sowie einigen Persönlichkeiten große symbolische Bedeutung zugeschrieben. Falls aus Erfahrung von anderen Minderheiten, wie beispielsweise den Sorben oder Friesen, besondere Kleidung oder Trachten bei der dänischen Minderheit erwartet würden, so muss an dieser Stelle betont werden, dass dies im Falle der dänischen Minderheit keine Rolle spielt. Trachten oder besondere Kleidung waren nie präsent, abgesehen von den Fantasieuniformen der reichsdänischen Spielmannszüge oder Turnvereine und der traditionellen dänischen Abiturient*innenmütze, der studenterbue.

\subsection{Dänischsein feiern und darstellen: (Jahres-)Feste}

Seit 1921 gibt es jährliche Feste der dänischen Minderheit, die sogenannten Arsmoderne, Jahrestreffen. Ein Jahr nach der Volksabstimmung über die Grenzziehung veranstaltete die Vorgängerorganisation des Sydslesvigsk Forening (SSF), Den Slesvigske Forening (SF), das erste Fest, um das Dänische in Südschleswig zu markieren und die dänischgesinnte Bevölkerungsgruppe zu mobilisieren. Es kamen damals 3.000 bis 4.000 Teilnehmende (Nissen 05.06.2013). 1938 fiel das Fest aufgrund einer Maul- und Klauenseuche aus. Auch in den Jahren 1943 bis $1945^{476}$ fanden aufgrund des Zweiten Weltkrieges keine Jahrestreffen statt (Nissen 07.06.2013; Nissen 08.06.2013; Sydslesvigsk Forening 2009a). 1946 wurde das erste Nachkriegsfest veranstaltet, diesmal nicht nur in und um Flensburg, sondern auch in den Städten Schleswig und Husum. In den ersten Nachkriegsjahren war das Hauptthema der Treffen der Wunsch nach der Eingliederung Südschleswigs oder Teilen Südschleswigs in das dänische Königreich und der vergebliche Wunsch nach einer erneuten Volksabstimmung. Ab 1948 gab es die Jahrestreffen an weiteren Orten wie Rendsburg, Tönning, Keitum auf Sylt und Eckernförde (Nissen 08.06.2013).

Heutzutage finden die Arsmoderne regelmäßig über drei Tage verteilt an einem Wochenende im Mai oder Juni statt. Es werden Besucher*innen aus Deutschland und Dänemark empfangen und Kaffeetafeln bereitet. An den Festen nehmen

4761945 fand nur ein jahresfestähnliches „Friedenstreffen“ statt (Nissen 08.06.2013). 
rund 18.000 Menschen in rund 40 Orten in sieben SSF-Bezirken ${ }^{477}$ teil (Sydslesvigsk Forening g). Am letzten Tag gibt es jeweils drei große, zentrale Freiluftarrangements, eines in Flensburg, eines an der Westküste im jährlichen Wechsel zwischen Husum und Tönning, und eines an der Ostküste in der Stadt Schleswig. Ergänzend dazu gibt es rund 20 weitere Veranstaltungen am Rande, die nicht direkt zum offiziellen SSF-Programm gehören, wie beispielsweise zusätzliche Konzerte der dänischen Spielmannszüge, die ohnehin für die musikalische Begleitung der Jahresfeste angereist sind, oder Vorträge und Diskussionsrunden.

Bei den Einzelveranstaltungen der Jahresfeste gibt es Kaffee und Kuchen oder andere Essensangebote, musikalische Begleitung und Vorführungen durch Kinder sowie Reden von Funktionär*innen, Expert*innen, Repräsentant*innen und Politiker*innen aus Deutschland und Dänemark. In einigen Orten gibt es Umzüge durch die Straßen mit Fahnen, Flaggen und Musik. Die Feiern finden an Versammlungsorten der Minderheit, in Vereinsheimen und Gemeindehäusern, auf Sportplätzen und Turnhallen, in Schulen und Kindergärten statt.

2011 wurde unter dem Motto „,Wie prägen wir Südschleswig “6478 gefeiert. 2012 lautete das Motto „Südschleswig - eine spannende Melodie“479 und 2013 „Südschleswig ruft ${ }^{\text {‘480 }}$. Es kamen im Jahre 2011 beispielsweise der Präsident des dänischen Parlaments, Thor Pedersen, und der schleswig-holsteinische Landtagspräsident Torsten Gerds als Redner, neben zahlreichen deutschen und dänischen Ministern, Regionsvorsitzenden, Landräten, Vereinsvorsitzenden, Stadtund Kreispräsidenten, Kreis- und Landtagsmitgliedern, Folketingsmitgliedern und Angehörigen des Südschleswigausschusses im dänischen Parlament (Folketinget), dem Vorsitzenden des färöischen Parlaments (Lagtinget) und dem dänischen Generalkonsul auch Historiker*innen, Bürgermeister*innen, Schulleiter*innen und Pastoren*innen und andere Funktionär*innen. Begleitet werden die Arsmoderne in der Regel durch T-Shirt-Verkäufe im Vorfeld der Feste. Jedes Jahr wird das jeweilige Logo der Treffen auf die T-Shirts gedruckt. Diese werden für knapp $10 €$ verkauft. Allerdings werden die Shirts an den drei von mir zur teilnehmenden Beobachtung besuchten Arsmode-Orten an der Westküste kaum von den Besuchenden getragen.

477 Flensburg Stadt, Flensburg Amt, Südtondern Amt, Husum Amt, Eiderstedt Amt, RendsburgEckernförde Amt und Gottorf Amt.

478 „Hvordan præger vi Sydslesvig““

479 „Sydslesvig - en spændende melodi“

480 „Sydslesvig kalder“. Dieses Motto soll, so die Vorsitzende des SFF-Arsmodendvalg (Jahrestreffenausschuss), Gitte Hougaard-Werner, die Botschaft aussenden, dass alle Südschleswiger und alle Dänen in Dänemark aufgerufen sind, am Jahrestreffen teilzunehmen, und in Richtung Dänemark soll verdeutlicht werden, dass die Minderheit südlich der Grenze noch existiert (Bruhn 07.12.2012). 
Nachfolgend werden die Abläufe und Aktivitäten bei drei Festen szenisch beschrieben. Die teilnehmenden Beobachtungen fanden in den Jahren 2011 (27. bis 29. Mai), 2012 (08. bis 10. Juni) und 2013 (07. bis 09. Juni) statt. ${ }^{481}$

\subsubsection{Freitag, 27. Mai 2011, Drage}

In Draget ${ }^{42}$, einem Dorf mit gut 600 Einwohner*innen, an der Eider gelegen, sechs Kilometer von Friedrichstadt entfernt, wird man am Ortsscbild mit einer Tafel auf Plattdeutsch begrïßt. Ich fahre in die Dorfmitte und parke mein Auto am Straßenrand. Es ist 18 Uhr. Los gehts beim dänischen Kindergarten in der Straße Achterum unterbalb des Flaggenmastes. Am Eingang zum Gelände werde ich von einem Mädchen auf Deutsch gefragt, ob ich auch dabin wolle. Sie zeigt auf die Veranstaltung binter sich. Ich sage, ,ja" und bekomme einen Zettel in die Hand gedrückt mit dem Programm und den Liedtexten, die an diesem Tag gesungen werden sollen. Ich betrete das Gelände und werde vom Folketingsmitglied Flemming Damgaard Larsen und Karl Heinz Blumenau, stellvertretender Leiter der dänischen Schule in Husum, am Eingang per Handschlag begrïßt, obwobl wir uns nicht kennen. Die Menschen machen einen ber:lichen und offenen Eindruck. Die SSF-Vorsitzende des Ortsvereins Drage-Schwabstedt ist auch da. Sie trägt eine Sportjacke, auf dem Rücken der Aufdruck des Ringreitervereins Drage.

Alle Interessierten, darunter auch viele Friedrichstädter Minderbeitsdän*innen, versammeln sich allmäblich auf der Rasenfläche vor dem Kindergarten. Kurz nach sechs Ubr stellt sich der 30-köpfige Spielmannszug FDF Gladsaxe Brass Band aus Dänemark in Marschposition auf und fübrt - binter einem Polizisten zu Fuß - den Straßenumzug durch das Dorf an. Dabinter folgen rund zehn Fahnenträger*innen und viele Menschen mit Flaggen. Insgesamt sind rund 100 Leute beteiligt. Am Rande des Umzugs stehen vereinzelt Drager Bürger*innen und schauen den dänischen Akteur*innen zu und winken ibnen.

Als wir alle nach einer halben Stunde wieder auf dem Festplatz, ankommen, geht es dort mit der offiziellen Begrïßung durch die SSF-Ortsvorsitzende Nadine Baumann-Petersen weiter. Danach sollen eigentlich die Kindergartenkinder auftreten, aber sie sind nirgends zu finden, was Moderatorin Nadine sichtbar stört. Stattdessen zieht Karl-Hein₹. Blumenau seine Rede über die dänische Sprache und ibre Bedeutung für Südschleswig vor, bevor die Kinder schließlich doch noch auftauchen und auftreten. Ibr Gesang ist geprägt von Unsicherheit und Dissonanzen, aber die dazugehörigen Eltern und Betrener*innen finden es süß und geben sich sebr wohlwollend. Die Kinder werden anscbließend mit Eis und einem Videofilm belohnt. Wäbrend die Eltern den anderen Rednern zubören (sollen) und Kaffee trinken, werden die Kinder durch einen Gaukler unterbalten und beschäftigt. Es folgt die Rede von Flemming Damgaard Larsen, Folketingsmitglied. Er spricht über die dänische Zollpolitik, was nur auf geringes Interesse seitens

481 In allen drei Jahren ist das Grundprinzip des Ablaufs dasselbe, sodass ich hier drei Beispiele darstelle und nicht alle neun (3x jeweils 3 Tage) besuchten Veranstaltungen im Einzelnen beschreibe. Da sich meine Feldforschung bei den Vereinen auf die Westküste und insbesondere die Region um Friedrichstadt konzentrierte, werden hier die besuchten Veranstaltungen in dieser Region beschrieben.

48225878 Drage, Kreis Nordfriesland 
der Zubörenden stößt. Während der beiden Reden kaufen sich die Besucher*innen Würstchen mit Brötchen, Kotelett mit Kartoffelsalat und frisch gebackene Waffeln sowie Eis und Getränke an den drei Verkaufsbuden. Die Konzentration auf die Reden und die Wertschätzung der Redner ist währenddessen nicht besonders hoch. Es gibt zwei Zelte mit Bierbänken und-tischen, wo die gekauften Dinge verzehrt werden können. Die Zelte werden gut genutzt, da es regnerisch und kalt ist. Einige Akteur*innen stehen aber auch außerhalb der Zelte in Regenkleidung.

Nach den Reden singt der Eiderstedtchor dänische Lieder und die Brass Band spielt nach einer kulinarischen Stärkung der Musiker*innen wieder auf. Es gibt ein abschließendes gemeinsames Singen, und die Kinder werden mit Spielen und einem Lagerfeuer mit Stockbrot von einigen Lebrerinnen und Betreuern unterbalten und beschäftigt.

Erik Nissen und seine Frau aus einem Nachbardorf Drages sind auch dabei, allerdings nicht beim Umzug durch das Dorf. Erik kommt mit Absicht etwas später, weil er es hasst, an solchen Umzügen teilzunehmen, wie er sagt. Als Kind wurde er dazu gezwungen, wurde immer nach Husum ,gekarrt", um da mitzulaufen, berichtet er mir im Interview (INT01). Heutzutage kommt er immer erst zur Feier, sobald der Umzug durch das Dorf schon vorbei ist, damit ibn niemand zum Mitlaufen drängen kann.

Der dänische Bücherbus der Zentralbibliothek ist auch vor Ort. Als ich eintrete, wird mir gleich ein Quizzettel in die Hand gedrückt. Man kann ein Buch gewinnen. Der Bibliotheksmitarbeiter meint, dass er die Zettel sowieso nicht kontrollieren würde, also ob alles richtig angekreuzt sei. Ich fülle den Zettel aus, lege ibn in eine Box und bekomme von ibm eine schwarze Bibliothekstasche geschenk.t.

Die Stimmung der am Fest involvierten Leute ist ausgelassen. Die Menschen auf dem Fest sprechen untereinander Deutsch, Dänisch und Plattdeutsch. Auffällig ist, dass wenn sich die Leute mit Dän*innen aus dem Königreich oder Funktionär*innen, wie z. B. Lehrer*innen, unterhalten, sie ins Dänische wechseln, untereinander aber überwiegend Deutsch und Plattdeutsch sprechen. Dies, so der anwesende Flensborg-Avis-Journalist Emil Umberg ${ }^{483}$, sei typisch so weit südlich in Schleswig. In der Gegend rund um Flensburg und Harrislee sei das anders, dänischsprachiger.

In den beiden folgenden Jahren verläuft das Fest sehr ähnlich. Nur die Vorführungen der Kinder sind ein wenig anders. Beispielsweise gibt es 2013 kein Vorsingen der Kindergartenkinder, sondern eine Zirkusvorführung mit artistischen Einlagen, die die Kinder vorher eingeübt haben. Stolz präsentieren sie ihre Kunststücke. Sie stellen sich zum Beispiel auf Stuhllehnen und kippen samt Stuhl nach vorne.

483 Name geändert. 
Im Gespräch mit dem Journalisten Umberg stellt dieser leicht verschwörerisch heraus, dass das mit den Kindern ein alter Trick sei, um möglichst viele Teilnehmende zu den Veranstaltungen der Minderheit zu locken. Natürlich werde das offiziell nie so zugegeben, sagt er, aber diese Strategie funktioniere. Sobald ein Kind auftritt, unabhängig von der Qualität des Dargebotenen oder der Voluntarität, werden die Eltern, die Geschwister, die Großeltern oder sogar die Onkel und Tanten der Kinder dabei sein. Zum einen müssen die Kinder zum Fest hin- und anschließend wieder nach Hause gebracht werden. Zum anderen wollen die stolzen Angehörigen den Auftritt sehen und ggf. fotografisch oder filmisch dokumentieren und den Kindern applaudieren. Kritikerin Karin Röh konstatiert: „[B]öse Zungen behaupten, dass , sie nur kommen weil ihre Kinder auftreten sollen“،6484 (Röh 2012: 120-121).

Viele Teilnehmende loben die lockere und offene Atmosphäre bei den Drager Festen und kritisieren gleichzeitig die Jahresfestveranstaltung in Friedrichstadt, da diese formeller und feierlicher arrangiert wird. Zahlreiche Mitglieder aus dem Ortsverein Friedrichstadt fahren nach Drage zum Jahresfest und andersherum. Ein Teil der Friedrichstädter*innen besucht ausschließlich das Drager Fest und nicht die Feier des eigenen Distrikts. Auch die Friedrichstädter Funktionärin Tina Zehntner und ihre Familie nimmt jedes Jahr am Jahresfest in Drage teil (INT10). Der Grund dafür ist, dass es dort „,immer schon cooler gewesen“ ist, und „weil das eben so schön“, „,total geil gemütlich“ ist (INT10). In Bezug auf ihr eigenes Fest sagt sie, dass sie „kein Drage kopieren“ wolle, sondern dass sie einfach ein etwas anderes Fest feierten, das „,immer 'n büschen formeller“ ist als das Fest des Nachbarortsvereins (INT10). Sie kritisiert allerdings auch, dass den eingeladenen Rednern in Drage keiner zuhöre, was sie „unhöflich“ findet (INT10). Diese beiden Aussagen decken sich mit meinen Beobachtungen.

\subsubsection{Samstag, 28. Mai 2011, Friedrichstadt}

Am nächsten Tag feiert Friedrichstadt das Jahrestreffen. Am Nachmittag geht es bereits um 14:30 Ubr in der dänischen Hans-Helgesen-Schule in der Schleswiger Straße los. Ich besuche das Fest gemeinsam mit meinem Interviewpartner Erik Nissen und dessen Frau. Als wir den Schulhof betreten, steht am Eingang eine Frau, die kleine Aufkleber mit der dänischen Flagge und der Jahreszabl 2011 für 50 Cent verkauft. Es sei Tradition, sich so einen Aufkleber bei jedem Jahrestreffen zu kaufen und ibn an die eigene Jacke oder den Pullover zu kleben, so erklären mir die Akteur*innen vor Ort diese Aktion. Die Einnahmen daraus gehen an einen guten Zweck, beispielsweise 2011 an den dänischen Kindergarten in Friedrichstadt. Da das Wetter schlecht ist, findet das Fest nicht draußen, sondern in der kleinen Turnhalle statt. Wir gehen hinein und setzen uns an das Ende eines der vielen langen, geschmückten Tische. Es ist

\footnotetext{
484 „ondsindede tunger hævder, at ,de kommer jo kun, fordi deres børn skal optræde! “ S. a. Kap.
} 8.1 . 
voll und eng, alle Tische sind besetzt. Die Turnhalle ist ausgeschmückt mit vielen kleinen und großen dänischen Steckflaggen und Flaggengirlanden. Sogar die Sprossenwände in der Turnhalle sind mit Flaggen dekoriert. Viele Gesichter von der Veranstaltung am Vortag in Drage tauchen hier wieder auf. Ebenso einige meiner Interviewpartner*innen. Die Friedrichstädter SSFVorsitzende Tina Zehntner begrüßst die Menschen und kündigt eine Vorführung der Kindergartenkinder im Verlauf der Feierlichkeiten an.

Der Vorsitzende des Südschleswigausschusses im Folketing, Kim Andersen, und der stellvertretende Vorsitzende des dänischen Grænseforeningen, Grenzverein, halten eine Rede, während die Leute Kaffee trinken und Kuchen essen. Es ist etwas unrubig in der Turnhalle, da das Büfett draußen im Flur aufgebaut ist und die Leute daher ständig aufstehen, um sich draußen mit Essen zu versorgen. Das Friedrichstadt-Orchester, eine Jazzband, sorgt für musikalische Unterhaltung, die Kinder müssen einige Lieder singen, bevor alle gemeinsam auf Dänisch singen. Nach Kaffee, Kuchen, Reden und Gesang ist das offizielle, formelle Programm zu Ende. Für diejenigen, die noch länger bleiben, gibt es gegen Abend Würstchen vom Grill, die wegen des Regens unter einem Unterstand vom Schulhausmeister, dem Vater Tina Zehntners, zubereitet und drinnen verspeist werden.

\subsubsection{Sonntag, 29. Mai 2011, Tönning}

Ich fahre durch die Marschlandschaft der Halbinsel Eiderstedt nach Tönning, einer Kleinstadt mit knapp 5.000 Einwohnern und dem Eiderhafen mit einem großen historischen Packhaus, welches als jährlicher, überdimensionaler, in das Guinnessbuch der Rekorde eingegangener Adventskalender genutzt wird. Unterwegs sehe ich drei große dänische Busse mit 150 Eftersko$1 \mathrm{e}^{485}$-Gymnastikschülern aus Vestbirk in Dänemark.

Treffpunkt bei diesem Abschlussfest an der Westküste ist das Skipperhuset, das Schifferhaus, eine ehemalige Navigationsschule und heute das Verwaltungs- und Versammlungshaus der dänischen Minderheit in Tönning. Das Haus ist direkt am Hafen gelegen und wird für Übernachtungen an Gruppen und Schulklassen vermietet. Hier startet um 13:30 Uhr der Umzug durch die Stadt zum Festplatz an der dänischen Uffe-Schule. Bevor es jedoch losgeht, laufen Kinder mit Spardosen umber und verkaufen wieder die kleinen Jahrestreffen-Flaggenaufkleber für 50 Cent pro Stück. Alle warten darauf, dass es losgeht. Zwei Jungen von der dänischen Gymnastikschule zeigen kurz den Hitlergruß, ein anderes Kind trägt ein Trikot der deutschen Fußballnationalmannschaft. Die beiden Spielmannszüge Tordenskjoldsgarden und FDF Gladsaxe Brass Band stellen sich auf und spielen eine balbe Stunde lang abwechselnd Musik, bevor der Straßenumzug schließlich beginnt. Die Menschen reiben sich ein, vorweg gehen rund ein

485 Eine dänische Efterskole, auf Deutsch Nachschule, ist eine spezielle dänische Schulform mit Internat für 14- bis 18-Jährige, die ein Jahr nach oder während der Schulzeit eine Alternativschule besuchen wollen. Es ist ein Pendant zur Heimvolkshochschule, nur mit einer jüngeren Zielgruppe. 
Dutzend Fabnen- und Flaggenträger*innen. Es sind viele Kinder dabei, viele Teilnehmende tragen Flaggen oder Protestschilder gegen die Sparmaßnahmen der konservativen Landesregierung, die 2011 den dänischen Schulen Gelder streichen wollte.

Am Rande des Umzugs durch Tönnings Straßen gibt es einige Zuschauer*innen sowie einige Tourist*innen, die sich das Spektakel anschauen. Gegen 14:30 Ubr erreicht der Umzug die dänische Uffe-Schule. Dort warten schon viele Menschen hinter der Schule auf dem Sportplatz: Es sind viele Stände unter zeltartigen Pavillons aufgebaut. Die Zeitung hat einen Stand, der dänische Gesundheitsdienst, der SSW sowie einige dänische Vereine, wie der Flaggenverein Danmarkssamfundet und der Sprachverein Sprogforeningen, haben ebenfalls Informations- und Werbestände aufgebaut. Es gibt ein Verkaufszelt für Kaffee und Kuchen sowie eines für Grillwaren. Schüler*innen verteilen Zettel mit Liedtexten und dem Programm des Tages. Es geht weiter mit einer Flaggenparade und dem dazugehörigen Singen eines dänisch-patriotischen Liedes ${ }^{486}$. Die Schule ist mit einer dänischen Flagge und mit der Tönninger Stadtflagge geschmück.t. Die Veranstaltung wird moderiert durch die SSF-Vorsitzende des Amtes Eiderstedt, Bente Moller.

Der Bücherbus ist ebenfalls wieder vor Ort, wie am Vortrag in Friedrichstadt auch, und der Bibliotheksmitarbeiter verteilt erneut seine unveränderten Quizzettel sowie seine schwarzen Stofftaschen. Zur Unterhaltung auf diesem Jahresfest gibt es eine Gymnastikvorführung mit 150 Turner*innen, die aufgrund ihrer Massenchoreografie und ihrer Einheitskleidung etwas befremdlich wirk.t. Das Bild erinnert an Propagandaaufführungen in Diktaturen.

Die Organisatoren des Festes haben Kindergartenkinder aus Bredstedt, Husum, Ohrstedt, Drage, Friedrichstadt, Tönning und Garding sowie die Schulkinder aus Tönning in das Programm eingebunden. Sie müssen etwas vorsingen oder auffübren. Einigen Kindern ist an ibrer Mimik und Gestik anzusehen, dass sie keine Lust haben, vor so einer großen Menschenmenge, rund 500 Personen, aufzutreten. Eine Mutter streitet sich mit ibrem Kind, welches lieber spielen will. Nein, es müsse erst singen, erst danach dürfe es spielen und sich frei auf dem Festplatz. bewegen, so der Einwand der Mutter.

Neben den Auffübrungen der Kinder werden wieder Reden gehalten. Der dänische Verkehrsminister Hans Christian Schmidt sowie der Vorsitzende des SSF-Amtes Husum, Lars Sorsensen, sprechen. Auch der nordfriesische Landrat, Dieter Harrsen, überbringt offizielle Grüße an die Minderheit. Es gibt zusätzlich noch eine Tombola sowie Spiele für Kinder. Das Fest endet gegen 17:30 Ubr. Viele gehen früher nach Hause, da es zu regnen angefangen hat. Es wird, wie auf den anderen Festen, viel Deutsch gesprochen, auch etwas Dänisch und Plattdeutsch. Offizielles wird auf Dänisch geregelt, aber viele Leute sprechen untereinander Deutsch, vor allem viele Eltern mit ihren Kindern.

Auffällig ist, dass den Vortragenden und Rednern nicht von allen Aufmerksamkeit geschenkt wird und es während des Vorsingens und Vortragens relativ laut ist. Nicht alle zeigen Respekt gegenüber den Redner*innen, sondern laufen herum, unterhalten sich, die Kinder schreien und rennen.

486

„Der er ingenting, der maner“ von Axel Juel aus den Jahren 1915/16. 
Zur Abdeckung der Veranstaltung durch Medien lässt sich Folgendes beobachten: Während die Flensborg Avis ausführlich im Vorfeld der Jahrestreffen darüber berichtet, das Programm detailliert ankündigt, auf fast jedes Fest einen oder zwei Reporter*innen schickt und eine Sonderausgabe herausgibt, wird das Fest 2011 in den Husumer Nachrichten des Schleswig-Holsteinischen Zeitungsverlags nicht erwähnt. Einige Veranstaltungen des Jahresfestes werden vom dänischen Radiosender Danmarks Radio Syd abgedeckt und durch Programminhalte ergänzt. Beispielsweise überträgt der Sender eine Grußrede des dänischen Staatsministers Lars Løkke Rasmussen am Vormittag des 27. Mai 2011 an die Minderheit in Südschleswig (Sydslesvigsk Forening 25.05.2011). Dass die deutsche Medienpräsenz nicht sehr hoch ist, könnte daran liegen, dass das „Wahrnehmungs- und Erlebnispotential" (Gyr 2005: 247) nicht so hoch ist, wie es sich die Funktionäre erhoffen, da die Feste jedes Jahr ähnlich ablaufen, also für nicht besonders berichtenswert gehalten werden.

\subsubsection{Samstag, 09. Juni 2012, Friedrichstadt}

Auch in diesem Jahr ist das Wetter schlecht und das dänische Jahrestreffen im sogenannten „Holländerstädtchen“ findet erneut in der Turnhalle der Hans-Helgesen-Schule statt. Am Eingang wird wieder der Jahrestreffenaufkleber - diesmal mit 2012-Aufdruck - für 50 Cent verkauft. Als ich ankomme, ist die Halle schon fast voll, ich finde aber einen Platz an einer der langen Tafeln. Neben mir sitzen zwei junge Väter mit zwei kleinen Kindern. Ich sehe bekannte Gesichter, einige Interviewpartner*innen oder deren Angehörige. Einige Funktionär*innen aus Drage sowie der Pastor der dänischen Gemeinde in Friedrichstadt sind anwesend. Beginn der Veranstaltung ist 14:30 Uhr. Sie dauert zwei Stunden. Es sind rund 150 Teilnehmende vor Ort. Die Turnhalle ist nicht so ausgiebig geschmückt wie letztes Jahr. Es gibt nur eine große Flagge in der Turnhalle und ein paar kleine an den Sprossenwänden, die ständig von diesen herunterfallen. Die Ursache für die etwas sparsamere Dekoration ist die kurafristige Entscheidung, das Fest aufgrund der Witterungsverbältnisse in der Turnhalle stattfinden zu lassen und nicht draußen auf dem Schulhof, wie es eigentlich vorgesehen war.

Die Menschen werden kurz auf Dänisch und auf Deutsch begrüßt. Anschließend singen alle gemeinsam das neu komponierte dänische Sydslesvigsangen, das Südschleswiglied, sowie En hjertesag, eine Herzenssache, begleitet durch das Friedrichstadt-Orchester unter der Leitung von Bente Stenger-Wulff, die die Musik zu beiden Liedern komponiert hat. Es folgen drei Lieder, die die Kindergartenkinder singen müssen. Diese sind kaum zu bören, es singen hauptsächlich die Erzieherinnen. Es folgen die Vorschulkinder, die einige Musikstücke vorführen. Diese singen etwas lauter, aber nicht schöner. Die Kinder wirken nicht glücklich in ihrer Situation, etwas vorsingen zu müssen. Sie wirken unkonzentriert, verziehen die Gesichter, machen nicht rich- 
tig mit, wirken, als würden sie zum Vorsingen genötigt worden sein. Sie reden miteinander anstatt zu singen und winken ibren Eltern von der Bübne zu und rufen während ibres Auftritts ins Publikum. Einige singen gar nicht, andere nur ganz leise.

Der Journalist Niels Tönnsen ${ }^{487}$, der neben mir an einem der langen Tische Platz genommen hat, bestätigt meine Beobachtung aus dem letzten Jahr. Die Kinder werden zum Vorsingen in die Veranstaltung eingebunden, damit die Eltern und Angehörigen kommen und die Turnhalle voll wird. Diesen Trick mit den Kindern bestätigt mir sogar Funktionärin Tina Zehntner selbst:

Das ist auch eben immer das, was ich sach, um die Leute auch einfach zu kriegen, die Eltern ... ham, ham wir jetzt auch eben beschlossen, dass wir auch immer den Kindergarten aufführen lassen in Friedrichstadt, weil so kommen die jungen Eltern auch zum Årsmøde (INT10).

Zehntner erzählt im Interview, dass das Ziel bei den Jahrestreffen daher auch sei, ein Unterhaltungsprogramm für Kinder dabei zu haben (INT10). Minderheitskritiker Egon Clausen schreibt, dass die dänischen Kindergärten und Schulen „,voll' ${ }^{\text {‘488 }}$ seien, aber die Eltern ohne konkreten Anlass nicht zu den dänischen Arrangements kämen (Clausen 2014: 79).

Nach ibren Auftritten bekommen alle Kinder ein Eis und werden in einen Klassenraum geschick.t, um dort einen Film zu schauen. Es wird daraufhin ruhiger im Saal. Das Programm geht weiter mit einer Rede des Probstes der Kirche der dänischen Minderheit, Viggo Jacobsen. Dieser fordert mehr Gesang in den dänischen Kindergärten, Schulen, Kirchen und anderen Einrichtungen. Singen und Gesang ist für Jacobsen ein „Instrument" qur Identitätsbildung und -konstruktion. Das Singen fördere die Gemeinschaft und vermittele Werte, sodass man ein besserer Mensch werde, sagt der Probst. Er plädiert in seiner Rede für mehr Gemeinschaft durch das Singen und das Benutzen von Psalmenbüchern und Hochschulgesangbüchern. Das Singen der darin enthaltenen dänischen Texte sei förderlich für die Sprachbildung, da durch die traditionellen Lieder die Klassische dänische Sprache statt der modernen SMS-Sprache vermittelt werde, so der Probst.

Nach dieser eindringlichen Rede gibt es erneut Musik durch das Jazzorchester, und das Kuchen- und Kaffeebüfett wird eröffnet, bevor der ehemalige Journalist und langjähriges Grenzvereinsmitglied Karsten Madsen die zweite Rede des Tages hält. Er fordert, dass mehr junge Politiker*innen und Funktionär*innen aus Dänemark an seine Stelle träten und Arsmode-Reden bielten. Madsen wünscht sich mehr Verbindungen und Freundschaften zwischen den jungen Leuten der Minderbeit und jungen Dän*innen, damit letatere mehr über die Minderheit erführen. Er appelliert an die Zubörenden, dass sie aktiver Kontakte nach Dänemark suchen sollten.

\footnotetext{
487 Name geändert.

488 „fyldt“
} 
Das Publikum reagiert auf die beiden Reden recht gleichgültig. Offene Diskussionen über die Redeinhalte kommen nicht zustande. Es scheint, dass viele nur wegen der eigenen Kinder am Fest teilnehmen und aus dem Wunsch heraus, alte Freunde und Bekannte wiederzutreffen, während andere als Funktionsträger*innen vor Ort sind, wie beispielsweise die Vereinsfunktionär*innen und Pädagog*innen.

Während des Gesangs und der Reden kümmert sich einer der beiden Väter, die neben mir sitzen, um seinen Sohn, der aus Langeweile Würfelzuckerstückchen essen will. Der andere Vater ist sichtlich genervt vom Jahresfest und rollt mit seinen Augen. Er erzählt seinem Gegenüber leise, dass er „solche Veranstaltungen“ schon früher als Kind gehasst habe. Er sei immer gezwungen worden, daran teilzunehmen. Dieser Mann nimmt heute nur teil, weil sein Sohn etwas vorführen muss. Bei rund 20 Vorschulkindern und 30 Kindergartenkindern kommen viele Angehörige zusammen.

Am Ende der Veranstaltung wird noch auf die kommende Sankt-Hans-Veranstaltung, Mittsommer am St.-Johannistag, und den darin integrierten dänischen Tag der offenen Tür Dansk Dag, Dänischer Tag - hingewiesen. Es werden Flyer dafür verteilt. Da würden sich alle dänischen Vereine einer breiten Öffentlichkeit präsentieren, so die Moderatorin des Jahrestreffens (s. Kap. 8.1.5).

Der Journalist Niels Tönnsen berichtet mir, dass der Schwerpunkt in seinem Zeitungsbericht über diese Veranstaltung - wie bei den Zeitungsberichten über die anderen Feiern auch - ein anderer wäre, als es der Schwerpunkt für die Leute vor Ort sei. Bei den Teilnehmenden gingen die Reden etwas unter, weil die Leute nicht viel Lust hätten zuzuhören. Im Zeitungsbericht dagegen würden die Inhalte der Hauptrede $70 \%$ des Gesamttextes ausmachen, da der Rest für die Zeitungsleser*innen nicht so interessant sei, weil „es eh immer das Gleiche ist“ (Niels Tönnsen am 09.06.2012): Die Kinder singen, die Halle ist mit dänischen Flaggen geschmückt, das Orchester spielt, die Leute trinken Kaffee und essen Kuchen und unterhalten sich. Zusätzlich zum Zeitungsbericht über die Reden werden viele Vorträge später peu à peu als ganzseitige Kronik, also als Zeitungsfeature, in der Flensborg Avis abgedruckt.

Der Ablauf des Jahrestreffens in Friedrichstadt wird nicht von der Amts- oder Landesebene vorgeschrieben. „Wir“ können auf lokaler Ebene „machen, wie wir wollen“ (INT10), sagt Tina Zehntner im Interview. Im Vorstand vor Ort überlegen sie sich selbst eine Struktur, testen den Programmablauf bei den einzelnen Festen und schauen, ob alles funktioniert. Wenn nicht, werde spontan der Ablauf von Reden, Kaffeetrinken, Musik und Grillen umstrukturiert oder es werde beim nächsten Mal anders geplant (INT10). Früher gab es beispielsweise einen Straßenumzug in Friedrichstadt. Sie seien sogar mal mit dem Spielmannszug auf einem 
Schiff bei einer Grachtenfahrt ${ }^{489}$ durch die Stadt geschippert, aber das werde nicht mehr gemacht (INT10). Die Ortsvereine können selbst die Redner*innen einladen oder bekommen sie ggf. von einer zentralen Liste zugeteilt. Der landesweite Jahrestreffenausschuss des SSF vermittelt potenzielle Redner*innen, die teilweise an zwei bis drei verschiedenen Orten dieselben oder ähnliche Reden halten und dafür oftmals extra aus Dänemark anreisen. Meistens handelt es sich dabei um Funktionär*innen von Grenz- oder Minderheitenvereinen oder um dänische oder südschleswigsche Politiker*innen.

Zehntner ist der Meinung, dass man das Frederiksstad Orkester in der Stadt mit seinen zwei Gruppen, der eigentlichen Band sowie der sogenannten Aspirantengruppe, möglichst jedes Mal für das Jahrestreffen engagieren sollte, da sie es ja vor Ort hätten und ihr die Musik gut gefalle (INT10). Die Jahrestreffen in Drage und auf Kreisebene in Tönning bzw. Husum hätten jedes Jahr dieselben zwei Spielmannszüge aus Dänemark dabei, so Zehntner mit einem leicht abwertenden Unterton (INT10).

\subsubsection{Samstag, 23. Juni 2012, Friedrichstadt: Sankt-Hans-Fest und Dansk Dag}

Am 23. Juni 2012 veranstalteten die Vereine der dänischen Minderheit in Friedrichstadt unabhängig von den Jahrestreffen einen Tag der offenen Tür, Dansk Dag genannt. Er wurde gemeinsam mit dem Sankt-Hans-Fest, dem dänischen Mittsommer, durchgeführt, welches jedes Jahr am 23. Juni stattfindet. Es kommen dazu regelmäßig, je nach Wetter, rund 90 Teilnehmende. Sie hören die Båltale, die Sankt-Hans-Feuer-Rede ${ }^{490}$, essen Gegrilltes, und die Kinder backen Stockbrot.

Zum Dansk Dag an Sankt Hans 2012 waren alle Interessierten eingeladen, sich die dänische Schule anzusehen, gemeinsam Kaffee zu trinken und Kuchen zu essen, zu grillen und sich über die dänischen Vereine und ihre Aktivitäten zu informieren. Eingeladen wurde auch via deutscher Tageszeitung, den Husumer Nachrichten. Des Weiteren wurden Einladungen an die Stadt und an die deutschen Schulen sowie den deutschen Kindergarten gesendet (Informelles Gespräch mit Tina Zehntner; Rebsdorf 25.06.2012). Zehntner berichtet, dass trotzdem fast keine Außenstehenden kamen, sehr viele Minderheitenakteur*innen waren aber vor Ort.

489 Eine Grachtenfahrt ist eine Bootsfahrt auf den Grachten, also den Kanälen der Stadt Friedrichstadt. Die Stadt und ihre Grachten wurden ab 1621 von Holländer*innen im Auftrag des Herzog Friedrichs III. von Schleswig-Holstein-Gottorf gebaut. Friedrichstadt wird daher heute auch als ,Klein-Amsterdam' bezeichnet.

490 Das Sankt-Hans-Feuer ähnelt dem in einigen Gegenden Deutschlands veranstalteten Osterfeuer oder dem in Nordfriesland üblichen Biikebrennen. 
Der Tag der offenen Tür beginnt um 15 Uhr auf dem Schulhof der Hans-Helgesen-Schule. Alle dänischen Vereine in Friedrichstadt sind präsent. Die Akteur*innen haben Stände aufgebaut und verteilen Flyer und Give-aways. Man bekommt Kugelschreiber, Flaggenaufkleber, Gummibärchen und Bleistifte oder einen Schreibblock mit SSF-Logo. Die Vertreter des SSW verteilen Schlüsselanhänger und Broschüren, informieren über die Partei und beantworten Fragen. Die dänische Kirche wird durch die Freiwilligen aus dem Kirchenvorstand vertreten. Dazu werden Stellwände mit Informationstexten auf Deutsch und Dänisch aufgebaut. Der Dänische Gesundheitsdienst bietet als Werbeaktion einen Sehtest an. Der Kanuklub ist mit einem PKW-Anhänger vertreten, der mit zwei Booten und zwei Schwimmwesten beladen auf dem Gelände steht. Ein Kajak liegt daneben im Gras. Es gibt aber keine Ansprechpartner*innen oder Informationen, und daher bleibt unklar, wie diese Aktion eigentlich vorgesehen war. Der Bibliotheksbus ist vor Ort und es gibt eine kleine Hüpfburg. Ein dänischer Bauchredner tritt auf und unterhält die Kinder auf Dänisch, diese antworten ihm auf Deutsch.

Die Schule präsentiert sich. Besucher*innen können in das Gebäude gehen und sich die Unterrichtsräume anschauen. Das Gleiche gilt für den Kindergarten, der um die Ecke liegt. Ich schaue mir mit meiner Interviewpartnerin Brigitte Thomsen (INT02) die Schule, die Nachmittagsbetreuungseinrichtung und den Kindergarten auf einem gemeinsamen Rundgang an. Brigitte ist ehemalige Schülerin dieser Schule, allerdings war diese zu ihrer Schulzeit noch in Baracken untergebracht und nicht im aktuellen Schulgebäude. In den drei Gebäuden erklären uns die dortigen Mitarbeiterinnen alles sehr ausführlich und zeigen uns jeden Raum. Auf dem Schulhof werden Kaffee und Kuchen serviert. Die Schüler*innen, denen wir dabei unterwegs begegnen, sprechen mit uns Deutsch.

Moderiert wird die Veranstaltung durch den stellvertretenden SSF-Ortsvorsitzenden Karl Günther, der über seine Ehefrau Tanja Günther ${ }^{491}$ zur Minderheit gekommen und CDU-Mitglied ist. Seine CDU-Mitgliedschaft wird von einigen Akteur*innen kritisiert, weil die Erwartung von Minderheitsangehörigen an Minderheitsangehörige ist, SSW-Mitglied zu sein. Karl Günther spricht beim Jahrestreffen 2013 als deutscher Muttersprachler in seiner Moderatorenrolle Dänisch, während der dänische Pastor als sein Co-Moderator Deutsch spricht, um das gegenseitige Bemühen, die jeweils andere Sprache zu sprechen, zu demonstrieren.

Die Veranstaltung richtet sich an Außenstehende. Die Informationen, die ausliegen, enthalten für Angehörige der Minderheit nichts Neues. Nur wenige NichtDän*innen sind vor Ort. Um 18 Uhr geht dieser Aktionstag in das Mittsommerfest Sankt Hans über. Eine zweiköpfige Band unterhält die Menschen und der

491 Beide Namen geändert. 
Grill wird angefeuert. Der dänische Pastor hält eine kurze Ansprache, es wird gesungen, bevor gegen halb acht der kleine, mit einer Hexenpuppe dekorierte Holzstoß auf dem Schulhof angezündet wird. Das Abbrennen geht schnell, es ist trocken und windig.

Insgesamt wird hier nicht so viel Dänischsein explizit performt, wie man als Außenstehender vielleicht erwarten würde. Die Akteur*innen treffen sich, reden miteinander, essen Kuchen und trinken gemeinsam Kaffee oder essen Grillwurst mit Brot.

Tina Zehntner organisiert die Jahresfeste in Friedrichstadt sowie gemeinsam mit den anderen Vereinen den Dansk Dag und Sankt Hans, reflektiert im Interview über die Veranstaltungen. Sie ist über deren fehlende Wahrnehmung seitens führender deutscher Kommunalpolitiker*innen enttäuscht. Zehntner berichtet, dass sie die Bürgermeister der umliegenden Gemeinden eingeladen habe. Nur aus Drage kam ein Vertreter zum Tag der offenen Tür, während der Bürgermeister aus Friedrichstadt dem Fest fernblieb. „Das fand ich nen büschen traurig eigentlich ... dass von da auch keine Rückmeldung irgendwie kriegte“ (INT10). Über die Vorgängerin des amtierenden Friedrichstädter Bürgermeisters beklagt sich Zehntner ebenfalls, denn die sei nie gekommen und habe immer nur ihre beiden Vertreter*innen $^{492}$ geschickt. Diese waren aber SSW-Mitglieder, die allerdings auf den Festen als Minderheitsdän*innen in ihrer Funktion als SSF-Mitglieder oder als Eltern von Kindergarten- oder Schulkindern sowieso „gesetzt“", also dabei gewesen (INT10). Daher erkennt Zehntner diese nicht als offizielle Gesandte der Stadt an.

\subsubsection{Sonntag, 09. Juni 2013, Tönning}

Auf dem abschließenden zentralen Jahrestreffen der Westküste 2013 in Tönning hält der Vorsitzende des Südschleswigausschusses des Folketings, Benny Engelbrecht, eine Rede. Darin überbringt er „einen Gruß aus dem offiziellen Dänemark $^{\text {“493 }}$ (Engelbrecht 09.06.2013). Engelbrecht kommentiert anschließend die schleswig-holsteinische Politik, bevor er die gängigen identitätsstiftenden Merkmale für die Konstruktion der dänischen Minderheit bedient: Er rekurriert in seiner Rede auf die Aussage des ehemaligen dänischen Staatsministers Poul Nyrup Rasmussen: „So lange ihr an uns festhaltet, halten wir an euch fest“ (s. S. 253). Engelbrecht zitiert danach Königin Margrethes Neujahrsansprache im dänischen Fernsehen, in der diese sich wiederum auf ,alte Traditionen“" ${ }^{\text {“494 }}$ bezieht, in denen „der dänische Geist“ ${ }^{6495}$ verankert sei. Des Weiteren lobe die Königin, so zitiert

\footnotetext{
492 Der dreizehnköpfige Friedrichstädter Stadtrat bestand im Jahre 2013 aus vier SPD-, vier CDU-, drei SSW- und zwei Bürgervereinsmitgliedern.

„en hilsen fra det officielle Danmark““

"gamle traditioner"

„den danske ånd“
} 
Engelbrecht (ebd.), dass das „Dänischsein südlich der Grenze blühen darf““496. Engelbrecht verweist nicht nur auf den Inhalt der Königinnenrede, also die Betonung der Geschichte und Tradition, sondern auch auf die Königin selbst als Symbol für eine Identifizierung mit dem Dänischen. ${ }^{497}$

Vor dem Hintergrund der Gleichstellungsdiskussion der dänischen Schulen 2013 (s. FN 123 a. S. 76) formuliert Engelbrecht den Appell an den Zusammenhalt in der Minderheit über Vereinsgrenzen hinaus. Auch das ist ein wiederkehrendes Element in der Minderheit. Mit diesem Zusammenhalt sollte, so der Vorsitzende des Sydslesvigudvalget ein sogenannter „Informations- und Aufklärungseinsatz ${ }^{\text {‘498 }}$ gestemmt werden (ebd.). Er plädiert also für Lobbyismus und Propaganda nach außen an Dänemark als Geldgeber und nach innen an die Minderheitsakteur*innen. Es würde ihm die eigene Arbeit im Ausschuss erleichtern, wenn in Dänemark mehr Verständnis für die Minderheit aufkäme und er nicht alleine für die Steuerausgaben für die Minderheit argumentieren müsse. Laut Engelbrecht müsse die Minderheit zusammenhalten, Traditionen beachten, aber auch die Ideen der Jugend integrieren (ebd.).

\subsection{7 Årsmøderne: Die Bedeutung der Jahrestreffen}

Zentrale Symbole mit Repräsentationsfunktion innerhalb der dänischen Minderheit sind die in Kapitel 8.1 beschriebenen Jahrestreffen. Ziel der Jahrestreffen ist, die Zugehörigkeit der Teilnehmer*innen zu Dänemark zu zeigen und mit einem gemeinsamen Erlebnis das Gruppengefühl der Akteur*innen zu stärken. Das ist zu vergleichen mit der von Wolfgang Kaschuba beschriebenen Funktion von „nationaler Massenkultur“: „Der einzelne [sic] und das Spezifische gehen dort im Gemeinsamen auf und finden in diesem Gefühl der Übereinstimmung wiederum ihre eigene Bestätigung und Überhöhung“ (Kaschuba 1995: 294). Die Jahrestreffen sind für viele Akteur*innen der dänischen Minderheit deshalb ein wichtiges Symbol, weil sie - analog zur „Nation zum Anfassen“ (ebd.: 294) - eine subjektive Zusammengehörigkeit oder eine imaginierte Minderheitengruppe greif- und erfahrbar machen (ebd.: 296). Denn „die nationalen Emotionen“ spielen „eine Rolle als letzte Erklärung für die nationale Mobilisierung, Legitimation und Integration“ (François et al. 1995: 17). „Durch gemeinsame Gesangs- oder Sportveranstaltungen wurden [...] Gefühle für Kollektivität und nationale Verbundenheit Teil des Körpers als auch des Geistes“ (Löfgren 1995: 118), so schildert der Kulturanthropologe Orvar Löfgren mit Verweis auf seinen Kollegen Jonas Frykman den

\footnotetext{
496 „danskheden får lov at blomstre syd for grænsen“

497 Über die Rolle des Königshauses für die dänische Nation s. (Møller 2016).

498 ,informations- og oplysningsindsats“
} 
schwedischen Nation-building-Prozess. Ähnlich funktioniert auch die Konstituierung der dänischen Minderheit in Südschleswig. Arthur Christiansen findet ebenfalls Parallelen zwischen der „Reproduktion der dänischen Minderheit“ (Christiansen 2008: 3) und der Bildung von Nationalstaaten: Wie das allgemeine Nationalstaatskonstrukt arbeitet auch das minderheitliche „Nationalstaats-Konstrukt“ mit der sprachlichen Homogenisierung und der personalen Vernetzung. Zum Einsatz kommen hier als Instrumente die dänisch-nationalen Identitätsbilder, die Instrumentalisierung der Vereine und Verbände und die politische (Minderheits-) Ordnung im Sinne von Ein- und Ausgrenzung (ebd.: 235). Der interviewte Akteur Erik Nissen formuliert es etwas konkreter:

Damit wollen wir einfach mal, ich sach jetzt wir, wir Dänen, Präsenz zeigen [...], dass wir eigentlich noch, dass wir noch da sind, dass man mal, ja eigentlich zeigt, wir sind nicht nur im stillen Kämmerlein da, eben nur oben in Flensburg, sondern wir sind nördlich der Eider doch stark vertreten (INT01).

Die Funktionär*innen der Minderheit haben auch erkannt, dass die Jahresfeste „Kollektiverlebnisse“ schaffen, die für den Zusammenhalt und die Konstituierung der Minderheit wichtig sind. Die Jahrestreffen sollen die Botschaft aussenden, dass sich die Minderheit als „ein Teil des dänisches Volkes“" ${ }^{\text {“49 }}$ sehe, so der SSW-Generalsekretär Martin Lorenzen in einer Jahrestreffenrede in Flensburg (Lorenzen 30.06.2015). Die dänische Sprache und das dänische Alltagsleben sollen durch die Jahrestreffen unterstützt und erhalten werden (Nissen 05.06.2013). Sie sind ein wichtiges Signal nach außen und nach innen für Gemeinschaftsbildung und Zusammenhalt (Nissen 07.06.2013), und sie dienen der Selbstbestätigung und Repräsentation.

Die dänischen Jahrestreffen sind eine [...] Sichtbarmachung einer Grenze. Einer Grenze zwischen dem Bekenntnis zu einem Bevölkerungsteil, der sich von der Majorität unterscheidet. Ein Bevölkerungsteil, der sich entschlossen hat, ein anderes Leben zu führen, sowohl kulturell als auch sprachlich ${ }^{500}$ (Kring 15.06.2016).

Sie sind eine Demonstration dafür, dass die Minderheit noch zahlreich präsent ist. „Die diskursive Repräsentation der Vergangenheit und Nation wird durch nationale Feiertage, Umzüge und Einweihungsfeiern ritualisiert" und inszeniert (Feischmidt 2003: 89). „Nationale Feste sind zentrale Ereignisse der Nationalisierung der Massen“ (ebd.: 89). Das gemeinsame Feiern und gemeinsame Ausüben

\footnotetext{
499 „en del af det danske folk“

500 „De danske årsmøder er en [...] synliggørelse af en grænse. En grænse mellem det at bekende sig til en befolkningsdel, der udskiller sig af en majoritet. En befolkningsdel, der har valgt at leve en lidt anden, så såvel kulturel som sproglig, tilværelse.“
} 
von invented traditions, wie dem Singen, erzeugt Zugehörigkeitsgefühle und dient der ,inculcation of beliefs, value systems and conventions of behaviour" (Hobsbawm 1994: 9), besonders im Hinblick auf die jährliche Wiederholung, die diese Praxen erstens historisch legitimiert und zweitens automatisiert (vgl. ebd.: 1). Sich wiederholend ist auch der Ablauf der einzelnen Feste. Erst gibt es Kaffee und selbst gebackenen Kuchen, danach Gesang und Unterhaltung (vgl. a. Clausen 2014: 79). Dänische Politiker*innen halten Reden und es werden national-patriotische Lieder gesungen (vgl. a. Röh 2012: 120).

Auch Funktionär Dieter Paul Küssner schreibt den Jahrestreffen eine ähnliche, wichtige Funktion zu:

Eine der Arten, als eine freiwillige, aber starke Gemeinschaft dazustehen, die einen Sichtbarkeitseffekt weit in die dänische und deutsche Öffentlichkeit hat, ist nun mal unsere Jahrestreffen [sic]. Ein Volksfest, welches über mehrere Tage Große und Kleine in einem gemeinsamen Engagement für die Bewahrung und Sichtbarmachung der dänischen Gemeinschaft verbindet, die das Rückgrat unseres Lebens ist. [...] die Jahrestreffen sind immer noch die Urkraft, die das vielfältige Minderheitenleben in einem offensiven und freundlichen Dialog mit dänischen Freunden und guten Nachbarn versammelt. ${ }^{501}$ (Küssner 2012: o. S.)

Diese Rhetorik verdeutlicht, dass Küssner mehr Nähe mit Dänemark sieht („Freunde“) als mit Deutschland („Nachbarn“). Die bewusste Verwendung des Wortes „Urkraft“ wirkt verherrlichend und romantisierend. Mit der Verwendung von „Ur-“" werde in der Regel Reinheit und Unschuldigkeit impliziert, so Alkier (Alkier 2010: 9), eine Bedeutungsinterpretation, die man hier auf Küssners Aussage übertragen kann, wenn man bedenkt, dass ,Sprache [...] kein neutrales Instrument [ist], um Sachverhalte lediglich zu bezeichnen. Sie verdichtet vielmehr Weltsichten und strukturiert das Denken mit" (ebd.: 9).

Die Arsmoderne, wie sie oben beschrieben wurden, mit Straßenumzügen durch die jeweiligen Orte, folgen bestimmten Abläufen und beinhalten immer wiederkehrende Elemente, wie Festreden, Gesang, Flaggenhissen und Fahneneinweihungen sowie Essen. Die dänische Minderheit konstituiert sich also über die auf Tradition und Vergangenheit rekurrierenden Rituale, die vom SSF mit Unterstützung

501 „En af måderne til at fremstå som et frivilligt, men stærkt fællesskab, der har synlighedseffekt langt ind i den danske og tyske offentlighed er nu engang vore årsmøder. En folkefest, der i flere dage forbinder store og små i et fælles engagement for bevarelse og synliggørelse af det danske fællesskab, der er rygraden i vores liv. [...] årsmøderne er fortsat den urkraft, der samler det mangfoldige mindretalsliv i en offensiv og venskabelig dialog med danske venner og gode naboer." 
der anderen dänischen Vereine inszeniert werden und durch den Besuch von Minderheitsangehörigen zu einem Erlebnis gemacht werden. Die Verwendung der beschriebenen nationalen Symbole, wie den dänischen Flaggen oder dem Singen von Südschleswigliedern und Nationalhymnen, sind Elemente einer nationalistischen Ideologie. Durch sie werden Bilder von nationaler Geschichte und Kultur vermittelt und aufrechterhalten (Coakley 2004). Über die Rituale und Symbole wird auf den Jahrestreffen die eigene Gruppe konstituiert und nach außen abgegrenzt, beispielsweise durch die Erwähnung des Königshauses und vor allem durch die immer wiederkehrende Nennung von loyalitätseinfordernden Aussprüchen der dänischen Staatsminister Niels Neergaard und Poul Nyrup Rasmussen. ${ }^{502}$

Der ehemalige dänische Journalist und Minderheitenkritiker Egon Clausen beschreibt die Jahrestreffen etwas überspitzt folgendermaßen:

Hier sprechen alle über die Freude des Zusammenhalts und der Zugehörigkeit mit dem Dänischen. Hier erinnert man an die alten Versprechungen, dass Südschleswig nicht vergessen werde. [...] Und mit Hilfe der ausgeteilten Gesangbücher singt man darüber, dass, falls alles schief gehen sollte, da immer noch ein Gott oben ist, der über die Sache Dänemarks wacht, und die Flaggen flattern im Wind, und alle tun so, als wären sie echte Vollblutdänen. ${ }^{503}$ (Clausen 2014: 78)

Diese Kritik an den Jahrestreffen hebt deren inszenierten Charakter und den dort dargestellten Nationalismus besonders deutlich hervor, ebenso wie die Massengymnastikvorführung in Tönning 2011, die eine gleichförmige Inszenierung von Gemeinschaft darstellt (s. Kap. 8.1.3). Die Inszenierung der Minderheit sowie die dazugehörige dänische Ideologie nennt Karin Röh eine „Lüge“6504 (Röh 2012: 125).

502 Niels Neergaard: „Sie sollen nicht vergessen werden!“ (1920); Poul Nyrup Rasmussen: „Solange ihr an uns festhaltet, halten wir an euch fest!“" (1999). S. S. 253.

503 „Her taler alle om glæden ved sammenhold og samhørighed med det danske. Her mindes man de gamle løfter om, at sydslesvigerne ikke skal blive glemt. [...] og med hjælp fra det omdelte sanghefte synger man om, at hvis alt skulle gå galt, er der endu en gud foroven, der råder for Danmarks sag, og flagende blafrer i vinden, og alle lader som om, de er ægte fuldblodsdansker.“

504 „løgn“" 


\subsection{Gemeinsames Singen}

Das Ausüben von Musik ist Teil der Gemeinschaftsbildung (vgl. Hobsbawm 1994: 12). Für die Akteur*innen und Funktionär*innen der dänischen Minderheit ist das gemeinsame Singen zentral für die gemeinschaftliche Anbindung zur Gruppe, wie anhand von Beobachtungen beim Integrationskurs durch die folgenden szenischen Schilderungen deutlich wird:

Am ersten Abend nach dem reichbaltigen Essen steht Sang for alle, Singen für alle, mit Signe Frandsen ${ }^{505}$ auf dem Programm. Wir treffen uns in der Dagligstue, dem großem Wohnzimmer. Dort stehen ein Klavier und ein Flügel. Wir setzen uns im Halbkereis um den Flügel und Signe hat Kopien mit den Liedtexten dabei. Diese liegen auf dem Flügel, neben blauen Heftern für die Zettel sowie einem Locher. Es herrscht etwas Chaos, die Kinder sind übermü det und unrubig wegen all der neuen Eindrücke. Die Erwachsenen sind etwas geschafft und probieren, die Kinder eher weniger als mehr in Schach qu halten. Es ist viel Lärm, obwohl wir eigentlich offizielle Unterrichtszeit haben. Inken steht zwischenzeitlich auf und will während des Singens alle ibre Zettel lochen. Signe wirkt genervt von der Störung durch Inken. Die Papiere könnten auch nach dem Unterricht noch gelocht werden. Wir singen Kinderlieder mit einfachen Texten, beispielsweise Hvilket Tøj, Welches Zeug, und Æblemand, Apfelmann. Letzteres stellt sich als ein grooviger Hit heraus, den alle mögen. Es folgen die Lieder Mariehønen Evigglad, Marienkäfer immerfroh, Tælle til én, Zähl bis Eins und Sigurds Godnatsang, Sigurds Gutenachtlied, während Signe auf dem Flügel spielt. Die Ersten gehen dann zeitig ins Bett, während einige Erwachsene sich noch kurz, unterhalten. Es zeigt sich, dass die besonders eingängigen, auch kindgerechten Lieder auch außerhalb der offiziellen Singzeiten von den Kindern immer wieder angestimmt werden. Sie rennen durch die Flure und summen leise vor sich hin.

Das Singen entfaltet also seine Wirkung, besonders dann, wenn die Lieder eine eingängige Melodie oder lustige Texte haben, wie beispielsweise Æblemand. Der Text dazu ist einfach und lebt von der Variation der Obstsorten, mit denen man die Äpfel ersetzen kann. Andere Stücke, die wir singen sollen, haben eher Lehrcharakter, wie beispielsweise das ABC-Lied auf Dänisch, bei dem man das Alphabet lernen soll. Es werden ausschließlich dänische Lieder performt. Bei der täglichen Morgenversammlung nutzen wir das offizielle dänische Heimvolkshochschulgesangbuch und singen daraus einige Lieder, die sich an Erwachsene richten. Dies ist in Dänemark und den anderen skandinavischen Ländern auch an allgemeinbildenden Schulen üblich (vgl. a. Werner 16.05.2016). Diese Praxis ist in deutschen Schulen nahezu unbekannt. Schülerin Emma aus Eckernförde erklärt im Radio, was Morgensang ist und was das auf sie selbst für eine Wirkung hat:

505 Alle Name aus teilnehmenden Beobachtungen geändert. S. a. Kap. 6.1. 
Morgensang, also Morgensingen ebend [sic]. Man singt da eben Lieder, dass man denn [sic] mal miteinander ist. [...] Ich könnte auch öfter Morgensang haben. Ich könnte auch jeden Tag Morgensang haben, weil Morgensang ist ja sowas, da blüht man auf, dann ist man gut gelaunt, auch wenn man dann am Rest des Tages vielleicht so ... nen Test hat. Mein Lieblingslied ist..., Dagen er ny, , Der Tag ist neu'. [...] Und dann lernt man ja immer noch $\mathrm{n}$ bisschen, weil Peter denn was erzählt und dann singen wir wieder ein Lied. Also wir singen immer zwei Lieder. Und dann erzählt er was zwischen den beiden Liedern (Emma in ebd.).

Der Schulleiter Peter Olesen Müller, ursprünglich aus Kolding in Dänemark, erläutert die zusammenschweißende Wirkung: „Das gibt ein [sic] Zusammenhörigkeit unter den Schülern. Das ist unsere Schule“ (Müller in ebd.). Den Schüler*innen erleichtert er die Konstruktion eines Zugehörigkeitsgefühl zu Dänemark mit der Information, „dass in allen Schulen in Dänemark aus dem gleichen Liederbuch wie hier in Eckernförde gesungen wird“ (ebd.). Das mehrmalige gemeinsame Singen soll Gruppen buchstäblich und im übertragenden Sinne in einem Klangkörper vereinen und Zusammenhalt schaffen ${ }^{506}$. Den meisten im Integrationskurs bringt das Singen von fetzigen Liedern und das Singen im Kanon Spaß. Das begrenzte Liedrepertoire, welches wir ständig wiederholen, soll dafür sorgen, dass wir wenigstens ein paar Lieder verinnerlichen und textsicher beherrschen, damit wir die Stücke auch ohne Kopien bei anderen Gelegenheiten singen können. Allerdings ist beim Integrationskurs festzustellen, dass die neudänischen Eltern die Lieder zwar mitsingen, ihnen aber keine große Bedeutung zuschreiben, wie es bei der Nachkriegsgeneration der Fall ist, die mit den Liedern seit ihrer frühen Kindheit aufgewachsen ist. Für die neudänischen Erwachsenen sind die Lieder beliebige Lieder mit pädagogischem Inhalt und dienen dem Erlernen der dänischen Sprache und ,Kultur'. Sie werden nur halbherzig performt, da die Neudän*innen nicht mit dem ritualisierten Singen aufgewachsen sind, die Praxis des gemeinsamen, dänischen Singens nicht verinnerlicht haben und ihnen daher der emotionale Bezug zum Singen dänischer Lieder fehlt.

In der Minderheit wird auch außerhalb des Integrationskurses viel gesungen. Dem gemeinschaftlichen Gesang schreibt der Probst der dänischen Kirche in Südschleswig, Viggo Jacobsen, eine immense Bedeutung zu. Auf dem Jahrestref-

506 Mit Rückgriff auf Alexander von Bormann beschreibt Alfred Roth in seinem Buch über die Bedeutung des Liedes im Nationalsozialismus allgemein das „Gemeinschaftslied als Gruppenlied“, welches „Gruppenidentität schafft und erhält“ über die Generierung von „Gefühle[n], Emotionen und Affekte[n]“. „Über den Appell an kollektive Gefühle und Affekte wird das Wir-Gefühl stimuliert.“ „In der Tat verdankte das nationalsozialistische Massenlied seine propagandistischen Erfolge seiner Emotionalität und Affektgeladenheit sowie der suggestiven Kraft sich stetig wiederholender Phrasen, Schlagwörter und emblematischer Bilder" (Roth 1993: 42; s. a. Bormann 1976: 267). 
fen der Minderheit in Friedrichstadt betonte er als Festredner, dass das gemeinsame Singen ein Instrument sei, um der Gemeinschaft zu dienen und Identität zu konstruieren. Weiter würden Lieder und Psalme auch die dänische Sprache vor dem Verfall schützen (TNB 09.06.2012). Bei den Jahrestreffen sowie bei den meisten anderen Versammlungen wird gesungen. Singen wird mit dem Dänischsein verbunden und weil man dänisch ist, singt man, um das Dänischsein wiederum zu markieren. Diese Praxis findet man nicht nur in Dänemark bzw. bei der dänischen Minderheit, sondern auch in anderen Ländern und Gruppierungen wieder (vgl. Kopiez, Brink 1998).

Bei der Landesdelegiertenversammlung des SSF am 09. November 2013 in Husum wurde zur Eröffnung gesungen, nachdem der 1. Vorsitzende Dieter Paul Küssner dazu aufgerufen hatte und Titel und Seitenangaben in „unserem Gesangbuch“ nannte: „Lasset uns singen Im Osten steigt die Sonne auf, Nr. 3, Seite 10, in unserem Gesangbuch“507 (Küssner in Sydslesvigsk Forening 2013a: 2). Dies ähnelt kirchlichen Praxen im Gottesdienst. Daniela Caspersen, Vorsitzende des SSF Husum berichtet auf derselben Versammlung, dass in ihrem Lokalverein auf den Ausflügen ,immer dänische Lieder gesungen werden“ (Caspersen in ebd.: 38). Durch dieses explizite Hervorheben dieser Praxis unter dem Tagesordnungspunkt „Verbindungslinien nach Dänemark“ gibt sie derselben eine noch größere Bedeutung. Diese quasireligiösen Praxen werden nicht ohne Grund auch vom ehemaligen dänischen Probst für Südschleswig, Christian B. Karstoft, hochgehalten. Dieser konstatiert in einem Interview mit der Flensborg Avis: „Wenn wir Dänen etwas können, dann ist es zusammen singen“" ${ }^{\text {508 }}$ (Karstoft in Peetz 27.04.2013). Für Birte Kohrts aus Harrislee, Dänin der Nachkriegsgeneration, bedeutet das Singen von dänischen Liedern sehr viel. Es weckt bei ihr „Kindheitserinnerungen“ (Werner 16.05.2016): „Das ist ja meine, ehm, Kultur, mit der ich aufgewachsen bin. Das ist ja etwas, was ich ehm immer gelebt habe und deswegen bedeutet es was für mich“ (Kohrts in ebd.). Der Grund für die vielen Anlässe zum Singen ist, dass durch die dabei gemachten „positiven Erfahrungen“ „Prozesse von Wiederholung und Reproduktion auslösen“" (Shove, Pantzar 2016: 109). Dies wiederum führt zu einer Festigung und Verstetigung der Praktik, was wiederum die Zusammengehörigkeit bestärkt.

Im Interview mit Otto Clausen kommen die wöchentlichen Treffen des SSFFreitagsklubs in Friedrichstadt zur Sprache. Clausen hakt - seinen Erwartungen an eine dänische Veranstaltung entsprechend - nach: „Und denn [dann] wurde ge-

\footnotetext{
507 „lad os synge „I østen stiger solen op“, nr. 3, side 10, i vores sangbog“

508 „Hvis vi danskere kan noget, så er det at synge sammen.“
} 
sungen?", fragt er. Ich verneine dies. „Was?", wundert er sich, während seine Frau ungläubig ergänzt: „Kein? Kein Lied?“. Daraus schließt Otto Clausen völlig entgeistert, aber lachend:

Denn [Dann] [...] wars kein dänischer Verein! [...] Also ich hab, ich hab so viel, so viele Sachen schon mitgemacht bei den Dänen, aber es wird immer vorher gesungen, und es wird immer zum Schluss gesungen, und in der Mitte wird auch noch mal gesungen. Das ist nämlich auch so dieses [...] hyggelige (INT04).

Diese Reaktion des Interviewpartners und seiner Frau zeigt, welche Anforderungen an ein Dänischsein die beiden in Flensburg gelernt haben. Sie bewerten das Fehlen des Singens an der Südgrenze Schleswigs als nicht dänisch bzw. ihr eigenes Dänischsein wird als wahrhaftiger eingestuft. Ihre Reaktion spiegelt einen Unterschied zwischen dem Minderheitenzentrum in und um Flensburg und der Minderheitsperipherie wieder. Auch kommt der Widerspruch zwischen Funktionärserwartungen und der Praxis einiger Akteur*innen zutage bzw. das breite Spektrum der unterschiedlichen Formen und Ausprägungen des Dänischseins. Aufgrund der geäußerten Erwartungen Otto Clausens wird erneut deutlich, dass für viele das Singen als ein Kriterium für das Dänischsein dient.

Musik und damit auch Singen schüttet im Gehirn Belohnungshormone aus und kann Glücksgefühle oder andere Emotionen hervorrufen. Dies kann ,erklären, warum Musik in allen menschlichen Gesellschaften ein so hoher Wert beigemessen wird“" und das Wohlbefinden fördert (Altenmüller, Kopiez 2011: 139). In der dänischen Minderheit spielt das Singen nicht aus dem Wissen heraus, dass es eine neurobiologische Wirkung hat, eine große Rolle, aber mithilfe der Neurobiologie kann erklärt werden, warum durch Singen Gefühle und damit Zusammenhalt erzeugt werden. „Musik [...] förderte die Gruppen-Synchronisierung, den Gruppenzusammenhalt", so die Musikwissenschaftler Altenmüller und Kopiez (ebd.: 152). Singen ist Musik, bei der jede*r mitmachen kann ohne besondere Instrumenten- oder Notenkenntnis. Musik ist ein ,identitätsstiftendes Medium“, so der Grazer Ethnomusikologe Gerd Gruppe (Grupe 2011: 7). Musik kann Gruppenzugehörigkeiten „zum Ausdruck bringen“ und zum Prozess der „Abgrenzung zwischen Insidern und Outsidern“ beitragen (ebd.: 8) und sie kann eine „Herausbildung und Darstellung ethnischer Identität“ und religiöser Zugehörigkeit fördern (ebd.: 11). Bei der dänischen Minderheit trifft das in Korrelation mit der Sprache der Lieder zu. Sie werden auf Dänisch gesungen, was sie von deutschsprachigen Liedern unterscheidet. Auch dass das Singen überhaupt eine große Rolle spielt im Vergleich zur deutschen Mehrheitsbevölkerung, in der seit dem Zweiten Weltkrieg das Singen national gefärbter Lieder kaum noch praktiziert wird, ist minderheitsspezifisch. 
Das Singen dänischer Lieder zu rein demonstrativen Zwecken findet Kritikerin Karin Röh, die selbst auf einer dänischen Schule war, „absurd“. Sie behauptet, die Lieder würden nicht gesungen, weil sie einfach schön seien (Röh 2012: 125). „Das Dänischsein wurde in mich hineingesungen“509, so beschreibt Röh das Singen als eine Arte Zwangsmaßnahme (ebd.: 126).

Zusammenfassend, lässt sich sagen, dass die Verwendung von Symbolen wie der Flagge und das Singen spezifisch dänischer Lieder nationale Gesinnung und Einheit symbolisiert und diese ständig neu beschwört werden, wie es Thomas Fröschl parallel für zivilreligiöse Praxen in den USA beschrieben hat (Fröschl 2007: 110).

\section{3 Æblekage und Boller ${ }^{510}$ : Speisen als Symbole}

$\mathrm{Zu}$ den als dänisch deklarierten Symbolen und den damit verbundenen Emotionen, die in der Minderheit eine Rolle spielen, gehören auch dänische Gerichte und Speisen, wie „dänische Boller [...], liebevoll serviert auf roter Tischdecke mit weiBen Streifen. Ein kleiner Dannebrog, die dänische Flagge en miniature rankt in der Mitte" beim monatlichen Kaffeetreffen in St. Peter-Ording während des Bücherbushaltes (Werner 16.05.2016).

Hella Lassen, vom Filmemacher Mads Kamp Thulstrup für den Film De glemte danskere bei den Vorbereitungen für das SSF-Jahrestreffen in ihrem Ortsverein Struktstrup/Struxdorf begleitet, möchte einen typisch dänischen Apfelnachtisch, ablekage, nach alter Art für alle Festteilnehmenden zubereiten (Lassen in Petersen [2014]). Sie betont dabei, dass das Dänische und das Dänischsein so wichtig für sie sei, dass es ihr nicht reiche, die Spezialität nach dänischem Rezept mit in Deutschland gekauften Zutaten ${ }^{511}$ zuzubereiten. Sie schreibt dem Gericht eine so starke spezifisch dänische Bedeutung zu, dass sie sich sogar mit ihrem Auto auf den einstündigen Weg nach Dänemark macht, um dort original dänische Zutaten

\footnotetext{
509 „Danskheden blev sunget ind i mig.“

510 Eblekage ist ein dänischer Nachtisch mit Apfelmus, Boller sind eine Art süße Brötchen bzw. ein rundes Gebäck.

511 Äpfel, Zucker, Vanille, Butter, Sahne, Paniermehl. Diese Grundzutaten sind nicht länderspezifisch geprägt, außer dem für diesen Nachttisch speziell vorbereiteten makronenkrümelähnlichen Paniermehl (ablekagerasp), das es in deutschen Supermärkten, abgesehen von deutschen Grenzshops mit dänischem Sortiment, nicht zu kaufen gibt, das aber durch zerkrümelte Makronen ersetzt werden kann.
} 
zu kaufen, damit der Nachtisch aus ihrer Sicht echt dänisch wird. Sie behauptet, die Zutaten in Dänemark schmeckten ihr besser. Sie könne sich das selbst nicht erklären. ${ }^{512}$

Im Gegensatz dazu fahren viele Dän*innen aus Dänemark zum Einkaufen nach Deutschland, weil Einkäufe in Deutschland aufgrund einer niedrigeren Mehrwertsteuer, besonders auf Lebensmittel ${ }^{513}$, Genussmittel, Getränke und Alkoholika, billiger sind. Hella erzählt, dass ihr bei der Fahrt über die Grenze das Herz aufgehe. Sie fühle sich, als käme sie nach Hause, so wird es im Film gezeigt (ebd.). Dabei ist ihr Zuhause der Lassenhof in Südschleswig. Hella versucht, dänischer zu sein als die Dän*innen in Dänemark. Deshalb betreibt sie einen großen Aufwand, um ihr Dänischsein zu pflegen und sich dadurch von der deutschen Mehrheit abzugrenzen. Für sie wird ihr Handeln, d. h. z. B. ihr Einkauf in Dänemark, bedeutungsvoll für ihr persönliches Dänischsein.

Das Essen ist folglich ein Beispiel für eine abgrenzende Symbolik von einigen Angehörigen der Minderheit. Sie dient der Identitätsstiftung nach innen und der Abgrenzung nach außen. Das Dänischsein und das Minderheitssein wird durch Essenssymbole mit Inhalten und Emotionen gefüllt. Eine noch größere symbolische Rolle für die Minderheit spielen allerdings Flaggen, wie im Folgenden gezeigt wird.

512 Ähnliches behauptet auch das Minderheitsurgestein, Karl Otto Meyer, ehemaliger SSW-Landtagsabgeordneter und Chefredakteur der Flensborg Avis in einem Gespräch mit dem jetzigen Chefredakteur Jørgen Møllekær über dänischen Kaffee, der ihm besser schmecke als deutscher Kaffee (Meyer in Møllekær 24.12.2013). Dabei ist das eine Generalisierung, da Kaffeemischungen und -röstungen sowohl in Dänemark als auch in Deutschland sehr vielfältig und unterschiedlich sein können, was rational gesehen nichts mit einer vermeintlich nationalen Herkunft des Produkts zu tun haben kann. Karl Otto Meyer betont weiterhin ähnlich wie Hella Lassen, dass ,alles, was dänisch ist, ist herrlich“ (,Alt hvad der er dansk er dejligt“, Meyer in ebd.). Auch einige Mitglieder des SSF St. Peter-Ording behaupten, bestimmte Lebensmittel müssten sie in Dänemark kaufen, da sie dort leckerer seien. Dafür nehmen sie sogar eine über $100 \mathrm{~km}$ lange Autofahrt in Kauf. „Bestimmte Dinge muss man in Dänemark kaufen, weil man die hier nicht kriegt" (Gerda Schuppich in Werner 16.05.2016). Dazu zählen die Mitglieder im Radiobeteitrag einstimmig Rødkall, Rotkohl, Leverpostej, Leberpastete, Gammeldansk, dänischer Schnaps, dänischen Käse und Schweinebraten (ebd.). Ein anderer Informant zählt auf, dass es folgende Lebensmittel in Deutschland nicht gebe, sondern nur in Dänemark: Kammerjunker (eine süße Zwiebacksorte), bestimmte Lakritzsorten, Zimtschnecken, Hot Dogs (Informelles Gespräch mit Ingvar Dorling am 04.09.2017).

513 Lebensmittel werden in Deutschland mit $7 \%$, in Dänemark mit $25 \%$ Mehrwertsteuer belegt. 


\subsection{Dannebrog: Flaggen und Fahnen als Symbole}

Im Vorfeld der Jahrestreffen arrangiert der SSF in Zusammenarbeit mit der Danmarks-Samfundet, der Dänemark-Gesellschaft, jedes Jahr einen kostenlosen Fahnenund Flaggenträger*innenkurs ${ }^{514}$ (Sydslesvigsk Forening 26.05.2016). Ziel des dreibis vierstündigen Kurses ist, den richtigen Umgang mit dänischen Fahnen und Flaggen $^{515}$ bei Veranstaltungen und anderen Gelegenheiten zu vermitteln. Alternativ kann auch ein sogenannter Instrukteurskurs besucht werden mit dem Ziel, anschließend selbst SSF-intern Fahnenträger*innenkurse durchführen zu können (FLA 15.01.2014). Die Dänemark-Gesellschaft sammelt darüber hinaus in Südschleswig und Dänemark Geld, um Organisationen der Minderheit dänische Fahnen und Flaggen kaufen und feierlich überreichen zu können.

Dieses Angebot ist, wenn man mit Coakley (2004) argumentiert, eine Vermittlung von Erwartungen und Regularien zum Symbolgebrauch der dänischen Flagge im Auftrag der ethno-nationalen Führung, also der Funktionär*innen der dänischen Minderheit. Benedict Anderson bezeichnet Flaggen als „Symbole das [sic] ,Nation-Seins““ (Anderson 2005: 133), und Eric Hobsbawm vergleicht die Funktion von Flaggen mit denen religiöser Ikonen. Flaggen seien die „Symbole[...] mo-

514 Der Kurs wurde laut SSF-Homepage kurzfristig abgesagt (Sydslesvigsk Forening 2017). Im Mai 2017 fand der Kurs an der A.-P.-Møller-Schule statt. Ein Vertreter der Dänemarkgesellschaft schulte die Teilnehmenden darin, wie dänische Fahnen und Flaggen bei beispielsweise Jahrestreffen zu halten sind, auch wenn der Wind weht. Zusätzlich wurden im einige Stunden dauernden Kurs der Fahnengruß und der Königinnengruß und das Ein- und Ausrollen der Fahne eingeübt, ohne dass diese den Boden berührt. Vorher gab es eine einstündige theoretische Einführung von ehemaligen Militärangehörigen aus dem Königreich. Abschließend gab es ein Fahnenträger*innendiplom, eine Dannebrog-Nadel zum Anstecken sowie ein Fahnenträger*innenhandbuch mit den Fahnenregeln, so der Kursbericht im SSF-eigenen Presseorgan Kontakt als Flensborg-Avis-Beilage (Sydslesvigsk Forening 18.05.2017; Cruys-Bagger 2013).

515 Auch wenn im umgangssprachlichen Gebrauch Fahnen und Flaggen synonym gebraucht werden, wird eigentlich zwischen Fahnen und Flaggen unterschieden. Eine Fahne ist ein ,an einer seiner Kanten dauerhaft oder beweglich befestigte[s] Stoffstück mit symbolischer Bedeutung“, meist an einer Fahnenstange angebracht. Es ist ein Unikat mit einmaliger Bedeutung und kann „nicht ohne Weiteres durch ein gleichartiges Stück ersetzt werden“ (Brockhaus Enzyklopädie Online 2012a). Fahnen wurden historisch vor allem im militärischen Bereich zur Kennzeichnung von Richtungen und Sammelpunkten und Truppen sowie als „Kampf- und Siegeszeichen und als Herrschaftssymbol“ (ebd.), aber auch zur Markierung von Lehen im Mittelalter oder liturgisch in der Kirche verwendet. Eine Flagge dagegen ist ein „Ehren- und Hoheitszeichen, um die Zugehörigkeit zu einer Körperschaft, besonders einer Nation [...], erkennen zu lassen“ (Brockhaus Enzyklopädie Online 2012b). „Flaggen können im Unterschied zu [...] Fahnen [...] durch gleich aussehende Stücke ersetzt werden. Das Zeremoniell der Flaggenhissung gilt nicht dem betreffenden Stück, sondern der Darstellung auf ihm“ (ebd.). Geschichtlich sind Flaggen aus der Kennzeichnung von Schiffen entstanden. Alle Rechtsgrundsätze zu Flaggen sind im Öffentlichen Recht geregelt (ebd.). 
derner Nationen“, die zu bestimmten „rituellen Anlässen“ verwendet würden (Hobsbawm 2005: 88). Durch sie werde ,identity and sovereignity“, „,respect and loyalty“ eingefordert und dargestellt (Hobsbawm 1994: 11). Zeichen und Symbole dienten der „vorgestellten Gemeinschaft“ (Hobsbawm 2005: 109). Flaggen „communicate meaning“ und ,identify groups and territories“ und ,illustrate distinctiveness“" (Elgenius 2007: 26). Thomas Hylland Eriksen bezeichnet Flaggen als Gemeinschaftssymbole bzw. Nationalsymbole mit einer gewissen emotionalen Stärke und Sakralisierung (Eriksen 2007: 1, 2, 12). Sie werden in verschiedenen Staaten und Kontexten mit unterschiedlichen Bedeutungen und Inhalten aufgeladen, die sogar gegensätzlich sein können, wie Eriksen und seine Kolleg*innen anhand der Beispiele USA, Großbritannien und Skandinavien zeigen (ebd.: 2-4). Flaggen erfüllen nur dann eine Funktion über ein Stück Stoff hinaus, wenn sie mit Emotionen und Bedeutungen und verkörperten Ideen, wie beispielsweise Abgrenzungen, verbunden werden und es dadurch eine Gemeinschaft gibt, die hinter der Flagge steht und deren Mitglieder sich die Bedeutung der Flagge teilen (ebd.: 4 5). Für nationale Gesinnungsgruppen wie der dänischen Minderheit stellen Flaggen und andere Symbole einen Verweis auf die vorgestellte Gemeinschaft der Minderheit her (vgl. Hase 2001: 92, 94). Diese Art von Symbol ist ,am besten geeignet, das Individuum subjektiv an die symbolisierte Gemeinschaft zu binden. Sie ermöglichen eine Identifizierung mit dieser Gemeinschaft“ (ebd.: 92). Flaggen „signalisieren Identität, Rechte und Interessen“, sie sind ein „Identitätssymbol“516 (Bjerg 2006: 7). Bei einigen Jahrestreffen der dänischen Minderheit gibt es feierliche Fahneneinweihungen, die mit großer symbolischer Bedeutung durch die teilnehmenden Akteur*innen, vor allem aber durch die Funktionär*innen aufgeladen werden. Die Fahnen werden würdevoll übergeben und nach vermeintlich alten und historischen Regeln geweiht, streng überwacht durch die Danmarks-Samfundet (Clausen 2014: 79) Der Ablauf ist folgendermaßen: die Fahne ist an einer Stange mit blanken Nägeln befestigt, nur die letzten drei Nägel fehlen. Diese werden bei der Einweihung mit einem Hammer durch den Vorsitzenden des dänischen Parlaments Folketing feierlich eingeschlagen. Dabei stehe der erste Nagel für die Königin, der zweite für das Vaterland und der dritte für den jeweiligen Ortsverein. Anschließend stehen alle auf und singen die Nationalhymne (ebd.: 79-80). Der erneute Rekurs auf die dänische Königin sowie das dänische Königreich unterstreicht die Verbundenheit mit Dänemark und konstruiert einen gemeinsamen Traditionsmythos (vgl. a. Coakley 2004).

516 „signalerer identitet, rettigheder og interesser“, ,identitetssymbol“ 
Der Dannebrog $^{517}$, die dänische Flagge, ist seit circa 700 Jahren das Symbol für Dänemark (Bjerg 2006: 7). Sie ist eng mit nationalen Gefühlen verbunden und schafft Zusammenhalt, so der dänische Historiker und Archivar Hans Christian Bjerg (ebd.: 8). Bei vielen Anlässen sei der Dannebrog als „ein natürliches Element" präsent, so die Pressemitteilung im Publikationsorgan des SSF (Sydslesvigsk Forening 26.05.2016). Die Flagge wird bei allen Veranstaltungen der dänischen Minderheit gehisst, nicht nur bei den Jahrestreffen, sondern beispielsweise an Sankt-Hans und bei anderen Festen (TNB am 27.05.-29.05.2011, 09.06.10.06.2012, 07.06.-09.06.2013; Werner 16.05.2016). Der Dannebrog ist also das Symbol für Dänemark und die Verkörperung der imaginierten „,community“ der dänischen Minderheit. Die Flagge ist Gegenstand des Glaubens an die eigene Gemeinschaft. Akteurin Angelika Hesselbarth schildert ihre Gefühle, die sie in Bezug auf die Flagge hat: „Man fühlt sich Dänemark so dermaßen verbunden, das Dannebrog, das ist einfach, das ist ja unsere Gesinnung. Irgendwie ist das unsere Gesinnung“" (Hesselbarth in ebd. ${ }^{518}$; s. a. Kap. 8.1).

\subsection{Die Rolle der Sprache}

In diesem Kapitel wird zuerst kurz der historische Hintergrund der sprachlichen Lage im ehemaligen Herzogtum Schleswig beleuchtet, bevor anschließend die Bedeutungen der Sprache(n) für die Minderheit heute sowie die aktuelle Sprachensituation dargestellt werden.

517 Mehr über die dänische Flagge s. Jenkins (2007), Jenkins (2012), Bjerg (2006) und insbesondere zum Ursprungsmythos der dänischen Flagge s. Bjerg (2006: 11-23). Zur Geschichte der europäischen Flaggen u. a. des Dannebrog als nationale Symbole s. a. Elgenius (2007). Die Toleranz der deutschen Mehrheitsgesellschaft und der deutschen Gesetze zum Gebrauch der dänischen Flagge in Deutschland ist im Vergleich zum Verbot, deutsche Flaggen in Dänemark zu hissen, sehr groß. In Dänemark können nur mit Sondergenehmigung ausländische, nicht-nordische Flaggen (mit Ausnahme der UN-Flagge) gehisst werden und das immer nur gemeinsam mit der dänischen Flagge.

518 Im Gegensatz zum Gebrauch des Dannebrog durch Akteur*innen der dänischen Minderheit wird als Distinktionsmerkmal der deutschen Minderheit in Dänemark die Nicht-Verwendung von Flaggen beschrieben. Dies rührt aus der Geschichte der deutschen Besatzung Dänemarks her, mit dem daraus folgenden Verbot, ausländische Flaggen in Dänemark privat zu hissen. Da Privatleute also nur dänische Flaggen hissen dürfen, aber nicht deutsche Flaggen, ist es kennzeichnend für die Angehörigen der deutschen Minderheit, gar keine Flaggenmasten und Flaggen zu besitzen - im Gegensatz zum weit verbreiteten Dannebrog-Gebrauch ihrer dänischen Nachbarn (informelles Gespräch mit Dorte Tönnsen aus der deutschen Minderheit in Dänemark am 23.07.2013; vgl. a. Jebsen 2008: 138, 139). 
Die politische Grenze zwischen den Landesteilen Schleswig und Holstein sowie die immer wieder verschobene Grenze zwischen Schleswig und dem Königreich Dänemark (Nielsen 2008: 240) bildeten nie Sprachgrenzen. ${ }^{519}$ In Schleswig wurden in sich verändernder Verbreitung die Sprachen Niederdeutsch, Südjütisch $^{520}$ und Friesisch gesprochen, während Reichsdänisch und Hochdeutsch hauptsächlich Kirchen- und Schulsprachen waren (Hansen 2003: 451; Henningsen 2009a: 10; Henningsen 2009b: 19). Die unscharfen Sprachgrenzen verliefen somit quer durch Schleswig und verschoben sich im Laufe der Zeit in Richtung Norden. Unabhängig vom jeweiligen staatsrechtlichen Status des Herzogtums war die Alltagssprache im Süden Schleswigs entweder Niederdeutsch oder Deutsch. Genauso verhält es sich bei der Kirchen- und Amtssprache in Süd- und Mittelschleswig (Hansen 2003: 434, 440; Henningsen 2009a: 10). Weiter nördlich wurden als Umgangssprachen traditionell Niederdeutsch, Friesisch und Südjütisch gesprochen, also kein rigsdansk, Reichsdänisch (Menke 1994: 120; Nygaard 07.06.2014b). ${ }^{521}$

Betrachten wir nun die Bedeutungszuschreibungen der Sprachverhältnisse in Bezug auf Zugehörigkeiten bei der dänischen Minderheit. Sprache und Nationalität bzw. Sprache und Identität hingen im Bewusstsein der Sprechenden vor 1800 nicht unbedingt zusammen, so die Flensburger Linguistin Elin Fredsted (Fredsted in Nygaard 07.06.2014b; Fredsted in Nygaard 11.06.2014; vgl. S. 34). „Für die Menschen waren weder im Mittelalter noch in der Frühen Neuzeit Sprache und Nationalität ein [...] Merkmal für eine nationalstaatliche Ein- oder Ausgrenzung“، (Christiansen 2008: 131). Die Frage der nationalen (deutschen oder dänischen) Zugehörigkeit stellte sich für das Gros der Bewohner*innen erst gegen Ende des 18. Jahrhunderts mit der aufkommenden Idee Johann Gottfried Herders von einer Nation, deren Grundlage „Sprache, Kultur und [...] gemeinsame Lebensweise“ waren (Hansen 2003: 434, m. Rückgriff auf Herder). Auch der Ansatz von Wilhelm Heinrich Riehls aus dem Jahre 1862, ein „Volk“ als ein „durch Gemeinsamkeit von Stamm, Sprache, Sitte und Siedlung verbundenen natürlichen Gliedes im großen Organismus der Menschenheit" (Riehl 1939: 28) zu sehen, trug dazu bei, dass der Sprache innerhalb des Diskurses um die nationale Frage eine

519 Die deutsch-dänische Grenze, ihre Verschiebungen, Deutungen und die Bedeutung von Sprache und Nationalität im Grenzraum in der Zeit von 1830 bis 1867 hat Graw-Teebken (2008) in ihrer in Aalborg erschienenen Dissertation untersucht. Ihr Schwerpunkt ist dabei die Frage nach der Nationalisierung von Grenzräumen durch Historiker, Sprachforscher und Kartografen im 19. Jahrhundert.

520 Sønderjysk ist ein dänischer Dialekt, der auch Südjütisch oder Plattdänisch genannt wird.

521 Allerdings ist historisch gesehen noch einiges zur Sprachsituation in Schleswig unerforscht, z. B. die Frage, wer genau, überhaupt deutsch- oder dänischsprachig war und was das in der Konsequenz bedeutete. War Sprache sozial oder geografisch bedingt?" (Bregnsbo in Weber 2015: 198). Ebenfalls ist unklar, in welchen Lebensbereichen und Kontexten welche Sprachen verwendet wurden und wie gut die Kenntnisse der jeweiligen Sprachen waren. 
große Bedeutung zugeschrieben wurde (Trenz 1937: 25; vgl. a. Köstlin 2007: 35). Durch die imaginierte Verbindung zwischen (Mutter- bzw. Erst-)Sprache und nationaler Zugehörigkeit nahm die Bedeutung von Loyalität gegenüber personenbezogenen „Fürstendynastie[n]“ ab (Hansen 2003: 434). Diese Ideen brachte N. F. S. Grundtvig nach Dänemark und dort werden sie bis heute kaum kritisch hinterfragt, so Pedersen (vgl. Pedersen 2000b: 325-326). Die ehemals vorherrschende, pragmatische Mehrsprachigkeit und Pluralität wurde ab der Mitte des 19. Jahrhunderts in der dänischen Geschichtsschreibung verschmäht und dann zum Teil bis heute vergessen, weil sie ,incompatible with the idea of a national culture“ im Zuge der Nationalisierung Dänemarks waren (Frandsen 2015: 255). Nicht nur auf Dänemark trifft diese historische Entwicklung zu, sondern auch auf andere Nationen, was Konrad Köstlin nicht verwundert:

$\mathrm{Zu}$ den Kontrollmechanismen der In-Group gehört vor allem die Sprachpflege, jene ,language awareness', die den bewussten Sprachgebrauch und die Sprache selbst zum Zentrum und Ausdruck der jeweiligen Kultur dekrediert. Das Bewusstsein über Sprachverwendung gehört daher - auch dies ein Ergebnis der Akzentsetzungen in der Moderne zu den Essentials der Minderheitenidee (Köstlin 2007: 33).

Die heutige Auffassung vieler Dän*innen, dass Dänischsein vor allem auf dänischen Sprachkenntnissen beruhe, ist folglich ein Konstrukt aus der Zeit der Romantik und keine naturgegebene Selbstverständlichkeit. Seit Ende der Napoleonischen Kriege gab es in Dänemark starke nationale Bewegungen, bei denen dem Dänischsein und der dänischen Sprache immer mehr Bedeutung zugeschrieben wurden, obwohl es vorher im Königreich in vielen Bereichen, vor allem in der Administration, üblich war, Deutsch und Französisch zu verwenden (Østergaard 1985: 148, 153). Im Zuge der Nationalisierung wurde der dänischen Sprache eine neue Relevanz als Identitätsmarker zugeschrieben (Frandsen 2015: 249). Dies trifft nicht nur auf Dänemark und Deutschland zu. Auch eine österreichische Studie zu „Zensus und Ethnizität“ kam zu dem Schluss, dass dort Ende des 19. Jahrhunderts nationale Zugehörigkeiten anhand von Sprachen definiert wurden, denn

[n]icht zuletzt auch aufgrund ihrer einfachen Erfassbarkeit hatten sich Sprachen als probates Merkmal von >Nationalität zu dieser Zeit bereits durchgesetzt. Der Nationalitätenstreit war in jeder Hinsicht ein genuiner Sprachenstreit (Göderle 2016: 279).

In ganz Europa wurden durch entsprechende Grammatiken, Wörterbücher und Literatur nationale Vorstellungen geschürt und Nationen anhand von vermeintlichen Sprachgrenzen definiert (vgl. Anderson 2005: 72-87; vgl. Köstlin 2007: 30). 
Benedict Anderson nennt das die „lexikographische Revolution“, die nach und nach „die Überzeugung, Sprachen seien [...] gleichsam der persönliche Besitz besonderer Gruppen - derer, die sie tagtäglich sprechen und lesen“, durchsetzte (Anderson 2005: 88-89). Daraus wurden abgrenzbare Eigenständigkeiten von Gruppe abgeleitet, und es wurde eine vermeintlich gemeinsame Sprache als Alleinstellungsmerkmal verwendet (ebd.: 89). Die ,wichtigste Eigenschaft der Sprache ist $[\ldots]$ ihre Fähigkeit, vorgestellte Gemeinschaften hervorzubringen, indem sie besondere Solidaritäten herstellt und wirksam werden läßt" (ebd.: 133). Für Nationalisten am Ende des 19. Jahrhunderts wurde das Merkmal Sprache zur „Seele einer Nation und [...] zunehmend das entscheidende Kriterium der Nationalität" (Hobsbawm 2005: 114; vgl. Hobsbawm 2005: 74). Sprache ist neben Religion eines der „key emblems or symbols of" „ethnic and national identifications“ (Brubaker 2015: 5). Daher ist es auch für die Funktionär*innen der dänischen Minderheit so wichtig, eine aktive Sprachpolitik zu betreiben, um die nationale Gesinnung konstruieren zu können, da Sprache als Zugehörigkeitskriterium die Identitifizierung mit einer Gruppe einfacher macht. In der Ideologie der deutschen Minderheit in Dänemark und der dänischen Minderheit in Deutschland dient „vor allem die Sprache als Identifikationsmittel“ und „Distinktionsinstanz“, so die Volkskundlerin Nina Jebsen (Jebsen 2008: 120, 131). Die Vielsprachigkeit im deutsch-dänischen Grenzgebiet mit Hochdeutsch, Niederdeutsch, Nordfriesisch, Dänisch und Südjütisch wurde durch einen konstruierten Antagonismus Deutsch-Dänisch verdrängt, der als Argument bei der gegenseitigen Abgrenzung der jeweiligen Nationen half (Frandsen 2015: 244, 252, 255). Dies bezieht sich auf die Ideologie von Funktionär*innen, Propagandist*innen und Akteur*innen, wobei alle fünf Sprachen bis heute, teilweise in deutlich geringerer Verbreitung, erhalten geblieben sind. ${ }^{522}$

Obwohl die essenzialistische Idee vom vermeintlich natürlichen Zusammenhang zwischen Sprache und nationaler Zugehörigkeit bzw. die Vorstellung, dass Sprachgrenzen auch Kulturgrenzen seien, in der Wissenschaft seit langem widerlegt ist (Seifert 2009: 43; vgl. Hobsbawm 2005: 31), glauben viele Menschen immer noch an diesen Zusammenhang, wie beispielsweise der dänische Autor Egon Clausen. Sprache ist für ihn kulturtragend und grenzendefinierend (E. Clausen in Mølvig 17.10.2012). Er kritisiert daher den seiner Meinung nach zu geringen Gebrauch der dänischen Sprache in der Minderheit (E. Clausen in ebd.). Obwohl das Minderheitensein offiziell auf Gesinnung beruht und nicht auf Dänischkenntnissen (vgl. a. Menke 1994: 116, 118-119) und obwohl die Geschichte zeigt, dass Sprache und nationale Gesinnung nicht natürlicherweise zusammengehören müssen (vgl. Henningsen 2013: 221), wird die Sprachbeherrschung von Angehörigen der Minderheit immer wieder von einigen Akteur*innen und vor allem von Funk-

\footnotetext{
522 Beispielsweise wirbt der Landkreis Nordfriesland mit der Fünfsprachigkeit (Kreis Nordfriesland 01.05.2013).
} 
tionär*innen als ein Kriterium für das Dänischsein herangezogen, so beispielsweise durch den SSW-Landtagsabgeordneten Lars Harms ${ }^{523}$ und den ehemaligen Amtssekretär Rolf Ingwersen ${ }^{524}$. Das Gleiche passierte auch bei anderen informellen Gesprächen während meiner Feldforschungen, beispielsweise mit dem Organisten der dänischen Kirchengemeinde in Friedrichstadt und seiner Frau und im Gespräch mit dem Eiderstedter Urgestein Sönnich Volquardsen auf dem Jahrestreffen in Tönning 2013. Die Akteur*innen ziehen oft Analogien zwischen dem Grad der Dänischbeherrschung und dem für sie daraus folgenden Grad der dänischen Gesinnung. Dies ist ebenso beim SSF zu beobachten, der in einer Pressemitteilung einerseits verlautbart, dass die dänische Minderheit eine Gesinnungsminderheit sei und man Mitglied sein könne, ohne die dänische Sprache zu beherrschen. Andererseits wird an gleicher Stelle bezweifelt, dass man sich ohne Dä-

523 Teilnehmende Beobachtung und informelles Gespräch mit Lars Harms, Landtagsabgeordneter des SSW, am 29.05.2011 auf dem Jahrestreffen in Tönning.

524 Nachdem ich einige Male beim Freitagsklub beobachtend teilgenommen hatte, wurde ich vom Amtssekretär Rolf Ingwersen (Name geändert) gefragt, ob ich nicht auch Interesse hätte, in den SSF einzutreten. Auf meine Frage hin, was das kostet und welche Vorteile ich davon hätte, machte er Werbung für seinen Verein, indem er sagte, dass es für Studierende nur $5 €$ pro Jahr koste, das erste Jahr beitragsfrei wäre, man bei Ausflügen und Konzerten, die der SSF organisiere, Rabatt auf den Eintrittspreis bekäme und dass es sich, wenn man mal nach Dänemark wolle, um dort zu studieren oder zu arbeiten, ,gut“ mache, in einem Verein der dänischen Minderheit in Südschleswig Mitglied zu sein. Das zeige das Interesse am und die Verbundenheit mit dem Dänischen. Dann fing er an, mit mir Dänisch zu reden. Mir erschien es, als wäre ich mitten in einem kleinen Test zur Überprüfung meiner Sprachkenntnisse. Rolf Ingwersen überreichte mir anschließend ein Beitrittsformular (,Ansøgning om optagelse i „Sydslesvigsk Forening e. V.“, SSF) für den SSF, welches ich ihm beim nächsten Freitagsklub ausgefüllt zurückgab. Das Aufnahmeformular ist zweisprachig (Dänisch und Deutsch). Die deutschsprachigen Angaben enthalten teilweise Rechtschreibfehler. Daraufhin sagte, er, dass er sich freue, dass ich Mitglied bei ihnen werden wolle, die (inoffiziellen) sprachlichen Voraussetzungen, das hätte er beim letzten Mal ja gemerkt, hätte ich ja. Weiterhin bemerkenswert an diesem Vorgang ist, dass im Formular offiziell nicht abgefragt wurde, ob oder wie gut der*die Antragsteller*in Dänisch spricht. Stattdessen wurde ich gefragt, ob ich eine dänische Schule besucht habe. Dies kreuzte ich wahrheitsgemäß mit „,nein“ an, woraus Rolf Ingwersen ein ,ja“ machte, da ich, wie er meinte, ja gut genug Dänisch sprechen würde, um ein ,ja“ hätte ankreuzen zu können. Im Prinzip verbirgt sich also hinter der offiziellen Frage nach dem Schulbesuch die eigentliche Information über die Dänischkenntnisse einer Person. Der SSF beabsichtigt Folgendes: „Der Zweck des Vereins ist die Verbreitung und Pflege der dänischen Sprache, dänische und nordische Kultur zu schützen und zu fördern, dänisches Volkstum in Südschleswig zu verwirklichen, das Verständnis für die südschleswigsche Heimat und ihre Eigenart zu mehren und den Zusammenhalt der Mitglieder untereinander zu stärken“ (Sigaard-Madsen 1995: 148; im dänischen Original in der Broschüre: Velkommen i Sydslesvigsk Forening - i Husum amt og dit lokale Distrikt Sydslesvigsk Forening Husum Amt). Man benutzt in dieser Formulierung den antiquierten Kulturbegriff des, Volkstums`. Da hier aber nicht konkretisiert wird, was eigentlich „dänische und nordische Kultur“ ist, und wie diese genau gefördert werden soll, ist die Formulierung sehr schwammig. 
nischkenntnisse in der dänischen Minderheit heimisch fühlen könne und daher der SSF eine Initiative für eine interne Sprachpolitik starten solle, damit alle Dänisch lernen: „Lasst uns einen gemeinsamen - und einen persönlichen - Einsatz für das Sprechen [des Dänischen] machen ${ }^{\text {c6525 }}$ ist die Devise des SSF (Sydslesvigsk Forening 19.11.2015), damit Dänisch nicht nur Institutionensprache bleibe. Hier tritt erneut die Ambivalenz zwischen der Offenheit der Minderheit einerseits und der Abgrenzung anhand mit Bedeutung aufgeladener Faktoren andererseits zutage.

Nils Vollertsen erläutert, warum Funktionär*innen und einige Akteur*innen heute immer noch Sprache als Kriterium für das Dänischsein propagierten und es ihnen nicht egal sei, welche Sprachen die Minderheitsangehörigen nutzten: Wenn man die sprachliche Realität und Pluralität in der Minderheit öffentlich zugebe und damit einräume, wie wenig Dänisch in der Minderheit gesprochen werde, dann würde dies von steuerzahlenden ,Reichsdänen` als Argument für das Ende des dänischen Geldflusses benutzt werden. Denn, so Vollertsen, wenn sie als Minderheitendän*innen ohnehin kein Dänisch sprächen, und damit in den Augen der ,Reichsdänen' keine Dän*innen seien, warum sollte man ihnen dann noch Gelder geben (Vollertsen 20.11.2012). Viele von ihnen sähen nur die beiden Kategorien Deutsch oder Dänisch, könnten sich eine Mischung oder Überlappung oder Mehrsprachigkeit aber nicht vorstellen. „Es scheint, als sei sowohl Zweisprachigkeit als auch die "Zwischensituation“ nationaler Minderheiten äußerst schwer nachzuvollziehen" (Graw-Teebken 2008: 64). Daher sei der dänische Staatszuschuss an die Minderheit gefährdet (Vollertsen 20.11.2012). Dänisch spiele „eine zentrale Rolle ${ }^{\text {c6526 }}$ und sei „Grundlagee „6527 für die finanzielle Unterstützung der Minderheit durch Dänemark (Kühl 27.07.2016), da Dänisch als „zentraler Identitätsmarker für die Minderheit ${ }^{\star 6528}$ vom dänischen Staat angesehen werde (ebd.). Das gelte auch dann, wenn in der Minderheit die meisten Deutsch als Erstsprache hätten (ebd.; s. a. Kap. 7.6). Das sind rund 90 bis $95 \%$ der Dänischgesinnten (Kühl 16.06.2016; Fredsted in Nygaard 07.06.2014a) ${ }^{529}$. Da viele Kinder Deutsch als Erstsprache hätten, reiche es sprachlich gesehen für das professionelle Erlernen einer Sprache nicht aus, dass sie nur in der Schule Dänisch redeten (Kühl 16.06.2016). Es gebe viele deutschsprachige Eltern, die für ihre Kinder das dänische Schulsystem wählten, aber im Laufe von 13 Jahren kein Dänisch lernten,

\footnotetext{
„Lad os gøre en fælles - og en personlig - indsats for så også tale det.“

„en central rolle“

"grundlaget"

„central identitetsmarkør for mindretallet"

Um einen vergleichenden Blick auf die Minderheit der Sorben zu werden: Bei ihnen könne ein „Großteil“ „,besser Deutsch“ „als Sorbisch“. „Die Minderheitenidentität wird dann eher durch Professionelle aufrechterhalten, „Berufssorben“, die ihren Lebensunterhalt damit bestreiten, daß sie sich um die Existenz der Sorben kümmern“ (Toivanen 2001: 39, s. a. 44). Das funktioniert also ähnlich wie bei vielen Funktionär*innen in der dänischen Minderheit auch.
} 
so die Kritik Kühls (Kühl in Rebsdorf 15.06.2016b). Obwohl Kühl der Sprache im Gegensatz zu einigen SSF-Funktonär*innen keine sehr große minderheitskonstituierende Bedeutung zuschreibt (Kühl 16.06.2016), hält er es für ungünstig, wenn die Eltern die Abiturreden nicht verstünden oder sich später nicht mit ihren Enkeln unterhalten könnten, wenn ihre Kinder nach der Schule nach Dänemark umzögen, dort blieben und ggf. eine Familie gründeten. Kühl betont in einer Arsmode-Rede, dass die deutsche Sprache „vorherrschend“530 sei und Dänisch vor allem die Sprache der Minderheitsinstitutionen sei (ebd.). Obwohl die dänischen Schulen das hauptsächliche Ziel hätten, Dänisch zu vermitteln, werde die Minderheitenzugehörigkeit „,nichtsprachlich“ ${ }^{\text {531 }}$ gedacht werden, so Kühl (ebd.) im Kontrast zu den Aussagen einiger Vereinsfunktionär*innen, die die sprachliche Realität in Schleswig kritisieren. So ist Dänischsein und Dänisch für viele Akteur*innen oftmals nur eine „leidenschaftslose Klammer“532 für die Dauer der Schulzeit ihrer Kinder, obwohl sie mit der Einschulung ihrer Kinder unterschrieben hätten, Dänisch zu lernen, sagt Jon Hardon Hansen (Rebsdorf 07.07.2016). Die Abiturient*innen aus Südschleswig, die zum Studieren an das University College Syddanmark (UC Syd) gingen, würden ein nicht so gutes Dänisch sprechen, so der Prorektor Alexander von Oettingen in der Flensborg Avis (Rebsdorf 15.06.2016a). Er erinnert daran, dass das Sydslesvig-Dansk, das südschleswigsche Dänisch, nicht gut genug sei für professionelle Kontexte in Dänemark, obwohl die Schulabgänger*innen ein dänisches Abitur hätten. Von Oettingen fordert nicht nur die Eltern auf, mehr Dänisch zu lernen und zu sprechen, sondern auch das Personal des Skoleforening solle besseres Dänisch lernen. Er fordert ein Sprachscreening des Personals vor deren Anstellung im Schulverein (Rebsdorf 15.06.2016a). Wird die Ausbildung an den Minderheitsschulen als Vorbereitung auf ein Leben in Dänemark gesehen, ist die geschilderte Erwartung an die Sprachkompetenz nachvollziehbar. Geht man von einer Ausbildung von Angehörigen der Minderheit für die Minderheit in Südschleswig aus, widerspricht die Forderung nach perfektem, standardisiertem Hochdänisch den historischen Begebenheiten, denn Hochdänisch war „niemals Umgangssprache der autochthonen Minoritätsmitglieder" (Menke 1994: 120).

Dänischkenntnisse werden also von vielen Ideolog*innen als Beweis und Indikator für das Dänischsein gewertet, auch wenn gleichzeitig behauptet wird, dass man auch Dänisch gesinnt sein könne, ohne die dänische Sprache zu beherrschen. Wer aber wirklich dänisch werden wolle, solle Dänisch lernen. Die angebotenen Sprachkurse werden zu Integrationsinstrumenten, und Dänischkenntnisse dienen als Abgrenzungsmomente nach außen. Die Minderheit verwendet dieses Mittel

\footnotetext{
530 ,altovervejende“

531 „,ikkesprogligt“

532 „ulidenskablig parentes“
} 
also als eine Art Lackmustest für den Integrations- und Lernwillen von Neudän*innen. Da aber theoretisch jede*r Dänisch lernen kann, ist die Argumentation, dass Dänisch als Erstsprache jemanden Dänisch mache, nicht plausibel. „Sprache ist kein Instrument für den Ausschluß: Im Prinzip kann jeder jede Sprache lernen“ (Anderson 2005: 134). Nicht jede*r, die*der einen Dänischsprachkurs besucht, möchte dänisch werden. Und es gibt heute Minderheitsdän*innen, die kaum Dänisch sprechen, sich aber dänisch fühlen. Auch bis ins 19. Jahrhundert zurück war es üblich, dass Menschen mit Deutsch als Erstsprache sich dänisch fühlten und dänischsprachige Schleswiger*innen sich nicht dänisch fühlten (Frandsen 2015: 249).

Obwohl Ideolog*innen die Sprache als Kriterium verwenden wollen, beschreiben auf der anderen Seite die Wissenschaftler*innen Peter Thaler (Jurist, Historiker, Skandinavist) und Karen Margrethe Pedersen (Linguistin), dass Sprachen beiderseits der Grenze abseits der Ideologien eigentlich nicht als sogenannte objektive Identitätsmarker fungieren: „on both sides of the border, national minorities developed a sense-of-self not rooted in language" (Thaler 2007: 159; vgl. a. Thaler 2006: 415). Er ergänzt: „minority affiliation is rooted in personal decision rather than in language" (Thaler 2009: 64; s. a. Jensen 2009; Pedersen 2000a). Für dänische Minderheitsakteur*innen seien „politische, wirtschaftliche und intellektuelle Gesichtspunkte wichtiger" (Thaler 2006: 414). Als Mutter- bzw. Erstsprache spielt Dänisch daher fast keine Rolle für die Minderheit, abgesehen von Menschen aus reichsdänischen Familien. Kühl betont, dass das Dänischsein nicht mit dem tatsächlichen Sprachgebrauch übereinstimme, sondern eher durch anderes geprägt werde, wie „Mentalität, Pädagogik, immaterielle und [...] materielle Werte“ ${ }^{\text {‘533 }}$ (Kühl 16.06.2016). Die Minderheit sei keine sprachliche Minderheit, sondern eine Gesinnungsminderheit, erläutert ebenso Kim Andersen aus dem Südschleswigausschuss (Nygaard 13.12.2014), auch wenn es Reichsdän*innen und Minderheitendän*innen gibt, die, wie oben beschrieben, anderer Auffassung sind. Die Widersprüche zwischen den Erwartungen einiger Funktionär*innen einerseits sowie die beobachtete sprachliche Alltagswirklichkeit andererseits ist „,weder neu noch überraschend “5334, sondern kennzeichnend für die Minderheitensituation (Kühl 16.06.2016). Das Paradoxon rund um die Spracherwartungen durchzieht die immer wiederkehrende Sprachdebatte in der dänischen Minderheit seit über 50 Jahren (ebd.). Entscheidend ist hier der Unterschied zwischen wissenschaftlicher Betrachtungsweise und der Auffassung der Akteur*innen und Ideolog*innen bzw. Funktionär*innen, die der Sprache eine kategoriale und identitätsmarkierende Bedeutung zuschreiben. Obschon Dänisch faktisch in der Minderheit außer-

\footnotetext{
533 „mentalitet, pædagogik, immaterielle og [...] materielle værdier“

534 „hverken nyt eller overraskende“
} 
halb offizieller Kontexte wenig genutzt werde, habe die Sprache eine große symbolische und imaginierte Bedeutung für „die Identität“535 (Kühl 27.07.2016). Sie könne daher „symbolische Muttersprache“ “536 genannt werden (ebd.). ${ }^{537}$

Die Position der Minderheitenlobbyorganisation FUEV geht in eine etwas progressivere Richtung: Die „Aneignung der Minderheitensprache ist wesentliche Voraussetzung für die Bewahrung und Förderung der eigenen Identität der Minderheitenangehörigen“ (Schultz, Walde 2007: 10; vgl. a. Rein, Hilger 2008: 56). Es wird gleichzeitig aber auch deutlich gemacht, dass das „parallele Erlernen der Minderheiten- und Mehrheitssprache(n) als natürliche Zwei- und Mehrsprachigkeit“ „europäischer Standard“ sei und „,auf natürliche Art die Erhaltung der europäischen Sprachenvielfalt“" unterstütze (Schultz, Walde 2007: 10) ${ }^{538}$. Dies kann - bezogen auf die dänische Minderheit - einerseits heißen, dass es zwar tatsächlich Zwei- oder Mehrsprachigkeit unter den Akteur*innen gibt (Pedersen 2000a: 7781; vgl. a. Werner 16.05.2016), Zweisprachigkeit andererseits aber nicht das ideologische Ziel von SSF und Skoleforeningen ist, sondern Dänischsprachigkeit. Daher

ist festzustellen, dass die zum Teil erhobene Forderung nach Beherrschen der dänischen Sprache eine wichtige Handlungsoption der zentralen Akteure darstellt, um das beschriebene „,minderheitliche Nationalstaats-Konstrukt“" zu stärken (Christiansen 2008: 130).

Bei einigen Funktionär*innen besteht die Angst, dass die Existenz der dänischen Minderheit und ihre Selbstauffassung als nationale Minderheit in Gefahr gerät, wenn die Angehörigen kein Dänisch mehr sprechen würden (Pedersen 2000b: 325). Kühl fragt etwas zynisch und sich auf die beschriebene Angst beziehend, wie diese Minderheit ihre Identität durch Sprachverlust verlieren könne, wenn sie ohnehin mehr Deutsch als Dänisch spreche (Kühl 27.07.2016). Die Angst zeigt sich in den regelmäßigen Abständen, in denen Funktionär*innen einiger dänischer Vereine immer wieder eine gemeinsame Sprachpolitik für die gesamte dänische Minderheit fordern und somit Diskussionen in der Minderheit und in der Flens-

\footnotetext{
,identiteten“

"symbolsk modersmål“

Hier kann wieder eine Parallele zu den Sorben gezogen werden, denn auch dort gelten die beiden sorbischen Sprachen als Hauptidentitätsmerkmale unabhängig von den Sprachkenntnissen. Es ist sogar so, dass je mehr die kommunikative Funktion der Sprache abnimmt, desto größer ihre symbolische Funktion wird, so Reetta Toivanen in ihrer Dissertation (ebd.: 44).

538 Zur Mehrsprachigkeit als pädagogische Herausforderung s. das Beispiel der slowenischen Minderheit in Kärnten (Gombos 2017).
} 
borg Avis lostreten, so beispielsweise der Generalsekretär des SSF, Jens A. Christiansen, im Oktober 2016 mit seinem Plädoyer für mehr Dänischgebrauch in der Minderheit zur Markierung des Dänischseins.

Die Sprachverwendung im Alltag sieht bei Akteur*innen weniger ideologisch und eher pragmatisch, aber vor allem deutschsprachig aus. Tina Zehntner spricht zu Hause Deutsch mit ihrem Mann und ihrer Tochter Emma ${ }^{539}$, wenn alle drei zusammen sind. Ihr Mann kann nicht viel Dänisch, aber sobald sie mit Emma alleine ist, zum Beispiel auf dem Weg zum Kindergarten, sprechen die beiden Dänisch miteinander. Gute-Nacht-Geschichten beim Zubettgehen werden von Tina Zehntner auf Dänisch vorgelesen, von ihrem Mann Uwe ${ }^{540}$ auf Deutsch. Dasselbe gilt auch für das Singen von Kinderliedern. Zehntner sieht in dieser Kombination das Typische für Südschleswiger: „das ist eben für mich eben, das ist für mich Sydslesvig eben dieses ... beides“ (INT10). Auch Abiturientin Stine plädiert für die Akzeptanz des Beidessein, denn ,man fühlt sich weder dänisch noch deutsch. Man ist so irgendwas dazwischen" (Abiturientin Stine in Werner 16.05.2016).

In den Interviews kommt Kritik an Neudän*innen auf, die in Vereinen oder Parteien der Minderheiten mitmachen oder ihre Kinder in die dänische Schule schicken, aber selbst keine solche Schule besucht haben. Aus Sicht derjenigen, die auf einer dänischen Schule waren und darin eine Art Echtheitsbestätigung ihres Dänischseins sehen, können die von ihnen Kritisierten oftmals nicht richtig Dänisch. Der Schulbesuch dient quasi als Zertifikat dafür, dass man sich dänisch nennen darf. Zwar betonen die Interviewten, dass alle willkommen seien, bei ihnen mitzumachen, auch wenn man nicht die dänische Schule besucht habe, aber sie erwarten trotzdem, dass die dänische Sprache erlernt wird. ${ }^{541}$ „Wenn sich jemand nur bemüht, 'nen paar Brocken Dänisch zu sprechen, dann sind die Dänen schon [...] mehr als zufrieden“ (INT04), dann sei, so Otto Clausen, ,jeder, jeder [...] herzlich, aber wirklich herzlich eingeladen und jeder kann mitmachen“ (INT04) bei der Minderheit.

Diejenigen, die Mitglieder in dänischen Vereinen oder der Partei sind und kein Dänisch sprechen, werden von den Interviewten größtenteils als merkwürdig oder unglaubwürdig aufgefasst. Sie distanzieren sich von ihnen. Die Kritik an Menschen in den dänischen Organisationen, die kein Dänisch sprechen können,

539 Name geändert.

540 Name geändert.

541 Das Südschleswigerwerden ,würde ich nicht unbedingt an die Schule binden, aber ich denke, 'nen bisschen Dänisch sollte man vielleicht schon können, ja, das, sonst würde mir das 'nen bisschen merkwürdig vorkommen“ (INT02). Vielleicht drückten sie sich auch im Hinblick auf ihre Vermutung, dass ich eventuell auch dänisch werden wollte und sie mich nicht direkt vor den Kopf stoßen wollten, so tolerant aus. 
dient der „kollektiven Selbstdefinition“ (Hansen 1995a: 153) von Dänischsprachigen durch Abgrenzung. Die Akteur*innen machen sich nämlich Gedanken darüber, wer nicht (richtig oder wirklich) zu ihnen gehört, denn

Gruppen [haben] mehr oder weniger konkrete Vorstellungen davon [...], was für sie charakteristisch ist. Jede Gruppe formuliert dabei mehr oder weniger explizit Kriterien, nach denen sie einerseits die Zugehörigkeit den Individuen zugesteht oder verweigert, und die andererseits als Modell dienen, wie diese, idealtypisch“ sein oder sich verhalten sollten (Schneider 2001: 38).

So kritisiert beispielsweise Frieda Thebens die Zusammensetzung des Hausfrauenvereins $^{542}$ : „Ist ja schön und gut, wenn die zur Fahne halten, aber dat ist nun wirk', [...] da kann keiner Dänisch von den[...], das war nun wirklich nicht mein Ding“ (INT05), ${ }^{53}$ denn die meisten seien nicht auf der dänischen Schule gewesen. Ein anderes Beispiel ist die Kritik einiger Gesprächspartner*innen an der aktuellen Vorsitzenden der Ortsgruppe der dänischen Minderheitenpartei SSW in Friedrichstadt, Frauke Likowski ${ }^{544}$. Sie sei, so die Aussage der Interviewten, nicht wirklich dänisch. Sie habe weder eine dänische Schule besucht, noch sei sie bereit Dänisch zu lernen (INT04, INT06). Der einzige Bezug zum Dänischen bestehe für sie darin, dass ihre Kinder die dänische Schule besuchen und sie sich politisch von ihren sehr konservativ-deutschen Eltern und nationalsozialistischen Großeltern emanzipiert habe (INT06, INT03). Otto Clausen hat jene SSW-Vorsitzende darauf angesprochen, warum sie kein Dänisch könne. Da habe sie geantwortet, dass sie „alles auf Dänisch“ verstehe, es aber nicht spreche (INT04). Das irritiert Otto Clausen sehr, denn

das kenn' ich anders in Flensburg. Also in Flensburg ist es so, wenn du so, so offiziell zusammenkommst von der Minderheit, dann sprichst du auch viel Dänisch. [...] Das würde man in Flensburg, 'nen Offizieller in Flensburg, der kann zumindest Dänisch sprechen (INT04).

\footnotetext{
542 Husmoderforeningen in Friedrichstadt.

543 Bei der teilnehmenden Beobachtung konnte ich feststellen, dass bei einem wöchentlichen Treffen dieses Vereins alle Deutsch sprachen. Nur drei Frauen konnten auch Dänisch. Die anderen waren aber in der Lage, die dänischen Lieder mitzusingen.

544 Name geändert. Diese Kritik der Interviewten bezieht sich nur auf das fehlende Dänischsein und die fehlenden Sprachkenntnisse der Funktionärin, nicht aber auf ihre Arbeit als Lokalpolitikerin oder auf sie als Person.
} 
Otto Clausen begründet das für sich damit, dass „,desto weiter du von der Grenze wegkommst, ist das doch etwas anders“ (INT04). Ihm ist noch mehr aufgefallen: Bei einer Wahlkampfveranstaltung vor der Kommunalwahl 2008 bot der SSWOrtsverein Friedrichstadt für alle Interessierten eine gemeinsame Grachtenfahrt auf den Gewässern Friedrichstadts an, ,und da [...] sind wir mitgewesen und da haben wir uns gewundert, also, die waren zwar alle von der dänischen Minderheit und, aber es sprach niemand Dänisch, also absolut nicht", erzählt Otto Clausen entsetzt (INT04).

Schauen wir auf andere Minderheiten in Europa und die Rolle von Sprachen für sie: Marija Jurić-Pahor bestätigt in ihrem Beispiel der slowenischen Minderheit in Triest im Habsburger Reich im 18. Jahrhundert die auch dort „zentrale Rolle“ des Schulsystems und der Verwendung einer gemeinsamen Sprache „für die Integration und innere Festigung“. „Sprache wird zum sichersten Kriterium der Nationalität, zum wesentlichsten Bestimmungsgrad der Identität“ (Jurić-Pahor 2001: 69). Sprache wird bei Minderheiten als bewahrenswerte kulturelle Praktik angesehen, um sich abzugrenzen (vgl. Glaser 2001: 84). Ganz ähnlich, hat es auch Konstanze Glaser für die Minderheiten der Ober- und Niedersorben beschrieben. Dort gibt es auch Wege, wie beispielsweise die Verwendung der Tracht, das Praktizieren von Bräuchen oder das Sich-berufen auf Vorfahren, um sich ohne die Beherrschung der sorbischen Sprache sorbisch zu fühlen. Allerdings sorgen die sorbischen Institutionen dafür, dass die Sprache ,in den übergreifenden identitätsstiftenden narrativen und in den offiziellen Bestrebungen zur Erhaltung der sorbisch-wendischen Kultur eine Schlüsselrolle“ spielt (ebd.: 90). Die Sprache wird

aber auf der Ebene des subjektiven Bekenntnisses sowie beim alltäglichen sozialen gatekeeping (d. h. im Kontext von Argumenten und Verhaltensweisen, die auf die Eingliederung oder Ausgrenzung von Individuen hinauslaufen) erheblich durch die jeweiligen örtlichen Gegebenheiten und persönlichen Umstände relativiert (ebd.: 91).

Die Funktion der Sprache als gatekeeping-Instrument ist auch bei der dänischen Minderheit in Schleswig zu beobachten, so ein Ergebnis dieser Arbeit. Die Rolle der Sprache für die Minderheit (s. a. Kap. 6.1.3 u. 6.1.4) ist also nicht nur Kommunikationsmittel in offiziellen Kontexten, sondern vor allem als Symbol für die Markierung des Dänischseins und des Zusammenhalts nach innen sowie nach auBen wichtig, auch wenn Dänisch in privaten Zusammenhängen in neudänischen Familien keine Rolle spielt. ${ }^{545}$

\footnotetext{
545 Vgl. zu diesem Aspekt auch Feischmidt, die die Rolle der Sprachen für zwei Volksgruppen in Siebenbürgen untersucht hat (Feischmidt 2003: 228).
} 
Im nächsten Kapitel wird beschrieben und analysiert, wie die Interviewten versuchen, ihre subjektive, auf Gefühlen beruhende Zugehörigkeit sich selbst und anderen gegenüber zu objektivieren und zu legitimieren und dafür Geschichtsmythen konstruieren.

\title{
8.6 Historisierungen, Mythen, Objektivierungs- und Legitimierungsversuche
}

\author{
„Nations are themselves myths. There is no \\ such 'real entity' as a nation: only a social \\ reality $[. .$.$] when enough people are prepared$ \\ to believe in the salience of a certain set of \\ characteristics as attributes of nationbood. \\ Such characteristics might include language, \\ culture, religion, belief in common descent or \\ ethnicity. [...] [M]yths have been seen as \\ central to the construction of a sense of being a \\ nation." \\ Mary Fulbrook (Fulbrook 1997: 72)
}

Wie sich in den vorherigen Kapitel schon gezeigt hat, basiert die Zugehörigkeit zur dänischen Minderheit auf subjektiven Kriterien und nicht auf objektiven Merkmalen, wie es zum Beispiel ein Geburtsort sein könnte. Man kann das Dänischsein an „nichts festmachen“ (INT03). Aus den Interviews wurde deutlich, dass sich einige Dänischgesinnte wegen dieser zufälligen, manchmal auch beliebigen Zugehörigkeit berufen fühlen, ihr Dänischsein oder die einmal oder immer wieder getroffene Entscheidung für das Dänische gegenüber sich selbst und anderen zu rechtfertigen. Diese „Selbstverortungen erfolgen nie im leeren Raum, sondern stets in historischen, situativen und strukturierten Kontexten" (Dannenbeck 2002: 36). ${ }^{546}$ Phänomene wie Sprache, Herkunft und ,Kultur' und Mythen darüber werden zur Konstruktion von Nationen verwendet, wie das Eingangszitat von Fulbrook belegt. Dies kann übertragen werden auf nationale Minderheiten und soll hier exemplarisch anhand der dänischen Minderheit beschrieben werden. „,[N]ationales Denken' stiftet feste politische und räumliche Horizonte und vermittelt [...] Wert- und Gefühlsorientierungen, die integrativ wirk[...]en, da sie Sicherheit, Bindung und Gemeinschaft" (Kaschuba 1995: 292) versprechen. Aus

546 Vgl. dazu auch das Beispiel Bönisch-Brednichs, welches Lehmann (Lehmann 2007: 193) beschreibt. 
diesem Grunde betreiben die Akteur*innen Historisierungen, Diskussionen über die ,Echtheit' des Dänischseins und Abgrenzungsstrategien. Vermeintliche oder reale Unterschiede werden als subjektiv wichtige Differenzierungskennzeichen verwendet (Sekulić 2008: 457). Man kann bei den Interviewten Objektivierungsund Legitimierungsversuche (Eriksen 2002: 71-72) ${ }^{547}$ für ihre Zugehörigkeiten beobachten, die durch eine in der Gegenwart konstruierte Geschichte oder durch vermittelte Geschichten untermauert werden (vgl. Henningsen 2009b: 12; Kaschuba 2001: 21; Kaschuba 2003: 141, 144; Schmidt-Lauber 2007b: 186, 212; Hutchinson, Smith 1996: 7; Jahnke 2016; Hobsbawm 1994: 7). ${ }^{548}$ Dabei wird von den Akteur*innen und Funktionär*innen als wichtigstes Argument ein Bogen in die Vergangenheit „als Rekurs auf die Geschichte“ im Allgemeinen (SchmidtLauber 2007b: 185) und zu persönlichen Vorfahren gespannt. Denn eine (imaginierte) ethnische Gruppe sei mit Rückgiff auf Max Weber „based on the subjective belief of group members in their common descent" (Sekulić 2008: 457). Dabei fällt auf, dass gezielt einige „passende“ Sachverhalte aus der Vergangenheit herausgegriffen, andere jedoch ausgelassen, nicht beachtet oder verdrängt werden (vgl. Engelhardt 1990: 197; Gellner 1991: 89; Coakley 2004). ${ }^{549}$

In recent years, anthropologists have been concerned with the ways in which history and cultural symbols are manipulated in the creation of ethnic identities and organisations. Such a focus implies that ethnic identity can in an important sense be consciously constructed (Eriksen 2002: 69).

Der Ethnologe, Ethnizitäts- und Migrationsforscher Jens Schneider nennt diese Art der Konstruktion „kollektive[s] historische[s] Bewußtsein“. Dieses werde durch Sozialisation vermittelt und führe zur „Begründung eines spezifischen $\mathrm{Na}$ tionalgefühls“ (Schneider 2001: 20), welches sich übertragen lässt auf die Versuche der interviewten Nachkriegsakteur*innen der dänischen Minderheit, ihr Dänischsein zu legitimieren. „, $[\mathrm{M}]$ it historischer und staatsrechtlicher Beweisführung“" (Scharff 1969c: 223) wird nationale Zugehörigkeit in der Minderheit legitimiert und objektiviert. ${ }^{550}$ Diese Strategie reicht bei der dänischen Minderheit in

\footnotetext{
547 „Anthropologists would stress that history is not a product of the past but a response to requirements of the present" (Eriksen 2002: 72).

548 Zur Bedeutung von Geschichte für „Identität“ s. a. Lowenthal (1985).

549 In dieser kulturanthropologischen Arbeit geht es nicht darum zu überprüfen, welche dieser Argumente auf historischen Tatsachen beruhen, sondern darum zu zeigen, welche Argumente wie verwendet werden.

550 Auch bei anderen europäischen Volksgruppen, wie z. B. den Ungarn und Rumänen in Siebenbürgen, konnten Legitimierungs- und Objektivierungsversuche für die eigene Nationalisierungsbewegung festgestellt werden. Margit Feischmidt beschreibt, dass „Archäologie und die Musealisierung ihrer Ergebnisse“ „zu einer allgemeinen Strategie der Nationalisierung und der kulturellen Objektivierung“" werden. Der diesen Ergebnissen und historischen Personen zuge-
} 
Schleswig, so der Historiker Scharff, bis in die Mitte des 19. Jahrhunderts zurück, als der dänische Gesamtstaat zerfiel (Scharff 1969c: 223; Frandsen 2013: 226). Steen Bo Frandsen beschreibt die Lage im Landesteil Schleswig folgendermaßen:

Die Danifizierung Schleswigs durch die Historiker und die Nationalisierung des Konflikts gehörten zu den Bestrebungen, die fließenden Übergänge zwischen Dänisch und Deutsch zugunsten einer dramatischen Betonung der Unterschiede zu überdecken. Niemand sprach mehr von der protestantischen Kulturgemeinschaft, die Dänemark und Norddeutschland drei Jahrhunderte lang verbunden hatte, oder von den engen Banden, die auf fast allen Gebieten jahrhundertelang bestanden hatten. Sprache war nicht länger ein Mittel der Kommunikation, sondern Ausdruck der Identität und Instrument der Abgrenzung. In Dänemark betonte man den Unterschied zwischen Dänisch und Deutsch so nachdrücklich, dass man die nordische und die germanische Philologie vollständig trennte. Die Idee der Eidergrenze entwickelte sich zu einem wichtigen Baustein des Konstrukts, das Dänemark in Skandinavien verortete (Frandsen 2013: 231-232).

Ein Beispiel für die symbolisch-historische Abgrenzung der dänischen Minderheit gegenüber der deutschen Mehrheit ist die große Bedeutungszuschreibung der Eider als historischem Grenzfluss. Dies steht im Gegensatz zur wissenschaftlich belegten geringen Bedeutung dieses Flusses als Grenze (vgl. Graw-Teebken 2008: 257; s. a. Kap. 3.1). Es findet ein „Umdeuten der Wirklichkeit“ als geschichtspolitische Strategie statt (Feischmidt 2003: 103). Die an einen geografischen Raum gebundene nationale Gesinnung erzeugt ein Gefühl von sogenannter Heimat. Der imaginierte Raum ist dabei das nach Süden hin durch die Eider begrenzte Südschleswig. ,[S]ymbolische Orte“ und regionale Verankerung unterstützen das Gefühl von Zugehörigkeit (Köstlin 2010: 38; vgl. a. Binder 2008: 8).

Die dänische Abgrenzung gen Süden und die Orientierung nach Norden, nach Skandinavien, zeigt sich heute symbolisch an der deutsch-dänischen Grenze. Auf deutscher Seite wehen die deutsche, die schleswig-holsteinische und die europäische Flagge. Auf dänischer Seite hingegen wehen neben der dänischen Flagge nur die Flaggen der nordischen Länder, aber nicht die europäische Flagge (vgl. Frandsen 2013: 233).

schriebene Symbolcharakter habe „die Aufgabe, als Katalysator der kollektiven Identifizierungen zu wirken" (Feischmidt 2003: 60, 65). 
Das Phänomen der historischen Legitimierung bezeichnet Schneider als „,tautologisch“, weil Minderheitsakteur*innen ihre Gruppe ,,aus dem Bewußtsein einer gemeinsamen Geschichte ab[leiten], aber diese Geschichte ist nur bewußt, wenn und weil [...] [die Gruppe] sie entsprechend vermittelt - und das ist niemals ,objektiv“ oder neutral““ (Schneider 2001: 20, m. Rückgriff auf Kedourie und Hobsbawm; vgl. Rheinheimer 2001: 7). Die verwendeten Mythen zur Legitimierung sind „stories which are not necessarily true“ (Fulbrook 1997: 73). Das „Selbstverständnis“ der dänischen Minderheit wird also wie bei Nationen durch „das historische Bewußtsein“" geschaffen, welches „fortlaufend, vielfach subtil oder unbewußt, konstruiert und rekonstruiert" wird (Schneider 2001: 20, m. Rückgriff auf Gadamer). Dabei spielen der Schulverein und der Kulturverein der dänischen Minderheit eine große Rolle. Bei der Konstruktion von Minderheitsbewusstsein ist es nicht relevant, ob und inwiefern die herangezogenen historischen Aspekte nachweisbar sind oder nicht, sondern nur, dass diese zur Legitimierung ${ }^{551}$ oder zur „Selbstvergewisserung“ (Schmidt-Lauber 2007b: 213; Kühl 2004: 322) des eigenen Dänischseins herangezogen werden können, ähnlich wie es Fredrik Barth für „Abgrenzungsmarkierungen und Identitätsmerkmale“ beschreibt (Barth 1994b: 175) ${ }^{552}$; (vgl. a. Østergård 2005: 564). Denn laut Barth geschieht die „Wahl von Symbolen für ethnische Mitgliedschaft im Prinzip [...] ohne notwendigen Zusammenhang mit kulturellen Fakten“553 (Barth 1994b: 175). Abgrenzung nach außen, womit auch immer, vereint Menschen nach innen (Hobsbawm 2005: 109).

Laut John Coakley dienen historische Mythen der Legitimierung und Rechtfertigung von gegenwärtigen Ideologien und politischen Entscheidungen (Coakley 2004: 531). Er betont, wie wichtig Geschichtsmythen und -bilder für den Nationalismus und für nationale Bewegungen in Staaten und nationalen Minderheiten sind (ebd.). Die Vergangenheit wird selektiv ausgewählt, überbetont, untertrieben, je nachdem, was den aktuellen Bedürfnissen der Eliten der betreffenden Nation oder Minderheit zur Durchsetzung ihrer Ziele entspricht (ebd.: 532-533). Historische Interpretationen werden zur Konstruktion und Aufrechterhaltung von ethnischer und nationaler Solidarität und einem für die Gruppe charakteristischen Weltbild von gemeinsam geteilter Geschichte benutzt und vermittelt, beispielsweise im nationalen Geschichtsunterricht (ebd.: 532$)^{554}$. In der nationalistischen Ideologie spielt die nationale Geschichte eine zentrale Rolle. Zusätzlich sind bei der Konstruktion und Aufrechterhaltung von nationalen Gruppen

\footnotetext{
551 Zum „Rechtfertigungsmotiv“ vgl. Luther (1990).

552 ,grensemarkører og identitetsmerker"

553 „valg av symboler for etnisk medlemskap i prinsippet [...] uten noen nødvendig sammenheng med kulturhistoriske fakta“"

554 Coakley nimmt dabei Bezug auf Ernest Renan, der Gemeinschaften und Nationen durch einen gemeinsamen Besitz eines reichen Erinnerungserbes beschreibt, also durch „la possession en commun d'un riche legs de souvenirs" (Renan 1996: 34).
} 
Rituale, wie z. B. Prozessionen, Paraden, Märsche, Gedenkfeiern sowie Symbole wie z. B. Flaggen und Hymnen wichtig. Die Verbreitung der Nationalkulturmythen geschieht durch Eliten über die Kanäle Massenmedien und Bildungseinrichtungen. Weiterhin werden implizit und explizit Loyalitätserwartungen vermittelt, zum Beispiel an das Verhalten von Personen mit Nationalflaggen bei Veranstaltungen (vgl. die Fahnenträgerkurse in der dänischen Minderheit, Kap. 8.4). Die Verbreitung ,offizieller“ Minderheitsgeschichtsversionen wird auch durch Bücher, Lehrpläne und Museen, wie beispielsweise dem Danevirke-Museum, betrieben. Die interviewten Akteur*innen der dänischen Minderheit konstruieren und narrativieren nicht alleine eine dänische Geschichte ihres eigenen Wohnortes bzw. Südschleswigs, sondern haben die dänische Geschichtsschreibung in der dänischen Schule gelernt und in dänischen Vereinen bzw. mit anderen dänischgesinnten Akteur*innen gefestigt.

Coakley führt aus, dass Nationen, hier angewendet auf die nationale Minderheit der Dän*innen, Grenzziehungen mithilfe von nationalen Herkunfts- und Entstehungsmythen und der Behauptung, dass die eigenen Vorfahren schon immer auf ihrem jetzigen Siedlungsgebiet ansässig gewesen seien, vollziehen (ebd.: 540553). So ist es auch bei der dänischen Überbetonung der Eider als symbolische, über 1.000 Jahre alte Südgrenze der Fall, mit deren Hilfe Schleswig als abgrenzbarer Siedlungsraum konstruiert wird. Durch die Bezeichnung der Grenzziehung von 1920 durch die Volksabstimmung als eine ,Trennung von Dänemark“ (Küssner in Sydslesvigsk Forening 2013a: 9) bedient der SSF-Funktionär Küssner die gleichen Mythen, die eine Auffassung von ungerechtfertigter und vom Redner nicht anerkannter Grenzziehung und von einer Vorläufigkeit der Grenze implizieren, die von staatlicher dänischer Seite seit Kriegsende 1945 stets zurückgewiesen wird. Küssner impliziert auch, dass Schleswig eigentlich zum dänischen Königreich gehöre, was historisch-staatsrechtlich gesehen nicht so eindeutig ist (s. Kap. 3). Selbst wenn es historisch eindeutig wäre, hätte es für die heutige Grenze rechtlich gesehen keine Bedeutung mehr. Küssner ${ }^{555}$ bezeichnet in seinem Jahresbericht

555 Dieter Paul Küssner war von November 2003 bis November 2013 SSF-Vorsitzender auf Landesebene. Er ist ein guter Rhetoriker und ein alter Kämpfer für das Dänische in Südschleswig. Er war von 1985 bis 1994 Redakteur des patriotischen, pro-dänischen Lobbyismusblattes „Slesvigland“ (vgl. Kühl 2011: 243-245) und vertrat anschließend als SSF-Vorsitzender die Minderheit ,,auf klarem nationalen Fundament stehend“, so die Einschätzung von Siegfried Matlok, dem ehemaligen Chefredakteur von Der Nordschleswiger, der Zeitung der deutschen Minderheit in Dänemark, in einem Leitartikel (Matlok 12.11.2013). Matlok fasst Küssners konservative Haltung zusammen als ein „Festhalten an einer dänischen Lebensgrundlage in einem überwiegend deutschen Umfeld, das Dänische und das Sprachliche dürfe nicht vernachlässigt werden, also eine Absage an deutsch-dänische Gleichmacherei und Multikulti“ (ebd.). Bei einer teilnehmenden Beobachtung während einer Grönlandreise mit Dieter Paul Küssner über die Jaruplund 
auf der SSF-Landesdelegiertenversammlung 2013 in Husum das dem SSF gehörende Danevirke-Museum als „ein Juwel, das in der großen Erzählung über Dänemarks tausendjährige Geschichte funkelt ${ }^{\text {“556 }}$ (Küssner in ebd.: 13). Küssner konstruiert und überhöht in seinen weltanschaulichen Reden die historische Verbindung der Minderheit zu Dänemark, indem er behauptet, dass „das Juwel stetig funkelt und gerade ein Pfand darauf ist, dass wir [die Minderheit] wesentliche Kapitel der dänischen Geschichte, die große Geschichte, die uns gemeinsam ist, besitzen und pflegen ${ }^{\text {‘557 }}$ (Küssner in ebd.: 14). Damit versucht Küssner, die Anbindung an die dänische Nation durch eine imaginierte Gemeinschaft und eine nationale Solidarität herzustellen. Er als Funktionär bedient sich dabei eines Vergangenheitsmythos (vgl. Coakley 2004: 532; vgl. Anderson 2005: 17). Küssner nennt das Danevirke-Museum sogar eine von zwei „Kultstätten“6558 (Küssner in Sydslesvigsk Forening 2013a: 14). Es bleibt unklar, wie er das meint und welche Kulte dort seiner Meinung nach praktiziert werden. An anderer Stelle sagt er nur, dass er hoffe, dass die Minderheit und das dänische Schulwesen das Museum, intensiv in der Entdeckung von Südschleswigs besonderer dänischen Identität ${ }^{\text {(559 }}$ nutzen werde (Küssner 2012). Dies verdeutlicht die Funktion des Museums als Vermittler von Minderheitsideologie und als Konstruktionsort von Minderheitsidentität (vgl. a. Coakley 2004).

Die nationalistische Propaganda mit Rekurs auf eigene Geschichtsdeutungen zeigt sich auch im Film mit dokumentarischem Anspruch De glemte danskere. Darin wird in den eingeblendeten Texten am Anfang konstatiert, dass es seit 1864, also seit der preußischen Annexion Nordschleswigs, ein Tauziehen zwischen deutsch und dänisch in Schleswig gäbe (Petersen [2014]). Diese Aussage schließt eine postmoderne, europäische Ansicht, nämlich Deutsches und Dänisches miteinander zu kombinieren, aus. „Tauziehen“ suggeriert einen Wettkampf, ein Entwederoder, ein klares Stellungbeziehen auf einer der beiden Seiten des Taus statt eines hybriden Zusammenlebens. Des Weiteren begehen die Autoren den Fehler, einen nationalen Blick, der ideengeschichtlich betrachtet erst im 19. Jahrhundert entwickelte wurde, auch auf die 800 Jahre davor zu übertragen, was ahistorisch und

Højskole im Jahre 2012 mit einer dänischsprachigen Reisegruppe konnte ich beobachten, dass Küssner sich auffällig betont dänisch zu verhalten versucht. Er verhält sich so, als könne er nicht richtig Deutsch, er spricht ausschließlich Dänisch mit den Teilnehmenden, auch wenn es manchmal sprachliche Schwierigkeiten gibt. Gleichzeitig liest er aber den deutschsprachigen Spiegel und deutsche Romane. Er macht sich auch etwas über deutsche Tourist*innen lustig. „en juvel, der funkler i den store fortælling om Danmarks tusindårige historie“

557 „Juvelen funkler stadig og er netop en pant på, at vi ejer og varetager væsentlige kapitler af Danmarkshistorien - den store historie, som vi er fælles om." 
konstruiert ist und zeitgenössische Auffassungen von „Nation“, „deutsch“ und „dänisch“ völlig außer Acht lässt (vgl. Oliver Auge in Weber 2015: 196; vgl. Michael Bregnsbo in Weber 2015: 197; vgl. Martin Krieger in Weber 2015: 198).

Der Bezug zwischen der nationalistischen Geschichtsschreibung und dem Thema des Films wird weiterhin durch die folgende archaisch anmutende Texteinblendung ohne Quellenangabe, Erläuterung oder Kontextualisierung hergestellt:

Tausend Jahre lang war Südschleswig Dänemarks Grenzland und der Kampf zwischen Dänisch und Deutsch im Landesteil wogte vor und zurück. Schritt für Schritt wurde das Dänischsein zurückgedrängt, aber es war doch immer eine treue Schar da, die im Kampf für die dänische Kultur ausgehalten hat ${ }^{560}$ (Petersen [2014]).

Dies ist eine Anspielung auf die große dänische Bedeutungszuschreibung von Schleswigs 1.000-jähriger Geschichte als Teil Dänemarks, was aus der Perspektive der deutschen Geschichtsschreibung anders gesehen wird (s. Kap. 3.1). Kritisch gesehen werden muss der Film auch deshalb, weil nach der Ziehung der deutschdänischen Grenze an der Königsau die Verpreußisierungsversuche in Nordschleswig mit den Worten „Roggenbrot raus, Sauerkraut rein“ geschildert werden. Dem Roggenbrot, welches auch in ein Norddeutschland gängiges Lebensmittel ist, wird ein besonderes Dänischsein zugeschrieben. Dahingegen wird das auch in Dänemark verwendete Sauerkraut als deutsch beschrieben. Der Film wurde bei der Kopenhagener Premiere kritisch aufgenommen. Der Historiker Niels Schou wirft dem Regisseur Geschichtsverfälschung vor, weil der eingeblendete Text im Film behauptet, dass die Deutschen dänisches Land gestohlen hätten und Dänen Deutsche nicht leiden könnten (Schou in Mølvig 09.04.2014: 6).

Ein weiteres Rechtfertigungsargument für das Dänischsein in Bezug auf die allgemeine Geschichte ist beispielsweise die starke Betonung der Tatsache, „daß Schleswig bis 1864 staatsrechtlich zu Dänemark gehört hatte“ und der Annahme, dass sich „[d]ie Menschen südlich und nördlich der Grenze von 1920“ „kaum“ „unterschieden“ hätten (Danker 1997: 8). Dieses Phänomen gehört zu den von Coakley (2004) allgemein beschriebenen nationalen, territorialen Entstehungsgeschichten, die bei der Minderheit darin bestehen, zu behaupten, dass das Gebiet ursprünglich dänisch gewesen sei. „Wir wohnen auf altem dänischen Land, welches einmal Dänemark war ${ }^{\text {‘651 }}$, sagt der ehemalige SSF-Generalsekretärs Karl

\footnotetext{
560 „I Tusind Aar var Sydslesvig Danmarks Grænseland og Kampen mellem Dansk og Tysk har gennem Tiderne bølget frem og tilbage i Landsdelen. Skridt for Skridt blev Danskheden trængt tilbage, men der var dog altid en trofast Flok, som holdt ud i Kampen for dansk Kultur.“ 
Kring im Film De glemte danskere (K. Kring in Petersen [2014]). Kring benutzt das auch bei vielen Lobbyist*innen der dänischen Minderheit und bei der Dansk Folkeparti (DF), einer rechtspopulistischen Partei in Dänemark, beliebte Narrativ des eigentlich dänischen Südschleswigs (vgl. Kap. 3.1). Gitte Hougaard-Werner vermittelt ebenfalls den Eindruck, dass Südschleswig eigentlich dänisch und heute von Deutschland besetzt sei (Hougaard-Werner 14.10.2013). Aus ihrer Aussage, dass es jahrhundertelange politische Bindungen zum Königreich gab und der gleichzeitigen Ausblendung, dass es ebenfalls sehr enge Beziehungen zu Holstein gab, wird eine Legitimierung des heutigen politischen Wunsches gestrickt, zu Dänemark gehören zu wollen.

Die Strategie der geografisch-historischen Legitimierung wenden nicht nur Funktionär*innen, sondern auch einige Akteur*innen an: Interviewpartner*innen benutzen diesen Rettungsanker zur Rechtfertigung der eigenen Gesinnung, indem sie einige Sätze in den Raum werfen wie „Die dänische Minderheit ist ja schon seit 1920, gabs die schon in Friedrichstadt, nech [...] oder noch früher, glaub' ich“ (INT05). Oder man sagt: „Aber es war ja auch mal dänisch hier, von daher könnten wir ja auch sagen, dann sind wir auch Ureinwohner" (INT01). Allerdings war Erik Nissens (INT01) Mutter nach dem Zweiten Weltkrieg aus den ehemaligen deutschen Ostgebieten nach Schleswig-Holstein geflüchtet. Diese Familienvergangenheit wird in Eriks Argumentation völlig ausgeblendet.

„Wir sind ursprünglich Dänen gewesen“ (INT03), meint auch Sarah Iversen. „Wir waren ja den größten Teil der [...] Geschichte waren wir [Südschleswiger*innen] ja dänisch“ (INT06), ergänzt Frieda Theben. Für Brigitte Thomsen ,,ist das klar, dass es hier dänisch gewesen ist, weitaus länger als die paar Jahre, die es dann schon deutsch ist" (INT02). Daraus zieht Brigitte eine Art Legitimierung dafür, dass sie dänisch sein darf, egal, ob ihre Vorfahren dänisch waren oder nicht, oder die Bewohner*innen des südlichen Teil Schleswigs, zu dem Friedrichstadt gehört, alltäglich nie dänisch gesprochen haben ${ }^{562}$, auch wenn sie staatsrechtlich als Teil des Herzogtums Schleswig zum dänischen Gesamtstaat, aber nicht zum eigentlichen dänischen Kernstaat gehörten (vgl. Henningsen 2009a: 10; Henningsen 2009b: 14; Hansen 2003: 451).

Der starke Zulauf zur dänischen Minderheit nach dem Zweiten Weltkrieg wird von Vertreter*innen der Grenzrevision und von Akteur*innen der Minderheit ,gerne als Wiederbesinnung auf eine bloß verschüttete Realidentität", die vorher dänisch gewesen sei, gedeutet (Thaler 2013: 35).

562 Dieses Argument der Sprache wird häufig von den Akteur*innen selbst verwendet, ist aber eigentlich kein Kriterium für nationale Gesinnung. 
Brigitte Thomsen schildert im Interview, dass sie beobachtet hat, dass sie eine andere Geschichtsauffassung habe als diejenigen Dorfbewohner*innen, die keine dänische Schule besucht haben und sich nicht dänisch fühlen. Mit diesen ist sie in einer Geschichtsarbeitsgemeinschaft in ihrem Dorf in der Nähe Friedrichstadts in Kontakt gekommen (INT02).

Ich hab das eigentlich auch zuerst für selbstverständlich genommen, dass es dann nun 'ne dänische Schule da gibt und uns wurde ja auch erzählt, das ist hier mal dänisch gewesen ist, ja ok, dann ist es auch klar, dass da mal wieder 'ne dänische Schule her muss, und dass man damit nicht überall gut ankommt, das habe ich natürlich auch gemerkt und dass einige das sogar total abstreiten und eh, das finde ich, kann man einfach nicht, man kann nicht sagen, hier ist nie was dänisch gewesen, dann muss man nur mal in die Kirchenarchive gehen und da sieht man schon, da stehen plötzlich die Eintragungen auf dänisch, also das haben die ja nicht so aus Jux und Tollerei gemacht, und das ist unter anderem auch ein Grund dafür, dass ich nicht im Geschichtsverein hier [im Dorf] mitarbeite, obgleich mich das sehr interessieren würde, denn das kam denn [sic] schon mal so in der ersten Diskussion, ja, ja, nee, nee, also dänisch war das hier nie und da hab ich gedacht, da will ich mich nicht an jeder Sitzung drüber aufregen, also denn, da sollen sie mal sehen, wie sie das, wenn sie das so sehen. [...] Das [Dänische] kann man nicht nicht ganz, nicht leugnen. [...] Man kann vielleicht d'rüber diskutieren, wie intensiv das gewesen ist, es ist ja anders gewesen, es waren ja nicht diese Nationalstaaten, es gab ja in dem Sinne auch kein Deutschland (INT02). ${ }^{563}$

Brigitte beschreibt hier, wie sie mit ihrer dänischen Geschichtsperspektive und ihrem dänischen Schulbesuch bei den deutschen Dorfbewohner*innen aneckt, die eine andere Geschichte in der deutschen Schule gelernt haben. Hier kommen zwei

563 Allerdings war die Kirchensprache im überwiegenden Teil Südsüdschleswig nie Dänisch (Hansen 2003: 451), auch wenn Brigitte das im Interview behauptet. Bereits vor der Reformation war die Kirche im Herzogtum Schleswig deutsch orientiert, wie Kirsi Salonen nachweisen konnte (Salonen 2016: 241). In Friedrichstadt gab es bis zum Wandel der Umgangssprache ins Hochdeutsche nur Niederdeutsch als „Volkssprache“ sowie Deutsch als „Kirchen- und Schulsprache" (Hansen 2003: 451). Über die Konstruktion der Eider als vermeintlich dänische Südgrenze s. a. S. 65. 
gegensätzliche nationale Geschichtsschreibungen über dieselbe Region zum Vorschein, die beide wahrscheinlich nicht weitreichend genug ausdifferenziert sind, um die historische, politische Lage möglichst objektiv abzubilden. ${ }^{564}$

Die Verbindung zu dänischen Elementen in der Vergangenheit und das dänische nationale Gefühl hat die Interviewte auf der dänischen Schule gelernt, denn die dänischen Schulen in Südschleswig haben ,eine nationale dänische Grundlage“ und einen Schwerpunkt auf „der dänischen Literatur, dänischen Liedern und Psalmen und der Geschichte Dänemarks“"565 (Pedersen 2000b: 362). In der Diskussion mit Dorfbewohner*innen, die nicht dänisch sozialisiert wurden, weil sie die deutsche Schule besucht haben, wird deutlich, dass diese durch ihre „deutsche“ Sozialisation ${ }^{566}$ andere Fakten aus der Historie herausgreifen, betonen und anders interpretieren, um ihre Majoritätszugehörigkeit (im Gegensatz zur dänischen Minorität) zu legitimieren. ${ }^{567}$ Denn Identitäten von (ethnischen) Gruppen ,are creations - whether they are created by historical circumstances, by strategic actors or as unintended consequences of political projects" (Eriksen 2002: 91). ${ }^{568}$ Die Kulturanthropologin Silke Göttsch-Elten weist ebenfalls auf die unterschiedlichen Geschichtsschreibungen im deutsch-dänischen Grenzraum hin (GöttschElten 2016: 164).

564 Mehr über die beiden nationalen Geschichtsschreibungen im Hinblick auf deutsch-dänische Beziehungen und ihre Charakteristika s. Weber (2015); Bregnsbo, Jensen (2016: 7).

565 „et national dansk grundlag“; , ,den danske litteratur, danske sange og salmer og Danmarkshistorien“"

566 Dazu auch: ,,[M]ass education can be an efficient aid in the establishment of standardised reifications of culture, which are essential in the legitimation of ethnic identities" (Eriksen 2002: 91).

567 Jørgen Kühl führt einen ähnlichen Aspekt der unterschiedlichen Interpretation von Geschichte durch Nichtdän*innen und Dän*innen in Südschleswig an. Er nennt das Stichwort „kulturelle[s] Gedächtnis“ (Kühl 2004: 337), unter dem er „die Geschichte“ und „die Kulturlandschaft Südschleswigs“ (ebd.: 329) versteht, wobei „Elemente der jeweiligen nationalidentifizierten Kulturlandschaft nebeneinander“ (ebd.: 329) bestehen, die „sich allerdings auch auf die gleichen physisch vorhandenen Dinge beziehen“ (ebd.: 329). Es komme dabei auf die jeweilige Bedeutungsauslegung der Akteur*innen an.

568 Vgl. a. (Dragsbo 2005). In diesem Aufsatz untersucht Dragsbo einen ähnlichen Vorgang. Im dänischen Sønderjylland/Südjütland werden im Gegensatz zum restlichen Dänemark viel weniger historische Gebäude bewahrt und gepflegt. Die Ursache sieht Dragsbo in der deutschen Geschichte vieler Bauwerke, die dadurch nicht in das heutige dänische Geschichtsbild passen und deswegen ,vergessen“ würden. 
Ähnlich wie bei ethnischen Gruppen - „ethnic groups or categories tend to have notions of common ancestry justifying their unity " (Eriksen 2002: 35) ${ }^{569}$ versuchen auch einige meiner Interviewpartner*innen zur besseren Rechtfertigung ihrer persönlichen Zugehörigkeit, Historisierungen auf persönlicher, familiärer Ebene zu schaffen. Beispielsweise bezieht Heinrich Schmied als Hintergrund für seine dänische Einschulung seine Vorfahren mit ein. Diese hätten unter dem dänischen König ${ }^{570}$ gelebt:

Und denn [...] kam die Geschichte wieder zum Vortragen durch mein, mein Großvater, meine Großmutter, die ist früher unter'm König und so gewesen $[\ldots]$, aber das ist auch alles auch schon relevant, denn die waren ja auch nur Arbeiter, und hier viel zu sagen mit [unter] dem dänischen König hatten sie auch nicht. Sie hatten unter Preußen nichts zu sagen und nichts unter dem dänischen König (INT07).

Seine „Vorvorfahren“ sieht er zwar nicht als positiv gestimmte Anhänger, aber doch als Untertanen der „dänischen Könige“, weil sie „,seit mehreren hundert Jahren" in Südschleswig wohnten (INT07). ${ }^{571}$ Die Entdeckung der dänischen Ge-

569 Analog zur Zugehörigkeit zu einer Gruppe funktioniert auch die Identifizierung mit einer Nation: „Drei Aspekte sind in diesem für die Konstituierung der Nation entscheidenden Prozeß immer vorhanden: Erstens wird die Konkretheit, die Verwurzelung und die Exemplarität der Identifikationsfiguren und -bilder betont (denn man identifiziert sich nicht mit der Idee, sondern mit einer konkreten Person, mit einer bestimmten Region oder mit einem bestimmten Ereignis).

Zweitens beruft man sich auf eine oft weit zurückreichende, aber zugleich immer aktualisierte, vermeintlich gemeinsame Vergangenheit. Drittens werden Ziele und Werte beschworen, die ergreifen und [S. 27] begeistern sollen, die es nachzuahmen gilt und die sich nur gemeinsam erreichen lassen - vor allem die Einheit, die Opferbereitschaft und die Liebe zum Vaterland“"

(François et al. 1995: 26-27).

570 König Friedrich VIII, Amtszeit als dänischer König von 1906 bis 1912, sowie König Christian X, Amtszeit von 1912 bis 1947, beide aus dem Hause Schleswig-Holstein-Sonderburg-Glücksburg (Hansen 2003: 457).

571 Allerdings erscheint mir die Aussage, dass Heinrich Schmieds Großeltern als Erwachsene unter einem dänischen König gelebt hätten, nicht besonders einleuchtend, da Schmied 1935 geboren wurde, seine Eltern um 1905 und seine Großeltern ca. 1875. Alle wohnten in Friedrichstadt und Umgebung. Seit 1864 aber gehört die Stadt nicht mehr zu Dänemark, sondern zu Preußen. Das bedeutet, dass höchstens seine Urgroßeltern die Zeit unter dänischen Königen noch miterlebt haben könnten. Dieses Detail spielt für Heinrich Schmied aber keine Rolle. Es zählt, dass das Gebiet, in dem seine Vorfahren wohnten, überhaupt einmal zu Dänemark gehört hat, auch wenn im südlichen Schleswig Dänisch beispielsweise nie Volkssprache war, abgesehen davon, dass dies kein objektives Kriterium für dänische oder deutsche Gesinnung ist (vgl. INT07; Rasmussen 2009). Sarah Iversens Erwähnung ihres Urgoßvaters erscheint mir dagegen plausibler zu sein (INT03). Friedrichstadt gehörte seit 1544 zum herzoglichen Gottorfer Teil Schleswigs (Henningsen 2008: 141.142). 
schichte des Landesteils Schleswig und der dänischen Verbindungen in der eigenen Familie führt auch die SSW-Politikerin Anke Spoorendonk, die aus einer neudänischen ${ }^{572}$ Familie kommt, in Bezug auf ihr Dänischwerden an:

Fragt man meine Familie, wieso sie dänisch geworden ist, geht die Antwort in zwei Richtungen, die teilweise mit der Wiederentdeckung von vergessenen dänischen Wurzeln zu tun hat, zu einem Zeitpunkt, wo sich die Bevölkerungszahl in Südschleswig aufgrund der Flüchtlinge aus den ehemaligen deutschen Ostgebieten mehr als verdoppelte. Teilweise ist es Ausdruck dafür, dass man nach dem Gräuel von Naziregime und Krieg jedwedes Vertrauen zu allem, was deutsch war, verloren hatte ${ }^{573}$ (Spoorendonk 2001: 40-41).

Auch Autorin Karin Johannsen-Bojsen behauptet, dass sie schon ,immer dänische Verwandte“ hatte und die Verbindung zum Dänischen durch eine Art „Wiedererwachen" nach dem Zweiten Weltkrieg betont wurde Johannsen-Bojsen in Paszel 2005: Anhang). Sie konstatiert im Interview mit Helena Paszel, dass „das Land Schleswig von Anfang an immer dänisch gewesen“ sei. Das zeige angeblich schon ein nicht näher benannter, ,runde[r] [...] Stein [...] auf dem wohl mit lateinischen Buchstaben steht: Eider ist die Grenze des Römischen Reiches“ (Johannsen-Bojsen in ebd.: Anhang). Daraus schließt Johannsen-Bojsen auf bedenklich dänisch-nationalistische Weise, dass ,schon um 800 [...] anerkannt [wurde], dass Dänemark nördlich der Eider beginnt. Daran kann es kein [sic] Zweifel geben“ (Johannsen-Bojsen in ebd.: Anhang). Das betrachte sie als „historische Legitimierung“ für ihr heutiges Dänischsein (Johannsen-Bojsen in ebd.: Anhang). Der Eidergrenzmythos stammt aus der nationalen Propaganda aus der Mitte des 19. Jahrhunderts (Hansen 2003: 437). Der sogenannte Eiderstein ist eine Steintafel, die erst 1670 in das Südportal der Festung Rendsburg eingebaut wurde, und die die lateinische Inschrift „Eidora Romani Terminus Imperii“ („Die Eider, die Grenze des römischen Reichs") trägt. Die Nordgrenze des Römischen Reiches ist nicht auch automatisch die Südgrenze des dänischen Königreiches.

Maike Lohse erläutert die Wahl des eigenen Dänischseins aufgrund der zwei Generationen vor ihr mit einer Rückbesinnung auf die Geschichte, ähnlich wie es Sarah Iversen für sich selbst macht (INT03). „,Maike Lohse weiß noch, dass ihre eigene Familie nach 1945 die dänische Herkunft erst wiederentdeckte“ (Werner 16.05.2016):

\footnotetext{
S. dazu a. S. 96.

„Spørger man min familie hvorfor den blev dansk, går svaret i to retninger som dels har med genopdagelsen af glemte danske rødder at gøre på et tidspunkt, hvor befolkningstallet i Sydslesvig var blevet mere end fordoblet på grund af flygtningene fra de tidligere tyske østområder. Og dels giver udtryk for at man efter nazistyrets og krigens rædsler havde mistet enhver tillid til alt hvad der var tysk."
} 
Meine Mutter erzählte, dass es für sie war es früher so, als sie das son bisschen näher erfuhr mit der Geschichte, dass es so war, als seien alte Tapeten heruntergerissen worden und da hat sie entdeckt, eigentlich ist es ja alles mal dänisch gewesen, ist ja alles unter dem dänischen König gewesen. Meine Mutter und mein Großvater sind beide bewusst dänisch geworden nach '45, weil sie das entdeckt haben, zumal auch der Vater meines Großvaters noch immer einen Ehrensold bekam vom dänischen König, weil er ja vor 1864 Soldat gewesen war und dann natürlich vor 1846 natürlich dänischer Soldat (Lohse in ebd.).

Auch Schulleiter Peter Müller, Eckernförde, verwendet die Eider als historische Legitimierung für das heutige Dänischsein gegenüber NDR Info:

Von Eckernförde bis zur dänischen Grenze sind es heute $70 \mathrm{~km}$, doch viele Jahrhunderte lang gehörte Eckernförde zum dänischen Hoheitsgebiet. Bis zum deutsch-dänischen Krieg von 1864. Schulleiter Peter Müller hat in seinem Büro eine alte dänische Karte. Seinen Neuankömmlingen führt er vor, dass bis 1864 Dänemark im Süden bis zur Eider reichte. Bei Rendsburg. Das ist für die meisten neu (ebd.).

Die Beispiele für die Rechtfertigung aufgrund von vermeintlicher Abstammung zeigen, dass ein Verwandter, der Verbindungen irgendeiner Art zu Dänemark hatte, aus der Masse der eigenen Vorfahren hervorgehoben wird, während die zahlreichen anderen Verwandten nicht erwähnt werden. Die Befragten versuchen gezielt, eine ,ancestral identity“ (Eriksen 2002: 70) zu schaffen, wobei nicht thematisiert wird, wie weit eine solche Verbindung zurückreichen muss (vgl. ebd.: 35). Nachdem Sarah Iversen im Interview von ihrer Diskriminierung im Nationalsozialismus, dem Kriegsende und der Gründung der neuen Hans-Helgesen-Schule erzählt hat, folgt sofort der objektivierende Hinweis auf einen ihrer Urgroßväter, während die anderen drei Urgroßväter gar nicht erwähnt werden:

Mein Urgroßvater hat 1864 mitgekämpft [...] gegen die Schleswig-Holsteiner, gegen die Österreicher und eh, der hat auch bis zu seinem Lebensende dänischen Sold bezogen, also [...] den Soldatenlohn, und daher hat mein Vater auch also eigentlich die Liebe, er liebte Dänemark, sicherlich aus seiner Kindheit, er konnte nie erklären, wieso das so war, aber ich denk' mir schon aus seiner Kindheit, dass weil sein Großvater 
ja, die waren Dänen, nech, und sein Vater und seine Mutter, die hatten ihm das irgendwie eingepflanzt, diese Liebe (INT03). ${ }^{574}$

Die historische Tatsache, dass laut Sarah Iversen einer ihrer Urgroßväter für den dänischen König gekämpft hat, dient als Sockel für ihre gesamte familiäre emotionale Säule. Diese trägt neben dem schulischen dänischen Unterbau ihr gesamtes Dänischsein. Eine Vielzahl von anderen Verwandten, die nicht für Dänemark gekämpft haben, werden also bei der Rechtfertigungsstrategie ausgeblendet. Aufgrund der Grenzverschiebungen und der komplexen schleswig-holsteinischen Geschichte könnten womöglich sehr viele Menschen im Landesteil, deren Familien schon lange dort wohnen, dänische Vorfahren haben. Sarah verwendet das Vorfahrenargument, welches für alle alteingesessenen Bewohner*innen des Landesteils Schleswig auf der Hand liegt, zur Legitimierung für ihr Dänischsein. Deutschgesinnte Menschen verwenden dieses Argument nicht. Sarah hält es für eine schlagkräftige Erklärung, da sie kaum andere historisch legitimierende Begründungen hat. Diese „,intense quasi-kinship feelings“ beschreiben Ruane und Todd als „characteristic“ für Gemeinschaften (Ruane, Todd 2004: 216). Der Rückgriff in die Vergangenheit und der Ausblick in die Zukunft (s. Kap. 9) sowie Raumbezüge (Eider, Südschleswig) sind ebenfalls typisch für Akteur*innen, die sich ethnischer Kategorien bedienen (ebd.: 216).

Würden keine individuellen Legitimierungen stattfinden, so wäre vielleicht aus der Sicht der Akteur*innen ihre Glaubwürdigkeit gegenüber Nichtdänischgesinnten gefährdet. Übertragen auf alle Dänischgesinnten in Südschleswig würde das bedeuten, dass

eine Gruppe, die ihre Legitimation als Minorität ausschließlich auf subjektive Identifikationen begründet, es auf längere Sicht schwer haben wird, Akzeptanz und Anerkennung als Minderheit zu bekommen. Deshalb wird die Gruppe als Ganzes sich an vorgestellte oder konkrete objektive Kriterien halten, die wiederum als symbolische Identifikationsmarkierungen dienen können (Kühl 2005d: 21). ${ }^{575}$

Des Weiteren hängt das Bedürfnis, das Dänischsein gegenüber sich selbst zu begründen, auch damit zusammen, dass das Bekenntnis beliebig und zufällig wirken kann. Mit der Legitimierung versucht man, eine einmal getroffene Entscheidung zu festigen. Dadurch muss diese nicht ständig überdacht oder vielleicht sogar re-

574 Es muss sich dabei um einen Urgroßvater handeln, der auf dänischer Seite im Zweiten Schleswig-Holsteinisch-Dänischen Krieg unter Christian IX., dänischer König von 1863 bis 1906, gekämpft hat.

575 Ganz Ähnliches schreibt auch Thomas Hylland Eriksen: Eine imaginierte Gruppe brauche, wenn sie bestehen solle, eine Möglichkeit „,sich selbst ideologisch zu legitimieren“ („,legitimere sig selv ideologisk“) und sie brauche „eine Begründung für ihre Existenz“ („en begrundelse for sin eksistens" (Eriksen 2005: 168). 
vidiert werden. Aufgrund der in den Kapiteln 4.2.1.2 und 5.1.1 geschilderten Diskriminierungen der Dänischgesinnten ist möglicherweise auch eine Art Gewohnheit zur Legitimierung entstanden, um sich gegen Anfeindungen zur Wehr zu setzen. Heute gibt es diesen äußeren Rechtfertigungsdruck nicht mehr in dieser Form, aber um sich selbst erklären zu können und um für Verständnis zu werben, sehen wohl einige Interviewte die Notwendigkeit, ihr Dänischsein im Interview zu legitimieren. Darüber hinaus beruht diese Legitimierungstendenz auch „auf institutionellen Veranlassungen“, ,weil wir gelernt haben“ uns „selbst zum Thema zu machen", so der Soziologe Alois Hahn (Hahn 1995: 127) und weil es um Akzeptanz und damit um die Bereitstellung finanzieller Mittel aus Dänemark geht. Das Bedürfnis, sich für ein von mir als Interviewerin nicht bezweifeltes Dänischsein zu legitimieren, könnte auch aus den früheren Diskriminierungserfahrungen aufgrund eben dieses Dänischseins entstanden sein. Beschimpfungen als "Speckdänen“ oder „Vaterlandsverräter“ führten bei einigen Akteuren zu dem Gefühl, dass das Dänischwerden eine „sozial nicht akzeptierte“, „erklärungsbedürftige Verhaltensweise“ sei (Lehmann 1980: 59, 58; s. a. Kap. 5.1.1).

Nicht nur in der Nachkriegsgeneration, sondern auch in der heutigen neudänischen Elterngeneration gibt es Legitimierungen aufgrund wiederentdeckter Historie: „Auch Lutz Müller-Thomsen wurde erst mit der Entscheidung für die dänische Schule bewusst, dass es in seiner eigenen Familie dänische Wurzeln gibt" (Werner 16.05.2016). Allerdings sieht er die Sache differenzierter:

Wo meine Großeltern herkommen, das war dänisch. Bis 1864. Da wurde aber auch Deutsch gesprochen, also jetzt zu sagen, ich gehör zur dänischen Minderheit, weil meine Familie jetzt immer dänischsprachig war. Nein, da gab es Brüche, wie das eigentlich bei allen ist. Also... man ... ich fand immer für mich schwierig zu sagen, dass, dass, sondern klar... wir haben uns da angeschlossen, der dänischen Minderheit, wir sind in der dänischen Schule, aber dass man jetzt sacht, ich bin jetzt der reine Däne, das wäre ja auch gelogen. Weil es ist, es ist ja im Grenzland zwischen Kolding und Altona ${ }^{576}$ (Müller-Thomsen in ebd.).

Der Wohnort seiner Großeltern im Landesteil Schleswig, der lange unter dänischer Herrschaft stand, wird hier als ausschlaggebende Rechtfertigung für die heutige Wahl des Dänischen genannt. Allerdings wird im Beispiel von Lutz MüllerThomsen die Bruchstückhaftigkeit und Konstruiertheit von Zugehörigkeiten und Grenzlandidentifizierungen hervorgehoben. Es bekennen sich heute ja nicht alle,

576 Die Stadt Altona, heute ein Stadtteil Hamburgs, gehörte zu Holstein und war Teil des Deutschen Reiches und des Deutschen Bundes, wurde aber bis 1864 von Dänemark aus verwaltet, weil es zum dänischen Gesamtstaat gehörte. 
deren Großeltern in Schleswig wohnten, zur dänischen Minderheit. Historisierende Rechtfertigungen und das Konstruieren von bestimmten, dänischen Verbindungslinien im eigenen Stammbaum kann Gefühle von Zugehörigkeit schaffen, nach welchen sich einige Akteur*innen sehnen.

Neben den hier geschilderten historischen Bezügen unterstreichen einige Gesprächspartner*innen ihr Dänischsein auch auf andere Art und Weise. Zwei Punkte sollen hier noch kurz genannt, aber nicht weiter ausgeführt werden. Erstens werden von den Interviewpartner*innen Verweise auf Freunde, Bekannte oder Verwandte, die in Dänemark wohnen, gemacht. Dazu gehören beispielsweise die Familien dänischer Ehepartner*innen, Geschwister und Freund*innen, die nach Dänemark ausgewandert sind oder bei eigenen Aufenthalten im Königreich kennengelernte dänische Bekannte.

Zweitens können bei den Interviewten Versuche beobachtet werden, ihren Außenseiterstatus in der Nachkriegszeit zu relativieren, indem ohne reale Grundlage, sondern nur aus einem Gefühl heraus behauptet wird, dass „halb Friedrichstadt [...] wollen wir mal so sagen [...] oder fast ganz Friedrichstadt, bis [auf] 'nen paar Ausnahmen“ (INT05) auf der dänischen Schule war. Oder wenigstens „ganz, ganz, ganz, ganz, ganz viele“ (INT03) die Hans-Helgesen-Schule besucht haben. Damit soll vielleicht der Eindruck vermittelt werden, dass sie selbst keine richtigen Außenseiter*innen waren und damals und heute nicht alleine dastanden und -stehen. Diese Umdeutung der Vergangenheit ist typisch für die Konstruktion von Geschichtsmythen. Die Verwendung von Geschichtsmythen und das Beschwören vermeintlicher Homogenität ist „ein intellektuelles Konstrukt der europäischen Aufklärung“ (Yildiz 2007: 55), in der „Identität historisch als ein Ordnungsprinzip fungiert hat, das Menschen oder Kulturen als klar begrenzte Einheiten auffasst" (ebd.: 55). Anhand von „Imaginationen“ „etablieren“ Menschen also „Zugehörigkeiten“ und „Gemeinschaft“ (Binder 2008: 16). ${ }^{577}$ Durch Geschichtsmythen und Ursprungsmythen wird versucht, die Minderheit nicht nur zu

577 Die hier beschriebenen historischen Legitimierungsversuche und historischen Argumentationen finden nicht nur in der dänischen Minderheit statt, sondern wurden auch bei Volksgruppen in Siebenbürgen beschrieben, wo sich rumänische Akteur*innen in den 1920er-Jahren auf das antike Rom und eine „,römisch-rumänische Kontinuität“ beziehen, um eine rumänische Nationalisierung der Stadt zu rechtfertigen (Feischmidt 2003: 80-81). Eine ähnliche historische Rechtfertigung wurde in derselben Stadt in den 1940er-Jahren vorgenommen, allerdings mit umgekehrten Vorzeichen, nämlich für die Magyarisierung durch ungarische Akteur*innen (ebd.: 82, 95). Man suchte im Stadtbild nach möglichst alten Beweisen für die ungarische Geschichte und die Existenz von ungarischer Kultur, wie beispielsweise ungarischen Gräbern, Siedlungen, Häusern, und es wurden sogar die Archäologie und dakische Mythologie sowie dazu passende Filme und Spiele benutzt, um der Stadt „eine historische Dimension“ zu geben (ebd.: 83, 86, 87, 200). Aufgrund von vereinzelten historischen Nachweisen wurde versucht, herauszufinden, welche Volksgruppen als erstes oder früher als andere an einem Ort waren, um daraus gegenwärtige Ansprüche zu rechtfertigen (ebd.: 87, 198), wie es auch bei der dänischen Minderheit mit der Eider als vermeintliche tausendjährige Südgrenze Dänemarks gemacht wird. 
legitimieren, sondern auch zu koordinieren und zu mobilisieren (vgl. Coakley 2004: 541). Speziell für die dänische Minderheit bestätigt Jørgen Kühl, dass „die Interpretation der Vergangenheit und das Geschichtsbewusstsein [...] für die Identitäts- und Sinnstiftung" wichtig sind (Kühl 2004: 321). Der individuellen „Geschichtsinterpretation“ der Akteur*innen „kommt eine sinnstiftende Funktion zu“ (ebd.: 322). „Dass es diese Tendenz zum legitimierenden Erzählen gibt, ist aus der Erfahrung bekannt", so Hermann Bausinger (Bausinger 2005: 199).

Im nächsten Unterkapitel soll der Prozess des Dänischwerdens mit Konversionsprozessen sowie religiösem Bekenntnis verglichen werden. Bei beiden spielen Gefühle und eine Sehnsucht nach Beheimatung eine große Rolle. Auch bei diesen Vorgängen kann man bei den Akteur*innen beobachten, dass sie ihren Wandel versuchen zu erklären, zu objektivieren und zu plausibilisieren.

\subsection{Bekenntnis, Konversion und Beheimatung}

Da die deutsche Kirche ebenso wie die dänische Kirche im Landesteil Schleswig evangelisch-lutherisch ist, funktioniert Religion oder die Zugehörigkeit zu einer der beiden Kirchen nicht als Abgrenzungskriterium oder „ethnic marker“ (Mitchell 2006: 1138) für die Angehörigen der dänischen Minderheit, wie es beispielsweise bei den nationalen Zugehörigkeiten in Irland und Nordirland der Fall ist. Daher soll hier nicht die Bedeutung der Religion für die Zugehörigkeit zur Minderheit untersucht werden, sondern welche Parallelen es zwischen Prozessen der Minderheits- und den Religionszugehörigkeitskonstruktionen und -zuschreibungen geben kann. In diesem Unterkapitel sollen die Abläufe von Konversionen anhand des Fallbeispiels Sarah Iversen (s. Kap. 4.1) beschrieben werden, da ihre Biografie am deutlichsten den Wandel durch die dänische Schule zeigt. ${ }^{578}$

Weiterhin sind Rekurse auf die Vergangenheit, archäologische Untersuchungen und die Suche nach archivarischen Belegen der eigenen Gruppe zur Konstruktion einer Identität in der Gegenwart auch im Hinblick auf die nationale Minderheit der Sorben beschrieben worden (Toivanen 2001: 30-32, 40-41).

578 Erik Nissen und Otto Clausen sind im Gegensatz zu Sarah Iversen sehr jung, nämlich als Dreijährige in das Dänische hineingewachsen und haben deshalb keinen nennenswerten Umbruch im Leben in Bezug auf das Dänische erlebt. Otto Clausen nennt in seiner Erzählung einen starken Auslöser für seine bis heute bestehende dänische Gesinnung: die Heilung seiner Lungenkrankheit in Dänemark. Er bezieht sein Dänischsein also sehr stark auf diesen Hintergrund, was aber aufgrund des damaligen Alters keinen wirklichen bewussten Umbruch im Leben darstellt. Generell gilt jedoch, dass Krankheiten „zu den wichtigsten Erzählthemen [gehören], und zwar als Eigen- und Fremderlebnis“ (Lehmann 2007: 198), wie man in Frauke Erhards Fall ansatzweise beobachten konnte. Mehr zu Krankheit als „,epochengenerierende lebensgeschichtliche Erfahrung“" s. a. ebd. (198-200); Lehmann (1983). 
Die Analogie zwischen Minderheits- bzw. Nations- und Religionsbekenntnis lässt sich aufgrund des Glaubens an ein Konstrukt ziehen. Allerdings muss man deutlich machen, dass bei Religion immer eine übermenschliche Komponente im Glauben vorhanden ist (Riesebrodt 2007). Benedict Anderson verweist auf die Parallelen zwischen der Imagination von Nationen und „religiösen Vorstellungen" (Anderson 2005: 18). Er betrachtet den Nationalismus nicht als Ideologie, sondern als ein „unhinterfragbare[s] gegebene[s] Bezugssystem[...]", wie es vorher ,[d]ie religiöse Gemeinschaft und das dynastische Reich“ gewesen seien (ebd.: 20). Hobsbawm nennt nationalen „Patriotismus“ auch „Bürgerreligion“, zu der die Bürger*innen im 19. Jahrhundert bekehrt werden sollten, zum Beispiel durch die Einbeziehung von nationalen „Institutionen“ (Hobsbawm 2005: 103, 104). Gruppenkonstituierende und von Religionsgemeinschaften verwendete Komponenten wie „symbols, rituals and organizations are used to boost ethnic identity“ (Mitchell 2006: 1140). Man kann hier Analogien zwischen Zugehörigkeiten zu Ethnien oder Minderheiten und zu Religionsgemeinschaften ziehen, da beide Imaginationen Wege des Sichselbstverstehens sind und soziale und kulturelle Identifikationen durch Gleichheits- und Differenzkonstruktionen vollzogen werden (Brubaker 2015: 6, 104). Religion und Nationalismus oder Ethnizität organisieren, rahmen und kanalisieren soziale Beziehungen durch ihre Institutionen, die parallel zu anderen Gesellschaften aufgebaut wurden (ebd.: 104), wie es bei der dänischen Minderheit als selbstbezeichnete Parallelgesellschaft deutlich wird. Diese Parallelorganisationen können „school systems, universities, media, political parties, hospitals, nursing homes, and institutionalized sporting, cultural, and recreational activities as well as churches and ethnic associations" sein (Brubaker 2015: 104-105; Brubaker 2007: 207-223).

Ein Aspekt des Vergleichs von religiösen und nationalisierenden Prozessen ist die Konversion von einer Religion bzw. nationalen Gesinnung zu einer anderen. Konversion ist ein Forschungsthema der soziologischen Verlaufs- und Ursachenforschung (vgl. Wohlrab-Sahr et al. 1998: 10) und wird als Übergangsprozess de- 
finiert. Hier ähnelt Konversion dem Liminalitätsbegriff aus der ethnologischen Ritualforschung. ${ }^{579}$ Konversion ist allgemein bekannter im Rahmen religiöser, konfessioneller Wechsel, es gibt aber auch eine „kulturelle Konversion“ (ebd.: 34). ${ }^{580}$

Konversion geht mit einem ,radikalen persönlichen Wandel“", einer „Wendung von einer Auffassung zu einer anderen“ oder „eine[r] besondere[n] Erfahrung“ einher (ebd.: 8). Das kann im Rahmen eines Wechsel der Zugehörigkeit geschehen oder als Annahme eines neuen „Sinnsystems“ einer konstruierten Gruppe (Wohlrab-Sahr et al. 1998: 8; vgl. Berger 1963: 62) oder als „Wandel der Deutungsmuster“ (Wohlrab-Sahr 1995: 288). Bei diesem Prozess kann man ,eine Uminterpretation der Vergangenheit" ähnlich wie bei nationalen Geschichtsschreibungen (s. Kap. 8.6) beobachten, die teilweise ,absichtlich und vollbewußt vorgenommen wird“ (Berger 1963: 71), um die eigene subjektive Zugehörigkeit gegenüber sich und anderen zu objektivieren, und um „Erfahrungen Sinn [zu] verleihen“ (Wohlrab-Sahr et al. 1998: 31). Der Begriff Konversion beinhaltet in der Regel ein neues Bekenntnis, eine neue Orientierung oder eine Umkehr zu einem anderen Glauben ${ }^{581}$ oder einer anderen nationalen Gesinnung, wie beispielsweise zur dänischen Minderheit (vgl. Gerlitz 1990: 559, 561; vgl. Kollar 1990: 566). Dabei muss Konversion „,nicht den vollständigen Austausch der Inhalte von Realitätsauffassungen“, „sondern die Neustrukturierung von neuen und alten Inhalten“ bedeuten (Wohlrab-Sahr 1995: 288). Konversion wird von Wohlrab-Sahr auch als ein „Paradigmenwechsel“ in biografischer, kultureller und sozialer Hinsicht be-

579 Liminalität bezeichnet darin einen ,permanenten Schwellenzustand“ (Turner 2000: 140), einem „betwixt and between“ (Turner, zit. n. Eriksen 2002: 62). „Schwellenwesen sind weder hier noch da, sie sind weder das eine noch das andere, sondern befinden sich zwischen [...] Gesetz, [...] Tradition, [...] Konvention“ (Turner 2000: 251). Gemeinsam ist Akteuren im Schwellenzustand, und das trifft auch auf viele Angehörige der dänischen Minderheit zu, dass sie sich bei ihrer Konversion an den „Grenzen“ „der Sozialstruktur“ aufhalten oder „,ihre niedrigsten Sprossen“ besetzen (ebd.: 258). Dabei kann es dazu kommen, dass sie sich weder einer imaginierten Mehrheits- noch Minderheitengruppe zugehörig fühlen, sondern beides miteinander vereinbaren, wie es bei Frieda Theben und Heinrich Schmied beschrieben wird. Allerdings muss man bei den Begriffen Liminalität und Konversion kritisieren, dass diese Ansätze eine „gruppistische“ Tendenz haben und man Gefahr läuft, einem Containermodell zu verfallen, indem man Konversion und Liminalität immer als zwei abgrenzbare Sinnsysteme oder kulturelle Einheiten begreift, zwischen denen man sich bewegt oder zwischen denen man wechselt.

580 Konversion muss sich also nicht nur „auf Religion im engeren Sinne“ beschränken (WohlrabSahr et al. 1998: 9, m. Rückgriff auf Peter L. Berger), „sondern [kann] sich auch in bezug [sic] auf Weltanschauungen, Ideologien und andere ,symbolische Wirklichkeiten' vollziehen" (ebd.: 30, m. Rückgriff auf Berger (1977) sowie Berger und Luckmann (1969)). Peter L. Berger bezeichnet die weltliche im Gegensatz zur religiösen Konversion auch als Alternation (Berger 1977: 62).

581 Sei diese nun religiöser Art oder der Glaube an eine Nation, Gruppe oder Ähnliches. 
trachtet (ebd.: 290-291), den sie anhand des Fallbeispiels einer Konversion „,vom Kommunismus zum Islam“ als Austausch von Glaubenssystemen beschreibt (ebd.: 309).

Eine kollektive Vorstellung von etwas resultiert in einer Gemeinsamkeit, an die man glaubt. ,[D]ieser gemeinsame Glaube bildet die Grundlage der Gemeinschaft" (Hase 2001: 92), egal, ob es sich um eine religiöse oder um eine zivilreligiöse Gemeinschaft, wie beispielsweise eine Minderheit, handelt. Der Religionswissenschaftler Thomas Hase spricht im Zusammenhang mit der Amerikanisierung von Immigrant*innen in den USA und einer konstruierten US-amerikanischen Identifizierung, genannt „American Civil Religion“, von „Konversion“ (ebd.: 167). Die sei eine „bewußte[...] Hinwendung zu einer Gemeinschaft, welche die eigene Existenz in einem umfassenden Sinn als bedeutungsvoll erfahrbar macht" (ebd.: 167). Irene Götz erläutert die Verbindung zwischen dem Glauben an eine Nation und dem religiösen Glauben anhand der Mystifizierung einer nationalen Geschichte und „durch quasi-religiöse, kultische Inszenierungen des Nationalen in prozessionsartigen Festveranstaltungen im gegenwärtigen Alltag“" (Götz 2011: 114), wie es auch bei den dänischen Jahresfesten zu beobachten ist (s. Kap. 8.1). Dadurch werde eine „metaphysische Sinn- und Gemeinschaftssuche befriedigt, also auch sich verschärfende soziale Gegensätze und lokale Entwurzelungen kompensiert" (Götz 2011: 114; vgl. a. Coakley 2004). Religion bzw. die Zugehörigkeit zur nationalen Minderheit der Dän*innen reduziert also die Komplexität der Welt und gibt einfache Erklärungen oder Rechtfertigungen für Probleme und Entscheidungen. Religiosität und analog dazu Minderheitenzugehörigkeit gibt emotionale Sicherheit und Schutz (vgl. a. Mitchell 2006: 1141, m. Rückgriff auf Hans Mol). Claire Mitchell bezeichnet diesen Prozess mit Rückgriff auf Nicholas Jay Demerath als „sacralization of ethnic group[s]“ (ebd.: 1139). Joseph Ruane und Jennifer Todd betonen, dass Religion und Ethnizität jeweils sehr wirkmächtige Grundlagen von Identität und Gruppenbildung sein können (Ruane, Todd 2010: 1) ${ }^{582}$ Dies ist vergleichbar mit der Konstruktion einer nationalen Minderheit. Auf die dänischen Akteur*innen der Nachkriegsgeneration kann das Konzept Konversion angewendet werden. ${ }^{583}$

582 Während sich Akteur*innen bei Ethnizität auf vermeintliche Abstammung als Kategorie, auf ein Territorium und einen Ursprungsmythos beziehen, werden bei Religion das Sakrale und spezifische religiöse Praxen hervorgehoben (Ruane, Todd 2010: 2). Über die Verschränkungen zwischen und Überlappungen von Ethnizität und Religion sowie ihre Auswirkungen generell s. ebd.

583 Leserbriefschreiber Peter Huber merkt in der Flensborg Avis an, dass er die dänische Minderheit für eine Konvertitenbewegung halte, in der Menschen aus der Mehrheit in die Minderheit wechselten (Huber 10.10.2014). 
Auch Hobsbawm vergleicht Nationalismus mit religiösem Glauben (Hobsbawm 2005: 24). Dabei glaube man statt an einen Gott an eine Nation. Die Konstruktion Minderheit existiere solange, die Akteur*innen ,an die Wirklichkeit dieser Repräsentation“ glauben „und sich entsprechend verhalten“ (Hase 2001: 199), denn

[z]ivilreligiöse Rituale dienen der Aufrechterhaltung und Tradierung dieses Glaubens; Sanktionen verhindern, daß die rituell hergestellte emotionale Bindung der Menschen an die Symbole dieses Glaubens - ihre kollektive Euphorie - allmählich erodiert (ebd.: 199).

Hase zeigt anhand seiner USA-Studie, dass die ,zivilreligiösen Symbole“ so stark mit Emotionen und Normen besetzt sein können, dass von „kollektiver Sakralisierung“ gesprochen werden könne, die auch mit einer „Sanktionierung“ einhergehe (ebd.: 200).

Ein Element der Konversion stellt der „dramatische[...] Wandel“ und eine „Neuorientierung“ im Verlaufe eines Leben einer Person dar, die sich „auf eine besondere Erfahrung beziehen“ kann (Wohlrab-Sahr et al. 1998: 8). Ursache für eine Konversion kann sein, dass Menschen nicht oder nicht mehr in die Gesellschaft oder Umgebung eingebunden sind, in der sie leben. In dieser Situation trauen sie sich, Experimente zu wagen, indem sie sich anderen Gruppierungen anschließen (vgl. ebd.: 12). Hier ist ein Bezug auf Sarahs geschilderte Diskriminierungen als Basis für ihren Zugehörigkeitswandel erkennbar (Kap. 4.1). Allerdings kann man bei meinem Sample keine umfassende „Verwandlung grundlegender Wirklichkeitsvorstellungen“ (Stenger 1998: 196) feststellen und auch keinen „Ausschlußzwang ,alter ' Deutungselemente“ (ebd.: 197) des Lebens vor der „Geburt“ (INT03), die Stenger einer vollständigen Konversion zuschreibt. Bei einer nichtvollständigen Konversion können die Personen „zwischen den Stühlen“ stehen, so Stenger (ebd.: 201). Dieser Zustand ähnelt der oben erwähnten Liminalität. Der Wandel ist, wie wir gesehen haben, nicht bei allen Interviewten gleich stark ausgeprägt und wird nicht von allen gleich stark thematisiert. Zur Konversion gehört aber auch das Element, das man bei Sarah Iversen wiederfinden kann: die Folgenreichhaltigkeit der Konversion. ${ }^{584}$ Denn Konversion heißt, „,von der eigenen Verwandlung erzählen zu können“ (ebd.: 201), unabhängig davon, ob Geschichten rund um den Wandel „real“ oder konstruiert sind. Dabei kommt es vor allem darauf an, „daß mit der Kommunikation die Konversion sozial objektiviert wird“

584 Allerdings entspricht der bei Stenger und Wohlrab-Sahr verwendete Kulturbegriff eher dem oben erwähnten Containermodell und dem „Gruppismus“ (Brubaker 2007: 11, 17) und ist deshalb kritisch zu sehen (s. Kap. 2.2.1). 
(ebd.: 202). Die Objektivierung von subjektiven Gefühlen und Entscheidungen ist ein wichtiger beobachteter Aspekt beim Dänischwerden und Dänischsein der Interviewten.

Bei „Konversionserzählungen“ bereiten die „Erzähler den Zuhörer [...] auf die Konversion vor“, indem sie schildern, welche „Umstände zu ihrer Konversion geführt haben“ (Ulmer 1990: 290) und dass diese Probleme existenziell und im Alltag relevant waren (ebd.: 290). Sarah Iversen erzählt im Interview, wie schlecht sie im deutschen, nationalsozialistischen Umfeld behandelt wurde. Gleich anschließend schildert sie den im Grunde ungewöhnlichen Wechsel zur dänischen Schule als eine Art „Bekehrungserlebnis“ (ebd.: 291), bei dem sie vor allem auch die emotionale Seite betont, welches typisch für Konvertit*innen ist (ebd.: 291). Dort, auf der dänischen Schule, machte sie „,außergewöhnliche Erfahrungen [...], die plötzlich und unerwartet eintreten“ (ebd.: 291). Sie erzählt dies möglicherweise auch, um die Plausibilität ihrer eigenen Geschichte des Dänischwerdens zu steigern. Dazu gehört, laut Konversionstheorie, auch das Berichten von der mit den Ereignissen zusammenhängenden ,tiefgreifende[n] emotionelle[n] Erschütterung“ (ebd.: 292). Ihr ganzes Leben bezieht Sarah Iversen auf ihre „Geburt“ in der dänischen Schule. Vorher habe sie keine Kindheit gehabt, danach habe ihr Leben erst angefangen. Bei der Konversion ist es so, dass der*die Konvertit*in typischerweise „,sein gesamtes Leben in eine Zeit vor und eine Zeit nach der Konversion ordnet“ (ebd.: 292). Die Beschreibungen der „unmittelbaren Auswirkungen des Konversionserlebnisses [werden] [...] spiegelbildlich zur Darstellung der vorkonversionellen biographischen Krise“ (ebd.: 292) erzählt. Auch dies trifft auf Sarah Iversens Geschichte zu. Vor dem Besuch der dänischen Schule wurde sie nicht akzeptiert, sondern diskriminiert, während sie auf der dänischen Schule beachtet und integriert wurde. Bei der Konversion beschreiben die ,Bekehrten“ den „Wandel als einen radikalen, einschneidenden, bedeutungsvollen und für das weitere Leben folgenreichen Bruch mit der Vergangenheit" (Wohlrab-Sahr et al. 1998: 27). „Die Bekehrung macht sich zuallererst im psychischen und emotionellen Bereich bemerkbar, z. B. durch die Empfindungen von Freude, Ausgeglichenheit und innerer Ruhe“ (Ulmer 1990: 292-293). Auch bei Sarah Iversen spielt die emotionale Seite des Beginns ihres Dänischwerden die größte Rolle. Sie äußert, wie bereits geschildert, welche positiven Gefühle sie mit dem Dänischen verbindet. Es handelt sich beim Wechsel auf die dänische Schule um eine ,grundlegende[...] Veränderung“ in der Biografie (ebd.: 293). Das Ende der Diskriminierung und Missachtung Sarah Iversens durch Mitschüler*innen und Lehrer*innen setzt in ihrer Erzählung schlagartig mit dem Besuch der dänischen Schule ein. Dort wird sie sofort akzeptiert und integriert. Sie erzählt von den „unmittelbaren Auswirkungen der Konversion, die spiegelbildlich zum Bericht über die vorkonversionellen Krisenaspekte“" geschildert werden (Wohlrab- 
Sahr et al. 1998: 21; vgl. Ulmer 1990: 293). Konversionen passieren nicht zufällig, sondern gehen immer mit der individuellen Lebensgeschichte der Konvertit*innen einher (vgl. a. Schröder 2012: 321).

Ähnlich dem Bedürfnis der Interviewten, sich für ihr Dänischsein zu rechtfertigen, zeigt das

Vorhandensein einer eigenständigen kommunikativen Gattung [...] ,Konversionserzählung' [...], daß das damit lösbare kommunikative Problem gesellschaftlich von größerer Bedeutung ist. Konversionserzählungen tragen vor allem dazu bei, den Status des Erzählers als ,echter ${ }^{6}$ Konvertit abzusichern. Das Durchleben einer persönlichen religiösen Erfahrung, die in den Konversionserzählungen als Ursache der Konversion geschildert wird, bildet dabei ein sozial anerkanntes Kriterium, das die Glaubwürdigkeit der Konversion verbürgt. In dem Maße, wie es den Konvertiten also gelingt, den erzählerischen ,Nachweis` für ein [...] Schlüsselerlebnis zu führen und es auf plausible Weise darzustellen, können sie damit rechnen, daß die Zuhörer ihren Status als Konvertit akzeptieren. So betrachtet entpuppt sich das kommunikative Problem von Konversionserzählungen zugleich auch als soziales Problem, das darin besteht, die anderen von der Echtheit der eigenen Konversion zu überzeugen (Ulmer 1990: 294).

Dies trifft ebenso auf die Südschleswiger*innen zu, die das Gefühl haben, die „Echtheit“ ihres Dänischseins nachweisen und die „Echtheit“ des Dänischseins bei anderen infrage stellen zu müssen, wie bereits im vorherigen Unterkapitel beschrieben. „In diesen Fällen erfüllen Konversionserzählungen eindeutig eine Legitimationsfunktion“" (ebd.: 294-295). Diese ist vielleicht insofern notwendig, als sie sich

jedes Mal, wenn sie ihre Konversionsgeschichte aufs Neue erzählen, vergewissern [...], daß sich tatsächlich alles so abgespielt hat, wie sie es in ihren Erzählungen immer wieder darstellen, und daß sie sich zu Recht als Bekehrter bezeichnen können (ebd.: 294-295).

Zur Ähnlichkeit des Dänischwerdens mit Bekehrungen gehört auch, dass Konversion immer subjektiv ist, auf persönlichen (oder elterlichen) Entscheidungen beruht (vgl. Wohlrab-Sahr et al. 1998: 23, m. Rückgriff auf Staples und Mauss 1987) und abhängig von gesellschaftlichen Umständen ist. An diesem Punkt kommt man wieder zu dem in der Einleitung beschriebenen Gesinnungsprinzip zurück, welches der dänischen Minderheit zugrunde liegt. Darin wird das freie Bekenntnis 
aufgrund eigener Entscheidungen betont. Der subjektive Charakter der Konversion steht im Einklang mit den Äußerungen der Interviewten, dass ihre Bindung an das Dänische durch Emotionen, Erlebnisse und Erfahrungen gefördert wird.

Schauen wir nun kurz auf die anderen Interviewpartner*innen, bei denen sich konversionsähnliche Prozesse vollzogen haben: Brigitte Thomsen hat, ähnlich wie Sarah Iversen, auch eine Art von Konversion erlebt. In ihrer Erzählung ist der Wandel aber nicht so stark ausgeprägt wie bei Sarah, was mit weniger Diskriminierungserfahrungen vor ihrem Dänischwerden zusammenhängen könnte. Doch auch Brigitte Thomsen grenzt sich klar zu Nichtdän*innen ab, zu denen sie beispielsweise auch ihre Halbgeschwister zählt, die eine deutsche Schule besucht haben (INT02).

Frieda Theben und Heinrich Schmied dagegen beurteilen in ihren Erzählungen ihr individuelles Dänischwerden kaum als Schnitt oder Umkehr im Leben, sondern eher als eine Bereicherung und Ergänzung ihres Alltags. Beide stehen dem Dänischsein positiv gegenüber, sie sind aber für vieles offen und betrachten vorgeblich Deutsches und Dänisches als nicht so oppositär wie Brigitte Thomsen oder Sarah Iversen. Deshalb trifft auf Frieda Theben und Heinrich Schmied eher Arthur Darby Nocks Begriff der Adhäsion zu (Nock 1933), also der „Erwerb einer zusätzlichen, aber nicht alternativen [...] Orientierung" (Wohlrab-Sahr et al. 1998: 9), die von der oben beschrieben Konversion unterschieden wird.

Die Analogie zwischen Minderheiten und Religion kann nicht nur anhand der Konversionserzählungen der Interviewten gezogen werden, sondern wird auch durch Aussagen von Funktionär*innen aktiv hergestellt: Der SSF-Landesvorsitzende Jon Hardon Hansen ist gleichzeitig auch Pastor der dänischen Kirchengemeinde auf Sylt. In einer Grundsatzrede auf der Südschleswig-Konferenz an der Jaruplund Hojskole am 4. März 2017 sieht Hansen eine explizite Verbindung zwischen dem Minderheitssein und der Religion. Diese erläutert er, indem er den kirchlichen Missionsbegriff auf die dänische Minderheit überträgt (Hansen 09.03.2017). Er weist die Konferenzteilnehmenden, Funktionär*innen und Aktive der Minderheit darauf hin, dass je deutlicher die Minderheitenmission formuliert werde, desto „einfacher ist es für potenzielle neue Mitglieder, ein Leben als Minderheitenbürger zu wählen oder abzuwählen “585 (ebd.), also zu konvertieren. Es würde dann für die Umwelt einfacher werden, „die Minderheit zu erkennen und wiederzuerkennen “586 (ebd.). Daher fordert Hansen von den Minderheitenvereinen eine Strategie, eine Mission, die davon handele, ,die dänische Kultur, Sprache, Pädagogik, Sport- und Jugendarbeit, den Gesundheitszustand, das Kirchenleben“ „zu verbreiten, zu bewahren, voranzubringen, zu pflegen, zu betreiben und aufrecht-

\footnotetext{
585 „enklere er det for potentielle nye medlemmer at vælge et liv som mindretalsborger hhv. fravælge"

586 „erkende og genkende mindretallet“
} 
zuerhalten $^{6587}$ (ebd.). Er betont, dass alle dänischen Minderheitsinstitutionen die gleiche Mission hätten, „nämlich das Dänischsein“ „,bei ihren Mitgliedern und in Südschleswig als Ganzes“ „zu verbreiten, bewahren, stärken, sichern und voran-

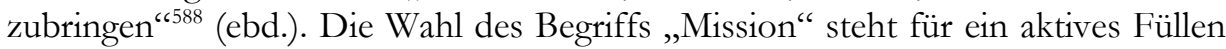
des Dänischseins mit Inhalten und eine Verbreitung der eigenen Ideologie oder Konstruktion der Minderheitenzugehörigkeit. Auch SdU-Funktionär Anders Kring vergleicht die dänische Gesinnung mit einem religiösen Bekenntnis.

Im Gegensatz zu den im Kapitel 5.1 beschriebenen überaus positiven Schilderungen der Nachkriegsgeneration, kritisiert Karin Röh gebürtig aus Schleswig, Jahrgang 1936, jetzt in Dänemark wohnend, in ihren veröffentlichten Erinnerungen einige Aspekte der dänischen Minderheit zu ihrer Schulzeit. Sie berichtet von Identitätsproblemen zwischen deutscher und dänischer Propaganda, zwischen, wie sie es schreibt, Verachtung, Beschimpfungen und Vorurteilen (Röh 2012: 119). Röh bezeichnet die dänischen Lehrer*innen und Funktionär*innen von damals daher als Missionare:

Die wohlmeinenden dänischen Nationalmissionare waren oftmals verwurzelte, starke Persönlichkeiten - sie waren Dänisch auf eine so selbstverständliche Weise - und das Paradoxe war, dass sie es aus bürgerlicher Observanz waren, während die Mehrheit der neuen „dänischgesinnten“ Südschleswiger der Arbeiterklasse angehörten [...] Die Dänen verdienten gut und bezahlten weniger Steuern als in Dänemark und lebten ein harmonisches Dasein miteinander. Sie waren eine Art Oberklasse, während wir, die Einheimischen, eine Art Unterklasse waren ${ }^{589}$ (ebd.: 119_ 120).

Weiter führt Röh aus, dass sie das Gefühl gehabt habe, dass die Südschleswiger*innen nur Statist*innen gewesen seien und diese umgeformt und verdänischt werden sollten (ebd.: 120, 123). Sie kritisiert das heutige dänische Schulsystem in Südschleswig als zu teuer. Es gehe dem dänischen Staat vor allem darum, möglichst viele dänische Fingerabdrücke im Landesteil zu setzen (ebd.: 156).

587 „at udbrede, værne, fremme, pleje, drive og opretholde dansk kultur, sprog, pædagogik, idrætsog ungdomsarbejde, sundhedstilstand, kirkeliv"

588 „,nemlig at udbrede, bevare, styrke, sikre og fremme danskheden blandt deres medlemmer såvel som i Sydslesvig i det hele taget"

589 „De velmenende danske nationalmissionærer var som oftest rodfæstede, stærke personligheder - de var danske på sådan en måde - og det paradoxale var, at de var af borgerlig observans, mens flertallet af nye „dansksindede“ sydslesvigere tilhørte arbejderklassen [...]. Danskerne tjente godt og betalte mindre skat end i Danmark og levede en indforstået tilværelse med hinanden. De var en slag overklasse, mens vi, de indfødte, war en slags underklasse.“ 
Vergleichen wir also Funktionen und Praxen in Religionsgemeinschaften mit denen der nationalen Minderheit: Im Unterschied zu Religionen bezieht sich das Dänischsein nicht auf „den institutionalisierten Charakter der Interaktion zwischen Mensch und Übernatürlichem“ (Haller 2010: 229). Der ganzheitliche Anspruch der Minderheitsfunktionär*innen an die Angehörigen der Minderheit sowie der konstruktive Charakter der Dänischsein-Ideologie, die einen Glauben an das Dänischsein und die dazugehörigen Geschichtskonstruktionen beinhaltet, sowie die oben beschriebenen Konversionsbeispiele ähneln einigen religiösen Praxen. Ebenso wie Religion hat auch das Dänischsein die Funktion von „Sinngebung“ (ebd.: 229). Das Dänischsein in Südschleswig setzt, ähnlich wie es Dieter Haller für Religionen beschreibt, „Rahmenrichtlinien für kulturell adäquates Verhalten, [...] und bemüht sich um die Erhaltung von Werten“ (ebd.: 229). Das sogenannte Minorityhood umfasst ebenso ,institutionalisierte Verhaltensmuster, also Rituale, die den [...] Glauben bekräftigen und erneuern“ (ebd.: 229). Hase äußert sich ähnlich: „Zivilreligiöse Rituale dienen also der Aufrechterhaltung und Tradierung des Glaubens an das zivilreligiöse Weltbild“" (Hase 2001: 206).

Es gibt keinen objektiven Beweis für die Wahrheit dieser geglaubten Ordnung. Die Plausibilität des Glaubens kann nur dadurch aufrecht erhalten werden, dass die Menschen sich gegenseitig der Wirklichkeit ihrer Weltbildkonstruktionen versichern. Die Symbole und die damit verbundenen kollektiven Rituale [...] sind die einzigen Mittel dieser gegenseitigen Versicherung (ebd.: 206).

Was Hase hier für die American Civil Religion formuliert, kann ebenfalls auf die dänische Minderheit übertragen werden, da es auch hier keine objektiven, sondern nur konstruierte Zugehörigkeitskriterien gibt. Hase erläutert anhand von Peter L. Bergers Aussage, dass „,[j]edes Weltbild“ „ein soziales Konstrukt“ sei „, und als solches“ „der kontinuierlichen Bestätigung“ bedürfe, die Crux der imaginierten Gemeinschaften: Die notwendige „Bestätigung geben sich die Menschen gegenseitig, und zwar dadurch, daß sie ihre Konstruktionen eben nicht [Hervorh. im Orig.] als Konstruktionen, sondern als Realität begreifen und sich entsprechend verhalten“ (ebd.: 152). Aus konstruktivistischer Sichtweise funktioniert diese Imagination also wie Religionszugehörigkeiten: Die Wirklichkeit wird konstruiert, damit sie möglichst plausibel erscheint, so Hase (ebd.: 152). Die Identifizierung mit der nicht klar definierten Gemeinschaft der dänischen Minderheit „muß hergestellt und gepflegt werden“ (ebd.: 165) und zwar umso mehr, je unklarer die Gemeinschaft umrissen und definiert ist und je mehr Druck sie von außen bekommt. Allerdings ist dies kein kurzer Vorgang, sondern „ein lebenslanger Prozeß der Identitätsbildung und -bewahrung“ (ebd.: 165), bei dem „Feste“ „,[e]ine wichtige stimulierende Funktion haben“ (ebd.: 165). Das Gleiche konnte bei den 
Interviewten beobachtet werden. Sarahs Beispiel zeigt, dass sie heute als Rentnerin immer noch ihre Konversion und ihr Dänischsein in identitätsstiftender Weise erzählt.

In Südschleswig werden also die identitätsstiftenden Symbole und Praxen, wie das Aufstellen dänischer Flaggen und das Singen dänischer Lieder, als symbolische Akte und nicht aus reinem Vergnügen verwendet. Auch das Verwenden der dänischen Sprache und die Vermittlung spezifischer Geschichtsbilder werden zur gegenseitigen Versicherung der Zusammengehörigkeit eingesetzt. Statt über religiöse Dogmen wird über Erwartungen an die Minderheitsangehörigen diskutiert und gestritten, wie zum Beispiel über das Engagement und die Dänischkenntnisse von Eltern, die ihre Kinder dänisch einschulen (s. Kap. 5.2, 6.1).

Als Konsequenz daraus ,rührt die Intoleranz gegenüber deviantem Verhalten, das immer in einer aktiven oder passiven Mißachtung der Gruppensymbole besteht, in der Weigerung, die euphorische Einstellung diesen Symbolen gegenüber zu teilen“ (ebd.: 206), was die Position mancher Hardliner*innen in der Minderheit erklären kann.

Hase nennt die aktiven Gestalter*innen der amerikanischen Zivilreligion „religiöse[...] Virtuosen“ (ebd.: 206). Analog dazu sind es in der dänischen Minderheit die Funktionär*innen, die durch dogmatische Vorgaben die Minderheitenvereine und ihre Mitglieder versuchen zu prägen. Nach psychologischem Ansatz sind Religionen eine Art „,therapeut. Möglichkeit, um Angst bzw. Ungewissheit zu reduzieren“ (Haller 2010: 231). Sie erleichtern die Suche „nach dem Umgang mit dem Chaotischen, Unsteuerbaren, Zufälligen im Leben“ (Meyer-Blanck, Weyel 2008: 31). Das Bekenntnis zu einer Religion oder einer Nation beinhaltet eine Art Beheimatung. Die Idee von Heimat ${ }^{590}$ hat in Zeiten globaler Migration und „der Wahrnehmung gesellschaftlicher Veränderungsprozesse, die unter dem Stichwort Globalisierung subsumiert werden" (Binder 2008: 4) sowie in Phasen der vermehrten Uneindeutigkeiten (Bauman 1992: 21) wieder Konjunktur (Binder 2008: 1, 6). Dieser Begriff sei mittlerweile eine „Projektionsfläche der aus dem modernen Leben sich ergebenden Sehnsüchte“ und rühre aus einem „Bedürfnis nach Vertrautheit, Sicherheit" her (Seifert 2010: 10, 11; vgl. a. Binder 2010: 199). Mit ihm lassen sich „spezifische Gefühlslagen und Imaginationen verbinden“ (Binder 2008: 1). Der Wunsch nach einer übersichtlicheren Alltagswelt und einem neuen Zugehörigkeitsgefühl sind die Gründe für die aktive Wahl der dänischen Gesinnung. Dabei spielen Hoffnungen und Ängste als Anreize eine wichtige Rolle (Gellner 1991:

590 Eine sprachwissenschaftliche Analyse des Begriffes Heimat liefert Andrea Bastian in ihrer Freiburger Dissertation von 1992 (Bastian 1995). 
83). Nach Fredrik Barth sind Beheimatung, Abgrenzung, Selbstethnisierung und -nationalisierung, wie in Kapitel 2.2.1 beschrieben, Handlungen der Positionierung und Orientierung in der Welt.

Die dänische Minderheit kann, so meine Beobachtungen, den Raum in einer globalen Welt für neu eingestiegene Akteur*innen im positiven Sinne eingrenzen und übersichtlicher machen, was ihnen Sicherheit und Orientierung, Identifikations- und Einflussmöglichkeiten bietet (vgl. a. Seifert 2010: 11-12). Die Eingrenzung der Welt erleichtert den Umgang mit den „Mobilitäts- und Flexibilitätsanforderungen in der postmodernen Informationsgesellschaft" (ebd.: 19). Abgrenzung schafft Sicherheit und reduziert die Komplexität des Alltags. Angehörige der Minderheit sind auf der Suche nach ,einer einfacheren Identität und einer selbstverständlicheren Richtung für [...] [ihr] Leben“"591 (Klausen 07.07.2016), denn Menschen suchen - besonders stark in einer globalisierten Welt - nach einer Selbstverortung (Köstlin 2010: 27). Das Bekenntnis zur dänischen Minderheit ist eine Beheimatung ${ }^{592}$ und damit ein „Versuch einer Homogenisierung in einer Welt, die als fragmentiert gedeutet und erfahren wird“, denn „,[p]lurale Gesellschaften konstruieren punktuelle Überschaubarkeiten“ und „Heimat wäre solch ein punktueller Rückzug in eine selbst hergestellte Übersichtlichkeit“, da „Menschen ihre Orientierungen selber schaffen müssen" und nichts mehr selbstverständlich erscheint (ebd.: 36). „Grenzen reduzieren die Komplexität unserer Welt, indem sie räumlich sowie kognitiv menschliche Umwelt strukturieren“, so der Kulturanthropologe und Grenzethnologe (Lozoviuk 2009: 15). Auch die Kulturanthroplogin Feischmidt schreibt, dass „Kategorisierung [...] eine grundlegende menschliche Orientierungsweise, ein Teil des Denkens, Handelns und der Rede“ sei (Feischmidt 2003: 177) und dass Stereotypen die ,kognitive Funktion“ der Erleichterung der „mentale[n] Orientierung in der Vielfältigkeit“ erfüllten (ebd.: 186).

Dass diese theoretischen Ansätze zutreffen, belegt auch Tina Zehntners Aussage „Das ist wieder son mindretals-Ding“, womit sie meint, dass sie weite Wege fahren müsse, weil die Minderheit im ganzen Landesteil zersteut lebe. Man kenne sich aber trotzdem untereinander. „Da denk ich immer, is Sydslesvig auch klein, weißt du“ (INT10). Margit Feischmidt nennt diese Kontakte, die durch den Besuch gemeinsamer Minderheitsinstitutionen parallel zur Mehrheit entstehen, „ethnisch geprägte[...] Beziehungsnetzwerke“ (ebd.: 173). Eine Art Heimat und sicherer Ort in der dänischen Minderheit fand auch die Eckernförder Elternratsvorsitzende Sylvia Grabowski-Fillmer, so ihre Schilderung auf NDR Info:

\footnotetext{
591 „en enklere identitet og mere selvfølgelig retning for sit liv“

592 Eine Vermischung von Minderheitszugehörigkeit und regionaler Identifizierung konnte auch Konstanze Glasers bei den Lausitzer Sorben und den gälischen Schotten beobachten (Glaser 2001: 83).
} 
Ich bin auch hier auf der Jes-Kruse-Skole zur Schule gegangen und für mich war das immer ja so ein kleiner Puffer, son kleines ja, so 'n Kokon, wo man sich wohl gefühlt hat, also ich bin immer gerne dort gewesen und wollte dieses Familiäre, was dort herrscht, eigentlich auch an meine Kinder weitergeben (Grabowski-Fillmer in Werner 16.05.2016).

Anknüpfend an Kapitel 4.2.2.2 lässt sich hieraus somit zusammenfassend schlieBen, dass ein Grund für die Wahl des dänischen Schulsystems und der dänischen Minderheit in der Vereinfachung, in der Reduzierung der Komplexität der Welt und einer damit verbundenen Flucht aus dem normalen, komplizierten, vielleicht unüberschaubaren Alltag in eine kleinere Welt hinein liegt.

Die Integrationskursteilnehmenden Klaus und Beate Mertens finden in der Minderheit Rückhalt, Zusammenhalt und Gemeinschaft, auch wenn sie Dänisch noch nicht so gut beherrschen. In diese Richtung geht auch die Begründung der Neudänin aus den 1980er-Jahren, Anke Schulz. Sie sitzt heute für den SSW im Kreistag von Schleswig-Flensburg und berichtet in ihrer Rede auf der Arsmode 2016 in Tarp, dass der Umgangston unter den Minderheitendän*innen offener und weniger formell sei. Sie sagt, es gebe ein Zusammengehörigkeitsgefühl und egal, wo man hinkomme, man treffe immer Leute, die man kenne (Schulz 21.06.2016). Sie konstatiert: „Das ist wie eine große Familie, wo ich mich sicher und bedeutungsvoll fühle ${ }^{\text {“593 }}$ (ebd.). „Ein dänisches Leben“, nennt sie ihr dänisches, informelleres Leben in Deutschland (ebd.). Wie viele andere auch betont sie, dass man sich immer mit dem Vornamen anspreche und sich alle duzten. Das sei in der Mehrheit anders (ebd.). Das Duzen wird immer wieder als etwas Typisches für das Dänischsein dargestellt, mit der Einschränkung auf die Königin, die gesiezt wird (Schülerin Emma in Werner 16.05.2016; TNB Signe Frantsen im Integrationskurs, 14.10.2013). Dieses Merkmal wird immer wieder dazu benutzt, sich zum Deutschen durch eine vermeintlich bessere Gemeinschaftlichkeit in dänischen Kreisen abzugrenzen. Allerdings liegt es an den sprachlichen Traditionen, dass man sich im Dänischen duzt. Dies hat nicht die gleiche Bedeutung wie im Deutschen, ist also nicht unbedingt eine Vertraulichkeitsgeste. In Deutschland und auf Deutsch ist es üblich, sich zu siezen. Wenn man sich in Dänemark und auf Dänisch duzt und das der Normalfall ist, sagt das noch nichts darüber aus, wie nah oder fern man fremden Leuten gegenüber steht, schließlich dutzt man sich in anderen Sprachen auch, ohne dass dabei den Sprechenden eine besondere Nähe zueinander zugeschrieben wird (vgl. a. Klausen 07.07.2016). Die Bedeutung, die die Unterscheidung zwischen Duzen und Siezen im Deutschen hat, wird ohne Hinterfragen auf das Dänisch übertragen und es wird dabei eine Nähe aller Spre-

593 „Det er som en stor familie, hvor jeg føler mig tryg og betydningsfuld.“ 
chenden untereinander angenommen. Anke Schulz als Minderheitendänin schreibt dem dänischen sprachlichen Normalfall des Duzens eine große Bedeutung zu, die objektiv gesehen nicht haltbar ist.

Ähnliche Beobachtungen im Zusammenhang mit der Suche nach Heimat hat auch Egon Clausen bei Recherchen zu seinem Buch „I grænselandet. Rejsebreve fra Sydslesvig“ (Im Grenzland. Reisebriefe aus Südschleswig) gemacht. Er ist der Auffassung, dass die Minderheit nicht ausschließlich durch das Dänischsein zusammengehalten werde, sondern durch „die Heimat ${ }^{\text {c } 594}$ (E. Clausen in Mølvig 17.10.2012). Die Hervorbringung eines Heimatgefühls ist für Frieda Theben die wichtigste Konsequenz aus dem Besuch der dänischen Schule. Das Dänische sieht sie als eine Art Zuhause: „Also dänisch ist für mich und wenn ich da bin, immer so'n büschen nach Hause kommen" (INT06). Ähnlich hat es schon Sarah Iversen geäußert. Das Dänische „hat mir sehr viel gebracht“, „,ist die Grundlage meines Lebens, würde ich so sagen“ resümiert Frieda (INT06). „Mein Herz schlägt nach wie vor dänisch“ (INT06). Diese und ähnliche Aussagen trifft sie im Interview fünfmal.

Eine Metapher, die für die Konstruktion von Zusammenhalt und Gruppengefühl immer wieder bei national-konstruierten Gruppierungen auftaucht, ist die Familienmetapher. Der Ausdruck Familie (s. a. Kap. 4.1) soll die Idee von der Nähe zwischen Personen erzeugen und auch die Idee, gemeinsamen Blutes' ansprechen, so der US-amerikanische Staatswissenschaftler Donald L. Horowitz (Horowitz 2000: 55). Er schreibt, dass Familien- und Verwandtschaftsmetaphern oft als Rechtfertigung für die Konstruktion von ethnischen Gruppen genutzt werden (ebd.: 57). Diese Familienmetaphern seien nicht nur Manipulationstricks der Funktionär*innen, sondern die Akteur*innen würden auf solche emotionalen Appelle ansprechen, auch wenn es sich nur um eine vermeintlich gemeinsame Herkunft der Menschen handelt. Mit Bezug auf Horowitz beschreibt Smith, dass für „ethnic nationalists and their followers" Ethnie eine „super-family" sei, die über Raum und Zeit zu weiten Verwandten und über viele Generationen in die Vergangenheit und Zukunft reiche (Smith 2009: 297). Sarah Iversen erzählt beispielsweise, dass die dänischen Vereine und die dänische Kirchengemeinde in Friedrichstadt für sie eine Beheimatung bedeuten: „Ich möchte wieder oder muss eigentlich das Wort Familie noch mal benutzen, denn in der, in den dänischen Vereinen ist man eine Familie, das ist also, alles duzt sich, alles" (INT03). Frieda Theben äußert sich ganz ähnlich zur dänischen Minderheit und zur dänischen Kirche „,Das] muss ich ganz ehrlich sagen, ich hab noch.. sehr viel Kontakt zu der dänischen Kirche in Friedrichstadt... ich war da lange im Kirchenvorstand und... also dänisch ist für mich und wenn ich da bin, immer son büschen nach Hause kommen“ (INT06).

594 „hjemstavnen“ 
Ein weiteres Beispiel für die Verwendung dieser Familienmetapher ist Dieter Paul Küssner, der im SSF-Mitgliedsblatt Kontakt die dänische Minderheit als „Großfamilie“ deklariert. Die Minderheit habe sich auf dem Jahrestreffen 2013 nicht nur sichtbarer in Dänemark gemacht, sondern das Fest war „eine interne Demonstration davon, dass die Großfamilie funktioniert“" ${ }^{\star 595}$ (Küssner 27.06.2013). Zur Familie gehören verschiedene Generationen und Solidarität zwischen den Familienmitgliedern. Auf diese Generationen und die Solidarität geht Küssner ebenfalls ein: „Kinder, Jugendliche und die ältere Generation sind zu den Jahrestreffen gekommen, um der Welt zu zeigen: Wir sind eine solidarische Minderheit ${ }^{\star 596}$ (ebd.).

Am ersten Jahrestreffen nach dem Zweiten Weltkrieg, 1946, nutzte bereits der Vorsitzende des Schleswigschen Vereins (SF), Samuel Münchow, in seiner Rede Familienmetaphern für die Minderheit und ihr Verhältnis zu Dänemark: „Mutter Dänemark“, spreche zu ,ihren Kindern“597 (Münchow in Nissen 08.06.2013). Auch in der Gegenwart werden Familienmetaphern benutzt, wie beispielsweise die Vorsitzende des Jahrestreffenausschusses und seit November 2013 stellvertretende Vorsitzende des SSF, Gitte Hougaard-Werner in ihrer Jahrestreffenrede 2013. Darin nennt sie Dänemark „unser Mutterland““598 (Hougaard-Werner 12.06.2013).

Interviewpartnerin Sarah Iversen betrachtet das jährliche schleswigweite Jahrestreffen der Minderheit mit Festen, Reden und Umzügen als ein wichtiges Zeichen, welches nach außen signalisiert, „, dass wir eine große Familie sind“ (INT03). Außerdem werden die Ausdrücke Euphorie, Solidarität, Fürsorge, Gruppen- und Gemeinschaftserleben, Duzen und „Halt-finden` genannt. Die Minderheitsbewegung bedeutet für die Interviewte eine heile Welt, eine Familie (dieser Begriff fällt im Interview achtmal) und ein Zuhause. Dieses Phänomen ähnelt auch den Prozessen, die in „nationalist discourse[s]“ ablaufen (Eriksen 2002: 107). Die metaphorische Verwandtschaft, wie Eriksen es nennt, macht aus einer abstrakten Einheit wie einer Nation eine Art Familie (ebd.: 107). Die Zugehörigkeit zur Minderheit wird im Nachhinein durch eine ,emotional aufgeladene Vorstellung [...] an Orte der Herkunft und Kindheit“ (Binder 2010: 190 in Bezug auf das Gefühl Heimat, welches sehr ähnlich funktioniert) konstituiert und aufrechterhalten. Ähnlich wie sich die Minderheit nach außen abzugrenzen versucht, bedeutet Beheimatung ebenfalls eine Abgrenzung zu anderen (vgl. ebd.: 192, 199).

\footnotetext{
595 „en intern demonstration af, at storfamilien Sydslesvig fungerer“

596 „Børn, ungdom og ældrestyrken var mødt frem til årsmøderne for at vise verden: vi er et solidarisk mindretal."

597 „Mor Danmark“, „sine Børn“

598 „,vores moderland“"
} 
Auch in diesem Punkt kann man Analogien zur deutschen Minderheit in Dänemark ziehen. Dort stellt Nina Jebsen einen ,emotionale[n] Bezug zur Minderheit fest“", der auf einem „Zusammengehörigkeitsgefühl“ basiert, „das sie mit der Minderheit verbindet“. Mit den anderen Akteur*innen der Minderheit hat „man immer wieder sozialen Kontakt" (Jebsen 2008: 142).

Nicht nur Symbole, das Erlernen von Wissen, Vorstellungen und Erwartungen sowie das Einüben von Praxen mithilfe von Institutionen wie der Schule und dem Kulturverein gehören also zum Dänischwerden und Dänischsein, sondern auch die evozierten schon beschriebenen Emotionen sind für die Konstitutierung und Aufrechterhaltung einer Minderheitenzugehörigkeit wichtig. ${ }^{599}$ So nennt Lotti Wiese die ,große Herzlichkeit“ (Lotti Wiese in Petersen [2014]) und das dadurch erzeugte Gemeinschaftsgefühl als einen Grund, ihr Bekenntnis zur dänischen Minderheit aufrechtzuerhalten. Dass Emotionen für die Zugehörigkeit zu einer Gemeinschaft generell wichtig sind, zeigt Thomas Hase am Beispiel der Amerikanisierung von Immigrierten und zivilreligiösen Praxen in den USA. Dort werde ,angestrebt",

den Menschen das Gefühl zu vermitteln, Mitglied einer Gemeinschaft zu sein. Dieses Gefühl kann man weder lehren noch erzwingen. Aber die Teilhabe an gemeinsamen Festen, die Partizipation an kollektiven Ritualen scheint geeignet, [...] die entsprechenden Emotionen zu stimulieren (Hase 2001: 135).

Emotionen und Symbole erzeugen bei der dänischen Minderheit eine Bindung an die imaginierte Gemeinschaft. Mit Rückgriff auf Durkheim betont Hase, dass diese „affektive[...] Gemeinschaftsbindung [...] für den Fortbestand einer Gesellschaft unerläßlich" ist (ebd.: 143). Auch Emile Durkheim äußert sich zur Bedeutung von gemeinsamen Erlebnissen für den Zusammenhalt von Gruppen, hier am Beispiel von Religionsgemeinschaften:

[D]ie Religion [ist] eine eminent soziale Angelegenheit [...]. Die religiösen Vorstellungen sind Kollektivvorstellungen, die Kollektivwirklichkeiten ausdrücken; die Riten sind Handlungen, die nur im Schoß von versammelten Gruppen entstehen können und die dazu dienen sollen, bestimmte Geistzustände dieser Gruppen aufrechtzuerhalten oder wieder herzustellen (Durkheim 1981: 28).

599 Der Religionspädagoge Bernd Schröder beschreibt diese beiden Komponenten des Aneignens von Gesinnung für den Bereich der Religiosität. Er bezeichnet die beiden Bereiche als „objektive Religion“ und „subjektive Religion“ (Schröder 2012: 203, 319). 
Die Funktionär*innen der dänischen Minderheit wissen um die große Bedeutung der emotionalen Zugehörigkeit und der schönen Erlebnisse und versuchen, möglichst viele gemeinschaftsstiftende Elemente in die Minderheit und in den Integrationskurs zu integrieren. Sie benutzen so oft wie möglich die dänische Sprache und schaffen schöne Erlebnisse, um die emotionale Bindung an die Minderheit zu stärken. Beispielsweise veranstalten die Dozent*innen des Integrationskurses Gemeinschaftsaktionen wie gemeinsames Singen, Laternelaufen und das Ansehen und Besprechen von dänischen Filmen. Diese Elemente werden nicht nur im Integrationskurs angewendet, sondern an vielen Stellen in der Minderheit, wie im Kulturverein oder in Kirchengruppen. Der Aufenthalt in der Jaruplund Højskole soll nicht nur die inhaltliche und sprachliche Kompetenz der Neudän*innen verbessern, sondern die Teilnehmenden sollen durch Gemeinschaftsaktionen, durch gemeinsames Essen und Zusammensitzen, durch gemeinsames Singen, durch die Generierung eines typischen Hojskole-Gefühls ${ }^{600}$ mitgerissen werden. „Laß deine Erlebnisse entscheiden, wo du zugehörst. Es gilt so viele positive Erlebnisse zu machen wie möglich. Das entscheidet, wo man hingehört" ${ }^{\text {(601 }}$, meint Karl Otto Meyer (Meyer in Auring 17.12.1998).

Das Bilden von Analogien zwischen Minderheits- und religiöser Zugehörigkeit hat sich insgesamt als Bereicherung für die Interpretation und Bewertung der Interviews herausgestellt, da viele Ähnlichkeiten in den ablaufenden Prozessen, Erzählungen und Wandlungen festgestellt werden konnten.

600 Mehr über das skandinavische Højskole-System, welches auf Ideen Nikolai Frederik Severin Grundtvigs basiert s. Reddy (1993).

601 „Lad dine oplevelser afgøre, hvor du hører til. Det gælder om at få så mange positive oplevelser som muligt. Det er det, der afgør, hvor man hører til.“ 



\section{Fazit und Ausblick: Dänischsein, Dänischwerden, Dänischbleiben}

„Wir haben jeder, mehr oder weniger bewusst
oder fast natürlich, gewählt der dänischen
Minderheit anzugebören. Wir balten an die-
ser Zugebörigkeit fest. Wir alle formen die
dänische Minderheit. An jedem einzelnen
Tag. In jedem Augenblick. Wir wählen be-
wusst der Minderheit anzugehören. Anders
zu sein. Südschleswig zu sein. " 602
Jorgen Kübl (16.06.2016)

In dieser Zusammenfassung wird zunächst der Blick auf die Ergebnisse in Bezug auf die Nachkriegsneudän*innen geworfen, bevor die aktuellen Entwicklungen bewertet und die eingangs gestellten Fragen beantwortet werden. Anschließend gibt es einen Zukunftsausblick auf die Minderheit, eine Einordnung in größere Zusammenhänge sowie Hinweise auf neu aufgetane Forschungsfragen und -lücken.

${ }^{602}$ „Vi har hver især, mere eller mindre bevidst eller næsten naturligt, valgt at høre til i det danske mindretal. Vi fastholder dette tilhørsforhold. Vi alle hver især skaber det danske mindretal. Hver eneste dag. Hvert øjeblik. Vi vælger bevidst at tilhøre mindretallet. At være anderledes. At være Sydslesvig." 
Bei der dänischen Minderheit gibt es keine Kriterien der Zugehörigkeit außer der freien Gesinnung. Es gibt keine äußeren Kennzeichen, wie typische Namen oder Kleidungsstile oder Aussehen, mit denen sich Angehörige der dänischen Minderheit von der Mehrheit abzugrenzen versuchen, abgesehen vom gelegentlichen Hissen dänischer Flaggen oder dem Anbringen von Dannebrog-Aufklebern auf PKW. Die Minderheitenzugehörigkeit ist subjektiv und veränderlich. Sie wird aktiv von Akteur*innen mit Inhalten gefüllt und dadurch konstruiert. Es werden aber von Akteur*innen Kriterien für das Dänischsein konstruiert, wie beispielsweise eine dänische Sprachkompetenz, die aber erlernbar ist, was den Aneignungscharakter des Minderheitenstatus verdeutlicht. Die Ambivalenz besteht darin, dass Sprache von Funktionär*innen als Voraussetzung für die Zugehörigkeit zur dänischen Minderheit definiert wird, obwohl das laut Landesgesetz als Kriterium für staatliche Stellen nicht zulässig ist. Gleichzeitig werden Menschen, die sich dänisch bekennen, aber die Sprache (noch) nicht beherrschen, von Minderheitsvereinsfunktionär*innen zum Dänischlernen angehalten. Auch wenn die ,brokers of power' immer wieder postulieren, dass die Sprachkompetenz ein Kriterium für das Dänischsein ist, wird gleichzeitig durch die Integration und die Dänischlernangebote das Dänischsein als (Lern-)Prozess bestätigt. Die Sprache ist hier also ein erlernbares, subjektives, veränderbares Kriterium für die Gesinnung. Nicht nur die dänische Sprache, sondern auch dänische Praxen sind erlernbar, selbst im Erwachsenenalter, auch wenn der Weg in die dänische Minderheit in der Regel über die Anmeldung von Kindern in das dänische Schulsystem führt. Um die Frage in der Einleitung zu beantworten: Ja, als Bayer kann man Däne werden, wenn man in den Landesteil Schleswig zieht und sich etwas bemüht, Dänisch zu lernen, sich bereit erklärt, in dänischen Vereinen aktiv zu werden und sich selbst und die eigene Familie der Minderheitsideologie aussetzt. Einzig das von Akteur*innen der Minderheit und dem dänischen Staat als objektiv angesehene Dänischseinkriterium, nämlich der dänische Schulbesuch, kann im Erwachsenenalter nicht mehr erfüllt oder nachgeholt werden, sondern nur noch für die nachfolgende Generation dadurch umgesetzt werden, dass man die eigenen Kinder dänisch einschult.

Das Resultat der vorliegenden Arbeit ist, dass Menschen nach dem Zweiten Weltkrieg aufgrund einer materiellen Not- und gesellschaftlichen Randlage in eine dänische Schule eingeschult wurden. Dort machten sie außerordentlich gute Erfahrungen im zwischenmenschlichen Umgang und konnten an vielen Gemeinschaftserlebnissen teilhaben, an die sich viele noch im Rentenalter gerne erinnern. Dazu zählen neben Erlebnissen in der Schule auch Freizeitaktivitäten in dänischen Vereinen und mit dänischen Betreuern sowie die bei vielen in der Erinnerung bis heute lebendig gebliebenen alljährlichen Kinderreisen in den Sommerferien nach Dänemark. Die geschilderten positiven Emotionen und Erlebnisse führten zu einem Zugehörigkeitsgefühl, zu einer (konstruierten) dänischen Minderheit, ohne dass diese als eine abgeschlossene Einheit betrachtet werden könn- 
te. Mit der dänischen Einschulung und entsprechender Sozialisation in den Institutionen wurde die Grundlage für das Dänischwerden und Dänischsein der Interviewten gelegt. Die dänische Gesinnung wurde im Laufe ihres Leben unterschiedlich stark aufrechterhalten. Das Dänischsein bzw. die Beeinflussung durch das Dänische wirkt aber bei allen heute noch nach. Unterstützt wird diese Aufrechterhaltung der Bindung an die Minderheit neben der Schule durch eine große Palette von Freizeit-, Sport- und Kulturvereinen, durch die Kirche, die dänische Partei, die Zeitung Flensborg Avis, die Dänische Bibliothek, den Gesundheitsdienst und durch zahlreiche weitere Organisationen.

Erlebte Diskriminierungen durch Schüler*innen der deutschen Schulen und später im Berufsleben durch Vorgesetzte und Kolleg*innen werden von den Interviewten rückblickend in ihrer Bedeutung im Gegensatz zu den positiven Gefühlen, die mit dem Dänischen verbunden werden, abgeschwächt. Nach dem Ende der Schulzeit hängt das Aufrechterhalten des individuellen Dänischseins der Interviewten im Alltag zum einen von ihrem individuellen Engagement in Vereinen ${ }^{603}$, der Partei und der Kirche ab, zum anderen aber auch davon, ob die Interviewten persönliche Kontakte zu anderen Dänischgesinnten oder Dän*innen pflegen. Durch familiäre Umstände und unterschiedlich ausgeprägte Dankbarkeit für unterschiedlich starke Hilfeleistungen im Kindesalter vergrößerte sich bei einem Teil des Samples die Aktivität in der Minderheit, bei anderen ging das Engagement hingegen zurück. Ein Gesprächspartner verlor die praktische Anbindung an die dänische Minderheit durch einen eineinhalb Jahrzehnte andauernden Aufenthalt außerhalb Südschleswigs. Er fühlt sich heute nur noch wenig mit dem Dänischen verbunden, während andere schon während ihrer Schulzeit in vielen dänischen Vereinen Mitglied wurden und ihr Engagement bis heute aufrechterhalten haben. Einige betrachten bestimmte Handlungen und Ansichten heute sogar als dänische Selbstverständlichkeiten, wie beispielsweise das Votieren für den Südschleswigschen Wählerverband bei Kommunal- und Landtagswahlen. Die meisten sehen dänische Angebote als eine Ergänzung ihres (deutschen) Freizeitangebotes. Niemand schließt die Beteiligung an gesellschaftlichen Ereignissen oder Veranstaltungen aus, nur weil diese von Nichtdänischgesinnten organisiert werden. Die Akteur*innen sprechen in ihrem Alltag kein Dänisch. Wenn sie jedoch mit anderen Dänischsprechenden zusammenkommen, gebrauchen sie Deutsch, Niederdeutsch und Dänisch, abhängig von der Situation, dem Thema, den Gesprächspartner*innen oder sonstigen Anwesenden, wie beispielsweise Reichsdän*innen oder Funktionär*innen der Minderheit.

603 Auch eine Untersuchung der Evangelischen Kirche in Deutschland (EKD) zeigt den Zusammenhang zwischen Engagement und Zugehörigkeit. Es gibt eine „,hohe Korrelation zwischen kirchlichem Engagement und Verbundenheitsgefühl mit der Kirche“ (Pollack et al. 2014: 43). 
Entgegen der Erwartung hat fast niemand seine dänischen Sprachkenntnisse, die eine Zusatzqualifikation gegenüber Absolvent*innen der deutschen Schule darstellen, im Berufsleben gebraucht. Um, aus Angst vor Nachteilen und aufgrund einer fehlenden materiellen und ideellen Notwendigkeit in den 1970er- und 1980er-Jahren, eine Alternative zum deutschen Schulsystem zu wagen, schickte der überwiegende Teil der Gesprächspartner*innen die eigenen Kinder nicht auf dänische Minderheitsschulen, sondern bevorzugte das deutsche Schulsystem. Es bestand in Friedrichstadt in den 1970er- und 1980er-Jahren kaum noch eine Notwendigkeit, sich dänisch zu gesinnen. Die dänische Schule hatte damals keinen guten Ruf. Sie galt als Alternative vor allem für sozial und kognitiv schwächere Schüler*innen.

Die Attraktivität des Dänischwerdens und Dänischseins hängt, so das Ergebnis dieser Dissertation, vor allem von ökonomisch-materiellen Interessen ab. Das Dänischwerden hatte Hochkonjunktur in den Jahren nach dem Zweiten Weltkrieg. Materielle Not führte bei einer großen Zahl von Deutschen im Landesteil Schleswig zu einem nationalen Gesinnungswechsel hin zum Dänischen. In guten ökonomischen Zeiten ließ das Bekenntnis zum Dänischen nach, es wurden weniger Kinder dänisch eingeschult. Erst mit der Wirtschaftskrise in den 2000er-Jahren wurde das Dänischsein erneut attraktiv. Dänemark stand damals wirtschaftlich besser als Schleswig-Holstein da und hatte Bedarf an Arbeitskräften aus Deutschland. Die dänischen Schulen bekamen bei deutschen Eltern auch durch die Eröffnung der A.-P.-Møller-Schule im Jahre 2008 einen Attraktivitätsschub, so das Ergebnis meiner Beobachtungen und Interviews mit neudänischen Eltern.

Die Vorteile für Menschen, die sich zur dänischen Minderheit bekennen und das dänische Kindergarten- und Schulsystem durchlaufen (haben), sind auf der politischen Ebene die Befreiung des SSW von der 5 \%-Hürde bei Landtagswahlen; „politisch lohnt sich das Dänentum“ also, um mit diesen Worten noch mal auf das Eingangszitat von Gunther Latsch zurückzukommen. Dies ist der einzige durch den deutschen Staat bzw. das Bundesland Schleswig-Holstein bereitgestellte Vorteil bzw. Nachteilsausgleich. Alle weiteren Vorteile sind Leistungen des dänischen Staates, wie zum Beispiel die materielle Hilfe nach dem Zweiten Weltkrieg. Die Hauptgründe, sich heute zur dänischen Minderheit zu bekennen, sind zwar auch materieller Art, allerdings ist das meiste davon indirekt bzw. eine langfristige Investition in spätere materielle und ggf. ideelle Vorteile. Dazu zählen der erleichterte Zugang zur dänischen Staatsbürgerschaft ${ }^{604}$, bessere schulische Bildung durch kleine Gruppengrößen und bessere Ausstattung in Privatschulen als in öffentlichen Schulen, mehr Ausbildungs- und Studienmöglichkeiten nicht nur in Deutschland, sondern auch in Dänemark sowie die dänische Ausbildungsfinan-

604 Damit verbunden ist die Hoffnung auf beispielsweise eine dänische Rente oder auf das Recht eines Ferienhauskaufs in Dänemark. 
zierung. Interkulturelle Kompetenz und Zweisprachigkeit erhöhen die Chancen auf einem vergrößerten Arbeitsmarkt, und eine dänische Gesinnung eröffnet Südschleswiger*innen die Möglichkeit, sich auf dänische Stipendien zu bewerben.

Aus diesen Vorteilen und der Ideologie der Funktionär*innen der Minderheitsvereine ergibt sich eine Ambivalenz. Beispielsweise konnte in dieser Arbeit gezeigt werden, dass die dänischen Schulen aus Funktionärssicht eigentlich nicht bikulturell bzw. bilingual sein sollen, da sie hauptsächlich durch das Königreich finanziert werden. Stimmen aus Dänemark, besonders solche der national-konservativen Dansk Folkeparti (DF), forcieren die Bildung von explizit dänischen Gesinnungsschulen. Aber auch einige in der Minderheit wünschen sich diese mononationale Ausrichtung, da sie glauben, diese Haltung würde von ihnen erwartet werden und mache sie zu,guten' dänischen Südschleswiger*innen.

Gleichzeitig werben einige Funktionär*innen aber damit, dass die Absolvent*innen der dänischen Schulen zweisprachig und mehrkulturell seien und damit Vorteile gegenüber Kindern auf deutschen Schulen hätten, da sie das alltägliche Handlungswissen des Dänischseins erlernt und eingeübt haben. Man ist also gleichzeitig offen gegenüber allen Interessierten, die dafür sorgen, dass die dänischen Einrichtungen genügend Schüler*innen haben, um weiterhin zu existieren. Anderseits möchte man am liebsten nur Leute integrieren, die mit einer gewissen Ernsthaftigkeit dänisch werden und die Sprache lernen wollen. Offenheit versus Abgrenzung ist ein immer wiederkehrendes Moment in der Minderheit, das sich aus der freien Gesinnung und den dazu teilweise gegensätzlichen Erwartungen speist.

In dieser Arbeit wurde gezeigt, welche Inhalte Akteur*innen und Funktionär*innen der dänischen Minderheit in Südschleswig nutzen, um ein Dänischsein zu konstruieren und zu praktizieren. Dabei konnte festgestellt werden, dass es verschiedene Wege des Dänischwerdens und unterschiedliche Ausprägungen des Dänischseins gibt. Letztlich wurde gezeigt, dass es Aspekte materieller Art oder rationalen Ursprungs gibt, die die Wahl des Dänischwerdens und Dänischseins begünstigen. Ruane und Todd postulieren etwa, dass nicht vermeintlich Ethnisches eine Bindung an eine nationale Gruppe verursacht, sondern ein System, dem Ethnizität zugeschrieben wird. Menschen hätten ein starkes Bedürfnis nach Zugehörigkeit (Ruane, Todd 2004: 227). Daraus kann man schließen, dass es nicht so relevant ist, zu welcher Art von Minderheit oder Gruppe Menschen sich bekennen; wenn sie aber erst einmal einen Weg eingeschlagen haben und dort Zugehörigkeit empfunden haben, sowie an die dort konstruierten und tradierten Geschichtsmythen glauben, dass sie dann auf diesem eingeschlagenen Weg bleiben und danach selten den Pfad wechseln. Das nationale Bekenntnis bzw. die Konstruktion einer „,inter-ethnic opposition“ sei, so Ruane und Todd, auch mit dem Verfolgen von rationalen und eigennützigen Interessen von Akteur*innen verbun- 
den (ebd.: 226). Anerkennung, kulturelles Kapital, wirtschaftliche oder politische Vorteile, strategische Interessen gehen beim Einschlagen eines ethnischen oder nationalen Pfades mit Emotionen und kulturellem Interesse einher (ebd.: 228). Für die Minderheit der Dän*innen in Südschleswig kann aus dieser Studie ersehen werden, dass die Motive der Akteur*innen, sich zum Dänischen zu bekennen, von Dankbarkeit für einst empfangene Hilfeleistungen und politische Entlastung nach dem Zweiten Weltkrieg bis zum Erreichen von alternativem und vermeintlich besserem Bildungskapital für schulpflichtige Kinder heutiger Eltern reichen. Von einer Reduzierung der Komplexität und Größe der eigenen Umgebung erhoffen sich viele Anerkennung, persönliche Bindung und Kontakte, Jobs in Minderheiteninstitutionen oder im Königreich und finanzielle Vorteile beim Studium in Dänemark sowie ein enges Netzwerk an engagierten Minderheitenangehörigen. Menschen erfahren ein Familien- und Beheimatungsgefühl durch das Bekenntnis zum Dänischsein. Zusätzlich erlangen einige Südschleswiger*innen Macht in lokalen dänischen Vereinen, und sie erlangen Ressourcen, wie Sprachkompetenz oder finanzielle Zuschüsse.

Die durch die Akteur*innen gefühlte "significance of the ethnic category“ (ebd.: 218) wird erhöht durch abgrenzende und zugehörigkeitskonstituierende Kategorien wie Sprache, Symbole, Gefühle, Bezüge zur Vergangenheit und zu einem geografischen Raum. Eigene Minderheitsschulen und „parades and processions" unterstützen eine ethnonationale Geschichte, die wiederum konstruierte Gruppenzugehörigkeiten unterstützt (Coakley 2004: 538-539). Dies sind bekannte Prozesse, die auch für die Nationsbildung beschrieben wurden, wie beispielsweise von Irene Götz in ihrer Habilitationsschrift: „Homogenisierung nach innen wird in der Regel durch die Abgrenzung von einem Außen vorangetrieben und motiviert" (Götz 2011: 111).

Bei der Identifikation und Zugehörigkeit zur deutschen Mehrheit oder zur dänischen Minderheit spielen Religion und Herkunft inhaltlich keine und sprachliche Aspekte faktisch kaum eine Rolle. Wichtiger waren und sind stattdessen politische, regionale, pädagogische und vor allem sozio-ökonomische Gründe für $\mathrm{Zu}$ gehörigkeiten (vgl. a. Thaler 2013: 25, 39-40) ${ }^{605}$ abseits der Bedeutungszuschreibungen und Konstruktionen in Bezug auf beispielsweise Herkunft und Sprache.

Was es heißt, dänisch zu werden und dänisch zu sein, ist in Südschleswig vom (deutschen) Staat und von der Minderheit selbst, wie ausgeführt wurde, nicht klar anhand objektiver Kriterien definiert, und dies ist aufgrund der Erfahrungen von (fremd)definierten und massiv bedrängten Minderheiten in aller Welt positiv hervorzuheben. Als Konsequenz daraus werden die Konstruktionen der Beteiligten besonders deutlich. Die Minderheit ist keine homogene, statische Gruppe, son-

605 Peter Thaler beschreibt hier auch die historische Entwicklung von Zugehörigkeiten im deutschdänischen Grenzgebiet (Thaler 2013: 24-28). 
dern das Spektrum reicht von Nationalist*innen bis zu Pragmatiker*innen, die sich bestimmter Praktiken und Symbole, Rechtfertigungen und Erzählungen bedienen, die die Abgrenzung sowie Gesinnungsstärkung und -rechtfertigung stärken sollen. Die Abgrenzung ist prozessual, dynamisch und kontextabhängig. Die Minderheit ist also keine feste Gruppe, sondern wird von Menschen als Kategorie zur Ordnung der Welt aufgefasst. Ist ein materielles Interesse da, sich zu einer Minderheit zu bekennen, so werden Kategorien und Abgrenzungsmerkmale und -praxen gelernt, angewendet, abgewandelt und weitergegeben und ggf. wieder abgelegt, wie die Nachkriegsgeneration gezeigt hat. Es gibt bei den Akteur*innen unterschiedliche, nicht objektivierbare Grade der Zugehörigkeit und der Reflexivität über diese. Auch wenn das Dänischsein als Konstruktion betrachtet wird, bedeutet dies jedoch nicht, dass das Dänischsein nicht auf Menschen wirkt. Menschen praktizieren ein Dänischsein im Alltag, und dies hat Auswirkungen und Funktionen, wie beispielsweise eine soziale Schließung oder Verortung und Schaffung von Zugehörigkeiten. Das Dänischsein wird im Alltag der Akteur*innen immer wieder neu gewählt, ausgehandelt und diskutiert oder auch abgeschwächt oder verdrängt. Viele haben sich im Laufe ihres Lebens eigene Deutungswelten geschaffen, warum sie das Dänische besser finden und warum sie dänisch sein wollen. Dazu zählt beispielsweise die dem Dänischsein zugeschriebene Gemütlichkeit, die beschriebenen Gefühle beim Anblick des Dannebrogs und die Praxis des Singens oder der empfundene Zusammenhalt durch Gruppenerlebnisse. Die konstruierten und selektiv ausgewählten Kriterien dienen dem Erhalt des Zugehörigkeitsgefühl wie beispielsweise die Rückgriffe von Akteur*innen auf eine bestimmte historische Sichtweise, die Suche nach einem persönlichen Dänemarkbezug, sei er noch so konstruiert, oder eine Umdeutung und Bedeutungsaufladung der Eider als über 1.000-jährige Grenze, die einen Rahmen um den imaginären Raum für das heutige Minorityhood konstruiert. Das Bekenntnis zur dänischen Minorität funktioniert nur in Anwesenheit einer deutschen Mehrheit, von der man sich abgrenzen kann. Dieses wird mit Objektivierungen untermauert und eigene Entscheidungen werden im Verhältnis zur persönlichen Lebensgeschichte plausibilisiert. Die eigene Lebensgeschichte wird an das heutige Leben und die damit zusammenhängenden „Selbstdarstellungsabsichten“ (Schulze 2001: 175) angepasst. Diese Vorgänge sind mit Nation-building-Prozessen im größeren Format vergleichbar. Dazu werden Rückgriffe auf gezielt ausgesuchte historische Ereignisse gemacht, wie an der $\mathrm{Zu}$ schreibung des Dänisch- oder Deutschseins an das ehemalige Herzogtum Schleswig je nach Gesinnung deutlich wurde. Nicht zuletzt gibt es Auseinandersetzungen über die vermeintliche Echtheit des Dänischseins von Menschen. Dänischgesinnte, die aus Sicht der Interviewten nicht wirklich dänisch sind, werden kritisiert. Dabei wird als Kriterium oftmals die Sprachbeherrschung angeführt. Für viele ist der Besuch einer dänischen Schule der sicherste Indikator für die Echtheit des 
Dänischseins. Schließlich zeigte sich, dass die Lebensverläufe und Erzählungen über das Dänischwerden und Dänischsein vergleichbar waren mit Prozessen, die aus der Migrationsforschung bekannt sind. Die im Fallbeispiel Sarah Iversen besonders deutliche Einteilung ihres Lebens in die Abschnitte vor und nach der dänischen Einschulung erlaubten außerdem einen Vergleich mit soziologischer Konversionstheorie.

Die Kontextabhängigkeit und Flexibilität der Zugehörigkeit zum Dänischen wurde anhand der wechselnden Besuche deutscher und dänischer Kirchen oder Vereine durch die Akteur*innen deutlich. Immer wenn eine Interviewpartnerin die dänische Kirche besucht, fühlt sie sich dänisch und markiert damit öffentlich ihr Dänischsein. Geht sie zur deutschen Kirche, wird in dem Moment ihr Dänischsein ausgeblendet.

Abschließend kann festgestellt werden, dass die Gesinnung einerseits frei ist, andererseits klare Erwartungen an ein konsequentes, starres und eindeutiges Bekenntnis kommuniziert werden. Die Erwartungen werden von Mitgliedern allerdings teilweise ausgeblendet und ignoriert oder abgewandelt. Die ständigen Aushandlungen und Diskussionen sowie die Konstruktion in der Minderheit darüber, was es heißt, dänisch zu sein und der Minderheit anzugehören, hängen auch mit der gesetzlichen Offenheit des Bekenntnisses zu ihr und der daraus entstehenden Uneindeutigkeit der Zugehörigkeit zusammen. Dabei ist diese Offenheit gesellschaftlich gesehen unbedingt als wünschenswert zu beurteilen, damit alle sich im Rahmen der geltenden Grundrechte und Gesetze so ausleben können, wie sie es wollen, ohne von anderen dafür diskriminiert zu werden. Prinzipiell kann in Schleswig also jede*r dänisch werden, wenn er oder sie es will.

Es stellt sich die Frage, ob Menschen, die sich zur dänischen Minderheit bekennen, den nationalistisch-ideologischen Vorgaben und der rhetorischen Propaganda der oberen Funktionär*innen inhaltlich folgen und ihr zustimmen. Bei den Jahrestreffen konnte beobachtet werden, dass viele Teilnehmende den Redner*innen kaum zuhörten, sie wenig beachteten. Einige verstanden aufgrund mangelnder Sprachkenntnisse die auf Dänisch gehaltenen Reden nicht, andere hörten nicht zu oder ließen die Reden kommentarlos über sich ergehen und ignorierten die Inhalte bzw. nahmen sie in Kauf.

Nicht nur die Akteur*innen und Funktionär*innen der dänischen Minderheit konstruieren ihre Zugehörigkeit zur Gruppe, sondern auch die Sorben in Brandburg und Sachsen sowie die Samen in Finnland suchen sich Argumente und Kriterien, die „das Vorhandensein ihrer Nation bzw. ihres Volkes erklären und begründen“" (Toivanen 2001: 123). Obwohl die dänische Minderheit, bzw. das fluide Konstrukt dänische Minderheit keine Ethnie ist, ähneln die Prozesse denen von Minderheiten, die sich durch als vermeintlich ethnisch bezeichnete Kriterien von anderen Gruppierungen abzugrenzen versuchen. Beispielsweise gibt es bei den Prozessen und Symbolen zahlreiche Parallelen zu den von Margit Feischmidt beschriebenen Volksgruppen der Ungarn und Rumänen im rumänischen Cluj-Na- 
poca/Klausenburg (Feischmidt 2003). Im Unterschied zu ihnen erscheint die dänische Minderheit in der Praxis der Akteur*innen allerdings kaum abgetrennt von der deutschen Mehrheit, auch wenn Funktionär*innen dies gerne postulieren. Meine Arbeit hat gezeigt, dass sich die Akteur*innen der dänischen Minderheit gleichzeitig auch als Teil der Mehrheit sehen; sie sind in ihrem Alltag, abgesehen vom Schulbesuch und einigen Freizeitaktivitäten, nicht von der Mehrheit getrennt. Sie kaufen in denselben Geschäften ein, wohnen in denselben Wohngebieten wie alle anderen Bewohner*innen des Landesteils auch. ${ }^{606}$ Minderheitenakteur*innen nehmen auch an Mehrheitsfreizeitaktivitäten teil. Eine Ausnahme sind diejenigen, die für eine der Minderheitenorganisationen, wie beispielsweise für den Schulverein oder den Gesundheitsdienst arbeiten.

Ferner gibt es nicht nur eine gesetzlich geregelte Offenheit des Bekenntnisses, sowie die Erlaubnis, eigene Schulen und Vereine zu betreiben, sondern auch eine gute finanzielle Unterstützung der Minderheit durch Deutschland, SchleswigHolstein und vor allem durch das dänische Königreich. Die Minderheitensituation ist also recht luxuriös.

Zukünftig könnte in anderen Arbeiten noch untersucht werden, ob und in welchem Umfang die ideologischen Reden und Beiträge, die in der Flensborg Avis und in der SSF-Beilage Kontakt abgedruckt oder online veröffentlicht werden, gelesen und rezipiert werden und welche Reaktionen und Wirkungen diese Texte auf Akteur*innen haben. Es bleibt zu vermuten, dass viele derjenigen, die sich bei der dänischen Minderheit wohl fühlen, sich kaum mit diesen lobbyistischen Texten auseinandersetzen.

Die in der vorliegenden Arbeit beschriebene Ideologie der nationalen Minderheit hält die Gruppe aufrecht und koordiniert die gemeinsamen Ansprüche gegenüber Dänemark als Geldgeber und gegenüber der deutschen Mehrheit. Menschen werden durch die genannten Vereine zum Dänischsein mobilisiert und zur Minderheit gemacht. Dänischsein ist in Anlehnung an Renan eine tägliche Wahl, die der Suche nach Beheimatung folgt.

Das Verhältnis der dänischen Minderheit zur deutschen Mehrheit sieht so aus, dass erstere kaum von der deutschen Mehrheitsgesellschaft wahrgenommen wird, abgesehen von den im Grenzland sichtbaren Jahrestreffen und den oben beschriebenen Flaggen, einigen zweisprachigen deutsch-dänischen Ortsschildern und der Partei SSW. Es geht bei der dänischen Minderheit nicht um eine Konkurrenz mit der deutschen Mehrheitsgesellschaft bezüglich der Verteilung von Ressourcen, wie es bei anderen Minderheiten in Europa beobachtet wurde, so beispielsweise in

\footnotetext{
${ }^{606}$ Die Minderheiten bzw. Volksgruppen sind also räumlich nicht voneinander separiert.
} 
Südtirol (Carstocea 21.08.2013; Constantin 28.08.2013; Baumann 2002: 114). Eine Rivalität findet nur unter Minderheitsorganisationen in Bezug auf dänische Finanzmittel statt.

Eine Herausforderung für die Zukunft der dänischen Minderheit speziell auf dem Lande, also auch in Friedrichstadt, ist die Abwanderung von jungen Erwachsenen, die das Gymnasium besuchen oder besucht haben (INT10). Hella Lassen befürchtet daher, dass, wenn die Jungen wegziehen und die Alten irgendwann nicht mehr leben, die Minderheit untergehen könnte, weil dann niemand mehr da sei (Lassen in Petersen [2014]). Von ihren ehemaligen Mitschüler*innen ist neben Tina Zehntner nur eine in Friedrichstadt geblieben. Viele Abiturienten gehen zum Studieren nach Dänemark oder in deutsche Universitätsstädte ${ }^{607}$ und kommen gut ausgebildet nur selten wieder zurück. Die Weggezogenen fehlen der Minderheit. Allerdings betrifft dieses Problem auch die Mehrheitsbevölkerung. Der Grund dafür ist die wirtschaftliche Lage des Landesteils Schleswig, besonders der Westküste, da es dort wenige Beschäftigungsmöglichkeiten für höher qualifizierte Arbeitskräfte gibt. Die stellvertretende SSF-Landesvorsitzende Gitte Hougaard-Werner betont zum Jahreswechsel 2013-14 gegenüber der Flensborg Avis, dass die Jugend die Zukunft der Minderheit sichere: „Wollen wir uns selbst sichern, ist es wichtig die Jugend mitzunehmen. ${ }^{\text {“608 }}$ Sie erläutert, dass die Minderheit die Jugend dazu bringen müsse, ein Verantwortungsgefühl zu entwickeln. „Ansonsten wird es in 20 Jahren keine Minderheit geben“609 (Hougaard-Werner in Dürr 02.01.2014). Eine entscheidende Frage wirft die nordschleswigsche Politikwissenschaftlerin Anne Fuglsang-Damgaard Sina in Bezug auf die deutsche Minderheit in Dänemark auf, die auf die dänische Minderheit übertragen werden kann: ,[W]ie findet man auch in Zukunft einen Weg, eine klare kollektive [...] Identität in der Minderheit zu haben und gleichzeitig jedem einzelnen seine eigene individuelle Identität zu sichern?" (Fuglsang-Damgaard Sina 2012: 66). Dieser Widerspruch lässt sich wohl nur schwer auflösen.

Der dänische Kulturminister Bertel Haarder gab im Sommer 2016 den Anstoß für die Idee, dass das deutsche-dänische Grenzland und seine Minderheiten in Zukunft eine Bewerbung bei der UNESCO als immaterielles Kulturerbe anstreben könnten. Dies wurde 2017 durch den SSF-Vorsitzenden Jon Hardon Hansen bei der SSF-Jahreshauptversammlung in Husum aufgegriffen (Hansen 2017: 5; s. a. Johannsen 14.11.2017; Hansen 12.01.2017; Sydslesvigsk Forening

607 Die beiden nächstgelegenen Volluniversitäten liegen in den 90 bzw. 140 Kilometern entfernt gelegenen Städten Kiel und Hamburg. Rund zwei Drittel der Abiturient*innen der beiden Minderheitengymnasien Duborg-Skolen und A.P. Moller Skolen gehen nach Dänemark zum Studieren (Nygaard 04.07.2014b).

608 „Skal vi sikre os selv, er det vigtigt at få de unge med.“

609 „Ellers er der ikke noget mindretal om 20 år.“ 
10.08.2017; Hansen 14.07.2016) ${ }^{610}$. Das eröffnet in den kommenden Jahren neue Forschungsfragen zu Deutschen in Dänemark, zu Dän*innen in Deutschland sowie zur selbst sogenannten Volksgruppe der Friesen. Dabei wird es wichtig sein, zu beobachten und zu analysieren, ob sich die fluide Minderheitensituation verändert, wie sie möglicherweise käseglockenartig konserviert wird oder wie die beteiligten Funktionär*innen das schleswigsche Minderheitenmodell und ihre Minderheiten durch eine mögliche Titelbewerbung und -verleihung touristisch oder anderweitig vermarkten.

Kulturanthropologisch gesehen wäre es in Zukunft ebenfalls interessant, eine Schulforschung in den dänischen Minderheitsschulen durchzuführen und anhand von teilnehmender Unterrichtsbeobachtung und Interviews zu untersuchen, wie ein Dänischsein dort durch die Lehrer*innen gelehrt wird und wie die Schüler*innen darauf reagieren. Die Perspektive der Mitarbeitenden des Schulvereins in Bezug auf die an sie gestellten Erwartungen könnte ebenso durch qualitative Interviews erhoben werden.

Die Bedeutung der Eltern und der Familie im Vergleich zur Schule bei der Gesinnungswahl, also dem Dänischwerden und Dänischsein bzw. dem Nichtdänischwerden und Nichtdänischsein, müsste noch genauer untersucht werden, auch wenn sich bei den Neudän*innen gezeigt hat, das die Schule die entscheidende Rolle beim Dänischsein spielt. Denn obwohl die Schule für die Konstituierung und Erhaltung der dänischen Minderheit eine entscheidende Bedeutung hat, gibt es Hinweise aus der Religionspädagogik, um hier noch einmal einen Vergleich zur religiösen Gesinnung zu ziehen, dass Angehörige der evangelischen Kirche in Deutschland in erster Linie durch ihre Eltern in ihrem positiven Verhältnis zu Kirche und Religion geprägt wurden und weit weniger durch die sekundäre, schulische Sozialisation (Schröder 2012: 334). Allerdings wird das Dänischsein in den dänischen Schulen ganzheitlicher und im kompletten Schulalltag gelehrt und gelernt, während Religion und Religionszugehörigkeit in öffentlichen Schulen nur im Religionsunterricht behandelt werden. Analog zur Religion wäre auch zu untersuchen, ob und wann es einen entscheidenden Zeitraum der Sozialisation von Kindern, Jugendlichen und Erwachsenen gibt, in dem ,nachhaltige Entscheidungen

${ }^{610}$ Über diese Initiative ist öffentlich kaum etwas bekannt. Sie soll laut Flensburg-Avis-Zeitungsartikel „stillschweigend“ (,lige så stille“) zwischen SSF, BDM (Bund Deutscher Nordschleswiger), dem dänischen Kulturministerium und der Kulturbeauftragten der Bundesregierung erarbeitet werden (Rebsdorf 07.07.2016). Es besteht der Wunsch, die Aufnahme in die Liste des immateriellen Kulturerbes im Jahre 2020, dem 100-jährigen Jubiläum der Grenzziehung, zu erreichen (Iwersen, Wasmund 25.06.2016). 
zu Gunsten oder gegen religiöse Bindungen“ (ebd.: 293) bzw. nationale Gesinnungen getroffen werden bzw. wie stark oder statisch diese ggf. sein können (s. a. S. 120 d. vorl. Arbeit).

Eine Untersuchung der Erinnerungskultur anhand von Sachkultur und übermittelter Geschichte und Sichtweisen auf die Historie Südschleswigs könnte das Wissen über die dänische Minderheit vergrößern. Auch eine systematische Propagandaanalyse von Reden der Minderheitsfunktionär*innen und dänischen und deutschen Politiker*innen auf Jahrestreffen könnte einen erweiterten Einblick in die konstruierten Mythen und Nationsmotive geben. Eine systematische Propagandanalyse der 1980 bis 2010 erschienenen zweisprachigen Heftchen Slesvigland wäre ebenfalls interessant (vgl. FN 555, S. 301).

Eine fachgeschichtliche Erforschung der deutschen und dänischen Geschichtsschreibung zum Landesteil Schleswig könnte die Unterschiede in den Darstellungen erhellen, ähnlich wie es Michael Bregnsbo und Kurt V. Jensen in ihrem Sammelband versucht haben (Bregnsbo et al. 2016). Aus deutscher Sicht wird die dänische Vergangenheit des Landesteils bisher oftmals verschwiegen oder heruntergespielt, wie sich kürzlich wieder zeigte. ${ }^{611}$

Wichtig wären weiterhin Forschungen zu anderen Minderheiten und die dort ablaufenden Prozesse der Abgrenzung sowie Identifizierung mit der Minderheit und die verwendeten und konstruierten Kriterien im Vergleich zur dänischen Minderheit im Landesteil Schleswig, die in einer recht komfortablen politischen und finanziellen Situation ist. Dies gilt insbesondere für Minderheiten, die von den Staaten, in denen sie leben, ignoriert, bedrängt oder gar bedroht werden. Möglicherweise könnten politische Akteur*innen in Krisenregionen von der Ungefährlichkeit von Minderheiten dadurch überzeugt werden, dass Freiheit und Toleranz, Gleichberechtigung sowie finanzielle Mittel für Minderheiten keine Gefahr für den entsprechenden Nationalstaat ausmachen, sondern ihn im Gegenteil bereichern können. Bedrängte Minderheiten werden eher Widerstand leisten als Minderheiten, die frei leben können. Auch können Analysen der dänischen Minderheit und der Situation im deutsch-dänischen Grenzland mit den drei Minderheiten/Volksgruppen teilweise zur Herausarbeitung von Best-Practice-Beispielen dienen, welche für andere, weniger freiheitliche Minderheitenkontexte hilfreich werden könnten, auch wenn viele Widersprüche zu beobachten sind.

611 S. die Sonderpublikation des SHZ-Verlags zum Thema 150 Jahre Schleswig-Holstein als preuBische Provinz. In dieser Publikation findet die Geschichte des Herzogtums Schleswig in Bezug auf das dänische Königreich vor 1867 kaum Erwähnung. 


\section{Anhang}

\section{1 Übersicht über die Interview- und Gesprächspartner*innen}

Tabelle 1: Übersicht über die interviewten Personen. Alle Namen wurden zur Anonymisierung geändert.

\begin{tabular}{|c|c|c|c|c|c|c|}
\hline $\begin{array}{c}\text { Inter- } \\
\text { view- } \\
\text { nr. }\end{array}$ & $\begin{array}{c}\text { Name } \\
\text { (geän- } \\
\text { dert) }\end{array}$ & $\begin{array}{c}\text { Jahr } \\
\text { der } \\
\text { Ge- } \\
\text { burt }\end{array}$ & $\begin{array}{c}\text { Ausbildung(en) und } \\
\text { (ehemalige) Beruf(e) }\end{array}$ & $\begin{array}{c}\text { Dauer } \\
\text { Inter- } \\
\text { view }\end{array}$ & $\begin{array}{c}\text { Seiten- } \\
\text { anzahl } \\
\text { Tran- } \\
\text { skript }\end{array}$ & $\begin{array}{c}\text { Datum } \\
\text { Inter- } \\
\text { view }\end{array}$ \\
\hline INT01 & $\begin{array}{c}\text { Erik } \\
\text { Nissen }\end{array}$ & 1946 & $\begin{array}{c}\text { Klempner-/Installateurgeselle; } \\
\text { Handelsreisender/Außen- } \\
\text { dienstvertreter; in Rente }\end{array}$ & $2 \mathrm{~h}$ & 22 & 11.6 .2008 \\
\hline INT02 & $\begin{array}{c}\text { Brigitte } \\
\text { Thomsen }\end{array}$ & 1938 & $\begin{array}{c}\text { Gelernte Bürokraft, Mitarbeiterin } \\
\text { in Handarbeitsgeschäft; in Rente; } \\
\text { Vermieterin von Ferien- } \\
\text { wohnungen }\end{array}$ & $\begin{array}{c}2 \mathrm{~h} 20 \\
\text { min }\end{array}$ & 37 & 13.6 .2008 \\
\hline INT03 & $\begin{array}{c}\text { Sarah } \\
\text { Iversen }\end{array}$ & 1933 & $\begin{array}{c}\text { Ungelernte Sekretärin; Pflege- } \\
\text { helferin, Hausfrau; in Rente }\end{array}$ & $\begin{array}{c}2 \mathrm{~h} 20 \\
\text { min }\end{array}$ & 37 & 14.6 .2008 \\
\hline
\end{tabular}




\begin{tabular}{|c|c|c|c|c|c|c|}
\hline INT04 & $\begin{array}{l}\text { Otto } \\
\text { Clausen }\end{array}$ & 1947 & $\begin{array}{l}\text { Elektrikergeselle bei den Stadt- } \\
\text { werken; in Rente }\end{array}$ & $2 \mathrm{~h}$ & 46 & 16.6.2008 \\
\hline INT05 & $\begin{array}{l}\text { Sönke } \\
\text { Nissen }\end{array}$ & 1940 & $\begin{array}{l}\text { Gelernter Maurergeselle, Fischge- } \\
\text { schäftsinhaber, diverse Nebentä- } \\
\text { tigkeiten u. a. als Gastwirt; in } \\
\text { Rente }\end{array}$ & $\begin{array}{c}1 \mathrm{~h} 30 \\
\min \end{array}$ & 39 & 10.7.2008 \\
\hline INT06 & $\begin{array}{l}\text { Frieda } \\
\text { Theben }\end{array}$ & 1940 & $\begin{array}{l}\text { Ungelernte Gastronomie- und } \\
\text { Pflegehelferin, Hausfrau; in Rente }\end{array}$ & $2 \mathrm{~h}$ & 52 & 17.7.2008 \\
\hline INT07 & $\begin{array}{l}\text { Heinrich } \\
\text { Schmied }\end{array}$ & 1935 & $\begin{array}{c}\text { Installateur- und Heizungs- } \\
\text { baumeister mit eigenem Gas-, } \\
\text { Wasser-, Elektroinstallations-, } \\
\text { Heizungs- und Klima- } \\
\text { technikbetrieb; in Rente }\end{array}$ & $3 \mathrm{~h}$ & 59 & 21.7.2008 \\
\hline INT08 & $\begin{array}{l}\text { Ingo } \\
\text { Erhard }\end{array}$ & 1940 & $\begin{array}{l}\text { Gelernter Malergeselle, arbeitete } \\
\text { als Feuerlöscherprüfer, später mit } \\
\text { eigener Firma; in Rente }\end{array}$ & \multirow{2}{*}{$\begin{array}{c}2 \mathrm{~h} 20 \\
\min \end{array}$} & \multirow{2}{*}{61} & \multirow{2}{*}{ 22.7.2008 } \\
\hline INT09 & $\begin{array}{l}\text { Frauke } \\
\text { Erhard }\end{array}$ & 1943 & $\begin{array}{l}\text { Ungelernte Verkäuferin, Büro- } \\
\text { hilfe, Fabrikarbeiterin, Putzfrau, } \\
\text { Hausfrau; in Rente }\end{array}$ & & & \\
\hline \multirow[t]{2}{*}{ INT10 } & $\begin{array}{c}\text { Tina } \\
\text { Zehntner }\end{array}$ & 1976 & $\begin{array}{l}\text { Ausgebildete Krankenschwester, } \\
\text { arbeitet als Altenpflegerin und } \\
\text { Sanitäterin; SSF-Vorsitzende in } \\
\text { einem Ortsverein }\end{array}$ & $\begin{array}{c}1 \mathrm{~h} 20 \\
\min \end{array}$ & 55 & 20.7.2013 \\
\hline & & & Gesamt & $17,5 \mathrm{~h}$ & 353 & \\
\hline
\end{tabular}


Tabelle 2: Teilnehmende am Integrationskurs in Jarplund-Weding (dän. Jaruplund) bei Flensburg, 14.-18.10.2013. Die Teilnehmenden waren im Alter von 30 bis 45 Jahren.

\begin{tabular}{|c|c|c|}
\hline $\begin{array}{c}\text { Name } \\
\text { (geändert) }\end{array}$ & Wohnort & In Jaruplund beteiligte Kinder \\
\hline Luise & in der Nähe Rendsburgs & $\begin{array}{c}\text { 1 Sohn (14 Jahre) (Luise hat zusätzlich noch eine } \\
\text { Tochter (17 Jahre), die nicht am Kurs teilnahm) }\end{array}$ \\
\hline Inken & $\begin{array}{c}\text { in der Nähe } \\
\text { Eckernfördes }\end{array}$ & $\begin{array}{c}\text { 1 Sohn (7 Jahre), 1 Sohn ihrer Arbeitskollegin } \\
\text { (7 Jahre) }\end{array}$ \\
\hline Larissa & in der Nähe Kiels & 1 Sohn (5 Jahre) \\
\hline Traute & in der Nähe Husums & 1 Tochter (8 Jahre) \\
\hline Klaus und Beate & in der Nähe Husums & 1 Tochter (8 Jahre) \\
\hline Beatrix & in der Nähe Bredstedts & 1 Sohn (2 Jahre) \\
\hline
\end{tabular}

\subsection{Amtszeiten und Funktionen der Funktionär*innen}

Asmussen, Kirstin: seit 2014 Vorsitzende der Sydslesvigs danske Ungdomsforeninger $(\mathrm{SdU})$

Christiansen, Jens A.: seit 2001 Generalsekretär des SSF

Gildberg, Per: 2008-2014 Vorsitzender des Dansk Skoleforening for Sydslesvig

Greve, Victor Madsen: 2004-2014 Pastor der dänischen Kirchengemeinde in Friedrichstadt/Frederiksstad

Hansen, Jon Hardon: seit 1991 Pastor der dänischen Kirchengemeinde auf Sylt/Sild; Nov. 2013- Nov. 2019 Vorsitzender des SSF

Hougaard-Werner, Gitte: seit 2013 Vorsitzende des SSF-Jahrestreffenausschusses;

Nov. 2013-2019 stellvertretende Vorsitzende, seit Nov. 2019 Vorsitzende des SSF; Lehrerin an einer dänischen Schule nahe Rendsburg

Jessen, Udo: seit 2014 Vorsitzender des Dansk Skoleforening for Sydslesvig; davor stellvertretender Vorsitzender

Küssner, Dieter Paul: 2003-2013 Vorsitzender des SSF; seit 2013 Vizepräsident der FUEV/FUEN, 1994-2014: Leiter der Jaruplund Højskole

Vogel, Ulrich: 2015-2019 Pastor der dänischen Kirchengemeinde in Friedrichstadt/Frederiksstad 


\subsection{Transkriptionsschlüssel}

Tabelle 3: Transkriptionsschlüssel (vgl. a. Bohnsack 2000; Nohl 2006)

\begin{tabular}{|c|c|}
\hline Zeichen & Funktion \\
\hline- & Abbruch eines Wortes \\
\hline [Ergänzung] & Wortergänzung L. Bittlinger \\
\hline (unsicher) & schlecht zu verstehende Äußerung, Transkription unsicher \\
\hline.. & Pause: je mehr Punkte, desto länger die Pause \\
\hline . & Satzende \\
\hline${ }^{\circ}$ leise $^{\circ}$ & sehr leise gesprochen \\
\hline kursiv & Parasprachliches \\
\hline GROSSBUCHSTABEN & außergewöhnliche Betonung \\
\hline\{\} & Beschreibung/Kommentar LB \\
\hline
\end{tabular}

\subsection{Abkürzungen}

AEMR: Allgemeine Erklärung der Menschenrechte. UN-Resolution 217 A (III) der Generalversammlung vom 10.12.1948

Bd.: Band

bes.: besonders

BGB: Bürgerliches Gesetzbuch

dän.: dänisch

DCBIB: Dansk Centralbibliotek for Sydslesvig (Dänische Zentralbibliothek für Südschleswig)

DF: Dansk Folkeparti

DKS: Dansk Kirke i Sydslesvig (Dänische Kirche in Südschleswig)

dt.: deutsch

d. vorl.: der vorliegenden (Arbeit)

ECMI: European Center of Minority Issues, Flensburg

EMRK: Konvention zum Schutz der Menschenrechte und Grundfreiheiten

FL: Flensburg

FLA: Flensborg Avis

FN: Fußnote 
fries.: friesisch

FUEN: Federal Union of European Nationalities, Flensburg (Dt. FUEV)

FUEV: Föderale Union Europäischer Volksgruppen, Flensburg (Engl. FUEN)

GG: Grundgesetz der Bundesrepublik Deutschland

GRCh: Charta der Grundrechte der Europäischen Union

Hervorh. i. Orig.: Hervorhebung im Original

INT: Interview

IPBPR: Internationaler Pakt über bürgerliche und politische Rechte der UN

Kap.: Kapitel

KErzG: Gesetz über die religiöse Kindererziehung

KSZE: Konferenz für Sicherheit und Zusammenarbeit in Europa (Vorgängerorganisation der OSZE)

LB: Levke Bittlinger

LWahlG: Wahlgesetz für den Landtag von Schleswig-Holstein - Landeswahlgesetz

MindSchRÜbk: Rahmenübereinkommen zum Schutz nationaler Minderheiten des Europarates, SEV Nr. 157 (auch RÜ abgekürzt)

Nov.: November

o. J.: ohne Jahresangabe

o. O.: ohne Verlagsortangabe

OSZE: Organisation für Sicherheit und Zusammenarbeit in Europa

PartG: Gesetz über die politischen Parteien (Parteiengesetz)

SdU: Sydslesvigsk danske Ungdomsforeninger (Südschleswigs dänische Jugendvereine)

SEV Nr. 157: Sammlung Europäischer Verträge Nr. 157 - Rahmenübereinkommen zum Schutz nationaler Minderheiten (MindSchRÜbk)

SchulG: Schleswig-Holsteinisches Schulgesetz i. d. F. vom 24.01.2007, GVOB1. 2007, 39, ber. S. 276

SHZ-Verlag: Schleswig-Holsteinischer Zeitungsverlag

SSF: Sydslesvigsk Forening, dt. Südschleswigscher Verein (SSV), Kulturverein der dänischen Minderheit im Landesteil Schleswig

SSV: Südschleswigscher Verein (SSV), s. SSF

SSW: Südschleswigscher Wählerverband, Sydslesvigsk Vælgerforening (Partei der dänischen Minderheit und der friesischen Volksgruppe) 
Sydslesvigloven: Lov om Sydslesvigudvalget og tilskudsordninger på undervisningsministerens område for det danske mindretal i Sydslesvig. Lov nr. $287 \mathrm{v}$. 29.03.2010. s. <www.retsinformation.dk/Forms/R0710.aspx?id=131017>, 07.07.2017

TNB: Teilnehmende Beobachtung

UN: United Nations, Vereinte Nationen

VereinsG: Gesetz zur Regelung des öffentlichen Vereinsrechts (Vereinsgesetz)

Verf SH: Verfassung des Landes Schleswig-Holstein, ehemals Landessatzung für Schleswig-Holstein

\subsection{Literatur- und Quellenverzeichnis}

\subsubsection{Literatur}

A.P. Møller Fonden: A.P. Møller Fonden. <www.apmollerfonde.dk>, 19.04.2016.

Achour, Sabine (2016): Welche Werte halten pluralistische Gesellschaften zusammen? Die Leitkulturdebatte im Kontext von Flucht und Migration. In: Unzicker, Kai; Bonnet, Gesine (Hg.): Vielfalt statt Abgrenzung. Wohin steuert Deutschland in der Auseinandersetzung um Einwanderung und Flüchtlinge. Gütersloh, S. 131-148.

Adriansen, Inge (1990): Fædrelandet, folkeminderne og modersmålet. Brug af folkeminder og folkesprog i nationale identitetsprocesser - især belyst ud fra striden mellem dansk og tysk i Sønderjylland. Sonderburg (Skrifter fra Museumsrådet for Sønderjyllands Amt, 4).

Adriansen, Inge (1994): Problemer ved forsking i nationale identiteter. In: BeckerChristensen, Henrik (Hg.): National identitet. Fem foredrag om dansk og tysk identitetsfølelse i grænselandet. Apenrade, S. 7-19.

Adriansen, Inge (2003): Nationale symboler i Det Danske Rige 1830-2000. Bind II. Fra undersåtter til nation. Kopenhagen (Etnologiske studier).

Adriansen, Inge (2010): Erindringssteder i Danmark. Monumenter, Mindesmærker og Mødesteder. Med Fotografier af Per Bak Jensen. Kopenhagen.

Adriansen, Inge (2011): Denkmal und Dynamit. DenkmälerSTREIT im deutschdänischen Grenzland. Neumünster.

Adriansen, Inge (2013): Dänemark bis an die Eider! Die deutsch-dänischen Grenzen als Erinnerungsorte im 19. und 20. Jahrhundert. In: Frandsen, Steen Bo; 
Krieger, Martin; Lubowitz, Frank (Hg.): 1200 Jahre deutsch-dänische Grenze. Tagungsband. Neumünster (Zeit + Geschichte, 28).

Adriansen, Inge (2016a): Hver tid sin dagsorden - 1864-jubilæerne i 1889, 1904, 1914, 1939, 1964, 1989 og 2014. In: Adriansen, Inge; Frandsen, Steen Bo (Hg.): Efter 1864. Krigens følger på kort og langt sigt. Odense (University of Southern Denmark. Studies in History and Social Sciences, 519; Skrifter udgivet af Museum Sønderjylland, 10), S. 165-291.

Adriansen, Inge (2016b): Jubiläumsfeiern im Dienste der Politik. Ein Vergleich der Gedenkfeiern zu den Jahrestagen der Schlacht von Düppel. In: Grenzfriedenshefte. Zeitschrift für deutsch-dänischen Dialog, Jg. 63, H. 1, S. 3-22.

Adriansen, Inge (2016c): The Controversy about Antiquity in Schleswig in the 19th and 20th Centuries. In: Bregnsbo, Michael; Jensen, Kurt Villads (Hg.): Schleswig Holstein - contested region(s) through history. Odense (University of Southern Denmark. Studies in History and Social Sciences, 520), S. 25-44.

Adriansen, Inge; Christiansen, Palle Ove; Stoklund, Bjarne (Hg.) (2003): Forskellige mennesker. Regionale forskelle og kulturelle særtræk. Tilegnet professor Bjarne Stoklund som en post festum hyldest til hans 75 års dag 17. januar 2003. Ebeltoft (Folkemindesamligens Kulturstudier, 3).

Alkier, Stefan (2010): Neues Testament. Tübingen (UTB basics, 3404).

Altenmüller, Eckart; Kopiez, Reinhard (2011): Ein Beitrag zum evolutionären Ursprung der Musik: Was kann uns die Gänsehaut lehren. In: Jahrbuch der Braunschweigischen Wissenschaftlichen Gesellschaft, S. 133-152. <publikationsserver.tu-braunschweig.de/receive/dbbs_mods_00048547>, 05.06.2017.

Andersen, Kristian Mørk (2014): Deltag i mindretalsdebat fra sofaen. TV Syd. <www.tvsyd.dk/artikel/266405:Deltag-i-mindretalsdebat-fra-sofaen>, 12.12.2014.

Anderson, Benedict (2005): Die Erfindung der Nation. Zur Karriere eines folgenreichen Konzepts. 2. Aufl. Frankfurt am Main (Reihe Campus, 1018).

Anderson, Benedict (2006): Imagined communities. Reflections on the origin and spread of nationalism. London.

Andresén, Arne (2000): Entwicklungen und aktuelle Probleme dänischer Heimvolkshochschulen. In: Brödel, Rainer (Hg.): Grenzüberschreitende Erwachsenenbildung. Für Walter Mertineit (1926 - 1987). Münster, New York, München, Berlin, S. 190-199. 
Andresen, Helga (2000): Erstsprache. In: Glück, Helmut (Hg.): Metzler Lexikon Sprache. 2. Aufl. Stuttgart, Weimar, S. 192.

Andresen, Tine (2014): Integrationsudvalgets Forlag til Drøftelse. Hrsg. v. Integrationsudvalget und Sydslesvigsk Forening. Integrationsudvalget; Sydslesvigsk Forening; Dansk Skoleforening for Sydslesvig. <www.skoleforeningen.org/media/1400300/DOP-5-18062014.pdf>, 06.04.2016.

Arquint, Romedi (2011): From the Protection of National Minorites towards Managing Diversity. In: Indian Journal of Applied Linguistics, Jg. 37, H. 2, S. 27-34.

Arquint, Romedi (2013): Volksgruppen und autochthone Völker ohne eigenen Staat in Europa - auf dem Weg vom Gestern ins Morgen. In: Kunz, Harry; Pingel, Fiete; Steensen, Thomas (Hg.): Die „freien Friesen“. Geschichte und Perspektiven der Selbstverwaltung in den Frieslanden. Beiträge von der Konferenz: Die „freien Friesen“ im 21. Jahrhundert. Geschichtsbilder, Traditionen und Selbstverständnis der friesischen Volksgruppe in Deutschland - 7. Historiker-Treffen des Nordfriisk Instituut. Bredstedt (Nordfriisk Instituut, Nr. 226), S. 121-134.

Assmann, Aleida; Friese, Heidrun (1999): Einleitung. In: Assmann, Aleida; Friese, Heidrun (Hg.): Identitäten. 2. Aufl. Frankfurt am Main (Erinnerung, Geschichte, Identität, 3), S. 11-23.

Avery, Helen (2008): Att medverka till förändring - kulturarv och demokrati. In: Jönsson, Lars-Eric; Wallette, Anna; Wienberg, Jes (Hg.): Kanon och kulturarv. Historia och samtid i Danmark och Sverige. Göteborg, Stockholm (Centrum för Danmarksstudier), S. 275-289.

Banks, Marcus (1996): Ethnicity. Anthropological Constructions. London, New York.

Barth, Fredrik (1969): Introduction. In: Barth, Fredrik (Hg.): Ethnic Groups and Boundaries. The Social Organization of Culture Differences. Bergen u. a., S. 9-38.

Barth, Fredrik (1994a): Innledning. In: Barth, Fredrik (Hg.): Manifestasjon og prosess. Oslo (Det blå bibliotek), S. 9-15.

Barth, Fredrik (1994b): Nye og evige temaer i studiet av etnisitet. In: Barth, Fredrik (Hg.): Manifestasjon og prosess. Oslo (Det blå bibliotek), S. 174-192.

Bastian, Andrea (1995): Der Heimat-Begriff. Eine begriffsgeschichtliche Untersuchung in verschiedenen Funktionsbereichen der deutschen Sprache. Tübingen (Reihe Germanistische Linguistik, 159). 
Bauman, Zygmunt (1992): Moderne und Ambivalenz. Das Ende der Eindeutigkeit. Hamburg.

Baumann, Gerd (2002): Fünf Verflechtungen im Zeitalter der »Globalisierung«: Migranten und Ethnologen in nationalen und transnationalen Kräftefeldern. In: Hauser-Schäublin, Brigitta (Hg.): Ethnologie der Globalisierung. Perspektiven kultureller Verflechtungen. Berlin, S. 111-123.

Baur, Siegfried; Guggenberg, Irma von; Larcher, Dietmar (1998): Zwischen Herkunft und Zukunft. Südtirol im Spannungsfeld zwischen ethnischer und postnationaler Gesellschaftsstruktur. Ein Forschungsbericht; 9.

Bausinger, Hermann (1999a): Ethnizität - Placebo mit Nebenwirkungen. In: Köstlin, Konrad; Nikitsch, Herbert (Hg.): Ethnographisches Wissen. Zu einer Kulturtechnik der Moderne. Referate der Tagung „Ethnographisches Wissen als Kulturtechnik“ im Internationalen Forschungszentrum Kulturwissenschaft (IFK). 6.-8. November 1997. Wien (Veröffentlichungen des Instituts für Volkskunde der Universität Wien, 18), S. 31-41.

Bausinger, Hermann (1999b): Identität. In: Bausinger, Hermann; Jaeggle, Utz; Korff, Gottfried; Scharfe, Martin (Hg.): Grundzüge der Volkskunde. Mit einem Vorwort zur vierten Auflage von Kaspar Maase. 4. Aufl. Darmstadt, S. 204-263.

Bausinger, Hermann (2002): Typisch deutsch. Wie deutsch sind die Deutschen. 3. Aufl. München.

Bausinger, Hermann (2005): Perlmanns Erzähltheorie. Erinnerung als Rechtfertigung. In: Hengartner, Thomas; Schmidt-Lauber, Brigitta (Hg.): Leben - erzählen. Beiträge zur Erzähl- und Biographieforschung. Festschrift für Albrecht Lehmann. Berlin (Lebensformen, 17), S. 199-208.

Becker-Christensen, Henrik (Hg.) (1994): National identitet. Fem foredrag om dansk og tysk identitetsfølelse i grænselandet. Apenrade.

Becker-Christensen, Henrik (Hg.) (1995): Grænsen i 75 år. 1920-1995. Apenrade.

Becker-Christensen, Henrik (1996): Der Sieg des Gesinnungsprinzips. Die endgültige Lösung der deutsch-dänischen Grenzfrage. In: Paul, Gerhard; Danker, Uwe; Wulf, Peter (Hg.): Geschichtsumschlungen. Sozial-und kulturgeschichtliches Lesebuch Schleswig-Holstein (1848-1948). Bonn, S. 310-316.

Becker-Christensen, Henrik; Lange, Ulrich (Hg.) (1998): Geschichte Schleswigs vom frühen Mittelalter bis 1920. Dänisch-deutsche Historikerkonferenz des 
Instituts für Grenzregionsforschung in Zusammenarbeit mit der Akademie Sankelmark vom 28. bis 30. September 1997 in Sankelmark. Apenrade.

Beck-Gernsheim, Elisabeth (2004): Wir und die Anderen. Vom Blick der Deutschen auf Migranten und Minderheiten. Frankfurt am Main (Edition Zweite Moderne).

Bendix, Regina (1989): Backstage Domains. Playing "William Tell” in two Swiss Communities. Bern u. a.

Bendix, Regina (1997): In Search of Authenticity. The Formation of Folklore Studies. Madison, London.

Bendix, Regina (2008): Kulturelles Erbe zwischen Wirtschaft und Politik. Ein Ausblick. In: Hemme, Dorothee; Tauschek, Markus (Hg.): Leben im Weltkulturerbe. Ethnographische Skizzen zum alltagskulturellen Umgang mit dem Prädikat „UNESCO-Welterbe“. Göttingen (Göttinger kulturwissenschaftliche Studien, 2), S. 337-356.

Bendix, Regina; Kraul, Margret; Keßler, Catharina; Nietert, Michaela; Koch, Katja (2010): Fenster in die Schulkultur: Organisation und Gestaltung ritueller Übergänge. In: Zeitschrift für Volkskunde, Jg. 106, H. 1, S. 1-21.

Bendix, Regina; Roodenburg, Herman (2000): Managing Ethnicity: An Introduction. In: Bendix, Regina; Roodenburg, Herman (Hg.): Managing Ethnicity. Perspectives from Folklore Studies, History and Anthropology. Amsterdam (Studies on Migration \& Ethnicity), S. ix-xviii.

Berger, Peter L. (1963): Einladung zur Soziologie. Eine humanistische Perspektive. München (dtv, 1203).

Binder, Beate (2008): Heimat als Begriff der Gegenwartsanalyse. Gefühle der Zugehörigkeit und soziale Imaginationen in der Auseinandersetzung um Einwanderung. In: Zeitschrift für Volkskunde, Jg. 104, H. 1, S. 1-17.

Binder, Beate (2010): Beheimatung statt Heimat. Translokale Perspektiven auf Räume der Zugehörigkeit. In: Seifert, Manfred (Hg.): Zwischen Emotion und Kalkül. ,Heimat' als Argument im Prozess der Moderne. Leipzig (Schriften zur sächsischen Geschichte und Volkskunde, 35), S. 189-204.

Bjerg, Hans Christian (2006): Dannebrog - historien om et kristent og nationalt symbol. [Højbjerg].

Bockhorn, Elisabeth; Bockhorn, Olaf (2000): Wem nützt ,Ethnizität‘. In: Dekker, Ton; Helsloot, John; Wijers, Carla (Hg.): Roots \& Rituals. The Construction of Ethnic Identities. Selected Papers of the 6th SIEF Conference on "Roots \& Rituals", Amsterdam 20-25 April 1998. Amsterdam, S. 3-10. 
Boehm, Carl (1992): Modell oder Irrtum. Bildungspolitik und Bildungssituation der dänischen und nationalfriesischen Minderheiten in Südschleswig. 2. Aufl. Hamburg (Beiträge aus dem Fachbereich Pädagogik der Universität der Bundeswehr Hamburg, 2/91).

Böhm, Andreas (2000): Theoretisches Codieren: Textanalyse in der Grounded Theory. In: Flick, Uwe; Kardorff, Ernst von; Steinke, Ines (Hg.): Qualitative Forschung. Ein Handbuch. Reinbek bei Hamburg (Rororo Rowohlts Enzyklopädie, 55628), S. 475-485.

Bohn, Robert (2001): Dänische Geschichte. München (Beck'sche Reihe. Wissen, 2162).

Bohn, Robert (2006): Geschichte Schleswig-Holsteins. München (Beck'sche Reihe. Wissen, 2615).

Bohnsack, Ralf (2000): Rekonstruktive Sozialforschung. Einführung in Methodologie und Praxis qualitativer Forschung. 4. Aufl. Opladen (Lehrtexte).

Boie, Jenni (2008): Volkstumsarbeit und Grenzregion. Volkskundliches Wissen als Ressource regionaler Identitätspolitik um 1920. [Basierend auf einer Magisterarbeit. Kiel 2007/2008]. In: Kieler Blätter zur Volkskunde, Jg. 40, S. 93-117.

Bönisch-Brednich, Brigitte (2002): Auswandern. Destination Neuseeland. Eine ethnographische Migrationsstudie. Berlin.

Borkert, Maren; Pérez, Alberto Martín; Scott, Sam; Tona, Carla de (2006): Einleitung: Migrationsforschung in Europa (über nationale und akademische Grenzen hinweg) verstehen. In: Forum: Qualitative Sozialforschung/Forum: Qualitative Social Research [Online Journal], Jg. 7, H. 3, Art. 3. <www.qualitative-research.net/index.php/fqs/article/download/132/280>, zuerst veröffentlicht: Mai 2006, 05.08.2017.

Bormann, Alexander von (1976): Das nationalsozialistische Gemeinschaftslied. In: Denkler, Horst; Prümm, Karl (Hg.): Die deutsche Literatur im Dritten Reich. Themen, Traditionen, Wirkungen. Stuttgart, S. 257-280.

Bregnsbo, Michael (2006): Die inneren Grenzen des dänischen Imperiums in der Frühen Neuzeit. Ein Essay mit besonderem Blick auf die Verhältnisse in den Herzogtümern. In: Rheinheimer, Martin (Hg.): Grenzen in der Geschichte Schleswig-Holsteins und Dänemarks. Neumünster (Studien zur Wirtschaftsund Sozialgeschichte Schleswig-Holsteins, 42), S. 211-218.

Bregnsbo, Michael (2013): Das dänische Imperium der Frühen Neuzeit in der norddeutschen Historiographie. In: Frandsen, Steen Bo; Krieger, Martin; Lu- 
bowitz, Frank (Hg.): 1200 Jahre deutsch-dänische Grenze. Tagungsband. Neumünster (Zeit + Geschichte, 28), S. 153-161.

Bregnsbo, Michael; Jensen, Kurt Villads (2016): Introduction. In: Bregnsbo, Michael; Jensen, Kurt Villads (Hg.): Schleswig Holstein - contested region(s) through history. Odense (University of Southern Denmark. Studies in History and Social Sciences, 520), S. 7-14.

Bregnsbo, Michael; Jensen, Kurt Villads (Hg.) (2016): Schleswig Holstein - contested region(s) through history. Odense (University of Southern Denmark. Studies in History and Social Sciences, 520).

Brockhaus Enzyklopädie Online (2012a): Fahne. Hrsg. v. Bibliographisches Institut \& F. A. Brockhaus AG. <sub-uni-goettingen.de.brockhaus.de/enzyklopaedie/fahne>, 03.11.2016.

Brockhaus Enzyklopädie Online (2012b): Flagge. Hrsg. v. Bibliographisches Institut \& F. A. Brockhaus AG. <sub-uni-goettingen.de.brockhaus.de/enzyklopaedie/flagge>, 03.11.2016.

Brockhaus Enzyklopädie Online (2012c): Verein. Hrsg. v. Bibliographisches Institut \& F. A. Brockhaus AG. < han.sub.uni-goettingen.de/han/BEO/www.brockhaus-enzyklopaedie.de/pdf_cache/Verein.pdf>, 07.11.2012.

Broo, Hanno (1989): Arbeiter- und Volksbildungsbewegung in Mainz. Ein volkskundlich-sozialhistorischer Beitrag zur Vereinsforschung. Mainz (Studien zur Volkskultur in Rheinland-Pfalz, 7).

Brubaker, Rogers (1996): Nationalism reframed. Nationhood and the national question in the New Europe. Cambridge [England], New York.

Brubaker, Rogers (2007): Ethnizität ohne Gruppen. Unter Mitarbeit von Frederick Cooper, Mara Lovemann und Peter Stamatov et al. Hamburg.

Brubaker, Rogers (2015): Grounds for Difference. Cambridge, London.

Brubaker, Rogers; Lovemann, Mara; Stamatov, Peter (2009): Ethnicity as Cognition. In: Ganguly, Rajat (Hg.): Ethnic Conflict. Volume 1. Ethnic Identity. London u. a. (SAGE library of international relations), S. 1-27.

Buck, Anna Christina Sophia (2008): „Dübbel, 18. April 1864“ - Repräsentation, Identifikation und Erinnerung. Zum Umgang mit Cultural Heritage. [Basierend auf der gleichlautenden Magisterarbeit. Kiel 2007]. In: Kieler Blätter zur Volkskunde, Jg. 40, S. 59-92.

Bühler, Walter (1978): Funktionale Vereinsanalyse. In: Bühler, Walter; Kanitz, Horst; Siewert, Hans-Jörg (Hg.): Lokale Freizeitvereine. Entwicklung, Aufgaben, Tendenzen. St. Augustin (Werkbericht, 3), S. 114-142. 
Bühler, Walter; Kanitz, Horst; Siewert, Hans-Jörg (Hg.) (1978): Lokale Freizeitvereine. Entwicklung, Aufgaben, Tendenzen. St. Augustin (Werkbericht, 3).

Bundesministerium des Innern (2014): Migration und Integration. Aufenthaltsrecht, Migrations- und Integrationspolitik in Deutschland. Berlin.

Byram, Michael (1986): Minority Education and Ethnic Survival. Case Study of a German School in Denmark. Clevedon (Multilingual matters, 20).

Byram, Michael (1990): Kulturkenntnisse und kulturelle Identitätsbildungen an Schulen mit zwei Sprachen. In: Pedersen, Karen Margrethe (Hg.): Sprache und Unterricht in der deutschen, dänischen und friesischen Minderheit. Vorträge der Tagung „Möglichkeiten des Unterrichts in den Minderheiten“. Foredrag fra konferencen „Veje inden for mindretalsundervisning“. 28.-30. September 1989, Knivsberg, Apenrade, Dänemark. Apenrade, Flensburg, S. 130-148.

Byram, Michael Stuart (1985): Language Choice in a Minority School. In: International Review of Education/Internationale Zeitschrift für Erziehungswissenschaft/Revue Internationale de l'Education, Jg. 31, H. 3, S. 323-333.

Byron, Reginald (2006): identity. In: Barnard, Alan; Spencer, Jonathan (Hg.): Encyclopedia of social and cultural anthropology. London, S. 292.

Christiansen, Arthur (2006): Die Selbstverständlichkeit eines gleichberechtigten politischen Mandats für den SSW aus interkultureller Sicht. Eine Dokumentenund Quellenanalyse aus Anlass der parteipolitischen Auseinandersetzungen über die Bildung der Landesregierung in Schleswig-Holstein nach der Landtagswahl am 20. Februar 2005. Tönning (Studien zu Pluralität in Bildung und Erziehung, 4).

Christiansen, Arthur (2008): Die Reproduktion der dänischen Minderheit im 21. Jahrhundert. Zwischen Kultur, Tradition und Gemeinsamkeitsglauben. Tönning, Lübeck, Marburg (Studien zu Pluralität in Bildung und Erziehung, 5).

Clausen, Egon (2014): I Grænselandet. Rejsebreve fra Sydslesvig. Kopenhagen.

Coakley, John (2004): Mobilizing the Past: Nationalist Images of History. In: Nationalism and Ethnic Politics, Jg. 10, H. 4, S. 531-560.

Cruys-Bagger, Søren (2013): Håndbog for Fanebærere. Hrsg. v. Danmarks-Samfundet. < danmarkssamfundet.dk/wp-content/uploads/2014/04/Danmarkssamfundet-H\%C3\%A5ndbog-for-faneb\%C3\%A6rere.pdf>, 31.05.2017.

Colberg-Schrader, Hedi; Derschau, Dietrich von (1991): Sozialisationsfeld Kindergarten. In: Hurrelmann, Klaus; Ulich, Dieter (Hg.): Neues Handbuch der Sozialisationsforschung. 4. Aufl. Weinheim, Basel. 
Danker, Uwe (1997): Südschleswig 1945-1955. Vom letzten Kampf um Südschleswig zum dauernden Grenzfrieden. Kiel (Labskaus, 7).

Dannenbeck, Clemens (2002): Selbst- und Fremdzuschreibungen als Aspekte kultureller Identitätsarbeit. Ein Beitrag zur Dekonstruktion kultureller Identität. Opladen (DJI-Reihe Jugend, 14).

Dansk Centralbibliotek for Sydslesvig: Bestand. Hrsg. v. Dansk Centralbibliotek for Sydslesvig. <www.dcbib.dk/om-biblioteket/foreningen/statistik/biblioteket-i-tal-2015/bestand>, 22.08.2016.

Dansk Centralbibliotek for Sydslesvig: Biblioteket i tal 2015. Hrsg. v. Dansk Centralbibliotek for Sydslesvig. <www.dcbib.dk/om-biblioteket/foreningen/statistik/biblioteket-i-tal-2015>, 22.08.2016.

Dansk Kirke i Sydslesvig (a): DKS-Generalforsamling. <www.dks-folkekirken.dk/om-dks/kirkedagen-dks-generalforsamling >, 27.11.2012.

Dansk Kirke i Sydslesvig (b): Folkekirken. <www.dks.folkekirken.dk>, 27.11.2012.

Dansk Kirke i Sydslesvig (c): Frederiksstad. <www.dks.folkekirken.dk/fredriks/Frstad.htm>, 27.11.2012.

Dansk Kirke i Sydslesvig (d): Kort Kirkehistorie. <www.dks.folkekirken.dk/DKS/kort_kirkehistorie.htm>, 27.11.2012.

Dansk Kirke i Sydslesvig (e): Vores Kirker. <www.dsuk.dk/vores-kirker/sydslesvig>, 27.11.2012.

Dansk Kirke i Sydslesvig (2016): Medlemskab. <www.dks-folkekirken.dk/medlemskab>, 15.07.2016.

Dansk Skoleforening for Sydslesvig (1990): Danske Skoler og Børnehaver i Sydslesvig. Dänische Schulen und Kindergärten in Südschleswig. Flensburg.

Dansk Skoleforening for Sydslesvig (a): Dansk Skoleforening for Sydslesvig e.V. $<$ www.skoleforeningen.de>, 08.10.2009.

Dansk Skoleforening for Sydslesvig (b): Forældrene har truffet et valg. <www.skoleforeningen.org/nyheder/artikler/nyheder-2015-2016/foraeldrene-hartruffet-et-valg>, 20.02.2017.

Dansk Skoleforening for Sydslesvig (c): Mål. <www.skoleforeningen.org/foreningen $/ \mathrm{maal}>$, 20.02.2017.

Dansk Skoleforening for Sydslesvig (o. J. a): Medlemskab. <www.skoleforeningen.org/foreningen/medlemskab>, 30.04.2016. 
Dansk Skoleforening for Sydslesvig (o. J. b): Skoleforenings informationspolitik. $<$ www.skoleforeningen.org/foreningen/vedtaegter-og-politikker/informationspolitik>, 30.04.2016.

Dansk Skoleforening for Sydslesvig: Vores institutioner. <www.skoleforeningen.org/institutioner>, 25.04.2016.

Dansk Skoleforening for Sydslesvig (2011): Vedtægter for Dansk Skoleforening for Sydslesvig e.V. Vedtaget af Fællesrådet den 24. februar 2011. <www.skoleforeningen.org/media/46171/Skoleforeningens-vedtaegter.pdf>, 06.04.2016.

Dansk Skoleforening for Sydslesvig; BDO Statsautoriseret Revisionsaktieselskab (2016): Årsrapport 2015. <www.skoleforeningen.org/media/3296902/\%C3\%85rsrapport-2015.pdf>, 05.05.2016.

Dansk Sundhedstjeneste for Sydslesvig (2009): Sundhedstjenesten. <www.dksund.de/index.php/sundhedstjenesten>, 08.07.2009.

Danske Sømands- og Udlandskirker: Danske Sømands- og Udlandskirker. <www.dsuk.dk>, 28.11.2012.

Danstrup, John; Koch, Hal; Ellehøj, Svend, et al. (Hg.) (1962): Danmarks historie. Kopenhagen.

Darieva, Tsypylma (2007): Migrationsforschung in der Ethnologie. In: SchmidtLauber, Brigitta (Hg.): Ethnizität und Migration. Einführung in Wissenschaft und Arbeitsfelder. Berlin (Reimer Kulturwissenschaften), S. 69-93.

Dawisha, Adeed (2009): Nation and Nationalism: Historical Antecedents to Contemporary Debates. In: Ganguly, Rajat (Hg.): Ethnic Conflict. Volume 1. Ethnic Identity. London u. a. (SAGE library of international relations), S. 56-73.

Degn, Christian (1994): Schleswig-Holstein. Eine Landesgeschichte. Historischer Atlas. Neumünster.

Det Sydslesvigske Samråd (2016): Mødeplan for Samrådet 2017. <www.samraadet.info/modeplan>, 07.07.2017.

Dittrich, Eckhard J.; Radtke, Frank-Olaf (Hg.) (1990a): Ethnizität. Wissenschaft und Minderheiten. Opladen.

Dobat, Andres S. (2016): A contested heritage - the Dannevirke as a mirror and object of military and political history. In: Bregnsbo, Michael; Jensen, Kurt Villads (Hg.): Schleswig Holstein - contested region(s) through history. Oden- 
se (University of Southern Denmark. Studies in History and Social Sciences, 520), S. 193-217.

Dragsbo, Peter (2005): Forsømt kulturarv i Sønderjylland. In: Adriansen, Inge; Dragsbo, Peter (Hg.): Sønderjysk kulturarv. Sønderjyske Museer 2003-2004. Hadersleben, [Apenrade], S. 118-123.

Duden (2017): Verein. <www.duden.de/rechtschreibung/Verein\#Bedeutung1>, 07.07.2017.

Durkheim, Emile (1981): Die elementaren Formen des religiösen Lebens. Unter Mitarbeit von Ludwig Schmidts. Frankfurt am Main (Theorie, [86]).

Dürkop, Daniel (2013): Samarbejde om de nye forældre. Skoleforeningen og SSF er enige om målet, når det gælder om at få integreret nye medlemmer i mindretallet. Hrsg. v. Dansk Skoleforening for Sydslesvig. <www.skoleforeningen.org/nyheder/artikler/nyheder-2013-2014/samarbejde-om-de-nye-foraeldre>, 08.08.2015.

Ebrecht, Jörg (2004): Die Kreativität der Praxis. Überlegungen zum Wandel von Habitusformationen. In: Ebrecht, Jörg; Hillebrandt, Frank (Hg.): Bourdieus Theorie der Praxis. Erklärungskraft - Anwendung - Perspektiven. 2. Aufl. Wiesbaden, S. 225-241.

Eisch, Katharina (1999): Grenzland Niemandsland: Eine ethnographische Annäherung an die Deutschen in Böhmen. In: Bohemia. Zeitschrift für Geschichte und Kultur der böhmischen Länder, Jg. 40, H. 2, S. 277-308.

Eisch, Katharina (2001): Interethik und interkulturelle Forschung. Methodische Zugangsweisen der Europäischen Ethnologie. In: Göttsch, Silke; Lehmann, Albrecht (Hg.): Methoden der Volkskunde. Positionen, Quellen, Arbeitsweisen der europäischen Ethnologie. Berlin (Ethnologische Paperbacks), S. 139_ 164.

Elgenius, Gabriella (2007): The origin of European national flags. In: Eriksen, Thomas Hylland; Jenkins, Richard (Hg.): Flag, Nation and Symbolism in Europe and America. London, New York, S. 14-30.

Elle, Ludwig (2011): Wie viele Sorben gibt es - noch? Oder: Kann und soll man Minderheiten zählen. In: Tschernokoshewa, Elka; Keller, Ines (Hg.): Dialogische Begegnungen. Minderheiten - Mehrheiten aus hybridologischer Sicht. Münster u. a. (Hybride Welten, 5), S. 209-217.

Engelhardt, Michael von (1990): Biographie und Identität. Die Rekonstruktion und Präsentation von Identität im mündlichen autobiographischen Erzählen. In: Sparn, Walter (Hg.): Wer schreibt meine Lebensgeschichte. Biographie, 
Autobiographie, Hagiographie und ihre Entstehungszusammenhänge. Gütersloh, S. 197-247.

Eriksen, Thomas Hylland (2002): Ethnicity and nationalism. 2. Aufl. London (Anthropology, culture, and society).

Eriksen, Thomas Hylland (2003): Hvad er Socialantropologi. Oversat af Morten Visby. Kopenhagen, 2005 (Hvad er).

Eriksen, Thomas Hylland (2007): Some questions about flags. In: Eriksen, Thomas Hylland; Jenkins, Richard (Hg.): Flag, Nation and Symbolism in Europe and America. London, New York, S. 1-13.

Europäische Bürgerinitiative (2017): Minority SafePack - eine Million Unterschriften für die Vielfalt Europas. <ec.europa.eu/citizens-initiative/32/public/\#>, 14.12.2017.

Federal Union of European Nationalities (2013): Über uns. Fakten. <www.fuen.org/de/ueber-uns/fakten>, 4.10.2013.

Federal Union of European Nationalities (2014): European Citizens Initiative. <www.fuen.org/key-topics/european-citizens-initiative>, 04.04.2014.

Federal Union of European Nationalities (2017): Minority Safepack Initiative. <www.minority-safepack.eu/main>, 14.12.2017.

Feischmidt, Margit (2003): Ethnizität als Konstruktion und Erfahrung. Symbolstreit und Alltagskultur im siebenbürgischen Cluj. Münster (Zeithorizonte Perspektiven Europäischer Ethnologie, 8).

Feischmidt, Margit (2007): Ethnizität - Perspektiven und Konzepte der ethnologischen Forschung. In: Schmidt-Lauber, Brigitta (Hg.): Ethnizität und Migration. Einführung in Wissenschaft und Arbeitsfelder. Berlin (Reimer Kulturwissenschaften), S. 51-68.

Felbick, Dieter (2003): Schlagwörter der Nachkriegszeit 1945-1949. Berlin.

Findeisen, Jörg-Peter (1999): Dänemark. Von den Anfängen bis zur Gegenwart. Regensburg (Geschichte der Länder Skandinaviens).

Flensborg Avis AG (2015): Årsberetning 2014. <www.e-pages.dk/flensborgavisextra/260>, 06.06.2016.

Flick, Uwe (2012): Qualitative Sozialforschung. Eine Einführung. 5. Aufl. Reinbek bei Hamburg (Rororo Rowohlts Enzyklopädie, 55694). 
Foltin, Hans-Friedrich (1984): Geschichte und Perspektiven der Vereinsforschung. In: Foltin, Hans-Friedrich; Kramer, Dieter (Hg.): Vereinsforschung, S. 3-31.

François, Etienne; Siegrist, Hannes; Vogel, Jakob (1995): Die Nation. Vorstellungen, Inszenierungen, Emotionen. In: François, Etienne; Siegrist, Hannes; Vogel, Jakob (Hg.): Nation und Emotion. Deutschland und Frankreich im Vergleich. 19. und 20. Jahrhundert. Göttingen (Kritische Studien zur Geschichtswissenschaft, 110), S. 13-35.

Frandsen, Steen Bo (2005): Dänemark - Ein Reich ohne Regionen. In: Gibas, Monika; Haufe, Rüdiger (Hg.): „Mythen der Mitte“. Regionen als nationale Wertezentren. Konstruktionsprozesse und Sinnstiftungskonzepte im 19. und 20. Jahrhundert. Weimar, S. 327-339.

Frandsen, Steen Bo (2009): Transnationale erindringssteder i et dansk-tysk perspektiv. In: Fossat, Sissel Bjerrum; Magnussen, Anne; Petersen, Klaus; Sørensen, Nils Arne (Hg.): Transnationale historier. Odense (University of Southern Denmark. Studies in History and Social Sciences, 386), S. 17-27.

Frandsen, Steen Bo (2013): Die deutsch-dänische Grenze im Zeitalter der nationalen Gegensätze. In: Frandsen, Steen Bo; Krieger, Martin; Lubowitz, Frank (Hg.): 1200 Jahre deutsch-dänische Grenze. Tagungsband. Neumünster (Zeit + Geschichte, 28), S. 225-234.

Frandsen, Steen Bo (2015): The Danish Composite State and the Lost Memory of a Multilingual Culture. In: Havinga, Anna; Langer, Nils (Hg.): Invisible Languages in the Nineteenth Century. Oxford u. a. (Historical Sociolinguistics, 2), S. 239-256.

Frandsen, Steen Bo (2016): Some reflections on Schleswig and Holstein as contested regions. In: Bregnsbo, Michael; Jensen, Kurt Villads (Hg.): Schleswig Holstein - contested region(s) through history. Odense (University of Southern Denmark. Studies in History and Social Sciences, 520), S. 15-24.

Frandsen, Steen Bo; Krieger, Martin; Lubowitz, Frank (Hg.) (2013): 1200 Jahre deutsch-dänische Grenze. Tagungsband. Neumünster (Zeit + Geschichte, 28).

Freudenthal, Herbert (1968): Vereine in Hamburg. Ein Beitrag zur Geschichte und Volkskunde der Geselligkeit. Hamburg (Volkskundliche Studien, 4).

Frevert, Ute (2000): Vertrauen. Historische Annäherungen an eine Gefühlshaltung. In: Benthien, Claudia; Fleig, Anne; Kasten, Ingrid (Hg.): Emotionalität. Zur Geschichte der Gefühle. Köln, Weimar, Wien (Literatur - Kultur - Geschlecht. Studien zur Literatur- und Kulturgeschichte. Kleine Reihe, 16), S. 178-197. 
Froschauer, Ulrike; Lueger, Manfred (2003): Das qualitative Interview. Zur Praxis interpretativer Analyse sozialer Systeme. Wien (UTB Soziologie, 2418).

Fröschl, Thomas (2007): Politischer Glaube und Konversion. In: Kurz, Marlene; Winkelbauer, Thomas (Hg.): Glaubenswechsel. Innsbruck (Wiener Zeitschrift zur Geschichte der Neuzeit, 7), S. 100-112.

Fuchs-Heinritz, Werner (2005): Biographische Forschung. Eine Einführung in Praxis und Methoden. 3. Aufl. Wiesbaden (Lehrbuch).

Fuglsang-Damgaard Sina, Anne (2012): Ein Kind des Grenzlandes - Aufwachsen in Nordschleswig. In: Oettingen, Alexander von; Komischke-Konnerup, Leo; Mikkelsen Buhl, Lisbet; Tästensen, Anke; Wagner, Michaela (Hg.): Mindretalspædagogik. Minderheitenpädagogik. Aarhus, S. 68-78.

Fulbrook, Mary (1997): Myth-Making and National Identity: The Case of the G.D.R. In: Hosking, Geoffrey; Schöpflin, George (Hg.): Myths and Nationhood. London, S. 72-87.

Geertz, Clifford (2002): Dichte Beschreibung. Beiträge zum Verstehen kultureller Systeme. 8. Aufl. Frankfurt am Main (Suhrkamp-Taschenbuch Wissenschaft, 696).

Gellner, Ernest (1991): Nationalismus und Moderne. Berlin.

Gemeinde Dannewerk: Dannewerk Museum.

$<$ www.dannewerk.de/museum.htm>, 13.11.2009.

Gerlitz, Peter (1990): Konversion. I. Religionsgeschichtlich. In: Theologische Realenzyklopädie. Berlin, S. 559-563.

Gerndt, Helge (1981): Kultur als Forschungsfeld. Über volkskundliches Denken und Arbeiten. 2. Aufl. München, 1986 (Münchner Beiträge zur Volkskunde, 5).

Girtler, Roland (2001): Methoden der Feldforschung. 4. Aufl. Wien, Köln, Weimar (UTB für Wissenschaft Soziologie, 2257).

Glaser, Konstanze (2001): Zur Wandlung des Ethnizitätsbegriffs bei autochthonen Minderheiten unter spezieller Berücksichtigung des Sorbischen (Wendischen) in der Lausitz und des Gälischen in Schottland. In: Tschernokoshewa, Elka; Kramer, Dieter (Hg.): Der allägliche Umgang mit Differenz. Bildung Medien - Politik. Münster, u. a. (Hybride Welten, 2), S. 83-92.

Glück, Helmut (2000): Zweitspracherwerb. In: Glück, Helmut (Hg.): Metzler Lexikon Sprache. 2. Aufl. Stuttgart, Weimar, S. 814. 
Göderle, Wolfgang (2016): Zensus und Ethnizität. Zur Herstellung von Wissen über soziale Wirklichkeiten im Habsburgerreich zwischen 1848 und 1910. Göttingen.

Goffman, Erving (2010): Wir alle spielen Theater. Die Selbstdarstellung im Alltag. 8. Aufl. Unter Mitarbeit von Peter Weber-Schäfer und Rolf Dahrendorf. München (Serie Piper, 3891).

Gombos, Georg (2017): Ein-, zwei-, mehrsprachig. Pädagogische Herausforderungen aus der Sicht von autochthonen sprachlichen Minderheiten. In: Steensen, Thomas (Hg.): Nationale Minderheiten. Beiträge vom 9. Internationalen Ferdinand-Tönnies-Symposium. Bräist/Bredstedt (Nordfriisk Instituut, 249), S. $51-70$.

Göttsch, Silke (2006): Grenzziehungen - Grenzerfahrungen. Das Beispiel Schleswig-Holstein und Dänemark 1800-1860. In: Hengartner, Thomas; Moser, Johannes (Hg.): Grenzen \& Differenzen. Zur Macht sozialer und kultureller Grenzziehungen. 35. Kongress der Deutschen Gesellschaft für Volkskunde, Dresden 2005. Leipzig (Schriften zur sächsischen Geschichte und Volkskunde, 17), S. 383-394.

Göttsch-Elten, Silke (2016): Deutsch oder Dänisch. Kulturelle Vielfalt als nationale Differenz in der Grenzregion Schleswig um 1900. In: Horatschek, Anna Margaretha; Pistor-Hatam, Anja (Hg.): Identitäten im Prozess. Region, Nation, Staat, Individuum. Berlin, Boston (Abhandlungen der Akademie der Wissenschaften in Hamburg, 6), S. 150-165.

Götz, Irene (2001): Arbeiten, etwas Leisten, Helfen. Leitmotive nationaler Identifizierung im biographischen Kontext. In: Binder, Beate; Kaschuba, Wolfgang; Niedermüller, Peter (Hg.): Inszenierung des Nationalen. Geschichte, Kultur und die Politik der Identitäten am Ende des 20. Jahrhunderts. Köln (Alltag \& Kultur, 7), S. 309-330.

Götz, Irene (2010): Nationale und regionale Identitäten. Zur Bedeutung von territorialen Verortungen in der Zweiten Moderne. In: Seifert, Manfred (Hg.): Zwischen Emotion und Kalkül. ,Heimat' als Argument im Prozess der Moderne. Leipzig (Schriften zur sächsischen Geschichte und Volkskunde, 35), S. 205-218.

Götz, Irene (2011): Deutsche Identitäten. Die Wiederentdeckung des Nationalen nach 1989. [Habilitationsschrift]. Köln, Weimar, Wien (Alltag \& Kultur, 14).

Graw-Teebken, Andrea (2008): Nationalisierte Grenzräume. Eine Untersuchung nationaler Diskurse in Ostfriesland und Schleswig, 1815 bis 1867. Aalborg. 
Grosshennrich, Franz-Josef (1980): Die Mainzer Fastnachtsvereine. Geschichte, Funktion, Organisation und Mitgliederstruktur. Wiesbaden (Mainzer Studien zur Sprach- und Volksforschung, 4).

Grupe, Gerd (2011): Zeichen der Zugehörigkeit und Mittel der Abgrenzung. Prozesse der Identitätsstiftung aus ethnomusikologischer Sicht. In: Musikpsychologie. Jahrbuch der Deutschen Gesellschaft für Musikpsychologie, Jg. 21, S. 729.

Grænseforeningen: Hvem er vi. <www.graenseforeningen.dk/?q=om>, 26.05.2017.

Grænseforeningen (2017): Sydslesvigske Børns Ferierejser. <www.graenseforeningen.dk/?q=sydslesvigske-borns-ferierejser.html>, 07.07.2017.

Gustafsson, Harald (1998): Gesamtstaat oder Konglomeratstaat? Schleswig in Dänemark-Norwegen im 18. Jahrhundert. In: Becker-Christensen, Henrik; Lange, Ulrich (Hg.): Geschichte Schleswigs vom frühen Mittelalter bis 1920. Dänischdeutsche Historikerkonferenz des Instituts für Grenzregionsforschung in $\mathrm{Zu}$ sammenarbeit mit der Akademie Sankelmark vom 28. bis 30. September 1997 in Sankelmark. Apenrade, 53-59.

Guttormsen, Hans (1995): Die Anfänge der Dänischen Schule in Friedrichstadt. Anna Elisabeth Bergs Erlebnisse im Jahre 1946. In: Mitteilungsblatt der Gesellschaft für Friedrichstäder Stadtgeschichte, Jg. 49, S. 109-126.

Gyr, Ueli (2005): Urbanität und Raumkultur. Festivalisierung und Eventisierung als urbane Identitätsleistungen. In: Binder, Beate; Göttsch, Silke; Kaschuba, Wolfgang; Vanja, Konrad (Hg.): Ort. Arbeit. Körper. Ethnografie Europäischer Modernen. 34. Kongress der Deutschen Gesellschaft für Volkskunde, Berlin 2003. Münster u. a. (Musuem Europäischer Kulturen, 3), S. 243-249.

Haarløv, Hans-Tyge B. T. T. (2014): Ejderen. Rønshoved.

Hahn, Alois (1995): Identität und Biographie. In: Wohlrab-Sahr, Monika (Hg.): Biographie und Religion. Zwischen Ritual und Selbstsuche. Frankfurt am Main, S. 127-152.

Hall, Stuart (2004): Wer braucht ıIdentitätı. In: Koivisto, Juha; Merkens, Andreas (Hg.): Stuart Hall. Ideologie. Identität. Repräsentation. Ausgewählte Schriften 4. Hamburg (Argument classics), S. 167-187.

Haller, Dieter (2010): dtv-Atlas Ethnologie. 2. Aufl. Unter Mitarbeit von Bernd Rodekohr. München (dtv-Atlas, 3259). 
Hammel-Kiesow, Rolf; Pelc, Ortwin (2003): Landesausbau, Territorialherrschaft, Produktion und Handel im hohen und späten Mittelalter (12.-16. Jh.). In: Lange, Ulrich (Hg.): Geschichte Schleswig-Holsteins. Von den Anfängen bis zur Gegenwart. 2. Aufl. Neumünster, S. 59-134.

Hannerz, Ulf (1995): „Kultur“ in einer vernetzten Welt. Zur Revision eines ethnologischen Begriffes. In: Kaschuba, Wolfgang (Hg.): Kulturen - Identitäten - Diskurse. Perspektiven europäischer Ethnologie. Berlin (Zeithorizonte, 1), S. $64-84$.

Hansen, Georg (1995a): Ethnie, Ethnozentrismus, Ethnizität. In: Schmalz-Jacobsen, Cornelia; Hansen, Georg (Hg.): Ethnische Minderheiten in der Bundesrepublik Deutschland. Ein Lexikon. München, S. 152-154.

Hansen, Georg (1995b): Vorurteil. In: Schmalz-Jacobsen, Cornelia; Hansen, Georg (Hg.): Ethnische Minderheiten in der Bundesrepublik Deutschland. Ein Lexikon. München, S. 546-549.

Hansen, Georg (1997): Diskriminierung. In: Schmalz-Jakobsen, Cornelia; Hansen, Georg; Polm, Rita (Hg.): Kleines Lexikon der ethnischen Minderheiten in Deutschland. Bonn, S. 196-198.

Hansen, Georg (2001): Die Deutschmachung. Ethnizität und Ethnisierung im Prozess von Ein- und Ausgrenzungen. Münster u. a. (Lernen für Europa, 7).

Hansen, Hans Schultz (2000a): Dänische Minderheit. In: Lorenzen-Schmidt, Klaus-Joachim; Pelc, Ortwin (Hg.): Schleswig-Holstein-Lexikon. Neumünster, S. 92-93.

Hansen, Hans Schultz (2003): Demokratie oder Nationalismus. Politische Geschichte Schleswig-Holsteins 1830-1918. In: Lange, Ulrich (Hg.): Geschichte Schleswig-Holsteins. Von den Anfängen bis zur Gegenwart. 2. Aufl. Neumünster, S. 427-485.

Hansen, Hans Schultz (2006): Die Schleswiger und die Teilung. Schleswigsche Gesinnungsgrenzen im 19. Jahrhundert. In: Rheinheimer, Martin (Hg.): Grenzen in der Geschichte Schleswig-Holsteins und Dänemarks. Neumünster (Studien zur Wirtschafts- und Sozialgeschichte Schleswig-Holsteins, 42), S. 339351.

Hansen, Hans Schultz (2016): The Influence of Economic and Social Interest on the Choice of National Identity in Schleswig, 1940-1848. In: Bregnsbo, Michael; Jensen, Kurt Villads (Hg.): Schleswig Holstein - contested region(s) through history. Odense (University of Southern Denmark. Studies in History and Social Sciences, 520), S. 121-145. 
Hansen, Jon Hardon (2017): Formandens beretning. In: Blå Beretning 2017. Sydslesvigsk Forenings 41. Landsmøde. 11. November 2017 i Husum. Flensburg, S. 3-20.

Hansen, Jørn (2002): Fra „enten-eller“ til „Zweiströmigkeit“. Idrætsforeningerne i det tyske og danske mindretal i Nord- og Sydslesvig fra 1939 til i dag. In: Mikkelsen, Flemming (Hg.): Bevægelser i demokrati. Foreninger og kollektive aktioner i Danmark. Aarhus, S. 177-197.

Hansen, Jørn; Danielsen, Anebine; Skovgaard, Thomas (1998): Idræt og identitet. En undersøgelse af det danske foreningsliv i Sydslesvig - specielt med henblik på Flensborg By's Hovedkreds. Odense.

Hansen, Reimer (2000b): Grenze. In: Lorenzen-Schmidt, Klaus-Joachim; Pelc, Ortwin (Hg.): Schleswig-Holstein-Lexikon. Neumünster, S. 186-189.

Harck, Sten (2005): Von Bonn nach Straßburg. Die Minderheitenrechte der Dänen, Deutschen und Friesen. In: Kühl, Jørgen; Bohn, Robert (Hg.): Ein europäisches Modell. Nationale Minderheiten im deutsch-dänischen Grenzland 1945-2005. Bielefeld (IZRG-Schriftenreihe, 11), S. 324-340.

Harms, Lars (11.10.2017): Antrag der Abgeordneten des SSW. Bestimmungen zur Charta der Regional- oder Minderheitensprachen nachmelden. Drucksache 19/275. Schleswig-Holsteinischer Landtag. Kiel, 11.10.2017. <www.landtag.ltsh.de/infothek/wahl19/drucks/00200/drucksache-19-00275.pdf>, 13.11.2017.

Hase, Thomas (2001): Zivilreligion. Religionswissenschaftliche Überlegungen zu einem theoretischen Konzept am Beispiel der USA. Würzburg (Religion in der Gesellschaft, 9).

Hattesen, Anni Bøgh (1990): Zweisprachigkeit in Unterricht und Ausbildung in der deutsch-dänischen Grenzregion. In: Pedersen, Karen Margrethe (Hg.): Sprache und Unterricht in der deutschen, dänischen und friesischen Minderheit. Vorträge der Tagung „Möglichkeiten des Unterrichts in den Minderheiten“. Foredrag fra konferencen „Veje inden for mindretalsundervisning“. 28.30. September 1989, Knivsberg, Apenrade, Dänemark. Apenrade, Flensburg, S. 7-20.

Haug, Karin; Kristensen, Lise; Henningsen, Lars N. (Hg.) (2008a): SSW i kommunalpolitik 1948-2008. En interviewbog. Flensburg (Studieafdelingen ved Dansk Centralbibliotek for Sydslesvig, 59).

Haugaard, Mark; Malešević, Siniša (2002): Introduction: The Idea of Collectivity. In: Malešević, Siniša; Haugaard, Mark (Hg.): Making sense of collectivity. Ethnicity, nationalism, and globalisation. London, S. 1-11. 
Häußer, Martina (2012): Kulturdörfer Europas. Eine Fallstudie zum Schachdorf Ströbeck. [Unpublizierte] Hausarbeit zur Erlangung des Magistergrades (M.A.) der Philosophischen Fakultät der Georg-August-Universität Göttingen. Göttingen.

Heckmann, Friedrich (2015): Integration von Migranten. Einwanderung und neue Nationenbildung. Wiesbaden.

Heinz, Marco (1993): Ethnizität und ethnische Identität. Eine Begriffsgeschichte. Bonn (Mundus Reihe Ethnologie, 72).

Helfferich, Cornelia (2005): Die Qualität qualitativer Daten. Manual für die Durchführung qualitativer Interviews. 2. Aufl. Wiesbaden.

Henecka, Hans-Peter; Wöhler, Karlheinz (1978): Schulsoziologie. Eine Einführung in Funktionen, Strukturen und Prozesse schulischer Erziehung. Stuttgart (Urban-Taschenbücher Soziologie, 288).

Henning, Eckart (2003): Selbstzeugnisse. In: Beck, Friedrich; Henning, Eckart (Hg.): Die archivalischen Quellen. Mit einer Einführung in die historischen Hilfswissenschaften. 3. Aufl. Köln, S. 119-127.

Henningsen, Lars N. (1998): Die Zusammenführung Schleswigs unter dänischer Herrschaft - Idee oder Realität. In: Becker-Christensen, Henrik; Lange, Ulrich (Hg.): Geschichte Schleswigs vom frühen Mittelalter bis 1920. Dänisch-deutsche Historikerkonferenz des Instituts für Grenzregionsforschung in Zusammenarbeit mit der Akademie Sankelmark vom 28. bis 30. September 1997 in Sankelmark. Apenrade, S. 61-79.

Henningsen, Lars N. (Hg.) (2000): Dagbøger fra Sydslesvig 1999. Flensburg (Studieafdelingen ved Dansk Centralbibliotek for Sydslesvig, 43).

Henningsen, Lars N. (Hg.) (2003a): Da Sydslesvig gik af lave. Erindringer fra sindelagsskiftets år. Flensburg (Studieafdelingen ved Dansk Centralbibliotek, 47).

Henningsen, Lars N. (2003b): Studieafdelingen i 40 års grænselandshistorie. In: Henningsen, Lars N. (Hg.): Grænselandshistorie gennem 40 år. Studieafdelingen ved Dansk Centralbibliotek for Sydslesvig 1963-2003. Flensburg (Studieafdelingens udgivelser, 46), S. 7-101.

Henningsen, Lars N. (2005): Kirchliches Leben und Identität. Die dänische Kirche in Südschleswig nach 1945. In: Kühl, Jørgen; Bohn, Robert (Hg.): Ein europäisches Modell. Nationale Minderheiten im deutsch-dänischen Grenzland 1945-2005. Bielefeld (IZRG-Schriftenreihe, 11), S. 221-234.

Henningsen, Lars N. (2008): Die Herzöge von Gottorf. In: Rasmussen, Carsten Porskrog; Imberger, Elke; Lohmeier, Dieter; Momsen, Ingwer (Hg.): Die 
Fürsten des Landes. Herzöge und Grafen von Schleswig, Holstein und Lauenburg. Neumünster, S. 141-185.

Henningsen, Lars N. (2009a): Indledning. In: Henningsen, Lars N. (Hg.): Sydslesvigs danske historie. Flensburg (Studieafdelingen ved Dansk Centralbibliotek for Sydslesvig, 62), S. 9-10.

Henningsen, Lars N. (Hg.) (2009a): Sydslesvigs danske historie. Flensburg (Studieafdelingen ved Dansk Centralbibliotek for Sydslesvig, 62).

Henningsen, Lars N. (2009b): Under Danmark. In: Henningsen, Lars N. (Hg.): Sydslesvigs danske historie. Flensburg (Studieafdelingen ved Dansk Centralbibliotek for Sydslesvig, 62), S. 11-46.

Henningsen, Lars N. (Hg.) (2011a): Zwischen Grenzkonflikt und Grenzfrieden. Die Dänische Minderheit in Schleswig-Holstein in Geschichte und Gegenwart. Flensburg (Studieafdelingen ved Dansk Centralbibliotek for Sydslesvig, Nr. 65).

Henningsen, Lars N. (2013): Sprach-, Kirchen- und Identitätsgrenzen. Schleswig als komplizierter Fall. In: Frandsen, Steen Bo; Krieger, Martin; Lubowitz, Frank (Hg.): 1200 Jahre deutsch-dänische Grenze. Tagungsband. Neumünster (Zeit + Geschichte, 28), S. 213-224.

Henningsen, Lars N.; Klatt, Martin; Kühl, Jørgen (1998): SSW. Dansksindet politik i Sydslesvig 1945-1998. Flensburg (Studieafdelingens udgivelser/Studieafdelingen, Dansk Centralbibliotek for Sydslesvig).

Herder, Johann Gottfried von (1997): Abhandlung über den Ursprung der Sprache. Kapitel 11. Hrsg. v. Philipp Reclam jun. < gutenberg.spiegel.de/buch/abhandlung-uber-den-ursprung-der-sprache-2013/11>, 13.12.2016.

Hirte, Christian (2003): Erste Konturen: Vor- und Frühgeschichte in SchleswigHolstein. In: Lange, Ulrich (Hg.): Geschichte Schleswig-Holsteins. Von den Anfängen bis zur Gegenwart. 2. Aufl. Neumünster, S. 11-57.

Hobsbawm, Eric J. (1994): Introduction: Inventing Traditions. In: Hobsbawm, Eric J.; Ranger, Terence (Hg.): The invention of tradition. Cambridge, S. 1-14.

Hobsbawm, Eric J. (2005): Nationen und Nationalismus. Mythos und Realität seit 1780. Mit einem aktuellen Vorwort des Autors und einem Nachwort von Dieter Langewiesche. 3. Aufl. Frankfurt, New York.

Hofmann, Rainer (2015): Landesbericht Deutschland. In: Hofmann, Rainer; Angst, Doris; Lantschner, Emma; Rautz, Günther; Rein, Detlev (Hg.): Rah- 
menübereinkommen zum Schutz nationaler Minderheiten. Handkommentar. Baden-Baden (NomosKommentar), S. 87-102.

Hopf, Christel (2000): Qualitative Interviews - ein Überblick. In: Flick, Uwe; Kardorff, Ernst von; Steinke, Ines (Hg.): Qualitative Forschung. Ein Handbuch. Reinbek bei Hamburg (Rororo Rowohlts Enzyklopädie, 55628), S. 349_ 360 .

Horowitz, Donald L. (2000): Ethnic Groups in Conflict. With a New Preface. 2. Aufl. Berkeley, Los Angeles, London.

Hutchinson, John; Smith, Anthony David (1996): Introduction. In: Hutchinson, John; Smith, Anthony David (Hg.): Ethnicity. Oxford (Oxford Readers), S. 3-14.

Ipsen, Anders Molt (2014): Dansk Skoleforening for Sydslesvig. Sikre mindretallets børn og unge de bedste rammer. In: Sydslesvigsk Årbog. Dansk virke i grænselandet, Jg. 54, S. 154-159.

$<$ syfo.de/fileadmin/syfo/KUNDE/pdf/Sydslesvigsk_\%C3\%85rbog $\% 202014 . p d f>, 11.01 .2015$.

Jackson, Phillip W. (1975): Einübung in eine bürokratische Gesellschaft: Zur Funktion der sozialen Verkehrsformen im Klassenzimmer. In: Zinnecker, Jürgen (Hg.): Der heimliche Lehrplan. Untersuchungen zum Schulunterricht. Weinheim, Basel (Beltz-Studienbuch, 94), 19-34.

Jacobsen, N. H. [sic] (1938): De gamle kongerigske Enklavers Oprindelse. In: Geografisk Tidsskrift, Jg. 41, S. 171-189.

<img.kb.dk/tidsskriftdk/pdf/gto/gto_0041-PDF/gto_0041_69651.pdf>, 07.04.2017.

Jahnke, Carsten (2016): "Nation" conflicts in medieval Schleswig-Holstein. In: Bregnsbo, Michael; Jensen, Kurt Villads (Hg.): Schleswig Holstein - contested region(s) through history. Odense (University of Southern Denmark. Studies in History and Social Sciences, 520), S. 147-175.

Janzen, Johann-Albrecht G. H. (2015): „... damit die jugend zu Gott gefälligen, dem negsten nützlichen und selbst seligen leuten gedeyen möge“. Eine Grundlegung der Geschichte des eiderstedtischen Schulwesens. Eiderstedt (Blick über Eiderstedt, 10).

Jaruplund Højskole; Sydslesvigsk Forening; Dansk Skoleforening for Sydslesvig (2013): Programmheft „Sydslesvig - und los geht's!!“ Efterårshøjskole for hele familien. 14.10.-18.10.2013. Jarplund.

Jebsen, Nina (2008): Leben in der Minderheit. Eine empirische Untersuchung zur Identitätskonstruktion der deutschen Minderheit in Dänemark. [Basierend auf 
einer Magisterarbeit. Universität Kiel 2007/2008]. In: Kieler Blätter zur Volkskunde, Jg. 40, S. 119-153.

Jebsen, Nina (2009): „Zu Hause haben wir eigentlich nicht bemerkt, dass wir eine Minderheit sind“". Eine Untersuchung zur Identitätskonstruktion der deutschen Minderheit in Dänemark. In: Grenzfriedenshefte. Zeitschrift für deutsch-dänischen Dialog, Jg. 56, H. 2, S. 89-102.

Jebsen, Nina (2010): Das Grenzland als sprachliches „Kampfgebiet“ - Nordschleswig von 1920 bis 1940. In: Kieler Blätter zur Volkskunde, Jg. 42, S. 23-60.

Jebsen, Nina (2011): Die deutsche Minderheit in Dänemark - Hybride Identitäten. In: Tschernokoshewa, Elka; Keller, Ines (Hg.): Dialogische Begegnungen. Minderheiten - Mehrheiten aus hybridologischer Sicht. Münster u. a. (Hybride Welten, 5), S. 289-309.

Jebsen, Nina (2015): Als die Menschen gefragt wurden. Eine Propagandaanalyse zu Volksabstimmungen in Europa nach dem Ersten Weltkrieg. Münster u. a. (Internationale Hochschulschriften, 610).

Jenkins, Richard (2007): Inarticulate speech of the heart. Nation, flag and emotion in Denmark. In: Eriksen, Thomas Hylland; Jenkins, Richard (Hg.): Flag, Nation and Symbolism in Europe and America. London, New York, S. 115-135.

Jenkins, Richard (2008): Social Identity. 3. Aufl. London, New York.

Jenkins, Richard (2012): Being Danish. Paradoxes of Identity in Everyday Life. 2. Aufl. Kopenhagen.

Jensen, Marianne Brink ([2016]): Sydslesvigske feriebørn i Danmark 1949-1974. [Examensarbeit Syddansk Universitet Odense] Odense.

Jensen, Ove (2009): Die Minderheit als „Nationalstaatskonstrukt“. Vortrag von Arthur Christiansen bei der Mitgliederversammlung des ADS-Grenzfriedensbundes 2009. In: Grenzfriedenshefte. Zeitschrift für deutsch-dänischen Dialog, Jg. 56, H. 4, S. 251-256.

Jessen, Udo (2012): Det Skoleuddannelsespolitiske Blik - hvad skal mindretallet bruge sine skoler til. In: Oettingen, Alexander von; Komischke-Konnerup, Leo; Mikkelsen Buhl, Lisbet; Tästensen, Anke; Wagner, Michaela (Hg.): Mindretalspædagogik. Minderheitenpädagogik. Aarhus, S. 99-114.

Johannsen, Per; Midskov, Hanne (2004): 85 år med Sydslesvigske Feriebørn. In: Sørensen, Ole Adrian (Hg.): På tværs af grænsen. Kopenhagen (Grænseforeningens årbog, 2004), S. 11-27. 
Johannsen-Bojsen, Karin (1981): Som vi ser os selv. Uddrag af samtaler med 60 sydslesvigere. Kopenhagen (Grænseforeningens årbog, 1981).

Jurczyk, Karin; Lange, Andreas; Thiessen, Barbara (2014): Doing Family als neue Perspektive auf Familie. Einleitung. In: Jurczyk, Karin; Lange, Andreas; Thiessen, Barbara (Hg.): Doing Family. Warum Familienleben heute nicht mehr selbstverständlich ist. Weinheim, Basel, S. 7-48.

Jürgensen, Kurt (2003): Der Grenzkampf und seine Überwindung. In: Lange, Ulrich (Hg.): Geschichte Schleswig-Holsteins. Von den Anfängen bis zur Gegenwart. 2. Aufl. Neumünster, S. 652-658.

Jurić-Pahor, Marija (2001): Mythos und Realität des nationalen Homogenitätsprinzips. Das Beispiel Triest. In: Tschernokoshewa, Elka; Kramer, Dieter (Hg.): Der alltägliche Umgang mit Differenz. Bildung - Medien - Politik. Münster u. a. (Hybride Welten, 2), S. 61-82.

Kaschuba, Wolfgang (1995): Einleitung. In: Kaschuba, Wolfgang (Hg.): Kulturen - Identitäten - Diskurse. Perspektiven europäischer Ethnologie. Berlin (Zeithorizonte, 1), S. 7-9.

Kaschuba, Wolfgang (2001): Geschichtspolitik und Identitätspolitik. Nationale und ethnische Diskurse im Vergleich. In: Binder, Beate; Kaschuba, Wolfgang; Niedermüller, Peter (Hg.): Inszenierung des Nationalen. Geschichte, Kultur und die Politik der Identitäten am Ende des 20. Jahrhunderts. Köln (Alltag \& Kultur, 7), S. 19-42.

Kaschuba, Wolfgang (2003): Einführung in die Europäische Ethnologie. 2. Aufl. München (C. H. Beck Studium).

Keményfi, Róbert (2009): Kulturelles Grenzgebiet - kulturelle „Wirkungskräfte“. Die Idee vom „ungarischen Mesopotamien“. In: Lozoviuk, Petr (Hg.): Grenzgebiet als Forschungsfeld. Aspekte der ethnografischen und kulturhistorischen Erforschung des Grenzlandes. Leipzig (Schriften zur sächsischen Geschichte und Volkskunde, 29), S. 55-75.

Kersten-Pejanič, Roswitha; Rajilić, Simone; Voß, Christian (Hg.) (2012): Doing Gender - Doing the Balkans. Dynamics and Persistence of Gender Relations in Yugoslavia and the Yugoslav Successor States. München, Berlin, Washington D.C. (Studies on language and culture in Central and Eastern Europe, 20).

Keßler, Catharina (2017): Doing School. Ein ethnographischer Beitrag zur Schulkulturforschung. Unter Mitarbeit von Regina Bendix und Margret Kraul. Wiesbaden (Studien zur Schul- und Bildungsforschung, 63).

Kirshenblatt-Gimblett, Barbara (1995): Theorizing Heritage. In: Ethnomusicology, Jg. 39, H. 3, S. 367-380. 
Klatt, Martin (2001): Flygtningene og Sydslesvigs danske bevægelse 1945-1955. Flensburg (Studieafdelingen ved Dansk Centralbibliotek for Sydslesvig, 44).

Klatt, Martin (2004): Nationalsozialismus und dänische Minderheit. Versuch einer Annäherung an einen zeitgenössischen Erklärungsversuch des nationalen Gesinnungswechsels in Südschleswig nach 1945. In: Demokratische Geschichte. Jahrbuch für Schleswig-Holstein, Jg. 16, S. 171-177.

Klatt, Martin (2005): Die dänische Minderheit in Schleswig-Holstein 1945-1955. Heimatbewegung - Speckdänen - Flüchtlingsfeinde. In: Kühl, Jørgen; Bohn, Robert (Hg.): Ein europäisches Modell. Nationale Minderheiten im deutschdänischen Grenzland 1945-2005. Bielefeld (IZRG-Schriftenreihe, 11), S. 109-125.

Klatt, Martin (2006): Was nützt die historische Einheit Schleswigs. Überlegungen zum Einfluss der Geschichte auf die heutige Tagespolitik in der deutsch-dänischen Grenzregion. In: Rheinheimer, Martin (Hg.): Grenzen in der Geschichte Schleswig-Holsteins und Dänemarks. Neumünster (Studien zur Wirtschaftsund Sozialgeschichte Schleswig-Holsteins, 42), S. 417-433.

Klatt, Martin (2009a): Existenzbedingungen der dänischen Minderheit. Buchbesprechung: Arthur Christiansen. Die Reproduktion der dänischen Minderheit im 21. Jahrhundert zwischen Kultur, Tradition und Gemeinschaftsglauben. In: Grenzfriedenshefte. Zeitschrift für deutsch-dänischen Dialog, Jg. 56, H. 2, S. 135-137, 26.06.2013.

Klatt, Martin (2009b): Genforening eller mindretal. 1945-1955. In: Henningsen, Lars N. (Hg.): Sydslesvigs danske historie. Flensburg (Studieafdelingen ved Dansk Centralbibliotek for Sydslesvig, 62), S. 177-236.

Klatt, Martin; Kühl, Jørgen (2006): SSW. Minderheiten- und Regionalpartei in Schleswig-Holstein 1945 - 2005. Flensburg (Studieafdelingen ved Dansk Centralbibliotek for Sydslesvig, 55).

Kohl, Karl-Heinz (1999): Ethnizität und Tradition aus ethnologischer Sicht. In: Assmann, Aleida; Friese, Heidrun (Hg.): Identitäten. 2. Aufl. Frankfurt am Main (Erinnerung, Geschichte, Identität, 3), S. 269-287.

Kollar, Rene (1990): Konversion. III. Historisch. 1.-5. In: Theologische Realenzyklopädie. Berlin, S. 566-673.

Kopiez, Reinhard; Brink, Guido (1998): Fußball-Fangesänge. Eine Fanomenologie. Würzburg. 
Kösemen, Orkan (2016): »Wir schaffen das!« Die Flüchtlingseinwanderung als Wendepunkt für das deutsche Selbstverständnis als Nation. In: Unzicker, Kai; Bonnet, Gesine (Hg.): Vielfalt statt Abgrenzung. Wohin steuert Deutschland in der Auseinandersetzung um Einwanderung und Flüchtlinge. Gütersloh, S. 95-109.

Kößler, Reinhart; Schiel, Tilman (1995): Nationalstaaten und Grundlagen ethnischer Identität. In: Kößler, Reinhart; Schiel, Tilman (Hg.): Nationalstaat und Ethnizität. 2. Aufl. Frankfurt am Main (Umbrüche der Moderne, 5), S. 1-21.

Köster, Birthe (2009): Der Minderheitenschutz nach der schleswig-holsteinischen Landesverfassung. Bredstedt (Studien und Materialien, Nr. 34).

Köstlin, Konrad (2000): Roots, Ritual and Ethnicity as Metaphors. In: Bendix, Regina; Roodenburg, Herman (Hg.): Managing Ethnicity. Perspectives from Folklore Studies, History and Anthropology. Amsterdam (Studies on Migration \& Ethnicity), S. 1-11.

Köstlin, Konrad (2007): Die Minderheit als „Erfindung“ der Moderne. In: Tschernokoshewa, Elka; Gransow, Volker (Hg.): Beziehungsgeschichten. Minderheiten - Mehrheiten in europäischer Perspektive. Bautzen (Schriften des Sorbischen Instituts, 42), S. 24-48.

Köstlin, Konrad (2010): Heimat denken. Zeitgeschichten und Perspektiven. In: Seifert, Manfred (Hg.): Zwischen Emotion und Kalkül. ,Heimat' als Argument im Prozess der Moderne. Leipzig (Schriften zur sächsischen Geschichte und Volkskunde, 35), S. 23-38.

Kowal, Sabine; O’Connell, Daniel (2000): Zur Transkription von Gesprächen. In: Flick, Uwe; Kardorff, Ernst von; Steinke, Ines (Hg.): Qualitative Forschung. Ein Handbuch. Reinbek bei Hamburg (Rororo Rowohlts Enzyklopädie, 55628), S. 437-447.

Kreis Nordfriesland (2013): Kultur und Bildung. <www.nordfriesland.de/KulturBildung >, 05.09.2017.

Kreisslová, Sandra (2009): Ethnische Identität im Grenzgebiet. Zur Dynamik der ethnischen Identifikation der deutschen Minderheit im Komotauer Gebiet (Chomutovsko). In: Lozoviuk, Petr (Hg.): Grenzgebiet als Forschungsfeld. Aspekte der ethnografischen und kulturhistorischen Erforschung des Grenzlandes. Leipzig (Schriften zur sächsischen Geschichte und Volkskunde, 29), S. 219-231.

Kronika, Jacob (2001): Gesinnungsdänen und Neudänen in Südschleswig. Auszüge aus einem Artikel von Jacob Kronika von 1923. Sindelagsdanske og nydanske i Sydslesvig. Uddrag af Jacob Kronikas artikel fra 1923. Originalquelle: Folkerøsten - ugentligt Efterretningsblad for Indlæg i folkelige og kir- 
kelige Spørgsmaal. 21.08.1923. In: Kraack, Gerhard; Lubowitz, Frank; Schultz Hansen, Hans (Hg.): Der nationale Gegensatz. De nationale modsætninger. 1914-1933. Schleswig, Apenrade, Flensburg (Quellen zur Geschichte der deutsch-dänischen Grenzregion. Kilder til den dansk-tyske grænseregions historie, 4), S. 408-413.

Kühl, Jørgen (1994): Dansk identitet i Sydslesvig. In: Becker-Christensen, Henrik (Hg.): National identitet. Fem foredrag om dansk og tysk identitetsfølelse i grænselandet. Apenrade, S. 50-67.

Kühl, Jørgen (1996): Zusammenleben von Mehrheit und Minderheit. Das deutsch-dänische Grenzland als Beispiel. In: Grenzfriedenshefte, H. 3, S. 188203.

Kühl, Jørgen (2003): Den dansk-tyske mindretalsmodel og Europa. Nationale mindretal og minoritetsordninger i det dansk-tyske grænseland belyst i en europæisk sammenhæng. Apenrade.

Kühl, Jørgen (2004): Nationale Identität und kulturelles Gedächtnis. Die dänische Minderheit in Schleswig-Holstein. In: Lundt, Bea (Hg.): Nordlichter. Geschichtsbewußtsein und Geschichtsmythen nördlich der Elbe. Köln (Beiträge zur Geschichtskultur, 27), S. 321-339.

Kühl, Jørgen (2005a): Die Organisationen der dänischen Minderheit. In: Kühl, Jørgen; Bohn, Robert (Hg.): Ein europäisches Modell. Nationale Minderheiten im deutsch-dänischen Grenzland 1945-2005. Bielefeld (IZRG-Schriftenreihe, 11), S. 341-377.

Kühl, Jørgen (2005b): Ein europäisches Modell. Schleswiger Erfahrung und die nationalen Minderheiten. In: Kühl, Jørgen; Bohn, Robert (Hg.): Ein europäisches Modell. Nationale Minderheiten im deutsch-dänischen Grenzland 19452005. Bielefeld (IZRG-Schriftenreihe, 11), S. 401-507.

Kühl, Jørgen (2005c): København-Bonn Erklæringerne 1955-2005. De dansk-tyske mindretalserklæringers baggrund, tilblivelse og virkning. Apenrade.

Kühl, Jørgen (2005d): Nationale Minderheiten im dänisch-deutschen Grenzland Eine Einführung. In: Kühl, Jørgen; Bohn, Robert (Hg.): Ein europäisches Modell. Nationale Minderheiten im deutsch-dänischen Grenzland 1945-2005. Bielefeld (IZRG-Schriftenreihe, 11), S. 9-58.

Kühl, Jørgen (Hg.) (2006a): Die Rechte der nationalen Minderheiten im deutschdänischen Grenzland. Ausgewählte Dokumente. Apenrade. 
Kühl, Jørgen (2006a): Minderheiten und ihr „Mutterland“. Nationale Identifikationen über die Grenzen. In: Rheinheimer, Martin (Hg.): Grenzen in der Geschichte Schleswig-Holsteins und Dänemarks. Neumünster (Studien zur Wirtschafts- und Sozialgeschichte Schleswig-Holsteins, 42), S. 387-404.

Kühl, Jørgen (2006b): Vom nationalen Konflikt zur friedlichen Koexistenz und Kooperation. Nationale Minderheiten und grenzüberschreitende Zusammenarbeit in der deutsch-dänischen Grenzregion. Apenrade (Notat/Institut for Grænseregionsforskning, 84).

Kühl, Jørgen (2009): Fra afgrænsning til medborderskab. 1955-2009. In: Henningsen, Lars N. (Hg.): Sydslesvigs danske historie. Flensburg (Studieafdelingen ved Dansk Centralbibliotek for Sydslesvig, 62), S. 237-333.

Kühl, Jørgen (2011): Von der Abgrenzung zum Miteinander 1955-2010. In: Henningsen, Lars N. (Hg.): Zwischen Grenzkonflikt und Grenzfrieden. Die Dänische Minderheit in Schleswig-Holstein in Geschichte und Gegenwart. Flensburg (Studieafdelingen ved Dansk Centralbibliotek for Sydslesvig, Nr. 65), S. 207-317.

Kühl, Jørgen (2017): Die Minderheiten in Europa im Zeitalter der Globalisierung. In: Steensen, Thomas (Hg.): Nationale Minderheiten. Beiträge vom 9. Internationalen Ferdinand-Tönnies-Symposium. Bräist/Bredstedt (Nordfriisk Instituut, 249), S. 27-49.

Kühl, Jørgen; Bohn, Robert (Hg.) (2005): Ein europäisches Modell. Nationale Minderheiten im deutsch-dänischen Grenzland 1945-2005. Bielefeld (IZRGSchriftenreihe, 11).

Kühl, Jørgen; Bohn, Robert (2005): Zeittafel 1815-2004. In: Kühl, Jørgen; Bohn, Robert (Hg.): Ein europäisches Modell. Nationale Minderheiten im deutschdänischen Grenzland 1945-2005. Bielefeld (IZRG-Schriftenreihe, 11), S. 556-580.

Kulturministeriet (2014): Drifttilskud og resultataftaler 2015. < kum.dk/kulturpolitik/internationaltkultursamarbejde/sydslesvigudvalget/tilskudsordninger/tilskud-2015/driftstilskud-og-resultataftaler-2015>, 07.07.2017.

Kulturministeriet (Hg.) (2016): Danmarkskanon - 10 værdier for fremtidens samfund. Kopenhagen. <www.danmarkskanon.dk>, 05.01.2018.

Kulturministeriet; Sydslesvigudvalget (Hg.) (2017): Det danske mindretal. $<$ kum.dk/kulturpolitik/internationaltkultursamarbejde/sydslesvigudvalget/det-danske-mindretal>, 09.12.2017. 
Küpers, Wendelin; Weibler, Jürgen (2005): Emotionen in Organisationen. Stuttgart (Organisation und Führung).

Küssner, Dieter Paul (2012): SSFs landsmøde 10.11.2012: Formandens skriftlige beretning. <syfo.de/vis/artikel/ssfs-landsmoede-10112012-formandens-skriftlige-beretning $>, 06.11 .2012$.

Küssner, Dieter Paul (2013): SSF-formandens beretning. Unter Mitarbeit von Sydslesvigsk Forening/SSFs Hovedstyrelse.

$<$ syfo.de/nyhedsoversigt/arkiv/singleview-archiv/artikel/ssf-formandens-beretning-3>, 23.03.2016.

Kütemeier, Erika (2000): ... weil ich kleine Schulen mag. In: Henningsen, Lars N. (Hg.): Dagbøger fra Sydslesvig 1999. Flensburg (Studieafdelingen ved Dansk Centralbibliotek for Sydslesvig, 43), S. 107-108.

Landesrechnungshof Schleswig-Holstein (Hg.) (2006): Bemerkungen 2006. Ministerium für Bildung und Frauen. 14. Zuschüssen an die privaten Schulen der dänischen Minderheit. <www.landesrechnungshofsh.de/file/bm2006_tz14.pdf>, 02.01.2018.

Landesrechnungshof Schleswig-Holstein (Hg.) (2014): Bemerkungen 2014. Ministerium für Bildung und Wissenschaft. 11. Zuschüsse an die Schulen der dänischen Minderheit. <www.landesrechnungshofsh.de/file/bemerkungen2014_tz11.pdf>, 02.01.2018.

Lange, Ulrich (2003a): Das Notwendige tun. In: Lange, Ulrich (Hg.): Geschichte Schleswig-Holsteins. Von den Anfängen bis zur Gegenwart. 2. Aufl. Neumünster, S. 659-681.

Lange, Ulrich (Hg.) (2003): Geschichte Schleswig-Holsteins. Von den Anfängen bis zur Gegenwart. 2. Aufl. Neumünster.

Lange, Ulrich (2003b): Stände, Landesherr und große Politik. Vom Konsens des 16. zu den Konflikten des 17. Jahrhunderts. In: Lange, Ulrich (Hg.): Geschichte Schleswig-Holsteins. Von den Anfängen bis zur Gegenwart. 2. Aufl. Neumünster, S. 153-265.

Langewiesche, Dieter (2003): Was heißt ,Erfindung der Nation'. Nationalgeschichte als Artefakt - oder Geschichtsdeutung als Machtkampf. In: Historische Zeitschrift, H. 277, S. 593-617.

Latsch, Gunther (29.04.2017): Der Däne in mir. Schleswig-Holstein. Bei der Wahl im Mai könnte wieder einmal die Dänenpartei SSW entscheiden, wer künftig in Kiel regiert. In: Der Spiegel, Jg. 71, H. 18, S. 52-53. 
Lauring, Palle (1964): Geschichte Dänemarks. Neumünster.

Lehmann, Albrecht (1980): Rechtfertigungsgeschichten. Über eine Funktion des Erzählens eigener Erlebnisse im Alltag. In: Fabula, Jg. 21, H. 1/2, S. 56-69. <pao.chadwyck.co.uk/PDF/1259225898567.pdf>, 26.11.2009.

Lehmann, Albrecht (1983): Erzählstruktur und Lebenslauf. Autobiographische Untersuchungen. [Habilitationsschrift]. Frankfurt am Main.

Lehmann, Albrecht (2007): Reden über Erfahrung. Kulturwissenschaftliche Bewusstseinsanalyse des Erzählens. Berlin.

Löfgren, Orvar (1995): Die Nationalisierung des Alltagslebens: Konstruktion einer nationalen Ästhetik. In: Kaschuba, Wolfgang (Hg.): Kulturen - Identitäten - Diskurse. Perspektiven europäischer Ethnologie. Berlin (Zeithorizonte, 1), S. 114-134.

Lozoviuk, Petr (2009): Grenze und Grenzgesellschaft im Visier der ethnografischen Forschung. In: Lozoviuk, Petr (Hg.): Grenzgebiet als Forschungsfeld. Aspekte der ethnografischen und kulturhistorischen Erforschung des Grenzlandes. Leipzig (Schriften zur sächsischen Geschichte und Volkskunde, 29), S. 15-28.

Lubowitz, Frank (2013): „Grenzland Schleswig“ - Die Clausen-Linie und die Grenzziehung von 1920 zwischen Eider und Königsau. In: Frandsen, Steen Bo; Krieger, Martin; Lubowitz, Frank (Hg.): 1200 Jahre deutsch-dänische Grenze. Tagungsband. Neumünster (Zeit + Geschichte, 28), S. 249-258.

Malešević, Siniša (2004): "Divine Ethnies" and "Sacred Nations": Anthony D. Smith and the Neo-Durkhemian Theory of Nationalism. In: Nationalism and Ethnic Politics, Jg. 10, H. 4, S. 561-594.

Malešević, Siniša (2006): Identity as Ideology. Understanding Ethnicity and Nationalism. Basingstoke, New York.

Malešević, Siniša (2013): Nation-states and Nationalisms. Cambridge, Malden (Political sociology).

Mannitz, Sabine (2002): Einschränkungen, Konvergenz und Cross-Over. Die individualisierte Suche nach dem Gück. Leistungsdenken und soziale Moblitität. Resümee. In: Schiffauer, Werner; Baumann, Gerd; Kastoryano, Riva; Vertovec, Steven (Hg.): Staat - Schule - Ethnizität. Politische Sozialisation von Immigrantenkindern in vier europäischen Ländern. Münster u. a. (Interkulturelle Bildungsforschung, 10), S. 323-357.

Mannitz, Sabine (2004): Limitations, Convergence and Cross-overs. In: Schiffauer, Werner; Baumann, Gerd; Kastoryano, Riva; Vertovec, Steven (Hg.): Civil 
Enculturation. Nation-State, Schools, and Ethnic Difference in four European Countries. New York, Oxford, S. 307-333.

Marselis, Randi (2005): Majoritetskvinden som grænsemarkør: Om perkerpiger og konvertitter i mediebilledet. In: Bech, Henning; Anne Scott Sørensen (Hg.): Kultur på kryds og tværs. Aarhus (Kunstkritik og kulturkamp, 1), S. 43-64.

Martini, Claudia (1997): Minderheit. In: Schmalz-Jakobsen, Cornelia; Hansen, Georg; Polm, Rita (Hg.): Kleines Lexikon der ethnischen Minderheiten in Deutschland. Bonn, S. 222-223.

McArthur, Marilyn; Weber, Georg; Nassehi, Armin; MacArthur, Marilyn (1990): Zum Identitätswandel der Siebenbürger Sachsen. Eine kulturanthropologische Studie. Köln, Wien (Studia Transylvanica, 16).

Meier, Dirk (2016): Die Eider. Flusslandschaft und Geschichte. Heide.

Meisner, Morten (2012): Mindretalspædagogik - en zombie i det 21. århundre. In: Oettingen, Alexander von; Komischke-Konnerup, Leo; Mikkelsen Buhl, Lisbet; Tästensen, Anke; Wagner, Michaela (Hg.): Mindretalspædagogik. Minderheitenpädagogik. Aarhus, S. 50-67.

Menke, Hubertus (1994): Dänisch im Norden Deutschlands. In: Mattheier, Klaus; Wiesinger, Peter (Hg.): Dialektologie des Deutschen. Forschungsstand und Entwicklungstendenzen. Tübingen (Reihe Germanistische Linguistik, 147), S. 116-126.

Meyer-Blanck, Michael; Weyel, Birgit (2008): Studien- und Arbeitsbuch Praktische Theologie. Göttingen (UTB Theologie, Religion, 3149).

Ministeriet for Børn, Undervisning og Ligestilling (2016): Det danske mindretal i Sydslesvig. <www.uvm.dk/Om-os/Ministeriets-internationale-arbejde/EU-ogEuropa/Sydslesvigudvalget/Det-danske-mindretal-i-Sydslesvig >, 08.11.2016.

Mitchell, Claire (2006): The Religious Content of Ethnic Identities. In: Sociology. The journal of the British Sociological Association, Jg. 40, H. 6, S. 1135-1152.

Møller, Jes Fabricius (2016): Dynasty and nation. The Schleswig question and the house of Glücksborg. In: Bregnsbo, Michael; Jensen, Kurt Villads (Hg.):

Schleswig Holstein - contested region(s) through history. Odense (University of Southern Denmark. Studies in History and Social Sciences, 520), S. 309-326.

Mortensen, Hans Kay (1990): Der Südschleswigsche Wählerverband (SSW). Eine Minderheiten-Partei im Wandel der Zeit. Hamburg. 
Münkler, Herfried; Münkler, Marina (2016): Die neuen Deutschen. Ein Land vor seiner Zukunft. Berlin.

Neergaard, Niels (2001): Aus der Rede von Staatsminister Niels Neergaard auf Düppel am 11.7.1920. Statsminister Niels Neergaards tale på Dybbøl 11.7.1920. Originalquelle: Hejmdal 12.07-1920. In: Kraack, Gerhard; Lubowitz, Frank; Schultz Hansen, Hans (Hg.): Der nationale Gegensatz. De nationale modsætninger. 1914-1933. Schleswig, Apenrade, Flensburg (Quellen zur Geschichte der deutsch-dänischen Grenzregion. Kilder til den dansk-tyske grænseregions historie, 4), S. 240-243.

Nielsen, M. H. [sic] (1922): De kongerigske Enklaver. In: Fra Ribe Amt, H. 5, S. 485-551. < bibliotek.dk/linkme.php?rec.id=870978-tsart\%3A16503835>.

Nielsen, Niels Kayser (2008): Kulturarv i det dansk-tyske grænseland - nationalliberalismens lange skygger i en centralistisk nation. In: Jönsson, Lars-Eric; Wallette, Anna; Wienberg, Jes (Hg.): Kanon och kulturarv. Historia och samtid i Danmark och Sverige. Göteborg, Stockholm (Centrum för Danmarksstudier), S. 221-246.

Nipperdey, Thomas (1976): Verein als soziale Struktur in Deutschland im späten 18. und frühen 19. Jahrhundert. Eine Fallstudie zur Modernisierung I. In: Nipperdey, Thomas: Gesellschaft, Kultur, Theorie. Gesammelte Aufsätze zur neueren Geschichte. Göttingen (Kritische Studien zur Geschichtswissenschaft, 18), S. 174-205.

Nittel, Dieter (2001): Kindliches Erleben und heimlicher Lehrplan des Schuleintritts. Über die Aneignung schulischer Sozialitätsformen. In: Behnken, Imbke; Zinnecker, Jürgen (Hg.): Kinder. Kindheit. Lebensgeschichte. Ein Handbuch. Seelze-Velber, S. 444-457.

Noack, Johan Peter (1989a): Det danske mindretal i Sydslesvig 1920-1945. Apenrade (1).

Noack, Johan Peter (1989b): Det danske mindretal i Sydslesvig 1920-1945. Apenrade (2).

Noack, Johan Peter (1991a): Det sydslesvigske graensespørgsmål 1945-1947. Apenrade (1).

Noack, Johan Peter (1991b): Det sydslesvigske graensespørgsmål 1945-1947. Apenrade (2).

Noack, Johan Peter (1995): Da grænsen »lå fast« - grænsestriden efter 2. verdenskrig. In: Becker-Christensen, Henrik (Hg.): Grænsen i 75 år. 1920-1995. Apenrade, S. 110-128. 
Noack, Johan Peter (1996): Als die Grenze „fest lag“ - der Grenzstreit nach dem Zweiten Weltkrieg. In: Grenzfriedenshefte, H. 1, S. 23-40.

Noack, Johan Peter (1997a): Det danske mindretal i Sydslesvig 1948-1955. Apenrade (1).

Noack, Johan Peter (1997b): Det danske mindretal i Sydslesvig 1948-1955. Apenrade (2).

Nock, Arthur Darby (1933): Conversion. The old and the new in religion from Alexander the Great to Augustine of Hippo. Lanham, 1988 (Brown classics in Judaica).

Nohl, Arnd-Michael (2006): Interview und dokumentarische Methode. Anleitungen für die Forschungspraxis. Wiesbaden (Qualitative Sozialforschung, 16).

Nonnenbroich, Karl-Friedrich (1973): Die dänische Minderheit in SchleswigHolstein nach 1945 unter besonderer Berücksichtigung des Südschleswigschen Wählerverbandes. Kiel.

Noyes, Dorothy (2010): Traditional Culture: How does it work. DFG-Forschergruppe Cultural Property, Georg-August-Universität Göttingen. (CP101 Concepts and Institutions in Cultural Property 1/2012. A Working Paper of the Göttingen Interdisciplinary Research Group on Cultural Property, 1). <webdoc.sub.gwdg.de/ebook/serien/qu/cp101/01_2010.pdf>, 03.01.2012.

O. A. (2009): Doppeleiche. < de.wikipedia.org/w/index.php? title $=$ Doppeleiche\&printable $=$ yes $>, 13.11 .2009$.

O. A. (2014): Støtten fra Danmark betyder alt. De mange millioner kroner fra Danmark er afgørende for det danske mindretals eksistens. TV Syd. <www.tvsyd.dk/artikel/stoetten-fra-danmark-betyder-alt>, 22.07.2016.

Oettingen, Alexander von (2012): Kan man lære at være i et mindretal? - pædagogiske spørgsmål til mindretalspædagogikken. In: Oettingen, Alexander von; Komischke-Konnerup, Leo; Mikkelsen Buhl, Lisbet; Tästensen, Anke; Wagner, Michaela (Hg.): Mindretalspædagogik. Minderheitenpädagogik. Aarhus, S. 21-32.

Oetzmann, Sabine (2014): Protokollat over styrelsesmødet onsdag den 18. juni 2014 kl. 16:30 på Christian Paulsen-Skolen [sic]. Hrsg. v. Dansk Skoleforening for Sydslesvig. <www.skoleforeningen.org/media/1526833/ProtokolStyrelsesmoede140618.pdf>, 06.04.2016.

Oltmer, Jochen (2007): Staat, Nation und Migration. Zur politischen Konstruktion von Minderheiten in der deutschen Geschichte. In: Schmidt-Lauber, Brigitta 
(Hg.): Ethnizität und Migration. Einführung in Wissenschaft und Arbeitsfelder. Berlin (Reimer Kulturwissenschaften), S. 134-154.

Opitz, Eckardt; Scheiblich, Reinhard (2002): Schleswig-Holstein. Das Land und seine Geschichte in Bildern, Texten und Dokumenten. 3. Aufl. Unter Mitarbeit von Regine Stützner und Dirk Brietzke. Hamburg.

Østergaard, Bent (1985): Nationalitetsfølelse og danskhed. In: Dansk Udsyn, Jg. 65, H. 3, S. 148-165.

Østergård, Uffe (1992): Europas ansigter. Nationale stater og politiske kulturer i en ny, gammel verden. Kopenhagen.

Østergård, Uffe (1998): Europa. Identitet og identitetspolitik. Kopenhagen.

Østergård, Uffe (2005): Stat, Nation og National Identitet. In: Andersen, Heine; Kaspersen, Lars Bo (Hg.): Klassisk og moderne Samfundsteori. 3. Aufl. Kopenhagen, S. 548-567.

Pan, Christoph (2016a): Die Minderheitenfrage in der Europäischen Union. In: Pan, Christoph; Pfeil, Beate Sibylle; Videsott, Paul (Hg.): Die Volksgruppen in Europa. Handbuch der europäischen Volksgruppen. Band 1. 2. Aufl. Wien, Berlin, S. 325-342.

Pan, Christoph (2016b): Die Minderheitenfrage in Europa. In: Pan, Christoph; Pfeil, Beate Sibylle; Videsott, Paul (Hg.): Die Volksgruppen in Europa. Handbuch der europäischen Volksgruppen. Band 1. 2. Aufl. Wien, Berlin, S. 221-234.

Pan, Christoph (2016c): Die nationale Frage als Schlüsselproblem des 20. Jahrhunderts. In: Pan, Christoph; Pfeil, Beate Sibylle; Videsott, Paul (Hg.): Die Volksgruppen in Europa. Handbuch der europäischen Volksgruppen. Band 1. 2. Aufl. Wien, Berlin, S. 235-252.

Pan, Christoph (2016d): Minderheitenschutz und Wirtschaft. In: Pan, Christoph; Pfeil, Beate Sibylle; Videsott, Paul (Hg.): Die Volksgruppen in Europa. Handbuch der europäischen Volksgruppen. Band 1. 2. Aufl. Wien, Berlin, S. 343-383.

Pan, Christoph; Pfeil, Beate Sibylle (2016): Einführung. In: Pan, Christoph; Pfeil, Beate Sibylle; Videsott, Paul (Hg.): Die Volksgruppen in Europa. Handbuch der europäischen Volksgruppen. Band 1. 2. Aufl. Wien, Berlin, S. 1-28.

Paszel, Helena (2005): Frauenleben in den zwei Kulturen der deutsch-dänischen Grenzstadt Flensburg nach dem Jahre 1945, dargestellt auf der Grundlage autobiographischer Schriften und Zeugnisse Birgit Hambach-Uldalls, Karin Johannsen-Bojsens und Ingeborg Philippsens. Warschau. 
Pedersen, Karen Margrethe (Hg.) (1990b): Sprache und Unterricht in der deutschen, dänischen und friesischen Minderheit. Vorträge der Tagung „Möglichkeiten des Unterrichts in den Minderheiten“. Foredrag fra konferencen „Veje inden for mindretalsundervisning“. 28.-30. September 1989, Knivsberg, Apenrade, Dänemark. Apenrade, Flensburg.

Pedersen, Karen Margrethe (2000a): Dansk sprog i Sydslesvig. Det danske sprogs status inden for det danske mindretal i Sydslesvig. 2 Bände. Apenrade (1).

Pedersen, Karen Margrethe (2000b): Dansk sprog i Sydslesvig. Det danske sprogs status inden for det danske mindretal i Sydslesvig. 2 Bände. Apenrade (2).

Pollack, Detlef; Laube, Martin; Liskowsky, Anne Elise (2014): Intensive Mitgliedschaftspraxis. In: Evangelische Kirche in Deutschland (Hg.): Engagement und Indifferenz. Kirchenmitgliedschaft als soziale Praxis. V. EKD-Erhebung über Kirchenmitgliedschaft. Hannover, S. 43-49.

Polm, Rita (1995): Minderheit. In: Schmalz-Jacobsen, Cornelia; Hansen, Georg (Hg.): Ethnische Minderheiten in der Bundesrepublik Deutschland. Ein Lexikon. München, S. 340-342.

Popova, Zora; Marken, Inga; Bădulescu, Lavinia (2016): Inter-Cultural Co-Existence and Cooperation: Is the Model of Schleswig-Holstein Transferrable. Hrsg. v. European Centre for Minority Issues (ECMI). (ECMI Working Paper, 94). <www.ecmi.de/publications/detail/94-intercultural-coexistence-and-cooperation-is-the-model-of-schleswig-holstein-transferrable-358>, 15.12.2017.

Poulsen, Bjørn (2013): Was trennte Schleswig von Holstein im späten Mittelalter? Vom frühen Nationalbewusstsein und Fürstentreue. In: Frandsen, Steen Bo; Krieger, Martin; Lubowitz, Frank (Hg.): 1200 Jahre deutsch-dänische Grenze. Tagungsband. Neumünster (Zeit + Geschichte, 28), S. 111-123.

Povlsen, Anne Krestina (2008): Kulturarv i et kulturteoretisk perspektiv. In: Jönsson, Lars-Eric; Wallette, Anna; Wienberg, Jes (Hg.): Kanon och kulturarv. Historia och samtid i Danmark och Sverige. Göteborg, Stockholm (Centrum för Danmarksstudier), S. 247-261.

Rasmussen, Carsten Porskrog (2008a): Die dänischen Könige als Herzöge von Schleswig und Holstein. In: Rasmussen, Carsten Porskrog; Imberger, Elke; Lohmeier, Dieter; Momsen, Ingwer (Hg.): Die Fürsten des Landes. Herzöge und Grafen von Schleswig, Holstein und Lauenburg. Neumünster, S. 73-109.

Rasmussen, Carsten Porskrog (2008b): Einleitung. In: Rasmussen, Carsten Porskrog; Imberger, Elke; Lohmeier, Dieter; Momsen, Ingwer (Hg.): Die Fürsten 
des Landes. Herzöge und Grafen von Schleswig, Holstein und Lauenburg. Neumünster, S. 11-27.

Rasmussen, Carsten Porskrog; Imberger, Elke; Lohmeier, Dieter, et al. (Hg.) (2008b): Die Fürsten des Landes. Herzöge und Grafen von Schleswig, Holstein und Lauenburg. Unter Mitarbeit von Inge Adriansen und Lennart S. Madsen. Neumünster.

Rasmussen, René (2009): Under Preussen. 1864-1945. In: Henningsen, Lars N. (Hg.): Sydslesvigs danske historie. Flensburg (Studieafdelingen ved Dansk Centralbibliotek for Sydslesvig, 62), S. 47-176.

Reddy, G. Prakash (1993): “Danes are like that!”. Perspectives of an Indian anthropologist on the Danish society. Mørke.

Reddy, G. Prakash ([2001]): Forenings-Danmark - set udefra. In: Børsch, Hanne; Egerod Israelsen, Annemette (Hg.): Foreningslivet i Danmark - Nye vilkår i en zappertid. Kopenhagen, S. 30-33.

Rein, Detlev (2014): Gewährung des Status einer öffentlich-rechtlichen Körperschaft an nationale Minderheiten. European Centre for Minority Issues (ECMI). (ECMI Working Paper, 76). $<$ www.ecmi.de/uploads/tx_lfpubdb/ECMI_Working_Paper_76.pdf>, 02.01.2018.

Rein, Detlev B.; Hilger, Ines (2008): Regional- und Minderheitensprachen in Deutschland. Hrsg. v. Bundesministerium des Innern, Referat Öffentlichkeitsarbeit. <www.bmi.bund.de>, 03.04.2017.

Reiterer, Albert F. (2007): Differenz und Diversität. Überlegungen zum Phänomen Ethnizität in Moderne und Postmoderne. In: Tschernokoshewa, Elka; Gransow, Volker (Hg.): Beziehungsgeschichten. Minderheiten - Mehrheiten in europäischer Perspektive. Bautzen (Schriften des Sorbischen Instituts, 42), S. 37-48.

Renan, Ernest (1947): CEuvres complètes de Ernest Renan. Tome I. Édition définitive établie par Henriette Psichari. Paris.

Renan, Ernest (1996): Was ist eine Nation. Rede am 11. März 1982 an der Sorbonne. Mit einem Essay von Walter Euchner. Hamburg (EVA-Reden, 20).

Rerup, Lorenz (1982): Danmarks Historie. Slesvig og Holsten efter 1830. Unter Mitarbeit von Svend Ellehøj und Kristof Glamann. [Kopenhagen].

Reuter, Astrid (2018): Praxeologie: Struktur und Handeln (Pierre Bourdieu). In: Pollack, Detlef; Krech, Volkhard; Müller, Olaf; Hero, Markus (Hg.): Handbuch Religionssoziologie. Wiesbaden (Veröffentlichungen der Sektion Religiosoziologie der Deutsche Gesellschaft für Soziologie), S. 171-202. 
Rheinheimer, Martin (2001): Lebenslauf, Generationen und Identität als Herausforderung der Geschichte. In: Rheinheimer, Martin (Hg.): Der Durchgang durch die Welt. Lebenslauf, Generationen und Identität in der Neuzeit. Neumünster (Studien zur Wirtschafts- und Sozialgeschichte Schleswig-Holsteins, 33), S. 7-19.

Rheinheimer, Martin (Hg.) (2006b): Grenzen in der Geschichte Schleswig-Holsteins und Dänemarks. Unter Mitarbeit von Robert Bohn, Uwe Danker und Karl Heinrich Pohl et al. Neumünster (Studien zur Wirtschafts- und Sozialgeschichte Schleswig-Holsteins, 42).

Riehl, Heinrich Wilhelm (1939): Die Naturgeschichte des deutchen Volkes. Unter Mitarbeit von Gunter Ipsen (Hrsg.). Leipzig.

Riesebrodt, Martin (2007): Cultus und Heilsversprechen. Eine Theorie der Religionen. München.

Robertson, C. Grant (1918): Bismarck. London (Makers ot the Nineteenth Century, [7]).

Roemheld, Regine (1983): Minorisierung als Herrschaftssicherung. Zur Innovationsfähigkeit des westdeutschen Parteiensystems. [Habilitationsschrift]. Frankfurt am Main, New York (Campus Forschung, 317).

Röh, Karin (2012): Statisterne. Erindringer fra Sydslesvig og tanker om den danske arv i landsdelen i dag. Kopenhagen.

Roland, Troels Peter (2016): Hinsides Markleddet. Dansk Grænselære og de store fortællinger. [Examensarbeit]. Kopenhagen.

Rolff, Hans-Günter (1997): Sozialisation und Auslese durch die Schule. Weinheim, München.

Rolshoven, Johanna (2003): Von der Kulturraum- zur Raumkulturforschung. Theoretische Herausforderungen an eine Kultur- und Sozialwissenschaft des Alltags. In: Zeitschrift für Volkskunde, Jg. 99, H. 2, S. 189-213.

Römhild, Regina (1998): Die Macht des Ethnischen: Grenzfall Rußlanddeutsche. Perspektiven einer politischen Anthropologie. Frankfurt am Main (Europäische Migrationsforschung, 2).

Römhild, Regina (2007): Fremdzuschreibungen - Selbstpositionierungen. Die Praxis der Ethnisierung im Alltag der Einwanderungsgesellschaft. In: SchmidtLauber, Brigitta (Hg.): Ethnizität und Migration. Einführung in Wissenschaft und Arbeitsfelder. Berlin (Reimer Kulturwissenschaften), S. 157-177. 
Roosens, Eugeen E. (1989): Creating ethnicity. The process of ethnogenesis. Newbury Park, London (Frontiers of anthropology, 5).

Roth, Alfred (1993): Das nationalsozialistische Massenlied. Untersuchungen zur Genese, Ideologie und Funktion. Würzburg (Epistemata. Würzburger Wissenschaftliche Schriften. Reihe Literaturwissenschaft, 112).

Roth, Juliana; Roth, Klaus (2001): Interkulturelle Kommunikation. In: Brednich, Rolf Wilhelm (Hg.): Grundriß der Volkskunde. Einführung in die Forschungsfelder der europäischen Ethnologie. 3. Aufl. Berlin (Ethnologische Handbücher), S. 391-422.

Ruane, Joseph; Todd, Jennifer (2004): The Roots of Intense Ethnic Conflict may not in fact be Ethnic: Categories, Communities and Path Dependence. In: European Journal of Sociology; Archives européennes de sociologie, Jg. 45, H. 2 , S. 209-232.

Ruane, Joseph; Todd, Jennifer (2010): Ethnicity and Religion. Redefining the Research Agenda. In: Ethnopolitics, Jg. 9, H. 1, S. 1-8.

Runge, Johann (1993): Die dänische Minderheit in Südschleswig. In: Hansen, Reimer; Johannsen, Peter Iver; Runge, Johann; Steensen, Thomas (Hg.): Minderheiten im deutsch-dänischen Grenzbereich. Kiel (Gegenwartsfragen, 69), S. 73-158.

Salonen, Kirsi (2016): Vatican Testimony of a German-Oriented Diocese of Schleswig. In: Bregnsbo, Michael; Jensen, Kurt Villads (Hg.): Schleswig Holstein - contested region(s) through history. Odense (University of Southern Denmark. Studies in History and Social Sciences, 520), S. 229-242.

Schäfer, Hilmar (2016): Einleitung. Grundlagen, Rezeption und Forschungsperspektiven der Praxistheorie. In: Schäfer, Hilmar (Hg.): Praxistheorie. Ein soziologisches Forschungsprogramm. Bielefeld (Sozialtheorie), S. 9-25.

Schaefer-Rolffs, Adrian; Schnapp, Kai-Uwe (2015): Dänische Minderheit deutlich größer als bisher angenommen. Ergebnisse der ersten repräsentativen Erhebung zur dänischen Minderheit im Norden Deutschlands. Hrsg. v. Universität Hamburg, Fakultät für Wirtschafts- und Sozialwissenschaften. <www.wiso.uni-hamburg.de/fileadmin/sowi/politik/methoden/WP_DDG_SizeDenMin_SH_20150325a_ASR.pdf>, 27.04.2015.

Scharff, Alexander (1969a): Deutsche Ordnungsgedanken zum volklichen Leben in Nordschleswig vor 1914. In: Jessen-Klingenberg, Manfred (Hg.): SchleswigHolstein in der deutschen und nordeuropäischen Geschichte. Gesammelte Aufsätze. Von Alexander Scharff. Stuttgart (Kieler Historische Studien, 6), S. 251-271. 
Scharff, Alexander (1969b): Schleswig-Holstein in der europäischen und nordischen Geschichte. In: Jessen-Klingenberg, Manfred (Hg.): Schleswig-Holstein in der deutschen und nordeuropäischen Geschichte. Gesammelte Aufsätze. Von Alexander Scharff. Stuttgart (Kieler Historische Studien, 6), S. 9-42.

Scharff, Alexander (1969c): Vom übernationalen zum nationalen Staat. Ursachen und Bedeutung des deutsch-dänischen Konflikts von 1864. In: Jessen-Klingenberg, Manfred (Hg.): Schleswig-Holstein in der deutschen und nordeuropäischen Geschichte. Gesammelte Aufsätze. Von Alexander Scharff. Stuttgart (Kieler Historische Studien, 6), S. 218-235.

Schatzki, Theodore R. (2016): Praxistheorie als flache Ontologie. In: Schäfer, Hilmar (Hg.): Praxistheorie. Ein soziologisches Forschungsprogramm. Bielefeld (Sozialtheorie), S. 29-44.

Scheer, Monique (Hg.) (2014): Bindestrich-Deutsche. Mehrfachzugehörigkeit und Beheimatungspraktiken im Alltag. Tübingen.

Schenk, Annemie (2001): Interethnische Forschung. Aktualisierung von Heike Müns. In: Brednich, Rolf Wilhelm (Hg.): Grundriß der Volkskunde. Einführung in die Forschungsfelder der europäischen Ethnologie. 3. Aufl. Berlin (Ethnologische Handbücher), S. 363-390.

Schiffauer, Werner (2002): Einleitung: Nationalstaat, Schule und politische Sozialisation. In: Schiffauer, Werner; Baumann, Gerd; Kastoryano, Riva; Vertovec, Steven (Hg.): Staat - Schule - Ethnizität. Politische Sozialisation von Immigrantenkindern in vier europäischen Ländern. Münster u. a. (Interkulturelle Bildungsforschung, 10), S. 1-19.

Schiffauer, Werner; Baumann, Gerd; Kastoryano, Riva, et al. (Hg.) (2002): Staat Schule - Ethnizität. Politische Sozialisation von Immigrantenkindern in vier europäischen Ländern. Münster, New York, München, Berlin (Interkulturelle Bildungsforschung, 10).

Schiffauer, Werner; Baumann, Gerd; Kastoryano, Riva, et al. (Hg.) (2004): Civil Enculturation. Nation-State, Schools, and Ethnic Difference in four European Countries. New York, Oxford.

Schlaber, Gerret Liebing (2016): Slagene i 1864 og deres skiftende betydning i tysk erindringskultur. In: Adriansen, Inge; Frandsen, Steen Bo (Hg.): Efter 1864. Krigens følger på kort og langt sigt. Odense (University of Southern Denmark. Studies in History and Social Sciences, 519; Skrifter udgivet af Museum Sønderjylland, 10), S. 243-264. 
Schleswig-Holstein (Hg.) (2017): Begleitprogramm Preussenausstellung. <www.schleswig-holstein.de/DE/Landesregierung/LASH/Service/Veranstaltungen/_documents/2017_Ankuendigungen/ausstellungPreussenBegleitprogramm.html>, 24.01.17.

Schleswig-Holsteinische Landesregierung (Hg.) (2016): Minderheiten in Schleswig-Holstein. Minderheitenbeauftrage des Ministerpräsidenten. <www.schleswig-holstein.de/DE/Fachinhalte/M/minderheiten/minderheiten_minderheitenbeauftragte.html>, 24.10.2016.

Schmalz-Jakobsen, Cornelia; Hansen, Georg; Polm, Rita (Hg.) (1997): Kleines Lexikon der ethnischen Minderheiten in Deutschland. Bonn.

Schmidt, Christiane (2000): Analyse von Leitfadeninterviews. In: Flick, Uwe; Kardorff, Ernst von; Steinke, Ines (Hg.): Qualitative Forschung. Ein Handbuch. Reinbek bei Hamburg (Rororo Rowohlts Enzyklopädie, 55628), S. 447-456.

Schmidt-Lauber, Brigitta (1996): „Wir sind doch Europäer“. Feldforschung in Namibia zur Konstruktion deutscher Identität. In: Kokot, Waltraud; Dracklé, Dorle (Hg.): Ethnologie Europas. Grenzen, Konflikte, Identitäten. Berlin (Ethnologische Paperbacks), S. 315-333.

Schmidt-Lauber, Brigitta (2000): Ethnizitätsstrategien im Alltag. Deutsche Namibier im Umgang mit Hausangestellten. In: Dekker, Ton; Helsloot, John; Wijers, Carla (Hg.): Roots \& Rituals. The Construction of Ethnic Identities. Selected Papers of the 6th SIEF Conference on "Roots \& Rituals", Amsterdam 20-25 April 1998. Amsterdam, S. 395-404.

Schmidt-Lauber, Brigitta (2001): Das qualitative Interview oder: Die Kunst des Reden-Lassens. In: Göttsch, Silke; Lehmann, Albrecht (Hg.): Methoden der Volkskunde. Positionen, Quellen, Arbeitsweisen der europäischen Ethnologie. Berlin (Ethnologische Paperbacks), S. 165-186.

Schmidt-Lauber, Brigitta (2003): Gemütlichkeit. Eine kulturwissenschaftliche Annäherung. Frankfurt am Main, New York.

Schmidt-Lauber, Brigitta (2007a): Ethnizität und Migration als ethnologische Forschungs- und Praxisfelder. Eine Einführung. In: Schmidt-Lauber, Brigitta (Hg.): Ethnizität und Migration. Einführung in Wissenschaft und Arbeitsfelder. Berlin (Reimer Kulturwissenschaften), S. 7-27.

Schmidt-Lauber, Brigitta (2007b): Maritime Denkmals(er)findung. Ein Küstenort inszeniert seine Geschichte. In: Fischer, Norbert; Müller-Wusterwitz, Susan; Schmidt-Lauber, Brigitta (Hg.): Inszenierungen der Küste. Berlin (Schriftenreihe der Isa-Lohmann-Siems-Stiftung, 1), S. 184-217. 
Schmitt, Heinz (1963): Das Vereinsleben der Stadt Weinheim an der Bergstraße. Volkskundliche Untersuchung zum kulturellen Leben einer Mittelstadt. Weinheim (Weinheimer Geschichtsblatt, 25).

Schneider, Jens (2001): Deutsch sein. Das Eigene, das Fremde und die Vergangenheit im Selbstbildnis des vereinten Deutschland. Frankfurt am Main.

Schöpflin, George (1997): The Functions of Myths and a Taxonomy of Myths. In: Hosking, Geoffrey; Schöpflin, George (Hg.): Myths and Nationhood. London, S. 19-35.

Schröder, Bernd (2012): Religionspädagogik. Tübingen (Neue theologische Grundrisse).

Schrøder, Emil (1995): Blikket blev rettet mod nord. In: Sønderjyske Årbøger, Jg. 39, S. 133-158.

Schulze, Theodor (2001): Rekonstruktion der Kindheit in autobiographischen Texten. In: Behnken, Imbke; Zinnecker, Jürgen (Hg.): Kinder. Kindheit. Lebensgeschichte. Ein Handbuch. Seelze-Velber, S. 167-181.

Schultz, Heinrich; Walde, Judith (2007): Das Recht auf Bildung der autochthonen, nationalen Minderheiten/Volksgruppen in Europa. 52. FUEV Nationalitätenkongreß vom 16.-20. Mai 2007 in Tallinn, Estland. Hrsg. v. d. Föderalistische Union Europäischer Volksgruppen (FUEV/FUEN) < www.fuen.org/filead$\mathrm{min} /$ user_upload/downloads/Das_Recht_auf_Bildung.pdf>, 09.01.2015.

Schwarz, Nerissa (2008): Minderheitenschutz in der Europäischen Union unter besonderer Berücksichtigung der Roma. In: Hentges, Gudrun; Hinnenkamp, Volker; Zwengel, Almut (Hg.): Migrations- und Integrationsforschung in der Diskussion. Biografie, Sprache und Bildung als zentrale Bezugspunkte. Wiesbaden, S. 111-138.

Schwering, Burkhard (1979): Nachbarschaften und Vereine in Ahaus. Studien zu Kultur und Bedeutung organisierter Gruppen. Münster (Beiträge zur Volkskultur in Nordwestdeutschland, 18).

Seifert, Manfred (2009): Begrenzte Ordnung - entgrenzte Dynamik. Der Faktor ,Raum`als Herausforderung an die Europäische Ethnologie. In: Lozoviuk, Petr (Hg.): Grenzgebiet als Forschungsfeld. Aspekte der ethnografischen und kulturhistorischen Erforschung des Grenzlandes. Leipzig (Schriften zur sächsischen Geschichte und Volkskunde, 29), S. 35-52.

Seifert, Manfred (2010): Das Projekt „Heimat“ - Positionen und Perspektiven. Zur Einführung. In: Seifert, Manfred (Hg.): Zwischen Emotion und Kalkül. 
,Heimat' als Argument im Prozess der Moderne. Leipzig (Schriften zur sächsischen Geschichte und Volkskunde, 35), S. 9-22.

Sekulić, Duško (2008): Ethnic Group. In: Schaefer, Richard T. (Hg.): Encyclopedia of race, ethnicity, and society. Volume 1. 3 Bände. Los Angeles (1), S. $456-459$.

Shove, Elizabeth; Pantzar, Mika (2016): Rekrutierung und Reproduktion. Karrieren und Träger von Digitalfotografie und Floorball. In: Schäfer, Hilmar (Hg.): Praxistheorie. Ein soziologisches Forschungsprogramm. Bielefeld (Sozialtheorie), S. 95-113.

Siewert, Hans-Jörg (1978): Freizeitverein und Gemeinde. In: Bühler, Walter; Kanitz, Horst; Siewert, Hans-Jörg (Hg.): Lokale Freizeitvereine. Entwicklung, Aufgaben, Tendenzen. St. Augustin (Werkbericht, 3), S. 143-183.

Sigaard-Madsen, Edith (1995): Die dänische Minderheit. In: Schmalz-Jacobsen, Cornelia; Hansen, Georg (Hg.): Ethnische Minderheiten in der Bundesrepublik Deutschland. Ein Lexikon. München, S. 134-152.

Skoleforening for Sydslesvig (2009a): Skolevedtægter. <www.skoleforeningen.org/Datasider/Skolevedtaegter.pdf, 13.11.2009>.

Skoleforening for Sydslesvig (2009b): Velkommen til Skoleforeningen. $<$ www.skoleforeningen.org>, 18.09.2009.

Skovmand, Sven (2006): Det danske mindretal i Sydslesvig og andre mindretal i Europa. Kopenhagen (Grænseforeningens årbog, 2007).

Smith, Anthony David (2009): The Ethnic Sources of Nationalism. In: Ganguly, Rajat (Hg.): Ethnic Conflict. Volume 1. Ethnic Identity. London u. a. (SAGE library of international relations), S. 295-307.

Snell, Gesa (1999): Deutsche Immigranten in Kopenhagen 1800-1870. Eine Minderheit zwischen Akzeptanz und Ablehnung. Münster u. a. (Internationale Hochschulschriften, 309).

Sökefeld, Martin (2007): Problematische Begriffe: »Ethnizität«, »Rasse«, »Kultur«, »Minderheit«. In: Schmidt-Lauber, Brigitta (Hg.): Ethnizität und Migration. Einführung in Wissenschaft und Arbeitsfelder. Berlin (Reimer Kulturwissenschaften), S. 31-50.

Sokolovskii, Sergey; Tishkov, Valery (2006): Ethnicity. In: Barnard, Alan; Spencer, Jonathan (Hg.): Encyclopedia of social and cultural anthropology. London, S. 190-193.

Sollors, Werner (1986): Beyond ethnicity. Consent and descent in American culture. New York. 
Søndergaard, Bent (1983): Öffnung ja - Identitätsverlust nein. Zur Problematik der deutsch-dänischen Minderheitenschulen. In: Grenzfriedenshefte, Jg. 30, H. 2, S. 84-89.

Sørensen, Ole Adrian (2008): Er de unge danske nok. In: Grænsen, H. 4, S. 4-7.

Spoorendonk, Anke (2001): Det danske sprog i Slesvig. In: Modersmål Selskabet (Hg.): Sprog og identitet. Kulturelt og politisk. Kopenhagen (Modersmål Selskabets årbog, 2001), S. 39-44.

Sprenger, Guido (2014): Unser Phantom Leitkultur. In: Bertels, Ursula (Hg.): Einwanderungsland Deutschland. Wie kann Integration aus ethnologischer Sicht gelingen. Münster u. a. (Praxis Ethnologie, 5), S. 53-65.

Stadt Flensburg: Bevölkerungsbestand. <www.flensburg.de/imperia/md/content/asp/flensburg/politik_verwaltung/daten-zahlen-fakten/2statistikengesamt/bevoelkerungsbestand.pdf $>, 29.11 .2009$.

Starke, Swea (2014): Zeitung als Zeichen. Identität und Mediennutzung nationaler Minderheit in Deutschland. Frankfurt am Main u. a.

Steigerwald, Jelena (2016): The Creation of Historical Material Realms of Memory within the Danish-German Borderland in the 19th and 20th Century. In: Bregnsbo, Michael; Jensen, Kurt Villads (Hg.): Schleswig Holstein - contested region(s) through history. Odense (University of Southern Denmark. Studies in History and Social Sciences, 520), S. 45-76.

Stenger, Horst (1998): Höher, reifer, ganz bei sich. Konversionsdarstellungen und Konversionsbedingungen im »New Age«. In: Knoblauch, Hubert; Krech, Volkhard; Wohlrab-Sahr, Monika (Hg.): Religiöse Konversion. Systematische und fallorientierte Studien in soziologischer Perspektive. Konstanz (Passagen \& Transzendenzen, 1), S. 195-222.

Stenger-Wullf, Bjarne (2012): Hverdagen for en Skoleleder. In: Oettingen, Alexander von; Komischke-Konnerup, Leo; Mikkelsen Buhl, Lisbet; Tästensen, Anke; Wagner, Michaela (Hg.): Mindretalspædagogik. Minderheitenpädagogik. Aarhus, S. 123-133.

Strachey, Lytton (1921): Queen Victoria. London, 1948 ('The Collected Works of Lytton Strachey).

Svensson, Inger Bjørn (1974): Dansk Kvindehverdag i Sydslesvig. Roskilde (Grænseforeningens Årbog, 1974).

Südschleswiger Wählerverband (SSW) (2017): SSW vor Ort. Nordfriesland. <www.ssw.de/de/ssw-vor-ort/nordfriesland.html>, 13.11.2017. 
Sydslesvigs danske Ungdomsforeninger SdU (2016a): Sydslesvigs danske Ungdomsforeningers vedtægter pr. 19. marts 2016. <www.sdu.de/fileadmin/content/Diverse/Dokumenter/2016/Vedtaegter_2016.pdf>, 07.07.2017.

Sydslesvigs danske Ungdomsforeninger SdU (2016b): Årsregnskab 2015. <www.sdu.de/fileadmin/content/Diverse/Dokumenter/2016/16AArsregnskab_2015.pdf>, 07.07.2017.

Sydslesvigsk Forening (a): Familiekursus: Sydslesvig - kom godt i gang!

25.02.2013. Sydslesvigsk Forening. <syfo.de/nyhedsoversigt/arkiv/singleview-archiv/artikel/familiekursus-sydslesvig-kom-godt-i-gang >, 11.04.2016.

Sydslesvigsk Forening (b): Kommentar 20.2.: Integrere de „nye“. 20.02.2013. Sydslesvigsk Forening. <syfo.de/nyhedsoversigt/arkiv/singleview-archiv/arti$\mathrm{kel} /$ kommentar-202-integrere-de-nye $>$, 31.03.2016.

Sydslesvigsk Forening (c): SSF Drage-Svavsted. < syfo.de/amter-distrikter/husum/distrikter/drage-svavsted $>$, 08.11.2016.

Sydslesvigsk Forening (d): SSF Frederiksstad. <syfo.de/amterdistrikter/husum/distrikter/frederiksstad>, 08.11.2016.

Sydslesvigsk Forening (e): St. Peter-Ording. < syfo.de/amter-distrikter/ejdersted$\mathrm{amt} /$ distrikter/st-peter-ording $>$, 29.07.2016.

Sydslesvigsk Forening (f): Udvalg. <syfo.de/om-ssf/struktur/udvalg>, 05.04.2016.

Sydslesvigsk Forening (g): Årtiers Årsmøder. <syfo.de/aarsmoede/historie>, 21.10.2016.

Sydslesvigsk Forening (2000): De danske i Sydslesvig. Et dansk mindretal udenfor Danmark. Flensburg.

Sydslesvigsk Forening (2009a): Årsmøderne. Sydslesvigsk Forening. <www.syfo.$\mathrm{de} /$ index.php?id=439>, 11.12.2009.

Sydslesvigsk Forening (2009b): Sydslesvigsk Forenings Vedtægter. <syfo.de/fileadmin/syfo/KUNDE/pdf/Vedtaegter_2009.pdf>, 22.11.2012.

Sydslesvigsk Forening (Hg.) (2010): Sydslesvigsk Årbog 2010. Dansk virke i grænselandet i 50 år. Flensburg (Sydslesvigsk Årbog, 50).

Sydslesvigsk Forening (Hg.) (2011): Sydslesvigsk Årbog 2011. Dansk virke i grænselandet. Flensburg (Sydslesvigsk Årbog, 51).

Sydslesvigsk Forening (Hg.) (2012): Sydslesvigsk Årbog 2012. Dansk virke i grænselandet i 50 år. Flensburg (Sydslesvigsk Årbog, 52). 
Sydslesvigsk Forening (2013a): Protokol fra Sydslesvigsk Forenings Landsmøde den 9. november 2013 på Husumhus i Husum. Hrsg. v. Sydslesvigsk Forening. Sydslesvigsk Forening. <syfo.de/fileadmin/syfo/KUNDE/pdf/protokol_2013.pdf>, 15.08.2016.

Sydslesvigsk Forening (Hg.) (2013b): Sydslesvigsk Årbog 2013. Dansk virke i grænselandet. Flensburg (Sydslesvigsk Årbog, 53).

Sydslesvigsk Forening (Hg.) (2014): Sydslesvigsk Årbog 2014. Dansk virke i grænselandet. Flensburg (Sydslesvigsk Årbog, 54).

Sydslesvigsk Forening (2017): Fanebærerkursus AFLYST. <syfo.de/index.php? $\mathrm{id}=1012 \&$ tx_ttnews[tt_news] $=6595 \&$ no_cache $=1 \& u t m \_$source $=S S F+$ nyheder\&utm_campaign $=33$ aa052bb6my_google_analytics_key\&utm_medium=email\&utm_term=0_df800bffea33aa052bb6-321313697>, 26.07.2017.

Sydslesvigsk Forening Drage-Svavsted (2011): Kom til julefest hos de danske i Drage-Svavsted. Hrsg. v. Sydslesvigsk Forening. Drage.

Sydslesvigsk Forening Drage-Svavsted (2012): Årsprogramm 2012. Drage.

Sydslesvigsk Forening Frederiksstad (2010): Sæsonprogramm 2010-2011. Friedrichstadt.

Sydslesvigsk Forening Frederiksstad (2011a): Aktivitetsprogram for andet halvår 2011. Friedrichstadt.

Sydslesvigsk Forening Frederiksstad (2011b): Årsprogramm for SSF Frederiksstad 2011-2012. Friedrichstadt.

Sydslesvigsk Forening Frederiksstad (2012): Årsprogramm 2012. Friedrichstadt.

Sydslesvigsk Forening Frederiksstad (2013): Årsprogramm 2013. Friedrichstadt.

Sydslesvigsk Forening Husum Amt: Velkommen i Sydslesvigsk Forening - i Husum amt og dit lokale distrikt. Husum.

Sydslesvigsk Forening Husum Amt (2013): Tag med SSF tilbage til 1864 og lær din historie at kende. Husum.

Sydslesvigudvalget; Dansk Centralbibliotek for Sydslesvig (2014): Resultataftale 2015 mellem Dansk Centralbibliotek for Sydslesvig og Sydslesvigudvalget.

Hrsg. v. Ministeriet for Børn, Undervisning og Ligestilling. <www.uvm.dk/-/media/UVM/Filer/Om-os/Sydslesvig-2015/150204Dansk-Centralbibliotek-2015.ashx>, 26.08.2016. 
Sydslesvigudvalget; Dansk Skoleforening for Sydslesvig (2015): Resultataftale mellem Dansk Skoleforening for Sydslesvig og Sydslesvigudvalget 2016. <www.skoleforeningen.org/media/3296950/Resultataftale-2016.pdf>, 25.04.2016.

Sydslesvigudvalget; Flensborg Avis (2014): Resultataftale 2015 mellem Flensborg Avis og Sydslesvigudvalget. Hrsg. v. Ministeriet for Børn, Undervisning og Ligestilling. <www.uvm.dk/-/media/UVM/Filer/Om-os/Sydslesvig2015/150204-Flensborg-Avis-2015.ashx>, 26.08.2016.

Sydslesvigudvalget; Sydslesvigsk Forening (2014): Resultataftale 2015 mellem Sydslesvigsk Forening og Sydslesvigudvalget. Hrsg. v. Ministeriet for Børn, Undervisning og Ligestilling. <www.uvm.dk/-/media/UVM/Filer/Omos/Sydslesvig-2015/150204-Sydslesvigsk-Forening-2015.ashx>, 24.08.2016.

Sydslesvigudvalget; Sydslesvigsk Vælgerforening (2014): Resultataftale 2015 mellem Sydslesvigsk Vælgerforening (SSW) og Sydslesvigudvalget. Hrsg. v. Ministeriet for Børn, Undervisning og Ligestilling.

<www.uvm.dk/-/media/UVM/Filer/Om-os/Sydslesvig-2015/150204-Sydslesvigsk-Vaelgerforening-2015.ashx>, 24.08.2016.

Teebken, Andrea (2006): Räumliche und mentale Grenzziehung im 19. Jahrhundert. Der Sprachenkampf im Herzogtum Schleswig. In: Rheinheimer, Martin (Hg.): Grenzen in der Geschichte Schleswig-Holsteins und Dänemarks. Neumünster (Studien zur Wirtschafts- und Sozialgeschichte Schleswig-Holsteins, 42), S. 353-366.

Terray, Emmanuel (1995): Das Wirkliche und das Mögliche. Handeln und Identität, Nation und Emotion aus der Perspektive des Anthropologen. In: François, Etienne; Siegrist, Hannes; Vogel, Jakob (Hg.): Nation und Emotion. Deutschland und Frankreich im Vergleich. 19. und 20. Jahrhundert. Göttingen (Kritische Studien zur Geschichtswissenschaft, 110), S. 383-388.

Thaler, Peter (2006): An den Grenzen des Selbst. Die dänische Minderheit in Südschleswig aus komparativer Sicht. In: Rheinheimer, Martin (Hg.): Grenzen in der Geschichte Schleswig-Holsteins und Dänemarks. Neumünster (Studien zur Wirtschafts- und Sozialgeschichte Schleswig-Holsteins, 42), S. 405-415.

Thaler, Peter (2007): A Tale of Three Communities. National Identification in the German-Danish Borderlands. In: Scandinavian Journal of History, Jg. 32, H. 2, S. 141-166. $<$ han.sub.uni-goettingen.de/han/4417/www.tandfonline.com/doi/pdf/10.10 80/03468750601159840>, 30.05.2012.

Thaler, Peter (2009): Of Mind and Matter. The Duality of National Identity in the German-Danish Borderlands. West Lafayette. 
Thaler, Peter (2013): Wie Tau in der Sonne. Die deutsche Minderheit in Dänemark in ihrem politischen und historischen Rahmen. In: Austausch, Jg. 2, H. 1, S. 21-41. <www.psa.ac.uk/sites/default/files/Die\%20deutsche\%20Minderheit $\% 20$ in $\% 20$ D $\%$ C3\%A4nemark $\% 20-\% 20$ Peter $\% 20$ Thaler_0.pdf $>$, 29.01.2016.

Therkelsen, Knud-Erik (2011): Meningsdiktatur i Sydslesvig. Hrsg. v. Grænsen.dk. $<$ www.graenseforeningen.dk/?q=node/10610>, 06.09.2013.

Thürer, Daniel (2015): Nationale Minderheiten und das Völkerrecht: Aktuelle Probleme und mögliche Lösungen. In: Hofmann, Rainer; Angst, Doris; Lantschner, Emma; Rautz, Günther; Rein, Detlev (Hg.): Rahmenübereinkommen zum Schutz nationaler Minderheiten. Handkommentar. Baden-Baden (NomosKommentar), S. 46-51.

Toivanen, Reetta (2001): Minderheitenrechte als Identitätsressource. Die Sorben in Deutschland und die Saamen in Finnland. Münster u. a. (Zeithorizonte. Perspektiven Europäischer Ethnologie, 6).

Toren, Christina (2006): socializsation. In: Barnard, Alan; Spencer, Jonathan (Hg.): Encyclopedia of social and cultural anthropology. London, S. 512-514.

Trenz, Klara (1937): Wilhelm Heinrich Riehls "Wissenschaft vom Volke" unter besonderer Heranziehung seiner Darstellung des saarpfälzischen Volkstums. Berlin (Neue Deutsche Forschungen. Abteilung Neuere Geschichte, 5).

Tschernokoshewa, Elka (2007): Beziehungsgeschichten: Fünf einleitende Thesen. In: Tschernokoshewa, Elka; Gransow, Volker (Hg.): Beziehungsgeschichten. Minderheiten - Mehrheiten in europäischer Perspektive. Bautzen (Schriften des Sorbischen Instituts, 42), S. 11-23.

Tschernokoshewa, Elka; Gransow, Volker (Hg.) (2007): Beziehungsgeschichten. Minderheiten - Mehrheiten in europäischer Perspektive. Bautzen (Schriften des Sorbischen Instituts, 42).

Tschernokoshewa, Elka; Keller, Ines (Hg.) (2011b): Dialogische Begegnungen. Minderheiten - Mehrheiten aus hybridologischer Sicht. Münster u. a. (Hybride Welten, 5).

Tschernokoshewa, Elka; Kramer, Dieter (Hg.) (2001): Der alltägliche Umgang mit Differenz. Bildung - Medien - Politik. Münster u. a. (Hybride Welten, 2).

Tschernokoshewa, Elka; Kramer, Dieter (2001): Einleitung: Anderssein und doch dazugehören. In: Tschernokoshewa, Elka; Kramer, Dieter (Hg.): Der alltägli- 
che Umgang mit Differenz. Bildung - Medien - Politik. Münster u. a. (Hybride Welten, 2), S. 7-17.

Tschernokoshewa, Elka; Mischek, Udo (Hg.) (2009b): Beziehungsgeflecht Minderheit. Zum Paradigmenwechsel in der Kulturforschung, Ethnologie Europas. Münster u. a.

Tucholsky, Kurt (1997): Das Mitglied. In: Tucholsky, Kurt (Hg.): Gesammelte Werke in zehn Bänden. Reinbek bei Hamburg (4), S. 455-456.

Turner, Victor W. (1969): Das Ritual. Struktur und Anti-Struktur. Frankfurt am Main, New York, 2000.

Udlændinge-, Integrations- og Boligministeriet - Infødsretskontoret (Hg.) (2015): Notat. Oversigt over hovedpunkterne i den nye aftale om dansk indfødsret af 5. oktober 2015. <uim.dk/filer/nyheder-2015/informationstekst-om-den-nyeaftale-om-indfoedsret.pdf $>$, 09.12.2017.

Ulmer, Bernd (1990): Die autobiographische Plausiblilität von Konversionserzählungen. In: Sparn, Walter (Hg.): Wer schreibt meine Lebensgeschichte. Biographie, Autobiographie, Hagiographie und ihre Entstehungszusammenhänge. Gütersloh, S. 287-295.

Unterweger, Gisela (2002): Klasse und Kultur. Verhandelte Identitäten in der Schule. Zürich (Zürcher Beiträge zur Alltagskultur, 12).

Vanghardt, Rasmus (2011): Formand for SSF anerkender ikke påstand om meningsdiktatur. Hrsg. v. Grænsen.dk.

<www.graenseforeninge.dk/node/10644>, 06.09.2013.

Vanghardt, Rasmus (2013): Pensioneret lærer kritiserer mindretallet hårdt. Hrsg. v. Grænsen.dk. <www.graenseforeningen.dk/?q=node/12661>,06.09.2013.

Vollertsen, Nils (1993): Dansk i en tysk stat 1945-1992. Kopenhagen (Grænseforeningens årbog, 1993).

Vollertsen, Nils (1994a): Det danske mindretal. En række studier om det danske i en tysk stat. Odense (Odense University. Studies in History and Social Sciences, 175).

Vollertsen, Nils (1994b): Sydslesvig. En landsdel i nationalt opbrud 1945-48. Odense (Odense University. Studies in History and Social Sciences).

Vosgerau, Gisbert (1990): Die deutsche Minderheit in Nordschleswig und die dänische Minderheit in Südschleswig. Ein soziologischer Vergleich. Diplomarbeit im Rahmen der Prüfung für Diplom-Pädagogen an der Universität der Bundeswehr Hamburg. Unveröffentlicht. Hamburg. 
Weber, Caroline Elisabeth (2015): »1000 Jahre dänisch-deutsche Beziehungen? Forschung und Perspektiven«. Symposium im Internationalen Begegnungszentrum der Christian-Albrechts-Universität zu Kiel, zusammen mit der Syddansk Universitet, in Kiel, 16. bis 17. Januar 2015. In: Militärgeschichtliche Zeitschrift, Jg. 74, H. 1-2, S. 195-201.

$<$ www.degruyter.com/view/j/mgzs.2015.74.issue-1-2/mgzs-2015-0011/mgzs2015-0011.xml>, 21.03.20127.

Weber, Max (1911): Geschäftsbericht. In: Deutsche Gesellschaft für Soziologie (Hg.): Verhandlungen des Ersten Deutschen Soziologentages vom 19.-22. Oktober 1910 in Frankfurt a. M. Reden und Vorträge von Georg Simmel, Ferdinand Tönnies, Max Weber, Werner Sombart, Alfred Ploetz, Ernst Troeltsch, Eberhard Gothein, Andreas Voigt, Hermann Kantorowicz und Debatten. Tübingen (Schriften der Deutschen Gesellschaft für Soziologie. I. Serie: Verhandlungen der Deutschen Soziologentage, 1), S. 39-62.

Weber, Max (2002): Wirtschaft und Gesellschaft. Grundriss der verstehenden Soziologie. 5. Aufl. Unter Mitarbeit von Johannes Winckelmann. Tübingen, 2002.

West, Candace; Zimmermann, H. Don (1991): Doing Gender. In: Lorber, Judith; Farrell, Susan A. (Hg.): The Social Construction of Gender. Newbury Park, London, New Delhi, S. 13-37.

Wiezorek, Christine (2005): Schule, Biografie und Anerkennung. Eine fallbezogene Diskussion der Schule als Sozialisationsinstanz. Wiesbaden (Studien zur Jugendforschung, 26).

Witzel, Andreas (2000): Das problemzentrierte Interview. In: Forum Qualitative Sozialforschung/Forum: Qualitative Social Research, Jg. 1, H. 1. <qualitativeresearch.net/fqs $>$, 13.05.2008.

Wohlrab-Sahr, Monika (1995): Das Unbehagen im Körper und das Unbehagen in der Kultur. Überlegungen zum Fall einer Konversion zum Islam. In: WohlrabSahr, Monika (Hg.): Biographie und Religion. Zwischen Ritual und Selbstsuche. Frankfurt am Main, S. 285-311.

Wohlrab-Sahr, Monika; Krech, Volkhard; Knoblauch, Hubert (1998): Religiöse Bekehrung in soziologischer Perspektive. Themen, Schwerpunkte und Fragestellungen der gegenwärtigen religionssoziologischen Konversionsforschung. In: Knoblauch, Hubert; Krech, Volkhard; Wohlrab-Sahr, Monika (Hg.): Religiöse Konversion. Systematische und fallorientierte Studien in soziologischer Perspektive. Konstanz (Passagen \& Transzendenzen, 1), S. 7-43. 
Wolff, H. Ekkehard (2017): Sprachen und „,nationale Minderheiten“ in Afrika. Kann Europa daraus etwas lernen. In: Steensen, Thomas (Hg.): Nationale Minderheiten. Beiträge vom 9. Internationalen Ferdinand-Tönnies-Symposium. Bräist/Bredstedt (Nordfriisk Instituut, 249), S. 83-99.

Wulf, Peter (2003a): Revolution, schwache Demokratie und Sieg in der „Nordmark". Schleswig-Holstein in der Zeit der Weimarer Republik. In: Lange, Ulrich (Hg.): Geschichte Schleswig-Holsteins. Von den Anfängen bis zur Gegenwart. 2. Aufl. Neumünster, S. 545-584.

Wulf, Peter (2003b): Zustimmung, Mitmachen, Verfolgung und Widerstand. Schleswig-Holstein in der Zeit des Nationalsozialismus. In: Lange, Ulrich (Hg.): Geschichte Schleswig-Holsteins. Von den Anfängen bis zur Gegenwart. 2. Aufl. Neumünster, S. 585-621.

Yildiz, Erol (2007): Umgang mit Differenz. Die Migrationsgesellschaft im Kontext globaler Öffnungsprozesse. In: Tschernokoshewa, Elka; Gransow, Volker (Hg.): Beziehungsgeschichten. Minderheiten - Mehrheiten in europäischer Perspektive. Bautzen (Schriften des Sorbischen Instituts, 42), S. 49-62.

Yüksekkaya, Mehmet (2002): Sydslesvigs danske historie. Kopenhagen (Grænseforeningens årbog, 2002).

Zimmermann, Peter (2006): Grundwissen Sozialisation. Einführung zur Sozialisation im Kindes- und Jugendalter. 3. Aufl. Wiesbaden.

\subsubsection{Zeitungsartikel}

Andersen, Uffe (26.05.2017): Flugten fra det fælles. Kronik. In: Flensborg Avis, Jg. 149, S. 24.

Auring, Hans Reinhold (17.12.1998): Hvad er det at være dansk. In: Flensborg Avis, Jg. 129, S. 10.

Bittlinger, Levke (03.09.2012): Fordringer om frihed og ansvar, Heimat og engagement. Kronik. In: Flensborg Avis, Jg. 144, S. 20.

Bohm, Henry (25.06.2016): Der mangler engagement. Kronik. In: Flensborg Avis, Jg. 148, S. 21.

Bornemann, Merle (13.09.2012): „Studium Sorgenfrei“ in Dänemark. Unsere nördlichen Nachbarn unterstützen ihre Studenten mit großzügigen Summen auch einige Deutsche nutzen diese Chance. In: Husumer Nachrichten, S. 22.

Boysen, Thede (15.03.2016): De danske skoler er forlængst blevet til rene sprogskoler. [Leserbrief]. In: Flensborg Avis, Jg. 148, S. 20. 
Bruhn, Mads (02.11.2012): Efterlyser en bred integrationspolitik. In: Flensborg Avis, Jg. 144, S. 5.

Bruhn, Mads (12.11.2012): De nye skal tages ved hånden. In: Flensborg Avis, Jg. 144, S. 6.

Bruhn, Mads (07.12.2012): Sydslesvig kalder til årsmøder. In: Flensborg Avis, Jg. 144, S. 5.

Danker, Uwe (05.08.2006): Südschleswig 1945 bis 1955. Von Speckdänen und großer Politik. Die Schleswig-Holstein-Story, 8. In: Husumer Nachrichten, S. 4-5.

Dansk Skoleforening for Sydslesvig (09.06.2012): En god koalitionsaftale for Skoleforeningens børn. Ligestilling. In: Fokus. Din medlemsavis. Flensborg Avis, Jg. 144, S. 1-2.

Dansk Skoleforening for Sydslesvig (24.12.2016): »Det særlige ansvar«. In: Fokus. Din medlemsavis. Flensborg Avis, Jg. 148, S. 2.

Davidsen, Hans Christian (12.04.2014): Forfatter: SSW bedrev nordkoreansk propaganda. In: Flensborg Avis, Jg. 146, S. 1.

Dechange, Marcus (23.08.2012): Må skoleforeningen kontrollere sindelaget. Læserne mener. In: Flensborg Avis, Jg. 144, S. 9.

Dibbern, Nikki (06.09.2012): Reaktion på brev om søskende-reglen. Læserne mener. In: Flensborg Avis, Jg. 144, S. 9.

Dibbern, Wolfgang (15.08.2007): Dansk og tysk - en hjertesag. Kronik. In: Flensborg Avis, Jg. 139, S. 8.

Dittrich, Per (14.07.2006a): Man skal være enig for at kunne samle mindretallet. In: Flensborg Avis, Jg. 139, S. 4-5.

Dittrich, Per (14.07.2006b): Medlemmerne skal også med. In: Flensborg Avis, Jg. 139, S. 1.

dpa (24.12.2012): Skoleforening sieht die Zukunft positiv. In: Flensborg Avis, Jg. 144, S. 14.

Dürr, Henrik (02.01.2014): Vigtigt at mindretallets unge føler et ansvar. In: Flensborg Avis, Jg. 146, S. 5, 21.06.2016.

FLA (15.01.2014): Fanebærere kan tage uddannelse. In: Flensborg Avis, Jg. 146, S. 7. 


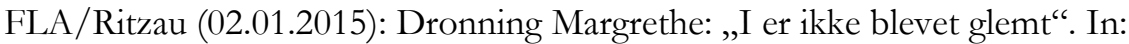
Flensborg Avis, Jg. 147, S. 1.

Flamming, Trine (01.03.2014): Flytning giver sorte pletter på landkortet. In: Flensborg Avis, Jg. 146, S. 6.

Flensborg Avis (12.08.2013): Skolestart på Hans-Helgesen-Skolen. In: Flensborg Avis, Jg. 145, S. 7.

Hansen, Jon Hardon (14.07.2016): Sydslesvig rager alle. In: Kontakt. Sydslesvigsk Forenings informationsblad/Flensborg Avis, Jg. 148, S. 4.

Hansen, Jon Hardon (21.07.2016): Mindretallet er en del af Danmark. In: Kontakt. Sydslesvigsk Forenings informationsblad/Flensborg Avis, Jg. 148, S. 2.

Hansen, Jon Hardon (12.01.2017): Nytårshilsen fra Sydslesvig. Bragt i DR Syd. In: Kontakt. Sydslesvigsk Forenings informationsblad/Flensborg Avis, Jg. 149, S. 1.

Hansen, Jon Hardon (09.03.2017): Mindretallets mission og vision. Kronik. In: Flensborg Avis, Jg. 149, S. 8.

Hansen, Peter (19.05.2016): Fik ny næstformand. In: Kontakt. Sydslesvigsk Forenings informationsblad/Flensborg Avis, Jg. 148, S. 3.

Heidtmann, Harald (23.08.2012): Urimeligt at smide børn ud af mindretallet. Læserne mener. In: Flensborg Avis, Jg. 144, S. 9.

Hoop, Katrine (01.03.2014): Uden patent. Ugerevyen. In: Flensborg Avis, Jg. 146, S. 21.

Hougaard-Werner, Gitte (12.06.2013): Derfor kalder Sydslesvig. Årsmødetale Askfeld/Ascheffel Danske Skole og Vestejderstedhallen Garding. Kronik. In: Flensborg Avis, Jg. 145, S. 19.

Huber, Peter (22.11.2013): Nationales Hütchenspiel. Synspunkt. In: Flensborg Avis, Jg. 145, S. 8.

Huber, Peter (10.10.2014): Sindelagspoliti. [Leserbrief]. In: Flensborg Avis, Jg. 146, S. 13.

Iwersen, Uwe; Wasmund, Sara (25.06.2016): Grænselandet. Historier og Historien. In: Flensborg Avis, Jg. 148, S. 8.

Jacobsen, Viggo (26.11.2013): Dansk Kirke i Sydslesvig. 1. del. In: Flensborg Avis, Jg. 145, S. 19.

Jessen, Udo (28.05.2016): Styrelsen: Stem på Simon Faber. In: Fokus. Din medlemsavis. Flensborg Avis, Jg. 148, S. 2. 
Johannsen, Holger (12.09.2003): Mit liv begynte i den danske skole. In: Flensborg Avis, Jg. 135, S. 7.

Johannsen, Holger (04.11.2014): Sydslesvigs bygmester fylder 90 år i dag. In: Flensborg Avis, Jg. 146, S. 9.

Johannsen, Holger (15.02.2017): Ny debat om doppelt statsborgerskab. In: FLA, Jg. 149, S. 5.

Johannsen, Holger (14.11.2017): Mindretallenes Hus stadig i live. In: Flensborg Avis, Jg. 149, S. 3.

Klausen, Søren Harnow (06.07.2016): Mindretalsidentitet og sindelag. 1. del. Kronik. In: Flensborg Avis, Jg. 148, S. 20.

Klausen, Søren Harnow (07.07.2016): Mindretalsidentitet og sindelag. 2. del. Kronik. In: Flensborg Avis, Jg. 148, S. 8.

Krarup, Søren (09.02.2013): Dansk og tysk. Kronik. In: Flensborg Avis, Jg. 145, S. 20 .

Kring, Anders (15.06.2016): Fleksible grænser. Kronik. In: Flensborg Avis, Jg. 148, S. 20.

Kring, Jens (17.09.2014): Udmeldt! Debat. In: Flensborg Avis, Jg. 146, S. 19.

Krogh, Niels Ole (11.01.2016): SSF-formand: Forsamlingshuse trænger til en støvekost. In: Flensborg Avis, Jg. 148, S. 4.

Krueger, Raning (20.09.2012): Enighed om krav til forældre. In: Flensborg Avis, Jg. 144, S. 1.

Kühl, Jørgen (23.09.2006): Hvem er det danske mindretal. Ugerevyen. In: Flensborg Avis, Jg. 138, S. 2.

Kühl, Jørgen (16.06.2016): Mindretallet som forpligtende fællesskab. Årsmødetale på Medelby Danske Skole, 10.06.2016. Kronik. In: Flensborg Avis, Jg. 148, S. 20 .

Kühl, Jørgen (27.07.2016): Nationalt mindretal eller sindelagsmindretal. 1. del. Kronik. In: Flensborg Avis, Jg. 148, S. 20.

Kühl, Jørgen (28.07.2016): Nationalt mindretal eller sindelagsmindretal. 2. del. Kronik. In: Flensborg Avis, Jg. 148, S. 8.

Küssner, Dieter Paul (27.06.2013): Storfamilien fungerer. In: Kontakt. Sydslesvigsk Forenings informationsblad/Flensborg Avis, Jg. 145, S. 1. 
Küssner, Dieter Paul (16.06.2014): Skæbnefællesskabet. In: Flensborg Avis, Jg. 146, S. 21.

Küssner, Dieter Paul (22.06.2016): Dobbeltkulturelle borgere. Årsmødetale 11.06.2016, Hattstedt. Kronik. In: Flensborg Avis, Jg. 148, S. 20.

Lorenzen, Martin (30.06.2015): Klø er bedre end tavshed. Årsmødetale 20.06.2015, Jørgensby-Skolen, Flensburg. Kronik. In: Flensborg Avis, Jg. 147, S. 19.

Lund, Lene (06.04.2017): Tallene trak i Hella. In: Flensborg Avis, Jg. 149, S. 6.

Matlok, Siegfried (12.11.2013): Leitartikel: Pardon, Hardon. In: Nordschleswiger, Jg. 70. <www.nordschleswiger.dk/SEEMS/19979.asp?artid=60742>, 13.11.2013.

Meyer, Flemming; Küssner, Dieter Paul (23.05.2013): Vi har brug for din støtte stem på SSW. In: Kontakt. Sydslesvigsk Forenings informationsblad/Flensborg Avis, Jg. 145, S. 24.

Meyer, Rasmus (14.05.2016): Lærere bør være medlemmer. In: Flensborg Avis, Jg. 148, S. 8.

Møllekær, Jørgen (24.12.2013): En samtale mellem redaktører. Om avisdrift, dyre kaffevaner, tysk forvaltningskultur, den fortsatte kamp for ligeberettigelse og den langsigtede betydning af fødselrater i Danmark und Tyskland. In: Flensborg Avis, Jg. 145, S. 7.

Møllekær, Jørgen (16.06.2014): Så tag dog debatten. Dagens leder. In: Flensborg Avis, Jg. 146, S. 20.

Møllekær, Jørgen (18.06.2014): Ret og pligt inføres i Sydslesvig. Leder. In: Flensborg Avis, Jg. 146, S. 14.

Møllekær, Jørgen (05.11.2014): Det er blevet alt for let at være mindretal. Leder. In: Flensborg Avis, Jg. 146, S. 13.

Mølvig, Annelise (17.10.2012): Misforhold mellem fortid og nutid. In: Flensborg Avis, Jg. 144, S. 5.

Mølvig, Annelise (09.04.2014): En skildring af identitetskrise med en duft af gamle lavendler. In: Flensborg Avis, Jg. 146, S. 6-7.

Mølvig, Annelise (08.07.2014): Svært at få de små passet efter klokken 16. In: Flensborg Avis, Jg. 146, S. 3.

Mølvig, Annelise (06.08.2016): Feriebørnene styrker dansk identitet i mindretallet. In: Flensborg Avis, Jg. 148, S. 4. 
Mølvig, Annelise (22.10.2016): Generalsekretær: Nødvendigt med fælles sprogpolitik. In: Flensborg Avis, Jg. 148, S. 5.

Munk Nielsen, Mette (23.08.2012): Søskende-regel giver Facebook-debat. In: Flensborg Avis, Jg. 144, S. 8.

Nielsen, Flemming (03.05.2014): Er mindretallet i gang med harakiri. Selvmord. Sådan tager dansk mindretal stille og roligt livet af sig selv. Kronik. In: Flensborg Avis, Jg. 146, S. 23.

Nielsen, Hans-Otto (27.03.2014): Tiltrængt oprydning i mindretallet. Kommentar. In: Flensborg Avis, Jg. 146, S. 19.

Nissen, Mogens R.; Petersen, Lars Feldballe (07.04.2014a): De glemte danskere. Kronik. In: Flensborg Avis, Jg. 146, S. 21.

Nissen, Mogens R.; Petersen, Lars Feldballe (07.04.2014b): De glemte danskere. Kronik. In: Flensborg Avis, Jg. 146, S. 21.

Nissen, Mogens Rostgaard (05.06.2013): Det første årsmøde. Kronikker om årsmøderne. Del 1. In: Flensborg Avis, Jg. 145, S. 10.

Nissen, Mogens Rostgaard (07.06.2013): Årsmøderne i mellemkrigstiden. Kronikker om årsmøderne. Del 2. In: Flensborg Avis, Jg. 145, S. 10.

Nissen, Mogens Rostgaard (08.06.2013): De første årsmøder efter Anden Verdenskrig. Kronikker om årsmøderne. Del 3. In: Flensborg Avis, Jg. 145, S. 10.

Nissen, Mogens Rostgaard (23.03.2017): Karl Otto Meyer - lærerstuderende og politisk aktivist. Kronik. In: Kontakt. Sydslesvigsk Forenings informationsblad/Flensborg Avis, Jg. 149, S. 8.

Nygaard, Jens (14.03.2013): En fantastisk chance for mindretallet og Sydslesvig. In: Flensborg Avis, Jg. 145, S. 8.

Nygaard, Jens (29.06.2013): Skarp kritik af det danske mindretal. In: Flensborg Avis, Jg. 145, S. 6.

Nygaard, Jens (12.10.2013): En ny begyndelse efter 1920. LoS. Lær om Sydslesvig. In: Flensborg Avis, Jg. 145, S. 7.

Nygaard, Jens (11.01.2014): Det skulle være så godt... og så var det faktisk skidt. LoS. Lær om Sydslesvig. In: Flensborg Avis, Jg. 146, S. 10.

Nygaard, Jens (22.02.2014): En dansk skole i Tyskland. LoS - Lær om Sydslesvig. In: Flensborg Avis, Jg. 146, S. 10. 
Nygaard, Jens (12.04.2014): Det danske bibliotek. In: Flensborg Avis, Jg. 146, S. 11.

Nygaard, Jens (11.05.2014): „I skal ikke blive glemt““. In: Flensborg Avis, Jg. 146, S. 11 .

Nygaard, Jens (24.05.2014a): Dansk - også efter skolen. In: Flensborg Avis, Jg. 146, S. 11.

Nygaard, Jens (24.05.2014b): De unges foreninger. LoS. Lær om Sydslesvig. In: Flensborg Avis, Jg. 146, S. 11.

Nygaard, Jens (07.06.2014a): Det danske mindretal taler tysk derhjemme. In: Flensborg Avis, Jg. 146, S. 11.

Nygaard, Jens (07.06.2014b): Sprogene i grænselandet. In: Flensborg Avis, Jg. 146, S. 11.

Nygaard, Jens (11.06.2014): Kraftig debat om de danske sydslesvigeres hjemmesprog. In: Flensborg Avis, Jg. 146, S. 2.

Nygaard, Jens (04.07.2014a): Børnehaver i Drage og Frederiksstad vil også sammenlægges. In: Flensborg Avis, Jg. 146, S. 7.

Nygaard, Jens (04.07.2014b): De siger faktisk: I er ikke danskere. In: Flensborg Avis, Jg. 146, S. 1.

Nygaard, Jens (13.12.2014): Hvorfor skulle vi dog forstille os. In: Flensborg Avis, Jg. 146, S. 8-9.

Nygaard, Jens (10.06.2015): Holgers vidunderlige rejse. In: Flensborg Avis, Jg. 147, S. 8-9.

Nygaard, Jens (18.01.2017a): Medlemskab blev til bestyrelsespost. In: Flensborg Avis, Jg. 149, S. 3.

Nygaard, Jens (18.01.2017b): Meget svært at blive dansk statsborger. In: Flensborg Avis, Jg. 149, S. 3.

Nygaard, Jens (23.12.2017): Lidt flere statspenge til det danske mindretal. In: Flensborg Avis, Jg. 149, S. 2.

Oettingen, Alexander von (05.09.2012): Mindretalsskolen mellem offentlighed og det private. Kronik. In: Flensborg Avis, Jg. 144, S. 19.

Pastorff, André (08.09.2012): Debatten om søskende-reglen. Debat. In: Flensborg Avis, Jg. 144, S. 8.

Peetz, Marc (27.04.2013): Recepten på et langt liv er en god cigar. In: Flensborg Avis, Jg. 145, Ausgabe 146, S. 7. 
Peetz, Marc (24.01.2014): Efterlyser ærlighed i mindretallet. In: Flensborg Avis, Jg. 146, S. 24.

Peetz, Marc (18.06.2014): Krav til forældre skal til debat. In: Flensborg Avis, Jg. 146, S. 9 .

Rasmussen, Poul Nyrup (07.10.2014): Lad os revitalisere vort samarbejde. Læserbrevet. In: Flensborg Avis, Jg. 146, S. 20.

Rebsdorf, Tilla (25.06.2012): Mindretalle havde inviteret de tyske naboer på besøg. In: Flensborg Avis, Jg. 144, S. 6.

Rebsdorf, Tilla (31.05.2013): Mindretallet på film. In: Flensborg Avis, Jg. 145, S. 2.

Rebsdorf, Tilla (15.06.2016a): Opsang om sproget giver genlyd på internettet. In: Flensborg Avis, Jg. 148, S. 1.

Rebsdorf, Tilla (15.06.2016b): Sydslesvigdansk rækker ikke til uddannelser. In: Flensborg Avis, Jg. 148, S. 3.

Rebsdorf, Tilla (07.07.2016): De snakker jo alligevel alle tysk sammen. In: Flensborg Avis, Jg. 148, S. 3.

Reese, Marc (21.08.2012): Ingen vaklen hos Skoleforeningen. In: Flensborg Avis, Jg. 144 , S. 5 .

Reese, Marc (23.08.2012): Skoleforening tager en del kritik til sig. In: Flensborg Avis, Jg. 144, S. 1.

Reese, Marc (24.08.2012): Skoledebat fører til en ombudsmand. In: Flensborg Avis, Jg. 144, S. 1.

Reese, Marc (14.02.2013): Flere medlemmer i Frederiksstad. In: Flensborg Avis, Jg. 145, S. 6.

Rung Nielsen, Karsten (11.06.2006): Præger børnene for livet. In: Flensborg Avis, Jg. 136, Årsmøde-Sonderausgabe, S. 10.

Schulz, Anke (21.06.2016): Et dansk liv. Årsmødetale på Trene-Skolen, 11.06.2016. Kronik. In: Flensborg Avis, Jg. 148, S. 20.

Simonsen, Anker (14.07.2006): Tysktalende ikke med til Danmarksmesterskaber. In: Flensborg Avis, Jg. 138, S. 1.

Simonsen, Anker (16.07.2006): Flertal på hold skal kunne dansk. In: Flensborg Avis, Jg. 138, S. 7. 
Simonsen, Anker (16.10.2014a): Identitet er et personligt valg. In: Flensborg Avis, Jg. 146, S. 7.

Simonsen, Anker (16.10.2014b): Krav ville være et tilbageskridt. In: Flensborg Avis, Jg. 146, S. 7.

Skoleforening for Sydslesvig (23.04.2016): Lige så stille smitter det af. In: Fokus.

Din medlemsavis. Flensborg Avis, Jg. 148, S. 2.

Spoorendonk, Anke (11.12.2014): TV Syd: Mere fordømmelse end nysgerrighed.

Debat. In: Flensborg Avis, Jg. 146, S. 19.

Sydslesvigsk Forening (06.09.2007): Seksmandudvalget i Frederiksstad. In: Kontakt. Sydslesvigsk Forenings informationsblad/Flensborg Avis, Jg. 139, S. 28.

Sydslesvigsk Forening (12.11.2009): Sydslesvig-Kalender. In: Flensborg Avis, Jg. 141.

Sydslesvigsk Forening (12.05.2011): Velkommen til årsmøderne 2011! In: Kulturkontakt. Kulturmagasinet for hele Sydslesvig. SSF-Beilage zu Flensborg Avis, S. 1.

Sydslesvigsk Forening (10.01.2013): Nyt arbejdsår. In: Kontakt. Sydslesvigsk Forenings informationsblad/Flensborg Avis, Jg. 145, S. 1. <syfo.de/nyhedsoversigt/arkiv/singleview-archiv/artikel/kommentar-91-nyt-arbejdsaar>, 24.03.2016.

Sydslesvigsk Forening (07.03.2013): Vil have fat i forældrene. In: Kontakt. Sydslesvigsk Forenings informationsblad/Flensborg Avis, Jg. 145, S. 2.

Sydslesvigsk Forening (19.11.2015): Så tal dog dansk! In: Kontakt. Sydslesvigsk Forenings informationsblad/Flensborg Avis, Jg. 147, S. 2.

Sydslesvigsk Forening (12.05.2016): Fællesprojekt Oplev Sydslesvig. Projektleder udnævnt. In: Kontakt. Sydslesvigsk Forenings informationsblad/Flensborg Avis, Jg. 148, S. 1.

Sydslesvigsk Forening (26.05.2016): Gratis fanebærerkursus. In: Kontakt. Sydslesvigsk Forenings informationsblad/Flensborg Avis, Jg. 148, S. 20. <syfo.de/index.php?

id=1012\&tx_ttnews[tt_news] $=6595 \&$ no_cache $=1 \& u t m \_s o u r c e=S S F+$ nyheder\&utm_campaign=33aa052bb6-my_google_analytics_key\&utm_medium=e mail\&utm_term=0_df800bffea-33aa052bb6-321313697>, 21.06.2016.

Sydslesvigsk Forening (02.06.2016a): Bak op om Simon Faber! En valgappel. In: Kontakt. Sydslesvigsk Forenings informationsblad/Flensborg Avis, Jg. 148, S. 1. 
Sydslesvigsk Forening (02.06.2016b): Stem på Simon Faber! Leder. In: Kontakt. Sydslesvigsk Forenings informationsblad/Flensborg Avis, Jg. 148, S. 1.

Sydslesvigsk Forening (18.05.2017): Hust, det er en ære... Nye fanebærere lærte at holde fanen højt. In: Flensborg Avis; Kontakt. Sydslesvigsk Forenings informationsblad, Jg. 149, S. 1.

Sydslesvigsk Forening (10.08.2017): Positivt møde med den nye mindretals-kommitterede. In: Kontakt. Sydslesvigsk Forenings informationsblad/Flensborg Avis, Jg. 149, S. 4.

Thöming, Dirk (18.08.2012a): - Min datter græd, da hun skulle forlade skolen. In: Flensborg Avis, Jg. 144, S. 5.

Thöming, Dirk (18.08.2012b): Flere børn ramt af søskende-regel. In: Flensborg Avis, Jg. 144, S. 1.

Thöming, Dirk (21.08.2012a): En dreng mere skulle i år forlade det danske system. In: Flensborg Avis, Jg. 144, S. 5.

Thöming, Dirk (21.08.2012b): Skoleledere kritiseres for at svigte. In: Flensborg Avis, Jg. 144, S. 1.

Thöming, Dirk (06.09.2012a): - Jeg følte mig ydmyget. In: Flensborg Avis, Jg. 144, S. 4.

Thöming, Dirk (06.09.2012b): Forældre klar til kamp. In: Flensborg Avis, Jg. 144, S. 4.

Thöming, Dirk (06.09.2012c): Forældrekritik af nyt udspil. In: Flensborg Avis, Jg. 144, S. 1.

Thöming, Dirk (06.09.2012d): Skoleforening holder fast. In: Flensborg Avis, Jg. 144, S. 4.

Thöming, Dirk (13.09.2012): SSF ønsker fælles indsats for nye familier. In: Flensborg Avis, Jg. 144, S. 8.

Thöming, Dirk (21.06.2013): Penge til dansk-tysk skolecentrum. In: Flensborg Avis, Jg. 145, S. 3.

Thöming, Dirk (13.06.2014): Ikke dansk nok til mesterskaber. In: Flensborg Avis, Jg. 146, S. 3.

Vollertsen, Nils (07.04.2006): Søren Krarup og det danske mindretal. Kronik. In: Flensborg Avis, Jg. 138, S. 22. 
Vollertsen, Nils (20.11.2012): Det tyske i det danske. Kronik. In: Flensborg Avis, Jg. 144, S. 19.

\subsubsection{Radio-und Fernsehbeiträge, Filme}

Güsten, Susanne: Vom Weltreich zur bedrohten Minderheit. Die letzten Griechen von Konstantinopel (Gesichter Europas). Ausgestrahlt am 10.06.2017. Deutschlandfunk. <www.deutschlandfunk.de/vom-weltreich-zur-bedrohtenminderheit-die-letzten-griechen.922.de.html?dram:article_id=384324>, 16.06.2017.

Mundzeck, Heike (2004): Wer wohnte in der Synagoge von Friedrichstadt?, ZDFDokumentarfilm.

Petersen, Lars Feldballe ([2014]): De glemte danskere. Medvirkende: Hella Lassen, Karl Otto Meyer, Claas Johannsen, Marc Peetz. Weitere Beteiligte: Film \& TV Compagniet (Red.). Thulstrup, Mads Kamp (Regie). DVD: Studieafdelingen \& Arkivet ved Dansk Centralbibliotek for Sydslesvig.

TV Syd: Her er mindretallets udfordringer. Ausgestrahlt am 11.12.2014. TV Syd. <www.tvsyd.dk/artikel/her-er-mindretallets-udfordringer>, 11.12.2014.

Werner, Ulrike: Grenzland - Dänisch gesinnt in Schleswig-Holstein. NDR Info Die Reportage. Ausgestrahlt am 16.05.2016. NDR Info. <www.ndr.de/info/sendungen/die_reportage/Grenzland,sendung503486.html>.

\subsubsection{Vorträge}

Carstocea, Andreea (21.08.2013): Minority Participation. 21.08.2013, ECMI Summer School "National Minorities and Border Regions". Flensburg.

Constantin, Sergiu (28.08.2013): The Autonomy of South Tyrol: From Conflict to Self-governance and Power Sharing. 28.08.2013, ECMI Summer School "National Minorities and Border Regions". Flensburg.

Diedrichsen, Jan (26.08.2013): International Minority Mobilization. 26.08.2013, ECMI Summer School "National Minorities and Border Regions". Flensburg.

Engelbrecht, Benny (09.06.2013): Tale ved friluftsmødet i Tønning. 09.06.2013, Årsmøde/Jahrestreffen 2013. Tönning. $<$ syfo.de/fileadmin/syfo/kunde/Aarsmoede_2013/Benny_Engelbrecht_Tønning.pdf>, 11.06.2013.

Greve, Victor Madsen (19.02.2009): Indføring i gudstjenestens liturgi: Hvorfor står præsten med ryggen til menigheden. Hvorfor knæler præsten ved ind- 
gangsbønnen? Hvorfor rejser menigheden sig under læsningerne. 19.02.2009. Friedrichstadt.

Hougaard-Werner, Gitte (14.10.2013): Intro til Sydslesvig. 14.10.2013, Intregrationskurs. Jarplund.

Jackson-Preece, Jennifer (19.08.2013): Keynote: National Minorities in Europe. 19.08.2013, ECMI Summer School "National Minorities and Border Regions". Flensburg.

Kühl, Jørgen (18.03.2008): Ein europäisches Modell. Minderheiten im deutsch-dänischen Grenzland. 18.03.2008. Friedrichstadt.

Kühl, Jørgen (19.08.2013): Keynote. The History of the Danish-German Border Region. 19.08.2013, ECMI Summer School "National Minorities and Border Regions". Flensburg.

Küssner, Dieter Paul (08.06.2013): Sydslesvig kalder Danmark: For hinanden med hinanden. 08.06.2013, Årsmøde/Jahrestreffen 2013. Eckernförde.

Mandler, Peter (24.09.2014): "Introduction". Sektion "The Psychology of National Difference in the Mid-20th Century Crisis". 24.09.2014, 50. Deutscher Historikertag. Göttingen.

Nielsen, Flemming (10.02.2013): Om mindretal og grænseland. Afstemningsfest Tale. 10.02.2013. Mögeltondern. <syfo.de/nyhedsoversigt/arkiv/singleviewarchiv/artikel/om-mindretal-og-graenseland $>$, 23.03.2016.

Rüpke, Jörg (11.05.2017): Religion als Option und Risiko. 11.05.2017, Wie Religöses vergeht und entsteht. Göttingen. <www.uni-goettingen.de/de/wie-religi $\%$ C3\%B6ses-vergeht-und-entsteht-pdf/560361.html>, 15.05.2017. 



\section{Danksagung}

Für die Betreuung dieser Arbeit danke ich ganz besonders Prof. Dr. Regina Bendix von Institut für Kulturanthropologie/Europäische Ethnologie der Universität Göttingen. Ich danke auch den Gutachterinnen sowie den Herausgeber*innen der Schriftenreihe „Göttinger Studien zur Kulturanthropologie/Europäischen Ethnologie“ sowie Jutta Pabst und vor allem Petra Lepschy vom Universitätsverlag Göttingen.

Ebenso danke ich der Graduiertenschule für Geisteswissenschaften Göttingen (GSGG) für Zuschüsse zu zwei Forschungs- und einer Tagungsreise nach Südschleswig, für die großzügige Bereitstellung eines Büros sowie für das großartige Beratungs- und Workshopangebot in den vergangenen Jahren. Ich danke auch dem DAAD für die Unterstützung durch ein PROMOS-Stipendium, welches mir einen Aufenthalt an der Fróðskaparsetur Føroya, der Universität der Färöer, ermöglichte.

Ein besonderer Dank geht an die Dansk Centralbibliotek for Sydslesvig, im Speziellen an die Filiale in Husum, die einen sehr guten Service anbot und in der Lage war, schnell, unkompliziert und kostenlos große Mengen an skandinavischund deutschsprachiger Fachliteratur zu beschaffen.

Ich danke vor allem denjenigen, die sich bereit erklärt haben, sich interviewen oder (teilnehmend) beobachten zu lassen, mich zeitweise in ihren Kreis aufgenommen haben. Besonders dankbar bin ich für die Hilfe von Erik Nissen (Name geändert/INT01), der mir viele Türen öffnen konnte. 
Für Motivation, Geduld, Feedback, Gespräche und allgemeinen kollegialen Austausch danke ich meinen Freund*innen und Kolleg*innen sowie meinen ehemaligen WeWiMento-Mitmentees.

Wiebke Blanck und meinem Vater danke ich ganz besonders für das Korrekturlesen. Auch bei Kristina Matt und Maria Munkholt Christensen bedanke ich mich. Alle ggf. noch vorhandenen Fehler liegen in meiner Verantwortung.

Da diese Dissertation nebenberuflich und ohne finanzielle Förderung entstanden ist, danke ich hier vor allem meinem Vater und meiner Großmutter für ihre Unterstützung und ihren großen Zuspruch sowie Ersterem auch für die zahlreichen Bibliotheksfahrten und das stete Offenhalten von Augen und Ohren.

Göttingen, Dezember 2019

Levke Bittlinger 
mbivalenzen und widersprüchliche Erwartungen, nationalistische und postnationale Standpunkte sind Teil eines Dänischwerdens, Dänischseins und Dänischbleibens (oder auch Nichtbleibens) im Landesteil Schleswig. Anhand von qualitativen Methoden und eines konstruktivistischen Ansatzes untersucht Levke Bittlinger Fragen des Minderheitsseins und der nationalen Zugehörigkeitsgefühle unter Akteur*innen und Institutionen der dänischen Minderheit. Die Studie beleuchtet Hintergründe für die Wahl einer dänischen (Teil-)Zugehörigkeit durch beispielsweise den Besuch einer dänischen Schule oder das Engagement im dänischen Kulturverein von der Nachkriegszeit bis heute. Es wird darüber hinaus die Bedeutung von Symbolen, Praxen und historischen Mythen für die Minderheitszugehörigkeit unter die Lupe genommen und analysiert, wie "Neudän*innen“ in Integrationskursen mit den an sie gestellten Erwartungen umgehen.

- vilke modstridende forventninger og (post)nationale indstillinger og sindelag kan observeres, når nogle indbyggere i Sydslesvig i Tyskland vælger at blive, være eller forblive danske? Med en konstruktivistisk synsvinkel og med hjælp af kvalitative metoder undersøger Levke Bittlinger spørgsmål om minoriteter og tilhørsforhold blandt aktører og institutioner i det danske mindretal. Bogen belyser motiver for valget af en dansk tilknytning og undersøger, i hvilke kontekster det danske tilhørsforhold etableres, herunder dansk (og ikke tysk) skolegang og engagement i danske foreninger i mindretallet fra efterkrigstiden til i dag. Studiet handler også om, hvilken betydning symboler og konstruerede historiske fortællinger har for den måde, der dannes et tilhørsforhold til det danske mindretal, og hvordan „nydanskere“ håndterer de forventninger, som de konfronteres med under integrationskurser.

ISBN: 978-3-86395-427-7

eISSN: 2512-7055

Universitätsverlag Göttingen 